
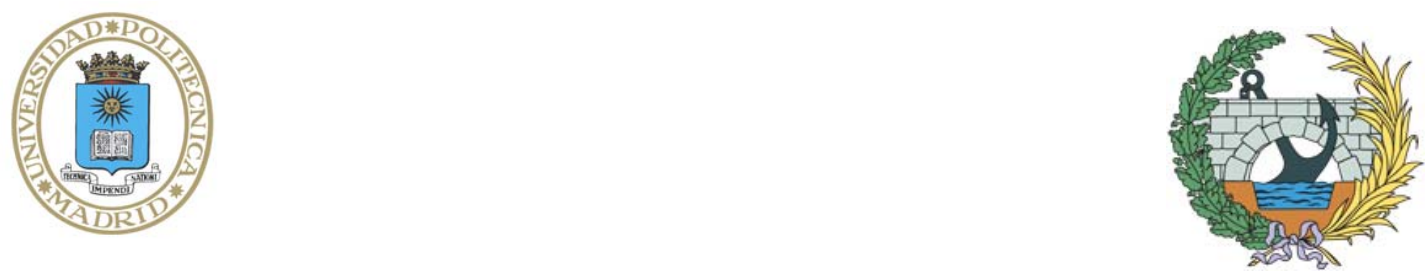

UNIVERSIDAD POLITÉCNICA DE MADRID

ESCUELA TÉCNICA SUPERIOR DE INGENIEROS DE Caminos, Canales y PUERToS

\title{
ESTUDIO MICROESTRUCTURAL DE PASTAS DE CEMENTO EXPUESTAS A MEDIOS SIMULADOS DE AGRESIVIDAD MODERADA FRECUENTES EN AMBIENTES RURALES
}

TESIS DOCTORAL

REBECA ANTón Fuentes

Licenciada en Ciencias Químicas

MADRID, 2016 

ESCUELA TÉCNICA SUPERIOR DE INGENIEROS DE Caminos, Canales y Puertos

DEPARTAMENTO DE INGENIERÍA CIVIL: CONSTRUCCIÓN

TESIS DOCTORAL

\title{
ESTUDIO MICROESTRUCTURAL DE PASTAS DE CEMENTO EXPUESTAS A MEDIOS SIMULADOS DE AGRESIVIDAD MODERADA FRECUENTES EN AMBIENTES RURALES
}

\author{
$\begin{array}{ll}\text { Autor } & \text { Rebeca Antón Fuentes } \\ \text { Licenciada en Ciencias Químicas }\end{array}$ \\ Directora $\quad$ Prof. $^{\text {a }}$ Amparo Moragues Terrades \\ Doctora en Ciencias Químicas

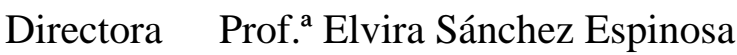 \\ Doctora Ingeniero Agrónomo
}

MADRID, 2016 

TESIS DOCTORAL

\section{ESTUDIO MICROESTRUCTURAL DE PASTAS DE CEMENTO EXPUESTAS A MEDIOS SIMULADOS DE AGRESIVIDAD MODERADA FRECUENTES EN AMBIENTES RURALES}

Tribunal nombrado por el Magnífico y Excelentísimo Señor Rector de la Universidad

Politécnica de Madrid, el día

de de 201 .

Presidente/a: Jaime C. Gálvez Ruíz

Vocal: $\mathrm{M}^{\mathrm{a}}$ Victoria Borrachero Rosado

Vocal: Moisés Frías Rojas

Vocal: Ma Isabel Sánchez de Rojas Gómez

Secretario/a: Encarnación Reyes Pozo

Suplente: Lourdes Soriano Martínez

Suplente: Pilar Leret Moltó

Realizado el acto de defensa y lectura de la Tesis el día de de 2016, en la Escuela Técnica Superior de Ingenieros de Caminos, Canales y Puertos.

PRESIDENTE/A

VOCALES 

A mi familia.

A Sergio y Daniel por su apoyo incondicional.

Si no conozco una cosa, la investigaré...Louis Pasteur 



\section{AGRADECIMIENTOS}

Quiero expresar mi más sincero agradecimiento a todas las personas que, de una manera u otra, han hecho posible que el trabajo desarrollado en esta investigación llegara a buen término. Durante la realización de esta tesis doctoral he aprendido muchas cosas. La mayoría son relativas a aspectos técnicos y científicos, pero también ha habido tiempo para aprender de las relaciones personales y de las experiencias de la vida cotidiana. He aprendido a valorar lo importante en la vida.

Quiero expresar mi agradecimiento hacia mis directoras de tesis, la Dra. Amparo Moragues Terrades y Dra. Elvira Sánchez Espinosa, por haberme dado la oportunidad de llevar a cabo esta tesis doctoral, y por su dedicación y confianza durante estos años. Gracias por animarme a seguir cuando las cosas se ponían cuesta arriba y por ser un ejemplo de esfuerzo y constancia.

Agradezco a los doctores Manuel Fernández Cánovas, Juan Gallego, Jaime C. Gálvez Ruiz, Ana M. Guerrero Bustos, Marisa López García, Ildelfonso Lucea Martínez, Jordi Massana Guitart, Encarnación Reyes Pozo, Miguel A. Sanjuán Barbudo, Ma Jesús Casati Calzada, Alejandro Enfedaque Díaz, así como a los técnicos del Laboratorio de Materiales de Construcción de la Escuela de Ingenieros de Caminos, Canales y Puertos por su ayuda en diversas fases del trabajo y de mi etapa en esta Escuela.

Del mismo modo, agradezco al personal de la Escuela de Ingenieros de Caminos, Canales y Puertos por su valiosa cooperación. En especial a la Dirección y Secretaría del Departamento de Ingeniería Civil Construcción y a Concepción García Viñuela de Biblioteca.

Deseo agradecer a mis compañeros, algunos ya doctores, los muchos y buenos momentos compartidos: Lis Pereira, Dr. Ignacio Segura, Dr. Omar Molina, Dra. Ghaida Al-Asadi, Dr. Safwat Mahmoud, Dra. Margarita Gónzalez, Dr. Fernando Suárez, Dr. Daniel Alonso, Dr. Néstor León, Patricia Mármol, Dr. Michiel Fenaux, Juan J. Conchillo, David Galé, Dra. Cristina Argiz, Dra. Silvia Monteagudo, Dr. Jesús Bernal y Dr. Marcos García. 
Mi agradecimiento más especial es para Arancha Hueso. Tu ayuda durante la realización de esta tesis es inestimable. Gracias por tu apoyo y tu amistad.

Agradezco la ayuda económica recibida por parte del Ministerio de Educación y Ciencia a través del Proyecto BIA2006-15188C03-03. Así como a Cementos Lafarge, a través de José Luis Hidalgo, la donación de los cementos empleados en la presente tesis doctoral.

Igualmente deseo expresar mi gratitud a todas aquellas personas que no siendo de mi entorno académico me han ayudado a seguir y a sacar fuerzas en los momentos difíciles. A mi marido Sergio y a mi hijo Daniel porque sois lo más importante en mi vida y hacéis que todo esfuerzo realizado tenga sentido. A mis padres, Gregorio y Remedios, que siempre me han ayudado y apoyado en todo. A mi hermana, Arantxa, por ser mi principal confidente. A mi familia política por su comprensión y apoyo. Y a mis amigas Marta López, Elena Villar, Marta Burgos, Aída Pereira y Esther Tomás porque siempre he podido contar con vosotras para todo. 


\section{RESUMEN}

Los materiales base cemento (pastas, morteros, hormigones y otros tipos de mezclas) son materiales ampliamente utilizados en la sociedad actual y son uno de los pilares de la ingeniería civil debido a sus buenas propiedades estructurales, facilidad de fabricación y bajo coste. Sus propiedades permiten su uso en ambientes industriales y naturales, siendo materiales muy versátiles siempre y cuando, se tenga en cuenta que sus propiedades durables son limitadas en ambientes donde se producen fenómenos de lixiviación y ataque por diversos iones agresivos.

El presente proyecto de investigación se desarrolló motivado por la necesidad de profundizar en el conocimiento del comportamiento de los materiales base cemento en situaciones concretas de exposición a cierto tipo de degradaciones que se producen frecuentemente en explotaciones agropecuarias ubicadas en ambientes naturales. Se diseñó un procedimiento experimental que nos permitiese evaluar el efecto que tienen los ácidos orgánicos sobre la matriz cementicia, así como la acción que presentan los sulfatos y las aguas naturales en los mismos. Teniendo muy presente siempre las características de las disoluciones a las cuales se ha expuesto el material. En último término, se trata de conocer los mecanismos de los procesos de ataque para poder definir el comportamiento del material en estos medios.

Los procedimientos de ensayo, así como las técnicas de caracterización son las herramientas fundamentales con las que profundizar en el conocimiento del material, por lo que resulta de vital importancia conocer a fondo las posibilidades que su empleo nos ofrece. En el presente trabajo se ha desarrollado un profundo estudio del uso del termoanálisis en la caracterización de pastas de cemento. Además se han optimizado los procedimientos de caracterización de las muestras con otro tipo de técnicas.

La caracterización de las probetas nos ha permitido comprobar el comportamiento del material en situaciones de exposición en ensayos acelerados de laboratorio. Los resultados obtenidos han permitido determinar que el $\mathrm{pH}$ del medio agresivo es una variable fundamental cuando se trata de evaluar la agresividad del mismo. La presencia de ciertos iones desarrollaría efectos de sinergia con respecto al $\mathrm{pH}$ y condicionaría los valores de las constantes termodinámicas que 
rigen los equilibrios. La posibilidad de formación de sales de ácidos orgánicos y la diferente solubilidad de las mismas derivaría en cambios en los comportamientos mecánicos. La proporción de compuestos de aluminio o la presencia de puzolanas capaces de fijar el calcio son también factores evidenciados como determinantes en el comportamiento del material. Además se podría afirmar que la disolución de la portlandita es un efecto determinante en el proceso de degradación. 


\begin{abstract}
Nowadays, cement based materials (pastes, mortars, concrete and other mixtures) are widely used. These kinds of material are one of the pillars of Civil Engineering due to their structural properties, easy manufacturing and low cost. Their properties allow the use in industrial and natural environments. They are very versatile materials for use in this type of environment. But it is necessary to to keep in mind that they have a durability limited when they are exposed to aggressives environments where leaching process occur and various aggressive ions can damage the materials.
\end{abstract}

This research work was developed motivated by the need to go in dept in the knoledge of the behavior of cement based materials. These kinds of materials frecuently are exposed to some types of damage that occur on farms located in natural environments. An experimental procedure that would allow us to evaluate the effect of organic acids on the cement matrix and the action presented by sulfates and natural waters in the same was designed. Always bearing in mind the characteristics of the solutions to which the material is exposed. Ultimately it comes to understanding the mechanisms of the processes leading to define the material behavior in this type of environment.

Test procedures and characterization techniques are fundamental tools which to deepen the knowledge of the material, so it is important to know in its potential uses. In this work we have developed a deep study of the use of thermal analysis in the characterization of cement pastes. Furthermore, we have optimized characterization procedures of samples with other techniques.

The characterization of the samples has allowed us to check the behavior of the material on exposure to accelerated laboratory tests. The results have established that the $\mathrm{pH}$ of the corrosive media is a fundamental variable when it comes to assessing the aggressiveness of it. The presences of certain ions develop synergies with respect to $\mathrm{pH}$ and would determine the values of the constants governing thermodynamic equilibria. The possible formation of salts of organic acids and the different solubility of the same would lead to changes in mechanical behavior. The proportion of aluminum compounds or the presence of pozzolans capable of 
binding calcium is also evidenced as determining factors in the material behavior. Besides we could assert that the dissolution of the portlandite is a determining effect on the degradation process. 


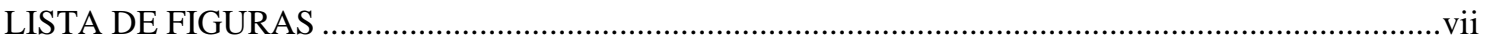

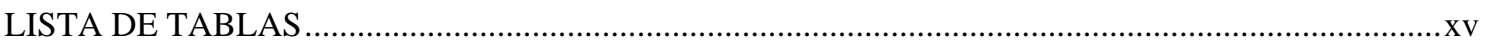

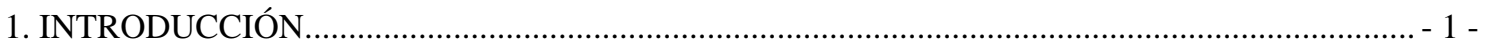

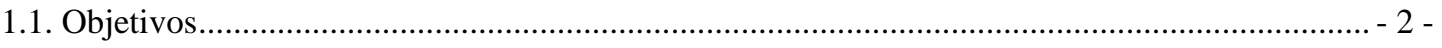

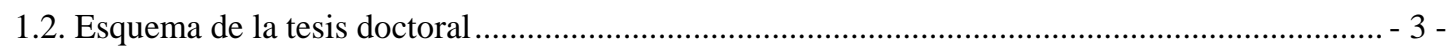

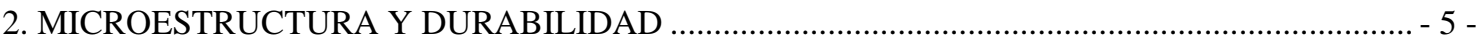

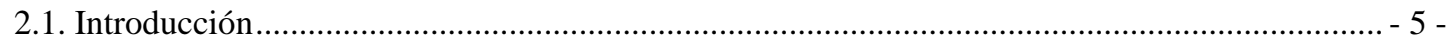

2.2. Características de la pasta de cemento hidratada .................................................................. - 6 -

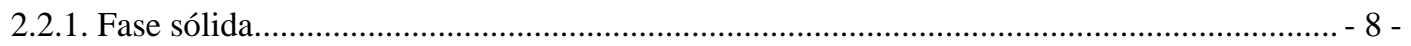

2.2.1.1. Silicatos cálcicos hidratados. Gel CSH. ........................................................... - 8 -

2.2.1.2. Hidróxido cálcico. Portlandita $(\mathrm{CH})$................................................................. - 11 -

2.2.1.3. Aluminatos y sulfoaluminatos cálcicos hidratados. ............................................. - 12 -

2.2.1.4. Cemento anhidro .............................................................................................. - 13 -

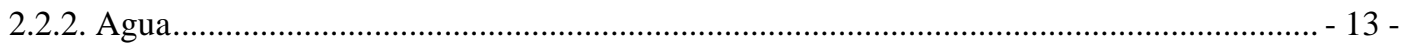


2.2.3.1. Poros de gel o microporos............................................................................... - 16 -

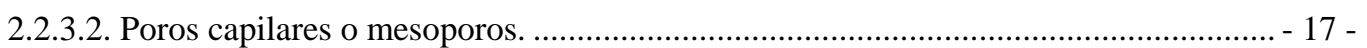

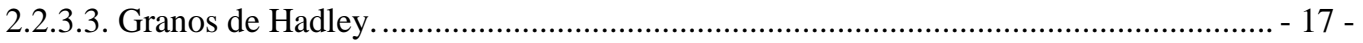

2.2.3.4. Macroporos. ................................................................................................. - 18 -

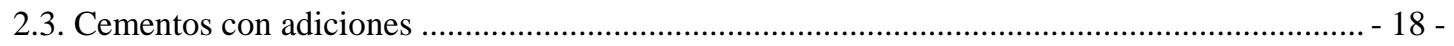

2.3.1. Puzolanas (P, Q)....................................................................................... - 20 -

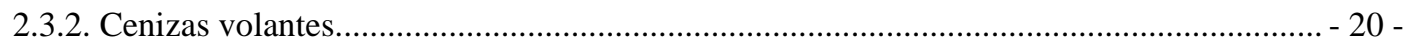

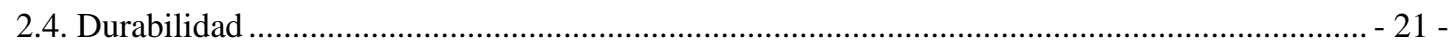

2.4.1. Mecanismos de transporte en el interior de los sistemas cementantes .............................. - 22 -

2.4.2. Degradación química ..................................................................................................... - 26 -

2.4.2.1. Degradación por lixiviación .................................................................................. - 26 -

2.4.2.2. Reacciones de intercambio iónico ......................................................................... - 27 -

2.4.2.3. Formación de compuestos expansivos ................................................................... - 28 -

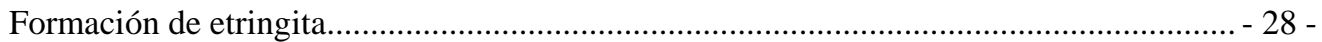

Formación de thaumasita......................................................................................... 29 -

Reacciones árido-álcali...................................................................................... - 29 -

Hidratación tardía de $\mathrm{CaO}$ y MgO.................................................................................... - 30 -

2.4.3. Durabilidad de materiales cementicios en contacto con aguas naturales ......................... - 31 -

2.4.4. Durabilidad de materiales cementicios en contacto con ácidos orgánicos ......................... - 34 -

3. MATERIALES Y METODOLOGÍA …................................................................................ - 39 -

3.1. Materiales empleados. ….......................................................................................... 39 -

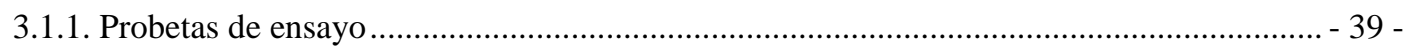

3.1.1.1. Tipo de material empleado ................................................................................. - 39 -

3.1.1.2. Características de los cementos empleados ........................................................... - 40 -

3.1.1.3. Dosificación y fabricación de la pasta de cemento................................................ - 41 - 
3.2. Esquema experimental del proceso de degradación acelerada................................................ - 44 -

3.2.1. Preparación de las muestras antes del proceso de degradación.......................................... - 44 -

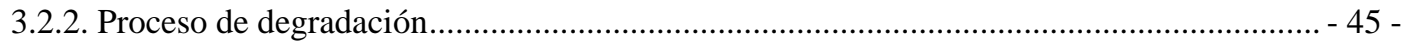

3.2.3. Preparación de las muestras de análisis para su caracterización ....................................... - 47 -

3.2.3.1. Muestras de pasta de cemento en fase sólida ...................................................... - 47 -

3.2.3.2. Muestras en fase líquida ............................................................................... -50 -

Alícuotas extraídas durante el periodo de exposición ................................................... - 50 -

Disolución de muestras sólidas .................................................................................... - 51 -

3.3. Ensayos de caracterización de las muestras de análisis ......................................................... - 52 -

3.3.1. Caracterización de las muestras durante el proceso de degradación.................................. - 54 -

3.3.2. Caracterización del estado de hidratación de las pastas de cemento a edad madura mediante

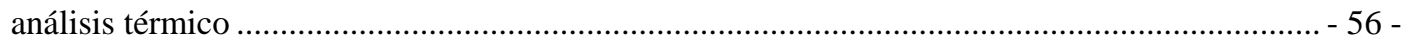

3.4. Metodología de análisis .................................................................................................... - 57 -

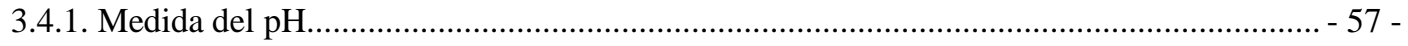

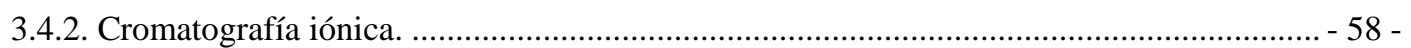

3.4.2.1. Fundamentos de la técnica .............................................................................. - 58 -

3.4.2.2. Condiciones de análisis .................................................................................. - 59 -

3.4.3. Método volumetríco - Análisis de ion férrico y alumnínico............................................ - 60 -

3.4.3.1. Fundamentos de la técnica ................................................................................... - 61 -

3.4.3.2. Condiciones de análisis .................................................................................... - 63 -

3.4.4. Difracción de rayos-X.............................................................................................. - 65 -

3.4.4.1. Fundamentos de la técnica ............................................................................... - 65 -

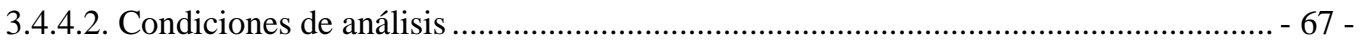

3.4.5. Análisis térmico ................................................................................................. - 68 -

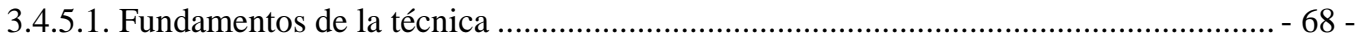

Interpretación de las señales térmicas ...................................................................... - 71 - 
Estimación de parámetros termodinámicos ....................................................................... - 73 -

Estimación del grado de hidratación mediante análisis térmico .............................................. - 77 -

3.4.5.2. Condiciones de análisis. ............................................................................................. - 82 -

4. RESULTADOS Y ANÁLISIS DE RESULTADOS ……………………………………………........ - 85 -

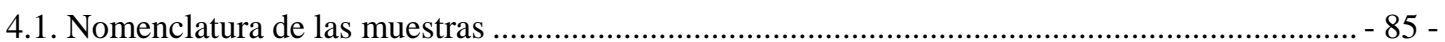

4.2. Resultados de la validación de métodos ........................................................................................ - 86 -

4.2.1. Evaluación del método de disolución de muestras de pasta de cemento............................... - 86 -

4.2.2. Evaluación de las técnicas de análisis empleadas .................................................................. - 93 -

4.2.3. Evaluación de los métodos de disolución y las técnicas de análisis simultáneamente........ - 96 -

4.3. Caraterización de los cementos de partida ..................................................................................... - 98 -

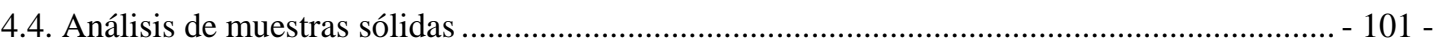

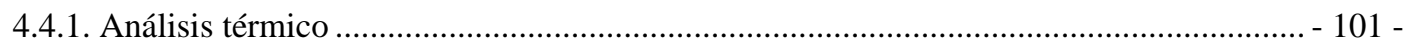

4.4.1.1. Influencia del uso de gas portador.......................................................................... - 102 -

4.4.1.2. Influencia de la velocidad de calentamiento .............................................................. - 106 -

4.4.1.3. Evaluación del mecanismo de deshidratación ............................................................. - 118 -

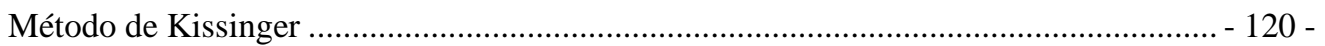

Método de Flynn-Wall-Ozawa (FWO).............................................................................. - 123 -

4.4.1.4. Análisis térmico de las muestras de referencia........................................................... - 128 -

4.4.1.5. Análisis térmico de las muestras a edad madura ………………………………......... - 134 -

4.4.1.6. Evaluación del grado de hidratación a partir de los datos de análisis térmico .......... - 139 -

Estimación del grado de hidratación según Bhatty........................................................... - 141 -

Estimación del grado de hidratación según Pane/Hansen .................................................. - 142 -

Estimación del grado de hidratación propuesto ................................................................. - 143 -

4.4.1.7. Análisis térmico sobre las muestras expuestas a los medios AC, SU y AN.............. - 148 -

Análisis térmico en el medio AC....................................................................................... - 148 -

Análisis térmico en el medio SU ..................................................................................... - 160 - 
Análisis térmico en el medio AN - 169 -

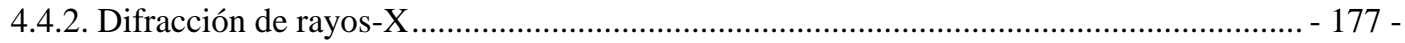

4.4.2.1. Difracción de rayos-X en las muestras expuestas al medio AC .............................. - 178 -

4.4.2.2. Difracción de rayos-X en las muestras expuestas al medio SU.............................. - 184 -

4.4.2.3. Difracción de rayos-X en las muestras expuestas al medio AN .............................. - 189 -

4.4.3. Composición de las muestras sólidas ......................................................................... - 191 -

4.4.3.1. Composición de las muestras en el medio AC ..................................................... - 192 -

4.4.3.2. Composición de las muestras en el medio SU.................................................. - 199 -

4.4.3.3. Composición de las muestras en el medio AN ...................................................... - 203 -

4.5. Análisis en los medios de exposición .................................................................................. - 205 -

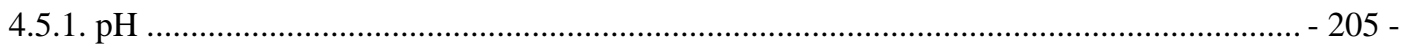

4.5.2. Fuerza iónica ...................................................................................................... - 208 -

4.5.3. Composición iónica de lixiviados ............................................................................ - 215 -

4.5.3.1. Análisis de iones en el medio AC ........................................................................ - 215 -

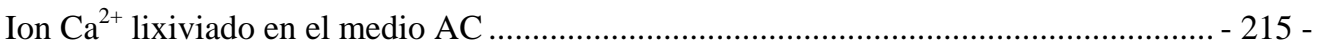

Ion $\mathrm{Mg}^{2+}$ lixiviado en el medio AC .......................................................................... - 218 -

Ion $\mathrm{SO}_{4}{ }^{2-}$ lixiviado en el medio AC ........................................................................ - 220 -

4.5.3.2. Análisis de iones en el medio SU .................................................................... - 223 -

4.5.3.3. Análisis de iones en el medio AN ................................................................. - 227 -

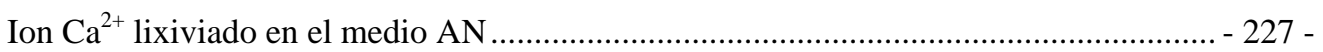

Otros iones en el medio AN ................................................................................. - 230 -

5. CONCLUSIONES Y LÍNEAS DE INVESTIGACIÓN FUTUTAS............................................. - 233 -

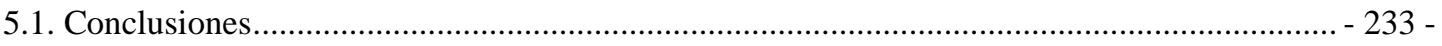

5.2. Líneas de investigación futuras............................................................................................ - 238 -

REFERENCIAS BIBLIOGRÁFICAS .................................................................................... - 239 - 


\section{LISTA DE FIGURAS}

Figura 1. .Diagrama esquemático de los procesos de hidratación (izquierda) y de formación de compuestos hidratados (derecha) del cemento (Odler, 1998)......................................................... - 7 -

Figura 2. Cementos comunes (RC-08, 2009) - 19 -

Figura 3. Esquema de difusión de iones y procesos de disolución/precipitación provocado por el agua - 32 -

Figura 4. (a) Moldes de acero inoxidable para la fabricación de probetas de pasta de cemento. (b) Probetas durante el proceso de curado. $42-$

Figura 5. (a) Detalle de las probetas recubiertas de resina mostrando la superficie de exposición. (b)

Detalle de las probetas durante el proceso de saturación de la superficie de ataque $-45-$

Figura 6. Sistema de agitación continuo empleado para mantener los medios homogéneos. $-46-$

Figura 7. Esquema de distribución de las probetas de ensayo en los medios de exposición $-47-$

Figura 8. Imagen las probetas inmersas en las cubetas durante el proceso de degradación $-47-$

Figura 9.Esquema de macro-probetas extraidas y cortes realizados en uno de los medios de exposición $48-$ 
Figura 11.Imágenes de las muestras tras eliminar la resina (a) y detalle del proceso de calibrado de las muestras de análisis (b) $50-$

Figura 12. Molino de mortero de ágata empleado para la molienda de las muestras ............................... - 50 -

Figura 13. Alícuotas recogidas de los medios de exposición durante el proceso de degradación .......... - 51 -

Figura 14. Esquema de ensayos llevados a cabo sobre las muestras implicadas en el proceso de degradación

Figura 15. Resumen de ensayos realizados en las muestras de lixiviados -55 -

Figura 16. Resumen de ensayos realizados en las muestras de sólidas implicadas en el proceso de exposición. - 56 -

Figura 17. pHmetros empleados. $-58-$

Figura 18. Cromatograma típico catiónico y aniónico - 59 -

Figura 19. Cromatógrafo iónico y procesador de muestras empleado. - 60 -

Figura 20. Curva de titulación de ion férrico con AEDT usando como indicador ácido sulfosalicílico - 62 Figura 21.Curva de titulación de ion alumínico con $\mathrm{ZnSO}_{4}$ usando como indicador naranja de xilenol

Figura 22. Valorador automático Mettler Toledo DL50 con fototrodo - 64 -

Figura 23. Esquema de onda con (a) intensidad reflejada cuando se cumple la ley de Bragg; (b) intensidad no reflejada cuando no se cumple la ley de Bragg - 66 -

Figura 24. Difractograma típico en una muestra de pasta de cemento - 67 -

Figura 25. Difractómetro X’Pert Pro MPD Alfa1. - 68 -

Figura 26. Material y analizador térmico simultáneo Labsys Evo 1600 de Setaram para ensayos de análisis térmico. - 82 -

Figura 27. Distribución de tamaño de partícula de los cementos $-100-$

Figura 28. ATD-TG de los cementos anhidros. $-100-$

Figura 29. Influencia de la presencia de gas portador sobre la temperatura a la cual se alcanza $\alpha . . . . . . .-103$ Figura 30. Influencia de la presencia de gas portador en la resolución de las curvas $-104-$

Figura 31. Influencia de la variación de la velocidad de calentamiento en la resolución de las curvas dTG. - 107 - 
Figura 32. Velocidad de pérdida de masa en función de la tempertura. Muestra SR a velocidad $10^{\circ} \mathrm{C} / \mathrm{min}$ - 109 -

Figura 33. Velocidad de pérdida de masa en función de la tempertura. Muestra II a velocidad $10^{\circ} \mathrm{C} / \mathrm{min}$... $-109-$

Figura 34. Velocidad de pérdida de masa en función de la tempertura. Muestra IV a velocidad $10^{\circ} \mathrm{C} / \mathrm{min}$.. - 110 -

Figura 35. Velocidad de pérdida de masa en función de la tempertura. Muestra SR a velocidad $0.5^{\circ} \mathrm{C} / \mathrm{min}$ - 111 -

Figura 36. Velocidad de pérdida de masa en función de la tempertura. Muestra II a velocidad $0.5^{\circ} \mathrm{C} / \mathrm{min}$ - 111 -

Figura 37. Velocidad de pérdida de masa en función de la tempertura. Muestra IV a velocidad $0.5^{\circ} \mathrm{C} / \mathrm{min}$. - 112 -

Figura 38 . Influencia de la variación de la velocidad de calentamiento sobre la temperatura a la cual se alcanza un determinado grado de conversión de la reacción en muestras de pasta de cemento SR .... - 113 Figura 39 . Influencia de la variación de la velocidad de calentamiento sobre la temperatura a la cual se alcanza un determinado grado de conversión de la reacción en muestras de pasta de cemento II ....... - 113 Figura 40 . Influencia de la variación de la velocidad de calentamiento sobre la temperatura a la cual se alcanza un determinado grado de conversión de la reacción en muestras de pasta de cemento IV ..... - 114 Figura 41. dTG de las curvas a diferentes velocidades de calentamiento de cada una de las muestras e los diferentes cementos empleados - 115 -

Figura 42.Temperatura del mínimo de la curva dTG en función de la velocidad de calentamiento. .. - 116 -

Figura 43. $\operatorname{Ln}\left(\beta / \mathrm{T}^{2}{ }_{\text {máx }}\right)$ frente a1/ $\mathrm{T}_{\text {máx }} \mathrm{y}$ ajustes para los tres tipos de muestras $-122-$

Figura 44. Log $\beta$ vs 1000/T en muestras de pasta de cemento SR $125-$

Figura 45. $\log \beta$ vs 1000/T en muestras de pasta de cemento II $-125-$

Figura 46. Log $\beta$ vs 1000/T en muestras de pasta de cemento IV $126-$

Figura 47. Ea calculada según el método FWO - 128 -

Figura 48. ATD-TG muestras de referencia cemento SR - 129 -

Figura 49. ATD-TG muestras de referencia cemento II - 129 -

Figura 50. ATD-TG muestras de referencia cemento IV -130 - 
Figura 51. ATD-TG muestras a edad madura $-135-$

Figura 52. Grados de hidratación ......................................................................................... - 146 -

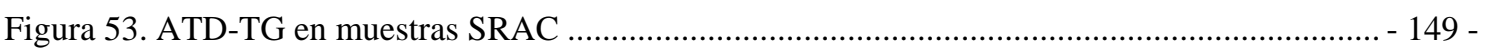

Figura 54. Pérdidas de masa en la región Ldh por tramos de temperatura en las muestras SRAC .... - 150 -

Figura 55. Contenidos de portlandita y portlandita equivalente en muestra SRAC .......................... - 151 -

Figura 56. ATD-TG en muestras IIAC .............................................................................. - 153 -

Figura 57. Pérdidas de masa en la región Ldh por tramos de temperatura en las muestras IIAC....... - 154 -

Figura 58. Contenidos de portlandita y portlandita equivalente en muestra IIAC............................. - 155 -

Figura 59. ATD-TG en muestras IVAC …............................................................................ 157 -

Figura 60. Pérdidas de masa en la región Ldh por tramos de temperatura en las muestras IVAC ..... - 158 -

Figura 61. Contenidos de portlandita y portlandita equivalente en muestra IVAC ........................... - 160 -

Figura 62. ATD-TG en muestras SRSU ................................................................................ 161 -

Figura 63. Pérdidas de masa en la región Ldh por tramos de temperatura en las muestras SRSU...... - 162 -

Figura 64. Contenidos de portlandita y portlandita equivalente en muestra SRSU........................... - 162 -

Figura 65. ATD-TG en muestras IISU .......................................................................................... - 164 -

Figura 66. Pérdidas de masa en la región Ldh por tramos de temperatura en las muestras IISU ........ - 165 -

Figura 67. Contenidos de portlandita y portlandita equivalente en muestra IISU ............................ - 166 -

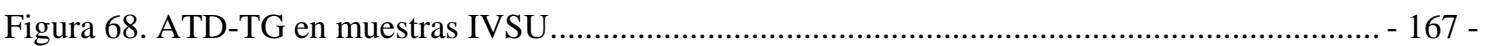

Figura 69. Pérdidas de masa en la región Ldh por tramos de temperatura en las muestras IVSU....... - 168 -

Figura 70. Contenidos de portlandita y portlandita equivalente en muestras IVSU.......................... - 169 -

Figura 71. ATD-TG en muestras SRAN …......................................................................... - 170 -

Figura 72. Pérdidas de masa en la región Ldh por tramos de temperatura en las muestras SRAN .... - 171 -

Figura 73. Contenidos de portlandita y portlandita equivalente en muestras SRAN........................ - 172 -

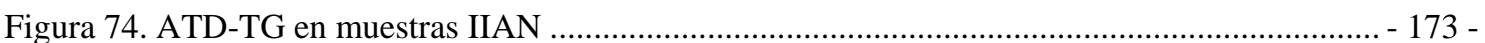

Figura 75. Pérdidas de masa en la región Ldh por tramos de temperatura en las muestras IIAN ....... - 174 -

Figura 76. Contenidos de portlandita y portlandita equivalente en muestras IIAN............................ - 174 - 
Figura 78. Pérdidas de masa en la región Ldh por tramos de temperatura en las muestras IVAN...... - 176 -

Figura 79. Contenidos de portlandita y portlandita equivalente en muestras IVAN $-176-$

Figura 80. Análisis por DRX de las muestras de referencia - 178 -

Figura 81. Análisis por DRX de las muestras SRAC2D $-179-$

Figura 82. Análisis por DRX de las muestras IIAC2D. $179-$

Figura 83. Análisis por DRX de las muestras IVAC2D $-180-$

Figura 84. Análisis por DRX de las muestras SRAC30D ..... $180-$

Figura 85. Análisis por DRX de las muestras IIAC30D. $-181-$

Figura 86. Análisis por DRX de las muestras IVAC30D $-182-$

Figura 87. Análisis por DRX de las muestras SRAC92D $-183-$

Figura 88. Análisis por DRX de las muestras IIAC92D. $-184-$

Figura 89. Análisis por DRX de las muestras IVAC92D $-184-$

Figura 90. Análisis por DRX de las muestras SRSU2D. $-185-$

Figura 91. Análisis por DRX de las muestras IISU2D $-185-$

Figura 92. Análisis por DRX de las muestras IVSU2D $-186-$

Figura 93. Análisis por DRX de las muestras SRSU30D $-187-$

Figura 94. Análisis por DRX de las muestras IISU30D $-188-$

Figura 95. Análisis por DRX de las muestras IVSU30D $188-$

Figura 96. Análisis por DRX de las muestras SRSU92D $-188-$

Figura 97. Análisis por DRX de las muestras IISU92D $189-$

Figura 98. Análisis por DRX de las muestras IVSU92D $-189-$

Figura 99. Análisis por DRX de las muestras SRAN $-190-$

Figura 100. Análisis por DRX de las muestras IIAN $-190-$

Figura 101. Análisis por DRX de las muestras IVAN.. $191-$

Figura 102. Composición de las pastas de cemento SR expuestas al medio AC. $194-$ 
Figura 103. Composición de las pastas de cemento II expuestas al medio AC ...................................... - 195 -

Figura 104. Composición de las pastas de cemento IV expuestas al medio AC .................................... - 197 -

Figura 105. Composición de las pastas de cemento SR expuestas al medio SU .................................... - 199 -

Figura 106. Composición de las pastas de cemento II expuestas al medio SU ..................................... - 201 -

Figura 107. Composición de las pastas de cemento IV expuestas al medio SU ..................................... - 203 -

Figura 108. Composición de las pastas de cemento SR expuestas al medio AN.................................... - 204 -

Figura 109. Composición de las pastas de cemento II expuestas al medio AN...................................... - 204 -

Figura 110. Composición de las pastas de cemento IV expuestas al medio AN ................................... - 205 -

Figura 111. Evolución del pH en las disoluciones a lo largo del proceso de exposición ...................... - 206 -

Figura 112. Evolución del coeficiente de actividad con la fuerza iónica de la disolución .................. - 209 -

Figura 113. Evolución de I en las disoluciones AC a lo largo del proceso de ensayo............................ - 210 -

Figura 114. Evolución de I en las disoluciones SU a lo largo del proceso de ensayo ............................ - 211 -

Figura 115. Evolución del I en las disoluciones a lo largo del proceso de ensayo ................................. - 212 -

Figura 116. Relación entre la fuerza iónica y el pH del medio.............................................................. - 214 -

Figura 117. $\left[\mathrm{Ca}^{2+}\right]$ lixiviado en función del tiempo - Medio AC (izquierda). Dependencia de la $\left[\mathrm{Ca}^{2+}\right]$ con

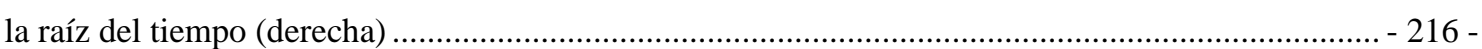

Figura 118. Evolución de la $\left[\mathrm{Ca}^{2+}\right]$ /unidades de lixiviación a lo largo del ensayo en el medio AC

(izquierda). Análisis de los tramos de la curva obtenida en función de la raíz del tiempo (derecha).. - 217 -

Figura 119. $\left[\mathrm{Mg}^{2+}\right]$ lixiviado en función del tiempo - Medio AC (izquierda). Dependencia de la $\left[\mathrm{Mg}^{2+}\right]$

con la raíz del tiempo (derecha)

- 219 -

Figura 120. Evolución de la $\left[\mathrm{Mg}^{2+}\right] /$ unidades de lixiviación a lo largo del ensayo en el medio AC.

Análisis de los tramos de la curva obtenida en función de la raíz del tiempo - 219 -

Figura 121. [ $\mathrm{SO}_{4}{ }^{2-}$ ] lixiviado en función del tiempo - Medio AC (izquierda). Dependencia de la [ $\mathrm{SO}_{4}{ }^{2-}$ ] con la raíz del tiempo (derecha) $220-$

Figura 122. Evolución de la [ $\left.\mathrm{SO}_{4}{ }^{2-}\right] /$ unidades de lixiviación a lo largo del ensayo en el medio AC.

Análisis de los tramos de la curva obtenida en función de la raíz del tiempo $-221-$

Figura 123. Análisis de la saturación de $\mathrm{CaSO}_{4}$ en los medios de exposición AC $223-$ 
Figura 124. $\left[\mathrm{Ca}^{2+}\right]$ lixiviado en función del tiempo - Medio SU (izquierda). Dependencia de la $\left[\mathrm{Ca}^{2+}\right]$ con la raíz del tiempo(derecha)

Figura 125. Evolución de la $\left[\mathrm{Ca}^{2+}\right] /$ unidades de lixiviación a lo largo del ensayo en el medio SU. Análisis de los tramos de la curva obtenida en función de la raíz del tiempo - 225 -

Figura 126. Análisis de la solubilidad de $\mathrm{CaSO}_{4}$ en el medio SU - 226 -

Figura 127. $\left[\mathrm{Ca}^{2+}\right]$ lixiviado en función del tiempo - Medio AN.... $-228-$

Figura 128. Análisis de la solubilidad de $\mathrm{CaCO}_{3} \mathrm{y} \mathrm{Ca}_{3}\left(\mathrm{PO}_{4}\right)_{2}$ en la disolución $-230-$

Figura 129. $\left[\mathrm{Mg}^{2+}\right]$ lixiviado en función del tiempo - Medio AN.. $-231-$

Figura 130. $\left[\mathrm{SO}_{4}{ }^{2-}\right]$ lixiviado en función del tiempo - Medio AN (izquierda). Dependencia de la [ $\mathrm{SO}_{4}{ }^{2-}$ ] con la raíz del tiempo (derecha) $231-$

Figura 131. Evolución de la [ $\left.\mathrm{SO}_{4}{ }^{2-}\right] /$ unidades de lixiviación a lo largo del ensayo en el medio AN. Análisis de los tramos de la curva obtenida en función de la raíz del tiempo $232-$ 
Tabla 1. Principales compuestos hidratados de la pasta del cemento Pórtland (UNE 80300:2000).......- 8 -

Tabla 2. Principales clasificaciones mencionadas por la literatura en pasta de cemento hidratado

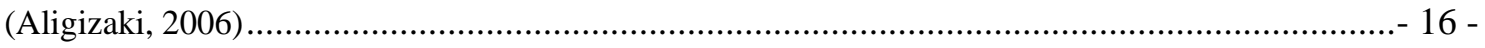

Tabla 3. Vida útil nominal de las estructuras según la EHE-08 (2008) .................................... 21 -

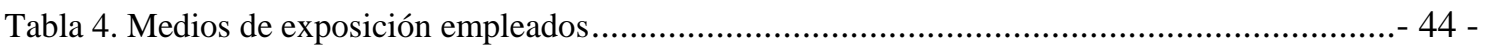

Tabla 5. Abreviaturas empleadas en la nomenclatura de las muestras....................................... 46 -

Tabla 6. Metodología de ensayos realizados a lo largo de la campaña experimental .......................- 53 -

Tabla 7. Abreviaturas empleadas en la nomenclatura de las muestras...................................... 54 -

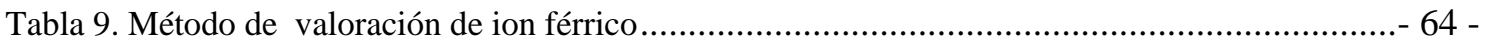

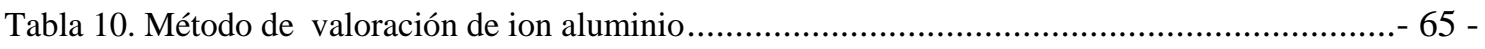

Tabla 11. Rangos de temperatura más comunes para identificar los distintos productos hidratados (Rivera,

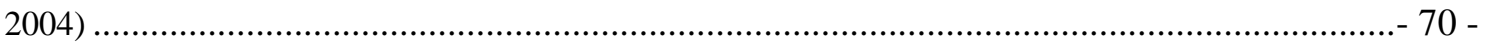

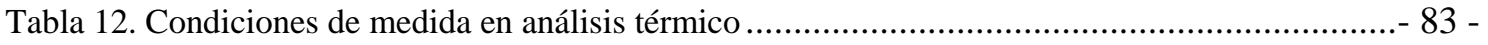

Tabla 13. Abreviaturas empleadas en la nomenclatura de las muestras....................................- 85 - 
Tabla 14. Desviación típica de de resultados en la determinación de CaO y MgO según UNE 196-2:2006$91-$

Tabla 15. Desviación típica de resultados en la determinación de CaO y MgO, empleando el método B de disolución de muestras $91-$

Tabla 16. Desviación típica de resultados en la determinación de CaO y MgO empleando los dos métodos de disolución $-92-$

Tabla 17. Desviación típica de resultados en la determinación de $\mathrm{CaO}$ y MgO, empleando el método A de disolución de muestras $95-$

Tabla 18. Desviación típica de resultados en la determinación de CaO y MgO empleando las dos técnicas de análisis y el método de disolución A. $96-$

Tabla 19. Desviación típica de resultados en la determinación de $\mathrm{CaO}$ y MgO, empleando el método B de disolución de muestras y la cromatografía iónica como técnica de análisis $97-$

Tabla 20. Desviación típica de resultados en la determinación de CaO y MgO empleando las dos técnicas de análisis y los dos métodos de disolución A y B......................................................... 97 -

Tabla 21. Características físicas, químicas y mecánicas .................................................. 98 -

Tabla 22. Composición química de los cementos empleados (ICP-OES).................................... 99 -

Tabla 23. Pérdidas de masa en cementos anhidros........................................................... 101 -

Tabla 24. Pérdidas de masa calculadas en presencia y ausencia de gas portador $\mathrm{N}_{2} \ldots \ldots \ldots \ldots \ldots \ldots \ldots \ldots . . . . . .104$ -

Tabla 25. Temperatura a la cual se produce el máximo grado de conversión de las reacciones ........- 116 -

Tabla 26. Energía de activación aparente estimada según la ecuación de Kissinger para cada uno de las muestras de pasta de cemento empleadas $-122-$

Tabla 27. Valores de pérdida de masa calculados en la muestras de referencia del cemento SR......- 130 -

Tabla 28. Valores de pérdida de masa calculados en la muestras de referencia del cemento II.........- 131 -

Tabla 29. Valores de pérdida de masa calculados en la muestras de referencia del cemento IV .......- 131 -

Tabla 30. Valores de portlandita y portlandita equivalente calculados en la muestras de referencia .- 134 -

Tabla 31. Pérdidas de masa calculadas en las muestras a edad madura de cemento SR $135-$

Tabla 33. Pérdidas de masa calculadas en las muestras a edad madura de cemento IV...... $138-$ 
ESTUDIO MICROESTRUCTURAL DE PASTAS DE CEMENTO EXPUESTAS A MEDIOS SIMULADOSDE AGRESIVIDAD MODERADA FRECUENTES EN AMBIENTES RURALES

Tabla 34. Valores de $\mathrm{W}_{\mathrm{B}}$ en muertras de referencia y a edad madura $\left(\mathrm{W}_{\mathrm{B} \infty}\right) \ldots \ldots \ldots \ldots \ldots \ldots \ldots \ldots \ldots \ldots \ldots . . . . . . . . . . . . . . . . .146-$

Tabla 36. Fuerza iónica inicial calculada en los medios de exposición ....................................... 209 - 


\section{INTRODUCCIÓN}

Los materiales base cemento (pastas, morteros, hormigones y otros tipos de mezclas) son materiales ampliamente utilizados en la sociedad actual y son uno de los pilares de la ingeniería civil debido a sus buenas propiedades estructurales, facilidad de fabricación y bajo coste. Sus propiedades permiten su uso en ambientes industriales y naturales. Si bien son materiales muy versátiles para su uso en este tipo de ambientes, hay que considerar que sus propiedades durables son limitadas cuando son expuestos en ambientes donde se producen fenómenos de lixiviación por el ataque por diversos iones agresivos.

La presente tesis doctoral surge como continuación a diversos estudios llevados a cabo en el grupo de investigación donde participa la doctoranda, y cuyo objeto de estudio se enmarca en el tipo de construcciones empleadas en el entorno de las explotaciones agropecuarias. Este tipo de construcciones está sometido a ambientes agresivos. Siendo de carácter físico, como la abrasión y desgaste superficial de los suelos por las pezuñas o los hocicos de los animales o la exposición a ciclos hielo-deshielo (León et al., 2014) y químico por su contacto con el estiércol y/o purines del ganado, así como otros compuestos, como los ácidos orgánicos, presentes en los productos obtenidos y/o usados en la explotación agro-ganadera (Sánchez et al. 2008 y 2009; Segura et al., 2010).

En este sentido, los procesos de degradación que se desencadenan en los materiales pueden dan lugar al colapso de los elementos tanto estructurales como a las instalaciones (separadores, suelo 
discontinuos...) suponiendo un considerable gasto económico, ya sea por la muerte del animal o por el cese de la producción debido a las labores de las reparaciones que precisan (Massana et al., 2013).

Los procesos que inciden en la microestructura de los materiales dependen del entorno y la climatología en la que el material se encuentra expuesto. A menudo se encuentran procesos de carbonatación, degradación por ataques de cloruros, por sulfatos, incidencia de los ciclos de hielo-deshielo, la reacción álcali-árido o los procesos de descalcificación. En este sentido, es preciso conocer el efecto aislado de cada uno de los tipos de agresivos que se encuentran en estos medios con el fin de postular un mecanismo de ataque que gobierne el proceso de deterioro en el material.

El agua está generalmente implicada en la mayoría de los procesos de degradación. Puede afectar a los materiales cementicios, al constituir un agresivo en sí mismo, como sucede en los fenómenos de descalcificación por lixiviación o en el ataque por ciclos de hielo-deshielo, o por ser el medio de transporte hacia el interior de la estructura de otras sustancias agresivas.

El presente proyecto de investigación se desarrolló motivado por la necesidad de profundizar en el conocimiento del comportamiento de los materiales base cemento en situaciones concretas de exposición.

Para ello se diseñó un procedimiento experimental que nos permitiese evaluar el efecto que tienen los ácidos orgánicos sobre la matriz cementicia, así como la acción que presentan los sulfatos y las aguas naturales en los mismos. Teniendo muy presente siempre el $\mathrm{pH}$ del medio en el cual se producía el proceso de degradación y la fuerza iónica del medio de exposición.

La caracterización de los parámetros microestrulturales, grado de hidratación, composición, etc. de las muestras, representa un parámetro fundamental de cara a estudiar la durabilidad de dichos materiales. En este sentido se ha realizado un profundo análisis de las posibilidades que presentan las técnicas de caracterización de los materiales originales y degradados.

\subsection{OBJETIVOS}

El objetivo general de este trabajo es el estudio microestructural y de los procesos de hidratación de las pastas de cemento para evaluar el comportamiento de las mismas expuestas en medios de agresividad moderada, ambientes muy frecuentes en el medio rural, así como la 
caracterización previa de los materiales de partida. Para alcanzar esta meta se plantean los siguientes objetivos.

- Analizar las metodologías de ensayo más adecuadas para caracterizar materiales cementicios. Y dentro de este objetivo:

- Evaluar las técnicas propuestas para la caracterización iónica de las muestras.

- Analizar los parámetros empleados en las técnicas de termoanálisis.

- Evaluar el grado de hidratación y la microestructura del material degradado a través del termoanálisis.

- Establecer las pautas de los procedimientos de ensayo acelerados que nos permitan simular situaciones de exposición en el laboratorio en un tiempo relativamente corto, evaluando la influencia del $\mathrm{pH}$ y las características iónicas de las disoluciones. Y dentro de este objetivo:

- Evaluar la influencia de las características del medio de exposición en el estado de degradación de la muestras.

- Establecer una relación entre la composición iónica y la microstructura del material y el comportamiento desarrollado en el medio de exposición

- Establecer las especificaciones más idóneas referentes al comportamiento durable de los materiales en los medios de exposición propuestos.

\subsection{ESQUEMA DE LA TESIS DOCTORAL}

La presente tesis está organizada en cinco capítulos y un apartado que contiene las referencias bibliográficas. A continuación se presenta una breve descripción del contenido de cada uno de los capítulos.

Se ha comenzado la redacción de la tesis con una descripción general del entorno en el cual se sitúan los materiales que se emplean en la misma. Una vez establecido el marco en el cual se va a llevar a cabo la investigación, se ha aprovechado este capítulo para describir los objetivos que pretendemos. 
En el capítulo dos se presenta un resumen de las principales características de los materiales que se van a tratar y una revisión del estado del conocimiento relativo a los temas que en la tesis se abordan, tales como el efecto que producen las disoluciones con distinto grado de agresividad sobre el material y los cambios microestructurales que se producen en el mismo.

El capítulo tres recibe el nombre de materiales y metodología porque en el se describen las características de los materiales empleados, las muestras ensayadas y la campaña experimental que se ha realizado. Se detallan además las metodologías empleadas.

A continuación, y en el capítulo cuatro, tiene lugar la descripción de los resultados obtenidos. En este capítulo además se lleva a cabo el análisis de los resultados, así como la discusión de los mismos.

El último capítulo recoge las conclusiones derivadas del análisis de resultados. Estas conclusiones sirven de punto de partida para el planteamiento de trabajos futuros. 


\section{MICROESTRUCTURA Y DURABILIDAD}

\subsection{INTRODUCCIÓN}

Los materiales base cemento son básicamente materiales compuestos, formados a partir de la mezcla de un conglomerante hidráulico -cemento-, agregados de diferentes formas y tamaños áridos- y agua. Tras un proceso de hidratación del cemento y un posterior curado se obtiene un material sólido y compacto, formado por una matriz de productos sólidos que aglutina a los áridos. Esta matriz sólida será más o menos porosa, en función de las condiciones iniciales de fabricación, el proceso de curado al que se la haya sometido, la situación medioambiental en la que se encuentre, etc. A nivel microscópico la complejidad del sistema aumenta debido a que las fases no poseen una distribución homogénea, ni son homogéneas entre sí.

De modo habitual, se suelen usar, en la fabricación de estos materiales, compuestos como aditivos y adiciones, para conferir propiedades específicas al material en estado fresco o en estado endurecido.

Los estudios con materiales base cemento pueden agruparse por el tipo de material empleado. En este sentido encontramos estudios con pasta de cemento, producto de la mezcla de cemento con agua, estudios con mortero, y hormigón. Tanto el mortero como el hormigón se logran a partir de la unión de áridos mediante pasta de cemento que actúa como conglomerante hidráulico. En el caso del mortero los áridos son finos y en el caso del hormigón la dosificación 
introduce una mezcla de áridos finos y gruesos según las curvas granulométricas estándar del método de dosificación empleado.

Teniendo en cuenta los objetivos de la presente tesis, se ha elegido como material de estudio la pasta de cemento. Si bien el hormigón se acerca más al tipo de materiales que se emplean en obra, la heterogeneidad de sus componentes y sus propiedades durables, lo hace un material difícil de estudiar a escala microscópica. El mortero constituiría un paso intermedio entre el hormigón y la pasta de cemento, pero la incorporación de los áridos en ocasiones resulta un problema para trabajar con determinadas técnicas analíticas.

\subsection{CARACTERÍSTICAS DE LA PASTA DE CEMENTO HIDRATADA}

Al ponerse en contacto el cemento y el agua comienza el proceso de hidratación. El proceso de hidratación del cemento es un conjunto de reacciones en las cuales los anhidros reaccionan con el agua para generar productos de hidratación. Durante el proceso se genera una disolución iónica que se mantiene en equilibrio con la fase sólida que se está formando. La cinética y la estequiometría de las reacciones son complejas. De forma simplificada puede dividirse en dos etapas sucesivas, el fraguado (inicial y final) y el endurecimiento posterior al fraguado final.

Las reacciones químicas de hidratación de los compuestos del cemento, son las responsables de los procesos de fraguado y adquisición de resistencias de los materiales base cemento. En estas reacciones se produce de forma mayoritaria gel $\mathrm{CSH}$ y portlandita, $\mathrm{Ca}(\mathrm{OH})_{2}$. Aparecen también otra serie de compuestos, como la etringita (fases AFt), monosulfatos hidratados (fases AFm) y otros compuestos amorfos. Algunas de las reacciones principales son:

$$
\begin{aligned}
& C_{3} S+(3-x+y) H \rightarrow C_{x} S_{y}+(3-x) C H \\
& C_{2} H+(2-x+y) H \rightarrow C_{x} S H_{y}+(2-x) C H \\
& C_{3} A+6 H \rightarrow C_{3} A H_{6} \\
& C_{3} A+3 C \bar{S} H_{2}+26 H \rightarrow C_{6} A \bar{S}_{3} H_{32} \\
& 2 C_{3} A+C_{6} A \bar{S}_{3} H_{32}+4 H \rightarrow 3 C_{4} A \bar{S} H_{12} \\
& C_{4} A F+3 C \bar{S} H_{2}+30 H \rightarrow C_{6} A \bar{S} 3 H_{32}+C H+F H_{3} \\
& 2 C_{4} A F+C_{6} A \bar{S}_{3} H_{32}+12 H \rightarrow 3 C_{4} A \bar{S} H_{12}+2 C H+2 F H_{3} \\
& C_{4} A F+10 H \rightarrow C_{3} A H_{6}+C H+F H_{3}
\end{aligned}
$$


El fraguado se produce en las primeras horas. En esta etapa se disuelven los componentes más solubles del cemento en la fase líquida de la pasta. A medida que esta fase se satura en iones comienzan a precipitar los compuestos que se incorporan a la fase sólida. Este es un proceso exotérmico que se da por terminado cuando el hormigón pierde su elasticidad y adquiere rigidez hasta consolidarse.

El endurecimiento es posterior al fraguado y de forma más pausada continúan los procesos de hidratación y solidificación del material. Esta fase puede durar años, pero las propiedades características o de diseño deben estar asentadas al cumplir 28 días desde el amasado.

Describir el proceso de hidratación es complicado porque cada compuesto presenta distintas velocidades de hidratación a lo largo del proceso. En la Figura 1 se puede apreciar las distintas velocidades de hidratación de los componentes básicos del cemento, así como la cantidad formada de cada compuesto hidratado.
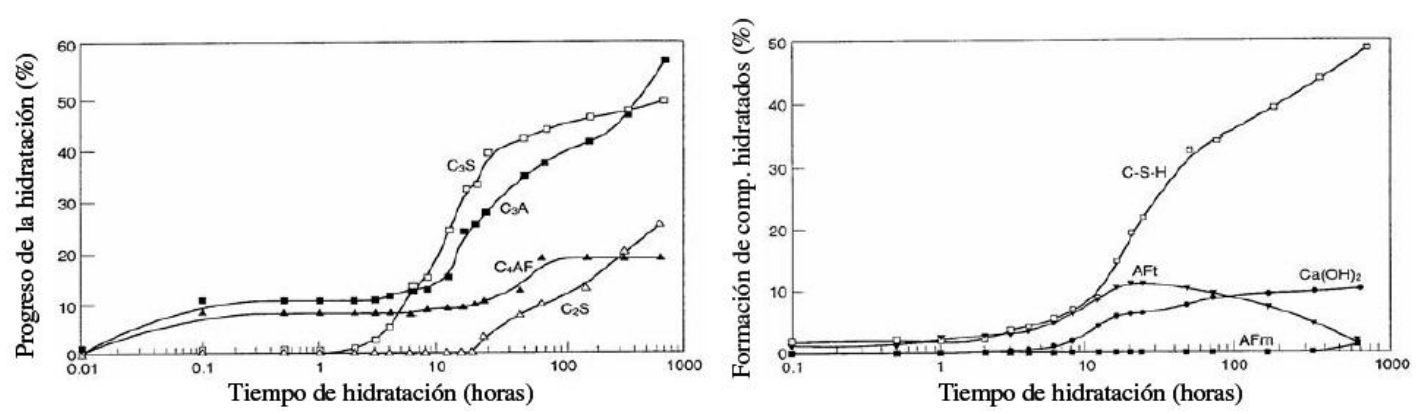

Figura 1. Diagrama esquemático de los procesos de hidratación (izquierda) y de formación de compuestos hidratados (derecha) del cemento (Odler, 1998)

Una vez que la pasta de cemento está conformada, se suele asumir que está compuesta por tres fases: la fase sólida, la red porosa y la fase acuosa, o electrolito en contacto con la fase sólida y que rellena parcialmente los poros.

Powers y Brownyard (Powers and Brownyard, 1948) describieron la pasta de cemento hidratada como un conjunto compuesto por tres componentes: cemento sin reaccionar, productos de hidratación y poros capilares. De este modo los productos sólidos denominados como "productos de hidratación” no son considerados individualmente, sino como una fase constituyente conjunta.

Con las aportaciones de Brunauer (Brunauer y Greenberg, 1960) se amplió este concepto, y la pasta de cemento pasa a ser considerada como un gel pobremente cristalizado formado por 
láminas, con una porosidad intrínseca y una elevada superficie específica. Los poros de gel sólo son accesibles por moléculas agua, al tener un diámetro inferior a $0.4 \mathrm{~nm}$ y toda área no ocupada por el gel de cemento es espacio capilar. Las láminas se hayan unidas mediante fuerzas de Van der Waals. Este modelo explica satisfactoriamente porqué no es posible la hidratación completa del cemento para valores por debajo de un valor umbral de relación a/c y proporciona una explicación parcial de algunas propiedades físicas importantes, en especial la resistencia a la compresión en función de la relación a/c y del grado de hidratación de la pasta de cemento hidratada. Recientemente, se ha realizado una revisión de las teorías de Powers y Brownyard (Brouwers, 2004, 2005 y 2007).

\subsubsection{FASE SÓLIDA.}

Los compuestos hidratados más importantes que se forman en el proceso de hidratación (fraguado y endurecimiento) de las pasta de cemento son los indicados en la Tabla 1.

Tabla 1. Principales compuestos hidratados de la pasta del cemento Pórtland (UNE 80300:2000)

\begin{tabular}{|c|c|c|}
\hline Compuesto & Fórmula & Abreviatura \\
\hline Silicato cálcico hidratado & $\mathrm{xCaO} \mathrm{ySiO}_{2} \cdot \mathrm{zH}_{2} \mathrm{O}$ & $\mathrm{CSH}$ \\
\hline Hidróxido de calcio (Portlandita) & $\mathrm{Ca}(\mathrm{OH})_{2}$ & $\mathrm{CH}$ \\
\hline Aluminato de calcio hidratado & $\begin{array}{c}4 \mathrm{CaO} \mathrm{Al} \mathrm{Al}_{2} \mathrm{O}_{3} \\
13 \mathrm{H}_{2} \mathrm{O}\end{array}$ & $\mathrm{C}_{4} \mathrm{AH}_{13(19)}$ \\
\hline $\begin{array}{l}\text { Trisulfoaluminato de calcio hidratado } \\
\text { (Ettringita) }\end{array}$ & $\begin{array}{c}3 \mathrm{CaO} \mathrm{Al} \mathrm{O}_{3} \\
3 \mathrm{CaSO}_{4} 32 \mathrm{H}_{2} \mathrm{O}\end{array}$ & $\begin{array}{c}\mathrm{C}_{3} \mathrm{~A} \cdot 3 \mathrm{Cs} \cdot 32 \mathrm{H}_{2} \mathrm{O} \\
\left(\mathrm{AF}_{\mathrm{t}}\right)\end{array}$ \\
\hline $\begin{array}{l}\text { Monosulfoaluminato de calcio hidratado } \\
\text { (Sal de Friedel) }\end{array}$ & $\begin{array}{c}3 \mathrm{CaO} \mathrm{Al} \mathrm{Al}_{3} \\
\mathrm{CaSO}_{4} 12 \mathrm{H}_{2} \mathrm{O}\end{array}$ & $\begin{array}{c}\mathrm{C}_{3} \mathrm{~A} \cdot \mathrm{Cs} \cdot 12 \mathrm{H}_{2} \mathrm{O} \\
\left(\mathrm{AF}_{\mathrm{m}}\right)\end{array}$ \\
\hline $\begin{array}{l}\text { Trisulfoferrito de calcio hidratado } \\
\text { (Ettringita férrica) }\end{array}$ & $\begin{array}{c}3 \mathrm{CaO} \mathrm{Fe}_{2} \mathrm{O}_{3} \\
3 \mathrm{CaSO}_{4} 32 \mathrm{H}_{2} \mathrm{O}\end{array}$ & $\mathrm{C}_{3} \mathrm{~F} \cdot 3 \mathrm{Cs} \cdot 32 \mathrm{H}_{2} \mathrm{O}$ \\
\hline
\end{tabular}

Estos, en adición a menores cantidades de otras fases y los componentes no hidratados del clínker, forman el conjunto de elementos sólidos de la pasta de cemento.

\subsubsection{Silicatos cálcicos hidratados. Gel CSH.}

Se denomina gel CSH al conjunto de compuestos de formula general $x[\mathrm{CaO}] \cdot \mathrm{SiO}_{2} \cdot y\left[\mathrm{H}_{2} \mathrm{O}\right]$, donde x e y son coeficientes variables. Constituye entre el $50 \%$ y el $60 \%$ de volumen total de los sólidos de la pasta de cemento completamente hidratada, y aporta al material endurecido una matriz que conecta y une los áridos. Es el componente mayoritario y se considera una de las 
fracciones más importante de la pasta de cemento por sus aportaciones a las propiedades mecánicas del material (Taylor, 2003).

La estructura interna del gel es compleja, se presenta en una fase pobremente cristalina y su composición química y morfología suelen variar en el tiempo, aunque está formada por silicatos cálcicos hidratados. Estos silicatos cálcicos hidratados pueden presentar relaciones calcio/sílice (Ca/Si) que pueden variar entre 0.7 y 2.3 (Heukamp, 2003 y Taylor, 2003). El gel CSH puede sufrir sustituciones isomórficas, admitiendo en su estructura cantidades considerables de otros iones, fundamentalmente $\mathrm{Fe}^{3+} \mathrm{y} \mathrm{Al}^{3+}$ (Taylor, 2003). Además, la cantidad de agua combinada por el gel es variable.

Casi todos los modelos moleculares del gel CSH están basados en algún tipo de estructura laminar donde el agua juega un papel muy importante en el desarrollo de la microestructura.

El modelo propuesto por Powers y Brownyard (Powers y Brownyard, 1948) es el primero históricamente. Se basa en los resultados del ensayo de adsorción de vapor de agua en el que una muestra de pasta endurecida se pone en contacto con vapor a una temperatura y presión determinadas. La teoría física de la adsorción permite medir la superficie interna de la pasta expuesta al aire como una magnitud proporcional a la presión de vapor aplicada y a la cantidad de agua absorbida.

Sin embargo el modelo más empleado para describir la microestructura del gel CSH es el de Feldman y Sereda (1970), que fue ligeramente modificada por Daimon (1977). El modelo de Feldman-Sereda constituyó un gran avance en la deducción de las características específicas de la microestructura del gel, porque es compatible con las evidencias microestructurales y con las probables relaciones entre el gel CSH y los compuestos cristalinos observadas hasta el momento. El modelo considera el gel como una estructura entrelazada de láminas de CSH, dispuestas al azar y con tendencia a formar grupos paralelos de unas pocas láminas de espesor. De esta manera se crean espacios de diferentes formas y tamaños.

Este modelo está basado en el estudio de medidas de absorción, porosidad y relaciones entre el contenido de agua y las propiedades físicas. Sin embargo el modelo aún presentaba algunas carencias, tales como que no específica la manera en la que el modelo relaciona la estructura con características físicas como la superficie específica. Carece de un algoritmo de cálculo que permita caracterizar cuantitativamente la estructura, y definir si la estructura es homogénea a mayor escala de 1 a $10 \mathrm{~nm}$ (Jennings, 2000). 
En los años sesenta las aportaciones de Brunauer permiten ampliar el modelo de Powers y definir el gel como una serie de láminas con una porosidad intrínseca y una elevada superficie específica, que se encuentran unidas entre sí por fuerzas de Van der Walls (Brunauer y Greenberg, 1960). El modelo clasifica el agua retenida en la pasta como:

- Agua interlaminar o de constitución: agua no evaporable que se sitúa entre las láminas, reacciona químicamente y forma parte de los cristales en forma de grupos hidróxidos, enlaces covalentes con moléculas de agua o puentes de hidrógeno.

- Agua de gel o adsorbida: incluye el agua retenida por las fuerzas de Vander Walls en la superficie de las láminas.

- Agua capilar: agua libre que queda dentro de los poros.

Tamás (1976) propuso un modelo a partir de los resultados de adsorción de argón. En él se justifica la ganancia de resistencias por las reacciones químicas de polimerización de los tetraedros de silicio $\mathrm{SiO}_{4}{ }^{4-}$ combinado con el $\mathrm{CH}$, aunque también da importancia a las fuerzas de Wander Waals y a los puentes de hidrógeno. El gel CSH endurecido se describe en este modelo como una conglomeración de polímeros con diferentes grados de polimerización (entre 0,4-0,5) donde cada polímero contiene de 8 a 10 átomos de silicio y forma a su vez una red tridimensional irregular con enlaces cruzados (Popovics, 1998).

El modelo Munich, desarrollado por Wittmann (1976) a partir de medidas de adsorción, presenta el gel CSH como una red tridimensional de partículas coloidales separadas sin estructura interna definida, que forman un xerogel (Wittmann, 1976 y 1982)). Las partículas del gel se separan por moléculas de agua, que contribuyen a la unión mediante fuerzas de Van der Waals en la superficie de los sólidos. Predominan los enlaces químicos iónico-covalentes sobre las fuerzas intramoleculares. El modelo no hace una distinción específica del tipo de agua, solo se considera una fuerte atracción de las moléculas de agua en la superficie de los sólidos, de tal forma que toda el agua es agua adsorbida. Este modelo se ha utilizado para explicar el comportamiento de la pasta de cemento endurecida bajo diferentes condiciones de humedad.

Jennings y Tennis (2010) desarrollaron un modelo capaz de describir las características del gel CSH en la escala de 1 a $100 \mathrm{~nm}$. Este modelo permite el cálculo de la cantidad de las fases sólidas mayoritarias y de la estructura de poro, incluyendo la porosidad capilar, así como la superficie específica en la pasta de cemento hidratada. El modelo propone como una de las claves fundamentales la división de los geles CSH en dos tipos, cada uno con un tipo de 
densidad característica, alta y baja densidad. La distinción se desprende de las observaciones llevadas a cabo durante ensayos de adsorción de nitrógeno.La densidad se asocia en este caso con el área de las superficies accesibles al gas, de tal manera que una densidad elevada vendrá determinada por una porosidad menor y por tanto por una accesibilidad del gas menor y viceversa. Con este ensayo se puede estimar la proporción relativa de cada uno de los dos tipos de gel y su variación durante el proceso de hidratación.

Otros autores como Richardson (2000) coinciden en este criterio para la clasificación de los tipos de gel. Básicamente se describen los geles de alta densidad ó "Inner” como productos de hidratación de matriz muy homogénea y poros muy pequeños distribuidos uniformemente. Los geles de baja densidad u “Outer” suelen aparecer adheridos a los “Inner” y contienen distintos tipos de fases amorfas y cristalinas, en este caso la porosidad aparece distribuida de modo heterogéneo.

\subsubsection{Hidróxido cálcico. Portlandita (CH).}

El hidróxido cálcico o portlandita, constituye entre el 20-25 \% del volumen de la pasta de cemento hidratada. Es un compuesto cristalino y por tanto posee una estequiometría definida. Presenta tendencia a formar grandes cristales de simetría hexagonal fácilmente reconocibles. La morfología en la que se presenta en la pasta puede ser muy variada en función del espacio disponible, la temperatura de hidratación y las impurezas del sistema, desde ser un tipo de cristalización aleatoria, hasta formar agrupaciones de grandes cristales (Mehta y Monteiro, 2001).

La presencia de portlandita en la pasta de cemento hidratada presenta aspectos positivos y negativos. Por un lado resulta beneficiosa porque actúa, junto con los álcalis $\mathrm{Na}^{+}$y $\mathrm{K}^{+}$, como reserva alcalina del hormigón. Puesto que es un compuesto bastante soluble, puede comportarse como disolución amortiguadora de $\mathrm{pH}$ aportando iones hidroxilo, e impedir que descienda el $\mathrm{pH}$ de la solución de los poros del hormigón. De esta manera puede proteger las armaduras contra la corrosión electroquímica. Su presencia también es beneficiosa cuando se buscan propiedades elásticas por su alto modulo de Young.

Como efectos negativos puede resaltarse su alta solubilidad en agua que la hace fácilmente lixiviable y responsable de teóricos descensos de densidad. Su carácter básico que hace al 
material sensible al contacto con compuestos ácidos, y su capacidad para reaccionar con los sulfatos y cristalizar en forma de hidratos que dan lugar a procesos de expansión.

\subsubsection{Aluminatos y sulfoaluminatos cálcicos hidratados.}

Estos compuestos constituyen un 15-20 \% del volumen de la pasta de cemento hidratada. Este tipo de compuestos tienen en común su composición principal como aluminatos cálcicos hidratados y la estructura que presentan. Sin embargo existen gran variedad de fases que difieren cualitativamente en la composición de la fase, el contenido de agua y la morfología. Las fases sulfoalumínicas cálcicas hidratadas más conocidas suelen denominarse fases AFm y AFt.

Las fases AFm $\left(\mathrm{Al}_{2} \mathrm{O}_{3}-\mathrm{Fe}_{2} \mathrm{O}_{3}\right.$-mono) presentan una fórmula general $\left[\mathrm{Ca}_{2}(\mathrm{Al}, \mathrm{Fe})(\mathrm{OH})_{6}\right] \cdot \mathrm{X} \cdot \mathrm{xH}_{2} \mathrm{O}$, donde $\mathrm{X}$ indica una unidad por fórmula de un anión monocargado, o la mitad de una unidad por fórmula de un anión doblemente cargado. Los aniones más importantes que actúan como X en la pasta de cemento hidratada son $\mathrm{OH}^{-}, \mathrm{SO}_{4}{ }^{2-}$ y $\mathrm{CO}_{3}{ }^{2-}$. La estructura de las fases $\mathrm{AFm}$ es laminar, procedente de la sustitución de átomos de $\mathrm{Ca}^{2+}$ en la red de la portlandita por otros de $\mathrm{Al}^{3+}$ ó $\mathrm{Fe}^{3+}$ de forma que la carga se ve compensada por aniones que se disponen entre las capas principales. En condiciones favorables se ordenan en láminas de cristales hexagonales, pero en las pastas de cemento habitualmente aparecen como fases pobremente cristalinas e íntimamente mezcladas con el gel CSH (Taylor, 2003).

La fórmula general de las fases AFt $\left(\mathrm{Al}_{2} \mathrm{O}_{3}-\mathrm{Fe}_{2} \mathrm{O}_{3} \text {-tri) es } \mathrm{Ca}_{3}(\mathrm{Al}, \mathrm{Fe})(\mathrm{OH})_{6} \cdot 12 \mathrm{H}_{2} \mathrm{O}\right]_{2} \cdot \mathrm{X}_{3} \cdot \mathrm{xH}_{2} \mathrm{O}$, donde $\mathrm{x} \leq 2$, y $\mathrm{X}$ indica una unidad por fórmula de una anión doblemente cargado, o dos unidades por formula de un anión con carga simple. Las fases AFt presentan una estructura en forma de prismas hexagonales o de cristales aciculares que intercalan moléculas de $\mathrm{H}_{2} \mathrm{O}$ (Taylor, 2003).

En los primeros estados del proceso de hidratación la relación de iones sulfato y alumina de la solución favorece la formación del trisulfoaluminato cálcico hidratado, también llamado etringita $\left[\mathrm{Ca}_{3}\left(\mathrm{Al}(\mathrm{OH})_{6} \cdot 12 \mathrm{H}_{2} \mathrm{O}\right]_{2} \cdot(\mathrm{SO} 4)_{3} \cdot 2 \mathrm{H}_{2} \mathrm{O}\right.$. La etringita es la fase AFt más importante y también se encuentra en forma de mineral natural. Otras fases AFt se forman por sustitución de cationes $\mathrm{Ca}^{2+}, \mathrm{Al}^{3+}$, o ambos. Un ejemplo de ellas es la thaumasita, cuya fórmula química es $\mathrm{Ca}_{3[}\left(\mathrm{Si}(\mathrm{OH})_{6} \cdot 12 \mathrm{H}_{2} \mathrm{O}\right]_{2} \cdot\left(\mathrm{CO}_{3}\right)\left(\mathrm{SO}_{4}\right)$ (Taylor, 2003). El crecimiento de la etringita en el cemento Pórtland alcanza el máximo en aproximadamente 24h. A partir de esa edad comienza la formación de monosulfoaluminato y el consiguiente descenso de etringita. 
En cementos con una relación $\mathrm{SO}_{3} / \mathrm{Al}_{2} \mathrm{O}_{3}$ relativamente alta puede que no desaparezca toda la etringita. Es presumible que la etringita que queda presente en la pasta de cemento indefinidamente se haya formado en el contorno de los granos de cemento (Taylor, 2003). La relación $\mathrm{SO}_{3} / \mathrm{Al}_{2} \mathrm{O}_{3}$ determina la composición de las fases formadas durante la hidratación, hay que recordar que el $\mathrm{C}_{3} \mathrm{~A}$ es un compuesto muy reactivo, por lo que si no se obtiene suficiente concentración de iones de sulfatos rápidamente, es posible que se formen AFm fases transitorias durante los primeros minutos de hidratación, como por ejemplo $\mathrm{C}_{4} \mathrm{AsH}_{12}, \mathrm{C}_{4} \mathrm{AH}_{13}, \mathrm{C}_{2} \mathrm{AH}_{8} \mathrm{o}$ composiciones intermedias. También se pueden formar pequeñas cantidades de $\mathrm{C}_{3} \mathrm{AH}_{6}$ durante la hidratación inicial o más tarde, debido a las fases de AFm.

Este tipo de compuestos contribuyen poco a la relación que existe entre la microestructura y las propiedades del material, sin embargo desempeñan un papel muy importante en cuanto a la durabilidad en medios sulfatados (Mehta y Monteiro, 2001). También pueden desempeñar un papel fundamental en pocesos de lixiviación dada la diferente estabilidad al pH que presentan las distintas fases (Taylor, 2003).

\subsubsection{Cemento anhidro}

Los granos de clínker anhidro en la pasta son una fase minoritaria. Su proporción depende de muchos factores, entre los que se encuentran: el tipo de distribución del tamaño de partícula del cemento empleado, la relación de agua/cemento empleada, el tipo de curado, etc. Durante el proceso de hidratación, debido al limitado espacio disponible entre las partículas, los productos que se generan tienden a cristalizar en las proximidades de las partículas de clínker, quedando alrededor de ellas. A edades mas largas, la hidratación de esas partículas resulta en la formación de productos de hidratación de alta densidad (Mehta y Monteiro, 2001).

\subsubsection{AGUA}

La pasta de cemento hidratada es capaz de contener un gran volumen de agua en función del grado de hidratación, humedad ambiental y estructura porosa. En esta se pueden encontrar disueltos los iones provenientes del propio cemento Pórtland: $\mathrm{OH}^{-}, \mathrm{SO}_{4}{ }^{2-}, \mathrm{Na}^{+}, \mathrm{K}^{+}$y Ca ${ }^{2+}$, y los que pueden penetran desde exterior, en concentraciones dadas por sus equilibrios con las fases sólidas (Mehta y Monteiro, 2001). 
La fase acuosa se encuentra llenando parte de la estructura porosa del hormigón. Su composición no es constante a lo largo del tiempo, y también varía en función de la composición cemento y del contenido de agua o la relación agua/cemento. Es un electrolito que habitualmente se encuentra saturado en hidróxido cálcico, lo que le confiere a la solución de los poros el pH alcalino característico.

Sin embargo, en la pasta de cemento podemos encontrarla formando parte de distintas fases, en función del tipo de asociación que presenta.

Se denomina agua capilar al agua presente en los poros mayores a $50 \AA$. Se considera como tal aquella que no recibe influencia de las fuerzas de atracción que ejerce la superficie de los sólidos. Existen dos tipos de agua en esta categoría: el agua libre, es el agua contenida en los poros grandes ( $>50 \mathrm{~nm}$ ) y cuya pérdida por evaporación no produce alteraciones volumétricas en el material. Un segundo tipo de agua capilar es el agua sujeta a tensión capilar que se localiza en los poros capilares pequeños (5-50nm) y cuya pérdida por evaporación puede producir la alteración de la estabilidad volumétrica de la masa.

El agua adsorbida es aquella que se encuentra muy próxima a la superficie de los sólidos y sujeta a los mismos por fuerzas de atracción. Una proporción alta de este tipo de agua se pierde cuando la pasta se expone a una humedad relativa del 30\%. Su pérdida supone problemas de contracción en la pasta.

Cuando el agua forma parte de la estructura de los geles CSH y solo se pierde en ambientes con una humedades bajas (alrededor del 10\%), se denomina agua interlaminar. Es un tipo de agua que se considera estructural. Se agrupa formando capas que se colocan entre las láminas de CSH y se encuentra fuertemente unida por enlaces de hidrógeno. La pérdida de este tipo de agua produce daños irreversibles en la estructura del material.

Por último, existe una categoría en el que la molécula de agua no conserva su entidad. Se conoce también como agua no evaporable. Esto sucede cuando la molécula de agua se combina químicamente pasando a formar parte de la microestructura de varios productos de la hidratación. Este tipo de agua no se pierde por secado, sino por descomposición de los compuestos hidratados. 


\subsubsection{POROSIDAD}

En los materiales cementicios la porosidad es uno de los factores que más afecta al comportamiento mecánico y durable. La fase acuosa queda dentro de la estructura porosa constituyendo un sistema termodinámicamente abierto y, por tanto, dinámico, cuyos equilibrios fluctuarán en función del medio ambiente exterior, la humedad relativa, la penetración de agentes agresivos, etc. El conjunto microestructura porosa y fase acuosa de los poros, determina el transporte de iones en el material y su interacción con los componentes de los materiales base cemento, así como las características de difusión de estos materiales (Segura, 2008).

Atendiendo al proceso que da lugar a la formación y localización de los poros encontramos poros formados en la matriz de la pasta, se engloban en esta categoria los poros de gel, poros capilares, granos de Hadley o huecos de aire. Además existe la porosidad intrínsea de los áridos. Los poros formados en la interfase árido-pasta. Lo huecos producidos por agua que queda atrapada. Y por último los huecos debidos a discontinuidades internas que aparecen en la pasta como consecuencia de la inestabilidad estructural que provocan las variaciones de humedad y temperatura.

A su vez, la porosidad que presentan los materiales base cemento depende de algunas variables relativas a la dosificación y el proceso de fraguado.

La microestructura porosa suele determinarse en función de tres propiedades estructurales (Haynes, 1973):

- Porosidad: es decir, parte del volumen total de la muestra ocupado por poros. Habitualmente en materiales base cemento, suele hablarse de porosidad total o de porosidad accesible, en función de la técnica empleada.

- Superficie específica interna de los poros: área o superficie accesible por unidad de volumen o de masa de una sustancia dada.

- Segregación de poros en función de sus tamaños: delimitación del volumen total de poros en rangos de poros de tamaños definidos.

En la Tabla 2 se esquematiza las principales clasificaciones mencionadas por la literatura en pasta de cemento hidratado. 
Esta estructura de poros se puede clasificar por su tamaño y distribución. Según la Unión Internacional de Química Pura y Aplicada (IUPAC, International Union of Pure and Applied Chemistry) los poros se clasifican en: micro-poros ( $\varnothing<2 \mathrm{~nm}$ ), capilares o meso-poros ( $2 \mathrm{~nm}<$ $\varnothing<50 \mathrm{~nm}$ ) y macro-poros ( $\varnothing>50 \mathrm{~nm}$ ). Los que suelen afectar a la durabilidad son los mesoporos y los macro-poros, especialmente en el caso de poros interconectados y porosidad abierta, lo que facilita el transporte de sustancias solubles en líquidos o gases. Particularmente la resistencia a ataques químicos y físicos se reduce considerablemente cuando se reduce la cantidad de poros capilares. Además, existen otras escalas, como la propuesta por Mehta (1986) o Mindess (2002).

Junto con las tres categorías que se describen anteriormente, existe una cuarta tipología de tipos de poro, que se denomina como granos de Hadley, tratándose de una porosidad debida a una tipología de productos de hidratación. Fueron primeramente descritos por Hadley et al. (2000), como describiremos más adelante.

Tabla 2. Principales clasificaciones mencionadas por la literatura en pasta de cemento hidratado (Aligizaki, 2006)

\begin{tabular}{|c|c|c|c|c|c|c|}
\hline \multicolumn{2}{|c|}{ IUPAC } & \multicolumn{2}{|c|}{ P. Metha, 1986} & \multicolumn{2}{|c|}{ S. Mindess, 2002} & \multirow{2}{*}{$\begin{array}{c}\text { Efecto } \\
\text { Retracción } \\
\text { Fluencia }\end{array}$} \\
\hline \multirow{2}{*}{ Microporos } & \multirow{2}{*}{$<2 \mathrm{~nm}$} & \multirow{3}{*}{$\begin{array}{c}\text { Espacio } \\
\text { interparticular } \\
\text { entre las } \\
\text { láminas de } \\
\text { C-S-H }\end{array}$} & \multirow{3}{*}{$\begin{array}{c}1 \mathrm{~nm} \\
\mathrm{a} \\
3 \mathrm{~nm}\end{array}$} & $\begin{array}{l}\text { Microporos } \\
\text { "intercapa" }\end{array}$ & $>0.5 \mathrm{~nm}$ & \\
\hline & & & & Microporos & $0.5-2.5 \mathrm{~nm}$ & $\begin{array}{l}\text { Retracción } \\
\text { Fluencia }\end{array}$ \\
\hline \multirow{2}{*}{ Mesoporos } & \multirow{2}{*}{$\begin{array}{c}2 \mathrm{~nm} \\
\mathrm{a} \\
50 \mathrm{~nm}\end{array}$} & & & $\begin{array}{l}\text { Capilares } \\
\text { pequeños } \\
\text { (gel) }\end{array}$ & $2.5-10 \mathrm{~nm}$ & Retracción \\
\hline & & $\begin{array}{c}\text { Poros } \\
\text { capilares } \\
\text { (a/c baja) }\end{array}$ & $\begin{array}{l}10 \mathrm{~nm} \\
\mathrm{a} \\
50 \mathrm{~nm}\end{array}$ & $\begin{array}{l}\text { Capilares } \\
\text { medianos }\end{array}$ & $10-50 \mathrm{~nm}$ & $\begin{array}{l}\text { Resistencia } \\
\text { Permeabilidad } \\
\text { Contracción }\end{array}$ \\
\hline \multirow{2}{*}{ Macroporos } & \multirow{2}{*}{$>50 \mathrm{~nm}$} & $\begin{array}{l}\text { Poros } \\
\text { capilares } \\
\text { (a/c alta) }\end{array}$ & $\begin{array}{c}3 \mu \mathrm{m} \\
\mathrm{a} \\
5 \mu \mathrm{m}\end{array}$ & $\begin{array}{l}\text { Capilares } \\
\text { grandes }\end{array}$ & $50-10 \mu \mathrm{m}$ & $\begin{array}{c}\text { Resistencia } \\
\text { Permeabilidad }\end{array}$ \\
\hline & & Aire atrapado & $\begin{array}{c}50 \mu \mathrm{m} \\
\mathrm{a} \\
1 \mathrm{~mm}\end{array}$ & $\begin{array}{c}\text { Aire } \\
\text { atrapado }\end{array}$ & $0,1-1 \mathrm{~mm}$ & Resistencia \\
\hline
\end{tabular}

2.2.3.1. Poros de gel o microporos.

Su nomencltura se debe Powers (Powers y Brownyard, 1948), según el cual, y basándose en datos de adsorción-desorción de vapor de agua, los poros de gel son los espacios entre las fibras 
del gel CSH. Otros autores han comprobado que realmente se trata del aire que queda retenido entre las láminas de gel CSH (Feldman y Sereda, 1976). Atendiendo a la clasificación hecha por Mindess (2002) su tamaño oscila entre $0,5 \mathrm{~nm}$ y $2,5 \mathrm{~nm}$. Se trata de espacios flexibles, en función de la cantidad de agua que los puede ocupar.

Constituyen el $28 \%$ de la pasta de cemento hidratada, pero por su pequeño tamaño, no influyen negativamente en la resistencia mecánica de los materiales base cemento. Sin embargo sí pueden afectar a la estabilidad de volumen modificando la retracción y la fluencia del material.

\subsubsection{Poros capilares o mesoporos.}

Este tipo de poros se forma cuando los productos de hidratación no rellenan el espacio anteriormente ocupado por el agua. El volumen y distribución de los mismos quedará determinado por la relación agua/cemento y el grado de hidratación del material. Al depender del grado de hidratación, es una propiedad cambiante que evoluciona con la hidratación del material. En función de su tamaño y distribución, los mesoporos pueden tener influencia en las propiedades de los materiales base cemento, permeabilidad, durabilidad, resistencia mecánica, etc., especialmente cuando forman una red interconectada.

Con el fin de limitar la formación de mesoporos numerosos autores han estudiado la relación agua/cemento mínima que permita hidratar el material reduciendo la la formación de mesoporos Brouwers, 2004, 2005 y 2007; Powers y Brownyard, 1948), concluyendo que si bien una relación agua/cemento de 0.39 asegura una buena hidratación del cemento, para evitar la autodesecación es necesario que los poros de gel queden llenos y esto se consigue a relaciones agua/cemento de 0.44 (Taylor, 2003).

\subsubsection{Granos de Hadley.}

Junto con los poros de gel y los poros capilares, son el tercer tipo de porosidad intrínseca presente en la pasta. Este tipo de poros fueron descritos por Hadley (2000), y han sido estudiados por otros autores (Barnes et al., 1978; Kjellsen et al., 1996; Kjellsen et al.1997; Hadley et al., 2000). Una vez que se ha formado un contorno de productos hidratados en torno a la partícula de cemento anhidro, el gel crece hacia afuera ocupando el espacio que dejan los poros capilares. Cuando no se forman los productos de hidratación en el interior del grano de cemento, queda un espacio hueco que recibe el nombre de "hollow shell pores" o grano de 
Hadley. Su tamaño oscila entre 1 y $20 \mu \mathrm{m}$. Inicialmente son poros cerrados que generalmente conservan la forma de la partícula de cemento de la que proceden y pueden encontrarse total o parcialmente huecos. A medida que prosigue la hidratación pueden rellenarse con otros productos de hidratación. La cantidad de estos poros generalmente disminuye siguiendo la misma tendencia que los poros capilares, aunque por el contrario, suelen ser generalmente estructuras regulares y cerradas, po lo que su identificación resulta complicada.

\subsubsection{Macroporos.}

Los macroporos suelen formarse cuando las burbujas de aire que se quedan atrapadas durante el proceso de amasado no afloran a la superficie. Suelen presentarse de forma esférica y su tamaño supera los $50 \mathrm{~nm}$.

Su presencia en el hormigón se debe a dos causas principales. Por un lado, su aparición durante el proceso de amansado. Para prevenir su formación es necesario que después de un correcto amasado, la masa sea compactada adecuadamente. Por otro, la formación justificada de burbujas de aire mediante aditivos, para mejorar las prestaciones del material frente a ciertos ambientes agresivos. En este caso, la distribución de estas es homogénea en toda la masa.

Normalmente no suelen tener conexión con otras burbujas de aire, por lo que no afectan a la permeabilidad del material. Si no se encuentran conectados, no influyen significativamente en la durabilidad del material, pero sí pueden influir muy negativamente en la resistencia mecánica.

\subsection{CEMENTOS CON ADICIONES}

La EHE 08 (2008) define como adiciones aquellos materiales inorgánicos, puzolánicos o con hidraulicidad latente que, finamente divididos, pueden ser añadidos al hormigón con el fin de mejorar alguna de sus propiedades o conferirle características especiales.

La adición puede tener lugar antes del molido del clínker o como sustitución parcial del cemento. En el segundo caso, el porcentaje de cemento en masa sustituido viene especificado por la Instrucción para la recepción de cementos, RC-08 (2009).

A lo largo de este punto describiremos las características particulares que presentan los cementos con las adiciones minerales empleadas en esta tesis doctoral, centrándonos en las características microestructurales particulares que provocan las cenizas volantes al clínker. 


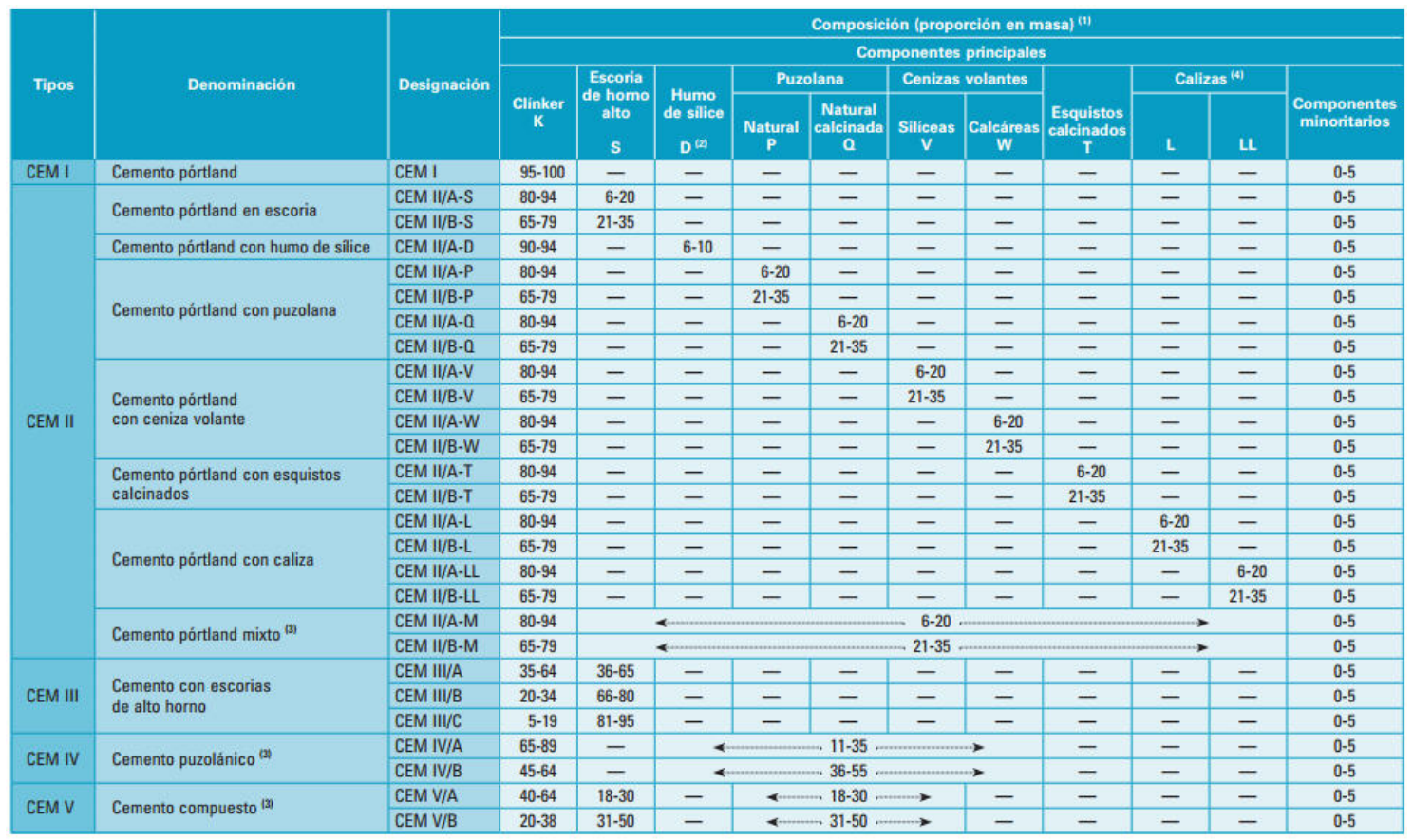

Figura 2. Cementos comunes (RC-08, 2009)

Los materiales puzolánicos suelen presentar en su composición elevados contenidos de $\mathrm{SiO}_{2}$ y $\mathrm{Al}_{2} \mathrm{O}_{3}$. Suelen ser materiales lo suficientemente reactivos como para que al mezclarlos con agua y $\mathrm{CaO}$ produzcan silicatos cálcicos hidratados y puedan actuar como cementos hidráulicos. Su contenido en $\mathrm{CaO}$ es bajo por lo que habitualmente este componente lo aporta el clínker. Como consecuencia se reduce la relación C/S y el contenido de portlandita en el material resultante.

Los materiales con capacidad cementante latente presentan composiciones intermedias entre los puzolánicos y los cementos Portland. Pueden actuar como material cementante al mezclarlos con agua y una cantidad mínima de alguna otra sustancia que actúe como catalizador o activador de la reacción.

Las propiedades técnicas de los materiales con adiciones puzolánicas, se derivan, principalmente, de tres características de la reacción puzolánica.

La primera, es que es una reacción bastante más lenta que la reacción de hidratación del cemento, por tanto, la velocidad de liberación del calor y el desarrollo de resistencias serán procesos también más lentos. 
La segunda, es que es una reacción que consume hidróxido de calcio en vez de generarlo, lo que es importante para la durabilidad de las pastas hidratadas en ambientes ácidos.

La tercera, es que al producirse en un tiempo posterior los productos de reacción rellenan, de forma muy eficiente, los espacios capilares que quedan después de la hidratación de los componentes del cemento. Así se mejora la compacidad del material, reduciendo la porosidad y aumentando la resistencia mecánicas del sistema.

\subsubsection{PUZOLANAS (P, Q)}

Las puzolanas son sustancias naturales o artificiales compuestas principalmente por dióxido de silicio reactivo $\left(\mathrm{SiO}_{2}\right)$ y óxido de aluminio $\left(\mathrm{Al}_{2} \mathrm{O}_{3}\right)$. Otros compuestos minoritarios son el óxido de hierro $\left(\mathrm{Fe}_{2} \mathrm{O}_{3}\right)$ y otros óxidos (RC-08, 2009). La fase cristalina de estos compuestos suele ser pequeña, siendo mayoritaria la fase vitrea, por lo que son materiales altamente reactivos.

La puzolana por sí misma posee un valor cementante nulo o muy pequeño. Sin embargo, en presencia de agua y finamente molidas reaccionan, a la temperatura ambiente normal, con el hidróxido de calcio disuelto (que actúa como activador) para formar compuestos de silicato de calcio y aluminato de calcio capaces de desarrollar resistencia. Estos compuestos son similares a los que se forman durante el endurecimiento de los materiales hidráulicos.

Las puzolanas naturales son normalmente materiales de origen volcánico o rocas sedimentarias con composición química y mineralógica adecuadas al uso del cemento en el que se encuentran incluidas.

Las puzolanas naturales calcinadas son materiales de origen volcánico, arcillas, pizarras o rocas sedimentarias activadas por tratamiento térmico, en España no se utilizan.

\subsubsection{CENIZAS VOLANTES.}

Las cenizas volantes se obtienen por precipitación electrostática o mecánica de partículas pulverulentas arrastradas por los flujos gaseosos de hornos alimentados con carbón pulverizado. Pueden ser de naturaleza silícea o calcárea. Las primeras tienen propiedades puzolánicas, y las segundas pueden tener, además, propiedades hidráulicas (RC-08, 2009). Las cenizas volantes de bajo contenido en calcio, silicoaluminosas, tienen un elevado contenido en sílice y alúmina y consisten principalmente en partículas esféricas vítreas de aluminosilicatos, que contienen 
hierro y álcalis. Si el enfriamiento no es lo suficientemente rápido, en el interior de las grandes partículas esféricas vítreas, se produce una cristalización (desvitrificación) de aluminosilicatos, principalmente silimanita $\left(\mathrm{Al}_{2} \mathrm{O}_{3} \cdot \mathrm{SiO}_{2}\right)$ y mullita $\left(3 \mathrm{~A}_{2} \mathrm{O}_{3} \cdot \mathrm{SiO}_{2}\right)$ en forma de delgadas agujas.

\subsection{DURABILIDAD}

El proyecto de una estructura se lleva a cabo considerando una serie de exigencias que dan cumplimiento al conjunto de requisitos que debe reunir dicha estructura. En la EHE-08 las exigencias que se refieren a los requisitos de seguridad, estabilidad y aptitud al servicio pueden ser expresadas en términos de probabilidad global de fallo, que está ligada al índice de fiabilidad. En esta instrucción la fiabilidad se asegura adoptando el método de los Estados Límite.

Tabla 3. Vida útil nominal de las estructuras según la EHE-08 (2008)

\begin{tabular}{cc}
\hline Tipo de estructura & $\begin{array}{c}\text { Vida útil nominal } \\
\text { (años) }\end{array}$ \\
\hline Estructuras de carácter temporal & $3-10$ \\
\hline $\begin{array}{c}\text { Elementos reemplazables que no forman } \\
\text { parte de la estructura principal }\end{array}$ & $10-25$ \\
\hline $\begin{array}{c}\text { Edificios o instalaciones agrícolas o } \\
\text { industriales y obras marítimas }\end{array}$ & $15-50$ \\
\hline $\begin{array}{c}\text { Edificios de viviendas u oficinas, puentes u } \\
\text { obras de paso de longitud inferior a 10 } \\
\text { metros y estructuras de ingeniería civil } \\
\text { (excepto obras marítimas) de repercusión } \\
\text { económica baja o media }\end{array}$ & 50 \\
\hline $\begin{array}{c}\text { Edificios de carácter monumental o de } \\
\text { importancia especial }\end{array}$ & 100 \\
\hline $\begin{array}{c}\text { Puentes de longitud igual o superior a 10 } \\
\text { metros y otras estructuras de ingeniería } \\
\text { civil de repercusión econóica alta }\end{array}$ & 100 \\
\hline
\end{tabular}

Cuando se proyecta una estructura, se deben cumplir los estados límites de agotamiento, servicio y durabilidad. Para ello han de considerarse las cargas o acciones mecánicas previstas a lo largo de su vidad útil así como condiciones ambientales y de uso ya sean de tipo físico, químico o biológico que puedan deteriorarlas, reduciendo su vida de servicio, o exigiendo para su conservación un costo importante de mantenimiento o reparación. 
La Instrucción Española del Hormigón EHE-08), asume este concepto, y define la durabilidad de las estructuras de hormigón armado y de las armaduras como "la capacidad para soportar, durante la vida útil para la que ha sido proyectada, las condiciones físicas y químicas a las que está expuesta, y que podrían llegar a provocar su degradación como consecuencia de efectos diferentes a las cargas y solicitaciones consideradas en el análisis estructural”, y añade en su apartado 37.3. que "la durabilidad del hormigón es la capacidad de comportarse satisfactoriamente frente a las acciones físicas o químicas agresivas y proteger, adecuadamente, las armaduras y demás elementos metálicos embebidos en el hormigón durante la vida de servicio de la estructura”.

En una primera aproximación, se puede decir que la durabilidad de una estructura de hormigón depende fundamentalmente de las condiciones ambientales y de uso a que esté sometida, y la mayor o menor resistencia que el hormigón presenta a su deterioro frente a dichas condiciones, es decir, su capacidad durable.

Las normas tienen en cuenta estos factores y, en función del tipo de exposición de la estructura durante su vida útil, exigen determinadas características al material.

\subsubsection{MECANISMOS DE TRANSPORTE EN EL INTERIOR DE LOS SISTEMAS CEMENTANTES}

El transporte combinado de calor, humedad y sustancias químicas a través del material, y el intercambio con el medio exterior, así como los parámetros que controlan estos mecanismos de transporte, constituyen los elementos principales de la durabilidad. Excepto el deterioro mecánico, la presencia de agua es el principal factor de deterioro. La estructura de la red de poros -tipo, tamaño y distribución- y la presencia y tipo de fisuras gobiernan la entrada y el transporte de agua a través del material, de modo que su conocimiento puede ser considerado como esencial.

La penetración de elementos agresivos desde el exterior -sustancias y gases disueltos- está controlada por la permeabilidad del material que depende, a su vez de la estructura de los poros, la configuración de las fisuras y el contenido de agua en los mismos (Shazali et al., 2006).

Los agentes potencialmente agresivos penetran a través de la estructura porosa del hormigón, en estado gaseoso o líquido. Del mismo modo, los iones disueltos en la fase acuosa contenida en los poros se abren paso por la red porosa. En general, los mecanismos de transporte difieren 
unos de otros por la fuerza impulsora que actúa, pudiendo ser ésta un gradiente de concentraciones (difusión), tensión superficial de los poros capilares (absorción), diferencia en presión (permeabilidad), diferencia en densidad o temperatura (convección) y diferencia de potencial electrostático (migración iónica). A continuación se describen los mismos:

- Difusión: es un proceso físico, en el que partículas materiales se introducen en un medio que inicialmente estaba ausente de ellas. Éste es inducido por la existencia de un gradiente de concentración que tiende a equilibrar los diferentes niveles de concentración. El proceso puede producirse en régimen estacionario (donde el caudal se mantiene constante en el tiempo) o transitorio.

- Absorción capilar: es una succión que se debe a que la superficie libre de los sólidos tiene un exceso de energía debido a la falta de enlaces con otras moléculas cercanas. Ésto tiende a compensarse absorbiendo moléculas de agua que están en la superficie y continúa hasta alcanzar un estado de equilibrio. El transporte de líquido a través de los poros capilares por la tensión superficial, se genera sobre el menisco provocando que el líquido se eleve en el poro. Este proceso depende de las propiedades de líquido (viscosidad, densidad, tensión superficial) y del sólido (estructura porosa).

- Permeabilidad: es la capacidad para permitir que un fluido atraviese sin alterar la estructura interna de un material. Ésta tiene lugar cuando un fluido líquido o gaseoso, atraviesan el material debido a la fuerza impulsora generada mediante un diferencial de presión hidráulica.

- Migración iónica: ocurre si entre distintos puntos de un electrolito se producen diferencias en el potencial electrostático. El campo eléctrico resultante es causa de un flujo de carga en sentido del campo. En los materiales cementicios el electrolito es la fase acuosa embebida en los poros del material.

- Convección: se produce por la diferencia de temperatura existente entre dos zonas del material. Los fluidos existentes en la zona de mayor temperatura aumentan de volumen, por lo tanto, disminuyen su densidad. El fluido tiende a homogenizar sus propiedades para lo que necesita desplazarse hacia las zonas más frías.

Junto a estos mecanismos existen varios factores que condicionan la entrada de los agentes agresivos. Entre ellos destacan las condiciones ambientales, la concentración local de las 
sustancias, la porosidad total, la distribución y el tamaño de poros en el material, anchura y número de microfisuras existentes, grado de saturación de la red de poros y la temperatura (RILEM, 1999).

En la práctica, el transporte a través del material depende de varios de los mecanismos y no suele ser función exclusiva de uno de ellos. Generalmente varios actúan simultáneamente como consecuencia del amplio rango de tamaños de poros y de la enorme variación de humedad que se produce en los materiales base cemento en función de las condiciones de exposición. Como consecuencia del transporte de los agentes agresivos, la matriz puede alterar su estructura física por la absorción química de determinados iones sobre las fases sólidas (Castellote, 1997).

Otro factor que tiene influencia en la capacidad de transporte de los iones a través del material es la composición química de las soluciones contenidas en los poros de la pasta de cemento. La naturaleza del solvente determina la viscosidad de la disolución y el grado de solvatación de los iones (Helfferich, 1962).

Como ya se ha expuesto, el transporte de iones a través del material se debe a varios mecanismos. A fin de determinar la importancia relativa de cada uno y poder resolver las ecuaciones de flujo que derivan de los mismos, la mayoría de los estudios existentes no consideran la absorción capilar y los provocados por gradientes de presión. No se cometen errores significativos si se considera el material saturado y en condiciones homogéneas.

En esas condiciones el transporte de los agentes agresivos se puede representar utilizando la ecuación de Nernst-Plank, como si de un electrolito se tratara. Esta ecuación considera el movimiento iónico total como la suma de los mecanismos de difusión, migración y convección (Bard y Faulkner, 2001)

$$
J_{j}=-D_{j} \nabla C_{j}-\frac{z_{j} F}{R T} D_{j} C_{j} \nabla \varnothing+C_{j} v_{j}
$$

Donde:

- $\mathrm{J}_{\mathrm{j}}$ es el flujo de la especie $\mathrm{j}\left(\mathrm{mol} \cdot \mathrm{cm}^{-2} \cdot \mathrm{s}^{-1}\right)$.

- $\mathrm{D}_{\mathrm{j}}$ es el coeficiente de difusión de la especie $\mathrm{j}\left(\mathrm{cm}^{-2} \cdot \mathrm{s}^{-1}\right)$.

- $\mathrm{C}_{\mathrm{j}}$ es la concentración de la especie j $\left(\mathrm{mol} \cdot \mathrm{cm}^{-3}\right)$.

- $z_{j}$ es la carga eléctica de la especie j. 
- $\mathrm{v}_{\mathrm{j}}$ es la velocidad del ion $\left(\mathrm{cm} \cdot \mathrm{s}^{-1}\right)$.

- F es el número de Faraday $\left(\mathrm{cal} \cdot \mathrm{v}^{-1} \cdot \mathrm{eq}^{-1}\right)$.

- $\mathrm{R}$ es la constante de los gases $\left(\mathrm{cal} \cdot \mathrm{mol}^{-1} \cdot \mathrm{K}^{-1}\right)$.

- $\mathrm{T}$ es la temperatura $(\mathrm{K})$.

- $\nabla$ es el vector operador gradiente para la transferencia de masa unidimensional y en coordenadas rectangulares $[\mathrm{i} \cdot(\partial / \partial \mathrm{x})]$ donde i es el vector unidad en eleje de abcisas y x la distancia.

- $\varnothing$ es la diferencia de potencial electróstatico (v).

En el estado no estacionario se emplea la ecuación:

$\frac{\partial C j}{\partial t}=D_{j} \nabla^{2} C j-\frac{z j F}{R T} D_{j} \nabla(C j \nabla \varnothing)-v_{j}$ Ecuación 2

En situaciones de presión y temperatura constantes, es posible descartar los fenómenos de convección en la fase acuosa de la estructura porosa. En condiciones naturales no se produce la migración. Debido a esto y con el fin de realizar simplificaciones para poder estudiar el transporte de los iones a través del hormigón, en los ensayos se intenta que el flujo de las especies se límite a un solo mecanismo, la difusión.

En 1855, Fick adaptó la ecuación empírica de Fourier para la conducción del calor al estudio de la difusión. De tal manera que el flujo de una sustancia a través de una sección definida es proporcional al gradiente de concentración medido en la dirección perpendicular a la sección de paso (McCabe y Smith, 1981). La primera ley de Fick para la difusión en estado estacionario se define como:

$$
F=-D \frac{\partial C}{\partial x}
$$

Donde:

- F es la velocidad de transferencia por unidad de área.

- D es el coeficiente de difusión.

- C es la concentración de la especie que difunde. 
- x es la longitud de penetración en el sentido normal de la sección.

$\mathrm{Al}$ relacionar las variaciones de la concentración con el tiempo y el espacio durante el proceso de difusión, el flujo se considera no estacionario y se aplica la segunda ley de Fick:

$$
\frac{\partial C}{\partial t}=-D \frac{\partial^{2} C}{\partial x^{2}}
$$

Donde:

- D es el coeficiente de difusión.

- C es la concentración de la especie que difunde.

- x es la longitud de penetración en el sentido normal de la sección.

La solución de la ecuación requiere definir las condiciones iníciales y de contorno de cada caso.

\subsubsection{DEGRADACIÓN QUÍMICA}

La degradación de los materiales cementicios es un fenómeno complejo que depende tanto de las propiedades del medio agresivo como de la microestructura del sistema cementante. La mayoría de los procesos químicos que influyen en la durabilidad de este tipo de materiales están asociados a los procesos de transporte. Los agentes químicos agresivos suelen estar disueltos siendo el agua el medio de transporte para los mismos. En ocasiones el agua constituye en sí mismo el agresivo para el sistema cementante.

Según las reacciones químicas que tienen lugar en el seno de la matriz cementicia podemos clasificar los tipos de degradación en tres tipos.

\subsubsection{Degradación por lixiviación}

Se producen por la acción extractiva o de lavado que sufren ciertos componentes de la pasta endurecida de cemento. La portlandita es la fase más soluble en aguas puras. Su disolución y/o lixiviación puede producir un incremento de la porosidad y la permeabilidad, además de pérdida de masa. La reducción de la alcalinidad es otro de los factores que puede influir en la durabilidad de sistemas cementantes donde se producen procesos de lixiviación de la 
portlandita, derivando en la formación de geles de ácidos silícicos con propiedades resistentes mermadas frente a los originales.

Cuando la lixiviación de compuestos se produce por acción del agua, ésta es más intensa cuanto mayor es la proporción de sales minerales que contiene, dado que se favorece una disolución mayor de compuesto.

También se produce lixiviación en contacto con disoluciones ácidas. Los compuestos hidratados del cemento son solubles en medios ácidos. Cuando se hace referencia a la acción de los ácidos, hay que tener en cuenta que debido a que este tipo de especies en disolución se encuentran total o parcialmente disociados, el anión conjugado también puede causar efecto. Tales son los casos de la acción del ácido sulfúrico y el ácido clorhídrico, donde tanto los protones como el sulfato y el cloruro ejercen una acción en el hormigón. En cuanto a la acción que produce el anión del ácido, depende de la capacidad de reacción con los iones $\mathrm{Ca}^{2+}$, y en menor proporción con los iones $\mathrm{Fe}^{2+} \mathrm{y} \mathrm{Al}^{3+}$ que se encuentran formando parte de los compuestos de la pasta. La agresión del anión dependerá de la solubilidad de las sales de calcio, hierro y aluminio formadas con él.

\subsubsection{Reacciones de intercambio iónico}

Las reacciones de intercambio iónico tienen lugar entre los iones presentes en la disolución agresiva y los compuestos de la matriz. Los compuestos originados pueden ser arrastrados por lixiviación, o permanecer en el lugar de su formación, pero habitualmente no poseen capacidad aglomerante.

Algunas de las sales que pueden ocasionar daños en el material son el cloruro de sodio, el sulfato de sodio o magnesio. La formación de yeso y brucita son dos de los principales procesos que tienen lugar mediante reacciones de intercambio iónico.

La formación de yeso es el resultado de una reacción de intercambio químico donde los iones sulfato reemplazan a los $\mathrm{OH}^{-}$del $\mathrm{CH}$ formado durante la hidratación. La cristalización de yeso comienza cuando cesa la cristalización de ettringita debido a la deficiente provisión de aluminatos desde la fase sólida a la solución. Si el contenido en sulfato es elevado y la concentración local de iones $\mathrm{Ca}^{2+}$ en la fase líquida intersticial del hormigón excede el producto de solubilidad del yeso, este último precipitará. 
Los cristales de yeso se encuentran generalmente localizados en los poros y en la interfase árido-pasta, fundamentalmente por dos razones: porque existe una cantidad portlandita mayor, y porque existen zonas de mayor porosidad que permiten el crecimiento de cristales. Por la incidencia que presenta este tipo de degradación sobre la interfase, la magnitud es diferente si los referimos pasta, mortero u hormigón.

La formación de yeso produce ablandamiento de la capa exterior de los morteros y hormigones, mientras que la zona interna puede permanecer cohesiva. Por eso una manifestación clásica de la formación de yeso es la degradación de esquinas y bordes.

La formación de brucita generalmente se asocia a la degradación conjunta con sulfatos por la existencia de sulfatos magnésicos en el medio. La reacción consiste en intercambio iónico del $\mathrm{Ca}^{2+}$ y el $\mathrm{Mg}^{2+}$ en el hidróxido.

Cuando la reacción surge a partir del sulfato de magnesio el resultado es la formación de una banda compuesta de yeso y brucita sobre la superficie. Como la solubilidad de la brucita es muy baja, el $\mathrm{pH}$ de la solución de los poros decae y eso produce a la inestabilización de los compuestos hidratados. Cuando se consume el $\mathrm{CH}$, otros compuestos compensan el aporte de iones, y llegado el caso, la descalcificación del gel CSH, que da lugar a la formación de un gel rico en sílice sin propiedades ligantes.

\subsubsection{Formación de compuestos expansivos}

Es debida a la formación de nuevos compuestos estables en la masa de cemento endurecido. En el momento inicial es posible que la martriz cementicia se vea reforzada por el relleno de los poros con cristales de nueva formación, aumentando su compacidad. Sin embargo el crecimiento progresivo de cristales puede producir un incremento de la tensión interna, causando fisuración por laminación, la deformación o la pérdida de resistencia.

Existen distintas vías de formación de compuestos expansivos: ataque por sulfatos, en sus distintas formas, que incluyen la formación de ettingita y thaumasita. En este apartado también pueden incluirse los procesos relacionados con las reacciones árido-álcali, la hidratación tardía de CaO libre y MgO.

\section{Formación de etringita}


El ataque por sulfatos supone una combinación de procesos físicos y químicos que implican la formación de etringita en el material expuesto. La etringita puede generar un aumento de volumen en el interior del sólido con la consiguiente fisuración. Podemos distinguir distintos tipos de etringita en función del origen de su formación.

La ettringita primaria se forma durante la etapa de hidratación, a partir de los sulfatos aportados por el yeso fundamentalmente y los aluminatos cálcicos del cemento. Presenta una distribución homogénea y no presenta problemas de expansión puesto que su formación tiene lugar mientras la pasta se encuentra en estado plástico.

La ettringita secundaria sin embargo se forma cuando el estado de la pasta es endurecido, dando lugar a un producto que ocupa un volumen mayor que los compuestos de partida. La composición de la fase líquida, en particular del contenido de calcio, determina que la cristalización de la etringita pueda ser expansiva o no. Si el contenido de calcio en la disolución es alto, la solubilidad de la etringita es muy pequeña, formándose una disolución sobresaturada, lo que determina que la velocidad de nucleación de la etringita sea superior a la de crecimiento de sus cristales. Esto incide en la formación de cristales pequeños, de naturaleza más o menos coloidal y de baja densidad. La masa sólida formada, con un volumen molar superior al de la masa inicial, desarrolla tensiones muy elevadas debidas a las presiones de cristalización que acompañan su formación. Por el contrario, en los cementos que liberan menos portlandita, la etringita precipita a partir de disoluciones menos concentradas, formando cristales de forma acicular bien formados y con una densidad mayor. El aumento de volumen que se produce es menor que en el caso anterior reduciendo los fenómenos de expansión.

\section{Formación de thaumasita}

La thaumasita es una sal compleja, que se encuentra presente en la naturaleza y contiene sulfato, sílice y carbonato, $\mathrm{CaO} \cdot \mathrm{SiO}_{2} \cdot \mathrm{CaSO}_{3} \cdot 15 \mathrm{H}_{2} \mathrm{O}$. La estructura de la thaumasita es muy similar a la de la ettringita. Presenta cristales hexagonales habitualmente dispuestos en forma de agujas. Las bajas temperaturas y la humedad generalmente aceleran la formación de thaumasita porque facilitan los cambios en las esferas de coordinación. La thaumasita produce en el material daños por expansión, similares a los producidos por la ettringita. Y puede producir daños por la deposición de yeso e inestabilización del gel CSH que produce la descohesión del material.

\section{Reacciones árido-álcali}


Las reacciones árido-álcali son reacciones que tienen lugar entre los componentes reactivos de los agregados y los álcalis contenidos en la fase acuosa del hormigón. En este grupo de reacciones la más conocida es la reacción que presentan los componentes silícicos de los áridos.

En la pasta endurecida, la fase acuosa presenta un $\mathrm{pH}$ altamente alcalino, superior a 12.5, por lo que la presencia de álcalis está prácticamente asegurada. Los áridos reactivos son aquellos que no son totalmente estables en presencia de una solución alcalina, y producen una reacción ácido base entre los $\mathrm{OH}^{-}$de la disolución de los poros y el grupo del ácido silanol (Si-OH). Para que tenga lugar la reacción es necesario que se solubilice parte de la sílice amorfa.

La solubilidad de la sílice amorfa depende del pH del medio de exposición y del grado de cristalinidad que presente, puesto que la estructura condiciona el acceso que los iones hidroxilo tienen a los grupos silanol. La neutralización de los grupos silanol, Si-OH, da lugar a un gel de silicato. La rotura de las uniones Si-O-Si de la sílice tiene como resultado la desintegración de la estructura y la formación de soluciones silico-alcalinas.

Un segundo grupo de reacción árido-alcali es la que tiene lugar entre los álcalis del hormigón y los áridos procedentes de rocas carbonatadas, especialmente áridos de naturaleza dolomítica que forman parte de rocas calizas. A este proceso se le denomina desdolomitización y tiene lugar junto con la formación de brucita.

\section{Hidratación tardía de CaO y MgO}

La presencia en el cemento de $\mathrm{CaO}$ y $\mathrm{MgO}$ en cantidades superiores a las permitidas conduce a que el material que las contenga muestre signos de aumento de volumen, fisuras y deterioro como consecuencia de cambios de su estructura interna por incorporación de moléculas de agua que producen expansiones volumétricas.

La presencia de $\mathrm{CaO}$ libre supone un problema cuando la reacción de hidratación transcurre durante el endurecimiento y aún cuando la pasta adquiere rigidez provocando hinchamiento, tensiones y fisuras, especialmente en estructuras de gran volumen o en situaciones de restricción al movimiento. Pero generalmente no produce efectos con consecuencias graves.

El MgO supone un problema cuando se forma magnesita libre, que expuesta a un gradiente térmico inadecuado forma periclasa. La periclasa posee una hidratación lenta que puede prolongarse más allá del periodo de endurecimiento. Puede producir núcleos expansivos que conducen al aumento de volumen progresivo, tensiones elevadas y fisuras. 


\subsubsection{DURABILIDAD DE MATERIALES CEMENTICIOS EN CONTACTO CON AGUAS NATURALES}

La interacción que presentan los materiales cementicios con el agua produce procesos de deterioro complicados influidos por diferencies parámetros. La acción de las aguas naturales en los materiales cementicios puede provocar descalcificación o lixiviación de las fases hidratadas, pero además es un proceso que suele aparecer asociado a otros procesos de deterioro.

El deterioro de los materiales cementicios por acción de las aguas naturales se produce en contacto con aguas blandas, que contengan pocas impurezas o por aguas de condensación industrial, aguas de fusión de glaciares, aguas de nieve, aguas de lluvia, aguas pantanosas y algunas aguas procedentes de grandes profundidades. Puede ser causada cuando la superficie de la estructura se pone en contacto con aguas débilmente mineralizadas, como por ejemplo arroyos cuando su cuenca de aportación está formada por tipos de rocas poco solubles, como basalto, granito, etc. En este caso la velocidad de degradación viene condicionada por la velocidad de desaparición del hidróxido cálcico disuelto. Este tipo de degradación puede ser intensa en el caso de que el agua agresiva presente un elevado poder disolvente y existe la posibilidad de una circulación de dicha agua, agravándose si la microestructura del material es altamente porosa (Llorente, 2008).

La fase acuosa en los poros del material cementicio es un sistema en equilibrio termodinámico con los productos de hidratación cercanos. Cuando este sistema se pone en contacto con el agua, se genera un gradiente de potencial químico entre la disolución de los poros y la disolución exterior que provoca la difusión de los iones. El gradiente generado es el responsable de que se produzcan cambios de concentración de los distintos iones dando lugar a la alteración de los equilibrios de disolución precipitación de compuestos en el material (Reardon, 1990).

De modo general, el proceso suele producir una descalcificación de los compuestos de la matriz producida por la disolución de portlandita y posteriormente de los silicatos cálcidos hidratados. En la Figura 3 (Segura, 2008) se muestra un esquema del proceso de difusión de iones y los procesos de disolución/precipitación que provocan las aguas desmineralizadas, al entrar en contacto con los materiales cementicios. Los compuestos de la matriz de cemento hidratado se disolverán o cambiarán su composición de acuerdo a determinados $\mathrm{pH}$ y a determinadas concentraciones de los iones principales iones $\left(\mathrm{Ca}^{2+}, \mathrm{SO}_{4}{ }^{2-}, \mathrm{CO}_{3}{ }^{2-}\right.$ en la fase acuosa de los poros (Segura, 2008). 
La concentración de $\mathrm{Ca}^{2+}$ en la solución de los poros es determiannte para conocer la estabilidad de los silicatos cálcicos hidratados en la matriz cementicia. A altas concentraciones de calcio (20 mM), el CSH y la portlandita permanecen insolubles. Cuando la concentración de calcio disminuye por debajo de un determinado nivel, los cristales de portlandita comienzan a disolverse. En ausencia de portlandita, el equilibrio está controlado por la descalcificación del gel el CSH. Por debajo de un nivel crítico, (2mM), el CSH llega a estar descalcificado y el producto resultante es un gel rico en sílice sin propiedades conglomerantes (Berner, 1992; Gérard y Le Bellego, 1999).

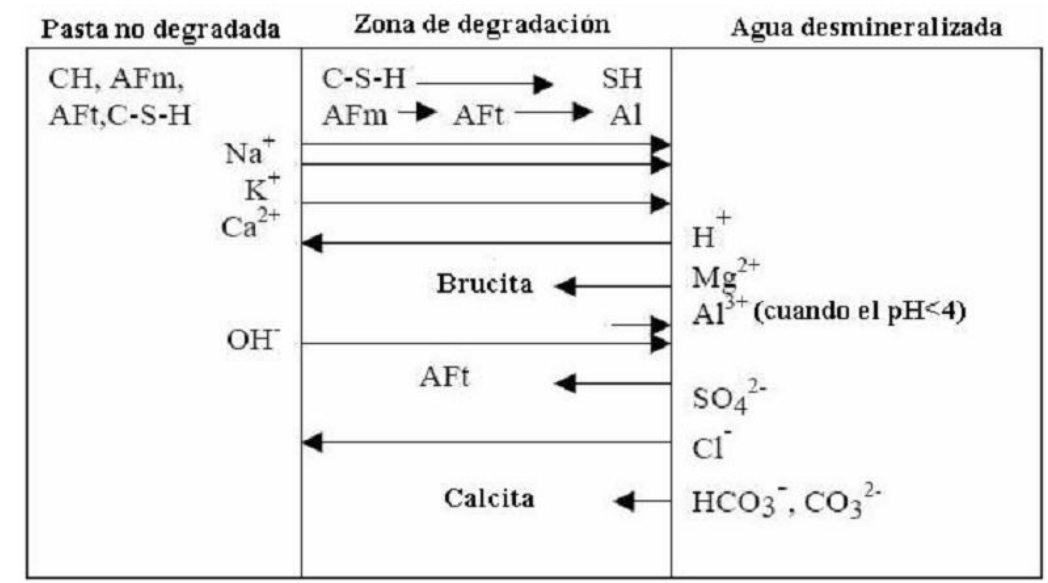

Figura 3. Esquema de difusión de iones y procesos de disolución/precipitación provocado por el agua

La disolución de portlandita además de incidir en los equilibrios termodinámicos que relacionan los distintos compuestos del material, afecta a la porosidad capilar de la matriz. Sin embargo, la disolución del calcio procedente del gel CSH parece no provocar cambios en la nanoporosidad ni afectar a la continuidad mecánica de la fase sólida microscópica, por lo que los cambios mecánicos y de transporte producidos no serán los mismos dependiendo de si el calcio proviene de la portlandita o del CSH (Llorente, 2008).

Así pues, la lixixiación de compuestos en el material es un proceso complejo en el que influyen multitud de mecanismos. El uso de moldelos resulta de grán utilidad cuando se trata de describir el comportamiento del material de estudio. En ocasiones puede ser empleado para predecir el comportamiento del material a largo plazo.

Los modelos termodinámicos establecen las ecuaciones termodinámicas implicadas en los procesos de reacción del material en base a datos empíricos Con estos datos implementan los parámetos constitutivos del modelo. El modelo de Berner constituye la base de muchos modelos 
numéricos exitentes por la gran compilación de datos de solubilidad que recoge (Berner, 1988 y 1992).

Los modelos numéricos emplean ecuaciones que describen los procesos fisico químicos que caracterizan la degradación del material, implementados sobre modelos de elementos finitos. Todos ellos toman como base la $2^{\circ}$ Ley de Fick, descrita por la ecuación 4, aplicada a la concentración del ion en estudio. Los modelos más conocidos son los de Adenot y Buil (1992) y Mainguy et al. (2000), el modelo de Gérard (1999), el modelo de Moranville et al. (2004) y el modelo Stadium (Maltais et al., 2004; Marchand y Delagrave, 1999; Marchand, 2001; Samson y Marchand, 1999 y 2007; Samson et al., 1999 y 2000).

Los modelos de Adenot y Buil (1992) y Mainguy et al. (2000) que estudian la cinética del proceso de degradación por agua desionizada y plantea un modelo que, tomando como factores dominantes la difusión y el equilibrio químico local, permite describir la zonificación que tiene lugar en el material (Segura, 2008).

El modelo de Gérard (1999) parte del modelo de Berner y toma la concentración de $\mathrm{Ca}^{2+}$ como la variable de estado que define el modelo. A partir de una serie de premisas establece la ley de conservación de masas en base al coeficiente de difusión del calcio, que es función de la porosidad (Segura, 2008).

El modelo de Moranville et al. (2004) simula el proceso mediante acoplamiento de las interacciones que se producen entre el la fase acuosa y los compuestos del material. Asume que la fase acuosa se encuentra saturada, lo que permite aceptar la hipótesis de un proceso controlado por la difusión.

El modelo Stadium modeliza el transporte multiiónico para materiales cementicios en estado saturado y no saturado. Tiene en cuenta los mecanismos clásicos de difusión de Fick, el acoplamiento eléctrico entre varios iones y los efectos de la actividad química. Considera también el fenómeno de la succión capilar y una amplia cantidad de reacciones químicas típicas en este tipo de materiales, por lo que constituye uno de los más completos y complejos (Segura, 2008).

Los modelos estadísticos emplean datos empíricos del proceso de degradación para obtener ecuaciones que permitan relacionar los parámetros implicados en el proceso de degradación. El proceso consiste en elaborar un cierto número de hipótesis sobre las causas que producen un 
determinado efecto y estas hipótesis son luego verificadas o no según el modelo estadístico. El modelo más clásico es la regresión múltiple, que se aplica cuando el conjunto de variables en juego son cuantitativas (Segura, 2008). En base a estudios previos llevados a cabo en el marco de la presente investigación se empleará este tipo de modelo para describir las alteraciones en la microestructura que se producen en el material en función de la disolución potencialmente agresiva empleada.

El modelo asume que la degradación se produce por la difusión de las especies agresivas en la matriz sólida siguiendo la $2^{\circ}$ Ley de Fick. Numerosos autores han demostrado que el proceso de descalcificación por agua desionizada, aguas naturales, u otros agresivos es un proceso controlado por la etapa de difusión (Adenot y Buil, 1992; Cardé y Francois, 1997; Carde et al. 1996; Gérard et al., 2002; Mainguy et al. 2000; Perlot et al., 2006). La cantidad de ion lixiviado en un proceso difusional es proporcional a la en raíz del tiempo, por lo que la velocidad de las reacciones químicas de disolución/precipitación es mayor que la difusión.

Los límites del modelo se encuentran cuando las características físicas del material se modifican de forma importante, como puede ser debido al aumento de la porosidad. El régimen controlado por difusión (lineal con raíz de t) deja paso a una cinética lineal en t cuando se agota la portlandita y comienza la disolución del CSH en la superficie del material (Faucon et al, 1997).

\subsubsection{DURABILIDAD DE MATERIALES CEMENTICIOS EN CONTACTO CON ÁCIDOS ORGÁNICOS}

Los compuestos presentes en la pasta de cemento hidratada son estables debido al equilibrio químico que existe entre a solución de los poros y los compuestos hidratados que proveen el medio alcalino para su preservación. El ataque químico al puede alterar este equilibrio y producir la descomposición de los compuestos. Este es el caso del ataque químico producido por los purines de cerdo en contacto con materiales cementicios. La composición del purín depende de numerosos factores, tales como, fisiología del animal, tipo de alimentación, tipología de la instalación, manejo de la misma, etc. Por lo que el purín de cerdo es el resultado de la dilución del estiércol animal por las aguas de lavado de la explotación ganadera. Su composición es variable a lo largo del tiempo y químicamente compleja. Contiene compuestos minerales y orgánicos. Los principales compuestos orgánicos son de tres grupos: ácidos orgánicos (acético, propiónico e isovalérico), compuestos nitrogenados (principalmente de tipo 
amoniacal) y distintas sales sulfhídricas procedentes de la urea. El resultado es un compuesto con un pH entre 7 y 8 (Massana, 2010).

Los estudios realizados respecto de la influencia que tiene este tipo de sustancia en los materiales base cemento, se refieren fundamentalmente al comportamiento de dichos materiales frente al ataque de los ácidos, principalmente de carácter orgánico. El ataque producido por este tipo de ácidos puede ser comparado con el producido por los ácidos fuertes (Bertron et al., 2004).

La resistencia a la corrosión del hormigón depende tanto de la composición y el tipo de cemento, como del $\mathrm{pH}$ al que se produce el ataque ácido. La velocidad a la que se produce la corrosión viene determinada por la concentración de ácido y el tipo y la cantidad de productos hidratados que toman parte en la reacción (Beddoe, 2005, Bertron et al. 2004, 2005a, 2005b, 2007 y 2009).

La liberación de $\mathrm{Ca}^{2+}$ procedente de la portlandita y el CSH suceden más rápidamente y a un pH mayor que la disolución de ferrita o aluminatos hidratados. Estas últimas conducen a la pérdida de $\mathrm{Fe}^{3+}$ y $\mathrm{Al}^{3+}$. Obviamente se produce una variación de $\mathrm{pH}$ en la solución de los poros del material en la capa corroída frente a las zonas inalteradas del material. Las zonas alteradas implican modificaciones en su composición y estructura. Estas alteraciones vienen determinadas por los $\mathrm{pH}$ de equilibrio de los compuestos hidratados y la solubilidad de los iones disueltos con respecto a las características físico-químicas de la matriz (Beddoe, 2005).

Cuando los valores de pH descienden se produce la alteración de los equilibrios de disoluciónprecipitación de los compuestos del material. Así se considera que el $\mathrm{pH}$ al cual la portlandita disuelve a pH por debajo de 12.5 unidades. Por debajo de 12 disuelve el monosulfoaluminato tetracálcico a y precipita etringita. A pH por debado de 11.6 puede precipitar yeso. Por debajo de $\mathrm{pH} 10.7$ disuelve la ettringita y puede formarse gibsita y a $\mathrm{pH}$ por debajo de 10.5 descomponen los silicatos cálcicos hidratados (Reardon, 1990 y Taylor, 2003). Los últimos compuestos en descomponer son los aluminatos cálcicos y la ferrita hidratada. A valores de $\mathrm{pH}$ por debajo de 6.5 se asume que la reacción de neutralización tiene lugar, estequiométricamente, entre el ácido y la portlandita (Beddoe, 2005).

La velocidad de la corrosión del material queda gobernada por una combinación de procesos que incluyen disolución, precipitación y transporte de especies. Todos estos procesos dependen de la composición química del cemento -especialmente el contenido en calcio-, la reactividad de 
la matriz cementicia y la reactividad de los ácidos. Asimismo, la resistencia del hormigón al ataque químico vendría también determinada la capacidad de penetración de los iones agresivos, que depende de la geometría y distribución de los poros (Beddoe, 2005 y De Belie, 1996).

Existen algunos estudios que simulan el efecto producido por los ácidos orgánicos sobre los materiales cementicios. La inmersion de probetas elaboradas con diferentes tipos de cementos en disoluciones de laboratorio, ha ayudado a profundizar en el conocimiento del comportamiento de este tipo de material en contacto con dichas sustancias (Beddoe, 2005; Bertron et al. 2004, 2005a, 2005b, 2007, 2009, 2014; De Belie et al., 2010; De Belie, 2000; Pavlik, 1995 y 1996; Pavlik y Uncik, 1997).

Bertron A. (2004, 2005a, 2005b, 2007, 2009, 20014) realizó diversos trabajos de investigación relacionados con el ataque producido por ácidos orgánicos sobre materiales cementicios. Su trabajo muestra que se producen en el material procesos de descalcificación en las zonas alteradas y pérdida de masa de las probetas sometidas a estudio. Estas observaciones son el producto de los procesos de lixiviación producidos en el material cuando las sales cálcicas derivadas de los aniones ácidos son solubles en agua. Las modificaciones en la microestructura de la matriz se caracterizan por la disolución progresiva de las fases cristalinas y la probable formación de un gel rico en sílice, aluminio y hierro en las zonas superficiales de las probetas de estudio. Las zonas así alteradas de la probeta, presentarían un resistencia mecánica escasa, sin embargo la baja solubilidad de las fases generadas conduce a la formación de una membrana semipermeable que frenaría la cinética de alteración. Usando combinaciones de ácidos orgánicos se llegó a la conclusión de que la acidez global del medio es la responsable de la degradación del material, y no la acción individual de cada uno de ellos, observando que la degradación producida por el proceso simulado era incluso menor que el producido en situaciones reales de exposición (Massana, 2010).

El tipo de cemento empleado en la construcción de estructuras que deben resistir el ataque químico es una variable fundamental, por ello diversos autores han publicado trabajos comparativos de la resistencia ofrecida por distintos tipos de cemento frente al ataque ácido (Antón et al., 2008, Beddoe, 2005, Bertron et al. 2004, 2005a, 2005b, 2007 y 2009, De Belie et al., 2010, De Belie, 1996, 2000 y 2008, Oueslati y Duchesne, 2011 y 2014, Sánchez, 2007, Sánchez, 2005).

La recomendaciones derivadas de algunos de estos trabajos se dirigen hacia el uso ligantes cementicios con bajo contenido en cemento y áridos silicios muy compactos (Beddoe, 2005). 
Así como a la reducción de la cantidad de hidróxido cálcico -susceptible de reacción con los ácidos- y una estructura porosa refinada que permita la reducción de la permeabilidad (De Belie, 1996). Haciendo referencia a las características deseables para resistir las condiciones de exposición, diversas investigaciones indican que algunos de los cementos que proveen mejores resultados en este tipo de exposición son: los cementos escoria de alto horno y los cementos puzolánicos (Bertron, 2004, 2005a, 2005b, 2007, 2009 y 2014).

Debido a las características ambientales donde se ubican los depósitos para almacenaje de purines, es necesario tener en cuenta tanto la composición del tipo de cemento como los requisitos para su puesta en obra. Los cementos con escoria de alto horno, pese a proveer buenos resultados respecto de la durabilidad, necesitan efectuar su endurecimiento en medio constantemente húmedo durante dos semanas al menos. Son sensibles a las bajas temperaturas porque retardan apreciablemente su endurecimiento, por lo que no deben utilizarse por debajo de los $5^{\circ}$ C, y también son sensibles a la sequedad y el calor (Cánovas, 1989). Si tenemos en cuenta estas consideraciones, se deduce que son cementos más delicados y exigen más precauciones en su empleo, que otros.

Los cementos puzolánicos endurecen lentamente, pero confieren al hormigón una elevada densidad, disminuyendo su porosidad y haciéndolo más compacto, lo que aumenta su resistencia química. Todo ello los hace recomendables para gran número de obras expuestas a los efectos climatológicos o ambientes medianamente agresivos (Sánchez et al., 2008 y 2009; Massana, 2010; Massana et al., 2013). 
- 38 - 


\section{MATERIALES Y METODOLOGÍA}

\subsection{MATERIALES EMPLEADOS.}

Los materiales usados en este trabajo son los que se emplean de forma preferente en las construcciones agrícolas y ganaderas, así como aquellos que se han comportado de forma más satisfactoria en investigaciones previas (Antón et al., 2008, Bertron et al., 2004, 2009).

\subsubsection{PROBETAS DE ENSAYO}

\subsubsection{Tipo de material empleado}

El hormigón y el mortero son los materiales que se emplean de forma preferente en las construcciones del medio agrícola y ganadero por su versatilidad. Las probetas fabricadas con este material son, a priori, las más adecuadas para simular los fenómenos de ataque que se dan en estructuras reales. Sin embargo, cuando se pretende aislar el comportamiento de la masa cementicia, y evitar la interferencia y heterogeneidad que producen los áridos resulta más adecuada la utilización de probetas de pasta de cemento.

El uso de probetas de pasta de cemento presenta varias ventajas para nuestro estudio. Por un lado facilita la caracterización de los cambios micro-estructurales que tienen lugar en la matriz de cemento hidratado, y por otro permite un proceso de degradación más rápido, ya que toda la 
masa de la probeta es susceptible de ser degradada, obteniendo cambios apreciables en menor tiempo.

Como inconvenientes presenta su fragilidad y facilidad de fisuración, así como su relativa representatividad de los materiales empleados habitualmente en las instalaciones agroganaderas. Los procesos de fisuración pueden reducirse mediante un buen curado de las muestras y una dimensión de probetas reducida. Sin embargo esto conlleva la obtención de pequeñas masas de muestra para los análisis. Para solucionar este inconveniente se han empleado varias probetas pequeñas que constituyen una probeta mayor, con lo que se aumenta la masa de muestra a la vez que se consiguen muestras más representativas.

Se ha seleccionado como material para el estudio la pasta de cemento. La ausencia de dos fases, el árido y la interfase nos permite identificar mejor los procesos de deterioro y la influencia que en su caso tiene la composición del cemento y su interacción con los distintos medios.

Existen algunos trabajos que relacionan los procesos que tienen lugar en el material en relación con las características del medio al que son expuestas, especialmente cuando se trata de la influencia que tiene el pH sobre la degradación del material. La mayoría de los estudios relacionan el comportamiento del material con el valor del $\mathrm{pH}$ del medio agresivo y no se tiene en cuenta las características físico-químicas de la disolución. Puesto que estamos hablando de equilibrios termodinámicos, si las variaciones entre concentración y actividad son significativas, medios con el mismo $\mathrm{pH}$ pueden presentar una agresividad significativamente diferente. El presente estudio pretende profundizar en el conocimiento que el efecto salino en su conjunto tenga en el comportamiento de la disolución.

A lo largo de la presente tesis también se ha llevado a cabo una revisión de los métodos de caracterización del material. Se han analizado tanto los protocolos establecidos como su nivel de sensibilidad. Se pretende con ello aportar metodologías sencillas de análisis que permitan conocer y evaluar la evolución del deterioro del material sometidos a ambientes agresivos.

\subsubsection{Características de los cementos empleados}

Atendiendo a las recomendaciones que se preconizan en la EHE-08 sobre la adecuación del tipo de cemento a emplear en distintas clases de exposición, se han ensayado los siguientes tipos de cementos (UNE-EN 197-1:2011): 
- CEM I SR 42.5R (CEM SR): cemento portland resistente a sulfatos. Este cemento se ha empleado como cemento de referencia.

- CEM II/A-V 32.5R (CEM II): cemento portland con un contenido entre un 94 y un 80\% de clínker, y con adición de cenizas volantes silíceas entre 6 y 20\%.

- CEM IV/B (P-V) 32.5R (CEMIV): cemento puzolánico con un contenido en cemento portland entre 45-64\% y adiciones de humo de sílice (D), puzolanas naturales (P) y cenizas volantes (V) del 36-55\%.

\subsubsection{Dosificación y fabricación de la pasta de cemento}

Se prepararon probetas prismáticas de pasta de cemento de 10x10x60 $\mathrm{mm}^{3}$. El tamaño viene determinado por la necesidad de impedir la fisuración de la pasta. El amasado se llevó a cabo en una amasadora planetaria. En ausencia de una norma específica para la fabricación de probetas de pasta de cemento, los tiempos de amasado empleados se han decidido en base a las premisas establecidas en la norma para determinar la consistencia normal de las pastas, UNE 196-3:2006.

La relación agua/cemento elegida es 0.4 en todas las muestras. La elección de la relación a/c se llevó a cabo de acuerdo con los trabajos realizados por diferentes autores (Bertron et al., 2014, De Belie, 2008, Moranville et al., 2004, Gaitero et al., 2008), además de cumplir con la UNE 196-3:2006. Además esta relación permite una buena reología de las pastas y una hidratación completa de las mismas.

Una vez preparada la pasta, se procedió a su colocación en moldes de acero (Figura 4.a). El llenado de los moldes se realizó en dos etapas. En la primera, se vertió, uniformemente, una capa de pasta, compactándose mediante 20 golpes en la mesa de sacudidas, después de lo cual se procedió al vertido de la segunda capa de pasta compactándose de igual forma. Tras el llenado y compactado de los moldes, se eliminaron los restos de pasta sobrantes y se colocaron dentro de una cámara climática durante 24 horas, con una humedad relativa del $96 \pm 2 \%$, y una temperatura de $20 \pm 2^{\circ} \mathrm{C}$.

Las probetas se desenmoldaron transcurridas las $24 \mathrm{~h}$ y a continuación se curaron en cámara climática durante 28 días para las muestras de cemento CEM I SR 42.5R, y de 90 días para los cementos CEM II/A-V 32.5R y CEM IV/B 32.5R. Se pretende con esto dar tiempo suficiente 
para que se produzcan las reacciones puzolánicas cuyo periodo de finalización, asumido por la comunidad científica, es de aproximadamente 90 días. Se trata de conseguir que el estudio del proceso de degradación no se vea afectado por otro tipo de reacciones. En la cámara de curado, para asegurar que cada probeta se encuentra aislada y separada de las demás, se colocaron las probetas encima de gradillas de acero, con un contacto mínimo entre las probetas y los soportes metálicos. (Figura 4.b).
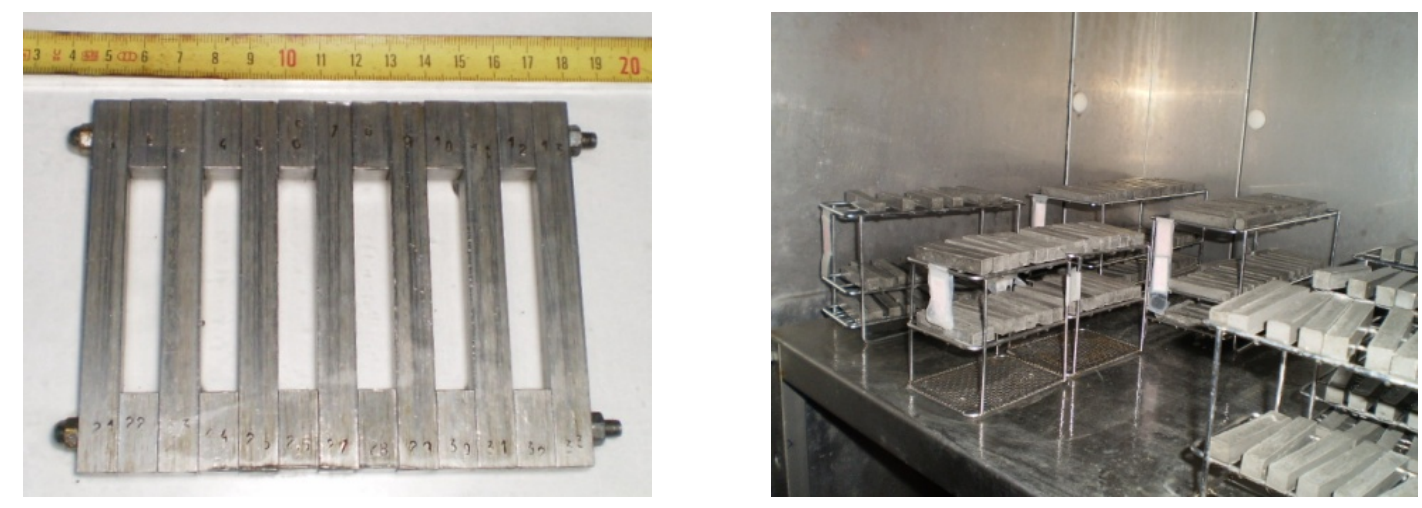

Figura 4. (a) Moldes de acero inoxidable para la fabricación de probetas de pasta de cemento. (b) Probetas durante el proceso de curado.

Las muestras se han amasado en grupos de 84 probetas. Se han realizado 4 grupos para cada uno de los cementos de ensayo, es decir, 336 probetas para cada tipo de cemento, agrupándose en macro-probetas de 9 probetas para asegurar una cantidad mínima de muestra. Para el cemento de referencia se realizaron 3 grupos de 84 probetas, es decir 252 probetas. El número total de probetas es de 924.

\subsubsection{MEDIOS DE EXPOSICIÓN}

A menudo, el uso de materiales base cemento en el medio agrícola supone un contacto continuo con compuestos que pueden resultar potenciales agresivos para el material. El agua, la presencia de ácidos, los sulfatos, etc., pueden desencadenar reacciones en el material que originen un deterioro de las estructuras e instalaciones agrícolas y ganaderas. Comprender estos mecanismos de deterioro que se producen, en ocasiones puede resultar una tarea compleja, ya que cada potencial compuesto agresivo puede actuar de forma individual, o de forma sinérgica con otros.

La simulación de las condiciones en las cuales se produce el contacto de los materiales con las disoluciones potencialmente agresivas nos permite conocer la respuesta del material expuesto, 
las características que presenta el material durante y tras la exposición y los procedimientos de análisis más adecuados para caracterizarlos.

La degradación por penetración de agresivos en medios porosos está controlado por mecanismos de difusión. En las condiciones habituales este proceso es lento por lo que la mayoría de los estudios hacen usos de ensayos de degradación acelerado. En la literatura consultada existen diversas opciones para acelerar los procesos de deterioro. En medios de origen agroganaderos se pueden resaltar los estudios desarrollados por los investigadores (Bertron A., et al., 2004, 2005a, 2005b, De Belie et al., 1996, 2000 y 2010, De Belie, 2008), en los cuales nos hemos basado para llevar a cabo la selección de los medios de degradación ensayados.

Para nuestro estudio se han seleccionado tres medios potencialmente agresivos y dos medios control.

Los medios agresivos han sido disoluciones de: ácido acético/acetato sódico con un pH próximo a 5, sulfato sódico con un $\mathrm{pH}$ próximo al neutro y un agua de composición típica granítica con un pH próximo al neutro (Llorente, 2008) y cierto contenido de bicarbonatos. En la Tabla 4 se resume la composición de los medios empleados.

Los medios de control elegidos son una disolución saturada de hidróxido cálcico y el ambiente de laboratorio. La disolución saturada de hidróxido sódico se considera la disolución de referencia frente a los compuestos agresivos en medio acuoso, por tanto representaría el valor límite de referencia respecto al estado de hidratación del material. El ambiente de laboratorio sería la referencia en un medio real sin hidratación adicional.

La mayor parte de las recomendaciones de uso en estos ambientes hacen referencia únicamente a la influencia del pH como único parámetro de referencia. En nuestro estudio hemos tratado de evaluar además de dicha variable, la influencia que la presencia de distintos tipos de iones, que modifican las características físico-químicas de las disoluciones, podría ejercer en la degradación del material.

Los reactivos empleados para la preparación de las disoluciones son de calidad analítica ACS. Se empleó agua destilada obtenida de un equipo Elix 3 de Millipore. 
Para cada medio de exposición se emplean $3.200 \mathrm{ml}$ de disolución. Los envases seleccionados para llevar a cabo los ensayos son recipientes cilíndricos de polipropileno transparentes con cierre hermético de 195 mm (Øsuperior) y 165 mm (Øinferior) y 176 mm de altura.

Tabla 4. Medios de exposición empleados

\begin{tabular}{|c|c|c|c|}
\hline Medio & $\mathrm{pH}$ & \multicolumn{2}{|c|}{ Concentración } \\
\hline Acético/Acetato (AC) & 4.8 & \multicolumn{2}{|c|}{$0.35 \mathrm{M}$} \\
\hline \multirow{9}{*}{ Agua Natural (AN) } & \multirow{9}{*}{$\approx 8$} & {$\left[\mathrm{SO}_{4}{ }^{2-}\right]$} & $1.14 \cdot 10^{-4} \mathrm{M}$ \\
\hline & & {$\left[\mathrm{Cl}^{-}\right]$} & $9.90 \cdot 10^{-4} \mathrm{M}$ \\
\hline & & {$\left[\mathrm{NO}_{3}^{-}\right]$} & $1.68 \cdot 10^{-3} \mathrm{M}$ \\
\hline & & {$\left[\mathrm{HCO}_{3}^{-}\right]$} & $2.14 \cdot 10^{-3} \mathrm{M}$ \\
\hline & & {$\left[\mathrm{CO}_{3}{ }^{2-}\right]$} & $3.06 \cdot 10^{-4} \mathrm{M}$ \\
\hline & & {$\left[\mathrm{Na}^{+}\right]$} & $2.14 \cdot 10^{-3} \mathrm{M}$ \\
\hline & & {$\left[\mathrm{K}^{+}\right]$} & $6.11 \cdot 10^{-4} \mathrm{M}$ \\
\hline & & {$\left[\mathrm{Mg}^{2+}\right]$} & $3.09 \cdot 10^{-4} \mathrm{M}$ \\
\hline & & {$\left[\mathrm{Ca}^{2+}\right]$} & $8.40 \cdot 10^{-4} \mathrm{M}$ \\
\hline Sulfato Sódico (SU) & $\approx 8$ & \multicolumn{2}{|c|}{$0.21 \mathrm{M}$} \\
\hline Hidróxido cálcico (CA) & $\approx 12.5$ & \multicolumn{2}{|c|}{ Saturada } \\
\hline Aire (AI) & --- & \multicolumn{2}{|c|}{ Ambiente de laboratorio } \\
\hline
\end{tabular}

\subsection{ESQUEMA EXPERIMENTAL DEL PROCESO DE DEGRADACIÓN ACELERADA}

\subsubsection{PREPARACIÓN DE LAS MUESTRAS ANTES DEL PROCESO DE DEGRADACIÓN}

Una vez fueron curadas las probetas, todas ellas fueron recubiertas con una pintura para revestimientos protectores, a base de resinas en todas sus caras (Sikaguard 62, SIKA). Según se especifica en la hoja de especificaciones del producto, esta pintura aplicada sobre hormigón o acero los protege contra la corrosión, intemperies y ataques químicos de tipo moderado a medio.

Para permitir el contacto entre la disolución y la pasta de la probeta se cortó la primera lámina, de aproximadamente $1 \mathrm{~mm}$ de espesor, de uno de los extremos (Figura 5.a). Se pretende con 
ello que el proceso de degradación sea unidireccional, lo que permitiría aplicar la segunda Ley de Fick en una dirección en los procesos de análisis de resultados posteriores.

Una vez preparada la cara de las probetas que va quedar expuesta, se sumergen las mismas en una disolución de hidróxido cálcico saturada (Figura 5.b). La saturación de la superficie de exposición elimina la posibilidad de mecanismo de succión capilar. En ausencia de campo eléctrico consideramos despreciables los procesos de migración. Por ello podemos considerar que el único proceso que se desarrolla es el de difusión/reacción.
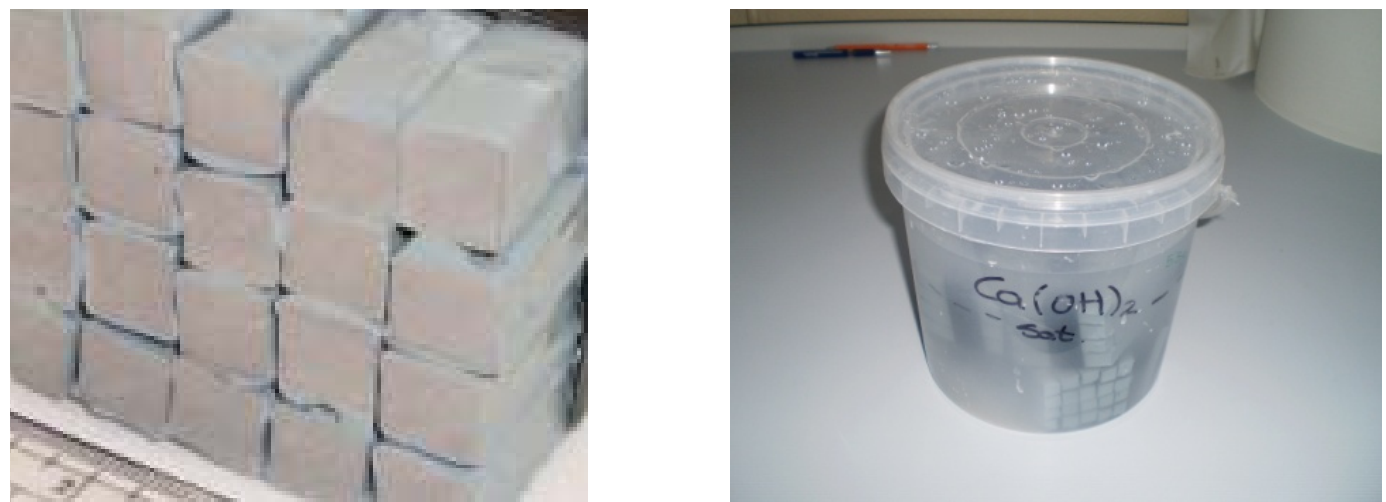

Figura 5. (a) Detalle de las probetas recubiertas de resina mostrando la superficie de exposición. (b) Detalle de las probetas durante el proceso de saturación de la superficie de ataque

\subsubsection{PROCESO DE DEGRADACIÓN}

Durante el tiempo de ensayo se trató de que las disoluciones se mantuviesen homogéneas mediante agitación. En la Figura 6 se muestra el dispositivo fabricado para tal fin.

Se prepararon las tapas de los envases para burbujear gas $\mathrm{N}_{2}$ sobre las disoluciones. Se pretendía con esto purgar el posible $\mathrm{CO}_{2}$ disuelto que podría dar lugar a fenómenos de carbonatación.

Se diseñaron unos dispositivos de apoyo de las macro-probetas que permitiesen asegurar que todas estuviesen a la misma altura y con las caras de exposición perpendiculares al fondo de la cubeta. Se buscaba con esto impedir la deposición de posibles precipitados formados durante el periodo de ensayo, y limitar los efectos de diferencia de presión hidrostática sobre la superficie de la probeta.

Los ensayos de degradación consistieron en la inmersión de las probetas de ensayo en las disoluciones agresivas correspondientes, contenidas en los tanques con agitador. Del mismo 
modo se colocaron las muestras de referencia. Recordemos que, como se explicó en el apartado 3.1.1.1, cada "macro-probeta" que se va a exponer, está compuesta por 9 probetas pequeñas en el caso de los cementos II y IV, y de 6 probetas en el caso del cemento SR. A los 2, 4, 7, 14, 30, 58 y 92 días se extrajo una macro-probeta de cada uno de los medios para su caracterización.

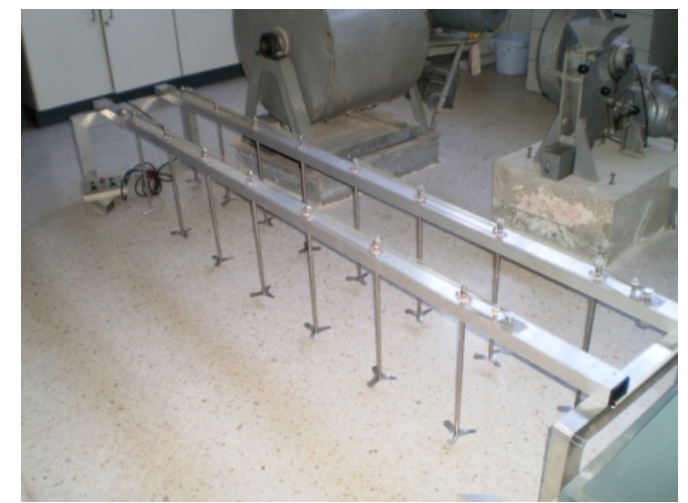

Figura 6. Sistema de agitación continuo empleado para mantener los medios homogéneos

En la Tabla 5 se explica el procedimiento empleado para identificar las cubetas de ensayo: las dos primeras letras hacen referencia al tipo de cemento ensayado, y las dos siguientes al medio de degradación.

Tabla 5. Abreviaturas empleadas en la nomenclatura de las muestras

\begin{tabular}{|c|c|c|}
\hline & Abreviatura & Correspondencia \\
\hline \multirow{3}{*}{ Cemento } & SR & CEM I SR 42.5R \\
\hline & II & CEM II/A-V 32.5R \\
\hline & IV & CEM IV/B(P-V) 32.5R \\
\hline \multirow{5}{*}{ Medio de exposición } & $\mathrm{AC}$ & Disolución Acético/Acetato \\
\hline & SU & Disolución Sulfato sódico \\
\hline & AN & Disolución Agua Natural \\
\hline & CA & Disolución Hidróxido Cálcico \\
\hline & AI & Exposición al aire \\
\hline
\end{tabular}

En la Figura 7 se muestra un esquema de la distribución de los grupos de probetas en los medios de exposición. En la Figura 8 se muestra una fotografía tomada a lo largo del proceso de exposición.

Durante el proceso de degradación se controló tanto el $\mathrm{pH}$ de las disoluciones, como la concentración de especies potencialmente agresivas. Para ello se realizaron medidas in situ, y se 
tomaron muestras semanales para determinar, tanto la concentración de los iones constituyentes del medio de exposición, como el contenido de iones lixiviados de las probetas.

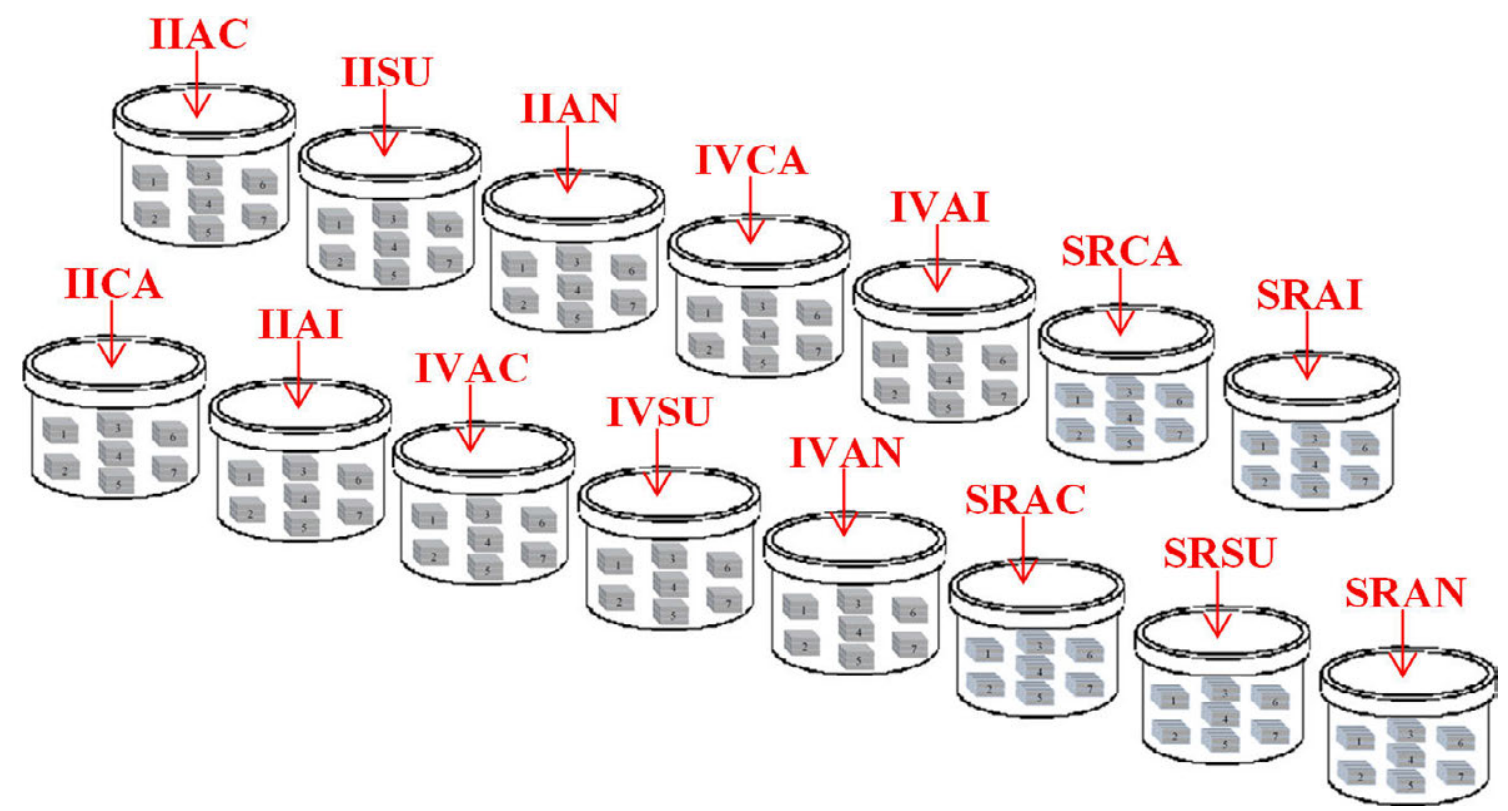

Figura 7. Esquema de distribución de las probetas de ensayo en los medios de exposición

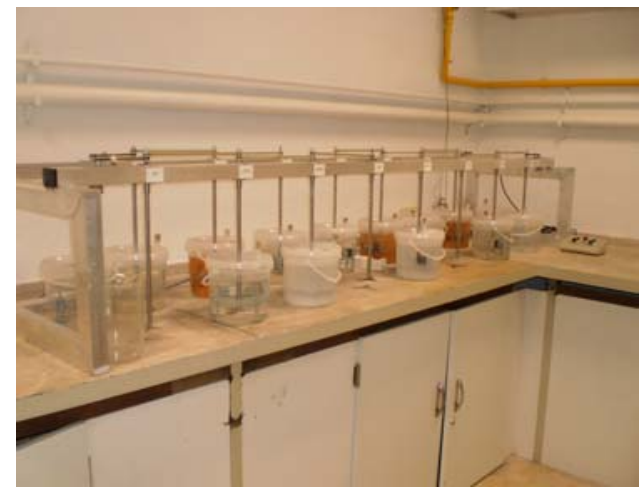

Figura 8. Imagen las probetas inmersas en las cubetas durante el proceso de degradación

\subsubsection{PREPARACIÓN DE LAS MUESTRAS DE ANÁLISIS PARA SU CARACTERIZACIÓN}

3.2.3.1. Muestras de pasta de cemento en fase sólida 
Durante el proceso de ensayo se extrajeron muestras a siete edades de exposición a cada uno de medios expuestos (tres potencialmente agresivos y dos medios de referencia) y para cada uno de los cementos empleados. Un total de 105 grupos de probetas o macro-probetas. En la. Figura 9 se muestra un esquema de las macro-probetas extraídas y los cortes realizados para obtener las muestras de análisis de cada tipo de cemento empleado para un determinado medio de exposición, y sería extensible al resto de los medios.

Macro-probetas extraídas en IIAC

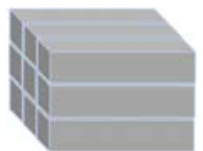

2 días

IIAC.2D

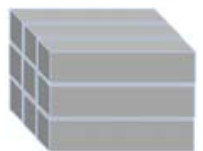

30 días

IIAC30D

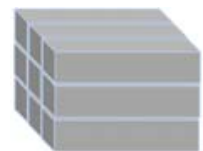

4 días

IIAC.4D

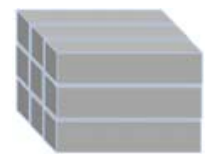

58 días

IIAC58D

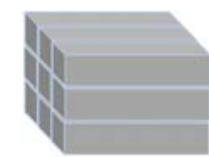

7 días

IIAC.7D

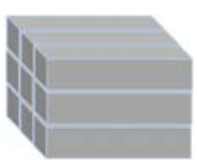

92 días

IIAC92D

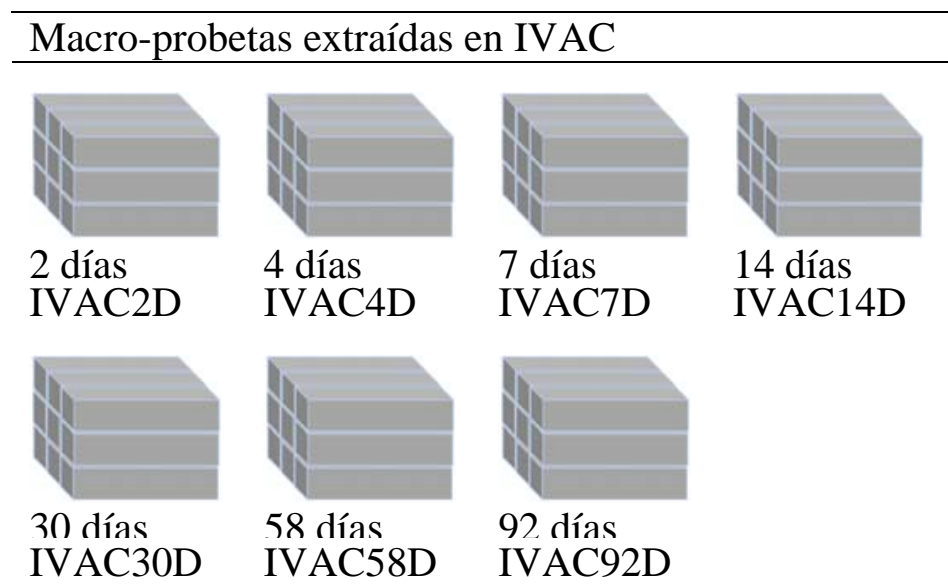

Sección en contacto con el medio de exposición (sin resina)

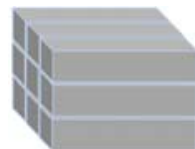

14 días IIAC.14D

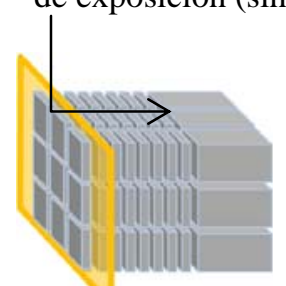

Resto de las caras de las probetas recubiertas de resina epoxi

8 profundidades de corte en cada macro-probeta

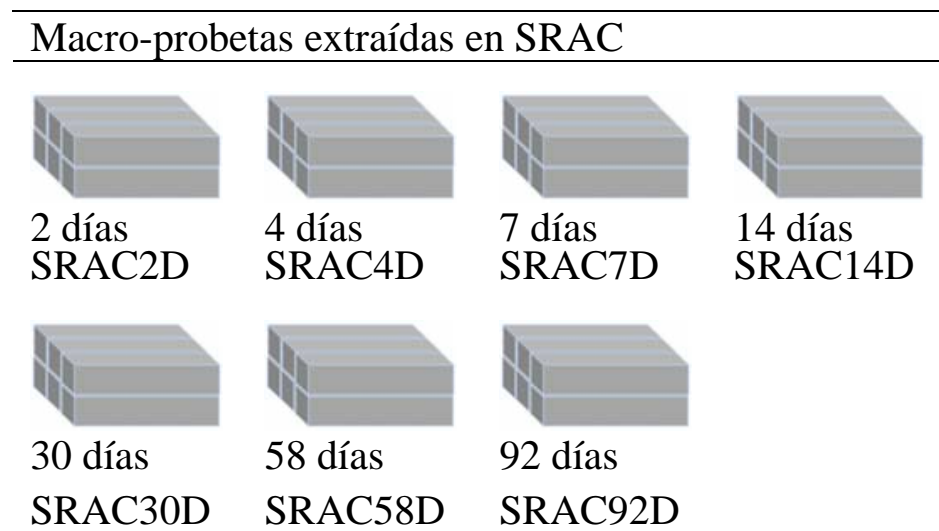

Sección en contacto con el medio de exposición (sin resina)
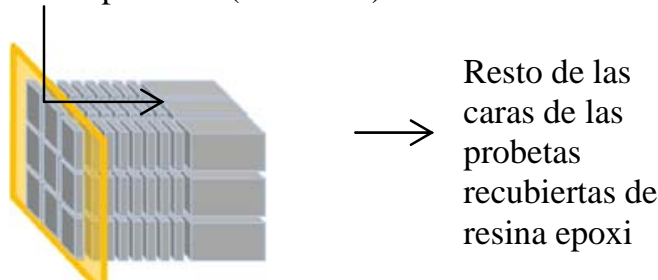

8 profundidades de corte en cada macro-probeta resina epoxi

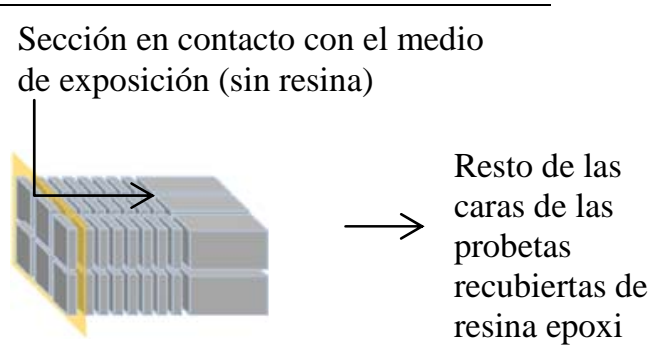

8 profundidades de corte en cada macro-probeta

Figura 9. Esquema de macro-probetas extraídas y cortes realizados en uno de los medios de exposición 
Una vez retiradas las macro-probetas del medio correspondiente se procedió a la parada del proceso de hidratación-degradación sumergiendo las muestras en acetona.

Cada una de las macro-probetas se cortaron en secciones de aproximadamente $2 \mathrm{~mm}$ de espesor perpendiculares al eje de la dirección de degradación, siguiendo el esquema mostrado en la Figura 9 (derecha). Las 9 ó 6 secciones que separa el plano amarillo representado en el esquema constituirían una muestra de análisis de un cemento, en un medio de degradación, a una edad determinada y a cada una de las profundidades cortadas.

De cada macro-probeta se obtuvieron muestras a 8 profundidades, correspondientes a las distintas profundidades susceptibles de alteración durante el proceso de degradación. El corte se realiza con una cortadora petrográfica de precisión Struers, Modelo Secotom-10, equipada con un disco de corte de diamante de espesor $0{ }^{\prime} 4^{1} \mathrm{~mm}$ (Figura 10).

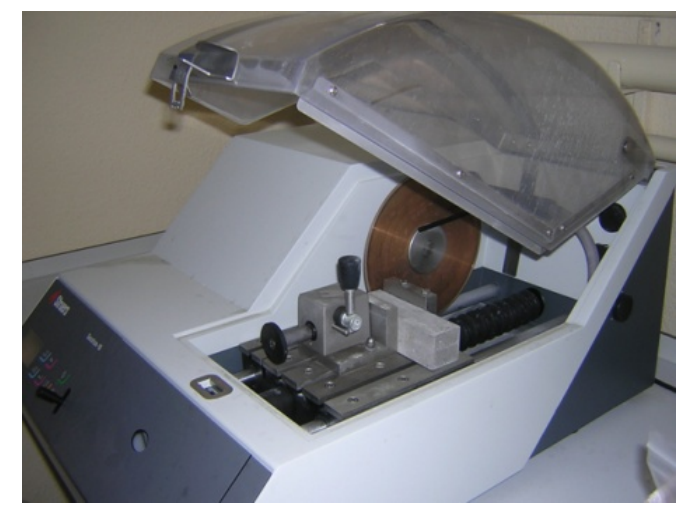

Figura 10. Cortadora petrográfica de precisión Struers, Modelo Secotom-10

Antes de pasar a la caracterización de las muestras se eliminó la resina y se calibró el espesor de las secciones obtenidas con un calibre analógico de precisión $0.05 \mathrm{~mm}$, para determinar la profundidad media de la sección en el conjunto de la probeta (Figura 11).

A continuación se procedió a la pulverización de las muestras, utilizando un molino de ágata automático Retsch RM 200, empleando como tiempo de molienda 2 minutos y a una profundidad de 7-8 (Figura 12). El polvo obtenido se hizo pasar por el tamiz de 0,16 mm de luz para limitar el diámetro máximo de partícula.

\footnotetext{
${ }^{1}$ A lo largo del proceso de corte fue necesario emplear discos de diferente espesor, lo cual fue tenido en cuenta en el posterior cálculo de la profundidad asignada al grupo de secciones obtenidas.
} 

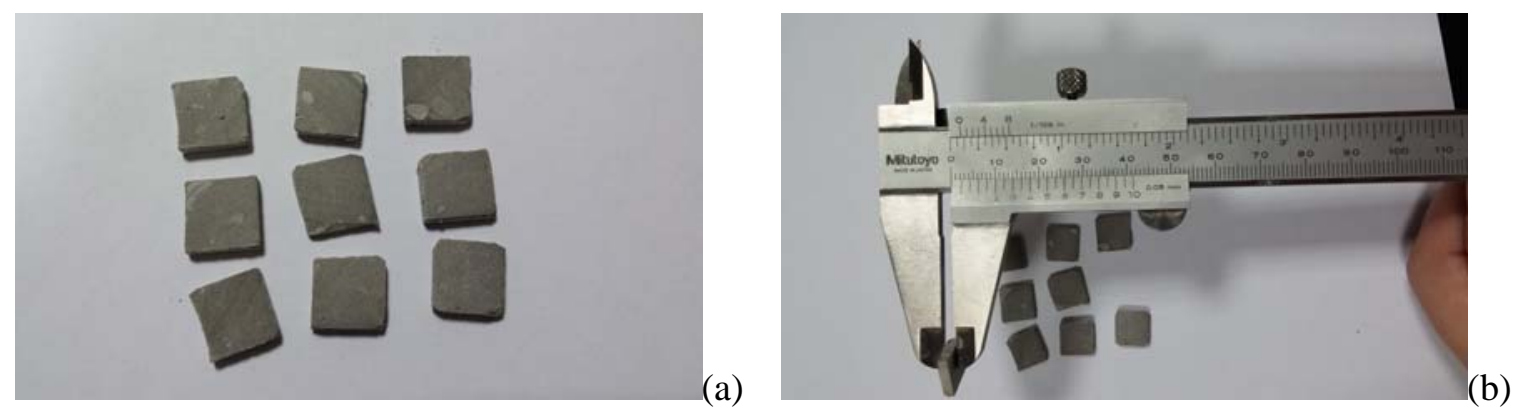

Figura 11. Imágenes de las muestras tras eliminar la resina (a), detalle del proceso de calibrado de las muestras de análisis (b).

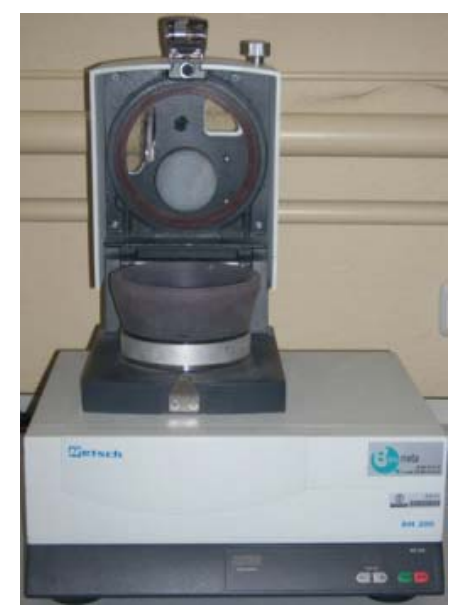

Figura 12. Molino de mortero de ágata empleado para la molienda de las muestras

\subsubsection{Muestras en fase líquida}

Durante el desarrollo de esta campaña experimental, se obtuvieron dos tipos de muestras en estado líquido, las alícuotas recogidas en los medios de exposición, y las obtenidas por disolución de las muestras de ensayo en estado sólido obtenidas según el procedimiento descrito en el apartado 3.2.3.1.

\section{Alícuotas extraídas durante el periodo de exposición}

Las alícuotas tomadas de los medios de exposición a diferentes tiempos de fueron extraídas para controlar la composición de los medios y determinar la lixiviación de iones procedente de las probetas. 
La nomenclatura de las muestras hace referencia a las abreviaturas mencionadas en la Tabla 5, para cada tipo de cemento y medio de exposición, incluyendo a continuación un número que indica la edad en días a la que fue tomada la muestra más una "D" . En la Figura 13 se muestra una imagen del tipo de alícuotas recogidas.

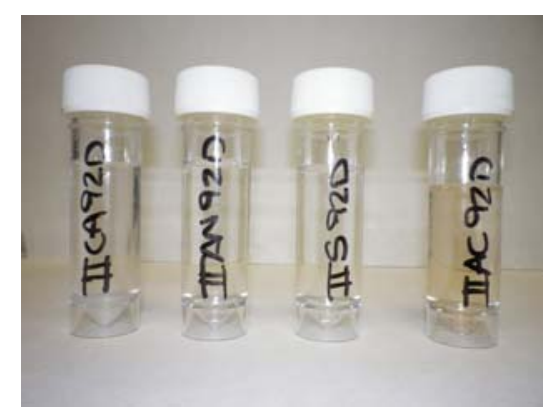

Figura 13. Alícuotas recogidas de los medios de exposición durante el proceso de degradación

\section{Disolución de muestras sólidas}

La determinación de iones en las muestras de pasta de cemento requiere la disolución de las muestras. El método de disolución varía en función de la determinación a realizar.

La evaluación de elementos mayoritarios, entre los que se incluye la determinación de $\mathrm{CaO}$, $\mathrm{MgO}, \mathrm{Fe}_{2} \mathrm{O}_{3}$ y $\mathrm{Al}_{2} \mathrm{O}_{3}$ precisa la disolución completa de la muestra (apartado 13, UNE 1962:2006). Según la norma la muestra ha de disgregarse por medio de una fusión con peróxido de sodio. La masa fundida se disuelve en $\mathrm{HCl}$ y se evapora hasta sequedad precipitándose la sílice impura (el procedimiento se realiza por duplicado para asegurar la completa precipitación). Esta sílice precipitada se trata con $\mathrm{HF}$ y $\mathrm{H}_{2} \mathrm{SO}_{4}$, consiguiéndose así la volatilización de la sílice pura y resultando de esta operación un residuo 1 y un filtrado 1 . El residuo 1 se trata con una mezcla de carbonato y cloruro sódicos con el fin de precipitar los silicatos solubles, se disuelve con $\mathrm{HCl}$ y se añade al filtado 1 . Hemos denominado este procedimiento de disolución de muestra Método A.

La determinación de $\mathrm{SO}_{4}{ }^{2-}$ implica la disolución de un gramo de muestra con $\mathrm{HCl}$ en caliente (apartado 8.2, UNE 196-2:2006). Se lleva a temperatura próxima a ebullición, se deja reposar y se filtra, lavando hasta ensayo negativo de iones cloruro con nitrato de plata y se enrasa a un volumen determinado. Hemos denominado este procedimiento de disolución de muestra Método B. 
El uso de procedimientos diferentes para cada una de las determinaciones implicaría un mínimo de 2 g de muestra, uno para cada procedimiento de disolución. Esto puede suponer un problema cuando la cantidad de muestra es limitada. En nuestro caso, cada muestra (6 secciones en el caso de cemento SR y 9 en el caso de los cemento II y IV) con un espesor medio de $1.5 \mathrm{~mm}$, y una densidad aproximada de $1,7 \mathrm{~g} / \mathrm{ml}$, oscilaría entre 1,5 y $2,5 \mathrm{~g}$, a lo que hay que descontar las pérdidas por tratamientos de la muestra como la molienda.

Tenemos que considerar además la cantidad de muestra que lleva la realización de ensayos en fase sólida (ATD-TG y DRX) y la posibilidad de reservar cierta cantidad de muestra de seguridad por si hubiese algún error en el proceso o se decidiese incluir alguna determinación posterior en virtud de los resultados obtenidos. En este estudio, incrementar la masa de cada muestra, implicaría incluir más probetas en cada macro-probeta, lo que conlleva un número mayor de amasadas, y en consecuencia una diferencia de tiempo mayor entre amasadas de las probetas unitarias incluidas en la macro-probeta definida como unidad de análisis. Es necesario tomar una solución de compromiso entre la cantidad máxima de muestra por análisis y la homogeneidad de la muestra.

La realización del procedimiento que hemos denominado A (disolución completa de la muestra), suma un número significativo de inconvenientes/dificultades: implica cierta pericia del operador que lleva a cabo la determinación, la inversión de gran cantidad de tiempo, el uso de numerosos reactivos y equipos a alta temperatura como el horno-mufla. Todo ello son factores a tener en cuenta desde el punto de la practicidad y rapidez en la realización de ensayos, especialmente cuando se van a realizar un número elevado de determinaciones.

Estos aspectos motivaron que comparáramos los dos métodos de disolución con el fin de saber si podíamos emplear un método único para todos los iones. Especialmente en la determinación de iones calcio, magnesio y sulfato, ya que éstos son los iones mas sensibles en lixiviación y se determinaban, además de en las muestras disueltas, en las muestras recogidas a lo largo del proceso de ensayo.

Las conclusiones derivadas de estos ensayos motivaron que optásemos por llevar a cabo la disolución de las muestras mediante el método de disolución para la determinación de sulfatos, es decir el Método B

\subsection{ENSAYOS DE CARACTERIZACIÓN DE LAS MUESTRAS DE ANÁLISIS}


A lo largo del presente trabajo se han llevado a cabo diferentes metodologías para caracterizar el material estudiado degradado y sin degradar. En la Figura 14 se muestra un esquema general de las determinaciones realizadas sobre cada tipo de muestra obtenida a lo largo de la campaña experimental.

El procero de caracterización de las muestras se ha llevado a cado en diferentes estadios de la campaña experimental. En la Tabla 6 se muestra un resumen de los ensayos realizados a tal fin.

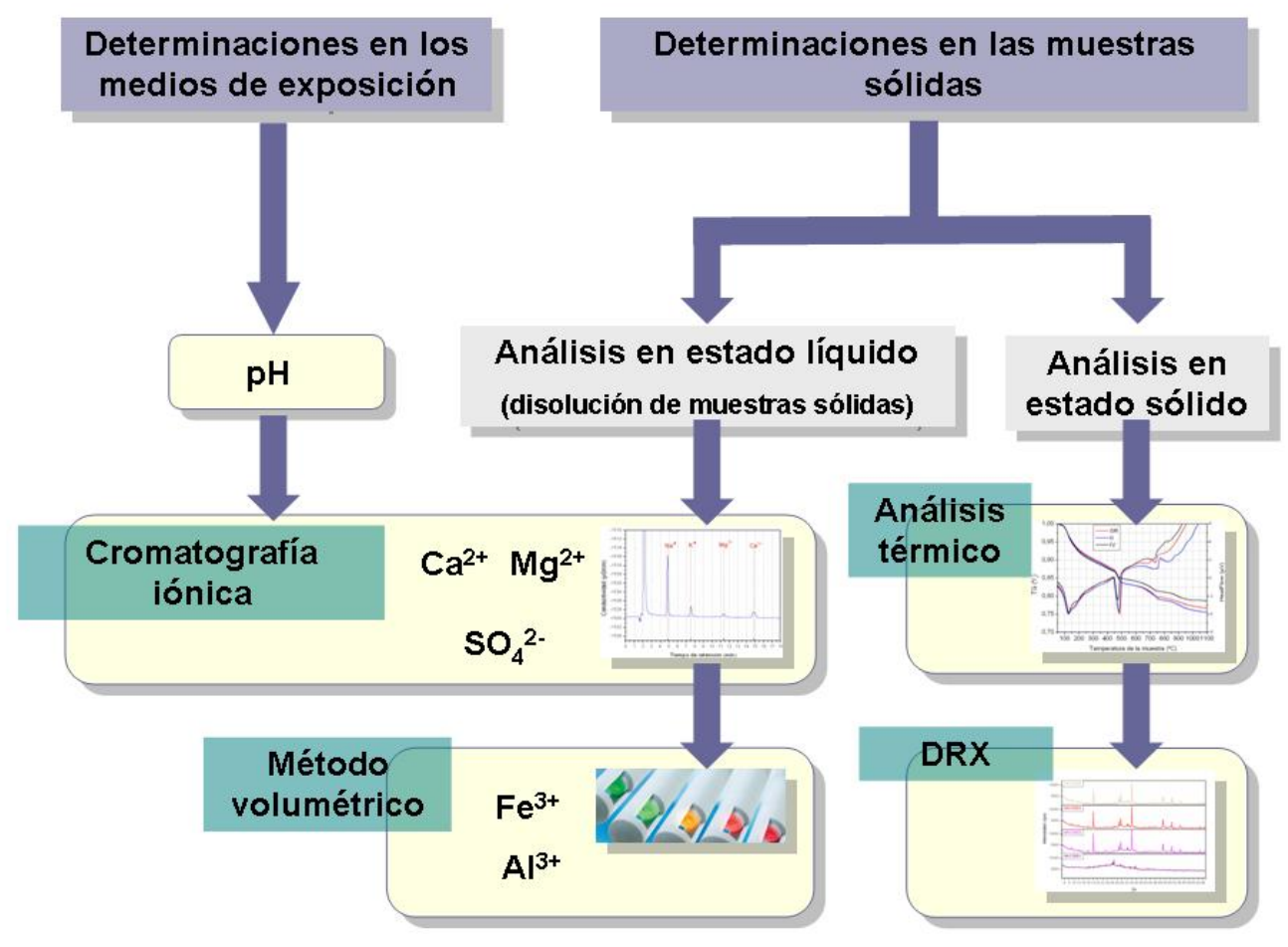

Figura 14. Esquema de ensayos llevados a cabo sobre las muestras implicadas en el proceso de degradación

Tabla 6. Metodología de ensayos realizados a lo largo de la campaña experimental

\begin{tabular}{cc}
\hline & Análisis elemental \\
\cline { 2 - 2 } $\begin{array}{c}\text { Caracterización de los } \\
\text { cementos anhidro }\end{array}$ & Tamaño de partícula \\
\cline { 2 - 2 } $\begin{array}{c}\text { Caracterización de las pastas de } \\
\text { cemento a } \mathrm{t}=0 \text { días }\end{array}$ & $\mathrm{Ca}^{2+}, \mathrm{Mg}^{2+}, \mathrm{SO}_{4}{ }^{2-}, \mathrm{Fe}^{3+}, \mathrm{Al}^{3+}$ \\
\cline { 2 - 2 } & Análisis térmicmico (ATD-TG) \\
\hline
\end{tabular}




\begin{tabular}{|c|c|c|c|}
\hline & & & DRX \\
\hline \multirow{7}{*}{$\begin{array}{c}\text { Caracterización } \\
\text { de las muestras } \\
\text { durante } \\
\text { el ensayo de } \\
\text { degradación }\end{array}$} & Análisis de lixiviados & & $\mathrm{pH}, \mathrm{Ca}^{2+}, \mathrm{Mg}^{2+}, \mathrm{SO}_{4}{ }^{2-}$ \\
\hline & \multirow{6}{*}{$\begin{array}{l}\text { Pasta de cemento } \\
\text { diferentes edades de } \\
\text { exposición }\end{array}$} & \multirow{3}{*}{$\begin{array}{l}\text { Muestras } \\
\text { de } \\
\text { referencia }\end{array}$} & $\mathrm{Ca}^{2+}, \mathrm{Mg}^{2+}, \mathrm{SO}_{4}^{2-}, \mathrm{Fe}^{3+}, \mathrm{Al}^{3+}$ \\
\hline & & & Análisis térmico (ATD-TG) \\
\hline & & & DRX \\
\hline & & \multirow{3}{*}{$\begin{array}{l}\text { Muestras } \\
\text { expuestas }\end{array}$} & $\mathrm{Ca}^{2+}, \mathrm{Mg}^{2+}, \mathrm{SO}_{4}^{2-}, \mathrm{Fe}^{3+}, \mathrm{Al}^{3+}$ \\
\hline & & & Análisis térmico (ATD-TG) \\
\hline & & & DRX \\
\hline \multirow{2}{*}{\multicolumn{2}{|c|}{$\begin{array}{l}\text { Caracterización del estado de hidratación } \\
\text { de las pastas de cemento a edad madura }\end{array}$}} & \multicolumn{2}{|c|}{$\begin{array}{c}\text { Evaluación del estado de hidratación mediante } \\
\text { análisis térmico (ATD-TG) }\end{array}$} \\
\hline & & \multicolumn{2}{|c|}{$\begin{array}{c}\text { Evaluación de la microestructura mediante el } \\
\text { cálculo de la energía de activación en ensayos de } \\
\text { análisis térmico (ATD-TG) }\end{array}$} \\
\hline
\end{tabular}

\subsubsection{CARACTERIZACIÓN DE LAS MUESTRAS DURANTE EL PROCESO DE DEGRADACIÓN}

Los ensayos correspondientes al periodo de caracterización de las muestras durante los ensayos de degradación suponen una parte importante de la campaña experimental planteada. Con el objetivo de que se pueda llevar a cabo un seguimiento de las determinaciones realizadas a cada edad de exposición en las muestras obtenidas se presentan la Figura 15 y la Figura 16. Se han identificado las muestras con la leyenda que se muestra en Tabla 7, donde el color de la símbolo se refiere al tipo de pasta de cemento empleado (SR, II ó IV), y la forma del símbolo identifica cada uno de los medios de exposición (medios de referencia y medios potencialmente agresivos para el material).

Tabla 7. Abreviaturas empleadas en la nomenclatura de las muestras

$\begin{array}{llllll}\text { SRAC } & \boldsymbol{\Delta} & \text { IIAC } & \boldsymbol{\Delta} & \text { IVAC } & \boldsymbol{\Delta} \\ \text { SRSU } & \circ & \text { IISU } & \circ & \text { IVSU } & \circ \\ \text { SRAN } & \text { - } & \text { IIAN } & \boldsymbol{~} & \text { IVAN } & \text { - } \\ \text { SRCA } & + & \text { IICA } & + & \text { IVCA } & + \\ \text { SRAI } & * & \text { IIAI } & * & \text { IVAI } & *\end{array}$




\begin{tabular}{|c|c|c|c|c|}
\hline Día & $\mathrm{pH}$ & $\mathrm{Ca}^{2+}$ & $\mathrm{Mg}^{2+}$ & $\mathrm{SO}_{4}{ }^{2}$ \\
\hline 0 & 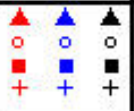 & $\square \square$ & घ & $\mathbf{a}$ \\
\hline 1 & $\begin{array}{lll}0 & 0 & 0 \\
+ & + & +\end{array}$ & & & \\
\hline 2 & 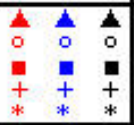 & $\begin{array}{l}\text { i } \\
\div\end{array}$ & 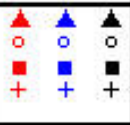 & 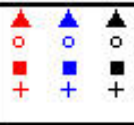 \\
\hline 4 & 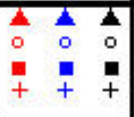 & $0 \quad 0 \quad 0$ & $\begin{array}{lll}0 & 0 & 0 \\
+ & + & +\end{array}$ & $+\quad+\quad+$ \\
\hline 5 & 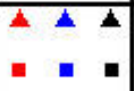 & $\begin{array}{l}\mathbf{A} \\
\| \quad \square\end{array}$ & 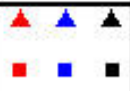 & 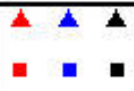 \\
\hline 6 & $\begin{array}{lll}0 & 0 & 0 \\
+ & + & +\end{array}$ & & & \\
\hline 7 & 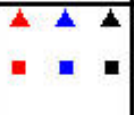 & 000 & $\begin{array}{lll}0 & 0 & 0 \\
+ & + & +\end{array}$ & $+\quad++$ \\
\hline 12 & $\begin{array}{r}\mathbf{4} \mathbf{L} \\
\square \quad \square\end{array}$ & 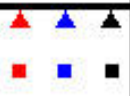 & 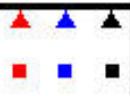 & 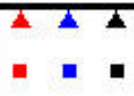 \\
\hline 14 & 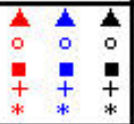 & 0 & $\begin{array}{lll}0 & 0 & 0 \\
+ & + & +\end{array}$ & + \\
\hline 21 & 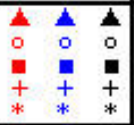 & $\begin{array}{lll} & \mathbf{1} & \mathbf{A} \\
0 & 0 & 0 \\
\mathbf{v}\end{array}$ & 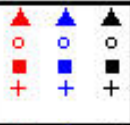 & 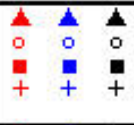 \\
\hline 30 & $\begin{array}{l}\mathbf{A} \\
\mathbf{1}\end{array}$ & $\begin{array}{l}\boldsymbol{L} \\
\|\quad\|\end{array}$ & 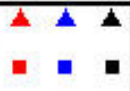 & $\begin{array}{l}\boldsymbol{k} \\
\|\quad\|\end{array}$ \\
\hline 32 & $\begin{array}{lll}0 & 0 & 0 \\
+ & + & +\end{array}$ & 0 & $\begin{array}{lll}0 & 0 & 0 \\
+ & + & +\end{array}$ & $+\quad+$ \\
\hline 41 & 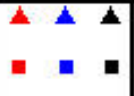 & 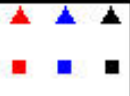 & 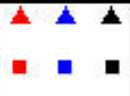 & 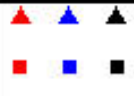 \\
\hline
\end{tabular}

\begin{tabular}{|c|c|c|c|c|}
\hline Día & $\mathrm{pH}$ & $\mathrm{Ca}^{2+}$ & $\mathrm{Mg}^{2+}$ & $\mathrm{SO}_{4}{ }^{2}$ \\
\hline 43 & $\begin{array}{lll}0 & 0 & 0 \\
+ & + & +\end{array}$ & 000 & $\begin{array}{ccc}0 & 0 & 0 \\
+ & + & +\end{array}$ & +++ \\
\hline 49 & $\begin{array}{l}\boldsymbol{L} \\
\square \quad \|\end{array}$ & 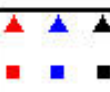 & $\begin{array}{l}\boldsymbol{\Lambda} \\
\square \quad \square\end{array}$ & $\begin{array}{l}<k \\
\|\quad\|\end{array}$ \\
\hline 51 & 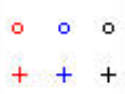 & $\circ \quad 0 \quad 0$ & $\begin{array}{rrr}0 & 0 & 0 \\
+ & + & +\end{array}$ & $+\quad+\quad+$ \\
\hline 58 & $\begin{array}{l}\mathbf{L} \\
\square=\mathbf{n}\end{array}$ & $\begin{array}{l}1 \mathrm{i} \\
\mathrm{a}\end{array}$ & 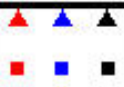 & $\begin{array}{l}\mathbf{L} \\
\square=\mathrm{a}\end{array}$ \\
\hline 60 & $\begin{array}{lll}0 & 0 & 0 \\
+ & + & +\end{array}$ & 00 & 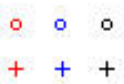 & +++ \\
\hline 64 & $\begin{array}{l}\mathbf{A} \\
\|\quad\|\end{array}$ & 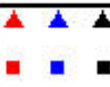 & 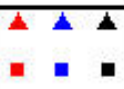 & $\begin{array}{l}\mathbf{k} \\
\| \quad \square\end{array}$ \\
\hline 66 & $\begin{array}{lll}0 & 0 & 0 \\
+ & + & +\end{array}$ & $0 \quad 0 \quad 0$ & 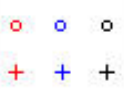 & $+\quad++$ \\
\hline 71 & $\begin{array}{l}7 \mathbf{i} \\
\square=\mathbf{n}\end{array}$ & 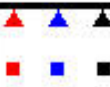 & $\begin{array}{l}\mathbf{L} \\
\square=\mathbf{n}\end{array}$ & $\begin{array}{l}\mathbf{k} \\
\square=\mathrm{a}\end{array}$ \\
\hline 73 & 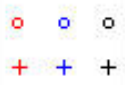 & 00 & 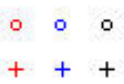 & +++ \\
\hline 77 & $\begin{array}{l}\mathbf{L} \\
\square \quad \|\end{array}$ & 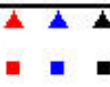 & $\begin{array}{l}\mathbf{i} \\
\square=\|\end{array}$ & $\begin{array}{l}\boldsymbol{L} \\
\square \quad \square\end{array}$ \\
\hline 79 & $\begin{array}{lll}0 & 0 & 0 \\
+ & + & +\end{array}$ & 0 & $\begin{array}{lll}0 & 0 & 0 \\
+ & + & +\end{array}$ & +++ \\
\hline 85 & $\begin{array}{lll} & \mathbf{A} & \boldsymbol{L} \\
0 & 0 & 0 \\
\mathbf{1} & \mathbf{1} & \mathbf{1} \\
+ & + & + \\
* & * & *\end{array}$ & $\frac{1}{0}$ & $\begin{array}{lll} & \mathbf{1} & \mathbf{A} \\
0 & 0 & 0 \\
+ & + & \mathbf{1}\end{array}$ & $\begin{array}{lll} & \boldsymbol{L} & \boldsymbol{L} \\
0 & 0 & 0 \\
+ & \mathbf{a} & \mathbf{0}\end{array}$ \\
\hline 92 & 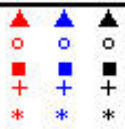 & $\begin{array}{lll} & \mathbf{1} & \boldsymbol{1} \\
0 & 0 & 0 \\
& 0\end{array}$ & 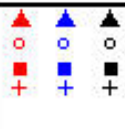 & 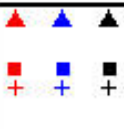 \\
\hline
\end{tabular}

Figura 15. Resumen de ensayos realizados en las muestras de lixiviados 

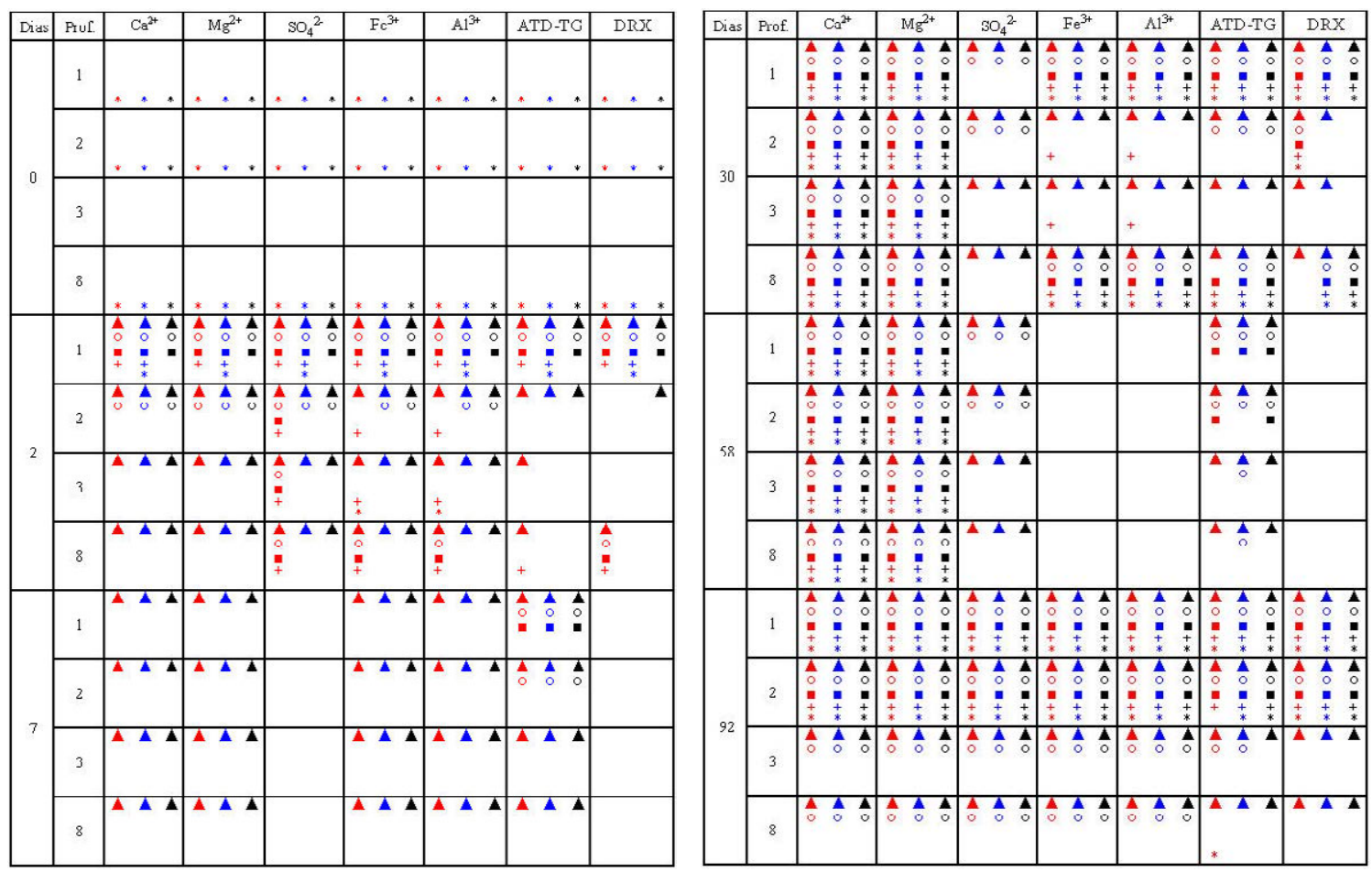

Figura 16. Resumen de ensayos realizados en las muestras de sólidas implicadas en el proceso de exposición

\subsubsection{CARACTERIZACIÓN DEL ESTADO DE HIDRATACIÓN DE LAS PASTAS DE CEMENTO A EDAD MADURA MEDIANTE ANÁLISIS TÉRMICO}

El estudio del estado de hidratación de las pastas fabricadas es un punto esencial desde el punto de vista del conocimiento de la microestructura del material. Ésta juega un papel determinante cuando se trata de evaluar el comportamiento del material ante determinadas situaciones de exposición a potenciales agresivos. Además constituye una herramienta eficaz con la que poder predecir determinadas propiedades que tienen repercusión en el desempeño de los materiales estructurales.

Se programaron ensayos que nos permitiesen estimar el grado de hidratación de las muestras en base al criterio de diferentes autores, y se evaluaron las condiciones de medida y los criterios en base a los cuales se efectúa dicho cálculo.

La variación en algunas condiciones de medida nos permitió evaluar el grado de resolución de los termogramas que podemos obtener. También analizar algunos aspectos termodinámicos como la energía de activación y la complejidad de las reacciones que influyen en el mecanismo 
a través del cual se producen las reacciones de descomposición térmica durante el proceso de calentamiento de una muestra en un ensayo de análisis térmico.

Se presentan las características de los ensayos realizados en el apartado 3.4.5. En la Tabla 8 se presenta un resumen de los ensayos realizados.

Tabla 8. Ensayos de análisis térmico realizados sobre muestras a edad madura

\begin{tabular}{cccc}
\hline \multirow{2}{*}{$\begin{array}{c}\text { Tipo de pasta } \\
\text { de cemento }\end{array}$} & $\begin{array}{c}\text { Rango de } \\
\text { temperatura } \\
\left({ }^{\circ} \mathrm{C}\right)\end{array}$ & $\begin{array}{c}\text { Velocidad } \\
\text { calentamiento } \\
\left({ }^{\circ} \mathrm{C} / \mathrm{min}\right)\end{array}$ & $\begin{array}{c}\text { Gas portador } \\
\mathrm{N}_{2} \\
(\approx 80 \mathrm{ml} / \mathrm{min})\end{array}$ \\
\cline { 3 - 4 } SR & & 0.5 & $\mathrm{NO}$ \\
\cline { 3 - 4 } II & $100-300$ & 5 & $\mathrm{NO}$ \\
\cline { 3 - 4 } IV & & 10 & $\mathrm{NO}$ \\
\cline { 3 - 4 } & & 10 & $\mathrm{SI}$ \\
\hline
\end{tabular}

\subsection{METODOLOGÍA DE ANÁLISIS}

A continuación se presentan los detalles de los procedimientos operatorios empleados a lo largo de la campaña experimental.

\subsubsection{MEDIDA DEL PH.}

El pH de los medios de exposición se midió diariamente durante la primera semana de ensayo y semanalmente a partir de la segunda semana. Para su lectura se empleó un sensor de pH Crison, con un rango de medida de 0 a 14 y una resolución de 0.01 ; para su calibración se emplearon disoluciones patrón Panreac de pH 4, 7 y 9 unidades.

En la Figura 17 se muestran los equipos empleados para llevara a cabo la determinación. 

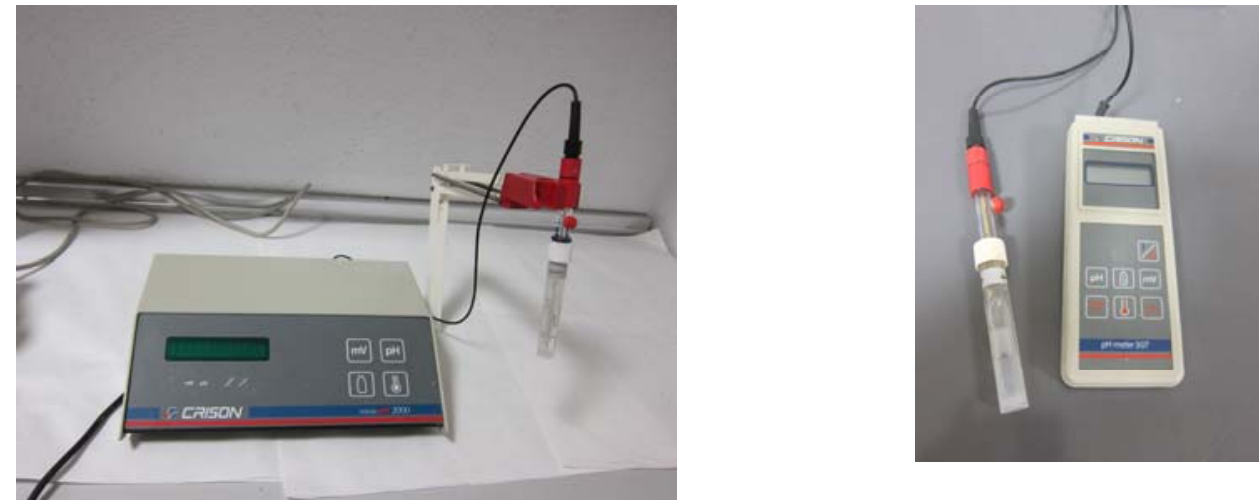

Figura 17. pHmetros empleados

\subsubsection{CROMATOGRAFÍA IÓNICA.}

\subsubsection{Fundamentos de la técnica}

La cromatografía iónica es una técnica de separación basada en el principio de adsorción selectiva. El objetivo es separar los distintos iones en una solución. En la cromatografía existe un contacto entre dos fases, una fija que suele llamarse fase estacionaria, y una fase móvil que fluye permanente durante el análisis y arrastra las muestras líquidas.

La fase estacionaria está compuesta por resinas de intercambio iónico que contienen puntos activos con carga electrostática (positiva o negativa). De esta forma, la muestra queda retenida sobre el soporte sólido por afinidad electrostática. El tiempo que la muestra queda retenida sobre la resina depende de la relación carga/tamaño iónico del constituyente (constante de equilibrio de intercambio iónico).

La elución de las muestras de la columna se produce con el paso por la misma de la fase móvil o eluyente. El tiempo de elución, o tiempo que tarda un ion en pasar a través de la columna, varía para cada especie, y es un dato característico para cada ion en unas condiciones de medida determinadas.

A la salida de la columna, el sensor de conductividad detecta la salida de iones y devuelve una señal proporcional a la concentración de cada especie. Gráficamente, las concentraciones de iones pueden ser calculadas usando el área bajo cada pico. En la Figura 18 se muestran cromatogramas típicos en la determinación de cationes y aniones de una muestra. 
Para emplear esta técnica los analitos deben ser iones o sustancias polares. La fase móvil es siempre polar o iónica. Y la determinación de aniones y cationes se realiza por separado, ya que forman enlaces iónicos con la fase estacionaria.

Esta técnica de análisis se ha empleado para determinar fundamentalmente los iones $\mathrm{Ca}^{2+}, \mathrm{Mg}^{2+}$, $\mathrm{y} \mathrm{SO}_{4}{ }^{2-}$.

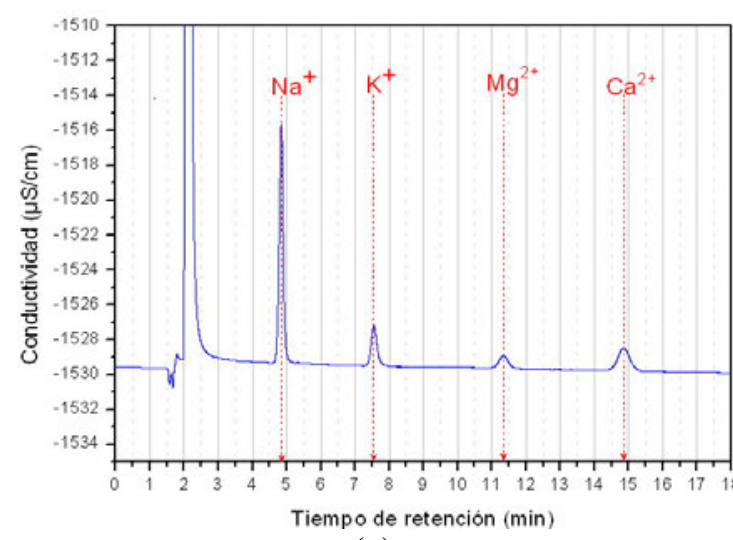

(a)

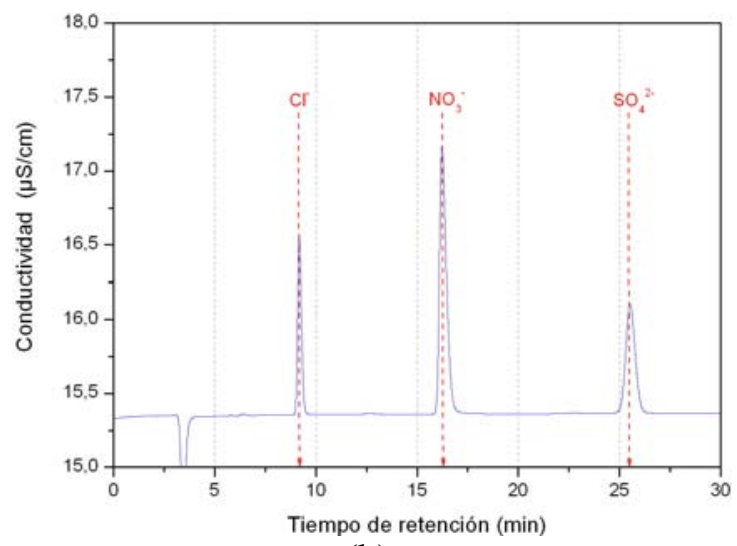

(b)

Figura 18. Cromatograma típico catiónico y aniónico

\subsubsection{Condiciones de análisis}

Los ensayos se realizan en un cromatógrafo iónico serie profesional marca Metrohm modelo 882 Compact IC, con procesador automático de muestras modelo 858 con ultrafiltración.

Se han utilizado dos tipos de columnas acopladas al cromatógrafo en función de si la determinación era de aniones o cationes.

La columna seleccionada para separar cationes es la Metrosep C-3-250x4. El material del soporte es alcohol polivinílico con grupos carboxilo. El flujo de trabajo $1 \mathrm{~mL} / \mathrm{min}$. El tamaño de partícula son 5 micras. Y el eluyente empleado ácido nítrico 5 mM.

La columna aniónica seleccionada es la Metrosep A Supp 5-250. El relleno de esta columna está constituido por una resina de alcohol polivinílico con grupos de amino-cuaternario. El flujo de trabajo $0.7 \mathrm{~mL} / \mathrm{min}$. El tamaño de partícula son 5 micras. Y el eluyente empleado $1 \mathrm{mM}$ en hidrógeno carbonato sódico y 3.2 mM en carbonato sódico.

Para este tipo de determinaciones el equipo funciona con un detector digital de conductividad de alta sensibilidad, una bomba isocrática de alta presión, una válvula de inyección eléctrica de 6 
vías y un módulo de supresión química de Metrohm MSM II (en el caso de las determinaciones de aniones)

En la Figura 19 se muestra una imagen del equipo empleado en las determinaciones.

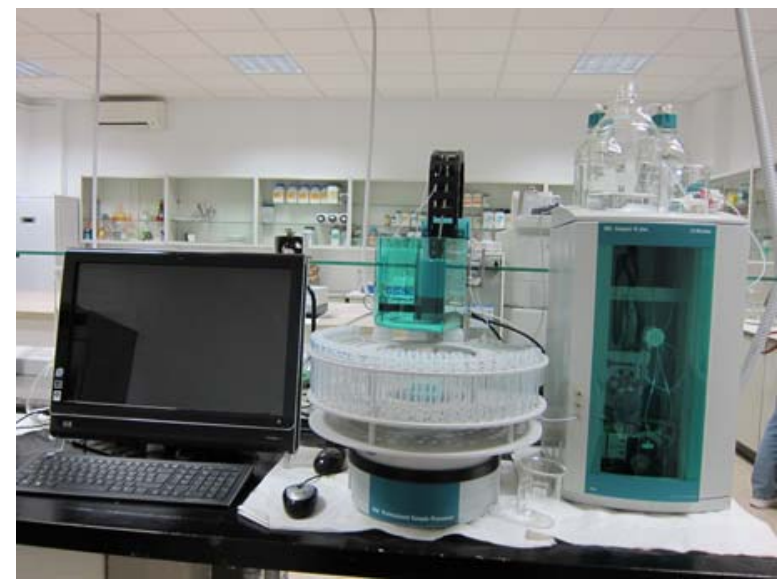

Figura 19. Cromatógrafo iónico y procesador de muestras empleado

Una vez analizadas las muestras se calculó el área bajo la curva de cada ion determinado y se interpolaron los resultados en rectas de calibración. Las rectas de calibración se construyeron determinando el área bajo la curva de disoluciones preparadas a partir de disoluciones estándar comerciales de 1000 ppm Fluka.

La determinación de iones mediante cromatografía iónica es un método sencillo que permite realizar determinaciones de varios iones en una misma muestra. Algunos iones se pueden determinar simultáneamente en el mismo análisis variando los tiempos de retención, y otros simplemente cambiando de columna, o la polaridad del eluyente. Es una técnica instrumental con un límite de detección muy bajo, lo que permite emplear diluciones y realizar varias medidas. Todos estos factores cobran importancia cuando la cantidad de muestra obtenida para los ensayos es escasa.

Sin embargo, hay que tener en cuenta que la determinación de la composición química de los cementos mediante cromatografía iónica no está incluida en los métodos descritos a este fin en la normativa española. Para verificar la validez del método de medida se realizaron ensayos de comprobación entre los métodos de determinación que propone la normativa española y el método propuesto. Los resultados obtenidos se presentan en el capítulo siguiente.

\subsubsection{MÉTODO VOLUMETRÍCO - ANÁLISIS DE ION FÉRRICO Y ALUMNINICO}


En las determinaciones de $\mathrm{Fe}^{3+}$ y $\mathrm{Al}^{3+}$ se empleó un método basado en la determinación de la transmisión de luz $(\mathrm{mV})$ de una disolución coloreada mediante un sensor fotométrico. Este método se asegura una mayor precisión que empleando un método visual.

\subsubsection{Fundamentos de la técnica}

Los métodos volumétricos de análisis cuantitativo se basan en medir una propiedad física o físico-química de la muestra relacionada con la masa de ésta mediante una ecuación matemática.

Las reacciones que se producen han de ser rápidas, cuantitativas y de estequiometría conocida.

El método de detección que se elige en cada caso depende de la reacción que tenga lugar y de la posibilidad de interferencias.

En este trabajo se empleó la variación de potencial producida en la disolución asociada a los cambios de color que se producen debidos a las reacciones químicas que tienen lugar.

El sistema de detección empleado es un fototrodo capaz de medir la transmitancia de la disolución a una longitud de onda fija. Ambas determinaciones se basan en la formación de iones complejos con el ácido etilediaminotetracético (AEDT) usando como indicadores especies capaces de formar compuestos coloreados.

Las curvas de valoración son la representación gráfica de la variación de la propiedad que se está midiendo ( $\mathrm{pH}$, potencial, conductividad, etc.) a lo largo de la valoración y proporcionan información relacionada de la precisión con la que se puede localizar el punto de equivalencia en relación con el punto final detectado.

Es importante conocer el tipo de curva de valoración que se produce cuando se emplean equipos de valoración automáticos, dado que los mismos trabajan con distintos criterios de determinación del punto final. Normalmente, los métodos instrumentales alcanzan una mayor sensibilidad y precisión.

Las curvas de valoración empleadas son lineales y se construyen uniendo los puntos de la valoración en tramos rectos entorno al punto de equivalencia. De la intersección entre ambas se obtiene la posición del punto final. Es habitual encontrar cierta curvatura de la curva de 
valoración cuando nos acercamos al punto de equivalencia, que refleja la amplitud de la reversibilidad de la reacción volumétrica.

En nuestro caso, resultó muy práctico calcular el punto de final de la valoración representando la curva derivada (variación del potencial respecto del incremento de volumen frente al incremento de volumen).

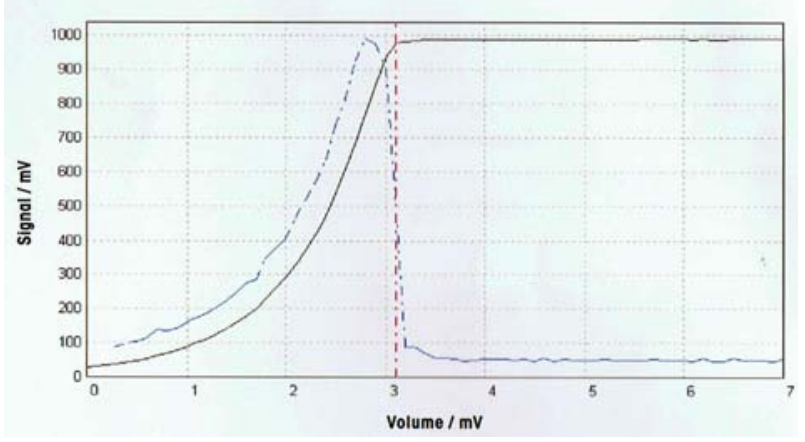

Figura 20. Curva de titulación de ion férrico con AEDT usando como indicador ácido sulfosalicílico

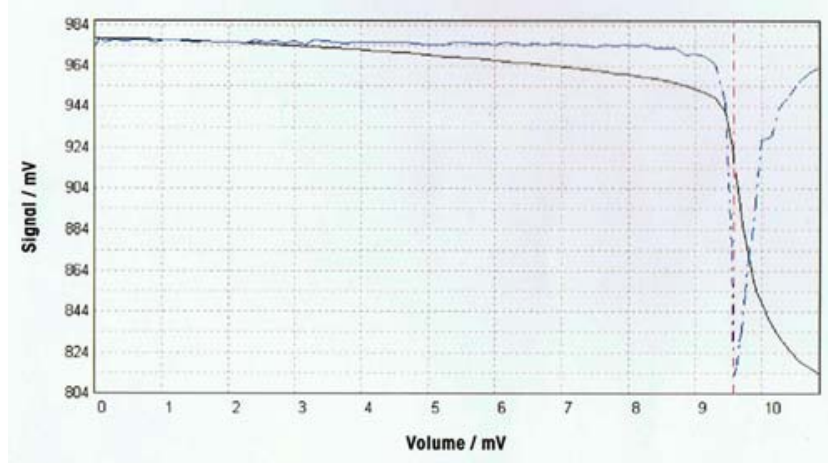

Figura 21. Curva de titulación de ion alumínico con $\mathrm{ZnSO}_{4}$ usando como indicador naranja de xilenol

\section{Determinación de ion férrico}

En el caso de la determinación de ion férrico, se siguieron las indicaciones de la norma UNEEN 196-2:2006. La determinación se llevó a cabo mediante una valoración directa, en la que cantidad de analito se determina a partir de la cantidad de valorante que se necesita para reaccionar completamente con él.

Como reactivo valorante se empleó AEDT. El punto de equivalencia de la reacción es un valor teórico que no se puede determinar experimentalmente, se estima cuando se pone de manifiesto un cambio asociado a la condición de equivalencia, por lo que se denomina punto final de la valoración. 
En la valoración de ion férrico con AEDT se emplea como indicador ácido sulfosalicílico. El ácido sulfosalicílico forma un complejo de color rojo vino con el ion férrico. El viraje de color se produce al amarillo pálido correspondiente al color de complejo $\left(\mathrm{Fe}^{3+}\right)$-AEDT. Se anota el valor del volumen al cual se produce el punto final de la valoración y se continúa adicionando AEDT hasta un volumen prefijado. La razón de adicionar un volumen de AEDT determinado es que sobre la muestra en la que se ha determinado el ion férrico podemos determinar el ion $\mathrm{Al}^{3+}$, ya que la estabilidad de los complejos formados con AEDT es muy diferente.

\section{Determinación de ion aluminio}

La determinación de $\mathrm{Al}^{3+}$ no pudo realizarse siguiendo exactamente el método de la UNE-EN 196-2:2006. Según se describe en esta norma, la determinación de $\mathrm{Al}^{3+}$ se lleva a cabo mediante valoración directa con AEDT empleando como indicador piridilazo 2-naftol (PAN).

La reacción se lleva a cabo a temperatura de ebullición, puesto que la formación del complejo $\left(\mathrm{Al}^{3+}\right)$-AEDT está termodinámicamente poco favorecida.

La dificultad surgió cuando tratamos de determinar el punto final de la valoración con el fototrodo, ya que la existencia de multitud de burbujas nos impedía obtener una medida de transmitancia adecuada. Para solventar este problema se probaron reacciones de valoración equivalentes que nos permitieran emplear el mismo sistema de detección que en las valoraciones de ion férrico.

Se llevó a cabo la determinación de ion aluminio mediante valoración indirecta. En este tipo de valoraciones es necesario añadir un exceso de valorante estándar que reaccione con el analito, y después determinar el exceso, mediante una segunda valoración con otro valorante estándar.

El valorante estándar elegido para determinar el exceso de AEDT después de las reacciones con $\mathrm{Fe}^{3+} \mathrm{y} \mathrm{Al}^{3+}$ fue el $\mathrm{ZnSO}_{4}$, usando como indicador naranja de xilenol. El viraje de color que se produce en esta valoración es de amarillo intenso-anaranjado al rojo intenso.

\subsubsection{Condiciones de análisis}

La determinación de $\mathrm{Fe}^{3+}$ y $\mathrm{Al}^{3+}$ se llevó a cabo en un titulador automático Mettler Toledo DL50 acoplado con un fototrodo DP550. En la Figura 22 se puede ver el equipo empleado. 


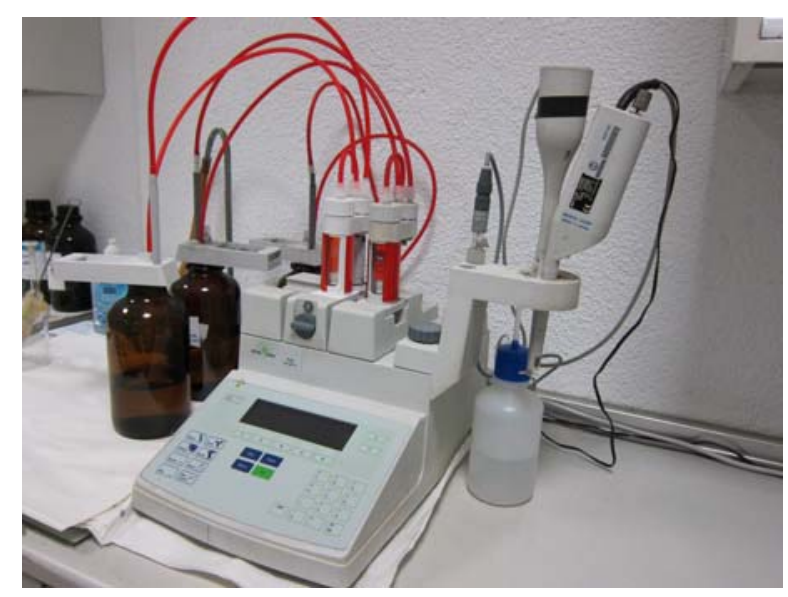

Figura 22. Valorador automático Mettler Toledo DL50 con fototrodo

Las valoraciones de ion férrico requerían una temperatura y un $\mathrm{pH}$ controlados en continuo. El pH se fijó a $1.5 \pm 0.1$ unidades, para lo cual se realizaron pequeñas adiciones de $\mathrm{H}_{2} \mathrm{SO}_{4}(1+1)$ y $\mathrm{NH}_{4} \mathrm{OH}(1+1)$ y $(1+10)$.

El control del pH se realizó empleando el pHmetro descrito en el apartado 3.4.1. La temperatura de la valoración fue $47.5 \pm 2.5^{\circ} \mathrm{C}$. Para mantener dicha temperatura se empleó una placa calefactora.

En la Tabla 9 se resumen los detalles del método puesto a punto para llevar a cabo la determinación del ion férrico.

Tabla 9. Método de valoración de ion férrico

\begin{tabular}{c|c}
\hline Reactivo valorante & AEDT 0.03M titulado \\
\hline Sénsor & DP550 Mettler Toledo \\
\hline Unidad de medida & $\mathrm{mV}$ \\
\hline \multirow{3}{*}{ Adición de reactivo } & $\Delta \mathrm{E}=8.0 \mathrm{mV}$ \\
& $\Delta \mathrm{V}$ mínimo $=0.02 \mathrm{~mL}$ \\
& $\Delta \mathrm{V}$ máximo $=0.2 \mathrm{~mL}$ \\
\hline \multirow{2}{*}{ Forma de medida } & Control del equilibrio \\
& $\Delta \mathrm{E}=0.5 \mathrm{mV}$ \\
& $\Delta \mathrm{t}=1 \mathrm{~s}$ \\
\hline Detección & $\Delta \mathrm{t}$ mínimo $=3 \mathrm{~s}$ \\
& Umbramo $=30 \mathrm{~s}$ \\
\hline Terminación & A volumeno de medida: $500-1500 \mathrm{mV}$ \\
& Tendencia positiva \\
\hline
\end{tabular}


La determinación de $\mathrm{Al}^{3+}$ se realizó a partir de la valoración indirecta del exceso de AEDT con $\mathrm{ZnSO}_{4}$, después de la reacción con $\mathrm{Fe}^{3+}$ y $\mathrm{Al}^{3+}$.

Antes de realizar la valoración había que favorecer la formación del complejo $\mathrm{Al}^{3+}$-AEDT ${ }^{2}$. Para ello se dosificaba una cantidad fija de AEDT que asegurara la completa reacción del ión aluminio, y se calentaron las muestras hasta ebullición. Después se dejaban enfriar a temperatura ambiente. La titulación a temperatura ambiente nos permite llegar a eliminar las burbujas producidas durante la ebullición, que dificultaba la medida del fototrodo. En la determinación también fue necesario fijar el $\mathrm{pH}$ a 5, para lo cual se adicionó un tampón compuesto por ácido acético-acetato sódico.

En la Tabla 10 se resumen los detalles del método puesto a punto para llevar a cabo la determinación del ion aluminio.

Tabla 10. Método de valoración de ion aluminio

\begin{tabular}{c|c}
\hline Reactivo valorante & $\mathrm{ZnSO}_{4} 0.03 \mathrm{M}$ titulado \\
\hline Sénsor & $\mathrm{DP550}$ Mettler Toledo \\
\hline Unidad de medida & $\mathrm{mV}$ \\
\hline Adición de reactivo & $\begin{array}{c}\text { Incremental } \\
\Delta \mathrm{V}=0.02 \mathrm{~mL}\end{array}$ \\
\hline Forma de medida & $\begin{array}{c}\text { Control del equilibrio } \\
\Delta \mathrm{E}=0.5 \mathrm{mV} \\
\Delta \mathrm{t}=1 \mathrm{~s} \\
\Delta \mathrm{t} \text { mínimo }=3 \mathrm{~s} \\
\Delta \mathrm{t} \text { máximo }=30 \mathrm{~s}\end{array}$ \\
\hline Detección & $\begin{array}{c}\text { Umbral }=100.0 \mathrm{mV} \\
\text { Rango de medida: } 500-1500 \mathrm{mV} \\
\text { Tendencia negativa }\end{array}$ \\
\hline Terminación & A volumen máximo prefijado \\
\hline
\end{tabular}

\subsubsection{DIFRACCIÓN DE RAYOS-X.}

\subsubsection{Fundamentos de la técnica}

\footnotetext{
${ }^{2}$ La formación de este complejo está termodinámicamente desfavorecida, por eso conviene aportar calor durante su formación. En el medio de reacción, una vez formado, su descomposición está cinéticamente desfavorecida.
} 
Los sólidos cristalinos poseen una estructura ordenada y periódica, que se mantiene unida por grandes fuerzas de cohesión. La distribución de las partículas que componen el material conforma lo que se denomina una celdilla unidad. Esta celdilla unidad está definida por los módulos y las direcciones de los vectores a, b y c, que definen los ejes cristalográficos y por los ángulos que forman entre sí. A estas seis magnitudes se las denomina parámetros de celdilla o parámetros de red.

Es interesante destacar que no existen en la naturaleza dos cristales con distinta composición que posean los mismos valores de los parámetros cristalográficos. Como las distancias entre planos dependen de dichos parámetros, puede decirse también que no existen dos cristales que tengan todos sus espaciados iguales y por eso cada patrón de difracción identifica un tipo de compuesto determinado.

El fundamento de esta técnica reside en el fenómeno conocido como dispersión "scattering" de una radiación $\mathrm{X}$ cuando incide sobre la materia. En este proceso, parte de la radiación $\mathrm{X}$ incidente se desvía de su dirección original por interacción con el material irradiado. El haz de rayos $\mathrm{X}$ que difracta se ve modificado por la orientación de los cristales que forman las redes cristalinas. La ley de Bragg permite relacionar la orientación del haz incidente y la del haz difractado con la distancia entre los planos de la red cristalina según la ecuación (BermúdezPolonio, 1981):

Ley de Bragg : $n \lambda=2 d_{h k l} \operatorname{sen} \theta$

\section{Ecuación 5}
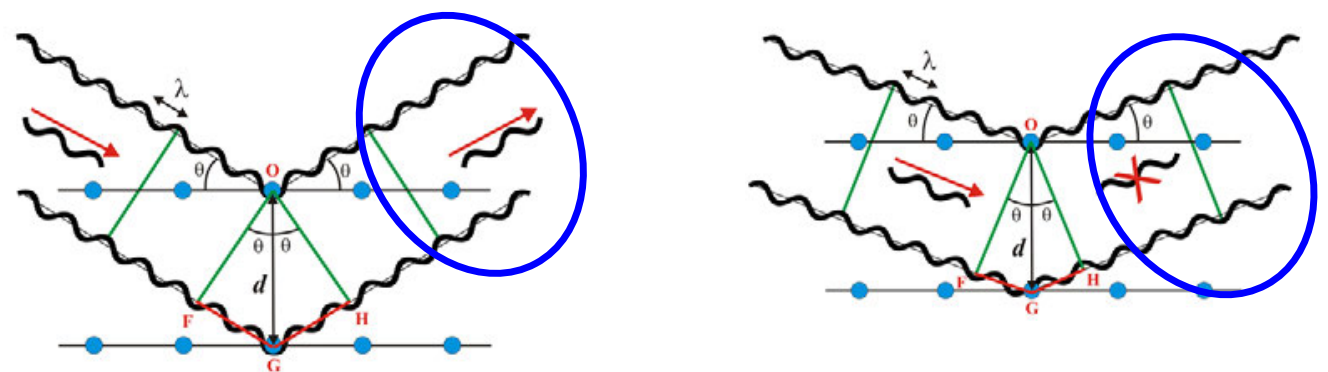

Figura 23. Esquema de onda con (a) intensidad reflejada cuando se cumple la ley de Bragg (los frentes de onda emergente tras la reflexión están en fase); (b) intensidad no reflejada cuando no se cumple la ley de Bragg (los frentes de onda emergente tras la reflexión no están en fase). Fuente: ${ }_{\text {http://www.xtal.iqfr.csic.es/ }}$

Si se representa la intensidad de radiación que llega al detector, frente al ángulo $\theta$, aparecerá un pico cuando se cumpla Ley de Bragg. A dicha representación se la denomina diagrama de 
difracción o difractograma. En la Figura 24 se muestra un difractograma típico de una muestra de pasta de cemento. Las líneas verticales en color representan patrones de difracción de compuestos cristalinos habituales presentes en la microestructura de la pasta de cemento.

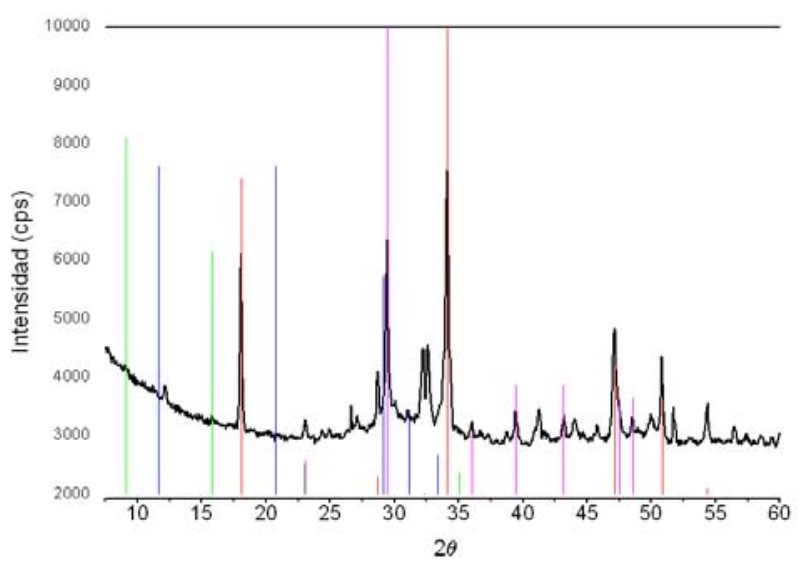

Figura 24. Difractograma típico en una muestra de pasta de cemento

La identificación de compuestos cristalinos en las muestras de pasta de cemento se lleva a cabo por comparación de los difractogramas de las muestras analizadas con los difractogramas de los compuestos aislados. Existen bases de datos que recogen los datos cristalográficos de las especies cristalinas naturales o sintéticas conocidas. En esta tesis doctoral se han empleado las fichas cristalográficas del ICDD.

Esta técnica es muy frecuente en la caracterización mineralógica de los cementos de partida. También se puede emplear para estimar el grado de hidratación de las muestras identificando la presencia de diferentes compuestos presentes en los materiales base cemento (Escalante-García et al., 2003).

\subsubsection{Condiciones de análisis}

Los análisis de difracción de rayos-X han sido realizados en un difractómetro X'Pert Pro MPD Alfa1, empleando radiación monocromática $\mathrm{Cu}-\mathrm{K}_{\alpha 1}$ de 1.5484 Å. En la Figura 25 se muestran los equipos empleados la determinación (Fuente: http://pendientedemigracion.ucm.es/centros/webs/cai5084/index.php?tp=Difracci\%F3n\%20de\% 20Polvo\&a=dir3\&d=23115.php). 

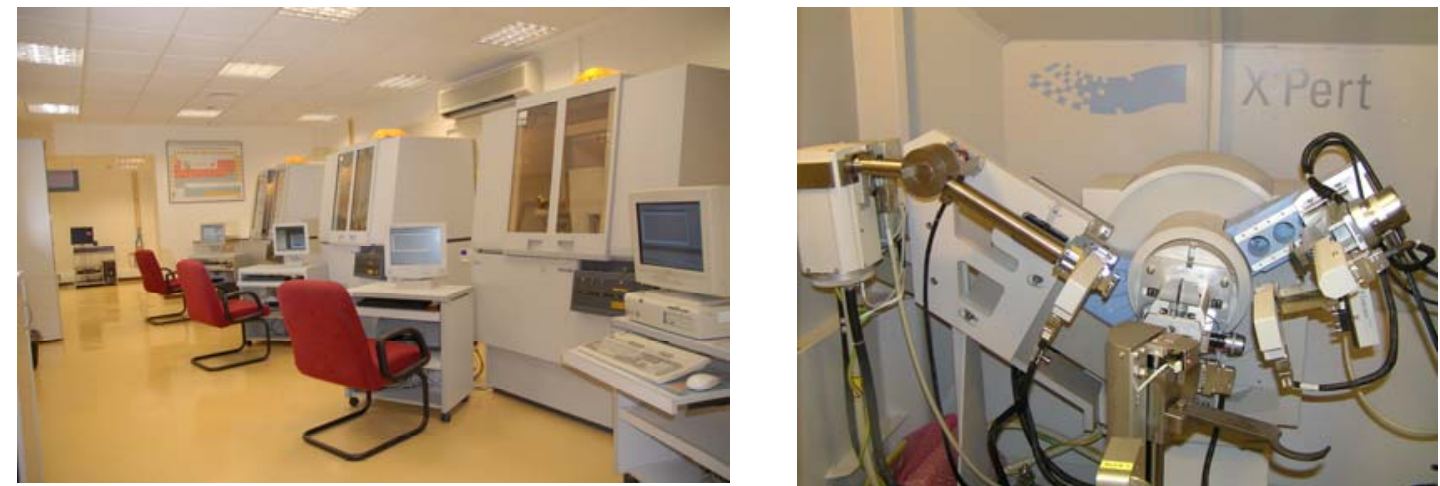

Figura 25. Difractómetro X'Pert Pro MPD Alfa1.

Los programas de barrido empleados contemplaron un intervalo entre pasos de 0,033 $(2 \theta)$. Para asegurar una buena resolución de los picos, se impuso un número de cuentas mínimo en el máximo de difracción de 10.000 cuentas.

Para el posterior proceso de identificación de las fases, se empleó un software de tratamiento de los difractogramas, DRX-TG (Vila, 1989) y las bases de datos cristalográficas del ICDD (Internacional Centre for Difraction Data).

Las muestras de análisis empleadas para llevar a cabo los análisis térmicos son las obtenidas mediante el procedimiento descrito en el apartado 3.2.

\subsubsection{ANÁLISIS TÉRMICO}

\subsubsection{Fundamentos de la técnica}

El análisis térmico una técnica de uso generalizado en el campo de la cerámica y el reconocimiento de materias primas y compuestos en el área de los materiales cementicios.

Las reacciones químicas suponen un cambio de estado cualitativo de equilibrio a otro, en los cuales siempre está implicada una cantidad de energía. Esta energía es la que permite establecer el nuevo estado de equilibrio y puede ser absorbida por la materia (en cuyo caso la reacción será endotérmica), o puede ser desprendida (en cuyo caso la reacción será exotérmica). Las transformaciones que se producen pueden ser cambios de estado físico, la formación de nuevos compuestos o la de nuevas fases mineralógicas.

Las variaciones en la propiedad medida se registran mediante picos o bandas producidas a partir de una línea base. En teoría, se definen mediante un punto inicial, un punto característico y un 
punto final de la reacción. En la práctica, la determinación de estos puntos característicos en muestras de materiales cementicios no siempre es sencilla.

Las condiciones a las cuales se llevan a cabo los ensayos juegan un papel importante no sólo en la adquisición de datos, también en el procesamiento de los mismos.

Además, cuando se produce solapamiento de las bandas, la interpretación del termograma se dificulta.

Para realizar medidas cuantitativas es necesario establecer una relación entre la propiedad medida (variación de masa, área o altura de pico de la banda observada, etc.) y la cantidad de energía implicada en la transformación de una cantidad de masa de compuesto. Esto conlleva la estandarización de las condiciones de trabajo y medidas empleadas en cada tipo de determinación.

Los métodos de análisis térmico empleado en este trabajo han sido el Análisis Térmico Diferencial -ATD- y el Análisis Termogravimétrico -TG-. La información extraída de los termogramas se ha tratado para obtener información referente a la microestructura de la matriz en materia referente a:

- Identificación de compuestos.

- Cuantificación de compuestos.

- Determinación de parámetros termodinámicos.

- Estimación del grado de hidratación.

El análisis termogravimétrico (TG) es una técnica en la que el cambio de masa de una sustancia se mide en función de la temperatura, mientras que la muestra está siendo expuesta a un programa controlado de calentamiento. Habitualmente se presentan los datos de masa de la muestra con respecto a la temperatura de la muestra. De este modo es fácil identificar las pérdidas de masa en cada rango de temperatura.

En el análisis térmico diferencial (ATD), el aumento de la temperatura del ambiente que rodea un sólido de manera uniforme produce una transferencia de energía calorífica al sólido. En ciertos puntos del ciclo de temperatura, el calor trasferido puede aportar la energía necesaria 
para que se produzca una transformación física o una reacción química. El efecto energético que acompaña a estas transformaciones hace que aparezca una diferencia entre la temperatura de la muestra y la de la muestra inerte o referencia. La representación de la diferencia de temperatura que se establece entre la muestra objeto de estudio y el material de referencia, cuando ambos se someten al mismo programa de calentamiento frente a la temperatura de la muestra nos proporciona la señal de ATD.

La información cuantitativa viene dada por el análisis de las pérdidas de masa en una región determinada. La identificación de los distintos componentes de la pasta de cemento es posible ya que éstos muestran una banda característica en el diagrama de análisis térmico diferencial, ATD. Las pérdidas de peso en cada tramo de calentamiento, se asocian a una transformación físico-química de la muestra.

Una vez determinadas las pérdidas de masa en cada tramo de calentamiento, se asocia cada tramo a un determinado proceso físico-químico. Puesto que las transformaciones estudiadas corresponden a diferentes compuestos del cemento hidratado, el porcentaje de pérdida sufrido estará relacionado con la proporción de cada componente.

Habitualmente se recurre a datos bibliográficos (Ramachandran et al., 2002) para interpretar el proceso químico que está teniendo lugar en función de la temperatura, sin embargo hay que tener en cuenta que las condiciones en la que se lleva a cabo el ensayo y la composición particular de cada muestra puede introducir variaciones en las temperaturas a las cuales se les asigna un determinado proceso, lo que dificulta la interpretación. En la Tabla 11 se muestra un resumen donde se recogen los rangos de temperatura que habitualmente se usan en termoanálisis de materiales cementicios. En los párrafos siguientes se indicaran algunas consideraciones adicionales que se han tenido en cuenta en la presente tesis en la interpretación de las bandas obtenidas mediante termoanálisis.

Tabla 11. Rangos de temperatura más comunes para identificar los distintos productos hidratados (Rivera, 2004)

\begin{tabular}{llll}
\hline \multirow{2}{*}{ Compuestos } & Abreviatura & $\begin{array}{l}\text { Rango de temperatura } \\
\left({ }^{\circ} \mathrm{C}\right)\end{array}$ \\
\hline \multirow{3}{*}{ Gel CSH } & Silicatos cálcicos hidratados & $\mathrm{C}_{\mathrm{x}} \mathrm{S}_{\mathrm{y}} \mathrm{H}_{\mathrm{z}}$ & $120-180$ \\
\cline { 2 - 4 } & Trisulfato cálcico hidratado & $\mathrm{AFt}$ & $130-150$ \\
\cline { 2 - 4 } & Monosulfato cálcico hidratado & $\mathrm{AFm}$ & $170-190$ \\
\cline { 2 - 4 } & Aluminatos cálcicos hidratados (cúbicos) & $\mathrm{C}_{\mathrm{x}} \mathrm{A}_{\mathrm{y}} \mathrm{H}_{\mathrm{z}}$ & $250-300$ \\
\hline Portlandita & Hidróxido cálcico & $\mathrm{Ca}(\mathrm{OH})_{2}$ & $400-500$ \\
\hline
\end{tabular}




\begin{tabular}{llll}
\hline Compuestos & Abreviatura & $\begin{array}{l}\text { Rango de temperatura } \\
\left({ }^{\circ} \mathrm{C}\right)\end{array}$ \\
\hline Carbonatos & Carbonatos & $\mathrm{CaCO}_{3}$ & $550-700$ \\
\hline
\end{tabular}

\section{Interpretación de las señales térmicas}

\section{Regíón Ldh}

Es la región comprendida entre temperatura ambiente y la temperatura a la cual comienza a deshidroxilar la portlandita, entorno a $\operatorname{los} 430^{\circ} \mathrm{C}$.

En esta zona se localiza la descomposición de numerosas fases. Las variaciones de masa en esta zona se asocian a la pérdida de moléculas de agua. El agua se encuentra presente en los poros del material, adsorbida sobre la superficie de los compuestos de la matriz o enlazada en diferentes formas. Las principales fases en las que se encuentra agua enlazada en esta región son el agua interlaminar que forma parte del gel de silicatos cálcicos hidratados, las fases sílicoalumínicas cálcicas hidratadas y los aluminatos cálcicos hidratados.

El proceso de deshidratación de las muestras se produce en etapas, y la energía necesaria para desligarlas depende de la fortaleza de la interacción con la que se encuentra unida.

En esta región encontramos habitualmente procesos de deshidratación simultáneos. La determinación de las condiciones más idóneas para llevar a cabo la identificación y la posible cuantificación del agua asociada a cada uno de los procesos resulta de especial interés cuando se trata de estimar magnitudes relevantes como el grado de hidratación del material.

Habitualmente se considera que las moléculas de agua libre se pierden entorno a los $100^{\circ} \mathrm{C}$. Sin embargo algunas referencias bibliográficas indican que existe una cierta cantidad de moléculas de agua adsorbida que se pierden en el rango entre $90-110^{\circ} \mathrm{C}$ y entre 120 y $150^{\circ} \mathrm{C}$ (Ramachandran et al., 2002, Pane y Hansen, 2005). La cantidad de agua libre y adsorbida puede presentar variaciones en función de las reacciones que tienen lugar en el material. Por ejemplo para presencia de alta cantidad de alumninatos en el material de partida puede propiciar una reducción rápida de la cantidad de agua libre, ya que este tipo de compuesto reacciona muy rápido.

Se asume que las pérdidas de gel de sílice se producen entorno a $115-125^{\circ} \mathrm{C}$. Se pueden encontrar geles como la tobermorita cuyo pico se localiza próximo a $180^{\circ} \mathrm{C}$. La estructura y la 
composición del gel pueden influir en la temperatura a la cual tiene lugar la deshidratación. La absorción de alcalinos sobre el gel, propicia la reducción de la relación $\mathrm{CaO} / \mathrm{SiO}_{2}$ y aumenta la retención de $\mathrm{OH}^{-}$. Si la relación C/S aumenta, la banda suele situarse a temperaturas mayores.

En este rango también se produce la deshidratación de yeso. Cuando esta sustancia se encuentra presente suelen producirse dos picos endotérmicos entorno a 180 y $220^{\circ} \mathrm{C}$. En ocasiones la primera pérdida de agua se produce hasta hemihidrato y la segunda hasta anhidrita, en estos casos la temperatura a las cuales se produce la pérdida de masa, y la cantidad de masa perdida en cada transición es variable.

Dentro de las fases AFt cabe destacar la deshidratación de etringita, que presenta una banda endotérmica en el rango de 120 a $130^{\circ} \mathrm{C}$. La thaumasita comienza a deshidratar a $110^{\circ} \mathrm{C}$, presenta su banda característica entorno a $150^{\circ} \mathrm{C}$ y un pico exotérmico hacia $710^{\circ} \mathrm{C}$.

El monosulfoaluminato tetracálcico como representante característico de las fases AFm presenta una banda a $180-200^{\circ} \mathrm{C}$.

Generalmente, inflexiones a temperaturas por debajo de $300^{\circ} \mathrm{C}$ se atribuyen a la presencia alumninatos tipo $\mathrm{C}_{4} \mathrm{AH}_{13}$. Cuando los alumninatos son hexagonales las bandas se producen a $150-200^{\circ} \mathrm{C}$ y $200-280^{\circ} \mathrm{C}$. Los aluminatos cúbicos deshidratan a temperaturas superiores de 300$350^{\circ} \mathrm{C}$ y $450-500^{\circ} \mathrm{C}$.

\section{Regíón Ldx}

Es la región que se caracteriza por la reacción de deshidroxilación de portlandita. Las temperaturas a las que tiene lugar oscilan entrono a $430^{\circ} \mathrm{C}$ y $530^{\circ} \mathrm{C}$. Estudios comparativos concluyen que el análisis térmico es la técnica que obtiene resultados más fiables para el cómputo de este compuesto. Este análisis permite obtener resultados cuantitativos directamente, a través de la termogravimetría (TG) (Escalante-García et al., 1999; Escalante-García, 2003, Feng, 2004; Rivera, 2004; Mouret, 1997; Vedalakshmi et al., 2003; Pane y Hansen, 2005).

Las variaciones de masa en esta zona se asocian a la pérdida de moléculas de agua procedentes de la portlandita. La reacción que se produce es la siguiente:

$\mathrm{Ca}(\mathrm{OH})_{2} \rightarrow \mathrm{CaO}+\mathrm{H}_{2} \mathrm{O}$

Ecuación 6 
La pérdida de peso por mol de agua es de $18 \mathrm{~g}$, que correspondería a la presencia en la muestra de un mol de $\mathrm{Ca}(\mathrm{OH})_{2}$ (74 g.). Aunque también existe la posibilidad de que parte de la portlandita se haya carbonatado según la reacción:

$\mathrm{Ca}(\mathrm{OH})_{2}+\mathrm{CO}_{2} \rightarrow \mathrm{CaCO}_{3}+\mathrm{H}_{2} \mathrm{O}$

Ecuación 7

Por este motivo puede ser necesario ajustar la cantidad de portlandita teniendo en cuenta las pérdidas en las zonas de los carbonatos

\section{Regíón Ldc}

La región de descarbonatación ocurre en un rango comprendido entre los $550^{\circ} \mathrm{C}$ y los $900^{\circ} \mathrm{C}$. En esta zona aparecen las pérdidas correspondientes a la descomposición de la calcita, dolomía o magnesita. La reacción descarbonatación principal es la de la calcita:

$\mathrm{CaCO}_{3} \rightarrow \mathrm{CaO}+\mathrm{CO}_{2}$

Ecuación 8

La temperatura a la cual tiene lugar la reacción de descarbonatación de una determinada especie depende del grado de cristalinidad de la sustancia, de la estructura cristalina del material, la presencia de impurezas, etc. La descarbonatación de carbonatos amorfos suele tener lugar a las temperaturas más bajas dentro del intervalo (Borges, 2010).

Algunos autores afirman que en este rango se pierden también agua de gel CSH y alumninatos hidratados (Ramachandran et al.,2002; Lilkov et al., 2012; Lilkov et al., 2014)..

\section{Estimación de parámetros termodinámicos}

La determinación de los compuestos anhidros e hidratados del cemento proporciona información cuantitativa y cualitativa que sirve de apoyo para una mejor identificación y descripción de los distintos compuestos presentes en la muestra. El proceso se basa en la identificación de los cambios producidos en la señal gravimétrica o eléctrica cuando se le aplica un calentamiento a una muestra respecto a una señal de referencia. Sin embargo no siempre es fácil realizar la asignación de una determinada reacción a una temperatura, ni determinar el mecanismo a través del cual tiene lugar.

Para comprender mejor el comportamiento de la degradación térmica de las muestras de pasta de cemento durante los ensayos de termogravimetría, se han analizado las curvas de TG a varias 
velocidades de calentamiento. El objetivo es estimar los valores de energía de activación aparentes y determinar la complejidad de las reacciones.

En base a los resultados obtenidos se han determinado las condiciones de análisis de las muestras que nos permiten obtener mayor información de los ensayos. También aplicar la información extraída en los métodos de cálculo empleados en el análisis cuantitativo de los compuestos de la muestra y en la estimación del grado de hidratación.

A continuación se resumen las premisas a partir de las cuales se lleva a cabo la estimación (Yuzay et al., 2010, Zelic et al. 2007).

Asumiendo que la velocidad de reacción de un proceso no isotérmico sigue la ecuación:

$$
\frac{d \alpha}{d t}=k(T) \cdot f(\alpha)
$$

Ecuación 9

Donde:

- $\quad \mathrm{t}$ es el tiempo.

- T es la temperatura.

- $\alpha$ es el grado de conversión de la reacción.

- $\mathrm{f}(\alpha)$ representa la expresión matemática del modelo cinético.

Si reemplazamos k(T) por la ecuación de Arrhenius:

$$
\frac{d \alpha}{d t}=A \cdot \exp \left(-\frac{E}{R T}\right) \cdot f(\alpha)
$$

Donde:

- A es un factor pre-exponenecial.

- R el la constante de los gases.

- E representa la energía de activación del proceso según Arrhenius. 
Esta ecuación se puede aplicar para experimentos realizados en condiciones isotérmicas. Si las condiciones del ensayo no son isotérmicas, como es el caso de los ensayos en termogravimetría, donde se aplica una velocidad de calentamiento constante, es necesario introducir este parámetro en la ecuación. De este modo, siendo $\beta=\mathrm{dT} / \mathrm{dt}$ la velocidad de calentamiento del ensayo, la ecuación que define la velocidad de degradación del proceso quedaría:

$$
\frac{d \alpha}{d t}=\frac{A}{\beta} \cdot \exp \left(-\frac{E a}{R T}\right) \cdot f(\alpha)
$$

\section{Ecuación 11}

Llegados a este punto, existen métodos que permiten estimar los parámetros cinéticos que definen la ecuación anterior a partir de datos de termo-gravimetría en condiciones isotérmicas o no.

En este estudio se han empleado los métodos de Kissinger y Flynn-Wall-Ozawa para estimar la energía de activación del comportamiento de la degradación térmica a partir de los datos de las curvas de termo-gravimetría. Para este fin se emplearon diferentes velocidades de calentamiento (0.5, 5, 10, 15 y 20 C/min) (Kissinger, 1956, Zelic et al., 2007, Yuzay et al., 2010).

\section{Método de Kissinger}

El método de Kissinger emplea el desplazamiento de la temperatura a la máxima velocidad de conversión del proceso, es decir la temperatura a la cual el proceso de deshidratación es mayor (según la curva de dTG), respecto a la variación de la velocidad de calentamiento. La energía de activación puede ser estimada empleando la siguiente ecuación (Kissinger, 1956, Yuzay et al., 2010).

$\ln \left(\frac{\beta}{T_{\max }^{2}}\right)=\left[\ln \frac{A R}{E_{a}}+\ln \left(n\left(1-\alpha_{\max }\right)^{n-1}\right]-\frac{E_{a}}{R T_{\max }}\right.$

Donde:

- $\beta$ es la velocidad de calentamiento.

- $T_{\text {máx }}$ es la temperatura a la cual se produce la máxima pérdida de masa.

- A es el factor pre-exponencial de Arrhenius. 
- R es la constante de los gases.

- $E_{a}$ es la energía de activación.

- $\alpha_{\text {máx }}$ corresponde al grado de conversión del proceso asociado a la temperatura a la cual se produce la máxima velocidad de pérdida de masa.

- n es el orden de reacción.

De acuerdo con la ecuación descrita por Kissinger, la $\mathrm{E}_{\mathrm{a}}$ puede obtenerse de la pendiente de la recta obtenida cuando representamos $\ln \left(\beta / \mathrm{T}_{\max }^{2}\right)$ frente a1/ $\mathrm{T}_{\max }$.

Para ello la primera parte del procedimiento consiste en determinar la temperatura a la cual se produce la máxima velocidad de conversión. Se emplea a tal fin el mínimo de la curva derivada de la señal de TG (dTG) a cada una de las velocidades analizadas.

A partir de los datos obtenidos y empleando la aproximación de Kissinger, se ha llevado a cabo el cálculo de la energía de activación aparente para cada uno de los cemento empleados.

\section{Método de Flynn-Wall-Ozawa (FWO)}

Es un método isoconversional integral que emplea la aproximación lineal de Doyle. La premisa básica del método asume que la velocidad a la cual se produce la reacción a un grado de conversión fijo depende de la temperatura, por lo que si la velocidad de la reacción sólo depende de la temperatura a un grado de conversión fijo, entonces valores constantes de Ea implican cinéticas de descomposición simples o en una etapa. Cuando Ea depende del grado de conversión, se pueden considerar simultaneidad de procesos, o reacciones en varias etapas.

El método FWO determina la temperatura a la cual se produce un grado de conversión de la reacción a diferentes velocidades de calentamiento y emplea la ecuación siguiente para estimar la energía de la reacción (Yuzay et al., 2010, Zelic et al., 2007).

$$
\log \beta=\log \left(\frac{A E}{R g(\alpha)}\right)-2.315-\frac{0.45 E_{a}}{R T}
$$

Donde:

- $\beta$ es la velocidad de calentamiento. 
- A es el factor pre-exponencial de Arrhenius.

- R es la constante de los gases.

- Ea es la energía de activación aparente.

- $\alpha$ corresponde al grado de conversión del proceso.

- $g(\alpha)$ es la función integral de $f(\alpha)$

Para $\alpha$ constante se puede obtener la Ea de la pendiente de la recta obtenida al representar $\log \beta$ frente a la inversa de la temperatura. Con los datos obtenidos se han representado las rectas correspondientes para los diferentes tipos de pasta y a diferentes porcentajes de conversión de la reacción.

\section{Estimación del grado de hidratación mediante análisis térmico}

El análisis termo-gravimétrico ha sido propuesto por diferentes autores como uno de los métodos más eficaces para evaluar el estado de hidratación de los materiales cementicios. Sin embargo, hasta el momento existe cierta dificultad para establecer un método de cálculo único.

En este apartado se han empleado los métodos de Bhatty y Pane/Hansen para estimar el grado de hidratación. Se han evaluado los resultados obtenidos, y se han propuesto ciertas correcciones que permitan comprender mejor los procesos de hidratación de las mezclas, todo ello teniendo en cuenta que las dosificaciones de cemento empleadas corresponden a cementos comerciales y no a mezclas elaboradas en el laboratorio.

En este apartado se analizaran algunas variables que se han mencionado a lo largo de apartados anteriores y que resultan determinantes a la hora de emplear un método de cálculo que nos permita estimar el grado de de hidratación $(\alpha)$ de una muestra de pasta de cemento.

Es necesario calcular los valores relativos de las pérdidas en cada tramo de temperatura, para ello es necesario establecer la temperatura a la que vamos a tomar la masa de referencia. En este sentido encontramos trabajos que emplean la masa calcinada resultante en el ensayo como masa de referencia mientras que otros emplean la masa a la temperatura inicial, y/o temperatura a la cual se estabiliza la muestra. Algunos autores emplean la masa a temperaturas que indican el 
inicio o fin de un proceso significativo, como la temperatura de evaporación del agua o procesos de combustión de inquemados.

En nuestro caso hemos planteado el cálculo de las pérdidas referenciado la masa a las siguientes temperaturas: $40^{\circ} \mathrm{C}$, temperatura a la cual se estabilizan las muestras y a la cual se inicia el ensayo; $100 / 105^{\circ} \mathrm{C}$ ó $140^{\circ} \mathrm{C}$, se atribuye a la temperatura a la cual se estima termina la evaporación de agua libre en el primer caso y la evaporación de agua libre y agua adsorbida sobre la superficie de la matriz en el segundo caso; y masa calcinada resultante al final del ensayo.

Para descartar la influencia que pueden tener la presencia de inquemados y la presencia de carbonatos en la composición del cemento se llevó a cabo corrección de la pérdida correspondiente en la pasta utilizando el valor obtenido en ese tramo por el material anhidro.

En base a los resultados obtenidos en la determinación del mecanismo de descomposición térmica de las muestras estudiadas mediante este tipo de análisis se han tomado las decisiones para elaborar una propuesta de cálculo para la cuantificación de compuestos y la estimación del grado de hidratación. Como ya se ha comentado en la bibliografía se siguen fundamentalmente dos metodologías para obtener la información mencionada.

\section{Estimación del grado de hidratación según Bhatty}

El cálculo se lleva a cabo a partir del valor de agua químicamente enlazada $\left(\mathrm{W}_{\mathrm{B}}\right)$. Entendiendo como tal la cantidad máxima de agua que una pasta de cemento puede fijar en su estructura. La bibliografía acepta que para un cemento I este valor es de 0.24 (Bhatty, 1986).

En el cálculo de $\mathrm{W}_{\mathrm{B}}$ se considera que parte de la portlandita presente en las muestras puede carbonatar, razón por la cual aumenta la cantidad de carbonatos encontrados en la muestra. Para transformar las perdidas de $\mathrm{CO}_{2}$ en pérdidas de agua se ha utilizado la relación de masas moleculares, transformando así la perdida de $\mathrm{CO}_{2}$ en el agua correspondiente de la portlandita que le ha dado origen.

Las ecuaciones empleadas son las siguientes:

$$
W_{B 105}=L d h_{105}+L d x+(18 / 44) L d c
$$


$\alpha=\frac{W_{B 105}}{0.24} \cdot 100$

Ecuación 15

Donde:

- $\mathrm{W}_{\mathrm{B} 105}$ : Agua químicamente combinada respecto a la masa a $105^{\circ} \mathrm{C},(\% / 1)$.

- $\mathrm{Ldh}_{105}$-Región de deshidratación- variación de masa entre $105^{\circ} \mathrm{C}$ y el inicio de pérdida de masa de la región $\operatorname{Ldx}\left(\approx 440^{\circ} \mathrm{C}\right)$, referido a la masa a $105^{\circ} \mathrm{C},(\% / 1)$.

- Ldx-Región de deshidroxilación- variación de masa entre $\approx 440^{\circ} \mathrm{C}$ y el inicio de pérdida de masa de la región $\mathrm{Ldc}\left(\approx 580^{\circ} \mathrm{C}\right)$, referido a la masa a $105^{\circ} \mathrm{C},\left({ }^{\circ} / 1\right)$.

- Ldc-Región de descarbonatación- variación de masa entre $\approx 580^{\circ} \mathrm{C}$ y la temperatura final del ensayo $\left(\approx 1000^{\circ} \mathrm{C}\right)$, referido a la masa a $105^{\circ} \mathrm{C},(\% / 1)$.

- $\quad \alpha$ : grado de hidratación (\%)

\section{Estimación del grado de hidratación según Pane/Hansen}

El cálculo se lleva a cabo a parir del cálculo de agua químicamente enlazada $\left(\mathrm{W}_{\mathrm{B}}\right)$ referida a la cantidad máxima que una pasta de cemento puede combinar de agua en su estructura $\left(\mathrm{W}_{\mathrm{B} \propto \text { }}\right)$ (Pane y Hansen, 2005).

$\mathrm{W}_{\mathrm{B}}$ se calcula como la pérdida de masa que sufre la muestra desde $140^{\circ} \mathrm{C}$ a $1100^{\circ} \mathrm{C}$, descontando las pérdida de carbonatos que sufren los cementos en estado anhidro en la región Ldc. Este método de cálculo refiere todas las cantidades a la masa de muestra calcinada.

Con respecto a $\mathrm{W}_{\mathrm{B} \infty}$ considera que para los cementos Portland su valor oscila entre 0.23 y 0.25 , asignando un valor de 0.23 de acuerdo con otros autores. Para otro tipo de cementos con adiciones este valor precisa ser medido en muestras de edad madura (más de 200 días), o ser estimado utilizando ecuaciones de hidratación.

La estimación consiste en calcular $\mathrm{W}_{\mathrm{B} \infty}$ según la ecuación triparamétrica, y extrapolar la recta obtenida al representar los valores frente a la temperatura.

Las expresiones empleadas son las siguientes: 
$W_{B 140}=L d h_{140}+L d x+L d c-L d c_{a}$

$W_{B}=W_{B \infty} \cdot \exp \left[-\left(\frac{\tau}{t}\right)^{a}\right]$

$\alpha=\frac{W_{B 140}}{W_{B \infty}} \cdot 100$
Ecuación 16

Ecuación 17

Ecuación 18

Donde:

- $\mathrm{W}_{\mathrm{B} 140}$ : Agua químicamente combinada respecto a la masa calcinada, $(\% / 1)$.

- $\operatorname{Ldh}_{140}$-Región de deshidratación- variación de masa entre $140^{\circ} \mathrm{C}$ y el inicio de pérdida de masa de la región $\operatorname{Ldx}\left(\approx 440^{\circ} \mathrm{C}\right)$, referido a la masa calcinada a $1100^{\circ} \mathrm{C},(\% / 1)$.

- Ldx-Región de deshidroxilación- variación de masa entre $\approx 440^{\circ} \mathrm{C}$ y el inicio de pérdida de masa de la región $\operatorname{Ldc}\left(\approx 520^{\circ} \mathrm{C}\right)$, referido a la masa calcinada a $1100^{\circ} \mathrm{C},(\% / 1)$.

- Ldc-Región de descarbonatación- variación de masa entre $\approx 520^{\circ} \mathrm{C}$ y la temperatura final del ensayo $\left(\approx 1100^{\circ} \mathrm{C}\right)$, referido a la masa calcinada a $1100^{\circ} \mathrm{C},(\% / 1)$.

- Ldc $_{\mathrm{a}}$-Región de descarbonatación- variación de masa de las muestras de cemento anhidro entre $\approx 520^{\circ} \mathrm{C}$ y la temperatura final del ensayo $\left(\approx 1100^{\circ} \mathrm{C}\right)$, referido a la masa calcinada a $1100^{\circ} \mathrm{C},(\% / 1)$.

- $\mathrm{W}_{\mathrm{B} \infty}$ : agua químicamente enlazada máxima respecto a la masa calcinada, $(\% / 1)$.

- $\tau$ y a, son parámetros que controlan el ajuste de la función.

- $\mathrm{t}$ es el tiempo de curado de las muestras (h).

- $\alpha$ : grado de hidratación (\%).

A partir de los datos obtenidos y teniendo en consideración los estudios anteriormente referidos se ha propuesto la siguiente metodología para calcular el grado de hidratación

\section{Estimación del grado de hidratación propuesto}


El cálculo se lleva a cabo a partir del valor de agua químicamente enlazada $\left(\mathrm{W}_{\mathrm{B}}\right)$ referida a la cantidad máxima que una pasta de cemento puede combinar de agua en su estructura $\left(\mathrm{W}_{\mathrm{B} \infty}\right)$.

Nuestra propuesta refiere las cantidades estimadas a la masa de muestra inicial, tomando ésta a la temperatura que presenta la muestra, y no a la temperatura que hay en el horno, cuando ha alcanzado un grado de estabilización en la cámara de la termobalanza. La temperatura a la cual se considera la masa de referencia $\left(40,100 / 105\right.$ ó $\left.140^{\circ} \mathrm{C}\right)$ se ha determinado en base a los resultados del estudio relativo a la descomposición térmica de muestras sin degradar presentados en el capítulo de resultados.

Los rangos de temperatura establecidos para delimitar las regiones Ldh, Ldx, Ldc, se calculan para cada muestra. La temperatura de corte viene delimitada por los cambios de pendiente que se producen a realizar la derivada sobre la curva de TG, o sobre la curva de ATD si precisamos evaluar el rango de un proceso sin variación de masa asociado.

Suelen ser necesarias operaciones matemáticas de suavizado sobre las funciones obtenidas dado el alto número de puntos asignados en la adquisición de datos. Para llevar a cabo esta operación será necesario comprobar que la función no desplace significativamente sus máximos y mínimos, y que la temperatura tomada no caiga en un tramo de la curva de TG situada en zona de máxima pendiente.

Si el modelo de adquisición de datos no varía, se puede establecer una pauta de suavizado para todos los termogramas. En nuestro caso hemos empleado un modelo de suavizado SavitzkyGolay con 100 puntos. En caso de duda con la asignación de la temperatura se ha comparado el dato con el obtenido al realizar la segunda derivada sobre la curva de TG, o comparando las derivadas primeras de las curvas de TG y ATD.

Para calcular $\mathrm{W}_{\mathrm{B} \text { o }}$ se han realizado ensayos de análisis térmico sobre muestras que fueron fabricadas al inicio de la campaña experimental y transcurridos aproximadamente 55 meses desde su fabricación. Las muestras se conservaron en bolsas herméticas dentro de un desecador.

Empleando este método podemos comparar los datos de hidratación completa con obtenidos con los encontrados en la bibliografía. 


\subsubsection{Condiciones de análisis.}

Para llevar a cabo los análisis térmicos se utilizó un Analizador Térmico Simultáneo Labsys Evo 1600 de Setaram, equipado con una balanza de precisión de $\pm 0,01 \mathrm{mg}$.

El detector empleado es una caña TG/ATD que incluye un transductor de platino-rodio capaz de operar hasta $1600^{\circ} \mathrm{C}$.

Los crisoles empleados fueron de alúmina $\left(\alpha-\mathrm{Al}_{2} \mathrm{O}_{3}\right)$. Como referencia para la adquisición de datos de ATD se empleó alúmina del propio crisol de referencia.

El material empleado en las determinaciones de análisis térmico (detector, crisoles, etc.) fue previamente calibrado como blanco en cada una de las condiciones del ensayo. Con las señales obtenidas en los blancos se corrigieron las correspondientes a las muestras de análisis.

La elaboración de las señales termoanalíticas obtenidas y el tratamiento de los datos registrados durante las medidas se realizó mediante el software CALISTO, suministrado por Setaram.

En la Figura 26 se muestra una imagen del equipo y material utilizado.
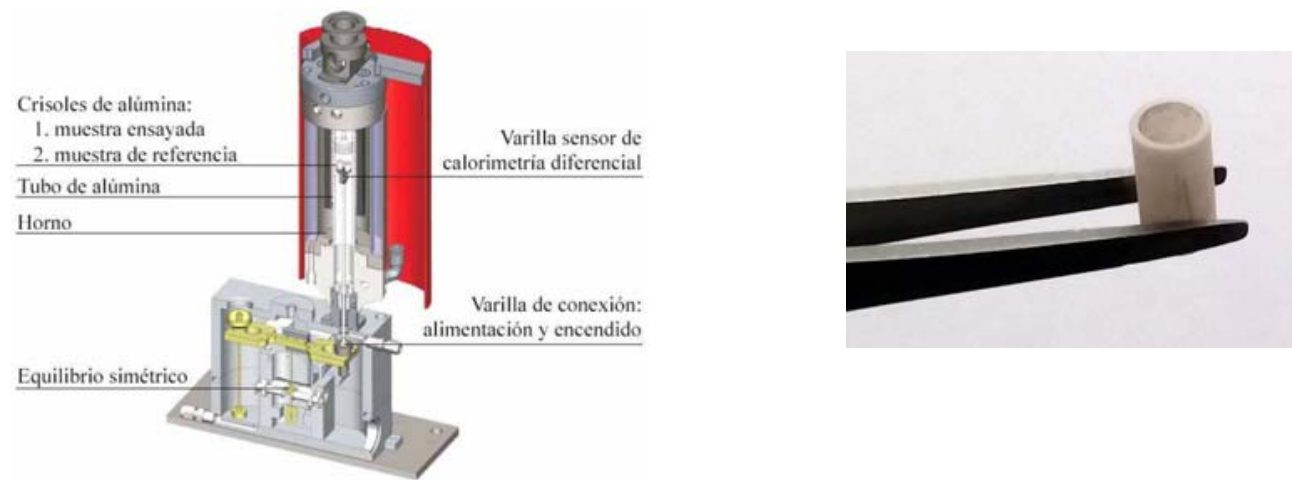

Fuente: (manual Setaram)
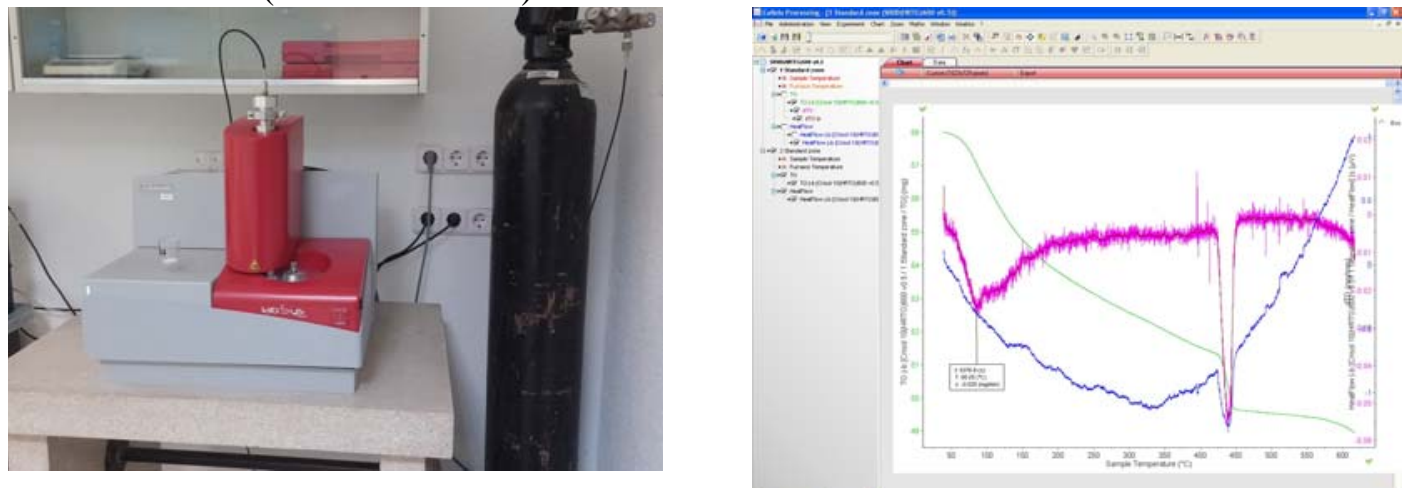

Figura 26. Material y analizador térmico simultáneo Labsys Evo 1600 de Setaram para ensayos de análisis térmico 
Los ensayos se llevaron a cabo con muestras sólidas pulverizadas. Se analizaron 5 grupos de muestras:

- Polvo de cementos de partida en estado anhidro.

- Muestras de pasta de cemento SR, II y IV a tiempo cero días.

- Muestras de pasta de cemento de referencia, obtenidas a lo largo del proceso de exposición a diferentes edades (obtenidas según el procedimiento descrito en el apartado 3.2.3.1)

- Muestras de pasta de cemento expuestas a los medios AC, SU y AN, obtenidas a lo largo de la campaña a diferentes edades (obtenidas según el procedimiento descrito en el apartado 3.2.3.1)

- Muestras de pasta de cemento a edad madura.

Antes de ser analizadas las muestras se introdujeron en una estufa de laboratorio a $40^{\circ} \mathrm{C}$ hasta masa constante. Posteriormente se conservaron en un desecador. El objetivo de este procedimiento es estabilizar y homogeneizar el grado de humedad de las mismas.

A continuación se describen las condiciones de análisis empleadas.

Tabla 12. Condiciones de medida en análisis térmico

\begin{tabular}{c|c|c|c|c}
\hline Tipo de ensayo & $\begin{array}{c}\text { Masa } \\
(\mathrm{mg})\end{array}$ & $\begin{array}{c}\text { Velocidad } \\
\left({ }^{\circ} \mathrm{C} / \mathrm{min}\right) \\
\text { Rango de } \\
\mathrm{T}\left({ }^{\circ} \mathrm{C}\right)\end{array}$ & $\begin{array}{c}\text { Flujo } \\
\text { de } \\
\mathrm{N}_{2}\end{array}$ & \multicolumn{1}{c}{ Muestras analizadas } \\
\hline $\begin{array}{c}\text { Ensayo de } \\
\text { rutina }\end{array}$ & $\approx 35$ & $\begin{array}{c}10 \\
\left(40-1100^{\circ} \mathrm{C}\right)\end{array}$ & Sí & $\begin{array}{l}\text { - Cementos de en estado anhidro. } \\
\text { - Pastas de cemento a tiempo cero días. } \\
\text { - Pastas de cemento obtenidas según el } \\
\text { procedimiento descrito en el apartado } \\
\text { 3.2.3.1 } \\
\text { - Pasta de cemento a edad madura. }\end{array}$ \\
\hline
\end{tabular}

\footnotetext{
${ }^{3}$ Previo a la realización de los ensayos de termoanálisis se comprobó que el empleo de masas de muestra superiores a $30 \mathrm{mg}$ no introducía errores en la comparación de las medidas de muestras con diferentes masas.
} 


\begin{tabular}{|c|c|c|c|c|}
\hline Tipo de ensayo & $\begin{array}{c}\operatorname{Masa}^{3} \\
(\mathrm{mg})\end{array}$ & $\begin{array}{c}\text { Velocidad } \\
\left({ }^{\circ} \mathrm{C} / \mathrm{min}\right) \\
\text { Rango de } \\
\mathrm{T}\left({ }^{\circ} \mathrm{C}\right)\end{array}$ & $\begin{array}{l}\text { Flujo } \\
\text { de } \\
\mathrm{N}_{2}\end{array}$ & Muestras analizadas \\
\hline \multirow{4}{*}{$\begin{array}{l}\text { Influencia de la } \\
\text { presencia de } \\
\text { gas portador }\end{array}$} & \multirow{4}{*}{$\approx 60$} & & Sí & \multirow{4}{*}{$\begin{array}{l}\text { Muestras de pasta de cemento a edad } \\
\text { madura. }\end{array}$} \\
\hline & & $\left(40-300^{\circ} \mathrm{C}\right)$ & No & \\
\hline & & 0.5 & Sí & \\
\hline & & $\left(40-300^{\circ} \mathrm{C}\right)$ & No & \\
\hline \multirow{6}{*}{$\begin{array}{l}\text { Evaluación de } \\
\text { la variación de } \\
\text { velocidad de } \\
\text { calentamiento } \\
(\beta) \text { - Estudio de } \\
\text { parámetros } \\
\text { termodinámicos }\end{array}$} & \multirow{6}{*}{$\approx 60$} & $\begin{array}{c}0.5 \\
\left(40-300^{\circ} \mathrm{C}\right)\end{array}$ & \multirow{6}{*}{ No } & \multirow{6}{*}{$\begin{array}{l}\text { Muestras de pasta de cemento a edac } \\
\text { madura. }\end{array}$} \\
\hline & & $\begin{array}{c}5 \\
\left(40-300^{\circ} \mathrm{C}\right)\end{array}$ & & \\
\hline & & $\begin{array}{c}10 \\
\left(40-300^{\circ} \mathrm{C}\right)\end{array}$ & & \\
\hline & & $\begin{array}{c}15 \\
\left(40-300^{\circ} \mathrm{C}\right)\end{array}$ & & \\
\hline & & $\begin{array}{c}20 \\
\left(40-300^{\circ} \mathrm{C}\right)\end{array}$ & & \\
\hline & & $\begin{array}{c}30 \\
\left(40-300^{\circ} \mathrm{C}\right)\end{array}$ & & \\
\hline
\end{tabular}




\section{RESULTADOS Y ANÁLISIS DE RESULTADOS}

\subsection{NOMENCLATURA DE LAS MUESTRAS}

En este capítulo se van a describir los resultados obtenidos a lo largo de la campaña experimental. Seguidamente se detalla la nomenclatura empleada:

En las muestra tomadas en los medios de degradación las dos primeras letras hacen referencia al tipo de cemento ensayado (SR, II ó IV) y las dos siguientes al medio de exposición (AC, SU, AN, CA ó AI). Cuando las muestras tomadas corresponden a una edad determinada se coloca a continuación de la abreviatura del medio empleado un número que corresponde al número de días de exposición de la muestra, más una "D”. Por último, para identificar la profundidad de la muestra se coloca un número comprendido entre 1 y 8.

Por ejemplo la muestra IIAN7D1 correspondería a una muestra de pasta fabricada con cemento tipo II, expuesta al medio denominado Agua Natural, durante 7 días y de la cual se ha tomado la primera sección (la que está en contacto con el medio de exposición).

Tabla 13. Abreviaturas empleadas en la nomenclatura de las muestras

\begin{tabular}{lcc}
\hline & Abreviatura & Correspondencia \\
\hline Cemento & SR & CEM I SR 42.5R \\
\cline { 2 - 3 } & II & CEM II/A-V 32.5R \\
\hline
\end{tabular}




\begin{tabular}{lcc}
\hline & Abreviatura & Correspondencia \\
\hline & IV & CEM IV/B(P-V) 32.5R \\
\hline \multirow{3}{*}{ Medio de exposición } & AC & Disolución ACético/acetato \\
\cline { 2 - 3 } & SU & Disolución SUlfato sódico \\
\cline { 2 - 3 } & AN & Disolución Agua Natural \\
\cline { 2 - 3 } & CA & Disolución hidróxido CÁlcico saturada \\
\hline
\end{tabular}

\subsection{RESULTADOS DE LA VALIDACIÓN DE MÉTODOS}

Como ya ha sido comentado en capítulos anteriores, existen diferentes técnicas/métodos de análisis previstos en la normativa vigente para la evaluación del contenido de cationes en el cemento. En este apartado se presenta la comparación de los resultados obtenidos al determinar óxidos de calcio y de magnesio por diferentes métodos. Se ha analizado la influencia del proceso de preparación de la muestra y la técnica de análisis.

\subsubsection{EVALUACIÓN DEL MÉTODO DE DISOLUCIÓN DE MUESTRAS DE PASTA DE CEMENTO}

En la presente campaña experimental eran objeto de estudio los iones $\mathrm{Ca}^{2+}, \mathrm{Mg}^{2+}, \mathrm{Fe}^{3+}, \mathrm{Al}^{3+} \mathrm{y}$ $\mathrm{SO}_{4}{ }^{2-}$. La determinación de estos elementos del cemento según la norma UNE-EN 196-2:2006 requiere la disolución de las muestras, siendo el método de disolución diferente en función de la determinación a realizar.

La evaluación de elementos mayoritarios, entre los que se incluye la determinación de $\mathrm{CaO}$, $\mathrm{MgO}, \mathrm{Fe}_{2} \mathrm{O}_{3}$ y $\mathrm{Al}_{2} \mathrm{O}_{3}$ precisa la disolución completa de la muestra (apartado 13, UNE-EN 1962:2006).

Según la norma la muestra ha de disgregarse por medio de una fusión con peróxido de sodio. La masa fundida se disuelve en $\mathrm{HCl}$ y se evapora hasta sequedad precipitándose la sílice impura (el procedimiento se realiza por duplicado para asegurar la completa precipitación). Esta sílice precipitada se trata con $\mathrm{HF}$ y $\mathrm{H}_{2} \mathrm{SO}_{4}$, consiguiéndose así la volatilización de la sílice pura y resultando de esta operación un residuo 1 y un filtrado 1 . El residuo 1 se trata con una mezcla de carbonato y cloruro sódicos con el fin de formar los silicatos solubles en ácido. Una vez 
formados se disuelve con $\mathrm{HCl}$ y la disolución resultante se añade al filtrado 1. A partir de esta disolución se determina la sílice soluble residual, mediante fotometría, y los óxidos $\mathrm{Fe}_{2} \mathrm{O}_{3}$, $\mathrm{Al}_{2} \mathrm{O}_{3}$, CaO y MgO, mediante complexometría. Hemos denominado a este procedimiento de disolución método A.

La determinación de $\mathrm{SO}_{4}{ }^{2-}$ implica la disolución de un gramo de muestra con $\mathrm{HCl}$ en caliente (apartado 8.2, UNE-EN 196-2:2006). Se lleva a temperatura próxima a ebullición, se deja reposar y se filtra, lavando hasta ensayo negativo de iones cloruro con nitrato de plata. Hemos denominado a este procedimiento de disolución método B.

El uso de estos dos procedimientos implicaría un mínimo de 2 g de muestra, uno para cada procedimiento de disolución. Esto puede suponer un problema cuando la cantidad de muestra es limitada.

En nuestro caso, con muestras (6 secciones en el caso de cemento SR y 9 en el caso de los cemento II y IV) con un volumen medio de $1.5 \mathrm{~mm}^{3}$, y una densidad aproximada de $1,7 \mathrm{~g} / \mathrm{ml}$, cada muestra obtenida oscilaría entre 1,5 y 2,5 g, a lo que hay que descontar las pérdidas por tratamientos de la muestra como la molienda.

Tenemos que considerar además la cantidad de muestra que lleva la realización de ensayos en fase sólida (ATD-TG y DRX) y la posibilidad de reservar cierta cantidad de muestra de seguridad por si hubiese algún error en el proceso o se decidiese incluir alguna determinación posterior en virtud de los resultados obtenidos. En este estudio, incrementar la masa de cada muestra, implicaría incluir más probetas en cada macro-probeta, lo que conlleva un número mayor de amasadas, y en consecuencia una diferencia de tiempo mayor entre amasadas de las probetas unitarias incluidas en la macro-probeta definida como unidad de análisis. Es necesario tomar una solución de compromiso entre la cantidad máxima de muestra por análisis y la homogeneidad de la muestra.

La realización del procedimiento que hemos denominado A (disolución completa de la muestra), suma un número significativo de inconvenientes/dificultades: implica cierta pericia del operador que lleva a cabo la determinación, la inversión de gran cantidad de tiempo, el uso de numerosos reactivos y equipos a alta temperatura como el horno-mufla. Todo ello son 
factores a tener en cuenta desde el punto de la practicidad y rapidez en la realización de ensayos, especialmente cuando se van a realizar un número elevado de determinaciones.

Estos aspectos motivaron que comparáramos los dos métodos de disolución con el fin de saber si podíamos emplear un método único para todos los iones. Especialmente en la determinación de iones calcio, magnesio y sulfato, ya que éstos son los iones mas sensibles en lixiviación y se determinaban, además de en las muestras líquidas recogidas a lo largo del proceso de ensayo.

Para la evaluación de las variables seleccionadas (método de disolución y técnica de análisis, se han utilizado los parámetros estadísticos de la norma: máxima desviación típica de la repetibilidad $\left(\sigma_{\text {repet. }}\right)$ y reproductibilidad $\left(\sigma_{\text {reprod. }}\right)$ de las medidas que deben presentar los resultados para ser considerados aceptables.

El primer dato nos proporciona información acerca de la variación más pequeña que podemos obtener entre lecturas de resultados analizados en condiciones similares: mismo método de disolución, mismo equipo, misma técnica de análisis.

La desviación típica de la reproductibilidad de las medidas nos proporciona información acerca de la precisión de resultados analizados mediante el mismo método de disolución, mismo equipo, misma técnica de análisis, pero en diferentes laboratorios lo que implica diferente operador, y distinto equipo.

Hemos empleado el dato de repetibilidad para asegurar la validez de las medidas, cuando las condiciones de medida son las especificadas por la norma (disolución completa de la muestra método A- y determinación fotométrica de $\mathrm{CaO}$ y $\mathrm{MgO}$ ).

Hemos empleado los valores máximos de la desviación típica de la reproductibilidad de la medida que especifica la norma, con el fin de asegurar la validez de los resultados obtenidos con las modificaciones propuestas cuando hemos realizado modificaciones en el método de determinación.

Los primeros resultados analizados se llevaron a cabo realizando los ensayos según especifica la norma, es decir empleando el método de disolución completa (metodo A) y la determinación fotométrica de $\mathrm{CaO}$ y $\mathrm{MgO}$. 
La determinación de $\mathrm{CaO}$ y $\mathrm{MgO}$ mediante el método fotométricó precisó la validación de la medida con nuestro fototrodo (DP550, Mettler Toledo), ya que éste mide a una longitud de onda diferente a la especificada en los métodos de la norma. El fototrodo DP550 empleado mide a $555 \mathrm{~nm}$ (luz verde) mientras que la norma especifica que la lectura de la absorbancia se realice con las especificaciones siguientes:

- Para la determinación de CaO: a 520 nm si se emplea indicador calceína y a 620 nm si se emplea indicador murexida. No se especifican las longitudes de onda cuando se realiza la medida con otros indicadores adecuados (según la norma) como son el calcón, el indicador mixto de calceína y azul de metiltimol o el reactivo de Patton y Readers.

- Para la determinación de MgO se especifica el ajuste a $620 \mathrm{~nm}$ si se emplea la combinación azul de metiltimol-calceína, más azul de metil timol ó si se emplea un indicador mixto ${ }^{4}$. No se especifican las longitudes de onda cuando se realiza la medida con otros indicadores adecuados (según la norma) como son el indicador púrpura de eftaleína o el indicador mezcla calceína-azul de metiltimol.

Para llevar a cabo la comparación de las medidas se solicitó de manera provisional un fototrodo DP5 a la empresa Mettler Toledo. En el fototrodo DP5 es posible regular la longitud de onda de medida.

Se realizaron medidas de determinación de iones $\mathrm{Ca}^{2+}, \mathrm{Mg}^{2+}, \mathrm{Fe}^{3+}$ y $\mathrm{Al}^{3+}$ por separado, en disoluciones preparadas con patrones y cuyas concentraciones estuvieron comprendidas entre $10^{-4} \mathrm{M}$ y $0.5 \mathrm{M}$. Las medidas realizadas con ambos fototrodos mostraron valores repetibles, por lo que se estimó que el fototrodo DP550 era válido para llevar a cabo las medidas.

También se realizaron medidas comparativas con los dos fototrodos en muestras disueltas de pasta de cemento. Se pretendía con esto evaluar por un lado la influencia que puede ejercer la matriz de la disolución, y por otro la influencia que la diferencia de concentraciones de iones $\mathrm{Ca}^{2+} \mathrm{y} \mathrm{Mg}^{2+}$ en la disolución puede suponer en la determinación conjunta de estos dos iones como especifica la norma.

\footnotetext{
${ }^{4}$ Apartado 4.77, UNE-EN 196-2:2006
} 
Las determinaciones de $\mathrm{CaO}$ se llevaron a cabo midiendo con ambos fototrodos en las muestras obtenidas mediante el método de disolución A. En el caso de las lecturas realizadas con el fototrodo DP550 se realizó la medida a 555 nm empleando como indicador murexida. En el caso del fototrodo DP5 se realizaron medidas a $620 \mathrm{~nm}$ empleando como indicador la murexida. Los resultados obtenidos presentaron una desviación típica de $0.11 \%$ por lo que se consideran precisos empleando ambos fototrodos.

Las determinaciones de $\mathrm{MgO}$ se llevaron a cabo midiendo con ambos fototrodos en las muestras obtenidas mediante el método de disolución A. En el caso de las lecturas realizadas con el fototrodo DP550 se realizó la medida a 555 nm empleando como indicador la mezcla calceínaazul de metiltimol. En el caso del fototrodo DP5 se realizaron medidas a $620 \mathrm{~nm}$ empleando como indicador la mezcla calceína-azul de metiltimol. Previa a la determinación de MgO se realizó la adición del volumen estequiométrico de AEDT necesario para llevar a cabo la titulación de $\mathrm{CaO}$.

En estas condiciones no fue posible la determinación fotométrica del MgO. El contenido de ion $\mathrm{MgO}$ en las muestras es pequeño. Esto a priori no debe suponer un problema puesto que hemos comprobado en las disoluciones patrón que el fototrodo es capaz de determinar concentraciones de $10^{-4} \mathrm{M}$ (similares o inferiores a las estimadas en las muestras) pero de forma individual. Se descartó por tanto que el límite de detección de los fototrodos fuera superior a la concentración de las muestras. Los resultados parecen indicar que en el caso de la determinación conjunta de Ca y Mg, los niveles mínimos de detección son superiores.

Puesto que los resultados en las determinaciones de $\mathrm{CaO}$ fueron satisfactorios con ambos fototrodos, y el uso del fototrodo DP5 no supuso una mejora en la determinación de MgO mediante el método fotométrico, se determinó como válido el uso del fototrodo DP550.

En la Tabla 14 se muestran los resultados obtenidos en la determinación de $\mathrm{CaO}$ y MgO según se establece en la norma UNE-EN 196-2:2006 (muestras disueltas según el método de disolución A y analizadas según el método fotométrico ${ }^{5}$ ). En la tabla se muestran en la última

\footnotetext{
${ }^{5}$ Con la salvedad del cambio de longitud de onda de $620 \mathrm{~nm}$ por el de $555 \mathrm{~nm}$.
} 
columna los valores de las desviaciones típicas máximas de repetibilidad y reproductibilidad que establece la norma para estas determinaciones.

Tabla 14. Desviación típica de de resultados en la determinación de CaO y MgO según UNE 196-2:2006

\begin{tabular}{cccc}
\hline $\begin{array}{c}\text { Método de } \\
\text { disolución }\end{array}$ & Técnica de análisis & $\sigma$ & Requisito UNE \\
\hline $\begin{array}{c}\text { Disgregación } \\
\mathrm{Na}_{2} \mathrm{O}_{2} \\
(\text { Método A })\end{array}$ & $\begin{array}{c}\text { Método fotométrico } \\
\text { (A.1) }\end{array}$ & $0.10 \% \mathrm{CaO}$ & $\begin{array}{c}\sigma_{\text {repet, máx. }}: 0.15 \% \\
\sigma_{\text {reprod, máx. }}: 0.43 \%\end{array}$ \\
\hline $\begin{array}{c}\text { Disgregación } \\
\mathrm{Na}_{2} \mathrm{O}_{2} \\
(\text { Método A })\end{array}$ & $\begin{array}{c}\text { Método fotométrico } \\
\text { (A.1) }\end{array}$ & $\begin{array}{c}\text { MgO, no se pudo } \\
\text { determinar }\end{array}$ & $\begin{array}{c}\sigma_{\text {repet, máx.: }}: 0.21 \% \\
\sigma_{\text {reprod, máx.: }} 0.25 \%\end{array}$ \\
\hline
\end{tabular}

Los resultados obtenidos en la determinación del $\mathrm{CaO}$ presentan una buena precisión, adecuándose a una desviación entre las medidas inferior al 0.15\% que especifica a norma.

No se pudo evaluar la dispersión de las medidas en la determinación de MgO del método que propone la norma UNE-EN 196-2:2006.

De manera paralela se llevó a cabo la disolución de las muestras mediante el método $\mathrm{B}$, y empleando la misma técnica de análisis. Los resultados de la desviación típica de repetibilidad se muestran en la Tabla 15.

Tabla 15. Desviación típica de resultados en la determinación de $\mathrm{CaO}$ y $\mathrm{MgO}$, empleando el método B de disolución de muestras

\begin{tabular}{ccc}
\hline Método de disolución & Técnica de análisis & $\sigma$ \\
\hline $\begin{array}{c}\text { Determinación de } \\
\text { sulfatos } \\
\text { (Método B) }\end{array}$ & $\begin{array}{c}\text { Método fotométrico } \\
\text { (B.1) }\end{array}$ & $0.17 \% \mathrm{CaO}$ \\
\hline $\begin{array}{c}\text { Determinación de } \\
\text { sulfatos } \\
\text { (Método B) }\end{array}$ & $\begin{array}{c}\text { Método fotométrico } \\
\text { (B.1) }\end{array}$ & MgO, no se pudo determinar \\
\hline
\end{tabular}

En este caso se aplica la misma hipótesis planteada con respecto a las causas por las que no se pudo realizar la determinación de ion magnesio mediante fotometría que la planteada en el caso anterior. 
Con respecto a los resultados de la determinación de ion calcio se puede decir que la dispersión de los resultados con respecto a repetibilidad entre medidas presenta un valor aceptable que supera ligeramente la impuesta por la normativa (0,17 frente a 0,15\%) en caso de emplearse el método de disolución A. Sí se cumpliría el requisito para reproductibilidad, entendiendo por tal la dispersión que presentan las medidas cuando se han introducido algún cambio con respecto al procedimiento operatorio.

Para poder dar validez al método de disolución de muestra en necesario analizar los resultados de forma conjunta, es decir calculando la dispersión entre las medidas realizadas empleando como técnica el método fotométrico pero con los dos métodos de disolución, obtenemos los resultados que se muestran en la Tabla 16.

Tabla 16. Desviación típica de resultados en la determinación de $\mathrm{CaO}$ y $\mathrm{MgO}$ empleando los dos métodos de disolución

\begin{tabular}{ccc}
\hline Método de disolución & Técnica de análisis & $\sigma$ \\
\hline $\begin{array}{c}\text { Método A } \\
\text { Método B }\end{array}$ & $\begin{array}{c}\text { Método fotométrico } \\
\text { (A.1)(B.1) }\end{array}$ & $0.27 \%$ CaO \\
\hline $\begin{array}{l}\text { Método A } \\
\text { Método B }\end{array}$ & $\begin{array}{c}\text { Método fotométrico } \\
\text { (A.1)(B.1) }\end{array}$ & MgO, no se pudo determinar \\
\hline
\end{tabular}

El resultado de desviación típica de $0.27 \% \mathrm{CaO}$ se encuentran dentro del rango permitido por la reproductibilidad de las medidas que impondría el método de la UNE-EN 196-2:2006, e indican que el método de disolución empleado no afecta a la dispersión de los resultados cuando la determinación de $\mathrm{CaO}$ es fotométrica.

No se puede evaluar los resultados de dispersión en la determinación de MgO porque no se obtuvieron lecturas estables.

Además, en las determinaciones realizadas, desde el punto de vista de la selección del método de disolución, se puede decir que el método B presenta algunas ventajas. Se pueden destacar:

- Se puede emplear la misma disolución que la realizada para llevar a cabo la determinación de iones sulfato.

- Precisa un tiempo de ensayo mucho menor. 
- Menor cantidad de disoluciones y reactivos para llevar a cabo la disolución.

- Uso de equipos eléctricos sencillos como son los agitadores magnéticos con calefacción.

- Y menor pericia del operador, lo que revierte en una mejora de la reproductibilidad de las medidas cuando no son realizadas por la misma persona.

Consideramos pues que el método B puede emplearse para disolver las muestras para el análisis de $\mathrm{Ca}^{2+} \mathrm{y} \mathrm{Mg}^{2+}$, si bien el grado de repetibilidad es algo menor.

\subsubsection{EVALUACIÓN DE LAS TÉCNICAS DE ANÁLISIS EMPLEADAS}

En el apartado anterior se comentó la dificultad que había entrañado la determinación de MgO según los métodos especificados por la UNE 196-2:2006 (apartado 13.13 y 13.15). Esta fue una de las razones que inspiró la propuesta de emplear técnicas de determinación alternativas a las propuestas de la normativa vigente. Además se contemplaron algunas otras que se exponen a continuación.

Se propuso la cromatografía iónica como técnica alternativa a la determinación fotométrica de la concentración de iones calcio, magnesio y sulfato porque es una técnica sencilla. Permite la determinación de un número elevado de iones en una misma muestra, lo que permite agilizar la obtención de datos y aumentar el número de determinaciones por muestra. Algunos iones se pueden determinar simultáneamente en el mismo análisis jugando con los tiempos de retención y otros simplemente cambiando de columna, o la polaridad del eluyente. Además es una técnica instrumental con un límite de detección muy bajo, lo que permite no sólo detectar bajas concentraciones de iones en las muestras, también emplear diluciones, lo que revierte en un mayor rendimiento del volumen obtenido en las disoluciones de muestras. Todos estos factores cobran importancia cuando la cantidad de muestra obtenida para los ensayos es escasa y el número de determinaciones elevado.

Sin embargo, hay que tener en cuenta que la determinación de la composición química de los cementos mediante cromatografía iónica no está incluida en los métodos descritos a este fin en la normativa española y por ello es necesario verificar su validez. 
La determinación de ion sulfato según la norma UNE-EN 196-2:2006 implica la disolución del cemento según el método B descrito en el apartado anterior. La disolución obtenida se lleva a un pH de 1.0-1.5, se calienta a ebullición comprobando que la disolución sea clara (en caso negativo es preciso empezar de nuevo el ensayo) y se precipita el ion sulfato con cloruro de bario en caliente, se deja la disolución 30 minutos a temperatura próxima a ebullición comprobando que no varíe el volumen en exceso y se deja reposar la disolución durante 12-24h antes de su filtrado. El filtrado ha de lavarse con agua hirviente hasta ensayo negativo de cloruros con nitrato de plata.

La determinación se realiza mediante gravimetría. Para ello se coloca el papel de filtro en un crisol previamente calcinado y tarado, se seca y se incinera en atmósfera oxidante sin inflamarlo hasta combustión completa, posteriormente se calcina todo a $950^{\circ} \mathrm{C}$ hasta constancia de masa y se pesa. Este procedimiento presenta como ventaja que es muy preciso, pero requiere que la destreza del operador sea elevada. Su mayor inconveniente es la gran cantidad de tiempo que precisa para llevarlo a cabo, lo que obliga a buscar procedimientos alternativos si el número de análisis es elevado.

La determinación de $\mathrm{CaO}$ y MgO en la norma UNE-EN 196-2:2006 se lleva a cabo mediante fotometría, tanto en los métodos de referencia como en los métodos alternativos descritos. Los métodos de referencia y los métodos alternativos describen procedimientos muy similares que difieren fundamentalmente en el reactivo valorante, el volumen de muestra de partida empleado, y en las posibilidades de indicadores a emplear.

En nuestro caso seleccionamos para comparar los resultados de la determinación de $\mathrm{CaO}$ y MgO los métodos alternativos (apartados 13.14 y 13.15 de la norma UNE-EN 196-2:2006), ya que el fototrodo empleado detectaba con precisión los cambios de color que se producen en los intervalos de viraje propuestos en los mencionados métodos. El procedimiento general consiste en tomar un volumen de muestra, añadirle un volumen de disolución de trietanolamina, adecuar el pH (12.5 en el caso de $\mathrm{CaO}$ y 10.5 en el caso de MgO), incorporar el indicador seleccionado, fijar la longitud de onda de medida en función del indicador y medir el volumen gastado hasta el punto de equivalencia. En el caso de la determinación de $\mathrm{MgO}$ es necesario añadir previa a la valoración el volumen estequiométrico de AEDT gastado en la determinación de CaO. 
Uno de los inconvenientes que presenta es que la presencia eventual de estroncio en las muestras se determina como $\mathrm{CaO}$, lo que introduce cierto error en la medida, si bien su influencia en el caso de muestras de cemento debería ser poco relevante., puesto que su concentración relativa frente al calcio es pequeña.

En la Tabla 17 se presentan los datos de desviación típica calculados sobre las muestras analizadas mediante cromatografía iónica empleando él método A de disolución de muestras.

Tabla 17. Desviación típica de resultados en la determinación de $\mathrm{CaO}$ y $\mathrm{MgO}$, empleando el método A de disolución de muestras

\begin{tabular}{ccc}
\hline Método de disolución & Técnica de análisis & $\sigma$ \\
\hline $\begin{array}{c}\text { Disgregación } \mathrm{Na}_{2} \mathrm{O}_{2} \\
\text { (Método } \mathrm{A})\end{array}$ & $\begin{array}{c}\text { Cromatografía iónica } \\
\text { (A.2) }\end{array}$ & $0.26 \% \mathrm{CaO}$ \\
\hline $\begin{array}{c}\text { Disgregación } \mathrm{Na}_{2} \mathrm{O}_{2} \\
\text { (Método } \mathrm{A})\end{array}$ & $\begin{array}{c}\text { Cromatografía iónica } \\
\text { (A.2) }\end{array}$ & $0.12 \% \mathrm{MgO}$ \\
\hline
\end{tabular}

La dispersión que presentan los datos de determinación de $\mathrm{CaO}$ cuando se emplea esta técnica de determinación es superior que cuando se empleó la determinación mediante fotometría (0.10\%).

Sin embargo está técnica nos ha permitido evaluar los resultados del contenido de ion magnesio en la muestras con una concentración muy baja $\left(\left[\mathrm{Mg}^{2+}\right]\right.$ mínima analizada en las muestras $=4.5 \cdot 10^{-6} \mathrm{M}$ ). La dispersión de los resultados en el caso de este ion es baja lo que cumpliría con el requisito del método propuesto en la norma.

Si analizamos los resultados obtenidos de forma conjunta, es decir analizando la dispersión entre las medidas realizadas empleando ambas técnicas y el método de disolución A obtenemos los resultados que se muestran en la Tabla 18.

El resultado de desviación típica de $0.22 \% \mathrm{CaO}$ se encuentran dentro del rango permitido por la reproductibilidad de las medidas que impondría el método de la UNE, e indican que la técnica de análisis empleada no afecta a la dispersión de los resultados cuando la determinación de $\mathrm{CaO}$ es la cromatografía iónica, lo cual daría validez al uso de esta técnica para determinar CaO, si bien la repetibilidad de los resultados presenta mayor dispersión de la admitida. 
Tabla 18. Desviación típica de resultados en la determinación de $\mathrm{CaO}$ y $\mathrm{MgO}$ empleando las dos técnicas de análisis y el método de disolución A

\begin{tabular}{ccc}
\hline Método de disolución & Técnica de análisis & $\sigma$ \\
\hline $\begin{array}{c}\text { Disgregación } \mathrm{Na}_{2} \mathrm{O}_{2} \\
\text { (Método A) }\end{array}$ & $\begin{array}{c}\text { Método fotométrico (A.1) } \\
\text { Cromatografía iónica } \\
\text { (A.2) }\end{array}$ & $0.22 \% \mathrm{CaO}$ \\
\hline $\begin{array}{c}\text { Disgregación } \mathrm{Na}_{2} \mathrm{O}_{2} \\
\text { (Método A) }\end{array}$ & $\begin{array}{c}\text { Método fotométrico (A.1) } \\
\text { Cromatografía iónica } \\
\text { (A.2) }\end{array}$ & MgO, no se pudo determinar \\
\hline
\end{tabular}

No fue posible analizar los resultados de dispersión en las medidas de MgO puesto que su detección fotométrica no fue posible.

Desde el punto de vista de la selección de la técnica de determinación se puede decir los resultados de la dispersión fueron comparables a los obtenidos si hubiésemos empleado la técnica de la norma en condiciones de reproductibilidad, además el uso de la cromatografía iónica presentó algunas ventajas:

- Permitió la determinación de concentraciones de ion magnesio de $4 \cdot 5 \cdot 10^{-6} \mathrm{M}$, que no fueron posibles mediante fotometría.

- Agilizó los tiempos de determinación de $\mathrm{Ca}^{2+}, \mathrm{Mg}^{2+}$ y especialmente de $\mathrm{SO}_{4}{ }^{2-}$.

- Permite la realización de múltiples determinaciones en la misma muestra de forma automatizada, lo que revierte en una precisión mayor en la medida.

- Todas las medidas fueron realizadas en un único equipo.

\subsubsection{EVALUACIÓN DE LOS MÉTODOS DE DISOLUCIÓN Y LAS TÉCNICAS DE ANÁLISIS SIMULTÁNEAMENTE}

Una vez analizados por separado la dispersión que introduce en las medidas la variación del método de disolución y de la técnica de determinación nos quedaría evaluar la dispersión de los resultados cuando se introducen las dos modificaciones juntas. 
En la Tabla 19 se presentan los resultados de la dispersión de las medidas cuando se emplea el método $\mathrm{B}$ de disolución de las muestras y la cromatografía iónica como técnica de determinación.

Tabla 19. Desviación típica de resultados en la determinación de $\mathrm{CaO}$ y $\mathrm{MgO}$, empleando el método B de disolución de muestras y la cromatografía iónica como técnica de análisis

\begin{tabular}{ccc}
\hline Método de disolución & Técnica de análisis & $\sigma$ \\
\hline $\begin{array}{c}\text { Determinación de } \\
\text { sulfatos } \\
\text { (Método B) }\end{array}$ & $\begin{array}{c}\text { Cromatografía iónica } \\
\text { (B.2) }\end{array}$ & $0.11 \% \mathrm{CaO}$ \\
\hline $\begin{array}{c}\text { Determinación de } \\
\text { sulfatos } \\
\text { (Método B) }\end{array}$ & $\begin{array}{c}\text { Cromatografía iónica } \\
\text { (B.2) }\end{array}$ & $0.06 \% \mathrm{MgO}$ \\
\hline
\end{tabular}

La dispersión que presentan las medidas es muy baja. Esto nos asegura que la repetibilidad de este método es muy fiable, pero para darle fiabilidad a nuestra propuesta de metodología debemos comparar los resultados obtenidos empleando este método de disolución/técnica de análisis con los resultados obtenidos empleando el método de disolución/técnica de análisis propuestos en la norma. Esto supone comparar los resultados de las muestras disueltas mediante el método A (disgregación con peróxido sódico) y analizada mediante fotometría (A.1) con las muestras disueltas mediante el método B (determinación de sulfatos) y analizadas mediante cromatografía iónica (B.2). Los resultados se presentan el la Tabla 20.

Tabla 20. Desviación típica de resultados en la determinación de $\mathrm{CaO}$ y $\mathrm{MgO}$ empleando las dos técnicas de análisis y los dos métodos de disolución A y B

\begin{tabular}{ccc}
\hline Método de disolución & Técnica de análisis & $\sigma$ \\
\hline $\begin{array}{c}\text { Método A } \\
\text { Método B }\end{array}$ & $\begin{array}{c}\text { Método fotométrico (A.1) } \\
\text { Cromatografía iónica } \\
\text { (B.2) }\end{array}$ & $0.26 \% \mathrm{CaO}$ \\
\hline $\begin{array}{c}\text { Método A } \\
\text { Método B }\end{array}$ & $\begin{array}{c}\text { Método fotométrico (A.1) } \\
\text { Cromatografía iónica } \\
\text { (B.2) }\end{array}$ & MgO, no se pudo determinar \\
\hline
\end{tabular}

Una vez más la ausencia de datos en las lecturas de la determinación de MgO mediante fotometría nos impidió comparar los resultados con otras técnicas de determinación. 
Con respecto a la determinación de $\mathrm{CaO}$ se puede decir que el valor de $0.26 \%$ de error en la precisión de la medida cumple con los requisitos de reproductibilidad especificados en la norma.

A la vista de los resultados obtenidos se puede afirmar que las variaciones propuestas cumplen con los requisitos de reproducibilidad especificados en la norma y optimizan la metodología de los ensayos planeados en esta campaña experimental.

\subsection{CARATERIZACIÓN DE LOS CEMENTOS DE PARTIDA}

En la Tabla 21 se muestran las características de los cementos empleados, así como las especificaciones normativas a cumplir durante su fabricación.

Tabla 21. Características físicas, químicas y mecánicas

\begin{tabular}{cccccc}
\hline & CEM SR & CEM II & UNE & CEM IV & UNE \\
\hline Inicio fraguado (min) & 284 & 146 & $\geq 60$ & 187 & $\geq 75$ \\
\hline Fin fraguado (min) & 337 & 192 & $\leq 720$ & 236 & $\leq 720$ \\
\hline Resistencia 2 días (MPa) & 31.2 & 29.8 & $\geq 20$ & - & - \\
\hline Resistencia 7 días (MPa) & - & - & - & 27.4 & $\geq 16$ \\
\hline Resistencia 28 días (MPa) & 58.2 & 55.5 & $42.5-62.5$ & 39.4 & $32.5-52.5$ \\
\hline Expansión Le Chatelier (mm) & 0.3 & 0.2 & $\leq 10$ & 0.3 & $\leq 10$ \\
\hline $\mathrm{Cl}^{-}(\%)$ & 0.03 & 0.01 & $\leq 0.1$ & 0.01 & $\leq 0.1$ \\
\hline $\mathrm{C}_{3} \mathrm{~A}(\%)$ & 3.5 & - & $\leq 5$ & & \\
\hline $\mathrm{C}_{4} \mathrm{AF}+\mathrm{C}_{3} \mathrm{~A}(\%)$ & 15.7 & - & $\leq 22$ & & \\
\hline PUZ & - & - & - & & 8 \\
\hline
\end{tabular}

El análisis químico correspondiente se muestra en la Tabla 22.

Las curvas mostradas en la Figura 27 muestra la distribución de tamaño de partícula.

En la Figura 28 se muestran los resultados del análisis térmico realizado a los cementos anhidros de partida. Los tres tipos de cemento presentan una banda endotérmica entorno a $130^{\circ} \mathrm{C}$ con pérdida de masa asociada. Esta señal se asocia con la deshidratación del yeso y la liberación de una pequeña proporción de agua fisisorbida sobre las partículas de los cementos anhidros. 
Entre 400 y $450^{\circ} \mathrm{C}$ los cementos II y IV presentan una banda endotérmica definida que también presenta pérdida de masa asociada. Esta señal corresponde a la deshidroxilación de una pequeña cantidad de $\mathrm{Ca}(\mathrm{OH})_{2}$ producida durante el almacenamiento de los cementos.

A partir de $450^{\circ} \mathrm{C}$ los tres cementos presentan las pérdidas de masa más significativas. La pérdida de masa hasta los $750^{\circ} \mathrm{C}$ se atribuye a la pérdida de $\mathrm{CO}_{2}$ procedente de los carbonatos, presentes en los cementos fundamentalmente como filler calizo.

A partir de $750^{\circ} \mathrm{C}$ sólo los cementos II y IV presentan pérdidas de masa. Esta pérdida de masa presenta la máxima pendiente entorno a $950^{\circ} \mathrm{C}$ y se atribuye a la combustión del carbón inquemado presente en las cenizas volantes que forman parte de la formulación de ambos tipos de cemento. Aunque la combustión de carbón inquemado se puede producir desde los $600^{\circ} \mathrm{C}$ en una atmósfera oxidante, en presencia de una atmósfera inerte de $\mathrm{N}_{2}$, como la empleada en la cámara, puede retrasar esta combustión y producirla a partir de los $880^{\circ} \mathrm{C}$ (Chávez et al., 2008, Yinghai et al., 2011).

Tabla 22. Composición química de los cementos empleados (ICP-OES)

\begin{tabular}{cccc}
\hline Análisis químico (\%) & SR & II & IV \\
\hline $\mathrm{Al}_{2} \mathrm{O}_{3}$ & 3.60 & 6.84 & 11.34 \\
\hline $\mathrm{Fe}_{2} \mathrm{O}_{3}$ & 2.94 & 4.37 & 7.73 \\
\hline $\mathrm{CaO}(\mathrm{FRX})$ & 62.39 & 53.33 & 43.82 \\
\hline $\mathrm{MgO}$ & 0.98 & 1.9 & 2.04 \\
\hline $\mathrm{SiO}_{2}$ & 18.50 & 20.64 & 26.63 \\
\hline $\mathrm{Na}_{2} \mathrm{O}$ & 0.81 & 0.73 & 0.51 \\
\hline $\mathrm{K}_{2} \mathrm{O}$ & 0.89 & 1.05 & 1.36 \\
\hline $\mathrm{TiO}_{2}$ & 0.17 & 0.33 & 0.50 \\
\hline $\mathrm{SrO}_{2}$ & 0.05 & 0.10 & 0.11 \\
\hline $\mathrm{P}_{2} \mathrm{O}_{5}$ & 0.44 & 0.38 & 0.62 \\
\hline $\mathrm{SO}_{3}$ & 3.02 & 2.71 & 2.64 \\
\hline $\mathrm{PF}$ & 2.19 & 2.93 & 1.96 \\
\hline
\end{tabular}




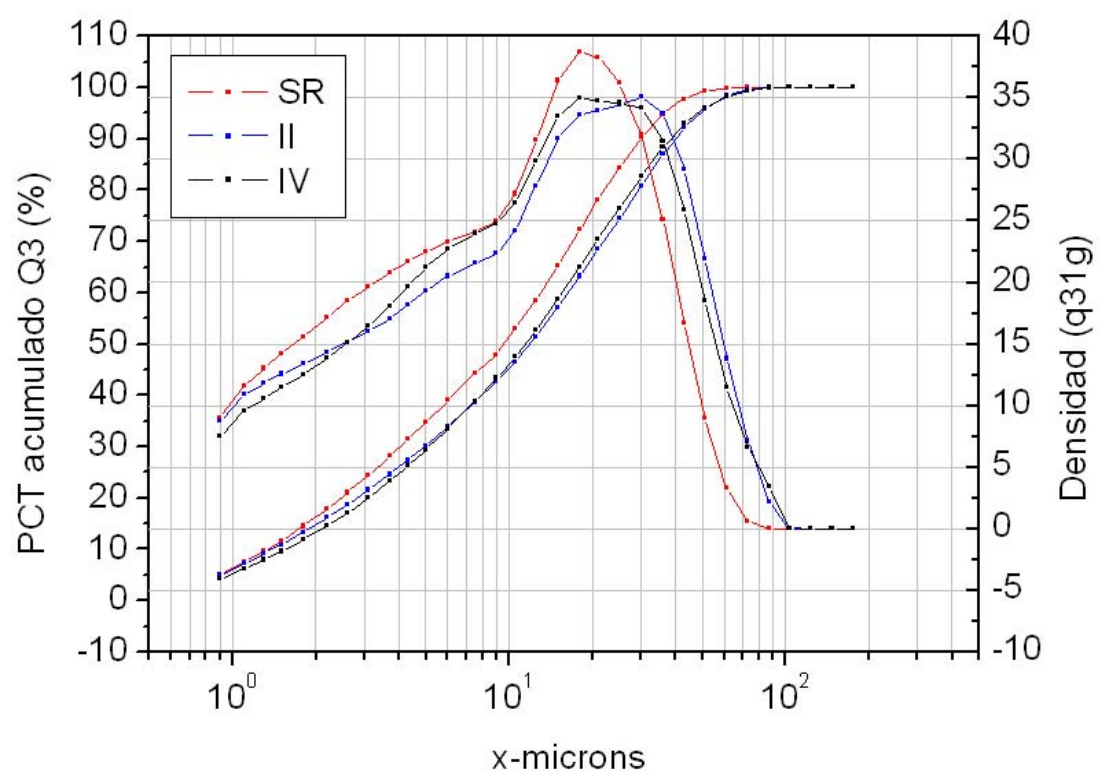

Figura 27. Distribución de tamaño de partícula de los cementos

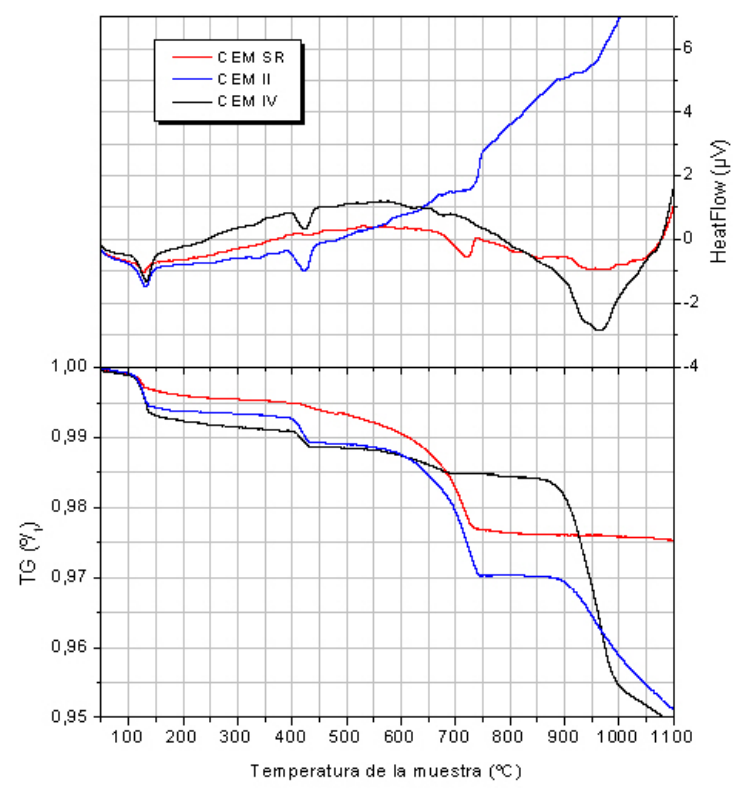

Figura 28. ATD-TG de los cementos anhidros

En Tabla 23 se muestran las pérdidas de masa calculadas en cada uno de los rangos de temperatura respecto a la masa de cemento a $40^{\circ} \mathrm{C}$. 
Las pérdidas de masa por encima de $\operatorname{los} 500^{\circ} \mathrm{C}$, que corresponderían a la liberación de moléculas de $\mathrm{CO}_{2}$ procedentes de los carbonatos y del carbón inquemado, han de tenerse en cuenta cuando se calculan las pérdidas de masa de muestras hidratadas, ya que estas pérdidas no pueden asociase a carbonatos formados con productos de la hidratación de las muestras.

Tabla 23. Pérdidas de masa en cementos anhidros ${ }^{6}$

\begin{tabular}{cccc}
\hline & CEM SR & CEM II & CEM IV \\
\hline$\Delta \mathrm{m}(\%)\left(40-300^{\circ} \mathrm{C}\right)$ & 0.41 & 0.62 & 0.96 \\
\hline$\Delta \mathrm{m}(\%)\left(300-480^{\circ} \mathrm{C}\right)$ & 0.22 & 0.37 & 0.31 \\
\hline$\Delta \mathrm{m}(\%)\left(480-785^{\circ} \mathrm{C}\right)$ & 1.68 & 1.90 & 0.42 \\
\hline$\Delta \mathrm{m}(\%)\left(785-1110^{\circ} \mathrm{C}\right)$ & - & 1.97 & 3.78 \\
\hline
\end{tabular}

\subsection{ANÁLISIS DE MUESTRAS SÓLIDAS}

\subsubsection{ANÁLISIS TÉRMICO}

En este apartado se estudiarán las diferencias que se producen cuando se emplean diferentes métodos para cuantificar los compuestos presentes en la matriz cementicia mediante análisis térmico. Se evaluarán las condiciones de ensayo más adecuadas y los criterios bajo los cuales se efectúan los cálculos.

En la primera parte se presentan los resultados del estudio relativo a los parámetros de medida empleados en el ensayo (masa, flujo de gas y velocidad de calentamiento, etc.), y los derivados de estudió del mecanismo de deshidratación de muestras de pasta de cemento no degradadas.

Los datos obtenidos en este apartado nos permiten conocer la influencia de parámetros del análisis y estimar valores termodinámicos como al energía de activación que nos permitan profundizar en el conocimiento de las reacciones que se producen en la región de deshidratación Ldh.

\footnotetext{
${ }^{6}$ Los rangos de temperatura mostrados son orientativos, en todos los casos se empleó para determinar las pérdidas de masa el método de la derivada de la curva de TG como se indica en el apartado 3.4.5.1 (apartado "Estimación del grado de hidratación propuesto)
} 
En el segundo y tercer apartado se muestran los resultados de las muestras de referencia y las muestras con larga edad de maduración (55 meses). En base a los resultados obtenidos en estas muestras se realiza una reflexión acerca de los parámetros que modifican el cálculo del grado de hidratación atendiendo a las consideraciones que realizan diferentes autores y en base a nuestros propios resultados.

Por último se muestran los resultados de las muestras expuestas en los medios AC, SU y AN.

\subsubsection{Influencia del uso de gas portador}

En este apartado se analizó la influencia que tiene el uso de gas portador en el ensayo de termoanálisis. Uno de los objetivos era evaluar si el uso de gas portador durante el ensayo tiene una influencia sobre la resolución de los termogramas.

Algunos autores apuntan que el uso de velocidades de calentamiento reducidas y la eliminación del uso de gas portador favorecen la formación de una atmósfera autogenerada de vapor de agua que permite un aumento de la presión de vapor de este gas permitiendo que la degradación de los hidratos se lleve a cabo de manera más estable durante la calefacción de la muestra (Tobón et al., 2012a, 2012b).

En la Figura 29 se muestra la influencia de la presencia de gas portador $\mathrm{N}_{2}$ con un flujo aproximado de $80 \mathrm{ml} / \mathrm{min}$. en un ensayo de análisis térmico de rutina donde se ha empleado como velocidad de calentamiento $10^{\circ} \mathrm{C} / \mathrm{min}$.

Como se observa en la Figura 29 la eliminación del uso de gas durante el ensayo implica alcanzar temperaturas mayores para el mismo grado de conversión de la reacciones $(\alpha)$. La figura muestra también que cuando se elimina el flujo de gas los tres cementos muestran pequeñas diferencias, que se anulan cuando existe flujo. Estos resultados confirmarían lo referenciado en la bibliografía. La ausencia de gas permite un más lento desarrollo de los procesos y evidencia las diferencias entre los mismos.

Otros autores empleando regímenes dinámicos de calentamiento (Tobón et al., 2012b) proponen una disminución de la temperatura a la cual se alcanza un determinado grado de conversión o pérdida de masa. Este razonamiento estaría relacionado con que mientras la reacción tiene lugar, 
la pérdida de masa registrada es suficiente para mantener el régimen de calentamiento en velocidad lenta, por lo cual la pérdida se registra a temperatura menor.

En nuestro caso, el aumento de temperatura para alcanzar un mismo grado de conversión al eliminar el uso de gas de purga puede estar relacionado con la presión de vapor que se genera en la cámara durante el ensayo. Al eliminar el gas de purga, el vapor de agua generado durante la descomposición permanece durante más tiempo en la cámara, aumentando la presión de vapor en la misma, lo que revertiría en un aumento de la temperatura a la cual tiene lugar la evaporación de agua.

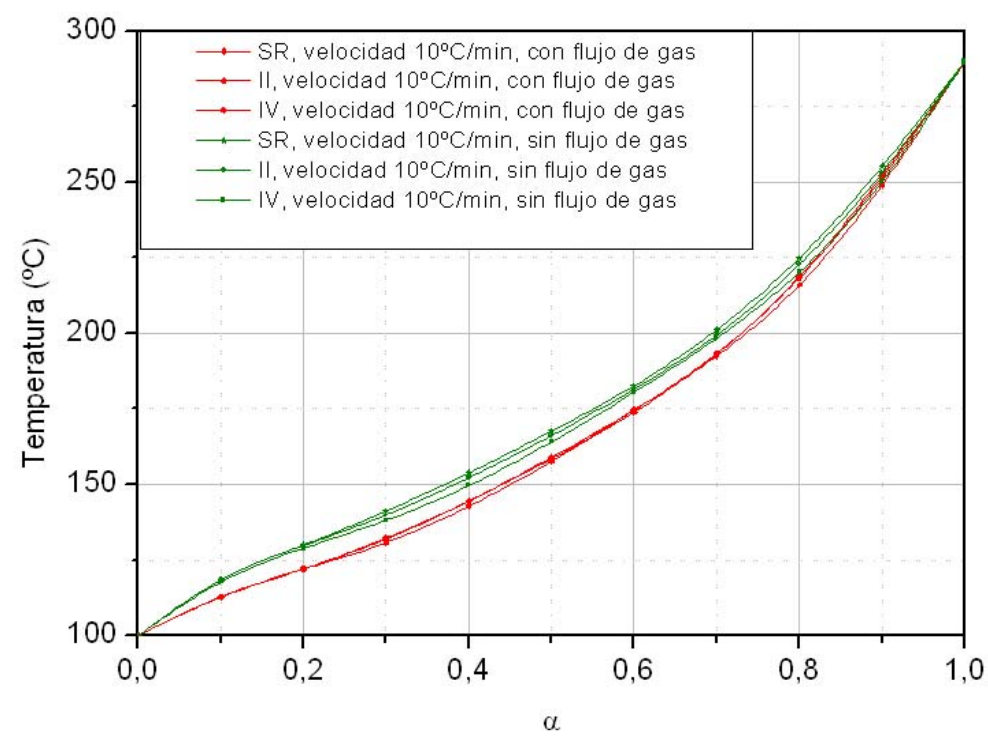

Figura 29. Influencia de la presencia de gas portador sobre la temperatura a la cual se alcanza $\alpha$

En la Figura 30 se presentan las curvas de TG y dTG los ensayos realizados a $10^{\circ} \mathrm{C} / \mathrm{min}$. en presencia y ausencia de gas portador. Si comparamos las curvas de TG, podemos observar que las muestras analizadas en presencia de gas portador presentan, en términos generales, una pérdida de masa mayor que las muestras analizadas en ausencia de gas portador.

En la Tabla 24 se presenta un resumen de las pérdidas de masa calculadas en las muestras en las diferentes condiciones de medida. Para el cálculo de la masa porcentual se ha tenido en cuenta la masa a la temperatura inicial. 


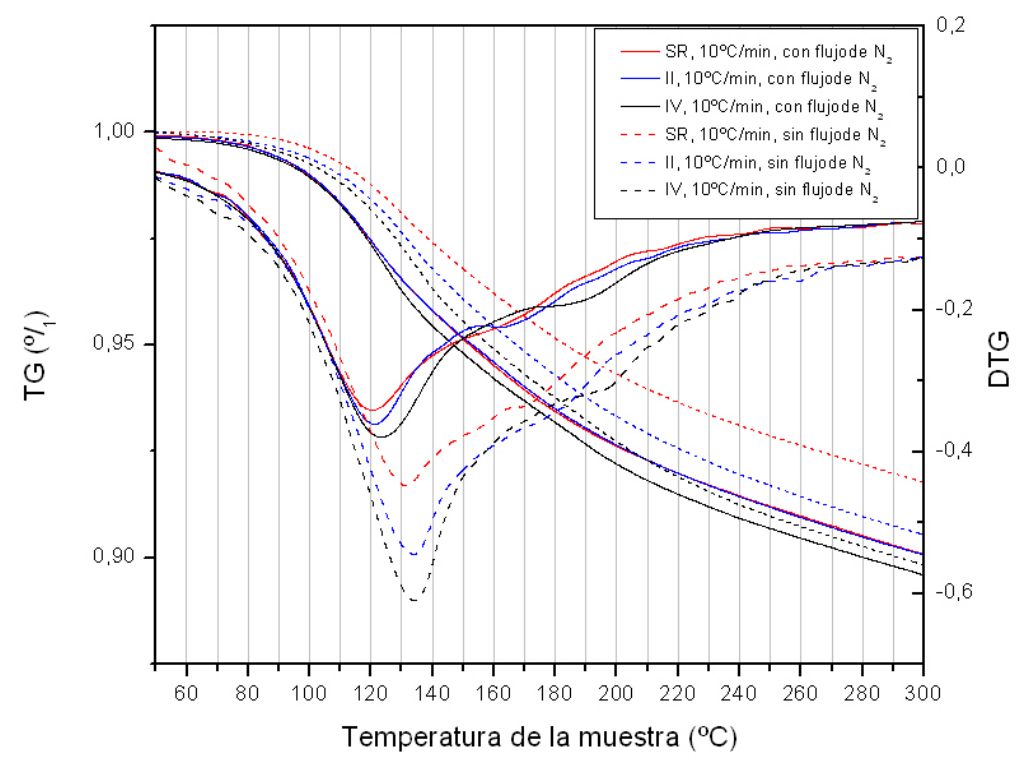

Figura 30. Influencia de la presencia de gas portador en la resolución de las curvas

Tabla 24. Pérdidas de masa calculadas en presencia y ausencia de gas portador $\mathrm{N}_{2}$

\begin{tabular}{c|c|c|c|c|c|c}
\hline Muestra & \multicolumn{3}{|c|}{ Sin $\mathrm{N}_{2}$} & \multicolumn{3}{c}{ Con $\mathrm{N}_{2}$} \\
\hline & $40-100^{\circ} \mathrm{C}$ & $100-300^{\circ} \mathrm{C}$ & $40-300^{\circ} \mathrm{C}$ & $40-100^{\circ} \mathrm{C}$ & $100-300^{\circ} \mathrm{C}$ & $40-300^{\circ} \mathrm{C}$ \\
\hline SR & $0.26 \%$ & $7.66 \%$ & $7.92 \%$ & $0.96 \%$ & $8.62 \%$ & $9.58 \%$ \\
\hline II & $0.56 \%$ & $8.68 \%$ & $9.24 \%$ & $0.91 \%$ & $8.84 \%$ & $9.75 \%$ \\
\hline IV & $0.68 \%$ & $9.27 \%$ & $9.95 \%$ & $0.96 \%$ & $9.13 \%$ & $10.09 \%$ \\
\hline
\end{tabular}

Se observan importantes diferencias entre las dos formas de realización del ensayo y entre los distintos cementos.

En presencia de gas portador la cantidad de agua pérdida entre 40 y $300^{\circ} \mathrm{C}$ se sitúa entorno al $10 \%$ en todas las muestras. Asimismo, la cantidad de agua perdida antes de los $100^{\circ} \mathrm{C}$ también se mantiene constante y próxima al 1\% (ó 10\% respecto a la pérdida total del tramo analizado).

Cuando eliminamos el gas portador la cantidad de agua total perdida no es constante en ninguno de los tramos estudiados para los tres tipos de muestras. Si comparamos las diferencias por tramos y cementos observamos que en las muestras de pasta de cemento SR sistemáticamente la 
pérdida de agua es menor en todos los tramos respecto a los otros dos tipos de muestras. Además, es la que mayor diferencia muestra en los dos métodos analizados. En el caso de las pastas de cemento IV, las diferencias entre las pérdidas en presencia y ausencia de gas portador son las menores en ambos tramos de temperatura.

La eliminación del gas portador afecta de manera más importante a la pérdida de agua entre 40 y $100^{\circ} \mathrm{C}$. En el caso de las muestras de pasta de cemento SR, sin la ayuda del gas de arrastre las pérdidas son pequeñas, e incrementan mucho su valor cuando empleamos gas portador. En el caso de las muestras de pasta de cementos II y IV las diferencias son menores, de aproximadamente la mitad con respecto al ensayo en presencia de gas portador. En este tramo de temperaturas se pierde el agua de mojado.

Las diferencia de masa pérdida en el intervalo de temperaturas entre 100 y $300^{\circ} \mathrm{C}$ es más significativa en el caso de las muestras de pasta de cemento SR y mucho menor para los otros dos tipos de muestras. Las muestras de pasta de cemento II y IV incorporan en su composición adiciones puzolánicas, lo que puede significar un aumento de hidratos minerales en la pasta. Si tenemos en cuenta que en este tramo de temperatura se pierde el agua de los silicatos y aluminatos cálcicos hidratados, una reducción de las diferencias de masa calculada respecto a los dos tipos de ensayo podría significar que la degradación de este tipo de compuestos se ve menos influenciada por el uso o no de gas portador durante el ensayo.

El hecho de que aumente la masa desprendida cuando se emplea gas portador reforzaría la hipótesis de que el uso de gas portador favorece la reacción de descomposición del material, por lo cual se obtienen rendimientos de la reacción mayores a temperaturas más bajas, es decir que se produce una pérdida de masa más rápido, lo que no implicaría que la pérdida de masa total sea mayor.

Se deduce por tanto que el uso de gas portador en el ensayo presenta influencia en las cantidades de masa perdida por las muestras. Pero las variaciones de masa en los tres tipos de muestra no son constantes, por lo que los resultados obtenidos con las dos técnicas mostrarán conclusiones diferentes y deberá ser tenido en consideración.

Se ha observado que el uso de gas portador presenta influencia cuando se trata de reducir la condensación de los productos de reacción y actúa como refrigerante en la cámara. 
La eliminación del gas portador en el ensayo no tiene un efecto claro en la resolución de los termogramas. Si analizamos las curvas dTG presentadas en la Figura 30 observamos como se diferencia claramente el desplazamiento del mínimo de la curva a temperaturas mayores cuando se elimina el uso de gas portador, pero no se obtiene una resolución mejor de las bandas correspondientes a las diferentes reacciones de descomposición que tienen lugar en el rango de temperatura estudiado.

\subsubsection{Influencia de la velocidad de calentamiento}

En este apartado se analizó la influencia que tiene la variación de la velocidad de calentamiento de la muestra sobre la temperatura a la cual se alcanza un determinado grado de conversión. Así como la posibilidad de que una reducción de la velocidad permita llevar a cabo una mejor identificación de la reacción que tiene lugar en cada rango de temperatura.

Con el objetivo de comprobar si podíamos lograr la resolución de las bandas y diferenciar los distintos procesos que tienen lugar como proponen diferentes autores se llevó a cabo la realización de los ensayos reduciendo la velocidad de calentamiento a $0.5^{\circ} \mathrm{C} / \mathrm{min}$. Esto permite analizar las muestras en condiciones cuasi-isotérmicas. Puesto que la velocidad a la que transcurre la reacción depende de la temperatura en el entorno, si reducimos la velocidad de calentamiento se prevé que podremos lograr una mejor resolución de las bandas, ya que de este modo permitimos que la reacción tenga lugar antes de alcanzar la energía de activación del proceso siguiente (Riesen, 1988, Tobón et al., 2012a, 2012b).

En el estudio se emplearon muestras de aproximadamente 60 miligramos, masa aconsejada por diferentes autores para obtener resultados reproducibles (Tobón et al., 2012b).

En la Figura 31 se muestran los resultado de la comparación de termogramas analizados a velocidad de calentamiento habitual $\left(10^{\circ} \mathrm{C} / \mathrm{min}\right.$. $)$ y a velocidad de calentamiento reducida $\left(0.5^{\circ} \mathrm{C} / \mathrm{min}\right.$.). En todos los casos se eliminó el uso de gas $\mathrm{N}_{2}$. 


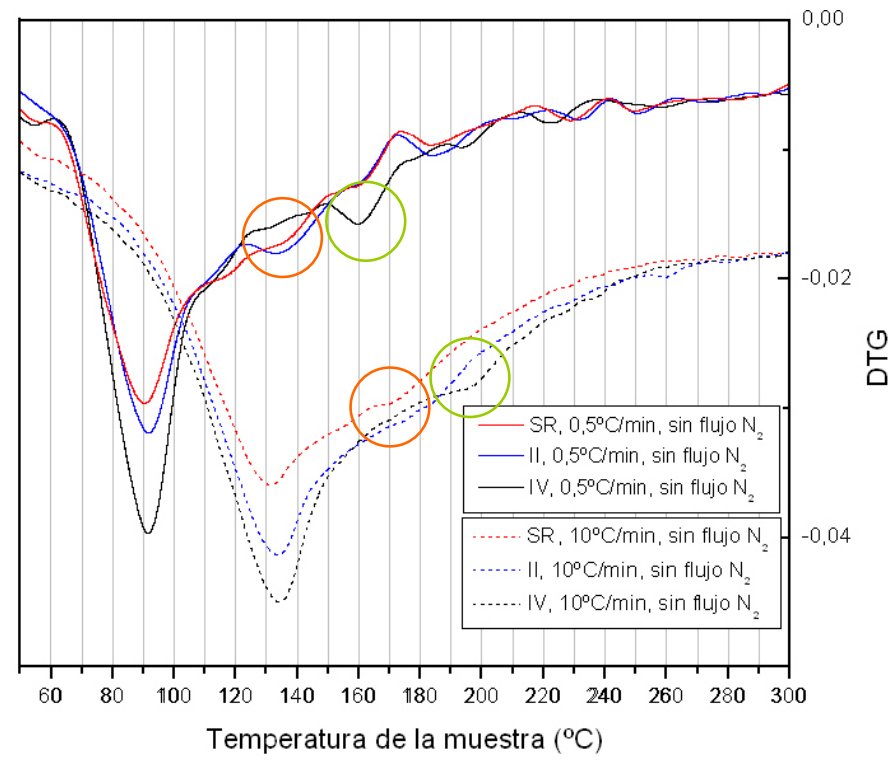

Figura 31. Influencia de la variación de la velocidad de calentamiento en la resolución de las curvas dTG

En la figura se observa que las bandas correspondientes al máximo de pérdida de masa son más agudas cuando se emplean velocidades de calentamiento menores. Algunas bandas secundarias se definen ligeramente. Es el caso de la banda situada entre 150 y $175^{\circ} \mathrm{C}$ correspondiente a la muestra $I V, 0.5^{\circ} \mathrm{C}$, sin $\sin$ flujo de $N_{2}$ que correspondería con la banda la banda situada entorno a $190-200^{\circ} \mathrm{C}$ de la muestra $I V, 10^{\circ} \mathrm{C} / \mathrm{min}$, sin flujo de $N_{2}$ que se presentaba mas difusa.

Este aumento en la resolución de algunas bandas también se observa en la situada entre 120 y $150^{\circ} \mathrm{C}$ para la muestra II, $0.5^{\circ} \mathrm{C} / \mathrm{min}$, sin flujo de $\mathrm{N}_{2}$, que a $10^{\circ} \mathrm{C} / \mathrm{min}$ apenas se podía apreciar.

Sin embargo pese a que se ha aumentado ligeramente la resolución del termograma, en el caso de nuestras muestras no se ha podido separar las bandas de las diferentes etapas del proceso de descomposición. Es posible que esto suceda porque los procesos presenten energías de activación muy próximas que impidan la separación.

Quizá, la eliminación del uso del gas portador para estabilizar la atmósfera en la cual tiene lugar el proceso de descomposición, junto con la reducción de la velocidad de calentamiento a condiciones cuasi isotérmicas, no sea suficiente para resolver el termograma. El uso de un método dinámico de calentamiento nos hubiese permitido establecer un control de la velocidad a la cual tiene lugar el proceso de descomposición de las muestras en función de la masa 
desprendida, lo que hubiese permitido ahorrar tiempo de ensayo, pero no mejorar la resolución de las bandas.

Se ha observado que la variación de la velocidad de calentamiento de las muestras tiene una gran influencia en la temperatura a la cual se producen las reacciones de descomposición. En la Figura 31 se observaba un desplazamiento de más de $40^{\circ} \mathrm{C}$ en los mínimos de las curvas dTG al variar la velocidad de calentamiento de $10^{\circ} \mathrm{C} / \mathrm{min}$. a $0.5^{\circ} \mathrm{C} / \mathrm{min}$.

Esto puede ser importante cuando se trata de asignar las bandas del termograma con los datos encontrados en la bibliografía. Además resulta llamativo que cuando la velocidad de calentamiento es muy lenta, la pérdida de masa asociada al mínimo de la curva de dTG se produzca por debajo de los $100^{\circ} \mathrm{C}$, siendo muy difícil atribuir estas bandas a la deshidratación de moléculas de agua enlazada en la estructura del material.

Con el fin de evaluar las temperaturas a las cuales se producen pérdidas de masa apreciables, en función de la velocidad de calentamiento, se han analizado las variacioines de pérdida de masa en función de la temperatura. Esta información puede ser empleada para estimar la temperatura a la cual tienen lugar un determinado proceso en función de la velocidad de calentamiento.

En la Figura 32, Figura 33 y Figura 34 se muestran los datos de la curva dTG obtenida para los tres tipos de muestra a velocidad de $10^{\circ} \mathrm{C} / \mathrm{min}$. En naranja se muestras los datos de velocidad de pérdida de masa expresados en $\mathrm{mg} /{ }^{\circ} \mathrm{C}$. Se ha establecido el límite de $0.05 \mathrm{mg} /{ }^{\circ} \mathrm{C}$ para señalar las velocidades de pérdida de masa más significativas, especialmente en la región hasta $150^{\circ} \mathrm{C}$ donde se puede producir solapamiento de las bandas de distintos procesos. 


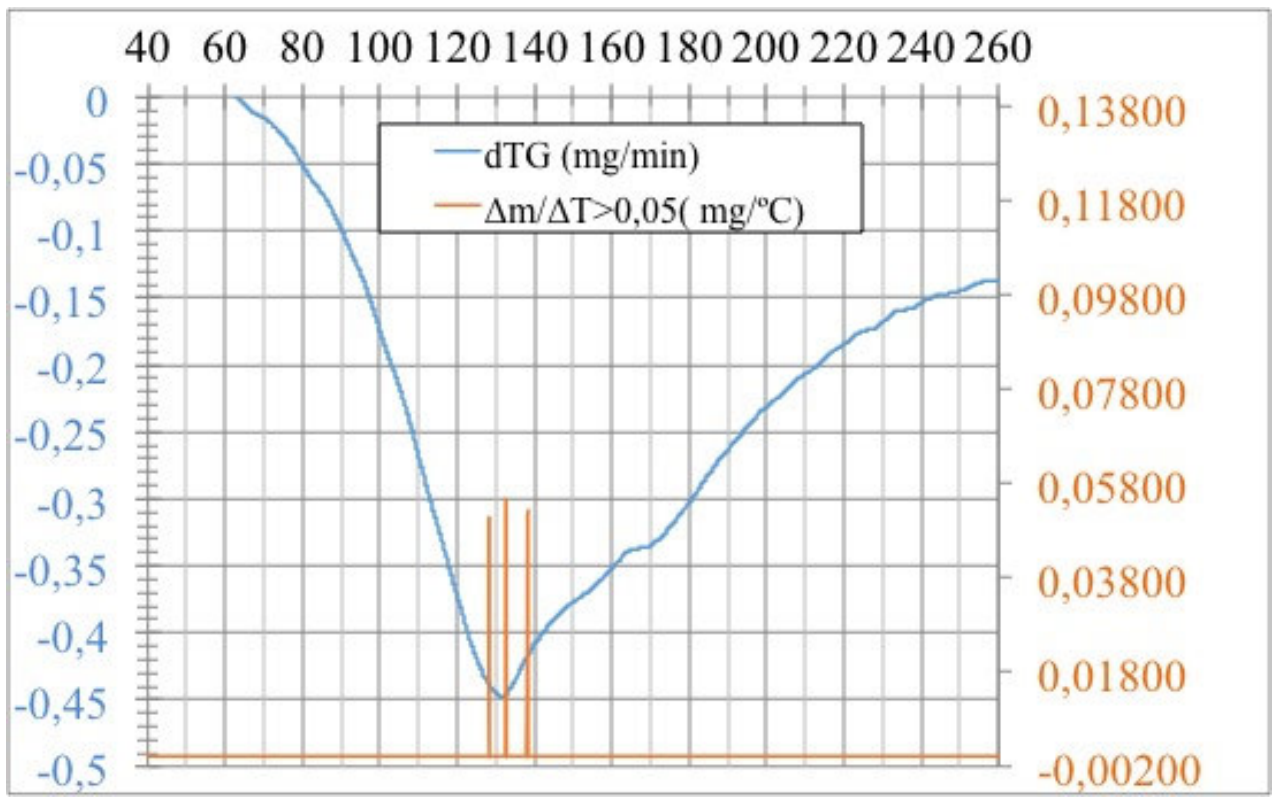

Figura 32. Velocidad de pérdida de masa en función de la tempertura. Muestra SR a velocidad $10^{\circ} \mathrm{C} / \mathrm{min}$

En el caso de las pastas de cemento SR se observan tres señales de pérdida de masa significativas. Estas señales se encuentran en $128.14^{\circ} \mathrm{C}, 132.55^{\circ} \mathrm{C}$ y $138.27^{\circ} \mathrm{C}$. Las señales coinciden temperaturas significativas que se asocian a la descomposición de compuestos en el material, en este caso con la pérdida de agua de las fases AFt y con pérdidas de agua fisisorbida.

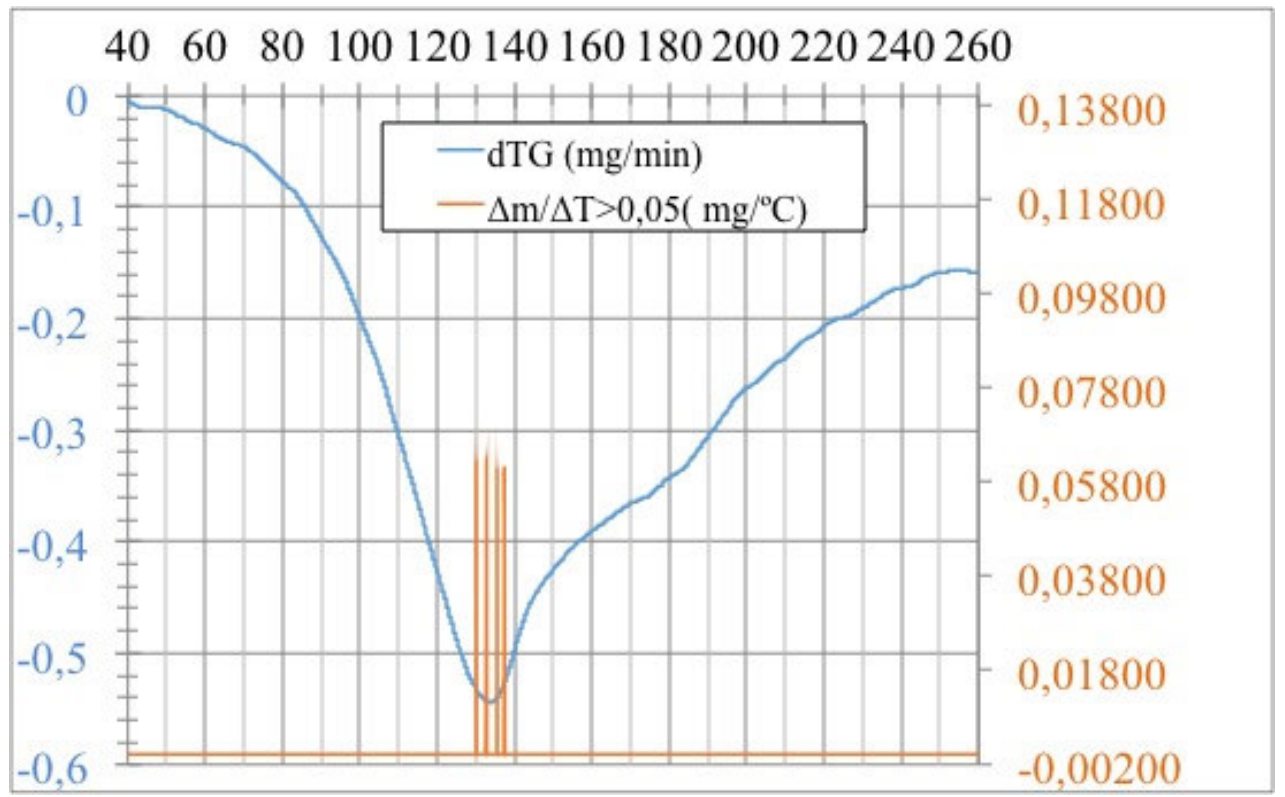

Figura 33. Velocidad de pérdida de masa en función de la tempertura. Muestra II a velocidad $10^{\circ} \mathrm{C} / \mathrm{min}$ 
En el caso de las muestras de pasta de cemento II, con el mismo criterio de velocidad, se observan cuatro bandas. Las temperaturas a las cuales se encuentran las señales son $130.05^{\circ} \mathrm{C}$, $132.76^{\circ} \mathrm{C}, 135.46^{\circ} \mathrm{C}$ y $137.38^{\circ} \mathrm{C}$.

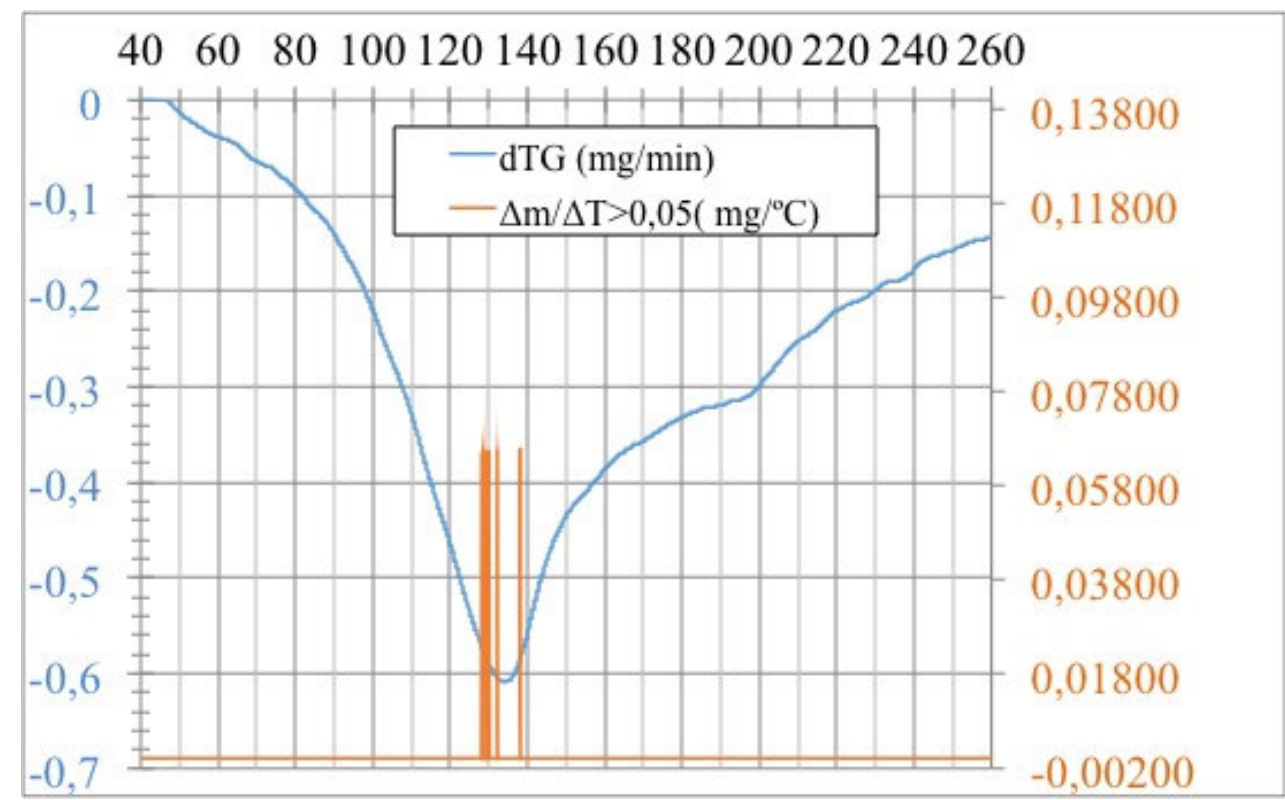

Figura 34. Velocidad de pérdida de masa en función de la tempertura. Muestra IV a velocidad $10^{\circ} \mathrm{C} / \mathrm{min}$

Para las muestras de pasta de cemento IV, con el mismo criterio de velocidad, se observan cuatro bandas. Las temperaturas a las cuales se encuentran las señales son $128.22^{\circ} \mathrm{C}, 129.17^{\circ} \mathrm{C}$, $130.20^{\circ} \mathrm{C}$ y $138.00^{\circ} \mathrm{C}$

En los tres casos analizados aparece una banda entorno a $138^{\circ} \mathrm{C}$ que diferencia la temperatura a la cual tiene lugar un proceso común en los tres tipos de pasta. Atendiendo a las condiceracines que realizan Pane y Hansen (2005), la temperatura $138^{\circ} \mathrm{C}$ estaría asociada con el inicio del la descomposición de geles, por lo que el agua pérdida hasta esa temperatura correspondería a la pérdida de agua libre y fisisorbida, así como a la descomposición de fases que no son propiamente productos de hidratación como las fases AFt.

En la Figura 34, Figura 35 y Figura 36 se muestran los resultados del proceso cuando los ensayos son realizados a $0.5^{\circ} \mathrm{C} / \mathrm{min}$. En este caso el límite para identificar las pérdidas de masa más significativas se ha establecido en $0.007 \mathrm{mg} /{ }^{\circ} \mathrm{C}$. El criterio de pérdida de masa es menor 
porque el ensayo se lleva a una velocidad de calentamiento más baja y por tanto la pérdida de masa en cada tiempo de adquisición es menor.

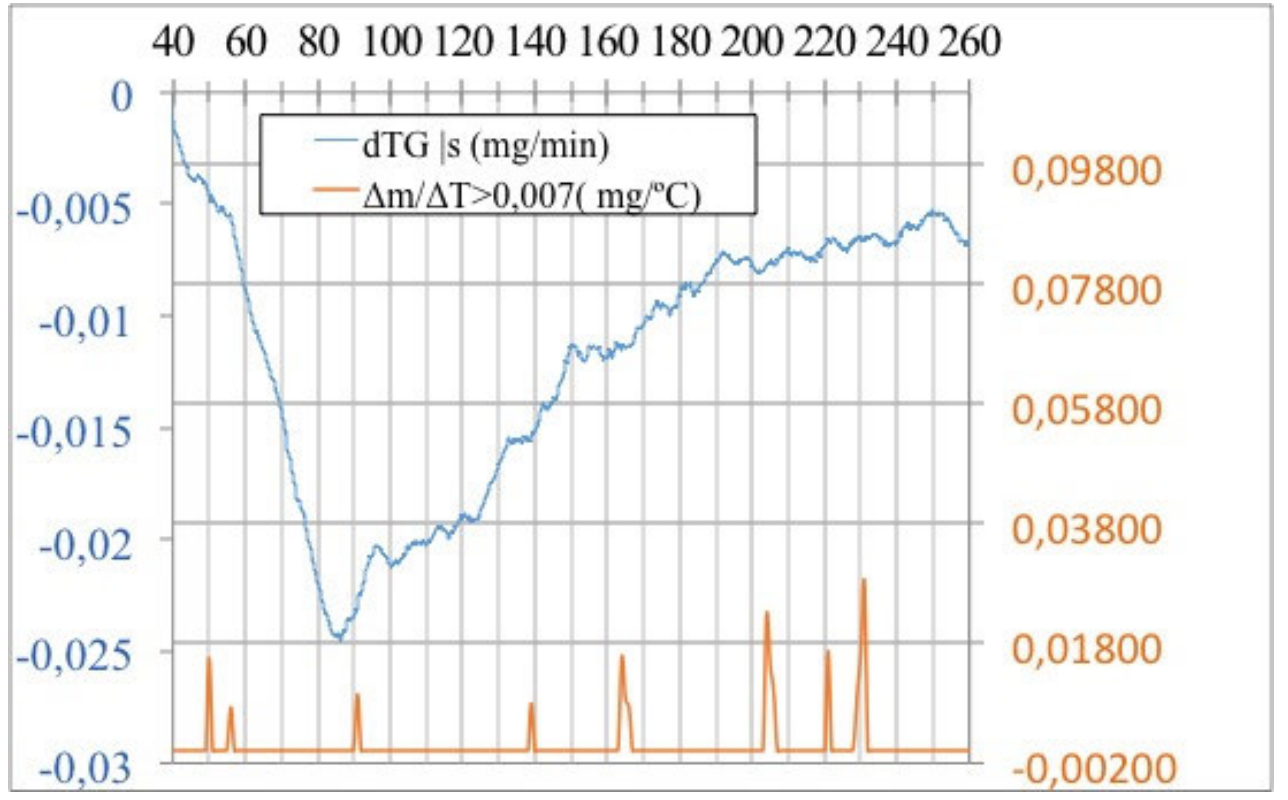

Figura 35. Velocidad de pérdida de masa en función de la tempertura. Muestra SR a velocidad $0.5^{\circ} \mathrm{C} / \mathrm{min}$

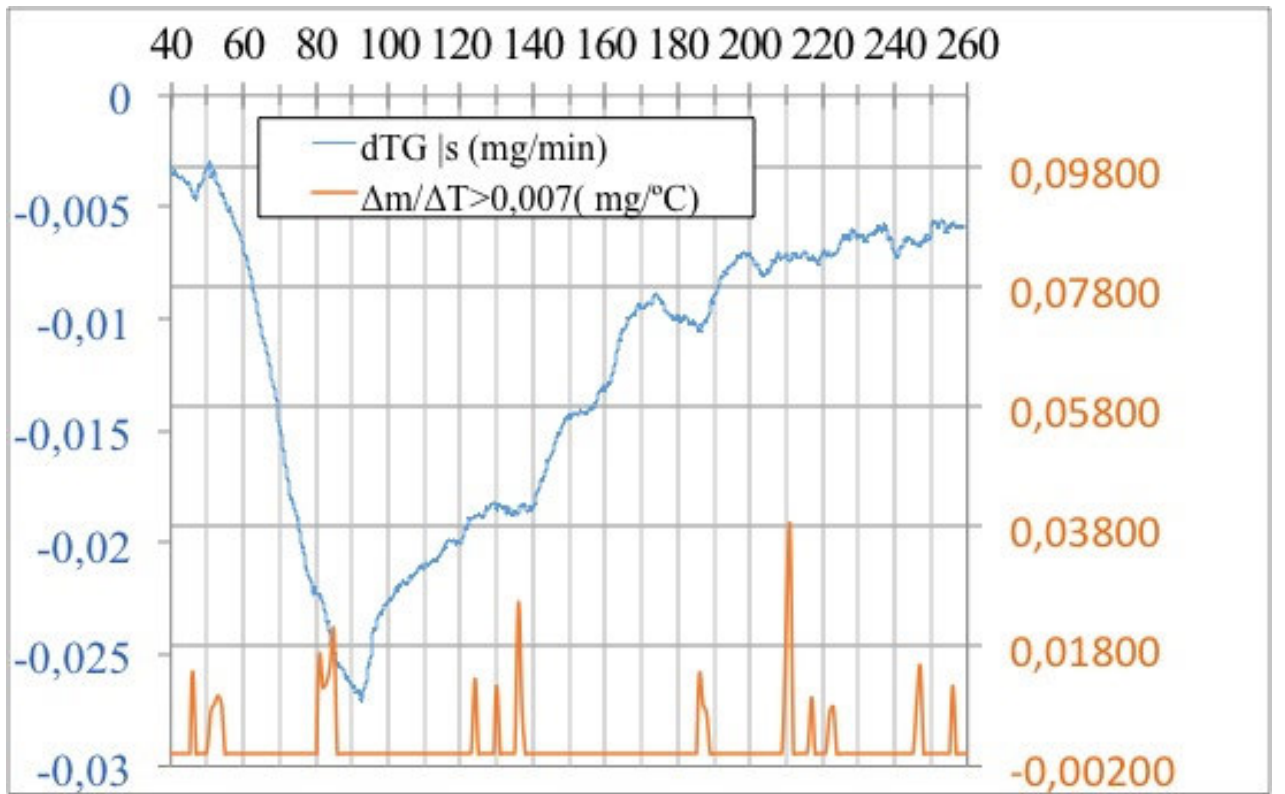

Figura 36. Velocidad de pérdida de masa en función de la tempertura. Muestra II a velocidad $0.5^{\circ} \mathrm{C} / \mathrm{min}$ 


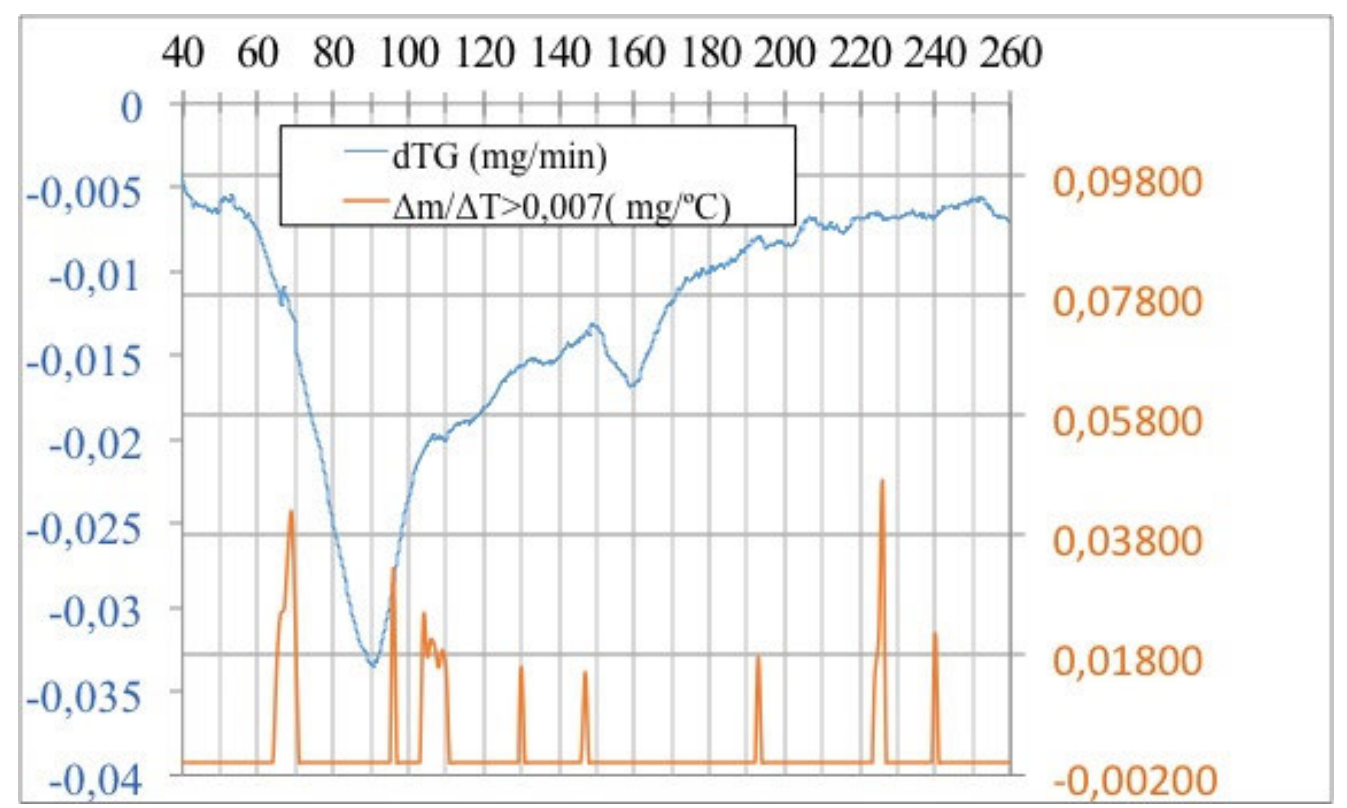

Figura 37. Velocidad de pérdida de masa en función de la tempertura. Muestra IV a velocidad $0.5^{\circ} \mathrm{C} / \mathrm{min}$

A diferencia de las pérdidas de masa que tenían lugar en los ensayos a $10^{\circ} \mathrm{C} / \mathrm{min}$, se observa que a temperaturas por debajo de $100^{\circ} \mathrm{C}$ hay pérdidas de agua apreciables, especialmente en el caso de las muestras de pasta IV. Sin embargo lo más significativo en estos gráficos es observar que las pérdidas de masa asociadas a la banda principal de la curva de dTG finalizan antes de $105^{\circ} \mathrm{C}$, lo cual indicaría que la pérdida de agua que está teniendo lugar rápidamente se puede identificar como agua libre o fisisorbida.

Con el fin de observar que variaciones se producen en las pérdidas de masa en función de la temperatura y velocidades de calentamiento del ensayo se llevaron a cabo ensayos de análisis térmico a diferentes velocidades de calentamiento.

El la Figura 38, Figura 39 y Figura 40 se presentan los resultados de la variación de la temperatura para alcanzar un determinado grado de reacción en función de la velocidad de calentamiento para las muestras de pasta de los diferentes cementos empleados. 


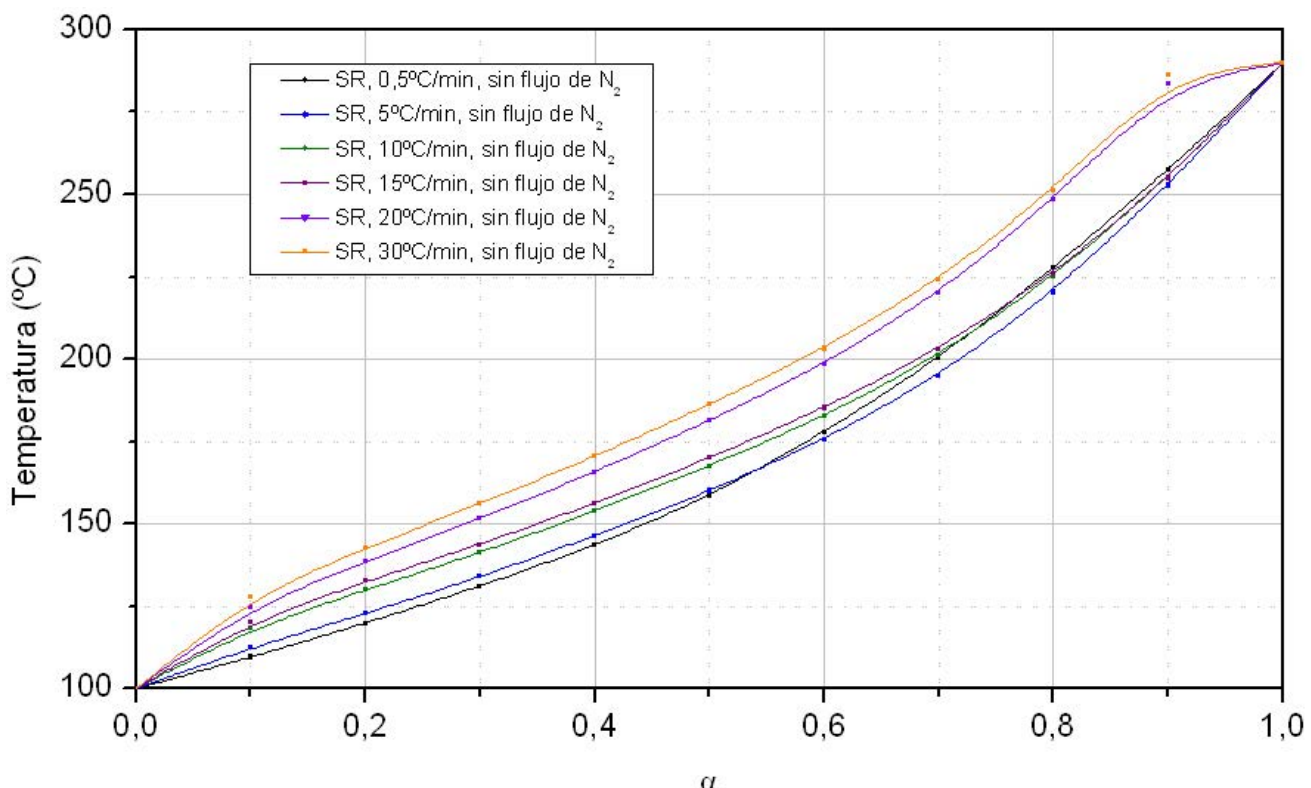

Figura 38 . Influencia de la variación de la velocidad de calentamiento sobre la temperatura a la cual se alcanza un determinado grado de conversión de la reacción en muestras de pasta de cemento SR

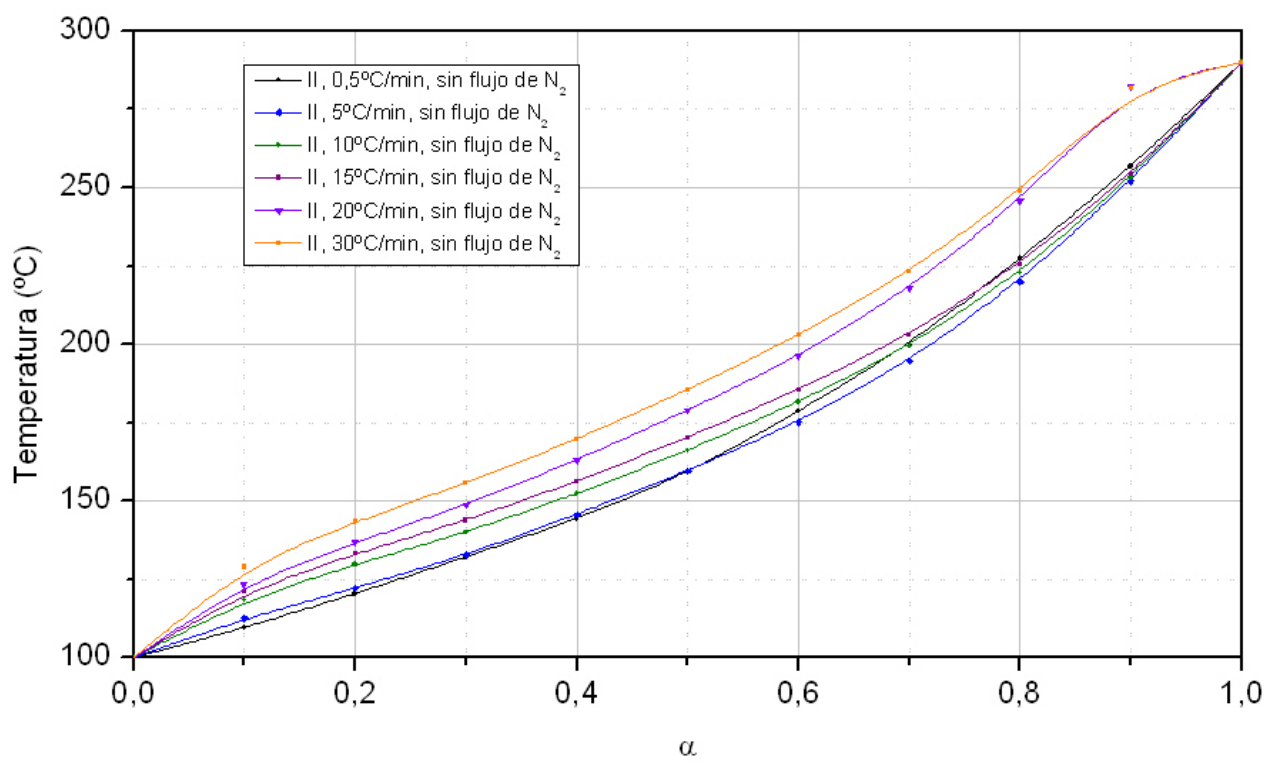

Figura 39. Influencia de la variación de la velocidad de calentamiento sobre la temperatura a la cual se alcanza un determinado grado de conversión de la reacción en muestras de pasta de cemento II 


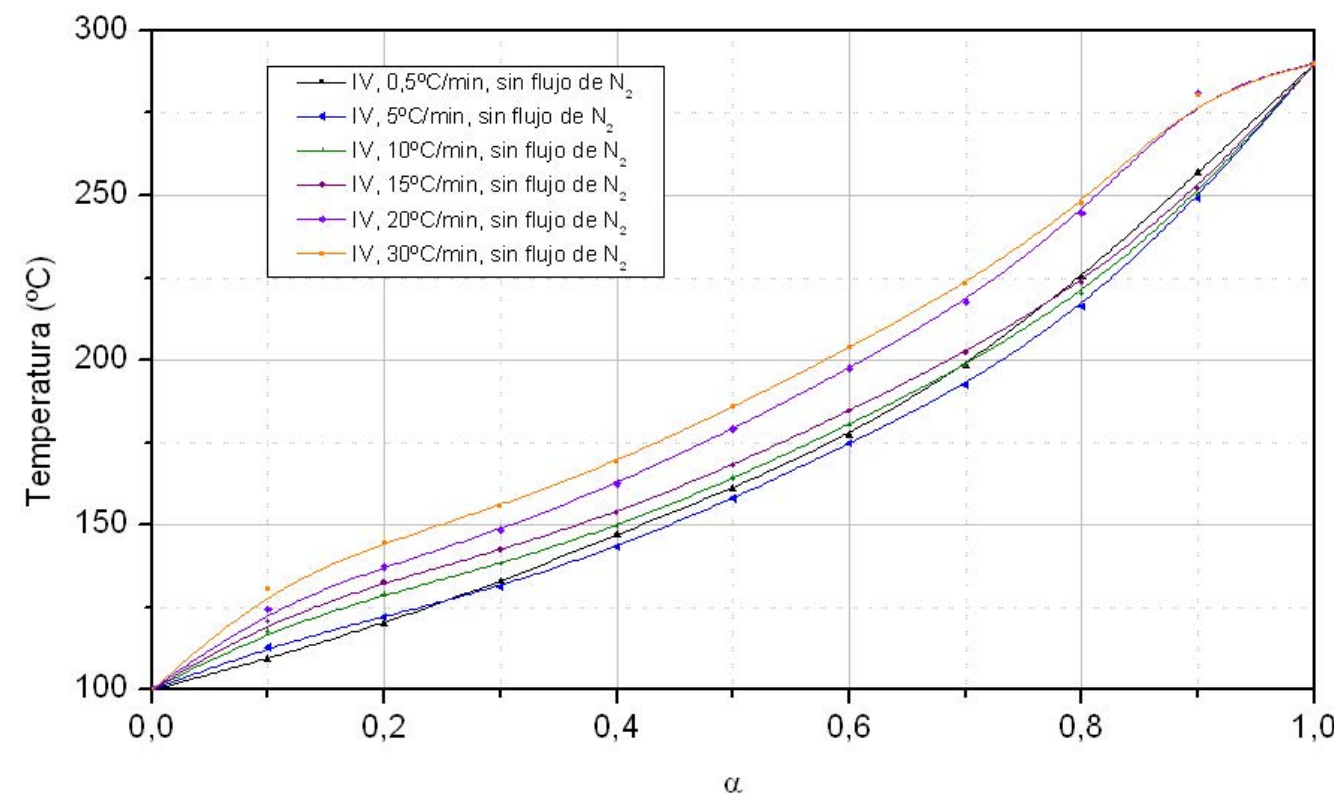

Figura 40. Influencia de la variación de la velocidad de calentamiento sobre la temperatura a la cual se alcanza un determinado grado de conversión de la reacción en muestras de pasta de cemento IV

El aumento de la velocidad de calefacción se traduce en un aumento gradual de la temperatura a la cual se alcanza un determinado grado de conversión de la reacción $(\alpha)$. Los procesos tardan en iniciarse, si la velocidad de calentamiento es muy rápida, la variación de masa asociada al proceso que está teniendo lugar se detecta a temperaturas mayores y esto explicaría que el agua libre en la muestra se compute como perdida a temperaturas superiores a $100^{\circ} \mathrm{C}$.

A velocidades comprendidas entre 0.5 y $15^{\circ} \mathrm{C} / \mathrm{min}$ se observa un desplazamiento de la temperatura a la cual se alcanza un determinado grado de reacción cuando este se encuentra por debajo del 70-80\%, a partir de este porcentaje se observa una convergencia de las temperaturas.

A velocidades de 20 y $30^{\circ} \mathrm{C} / \mathrm{min}$ el desplazamiento de la temperatura para alcanzar un determinado grado de conversión se mantiene a lo largo de todo el rango.

Es posible que un incremento en la velocidad de calentamiento no permita que las reacciones de deshidratación tengan lugar de manera completa y propicie un solapamiento mayor, por lo que para llevar a cabo ensayos de interpretación cualitativa conviene reducir al máximo la velocidad de calentamiento siempre que el tiempo de ensayo lo permita. 
Se realizaron ensayos a diferentes velocidades de calentamiento para evaluar los rangos de temperatura que se pueden emplear en el cómputo de las pérdidas de masa de las muestras.

En la Figura 41 se muestran los gráficos de las curvas dTG obtenidos para cada uno de los cementos y a las velocidades de calentamiento ensayadas.

En la Tabla 25 se recogen las temperaturas a las cuales se produce el mínimo de la curva dTG correspondiente a la temperatura a la cual se produce la máxima velocidad de deshidratación.

Los datos de la temperatura a la cual se produce la máxima velocidad de deshidratación frente a la velocidad de calentamiento se presentan en la Figura 42.

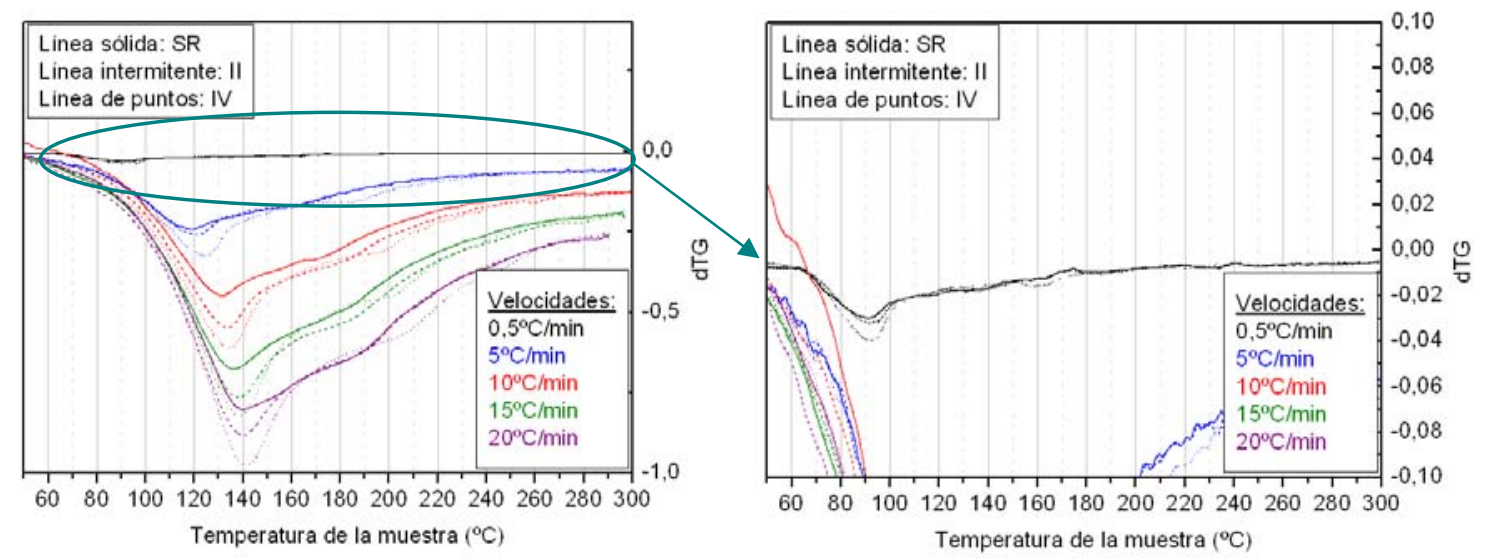

Figura 41. dTG de las curvas a diferentes velocidades de calentamiento de cada una de las muestras e los diferentes cementos empleados

A valores de velocidades de calentamiento habituales en los ensayos de termogravimetría, entre 5 y $20^{\circ} \mathrm{C} / \mathrm{min}$, se puede decir que la máxima conversión de la reacción se produce entre 120 y $140^{\circ} \mathrm{C}$. Mientras que a velocidades menores la pérdida de masa asociada a la misma transición se localiza a temperaturas menores a $100^{\circ} \mathrm{C}$. Esta observación nos lleva a plantearnos que tipo de agua se está perdiendo en este tramo de temperatura. Es posible que el agua que se pierde a temperaturas mayores cuando el régimen de calentamiento es mas rápido sea agua libre o unida mediante fisisorción, por lo que considerarla como agua enlazada puede llevar a sobreestimar el grado de grado de hidratación del material. 
En todos los casos, a medida que aumentamos la velocidad de calentamiento los valores de la temperatura a la cual se alcanza el máximo de conversión de la reacción alcanzan un valor asintótico entre 140 y $141^{\circ} \mathrm{C}$.

Tabla 25. Temperatura a la cual se produce el máximo grado de conversión de las reacciones

\begin{tabular}{c|c|c}
\hline Muestra & Velocidad de calentamiento $(\beta)$ & $\mathrm{T}_{\max }$ \\
\hline \multirow{4}{*}{ SR } & $\left({ }^{\circ} \mathrm{C} / \mathrm{min}\right)$ & $\left({ }^{\circ} \mathrm{C}\right)$ \\
\hline \multirow{5}{*}{ II } & 0.5 & 90.9 \\
\cline { 2 - 3 } & 5 & 118.3 \\
\cline { 2 - 3 } & 10 & 131.0 \\
\cline { 2 - 3 } & 15 & 136.2 \\
\cline { 2 - 3 } & 20 & 139.9 \\
\cline { 2 - 3 } & 0.5 & 92.3 \\
\cline { 2 - 3 } & 5 & 121.9 \\
\cline { 2 - 3 } & 10 & 133.9 \\
\cline { 2 - 3 } & 15 & 138.2 \\
\hline \multirow{5}{*}{ IV } & 20 & 140.1 \\
\cline { 2 - 3 } & 0.5 & 131.5 \\
\cline { 2 - 3 } & 5 & 133.9 \\
\cline { 2 - 3 } & 10 & 141.3 \\
\cline { 2 - 3 } & 15 &
\end{tabular}

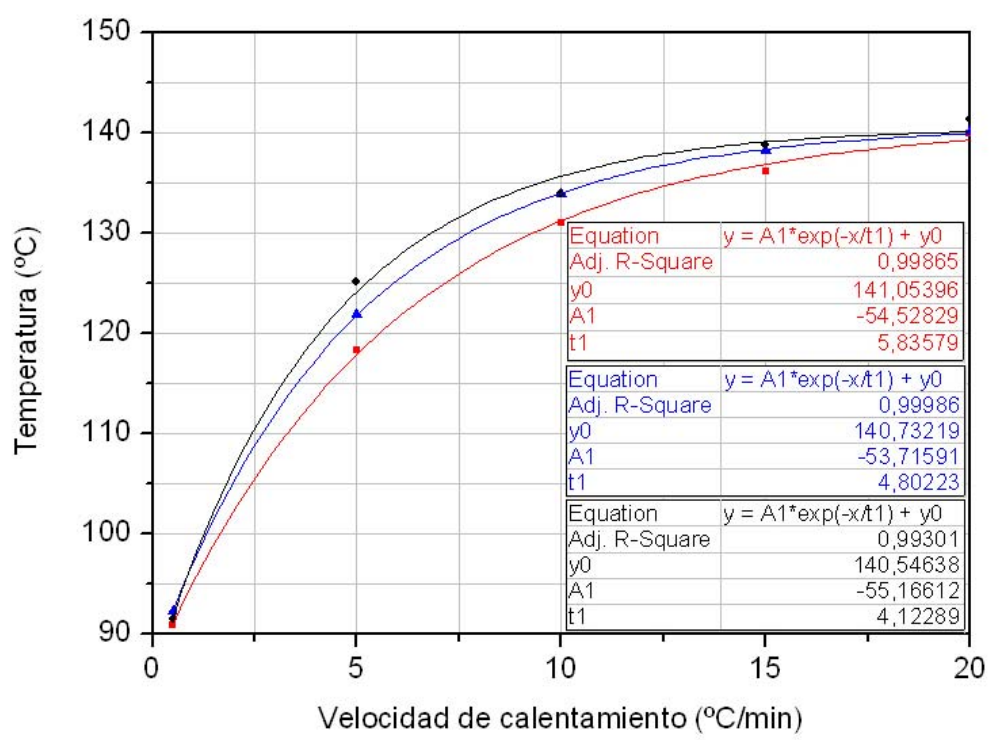

Figura 42. Temperatura del mínimo de la curva dTG en función de la velocidad de calentamiento. 
En los tres casos se observa una tendencia exponencial de los datos. El la Figura 42 se han incluido los datos del ajuste realizado que presentan un grado de correlación muy bueno.

Las muestras de cemento SR presentan una temperatura en el máximo de deshidratación más baja que el resto de las muestras a todas las velocidades de calentamiento. Las muestras de cemento IV presentan la temperatura más alta para el máximo de conversión de la reacción.

Cuando la velocidad de calentamiento es lenta, los tres tipos de muestras de pasta de cemento presentan una temperatura muy próxima para la máxima velocidad de deshidratación. A medida que aumenta la velocidad de calentamiento aumenta la dispersión a la cual se registra la máxima velocidad de calentamiento en los tres tipos de muestras. A partir de $15^{\circ} \mathrm{C} / \mathrm{min}$ se observa de nuevo una convergencia que de la temperatura a la cual se produce la máxima velocidad de deshidratación del material. Esta temperatura se sitúa en próxima a $140^{\circ} \mathrm{C}$.

Se podría postular que el agua que se encuentra en el material en forma libre y fisisorbida comienza a evaporar a temperaturas próximas o ligeramente inferiores a $100^{\circ} \mathrm{C}$. En tanto en cuanto el proceso tiene lugar en condiciones de equilibrio térmico, la dispersión de la temperatura a la cual tiene lugar la máxima velocidad de deshidratación es escasa. Sin embargo cuando aumentamos la velocidad a la cual tiene lugar el calentamiento de las muestras, estamos incrementando el aporte de energía al entorno. Un aumento de la cantidad de agua desprendida podría producir un aumento de la presión en la cámara, ya que no existe gas de arrastre, lo que incidiría en el aumento de la temperatura a la cual tiene lugar la evaporación de la misma. El efecto sería similar a cuando eliminamos el gas de purga en el ensayo.

A velocidades de calentamiento entre 5 y $15^{\circ} \mathrm{C} / \mathrm{min}$. se ha observado que las pastas de cemento con adición puzolánica desplazan la posición de los máximos de conversión a temperaturas mayores. Esto implicaría una presión de vapor mayor en la cámara y podría estar relacionado con un cambio de estequiometría en los geles del material.

A velocidades superiores a $15-20^{\circ} \mathrm{C}$, la energía aportada con el incremento de temperatura es suficientemente rápida para que las reacciones de evaporación tengan lugar de manera completa. Se registra la máxima velocidad de pérdida de masa a $140^{\circ} \mathrm{C}$ aprox. como consecuencia del retardo que sufre el registro de la masa en la termobalanza cuando la velocidad 
de calentamiento es rápida, y asociado a la fuerzas de unión que se establecen entre el agua y la superficie de los compuestos de la pasta de cemento.

\subsubsection{Evaluación del mecanismo de deshidratación}

El uso del termoanálisis en el estudio de materiales cementicios proporciona información cuantitativa y cualitativa referente a los compuestos que integran la matriz cementicia. El proceso se basa en la identificación de los cambios producidos en la señal gravimétrica o eléctrica cuando se le aplica un calentamiento a una muestra respecto a una señal de referencia.

Sin embargo hay que tener en cuenta que las condiciones a las cuales se lleva a cabo la determinación juegan un papel importante en los resultados obtenidos. Además la asignación de una determinada reacción a una banda no siempre es fácil, ya que las bandas sufren desplazamientos de temperatura característica en función de las condiciones de ensayo y de la naturaleza de la muestra. La naturaleza de la muestra puede influir en el mecanismo a través del cual tienen lugar las reacciones estudiadas.

Para comprender mejor el comportamiento de la degradación térmica de las muestras de pasta de cemento durante los ensayos de termogravimetría, se han analizado las curvas de TG a varias velocidades de calentamiento. El objetivo es estimar los valores de energía de activación aparentes y determinar la complejidad de las reacciones que tienen lugar.

Se han considerado las premisas que se expusieron en el apartado 3.4.5.1 (Estimación de parámetos termodinámicos) para llevar a cabo la estimación de parámetros termodinámicos relacionados con el mecanismo a través del cual se lleva a cabo la deshidratación de las muestras de análisis en la región Ldh. En los párrafos siguientes se recuerdan las aproximaciones empleadas para la determinación de las ecuaciones de análisis (Yuzay et al., 2010, Zelic et al. 2007)

Asumiendo que la velocidad de reacción de un proceso no isotérmico sigue la ecuación:

$$
\frac{d \alpha}{d t}=k(T) \cdot f(\alpha)
$$

Donde: 
- $\mathrm{t}$ es el tiempo.

- T es la temperatura.

- $\alpha$ es el grado de conversión de la reacción.

- $\mathrm{f}(\alpha)$ representa la expresión matemática del modelo cinético.

Si reemplazamos k(T) por la ecuación de Arrhenius:

$\frac{d \alpha}{d t}=A \cdot \exp \left(-\frac{E}{R T}\right) \cdot f(\alpha)$

Ecuación 20

Donde:

- A es un factor preexponenecial.

- R el la constante de los gases.

- E representa la energía de activación del proceso según Arrhenius.

Esta ecuación se puede aplicar para experimentos realizados en condiciones isotérmicas. Si las condiciones del ensayo no son isotérmicas, como es el caso de los ensayos en termogravimetría, donde se aplica una velocidad de calentamiento constante, es necesario introducir este parámetro en la ecuación. De este modo, siendo $\beta=\mathrm{dT} / \mathrm{dt}$ la velocidad de calentamiento del ensayo, la ecuación que define la velocidad de degradación del proceso quedaría:

$$
\frac{d \alpha}{d t}=\frac{A}{\beta} \cdot \exp \left(-\frac{E a}{R T}\right) \cdot f(\alpha)
$$

Ecuación 21

Llegados a este punto, existen métodos que permiten estimar los parámetros cinéticos que definen la ecuación anterior a partir de datos de termogravimetría en condiciones isotérmicas o no. 
En este estudio se han empleado los métodos de Kissinger y Flynn-Wall-Ozawa para estimar la energía de activación del comportamiento de la degradación térmica a partir de los datos de las curvas de termogravimetría. Para este fin se emplearon diferentes velocidades de calentamiento $\left(0.5,5,10,15\right.$ y $\left.20^{\circ} \mathrm{C} / \mathrm{min}\right)$.

\section{Método de Kissinger}

El método de Kissinger emplea el desplazamiento de la temperatura a la máxima velocidad de conversión del proceso, es decir la temperatura a la cual el proceso de deshidratación es mayor, con la variación de la velocidad de calentamiento. La energía de activación puede ser estimada empleando la siguiente ecuación (Yuzay et al., 2010, Kissinger, 1956):

$$
\ln \left(\frac{\beta}{T_{\max }^{2}}\right)=\left[\ln \frac{A R}{E_{a}}+\ln \left(n\left(1-\alpha_{\max }\right)^{n-1}\right]-\frac{E_{a}}{R T_{\max }}\right.
$$

Donde:

- $\beta$ es la velocidad de calentamiento.

- $\mathrm{T}_{\text {máx }}$ es la temperatura a la cual se produce la máxima pérdida de masa.

- A es el factor pre-exponencial de Arrhenius.

- R es la constante de los gases.

- $E_{a}$ es la energía de activación.

- $\alpha_{\text {máx }}$ corresponde al grado de conversión del proceso asociado a la temperatura a la cual se produce la máxima pérdida de masa.

- n es el orden de reacción.

De acuerdo con la ecuación descrita por Kissinger, la $E_{a}$ puede obtenerse de la pendiente de la recta obtenida cuando representamos $\ln \left(\beta / \mathrm{T}_{\text {max }}^{2}\right)$ frente $\mathrm{a} 1 / \mathrm{T}_{\max }$.Para ello la primera parte del procedimiento consiste en determinar la temperatura a la cual se produce la máxima la máxima velocidad de conversión de las reacciones, es decir la zona de la curva de termogravimetría con 
máxima pendiente. Para identificar el tramo de máxima pendiente se emplea por tanto el mínimo de la curva derivada de la señal de TG (dTG) a cada una de las velocidades analizadas.

En la Figura 41 se mostraron los resultados de las curvas dTG obtenidos para cada uno de los cementos y a las velocidades de calentamiento ensayadas. En la Tabla 25 se recogieron las temperaturas a las cuales se producía el mínimo de la curva dTG.

A partir de los datos obtenidos y empleando la aproximación de Kissinger (ecuación 4), se ha llevado a cabo el cálculo de la energía de activación aparente para cada uno de los cemento empleados.

En el cálculo, se han analizado las diferencias que se producen cuando se incluyen los datos de los ensayos realizados a la velocidad de $0.5^{\circ} \mathrm{C} / \mathrm{min}$., por dos motivos. En primer lugar porque se ha observado una posición del mínimo de la curva dTG a temperatura inferior a $100^{\circ} \mathrm{C}$, lo que dejaría $\alpha_{\text {máx }}$ fuera de nuestro rango de estudio inicial en la región Ldh. En segundo lugar porque ésta no es una velocidad de calentamiento empleada con asiduidad en los ensayos de termogravimetría por el tiempo que supone el ensayo (suele emplearse para obtener termogramas de alta resolución en una región de temperaturas determinada).

En la Figura 43 se muestran los datos obtenidos al representar la inversa de la temperatura en el máximo de conversión de la reacción frente al logaritmo del cociente de la velocidad de calentamiento entre la temperatura máxima al cuadrado, según la ecuación de Kissinger.

De las pendientes de las rectas ajustadas por mínimos cuadrados se ha calculado la energía de activación aparente. Los resultados presentados se ajustan a una recta con coeficientes de correlación razonablemente buenos, por los que se pueden emplear para el cálculo de la energía de activación aparente a la temperatura a la cual se produce la máxima velocidad de conversión de la reacción.

En la Tabla 26 se muestran los valores obtenidos para cada uno de las muestras de cemento estudiadas. 
Tabla 26. Energía de activación aparente estimada según la ecuación de Kissinger para cada uno de las muestras de pasta de cemento empleadas

\begin{tabular}{c|c|c}
\hline Muestra & $\begin{array}{c}\text { Ea }(\mathrm{KJ} / \mathrm{mol}) \\
5-30^{\circ} \mathrm{C} / \mathrm{min}\end{array}$ & $\begin{array}{c}\mathrm{Ea}(\mathrm{KJ} / \mathrm{mol}) \\
0.5-30^{\circ} \mathrm{C} / \mathrm{min}\end{array}$ \\
\hline SR & 66.06 & 70.58 \\
\hline II & 75.00 & 71.56 \\
\hline IV & 80.65 & 68.57 \\
\hline
\end{tabular}

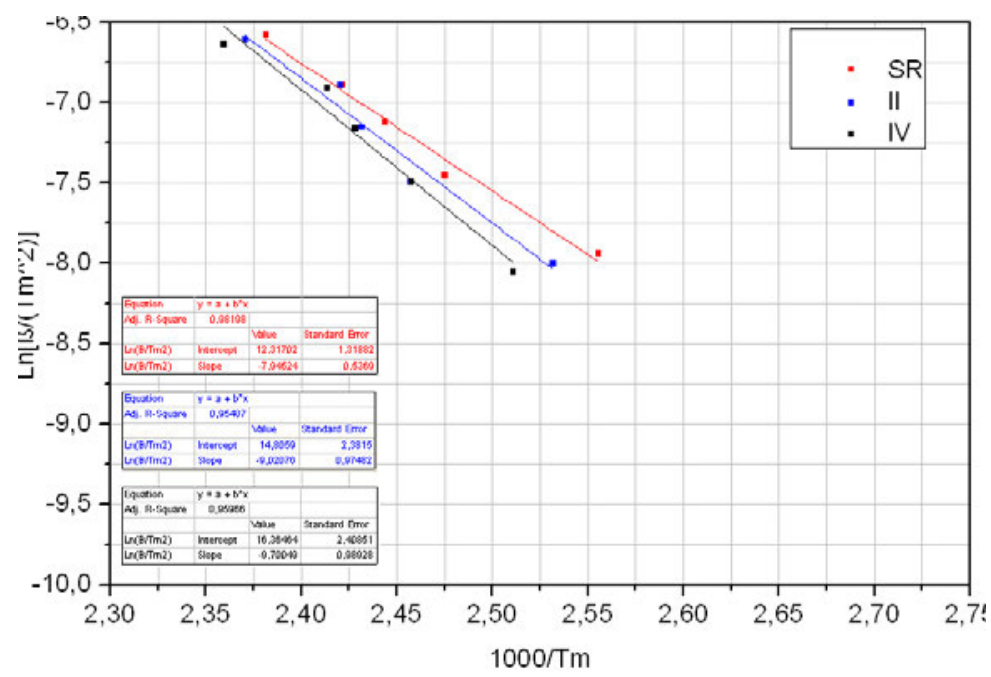

(a) Rango de velocidades estudiadas: $5-30^{\circ} \mathrm{C} / \mathrm{min}$

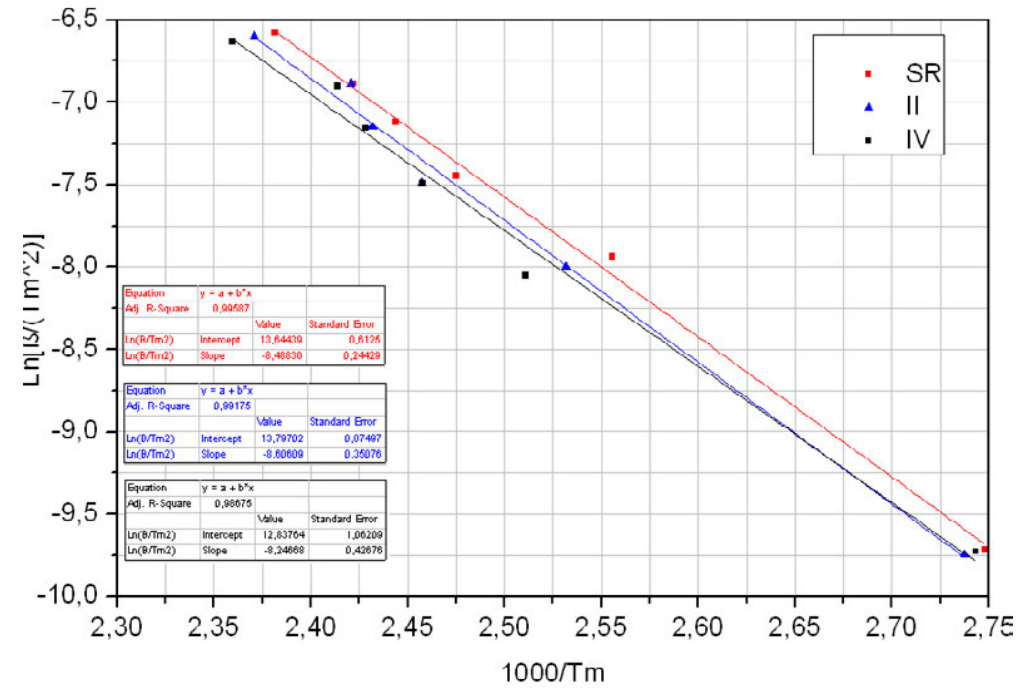

(b) Rango de velocidades estudiadas: $0.5-30^{\circ} \mathrm{C} / \mathrm{min}$

Figura 43. $\operatorname{Ln}\left(\beta / T_{\text {máx }}^{2}\right)$ frente a1/ $T_{\text {máx }} y$ ajustes para los tres tipos de muestras 
La energía de activación aparente obtenida según el método de Kissinger nos permite realizar una estimación de la facilidad con la que se lleva a cabo la degradación térmica de la materia en el máximo de conversión de la reacción.

Si tenemos en cuenta los ensayos a los cuales se llevan a cabo los ensayos de rutina en termoanálisis (velocidades comprendidas entre 5 y $30^{\circ} \mathrm{C} / \mathrm{min}$.), se puede decir que los cementos con adición presentan una estabilidad mayor frente a la degradación que el cemento sin adición, y siguiendo este razonamiento una estabilidad mayor a medida que aumenta el porcentaje de adición de entre los cementos empleados.

Sin embargo los resultados obtenidos no son consistentes cuando se incorpora la velocidad de $0.5^{\circ} \mathrm{C} / \mathrm{min}$ al rango de velocidades estudiada. Cuando se tiene en cuenta esta velocidad de calentamiento los resultados de energía de activación de la reacción en el máximo de velocidad de deshidratación se igualan.

Esto reforzaría la hipótesis de que cuando el proceso se lleva a cabo en condiciones de equilibrio térmico, la evaporación de agua en el material tiene lugar independientemente de la microestructura que posea la pasta y de manera separada a la evaporación de agua en otros procesos. La dispersión de los datos referentes a la temperatura a la cual se produce la máxima velocidad de masa a alta y baja velocidad de calentamiento se reducía como veíamos en la Figura 42. Por ello, cuando incluimos todas las velocidades en el cálculo, las pendientes de las rectas se igualan y obtenemos energías de activación aparente similares.

Que la energía de activación calculada sea similar en los tres tipos de muestra indica reacciones similares, por lo que podría estar indicando que, una vez eliminada el agua libre o fisisorbida en el material, la estabilidad térmica de los geles formados es similar, al margen de si se han generado a partir de cemento anhidro o a partir de las reacciones puzolánicas, y que por ello apenas se observan diferencias en las muestras de los diferentes tipos de cemento empleadas.

\section{Método de Flynn-Wall-Ozawa (FWO)}

Es un método isoconversional integral que emplea la aproximación lineal de Doyle. La premisa básica del método asume que la velocidad a la cual se produce la reacción a un grado de conversión fijo depende de la temperatura, por lo que si la velocidad de la reacción sólo 
depende de la temperatura a un grado de conversión fijo, entonces valores constantes de Ea implican cinéticas de descomposición simples o en una etapa. Cuando Ea depende del grado de conversión, se pueden considerar simultaneidad de procesos, o reacciones en varias etapas.

El método FWO determina la temperatura a la cual se produce un grado de conversión de la reacción a diferentes velocidades de calentamiento y emplea la ecuación siguiente para estimar la energía de la reacción:

$\log \beta=\log \left(\frac{A E}{R g(\alpha)}\right)-2.315-\frac{0.45 E_{a}}{R T}$

Ecuación 23

Donde:

- $\beta$ es la velocidad de calentamiento.

- A es el factor pre-exponencial de Arrhenius.

- R es la constante de los gases.

- Ea es la energía de activación aparente.

- $\alpha$ corresponde al grado de conversión del proceso.

- $g(\alpha)$ es la función integral de $\mathrm{f}(\alpha)$

Para $\alpha$ constante se puede obtener la Ea de la pendiente de la recta obtenida al representar $\log \beta$ frente a la inversa de la temperatura. Con los datos obtenidos se han representado las rectas correspondientes para los diferentes tipos de pasta y a diferentes porcentajes de conversión de la reacción. Los resultados se presentan en la Figura 44 a la Figura 46. 
RESULTADOSY ANÁLISIS DE RESULTADOS

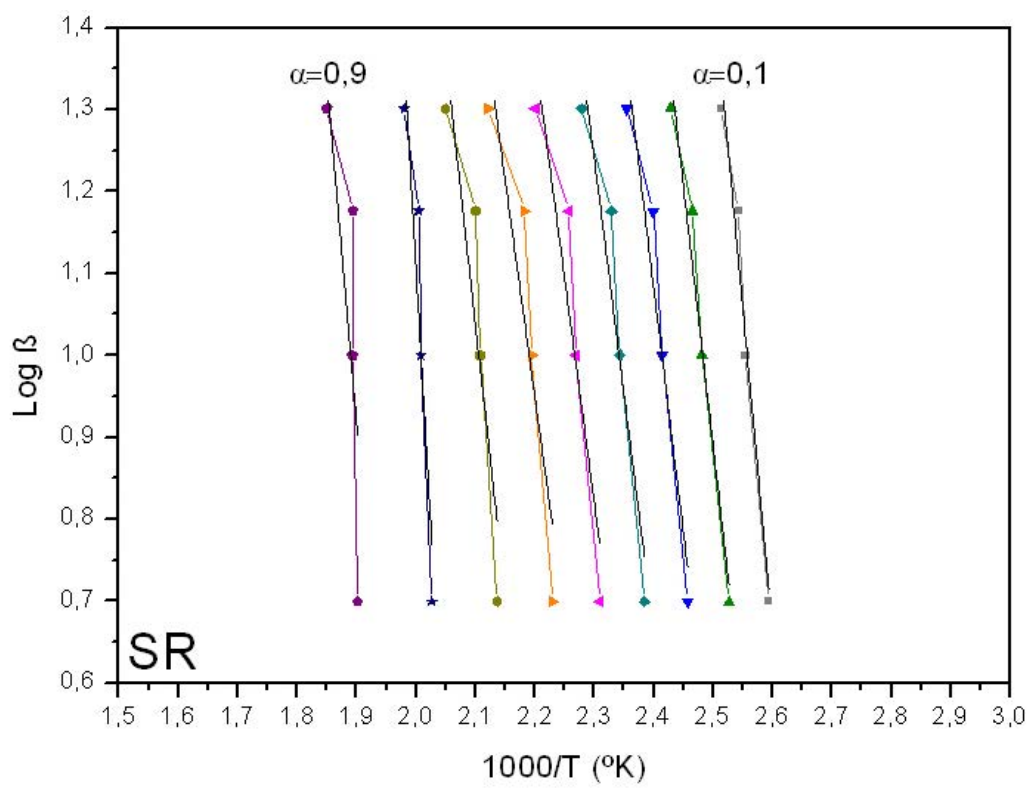

Figura 44. Log $\beta$ vs 1000/T en muestras de pasta de cemento SR

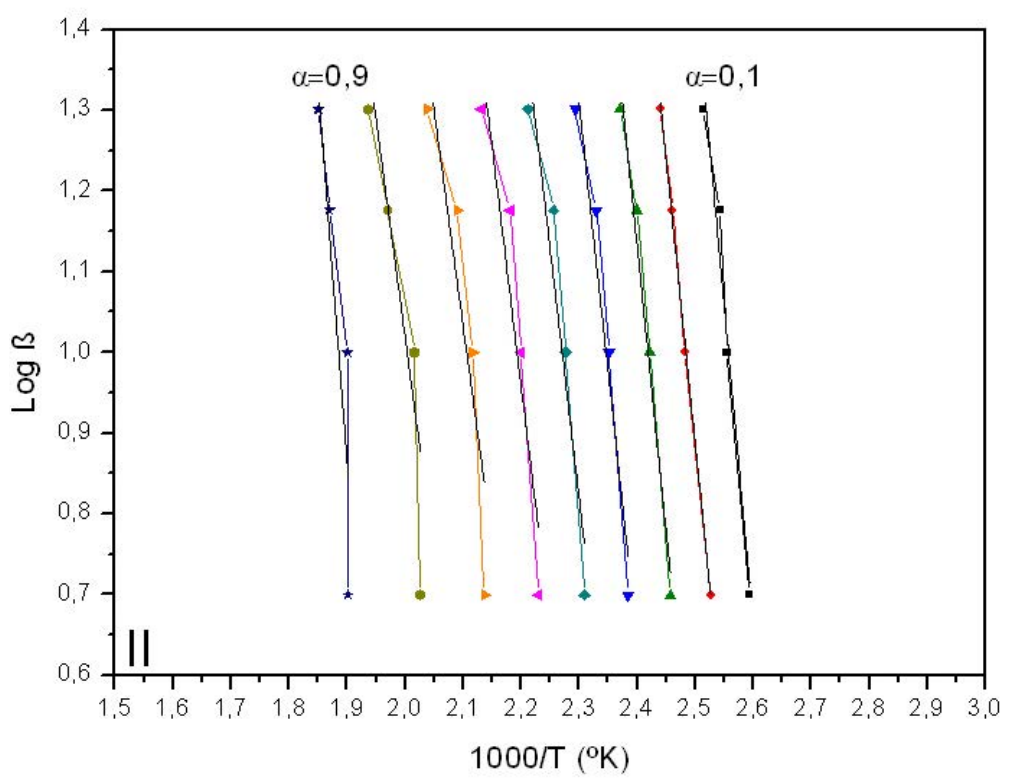

Figura 45. Log $\beta$ vs 1000/T en muestras de pasta de cemento II 


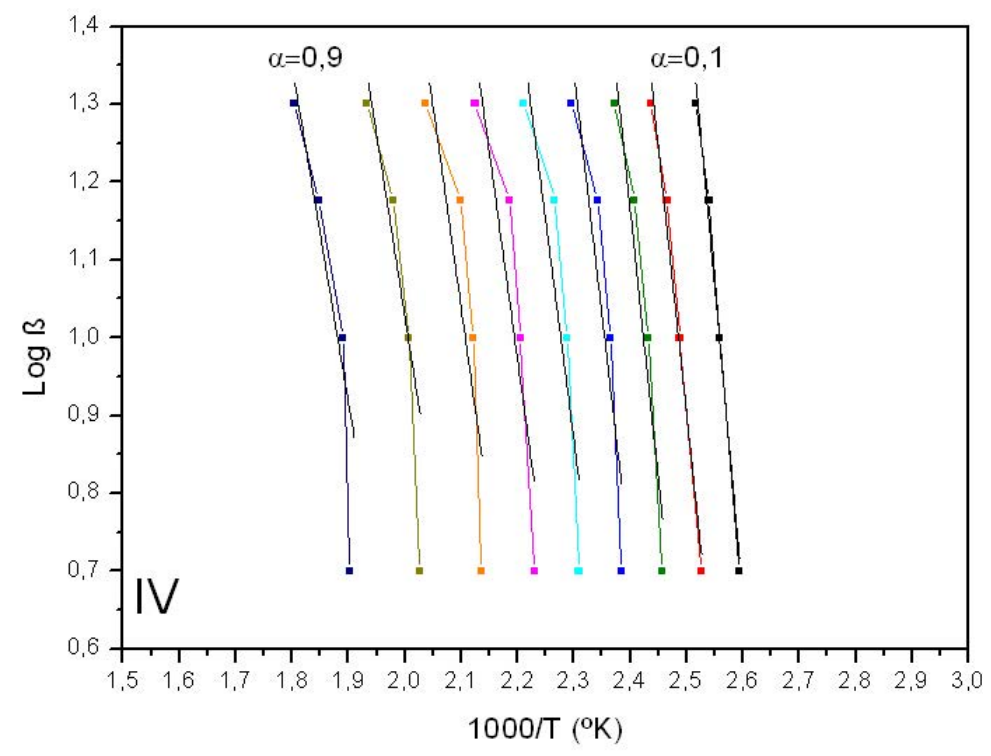

Figura 46. Log $\beta$ vs 1000/T en muestras de pasta de cemento IV

En todos los casos se ha realizado un ajuste lineal de las series de datos. Se han obtenido ajustes razonablemente correctos de los mismos observándose que a medida que aumenta el grado de conversión de las reacciones de deshidratación el proceso se obtiene una linealidad peor. A medida que disminuimos la velocidad de calentamiento de las muestras, se requiere menor temperatura para conseguir el mismo grado de conversión de la reacción. Eso se traduce en un valor de la abcisa relativamente inferior a lo que correspondería si partiésemos de velocidades de calentamiento superiores.

La elección del rango de las velocidades de calentamiento de las muestras para la estimación de la energía de activación es determinante. Pequeñas variaciones en la asignación de las temperaturas a las cuales se alcanza un porcentaje de conversión de la reacción resulta en una variación importante de la energía de activación calculada, dada la gran pendiente que presentan las rectas que describen el comportamiento de la dependencia del logaritmo de la velocidad de calentamiento con la inversa de la temperatura.

A partir de los datos calculados de energía de activación se puede decir que la evaporación de moléculas de agua en el tramo de temperaturas estudiado es un proceso complejo compuesto por varias etapas o la superposición de varios procesos ya que Ea depende del grado de conversión de la reacción. 
No debemos esperar que la energía de activación aparente calculada represente la barrera de energía y teoría de colisiones asociada con los parámetros de Arrhenius como en cinética de liquidos y sólidos. Más bien representa el exceso de energía obtenido para cada molécula a cierta temperatura, y estaría relacionada con la ruptura de enlaces químicos (Yuzay et al., 2010).

Al inicio del proceso de descomposición térmica de las muestras, la Ea es más elevada en las pastas de cemento II y IV. Las muestras de pasta de cemento SR presentan una Ea menor. Si asumimos que para iniciar el proceso de descomposición es necesario superar la energía que define la inercia térmica de las mismas, se puede afirmar que las muestras de pasta de cemento SR presentan una inercia térmica menor que el resto.

Las pastas de cemento SR son menos estables frente a la descomposición térmica al inicio del proceso. Alcanzado el 30\% de descomposición de las muestras, las energías de activación de los tres tipos de muestras se igualan. Se deduce por tanto que a partir de este momento las reacciones que están teniendo lugar en el material son similares en los tres tipos de muestra.

El 30\% de rendimiento se alcanza a temperaturas comprendidas entre los 130 y los $140^{\circ} \mathrm{C}$, coincidiendo con las temperaturas a las cuales se determinaban los máximos de conversión de la reacción según el método de Kissinger. Se puede pensar que la variación en la energía de activación inicial está relacionada con la evaporación de agua libre en el material. Una vez empiezan a descomponerse los compuestos hidratados de la pasta (a partir de la temperatura alcanzada en los máximos de conversión) las reacciones de descomposición presentan energías de activación similares, razón por la cual se podría pensar que los compuestos hidratados de los tres tipos de muestra son similares con independencia del contenido de clinker en el cemento.

Los valores de energía de activación aparente obtenidos mediante el método FWO mantienen la misma tendencia que los obtenidos mediante el método de Kissinger cuando se calculan con velocidades de calentamiento entre 5 y $30^{\circ} \mathrm{C} / \mathrm{min}$. El método de Kissinger calcula la Ea en el mínimo de la curva dTG, que corresponde con el punto de máximo rendimiento. Esto sucede a temperaturas comprendidas entre 120 y $140^{\circ} \mathrm{C}$ (Figura 41). Por ello, la comparación de los resultados de Ea de los métodos se refiere al intervalo 0.1-0.2 de rendimiento de la reacción. Los cementos sin adición o con un porcentaje menor presentan una Ea menor al cemento puzolánico con adición de cenizas volantes. 


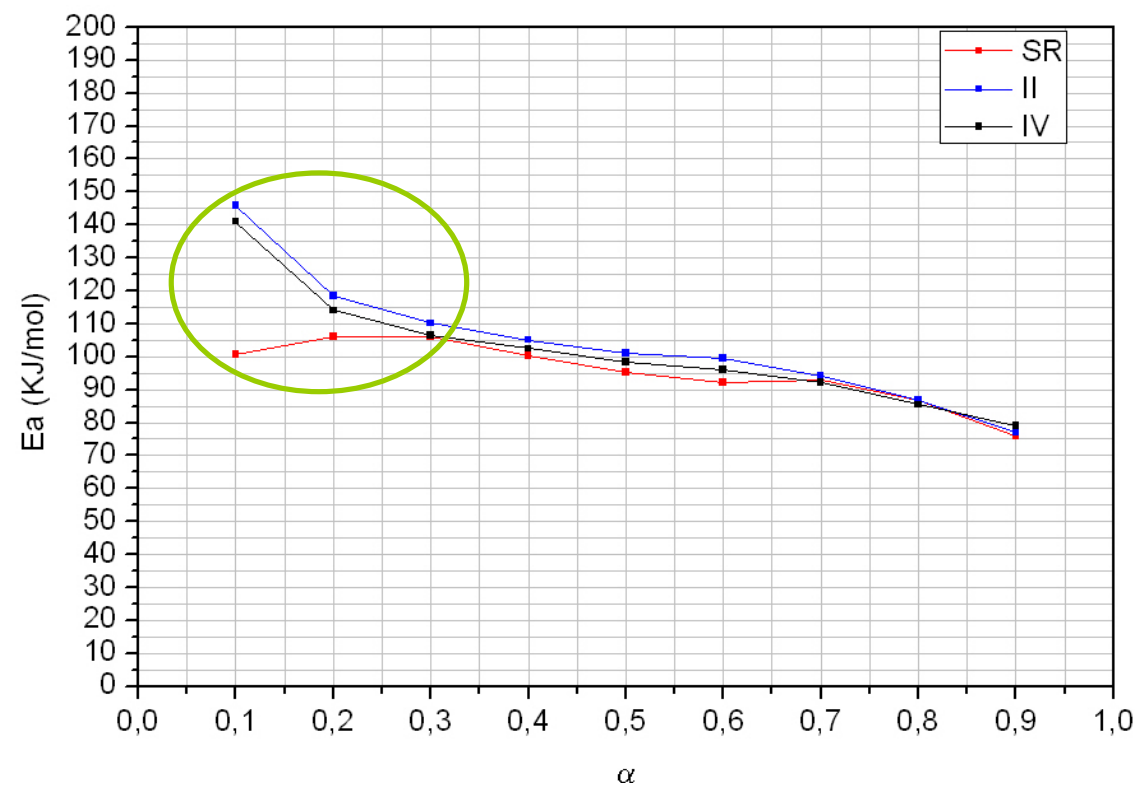

Figura 47. Ea calculada según el método FWO

\subsubsection{Análisis térmico de las muestras de referencia}

En las figuras mostradas y con el fin de observar los efectos del medio en la profundidad de las probetas se han representado las muestras de una misma edad, medio y cemento a distintas profundidades con respecto a la cara de exposición y se ha señalado en la leyenda la profundidad media calculada a la que corresponde el análisis de la sección analizada.

Con respecto a las muestras de referencia se muestran los resultados a 30 y 92 días a modo representativo. Los resultados de las muestras fueron muy homogéneos, tanto en la profundidad de la probeta, como en la edad de exposición, como en el medio de referencia analizado. No se observan diferencias cualitativas apreciables ni en las curvas obtenidas, ni en los resultados calculados. En este sentido se puede decir que las muestras de referencia en medio AI y en medio CA se pueden emplear de forma indistinta.

En total se analizaron 10 muestras de referencia para cada uno de los cementos analizados. Se llevó a cabo el cálculo de las pérdidas de masa en cada una de las regiones significativas especificadas en el apartado 3.4.5. Estos valores se emplearon para determinar los valores promedio y la desviación estándar de las medidas. Los valores obtenidos se emplearon para discriminar las variaciones significativas cuando las muestras se expusieron a los medios AC, SU y AN. 
En la Tabla 27, y Tabla 29 se muestran los resultados del cálculo.

(a) Medio CA

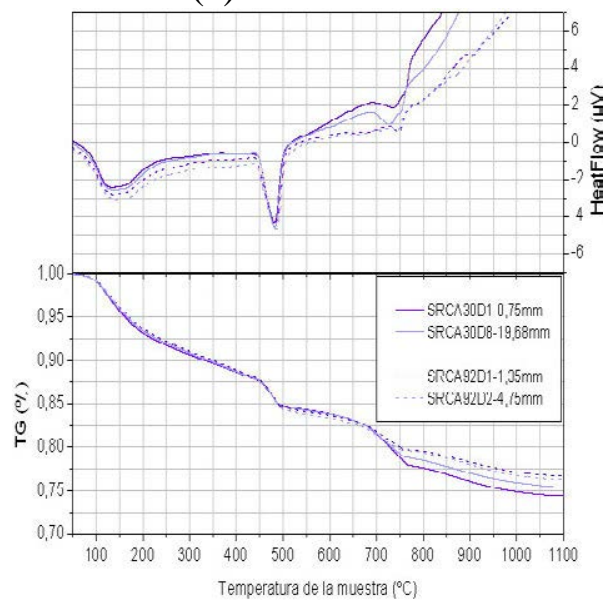

(b) Medio AI

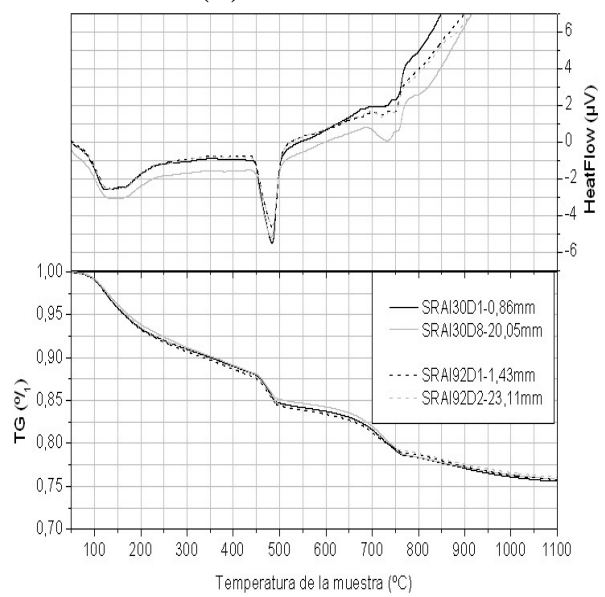

Figura 48. ATD-TG muestras de referencia cemento SR

(a) Medio CA

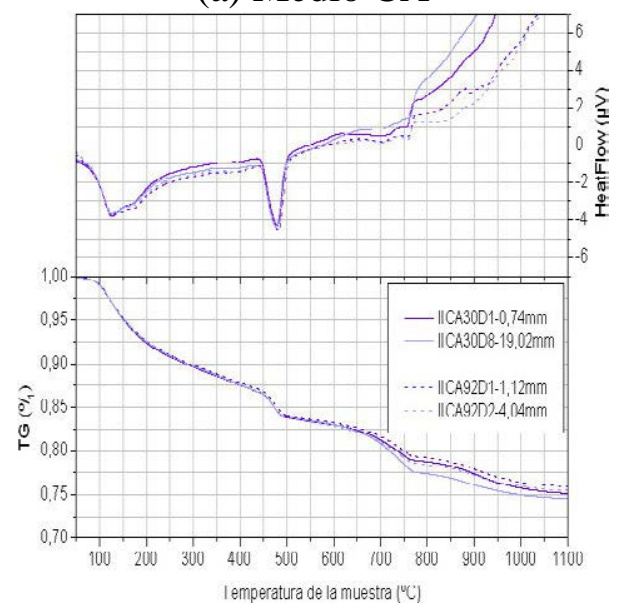

(b) Medio AI

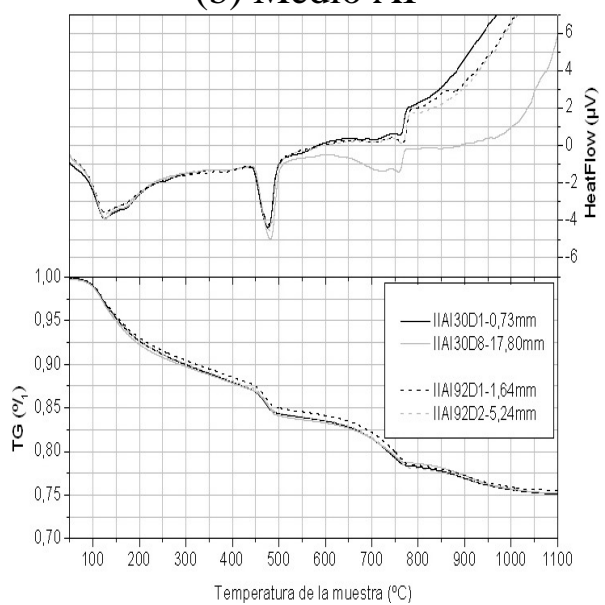

Figura 49. ATD-TG muestras de referencia cemento II

${ }^{7}$ Los rangos de temperatura mostrados son orientativos, en todos los casos se empleó para determinar las pérdidas de masa el método de la derivada de la curva de TG como se indica en el apartado 3.4.5.1 
(a) Medio CA

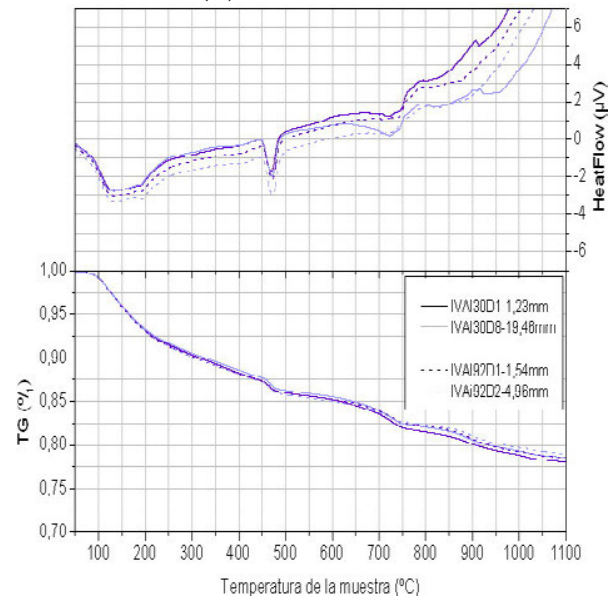

(b) Medio AI

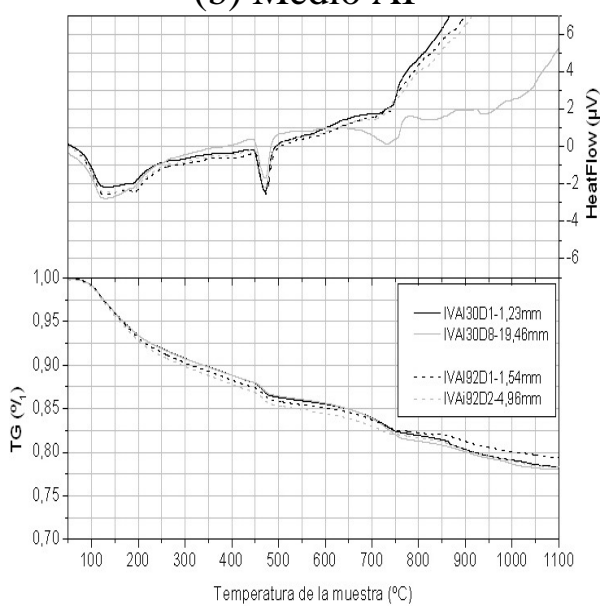

Figura 50. ATD-TG muestras de referencia cemento IV

Tabla 27. Valores de pérdida de masa calculados en la muestras de referencia del cemento SR

\begin{tabular}{|c|c|c|c|c|c|}
\hline & & \multicolumn{4}{|c|}{$x(\%)$} \\
\hline & $\mathrm{m}_{\mathrm{f} /} \mathrm{m}_{40^{\circ} \mathrm{C}}$ & \multicolumn{4}{|c|}{76.0} \\
\hline \multirow{4}{*}{ Región Deshidratación } & $\Delta \mathrm{m}_{40-100^{\circ} \mathrm{C}} / \mathrm{m}_{40^{\circ} \mathrm{C}}$ & & 0.86 & 337 & \multirow{4}{*}{12.25} \\
\hline & $\Delta \mathrm{m}_{100-140^{\circ} \mathrm{C}} / \mathrm{m}_{40^{\circ} \mathrm{C}}$ & \multirow{3}{*}{11.39} & 2.51 & 3.31 & \\
\hline & $\Delta \mathrm{m}_{140-200^{\circ} \mathrm{C}} / \mathrm{m}_{40^{\circ} \mathrm{C}}$ & & 3.97 & 888 & \\
\hline & $\Delta \mathrm{m}_{200-430^{\circ} \mathrm{C}} / \mathrm{m}_{40^{\circ} \mathrm{C}}$ & & 4.91 & ర.ర0 & \\
\hline Región Deshidroxilación & $\Delta \mathrm{m}_{430-530^{\circ} \mathrm{C}} / \mathrm{m}_{40^{\circ} \mathrm{C}}$ & \multicolumn{4}{|c|}{3.32} \\
\hline \multirow{2}{*}{ Región Descarbonatación } & $\Delta \mathrm{m}_{530-800^{\circ} \mathrm{C}} / \mathrm{m}_{40^{\circ} \mathrm{C}}$ & & 5.32 & \multirow{2}{*}{8.54} & \\
\hline & $\Delta \mathrm{m}_{800-1100^{\circ} \mathrm{C}} / \mathrm{m}_{40^{\circ} \mathrm{C}}$ & & 3.22 & & \\
\hline \multirow{4}{*}{ Región Deshidratación } & $\Delta \mathrm{m}_{40-100^{\circ} \mathrm{C}} / \mathrm{m}_{\mathrm{f}}$ & & 1.14 & 445 & \multirow{4}{*}{16.15} \\
\hline & $\Delta \mathrm{m}_{100-140^{\circ} \mathrm{C}} / \mathrm{m}_{\mathrm{f}}$ & \multirow{3}{*}{15.01} & 3.31 & 4.45 & \\
\hline & $\Delta \mathrm{m}_{140-200^{\circ} \mathrm{C}} / \mathrm{m}_{\mathrm{f}}$ & & 5.23 & 11.70 & \\
\hline & $\Delta \mathrm{m}_{200-430^{\circ} \mathrm{C}} / \mathrm{m}_{\mathrm{f}}$ & & 6.47 & 11.70 & \\
\hline Región Deshidroxilación & $\Delta \mathrm{m}_{430-530^{\circ} \mathrm{C}} / \mathrm{m}_{\mathrm{f}}$ & \multicolumn{4}{|c|}{4.37} \\
\hline \multirow{2}{*}{ Región Descarbonatación } & $\Delta \mathrm{m}_{530-800^{\circ} \mathrm{C}} / \mathrm{m}_{\mathrm{f}}$ & & 7.03 & \multirow{2}{*}{11.27} & \\
\hline & $\Delta \mathrm{m}_{800-1100^{\circ} \mathrm{C}} / \mathrm{m}_{\mathrm{f}}$ & & 4.24 & & \\
\hline
\end{tabular}


Tabla 28. Valores de pérdida de masa calculados en la muestras de referencia del cemento II

\begin{tabular}{|c|c|c|c|c|c|}
\hline & & \multicolumn{4}{|c|}{$\bar{x}(\%)$} \\
\hline & $\mathrm{m}_{\mathrm{f} /} \mathrm{m}_{40^{\circ} \mathrm{C}}$ & \multicolumn{4}{|c|}{75.3} \\
\hline \multirow{4}{*}{ Región Deshidratación } & $\Delta \mathrm{m}_{40-100^{\circ} \mathrm{C}} / \mathrm{m}_{40^{\circ} \mathrm{C}}$ & & 1.00 & 400 & \multirow{4}{*}{12.99} \\
\hline & $\Delta \mathrm{m}_{100-140^{\circ} \mathrm{C}} / \mathrm{m}_{40^{\circ} \mathrm{C}}$ & \multirow{3}{*}{11.99} & 3.09 & 4.09 & \\
\hline & $\Delta \mathrm{m}_{140-200^{\circ} \mathrm{C}} / \mathrm{m}_{40^{\circ} \mathrm{C}}$ & & 4.33 & 890 & \\
\hline & $\Delta \mathrm{m}_{200-430^{\circ} \mathrm{C}} / \mathrm{m}_{40^{\circ} \mathrm{C}}$ & & 4.57 & 8.90 & \\
\hline Región Deshidroxilación & $\Delta \mathrm{m}_{430-530^{\circ} \mathrm{C}} / \mathrm{m}_{40^{\circ} \mathrm{C}}$ & \multicolumn{4}{|c|}{2.97} \\
\hline \multirow{2}{*}{ Región Descarbonatación } & $\Delta \mathrm{m}_{530-800^{\circ} \mathrm{C}} / \mathrm{m}_{40^{\circ} \mathrm{C}}$ & & 5.40 & \multirow{2}{*}{8.65} & \\
\hline & $\Delta \mathrm{m}_{800-1100^{\circ} \mathrm{C}} / \mathrm{m}_{40^{\circ} \mathrm{C}}$ & & 3.25 & & \\
\hline \multirow{4}{*}{ Región Deshidratación } & $\Delta \mathrm{m}_{40-100^{\circ} \mathrm{C}} / \mathrm{m}_{\mathrm{f}}$ & & 1.37 & 5.45 & \multirow{4}{*}{17.31} \\
\hline & $\Delta \mathrm{m}_{100-140^{\circ} \mathrm{C}} / \mathrm{m}_{\mathrm{f}}$ & \multirow{3}{*}{15.94} & 4.08 & 5.45 & \\
\hline & $\Delta \mathrm{m}_{140-200^{\circ} \mathrm{C}} / \mathrm{m}_{\mathrm{f}}$ & & 5.79 & 11.86 & \\
\hline & $\Delta \mathrm{m}_{200-430^{\circ} \mathrm{C}} / \mathrm{m}_{\mathrm{f}}$ & & 6.07 & & \\
\hline Región Deshidroxilación & $\Delta \mathrm{m}_{430-530^{\circ} \mathrm{C}} / \mathrm{m}_{\mathrm{f}}$ & \multicolumn{4}{|c|}{3.94} \\
\hline \multirow{2}{*}{ Región Descarbonatación } & $\Delta \mathrm{m}_{530-800^{\circ} \mathrm{C}} / \mathrm{m}_{\mathrm{f}}$ & & 7.18 & \multirow{2}{*}{11.51} & \\
\hline & $\Delta \mathrm{m}_{800-1100^{\circ} \mathrm{C}} / \mathrm{m}_{\mathrm{f}}$ & & 4.33 & & \\
\hline
\end{tabular}

Tabla 29. Valores de pérdida de masa calculados en la muestras de referencia del cemento IV

\begin{tabular}{|c|c|c|c|c|c|}
\hline & & \multicolumn{4}{|c|}{$x(\%)$} \\
\hline & $\mathrm{m}_{\mathrm{f} /} \mathrm{m}_{40^{\circ} \mathrm{C}}$ & \multicolumn{4}{|c|}{78.5} \\
\hline \multirow{4}{*}{ Región Deshidratación } & $\Delta \mathrm{m}_{40-100^{\circ} \mathrm{C}} / \mathrm{m}_{40^{\circ} \mathrm{C}}$ & & 0.87 & 345 & \multirow{4}{*}{12.30} \\
\hline & $\Delta \mathrm{m}_{100-140^{\circ} \mathrm{C}} / \mathrm{m}_{40^{\circ} \mathrm{C}}$ & \multirow{3}{*}{11.43} & 2.58 & 3.40 & \\
\hline & $\Delta \mathrm{m}_{140-200^{\circ} \mathrm{C}} / \mathrm{m}_{40^{\circ} \mathrm{C}}$ & & 4.24 & 885 & \\
\hline & $\Delta \mathrm{m}_{200-430^{\circ} \mathrm{C}} / \mathrm{m}_{40^{\circ} \mathrm{C}}$ & & 4.61 & & \\
\hline Región Deshidroxilación & $\Delta \mathrm{m}_{430-530^{\circ} \mathrm{C}} / \mathrm{m}_{40^{\circ} \mathrm{C}}$ & \multicolumn{4}{|c|}{1.72} \\
\hline \multirow{2}{*}{ Región Descarbonatación } & $\Delta \mathrm{m}_{530-800^{\circ} \mathrm{C}} / \mathrm{m}_{40^{\circ} \mathrm{C}}$ & & 3.71 & \multirow{2}{*}{7.30} & \\
\hline & $\Delta \mathrm{m}_{800-1100^{\circ} \mathrm{C}} / \mathrm{m}_{40^{\circ} \mathrm{C}}$ & & 3.59 & & \\
\hline \multirow{4}{*}{ Región Deshidratación } & $\Delta \mathrm{m}_{40-100^{\circ} \mathrm{C}} / \mathrm{m}_{\mathrm{f}}$ & & 1.10 & 4.39 & \multirow{4}{*}{15.67} \\
\hline & $\Delta \mathrm{m}_{100-140^{\circ} \mathrm{C}} / \mathrm{m}_{\mathrm{f}}$ & \multirow{3}{*}{14.57} & 3.29 & & \\
\hline & $\Delta \mathrm{m}_{140-200^{\circ} \mathrm{C}} / \mathrm{m}_{\mathrm{f}}$ & & 5.41 & 11.28 & \\
\hline & $\Delta \mathrm{m}_{200-430^{\circ} \mathrm{C}} / \mathrm{m}_{\mathrm{f}}$ & & 5.87 & 11.28 & \\
\hline Región Deshidroxilación & $\Delta \mathrm{m}_{430-530^{\circ} \mathrm{C}} / \mathrm{m}_{\mathrm{f}}$ & \multicolumn{4}{|c|}{2.20} \\
\hline \multirow{2}{*}{ Región Descarbonatación } & $\Delta \mathrm{m}_{530-800^{\circ} \mathrm{C}} / \mathrm{m}_{\mathrm{f}}$ & & 4.75 & \multirow{2}{*}{9.51} & \\
\hline & $\Delta \mathrm{m}_{800-1100^{\circ} \mathrm{C}} / \mathrm{m}_{\mathrm{f}}$ & & 4.76 & & \\
\hline
\end{tabular}

El cemento que presenta una proporción de residuo mayor es el cemento tipo IV, probablemente por la presencia de compuestos inertes habituales en las cenizas volantes como la mullita. Los 
cementos SR y II presentan una cifra muy similar (a pesar de que el cemento tipo II también presenta cenizas volantes, su porcentaje de sustitución es pequeño)

La referencia de la masa final con respeto a la masa inicial también puede ser un indicativo de la cantidad de compuestos hidratados alterables en medios de agresividad moderada, ya que como han comprobado estudios de otros autores (Berton et al., 2004, 2005b, 2014, Oueslati y Duchesne, 2011, 2012, 2014) la presencia de partículas anhidras y minerales puede favorecer la resistencia del material en determinadas condiciones de exposición a medios agresivos.

El uso de la masa calcinada puede ser una buena referencia para corregir muestras que presentan diferencias en el peso del residuo. Sin embargo los ensayos de termogravimetría no siempre se llevan a temperaturas finales iguales por lo que el uso de esta referencia puede dificultar su comparación.

A la hora de evaluar los resultados es necesario tener presente que existen algunas variables que afectan a la masa inicial de la matriz cementicia y que pueden tener una influencia en el resultado numérico. Por un lado la cantidad de agua libre presente en las muestras, muy sujeta a condiciones de estabilización de muestras y variable por la alta superficie específica de las muestras tratadas y las reacciones químicas que tienen lugar en el seno de la matriz cementicia.

Por otro lado la dependencia de la masa de la muestra con la carbonatación de la misma durante su manipulación, puesto que una muestra carbonatada modifica su masa por incorporación de moléculas de $\mathrm{CO}_{2}$.

Si analizamos la cantidad de agua perdida en la región de deshidratación se observa que los tres tipos de muestras presentan cantidades muy similares, siendo las muestras de cemento II las que presentan un contenido ligeramente superior. En esta muestra el contenido de agua hasta $140^{\circ} \mathrm{C}$ es la mayor. Por encima de $140^{\circ} \mathrm{C}$ los tres tipos de muestras pierden un porcentaje de masa similar (8.88, 8.93 y $8.85 \%$ respectivamente).

Las pastas pierden una considerable cantidad de agua entre los $200^{\circ} \mathrm{C}$ y la región de deshidroxilación. En esta región continúan deshidratando geles CSH, pero suele ser significativa la pérdida de agua asociada a la deshidratación de fases AFm transitorias, como $\mathrm{C}_{4} \mathrm{ASH}_{12}$, $\mathrm{C}_{4} \mathrm{AH}_{13}, \mathrm{C}_{2} \mathrm{AH}_{8}$, o de composiciones intermedias, incluso de hidrogranate $\left(\mathrm{C}_{3} \mathrm{AH}_{6}\right)$, formadas 
durante la hidratación de los aluminatos cálcicos en función de la disponibilidad de otras especies como los iones sulfato. La presencia de estas especies puede resultar relevante desde el punto de vista de la estabilidad de las fases en situaciones de exposición a agresivos.

En cuanto a la cantidad de portlandita en las muestras se puede decir que se observa la incidencia de las reacciones puzolánicas en el contenido de la misma. El cemento que mayor cantidad presenta es el SR, seguido del cemento II con una reducción ligera, probablemente acorde al porcentaje de sustitución de cenizas volantes en el cemento comercial. Por último se encontraría el cemento IV con un contenido entorno al 60\% en contenido de portlandita respecto al cemento SR.

En la región de descarbonatación se observan pérdidas de masa apreciables. Las pérdidas de masa por encima de $800^{\circ} \mathrm{C}$ (segundo tramo de descarbonatación) presentan valores prácticamente constantes en el caso de las muestras de pasta de cementos SR y II, y ligeramente superiores en el caso de las muestras de pasta de cemento IV. Lo mismo sucede cuando comparamos los valores calculados en el primer tramo de pérdidas de la región de descarbonatación, las muestras de pasta de cemento SR y II presentan valores muy próximos entre sí y superiores a los calculados para las muestras tipo IV.

Es posible que esta cantidad diferencial en el cálculo de la pérdida de masa con respecto a las muestras tipo IV esté relacionado con el contenido de portlandita de las muestras. Si el carbonato formado en la reacción de carbonatación se descompone en este primer tramo de temperaturas, un menor contenido de portlandita en las muestras se traduciría en una pérdida de masa menor.

Es necesario por tanto considerar la pérdida de masa en esta región con el fin de estimar el porcentaje de portlandita carbonatada. Se introduce así el término agua de portlandita equivalente $\left(\mathrm{H}_{\mathrm{CH}}\right)$ o portlandita equivalente (CHeq).

Para los cálculos se descontaron las pérdidas obtenidas en el análisis de las muestras anhidras de cada uno de los tipos de cemento, según se indica en la Tabla 23, correspondientes a las regiones comprendidas entre 480 y $1100^{\circ} \mathrm{C}$, en el caso del cálculo del equivalente total; y 480 $785^{\circ} \mathrm{C}$ en el caso de la corrección con el primer tramo. Las cantidades de agua de portlandita equivalente quedarían como muestra la Tabla 30. 
A primera vista los resultados indican que considerar el equivalente total de portlandita puede conllevar una sobreestimación de la misma. Será preciso valorar la evolución de estas cantidades en las muestras de edad madura para saber si podemos discriminar qué tramo de pérdida corresponde a $\mathrm{CO}_{2}$ procedente de la carbonatación de la portlandita.

Tabla 30. Valores de portlandita y portlandita equivalente calculados en la muestras de referencia

\begin{tabular}{cccc}
\hline & & $\begin{array}{c}\text { Agua de portlandita } \\
\mathrm{H}_{\mathrm{CH}}(\%)\end{array}$ & $\begin{array}{c}\text { Portlandita } \\
\mathrm{CH}(\%)\end{array}$ \\
\hline \multirow{3}{*}{$\mathrm{SR}$} & $\Delta \mathrm{m}_{430-530^{\circ} \mathrm{C} / \mathrm{m}_{100^{\circ} \mathrm{C}}}$ & 3.32 & 13.64 \\
\cline { 2 - 4 } & Equivalente total $^{8}$ & 6.81 & 28.00 \\
\cline { 2 - 4 } & Equivalente primer rango $^{9}$ & 5.50 & 22.59 \\
\hline \multirow{3}{*}{$\mathrm{II}$} & $\Delta \mathrm{m}_{430-530^{\circ} \mathrm{C} / \mathrm{m}_{100^{\circ} \mathrm{C}}}$ & 2.97 & 12.20 \\
\cline { 2 - 4 } & Equivalente total & 6.51 & 26.76 \\
\cline { 2 - 4 } $\mathrm{IV}$ & Equivalente primer rango $^{*}$ & 5.18 & 21.28 \\
\cline { 2 - 4 } & $\Delta \mathrm{m}_{430-530^{\circ} \mathrm{C} / \mathrm{m}_{100^{\circ} \mathrm{C}}}$ & 1.72 & 7.09 \\
\cline { 2 - 4 } & Equivalente total & 4.71 & 19.37 \\
\hline
\end{tabular}

\subsubsection{Análisis térmico de las muestras a edad madura}

En la Figura 51 se muestran los termogramas obtenidos sobre las muestras a larga edad de maduración. Se emplearon las mismas muestras que las analizadas a tiempo inicial de ensayo pero después de aproximadamente 55 meses desde su fabricación.

Desde el punto de vista cualitativo se observa cierta evolución en la forma de las curvas de ATD en la región de deshidratación (40-430 $\mathrm{C}$ aprox.) de las muestras de pasta de cementos SR y IV.

Las muestras de pasta de cemento SR han desdoblado ligeramente la banda ancha que anteriormente presentaba entre 100 y $200^{\circ} \mathrm{C}$, presentando ahora dos bandas, una banda más

$$
\begin{aligned}
& { }_{8}\left[\left(\Delta m_{430-530^{\circ} \mathrm{C}}\right) / m_{40^{\circ} \mathrm{C}}\right]+\left[\left(\frac{18}{44}\right) \cdot\left(\Delta m_{530-1100^{\circ} \mathrm{C}}\right) / m_{40^{\circ} \mathrm{C}}\right] \\
& { }_{9}\left[\left(\Delta m_{430-530^{\circ} \mathrm{C}}\right) / m_{40^{\circ} \mathrm{C}}\right]+\left[\left(\frac{18}{44}\right) \cdot\left(\Delta m_{530-800^{\circ} \mathrm{C}}\right) / m_{40^{\circ} \mathrm{C}}\right]
\end{aligned}
$$


aguda entorno a $125^{\circ} \mathrm{C}$, y otra ligeramente inferior asociada hacia $165^{\circ} \mathrm{C}$. Las muestras de pasta de cemento II se mantienen similares. Las muestras de pasta de cemento IV mantienen la banda a $190^{\circ} \mathrm{C}$ y presentan más aguda la banda de $125^{\circ} \mathrm{C}$.

En la Tabla 31 se presentan los valores calculados en las pérdidas de masa de las muestras a edad madura comparadas con las de referencia para las pastas de cemento SR.

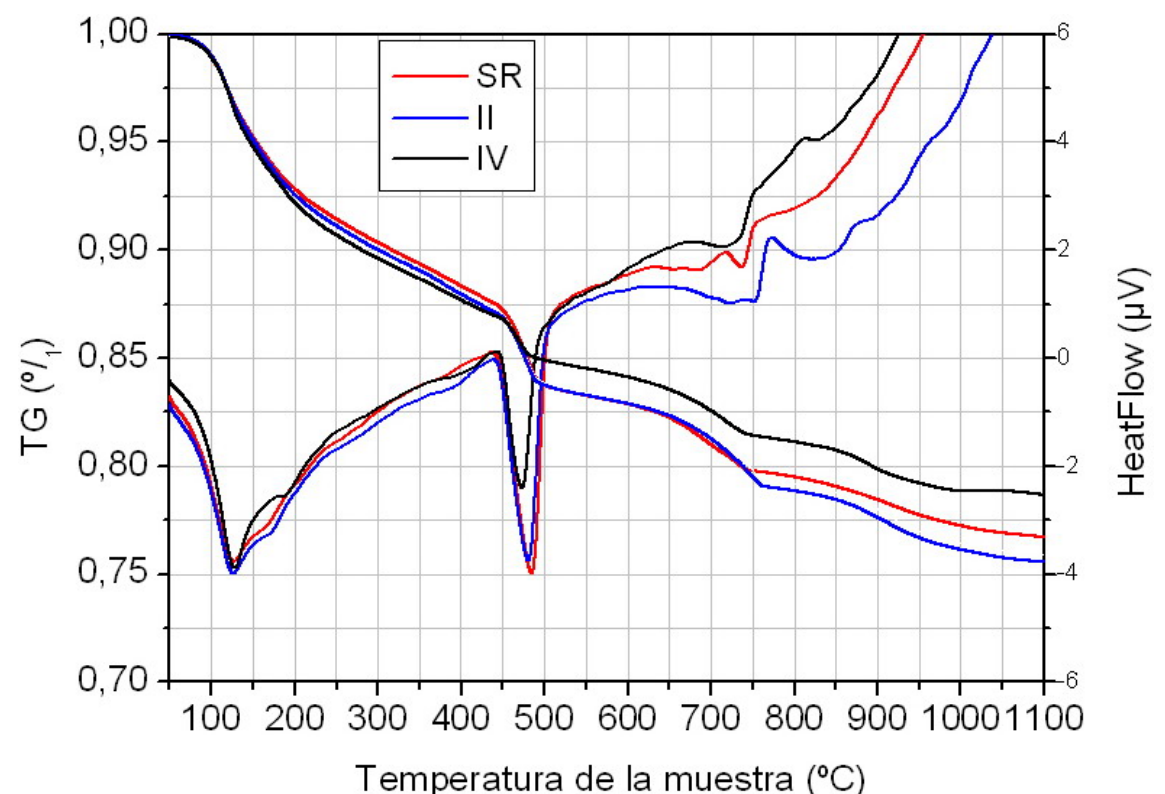

Figura 51. ATD-TG muestras a edad madura

Tabla 31. Pérdidas de masa calculadas en las muestras a edad madura de cemento SR

\begin{tabular}{|c|c|c|c|c|c|}
\hline & & \multicolumn{2}{|c|}{ SR ref } & \multicolumn{2}{|c|}{ SR em } \\
\hline & & \multicolumn{2}{|c|}{$x(\%)$} & \multicolumn{2}{|c|}{$\bar{x}(\%)$} \\
\hline & $\mathrm{m}_{\mathrm{f} /} \mathrm{m}_{40^{\circ} \mathrm{C}}$ & \multicolumn{2}{|c|}{76.0} & \multicolumn{2}{|c|}{76.4} \\
\hline \multirow{4}{*}{ Ldh } & $\Delta \mathrm{m}_{40-100^{\circ} \mathrm{C}} / \mathrm{m}_{40^{\circ} \mathrm{C}}$ & 0.86 & \multirow{4}{*}{12.25} & 1.05 & \multirow{4}{*}{12.59} \\
\hline & $\Delta \mathrm{m}_{100-140^{\circ} \mathrm{C}} / \mathrm{m}_{40^{\circ} \mathrm{C}}$ & 2.51 & & 3.11 & \\
\hline & $\Delta \mathrm{m}_{140-200^{\circ} \mathrm{C}} / \mathrm{m}_{40^{\circ} \mathrm{C}}$ & 3.97 & & 4.16 & \\
\hline & $\Delta \mathrm{m}_{200-430^{\circ} \mathrm{C}} / \mathrm{m}_{40^{\circ} \mathrm{C}}$ & 4.91 & & 4.27 & \\
\hline Ldx & $\Delta \mathrm{m}_{430-530^{\circ} \mathrm{C}} / \mathrm{m}_{40^{\circ} \mathrm{C}}$ & \multicolumn{2}{|c|}{3.32} & \multicolumn{2}{|c|}{4.21} \\
\hline \multirow{2}{*}{ Ldc } & $\Delta \mathrm{m}_{530-800^{\circ} \mathrm{C}} / \mathrm{m}_{40^{\circ} \mathrm{C}}$ & 5.32 & \multirow{2}{*}{8.54} & 3.85 & \multirow{2}{*}{6.84} \\
\hline & $\Delta \mathrm{m}_{800-1100^{\circ} \mathrm{C}} / \mathrm{m}_{40^{\circ} \mathrm{C}}$ & 3.22 & & 2.99 & \\
\hline
\end{tabular}

La relación que existe entre la masa calcinada y la masa al inicio del ensayo apenas ha variado a lo largo del tiempo. Se puede decir que la masa degradable es prácticamente constante. 
En la región Ldh, la cantidad total de agua perdida presenta un ligero incremento. La principal aportación a este incremento se debe a la cantidad de agua perdida hasta $140^{\circ} \mathrm{C}$. A partir de esta temperatura se observa una reordenación de las cantidades perdidas por tramos de temperatura. Aumenta en la región correspondiente a la deshidratación del gel y se reduce en las asociadas a la transformación de las fases alumínicas.

Se observan diferencias en el grado de carbonatación de las muestras. La incorporación de moléculas de $\mathrm{CO}_{2}$ en la matriz cementicia en forma de $\mathrm{CaCO}_{3}$ puede suponer una reducción de los porcentajes calculados. En este caso, no se considera que la masa diferencial correspondiente a procesos de carbonatación tenga una influencia notable en el cálculo numérico de las pérdidas de masa. Pese a existir un incremento de $1.7 \%$ en la masa desprendida en la región de descarbonatación, al referir las pérdidas respecto a la masa inicial del ensayo, el porcentaje de variación respecto a la cantidad de $\mathrm{CO}_{2}$ en la muestras apenas influye en el resultado porcentual.

La cantidad de agua de portlandita se incrementa y la de carbonato desciende, lo que podría atribuirse a diferencias en la cantidad de portlandita carbonatada. Si asumimos una pérdida correspondiente a carbonato de $6.84 \%$ (la correspondiente a Ldc de SR em), el agua de portlandita estequiométrica que hubiera debido presentar la muestra SR ref sería de 4.016\%, por lo que se ha producido un incremento de portlandita de $0.194 \%$, que en términos de porcentaje supone un incremento de casi el 5\% en agua de portlandita. La reducción de la cantidad de portlandita carbonatada se advierte además en la reducción de la masa desprendida en el primer tramo de pérdida en la región Ldc.

Considerando que se produce un incremento de las pérdidas calculadas en la región Ldh, y un incremento en la cantidad de portlandita estimada en la muestras de edad madura, se podría afirmar que estas muestras presentan un grado de hidratación ligeramente superior a las muestras de referencia, si bien el cambio es poco importante.

En la Tabla 32 se presentan los valores calculados en las pérdidas de masa de las muestras a edad madura comparadas con las de referencia para las pastas de cemento II.

La relación que existe entre la masa calcinada y la masa al inicio del ensayo apenas ha variado a lo largo del tiempo. Podemos considerar que la masa total perdida en el ensayo es constante. 
En la región Ldh las variaciones en la pérdida de masa son similares.

La pérdida de masa correspondiente a la deshidroxilación de la portlandita aumenta. Este aumento de la masa desprendida en la región Ldx se produce en detrimento de la pérdida calculada en la región Ldc. Si asumimos niveles de carbonatación similares, el agua de portlandita estequiométrica que hubiera debido presentar la muestra II ref sería de 3.31\%, por lo que se estima que la portlandita incrementó su valor en aproximadamente un 13\%. Se produce por tanto un incremento en la cantidad de portlandita estimada en la muestras de edad madura, sin embargo el contenido de agua en la región Ldh apenas ha variado.

Si tenemos en cuenta que las muestras de pasta de cemento II presentan en su composición cenizas volantes, es previsible que la reacción puzólanica tenga lugar de manera más lenta que las reacciónes de hidratación. El consumo de portlandita en la reacción puzolánica desplazaría las reacciones de hidratación aumentando su rendimiento. Si esto es así, en el material se estarían formando geles primarios y secundarios simultaneamente. Los primeros, producto del aumento del rendimiento de las reacciones de hidratación, y los segundos, fruto de la reacción puzolánica. El hecho de que el contenido de agua perdido en la region Ldh no varie puede ser debido a que la morfología de los geles resultantes sea más densa, y contenga menor cantidad de agua en su composición. Incluso, se puede interpretar que una variación de la morfología del gel, asociada a una variación de la relación en el contenido C/S del mismo podría condicionar que cambiara su temperatura de deshidratación como afirman algunos autores (Lilkov et al., 2012, Taylor, 2003)

Tabla 32. Pérdidas de masa calculadas en las muestras a edad madura de cemento II

\begin{tabular}{|c|c|c|c|c|c|}
\hline & & \multicolumn{2}{|c|}{ II ref } & \multicolumn{2}{|c|}{ II em } \\
\hline & & \multicolumn{2}{|c|}{$x(\%)$} & \multicolumn{2}{|c|}{$x(\%)$} \\
\hline & $\mathrm{m}_{\mathrm{f} /} \mathrm{m}_{40^{\circ} \mathrm{C}}$ & \multicolumn{2}{|c|}{75.3} & \multicolumn{2}{|c|}{75.7} \\
\hline \multirow{4}{*}{ Ldh } & $\Delta \mathrm{m}_{40-100^{\circ} \mathrm{C}} / \mathrm{m}_{40^{\circ} \mathrm{C}}$ & 1.00 & \multirow{4}{*}{12.99} & 1.00 & \multirow{4}{*}{13.01} \\
\hline & $\Delta \mathrm{m}_{100-140^{\circ} \mathrm{C}} / \mathrm{m}_{40^{\circ} \mathrm{C}}$ & 3.09 & & 3.52 & \\
\hline & $\Delta \mathrm{m}_{140-200^{\circ} \mathrm{C}} / \mathrm{m}_{40^{\circ} \mathrm{C}}$ & 4.33 & & 4.18 & \\
\hline & $\Delta \mathrm{m}_{200-430^{\circ} \mathrm{C}} / \mathrm{m}_{40^{\circ} \mathrm{C}}$ & 4.57 & & 4.31 & \\
\hline Ldx & $\Delta \mathrm{m}_{430-530^{\circ} \mathrm{C}} / \mathrm{m}_{40^{\circ} \mathrm{C}}$ & \multicolumn{2}{|c|}{2.97} & \multicolumn{2}{|c|}{3.74} \\
\hline \multirow{3}{*}{ Ldc } & $\Delta \mathrm{m}_{530-800^{\circ} \mathrm{C}} / \mathrm{m}_{40^{\circ} \mathrm{C}}$ & 5.40 & \multirow{2}{*}{8.65} & 5.46 & \multirow{2}{*}{7.83} \\
\hline & $\Delta \mathrm{m}_{800-1100^{\circ} \mathrm{C}} / \mathrm{m}_{40^{\circ} \mathrm{C}}$ & 3.25 & & 2.37 & \\
\hline & & \multicolumn{2}{|c|}{6.51} & \multicolumn{2}{|c|}{6.95} \\
\hline
\end{tabular}


En la Tabla 33 se presentan los valores calculados en las pérdidas de masa de las muestras a edad madura comparadas con las de referencia para las pastas de cemento IV.

Tabla 33. Pérdidas de masa calculadas en las muestras a edad madura de cemento IV

\begin{tabular}{|c|c|c|c|c|c|}
\hline & & \multicolumn{2}{|c|}{ IV ref } & \multicolumn{2}{|c|}{ IV em } \\
\hline & & \multicolumn{2}{|c|}{$x(\%)$} & \multicolumn{2}{|c|}{$\bar{x}(\%)$} \\
\hline & $\mathrm{m}_{\mathrm{f} /} \mathrm{m}_{40^{\circ} \mathrm{C}}$ & \multicolumn{2}{|c|}{78.5} & \multicolumn{2}{|c|}{78.2} \\
\hline \multirow{4}{*}{ Ldh } & $\Delta \mathrm{m}_{40-100^{\circ} \mathrm{C}} / \mathrm{m}_{40^{\circ} \mathrm{C}}$ & 0.87 & \multirow{4}{*}{12.3} & 1.06 & \multirow{4}{*}{12.93} \\
\hline & $\Delta \mathrm{m}_{100-140^{\circ} \mathrm{C}} / \mathrm{m}_{40^{\circ} \mathrm{C}}$ & 2.58 & & 3.43 & \\
\hline & $\Delta \mathrm{m}_{140-200^{\circ} \mathrm{C}} / \mathrm{m}_{40^{\circ} \mathrm{C}}$ & 4.24 & & 4.29 & \\
\hline & $\Delta \mathrm{m}_{200-430^{\circ} \mathrm{C}} / \mathrm{m}_{40^{\circ} \mathrm{C}}$ & 4.61 & & 4.15 & \\
\hline Ldx & $\Delta \mathrm{m}_{430-530^{\circ} \mathrm{C}} / \mathrm{m}_{40^{\circ} \mathrm{C}}$ & \multicolumn{2}{|c|}{1.72} & \multicolumn{2}{|c|}{2.17} \\
\hline \multirow{3}{*}{ Ldc } & $\Delta \mathrm{m}_{530-800^{\circ} \mathrm{C}} / \mathrm{m}_{40^{\circ} \mathrm{C}}$ & 3.71 & \multirow{2}{*}{7.30} & 3.57 & \multirow{2}{*}{6.57} \\
\hline & $\Delta \mathrm{m}_{800-1100^{\circ} \mathrm{C}} / \mathrm{m}_{40^{\circ} \mathrm{C}}$ & 3.59 & & 3.00 & \\
\hline & $\mathrm{H}_{\mathrm{CH}}$ eq total & \multicolumn{2}{|c|}{4.71} & \multicolumn{2}{|c|}{4.86} \\
\hline
\end{tabular}

La relación que existe entre la masa calcinada y la masa al inicio del ensayo apenas ha variado a lo largo del tiempo. Podemos considerar que la masa total perdida en el ensayo es constante.

En la región Ldh se observa un incremento neto de la cantidad total de agua perdida. Este incremento del $0.63 \%$ supone un aumento del $5 \%$ sobre a cantidad de agua calculada para las muestras de pasta IV ref y una reordenación de las cantidades perdidas por tramos de temperatura. Como ocurre en las anteriores muestras aumenta el agua hasta $140^{\circ} \mathrm{C}$ y se reduce la correspondiente a la zona de los aluminatos.

La cantidad de portlandita se incrementa y la de carbonato desciende, lo que podría atribuirse a diferencias en la cantidad de portlandita carbonatada. Si asumimos una pérdida correspondiente a carbonato de $6.57 \%$ (la correspondiente a IV em), el agua de portlandita estequiométrica que hubiera debido presentar la muestra IV ref para un mismo nivel de carbonatación sería de $1.98 \%$. Esto indica que se ha producido un incremento de agua de portlandita de $0.19 \%$, que en términos de porcentaje respecto a la masa de agua de portlandita calculada en el ensayo supone un incremento del $10 \%$.

En vista de los resultados parece intuirse un ligero incremento en el grado de hidratación de las muestras que será evaluado en el apartado 4.4.1.6, si bien este incremento es poco importante. 
4.4.1.6. Evaluación del grado de hidratación a partir de los datos de análisis térmico

El análisis termogravimétrico ha sido propuesto por diferentes autores como uno de los métodos más eficaces para evaluar el estado de hidratación de los materiales cementicios, sin embargo hasta el momento existe cierta dificultad para establecer un método de cálculo único. En este apartado se han empleado los métodos de Bhatty y Pane/Hansen (Bhatty, 1986, Pane y Hansen, 2005) para estimar el grado de hidratación, se han evaluado los resultados obtenidos, y se han propuesto ciertas correcciones que permitan comprender mejor los procesos de hidratación de las mezclas, todo ello teniendo en cuenta que las dosificaciones de cemento empleadas corresponden a cementos comerciales y no a mezclas elaboradas en el laboratorio.

En este apartado se analizaran algunas variables que se han mencionado a lo largo de apartados anteriores y que resultan determinantes a la hora de emplear un método de cálculo que nos permita estimar el grado de de hidratación $(\alpha)$ de una muestra de pasta de cemento.

Es necesario calcular los valores relativos de las pérdidas en cada tramo de temperatura, para ello es necesario establecer la temperatura a la que vamos a tomar la masa de referencia. En este sentido encontramos trabajos que emplean la masa calcinada resultante en el ensayo como masa de referencia mientras que otros emplean la masa a la temperatura inicial, y/o temperatura a la cual se estabiliza la muestra. Algunos autores emplean la masa a temperaturas que indican el inicio o fin de un proceso significativo, como la temperatura de evaporación del agua o procesos de combustión de inquemados.

En nuestro caso hemos planteado el cálculo de las pérdidas referenciado la masa a las siguientes temperaturas: $40^{\circ} \mathrm{C}$, temperatura a la cual se estabilizan las muestras y a la cual se inicia el ensayo; $100 / 105^{\circ} \mathrm{C}$ ó $140^{\circ} \mathrm{C}$, rango de temperatura para la evaporación de agua; y masa calcinada resultante al final del ensayo.

Algunos autores desplazan la temperatura de inicio de ebullición del agua a $105^{\circ} \mathrm{C}$, es posible que la razón para este desplazamiento sea la deriva de temperatura que existe entre la temperatura que fijamos en el horno de medida y la que posee la muestra (en nuestro caso esta deriva oscila sobre los $3^{\circ} \mathrm{C}$ ), pero lo cierto es que nosotros podemos conocer tanto la temperatura del horno, como la temperatura de la muestra, por lo que nos parece más correcto 
emplear la temperatura de $100^{\circ} \mathrm{C}$ a fin de cuantificar el agua libre que empieza a evaporar a esta temperatura. Con todo, y con el fin de poder comparar los resultados con otros encontrados en la bibliografía, se comprobó la diferencia entre usar la masa a $100^{\circ} \mathrm{C}$ o $105^{\circ} \mathrm{C}$ y resultó que numéricamente es prácticamente inapreciable.

El método de Pane/Hansen establece una masa referencia a la temperatura de $140^{\circ} \mathrm{C}$ porque consideran que a esta temperatura se ha terminado de evaporar toda el agua libre.

El uso de la masa calcinada para referenciar los resultados es otra de las opciones que emplean distintos autores. La masa calcinada de la muestra es una proporción de la masa que tomamos para iniciar el ensayo, por lo que no deja de depender de ciertas variables que afectan a la masa inicial de la matriz cementicia, como son la cantidad de agua libre presente en las muestras y la variabilidad de masa en función del grado de carbonatación de la misma durante su manipulación, puesto que una muestra carbonatada modifica su masa por incorporación de moléculas de $\mathrm{CO}_{2}$.

Si empleamos la masa calcinada para referenciar los datos es necesario tener presente otras variables como la variabilidad en el peso del residuo que pueden presentar las muestras de distintos tipo de cemento. El método de Pane/Hansen emplea este sistema para referenciar las pérdidas. Para realizar la conversión y referenciar los datos respecto a la pasa inicial basta con multiplicar por la relación entre masa final y masa inicial, razón por la cual se aporta esta cantidad como uno de los datos en las tablas.

Para descartar la influencia que pueden tener la presencia de inquemados y la presencia de carbonatos en la composición del cemento se llevó a cabo corrección de la pérdida correspondiente en la pasta con la que tiene lugar en el material anhidro, como ya hicieran Pane y Hansen. (2005).

Para realizar la corrección se calculó la pérdida en los cementos anhidros (según indica la Tabla 23) y se restó de la pérdida registrada en el mismo tramo de temperatura teniendo en cuenta la cantidad de cemento anhidro en la pasta de cemento hidratada.

Para calcular la masa de cemento anhidro en la pasta hidratada se tuvo en cuenta que la masa de cemento anhidro empleada esta compuesta principalmente por el clínker (minerales y 
compuestos sinterizados a alta temperatura), yeso, filler calizo y la adición (cuando corresponde). La diferencia de masa que existe entre la pasta de cemento hidratada y el cemento anhidro es el agua que la matriz fija dentro de su estructura en diferentes formas, y el $\mathrm{CO}_{2}$ incorporado por la carbonatación de las muestras.

Si tenemos en cuenta esto, se puede decir que la masa de cemento anhidro se conserva en el residuo y que la masa perdida correspondería a la masa de agua y $\mathrm{CO}_{2}$ fijada en la muestra ${ }^{10}$, por lo que la relación entre la masa de la pasta de cemento y los cementos anhidros quedaría definida por la relación entre la masa inicial del ensayo (tomando ésta la de referencia elegida, en nuestro caso $40^{\circ} \mathrm{C}$ ) y la masa final del residuo obtenido al final del ensayo.

El resultado de este cálculo se ha aplicado en la corrección de la pérdida de masa en la región Ldc de todas las muestras, si bien hay que indicar que los resultados de la corrección inciden muy poco en el resultado numérico obtenido. Antes de resumir los resultados obtenidos para el cálculo de los grados de hidratación resumimos las consideraciones que dos de los autores reconocidos establecen para su cálculo:

\section{Estimación del grado de hidratación según Bhatty}

El cálculo se lleva a cabo a parir del cálculo de agua químicamente enlazada $\left(\mathrm{W}_{\mathrm{B}}\right)$ referida a la cantidad máxima que una pasta de cemento puede combinar de agua en su estructura, y aceptado en un valor de 0.24 . En el cálculo de $W_{B}$ considera que parte de la portlandita presente en las muestras puede carbonatar, razón por la cual multiplica la cantidad de carbonatos encontrados en la muestra por la relación de masas moleculares, transformando asi el $\mathrm{CO}_{2}$ desprendido en agua que provendría de portlandita. Las ecuaciones empleadas son las siguientes:

$W_{B 105}=L d h_{105}+L d x+(18 / 44) L d c$

Ecuación 24

\footnotetext{
${ }^{10}$ Cabría realizar una pequeña corrección adicional en esta cantidad respecto a la cantidad de agua que ya se perdía antes del proceso de hidratación en los cementos anhidros y que se ha comprobado que al ser muy pequeña apenas introduce variación.
} 
$\alpha=\frac{W_{B 105}}{0.24} \cdot 100$

Ecuación 25

Donde:

- $\mathrm{W}_{\mathrm{B} 105}$ : Agua químicamente combinada respecto a la masa a $105^{\circ} \mathrm{C},\left({ }^{\circ} / 1\right)$.

- $\mathrm{Ldh}_{105}$-Región de deshidratación- variación de masa entre $105^{\circ} \mathrm{C}$ y el inicio de pérdida de masa de la región $\operatorname{Ldx}\left(\approx 440^{\circ} \mathrm{C}\right)$, referido a la masa a $105^{\circ} \mathrm{C},(\% / 1)$.

- Ldx-Región de deshidroxilación- variación de masa entre $\approx 440^{\circ} \mathrm{C}$ y el inicio de pérdida de masa de la región $\operatorname{Ldc}\left(\approx 580^{\circ} \mathrm{C}\right)$, referido a la masa a $105^{\circ} \mathrm{C},(\% / 1)$.

- Ldc-Región de descarbonatación- variación de masa entre $\approx 580^{\circ} \mathrm{C}$ y la temperatura final del ensayo $\left(\approx 1000^{\circ} \mathrm{C}\right)$, referido a la masa a $105^{\circ} \mathrm{C},(\% / 1)$.

- $\alpha$ : grado de hidratación (\%)

\section{Estimación del grado de hidratación según Pane/Hansen}

El cálculo se lleva a cabo a partir del cálculo de agua químicamente enlazada $\left(\mathrm{W}_{\mathrm{B}}\right)$ referida a la cantidad máxima que una pasta de cemento puede combinar de agua en su estructura $\left(\mathrm{W}_{\mathrm{B} \infty}\right)$. Este método de cálculo refiere todas las cantidades a la masa de muestra calcinada. $\mathrm{W}_{\mathrm{B}}$ se calcula como la pérdida de masa que sufre la muestra desde $140^{\circ} \mathrm{C}$ a $1100^{\circ} \mathrm{C}$, descontando las pérdida de carbonatos que sufren los cementos en estado anhidro en su la región Ldc. Con respecto a $\mathrm{W}_{\mathrm{B} \infty}$ considera que para los cementos Portland su valor oscila entre 0.23 y 0.25 , asignando un valor de 0.23 de acuerdo con otros autores. Para otro tipo de cementos con adiciones precisa su medida en muestras de edad madura (más de 200 días), o ser estimado. La estimación consiste en calcular $\mathrm{W}_{\mathrm{B} \infty}$ según la Ecuación 4 (ecuación triparamétrica) y extrapolar la recta obtenida al representar los valores frente a la temperatura. Las expresiones empleadas son las siguientes:

$W_{B 140}=L d h_{140}+L d x+L d c-L d c_{a}$

Ecuación 26

$W_{B}=W_{B \infty} \cdot \exp \left[-\left(\frac{\tau}{t}\right)^{a}\right]$

Ecuación 27 
RESULTADOSY ANÁUSIS DE RESULTADOS

$\alpha=\frac{W_{B 140}}{W_{B \infty}} \cdot 100$

Ecuación 28

Donde:

- $\mathrm{W}_{\mathrm{B} 140}$ : Agua químicamente combinada respecto a la masa calcinada, $(\% / 1)$.

- $\operatorname{Ldh}_{140}$-Región de deshidratación- variación de masa entre $140^{\circ} \mathrm{C}$ y el inicio de pérdida de masa de la región $\operatorname{Ldx}\left(\approx 440^{\circ} \mathrm{C}\right)$, referido a la masa calcinada a $1100^{\circ} \mathrm{C},(\% / 1)$.

- Ldx-Región de deshidroxilación- variación de masa entre $\approx 440^{\circ} \mathrm{C}$ y el inicio de pérdida de masa de la región $\operatorname{Ldc}\left(\approx 520^{\circ} \mathrm{C}\right)$, referido a la masa calcinada a $1100^{\circ} \mathrm{C},(\% 1)$.

- Ldc-Región de descarbonatación- variación de masa entre $\approx 520^{\circ} \mathrm{C}$ y la temperatura final del ensayo $\left(\approx 1100^{\circ} \mathrm{C}\right)$, referido a la masa calcinada a $1100^{\circ} \mathrm{C},\left({ }^{\circ} / 1\right)$.

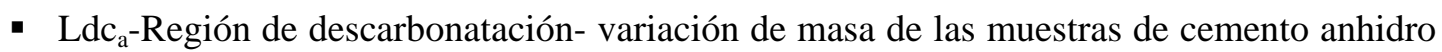
entre $\approx 520^{\circ} \mathrm{C}$ y la temperatura final del ensayo $\left(\approx 1100^{\circ} \mathrm{C}\right)$, referido a la masa calcinada a $1100^{\circ} \mathrm{C},(\% / 1)$.

- $\mathrm{W}_{\mathrm{B} \infty}$ : agua químicamente enlazada máxima respecto a la masa calcinada, $\left({ }^{\circ} / 1\right)$.

- $\tau$ y a, son parámetros que controlan el ajuste de la función.

- $\mathrm{t}$ es el tiempo de curado de las muestras (h).

- $\alpha$ : grado de hidratación (\%).

\section{Estimación del grado de hidratación propuesto}

El cálculo se lleva a cabo a parir del cálculo de agua químicamente enlazada $\left(\mathrm{W}_{\mathrm{B}}\right)$ referida a la cantidad máxima que una pasta de cemento puede combinar de agua en su estructura ( $\left.\mathrm{W}_{\mathrm{B}_{\infty}}\right)$. Atendiendo a las consideraciones descritas en el epígrafe 4.4.1.6, se han realizado las siguientes modificaciones con respecto a los métodos de cálculo estudiados anteriormente.

Nuestra propuesta refiere las cantidades estimadas a la masa de muestra inicial, tomando ésta la que presenta la muestra a $40^{\circ} \mathrm{C}$. 
Los rangos de temperatura establecidos para delimitar las regiones Ldh, Ldx, Ldc, se calculan para cada muestra. La temperatura de corte viene delimitada por los cambios de pendiente que se producen a realizar la derivada sobre la curva de TG, o sobre la curva de ATD si precisamos evaluar el rango de un proceso sin variación de masa asociado. Suele ser necesario operaciones matemáticas de suavizado sobre las funciones obtenidas dado el alto número de puntos asignados en la adquisición de datos.

Para llevar a cabo esta operación será necesario inspeccionar que la función no desplace significativamente sus máximos y mínimos, y que la temperatura tomada no caiga en un tramo de la curva de TG situada en zona de máxima pendiente. Si el modelo de adquisición de datos no varía, se puede establecer una pauta de suavizado para todos los termogramas.

En nuestro caso hemos empleado un modelo de suavizado Savitzky-Golay con 100 puntos. En caso de duda con la asignación de la temperatura se ha comparado el dato con el obtenido al realizar la segunda derivada sobre la curva de TG, o comparando las derivadas primeras de las curvas de TG y ATD.

$\mathrm{W}_{\mathrm{B}}$ se calcula como la pérdida de masa que sufre la muestra desde $140^{\circ} \mathrm{C}$ a $1100^{\circ} \mathrm{C}$. Ldh se considera la pérdida de masa entre $140^{\circ} \mathrm{C}$ y aproximadamente $430^{\circ} \mathrm{C}$, referida a la masa de muestra a $40^{\circ} \mathrm{C}$. $\mathrm{Ldx}$ se considera la pérdida de masa desde $430^{\circ} \mathrm{C}$ aproximadamente y $530^{\circ} \mathrm{C}$, referida a la masa de muestra a $40^{\circ} \mathrm{C}$. Ldc se considera la pérdida de masa desde $530^{\circ} \mathrm{C}$ aproximadamente y $1100^{\circ} \mathrm{C}$, referida a la masa de muestra a $40^{\circ} \mathrm{C}$, descontando la cantidad de masa que desprenden los anhidros en esta misma región (ver Tabla 23), ponderada con la cantidad de cemento que existe en la pasta según se indicó en el último párrafo del epígrafe 4.4.1.6.

Para calcular $\mathrm{W}_{\mathrm{B} \infty}$ se han realizado ensayos de análisis térmico sobre muestras que fueron fabricadas al inicio de la campaña experimental y transcurridos aproximadamente 55 meses desde su fabricación. En este sentido podemos comparar los resultados obtenidos con algunos encontrados en la bibliografía.

Las expresiones para llevar a cabo la estimación son: 


$$
\begin{aligned}
& W_{B 100}=L d h_{100}+L d x+\left[\left(\frac{18}{44}\right)\left(L d c-L d c_{a}\right)\right] \\
& \alpha=\frac{W_{B 100}}{W_{B \infty}} \cdot 100
\end{aligned}
$$

Donde:

- $\mathrm{W}_{\mathrm{B} 40}$ : Agua químicamente combinada respecto a la masa a $40^{\circ} \mathrm{C},(\% / 1)$.

- $\mathrm{Ldh}_{40}$-Región de deshidratación- variación de masa entre $140^{\circ} \mathrm{C}$ y el inicio de pérdida de masa de la región $\mathrm{Ldx}\left(\approx 430^{\circ} \mathrm{C}\right)$, referido a la masa a $40^{\circ} \mathrm{C},\left({ }^{\circ} / 1\right)$.

- Ldx-Región de deshidroxilación- variación de masa entre $\approx 430^{\circ} \mathrm{C}$ y el inicio de pérdida de masa de la región $\operatorname{Ldc}\left(\approx 530^{\circ} \mathrm{C}\right)$, referido a la masa a $40^{\circ} \mathrm{C},(\% / 1)$.

- Ldc-Región de descarbonatación- variación de masa entre $\approx 530^{\circ} \mathrm{C}$ y la temperatura final del ensayo $\left(\approx 1100^{\circ} \mathrm{C}\right)$, referido a la masa a $40^{\circ} \mathrm{C},(\% / 1)$.

- Ldc $_{\mathrm{a}}$-Región de descarbonatación- variación de masa de las muestras de cemento anhidro entre $\approx 530^{\circ} \mathrm{C}$ y la temperatura final del ensayo $\left(\approx 1100^{\circ} \mathrm{C}\right)$ ponderada, $(\%)$.

- $\mathrm{W}_{\mathrm{B} \infty}$ : agua químicamente enlazada máxima calculada en muestras de edad madura en respecto a la masa a $40^{\circ} \mathrm{C},(\% / 1)$.

- $\alpha$ : grado de hidratación (\%).

En la tabla siguiente se muestra la estimación del grado de hidratación según los distintos métodos. 
Tabla 34. Valores de $\mathrm{W}_{\mathrm{B}}$ en muertras de referencia y a edad madura $\left(\mathrm{W}_{\mathrm{B} \infty}\right)$

\begin{tabular}{l|c|c|c|c|c}
\hline & & $\begin{array}{c}\mathrm{W}_{\mathrm{B} 105} \\
(\%)\end{array}$ & $\begin{array}{c}\mathrm{W}_{\mathrm{B} 140}{ }^{11} \\
\text { referido } \mathrm{a}_{40} \\
(\%)\end{array}$ & $\begin{array}{c}\mathrm{W}_{\mathrm{B} 140} \\
\text { referido a } \mathrm{m}_{\mathrm{f}} \\
(\%)\end{array}$ & $\begin{array}{c}\mathrm{W}_{\mathrm{B} 40} \\
(\%)\end{array}$ \\
\hline & Método & Bhatty & \multicolumn{2}{|c}{ Pane/Hansen } & Propuesto \\
\hline SR ref & $\mathrm{W}_{\mathrm{B} \infty}$ & 24.00 & \multicolumn{2}{|c}{$\begin{array}{c}\text { Valores de muestras } \\
\text { a edad madura }\end{array}$} & $\begin{array}{c}\text { Valores de muestras } \\
\text { a edad madura }\end{array}$ \\
\hline SR em & & 18.37 & 18.16 & 23.90 & 14.83 \\
II ref & 18.75 & 16.71 & 21.87 & 14.38 \\
II em & 18.71 & 15.46 & 20.53 & 14.41 \\
\hline IV ref & 18.84 & 15.00 & 19.82 & 14.43 \\
IV em & 16.36 & 12.75 & 16.24 & 12.70 \\
\hline
\end{tabular}

Con este cálculo, y teniendo en cuenta los valores de $\mathrm{W}_{\mathrm{B} \infty \text {, el }}$ grado de hidratación de las muestras quedaría como muestra la Figura 52.

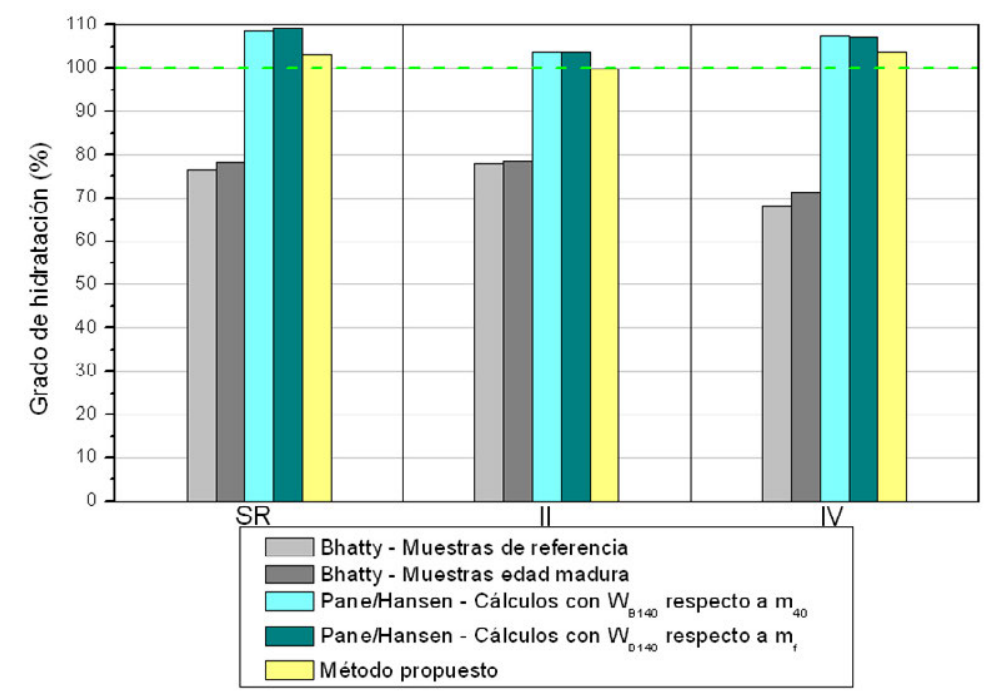

Figura 52. Grados de hidratación

El grado de hidratación de las muestras calculado por el método de Bhatty se encuentra entre el 75 y el 80 por ciento. Las muestras no alcanzan el valor de $\mathrm{W}_{\mathrm{B}}=24 \%$ que este autor propone

${ }^{11}$ Para llevar a cabo la comparación se han referido los datos a la masa a $40^{\circ} \mathrm{C}$. El método de Pane/Hansen establece la referencia sobre la masa calcinada. Para expresar el resultado de $\mathrm{W}_{\mathrm{B} 140}$ respecto a la masa calcinada bastaría con multiplicar esta cifra por la inversa de la relación $\mathrm{m}_{\mathrm{f}} \mathrm{m}_{40^{\circ} \mathrm{C}}$ mostrada para cada tipo de muestra en la Tabla 31 a la Tabla 33. 
para la hidratación completa (Bhatty, 1986). A edad madura las muestras presentan un ligero aumento de la hidratación que ya se observaba en el aumento del valor $\mathrm{W}_{\mathrm{B}}$ (Tabla 34).

Se observan difencias en el valor de $\mathrm{W}_{\mathrm{B} 140}$ en función de la masa a la que se refiera el resultado, pero cuando este valor se emplea para calcular el grado de hidratación las diferencias desaparecen.

Con respecto a los valores de $\mathrm{W}_{\mathrm{B} 140}$ calculados por este método, se puede decir que los valores se encuentran por debajo del intervalo entre el 23 y el 25\% (dato referenciado frente a la masa del residuo) que este autor considera habituales en cemento tipo I. Respecto a los valores en cemento con con adición, los valores son inferiores frente al valor de $21.7 \%$ que propone para un cemento portland con un 25\% de adición de cenizas volantes (Pane y Hansen, 2005). Esto puede ser debido al bajo contenido en clínker en el cemento de partida y del consumo de portlandita en la reacción puzolánica que tiene lugar por la composición del tipo de cemento y adición empleados.

Los valores que presenta $\mathrm{W}_{\mathrm{B} 140}$ calculados por el método de Pane/Hansen parecen indicar que el contenido de agua químicamente enlazada en las muestrasa edad madura es inferior al contenido calculado para las muestras de referencia. Sin embargo, si comparamos estos datos con los mostrados en la Tabla 31 a la Tabla 33 se observa que si igualamos el nivel de carbonatación de las muestras, los contenidos de portlandita son superiores en las muestras de edad madura, y los cotenidos de agua entre $100^{\circ} \mathrm{C}$ y el inicio de la región de deshidroxilación aumentan ligeramente en los tres tipos de muestras a edad madura.

La explicación a porqué las muestras a edad madura presentan un contenido menor de $\mathrm{W}_{\mathrm{B} 140}$ que las muestras de referencia, calculado mediante este método, es que no tomamos el agua que se pierde por debajo de $140^{\circ} \mathrm{C}$, que se atribuye a agua libre. Los contenidos de agua pérdida por encima de $140^{\circ} \mathrm{C}$ sólo se reducen en $0.4 \%$ en los tres tipos de muestra.

El método de Pane/Hansen no tiene en cuenta la posible carbonatación diferencial de las muestras y asume la pérdida de carbonato como tal. Computando la pérdida de una molécula de $\mathrm{CO}_{2}$ en vez de una molécula de $\mathrm{H}_{2} \mathrm{O}$. Las muestras de referencia presentan un nivel de carbonatación superior a la muestras a edad madura por lo que la pérdida de $\mathrm{CO}_{2}$ calculada eleva el valor de $\mathrm{W}_{\mathrm{B} 140}$. Esto, sumado a la reducción del contenido de agua en el intervalo 140- 
$430^{\circ} \mathrm{C}$ de las muestras a edad madura supone que los grados de hidratación calculados por el método de Pane/Hansen estén sobreestimados.

Los valores de $\mathrm{W}_{\mathrm{B} 40}$ calculados por el método propuesto presentan valores infereiores respecto de los otros métodos analizados. Esto se debe a que empleamos el valor de Ldh desde $140^{\circ} \mathrm{C}$ como el método de Pane/Hansen, pero sí corregimos la pérdida de portlandita con el valor de portlandita equivalente. El grado de hidratación de las muestras calculado por este método indica que las muestras de referencia presentan un grado de hidratación completa respecto al alcanzado por las muestras a edad madura.

\subsubsection{Análisis térmico sobre las muestras expuestas a los medios AC, SU y AN}

\section{Análisis térmico en el medio AC}

En la Figura 53 se muestran el resultado de los termogramas registrados sobre las muestras de pasta de cemento SR sumergidas en la disolución AC.

Con el paso del tiempo de exposición se observa una disminución progresiva de portlandita que afecta a una profundidad cada vez mayor. Este mineral está presente en todas las profundidades hasta los 30 días. Durante el primer mes de exposición su disolución es rápida, mientras que entre 30 y 58 días se observa una ralentización de la disolución de portlandita condicionada probablemente por la velocidad de difusión.

La desaparición de portlandita aparece asociada a la disolución de los carbonatos. Se observa asimismo la degradación de compuestos en la zona de deshidratación. El agua se pierde con rapidez en esta zona, aumentando la pendiente de la curva de TG y ensanchando la banda en la curva de ATD, que podría asociarse con la desnaturalización de compuestos y la formación de un gel rico en sílice.

En la Figura 54 se muestran los datos de las pérdidas de masa calculadas en las muestras de pasta de cemento SRAC. En ella se muestran, en línea roja discontinua, los valores de masa perdida de las muestras de referencia correspondientes a los tramos de $40^{\circ} \mathrm{C}$ hasta $140^{\circ} \mathrm{C}$, hasta el inicio de la banda de deshidroxilación (entorno a $430^{\circ}$ ) y el contenido total de agua desde $40^{\circ} \mathrm{C}$ hasta el inicio de la banda de deshidroxilación. 
(a) 2 días

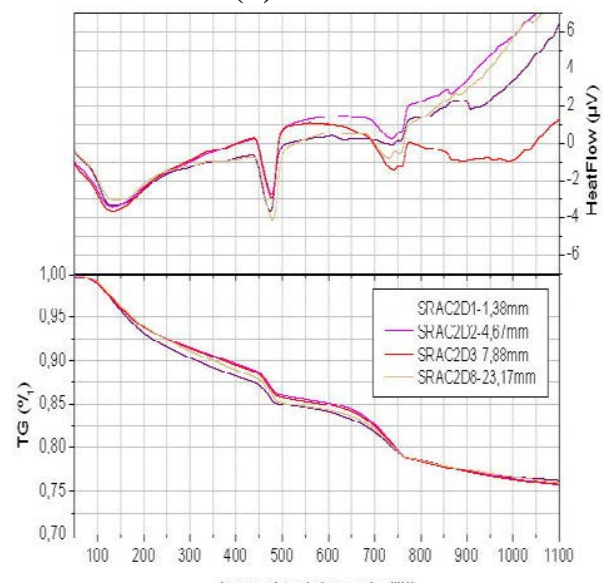

(c) 30 días

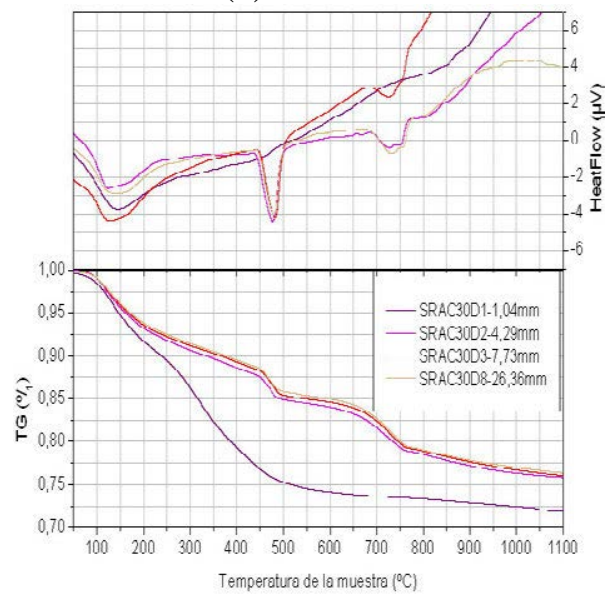

(e) 92 días

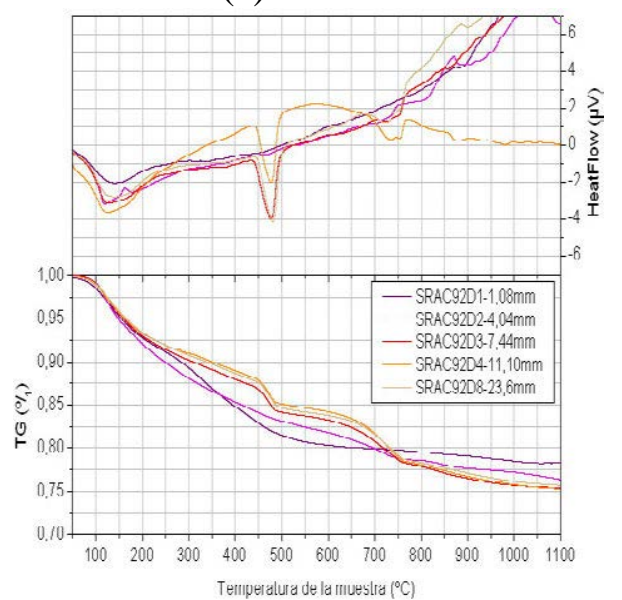

(b) 7 días

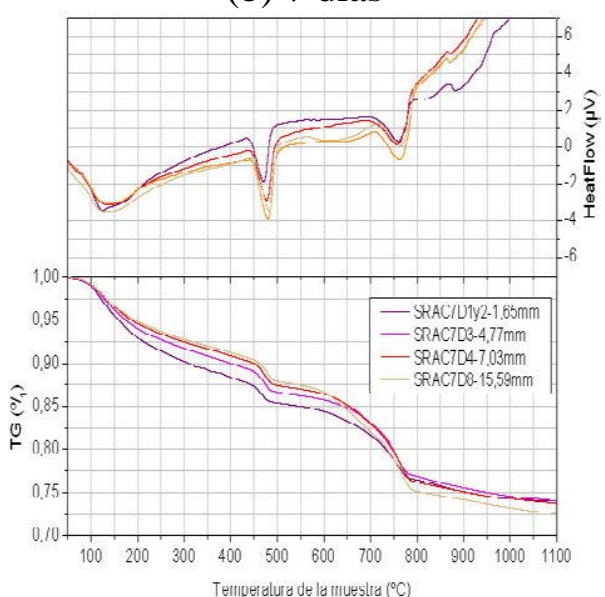

(d) 58 días

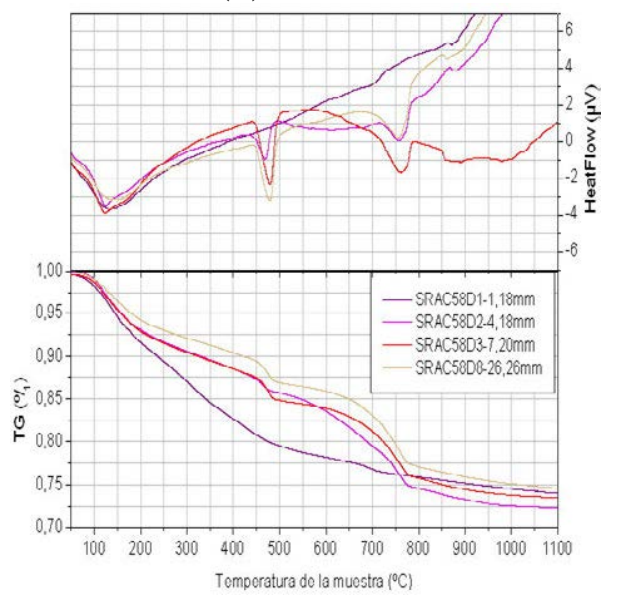

Figura 53. ATD-TG en muestras SRAC 


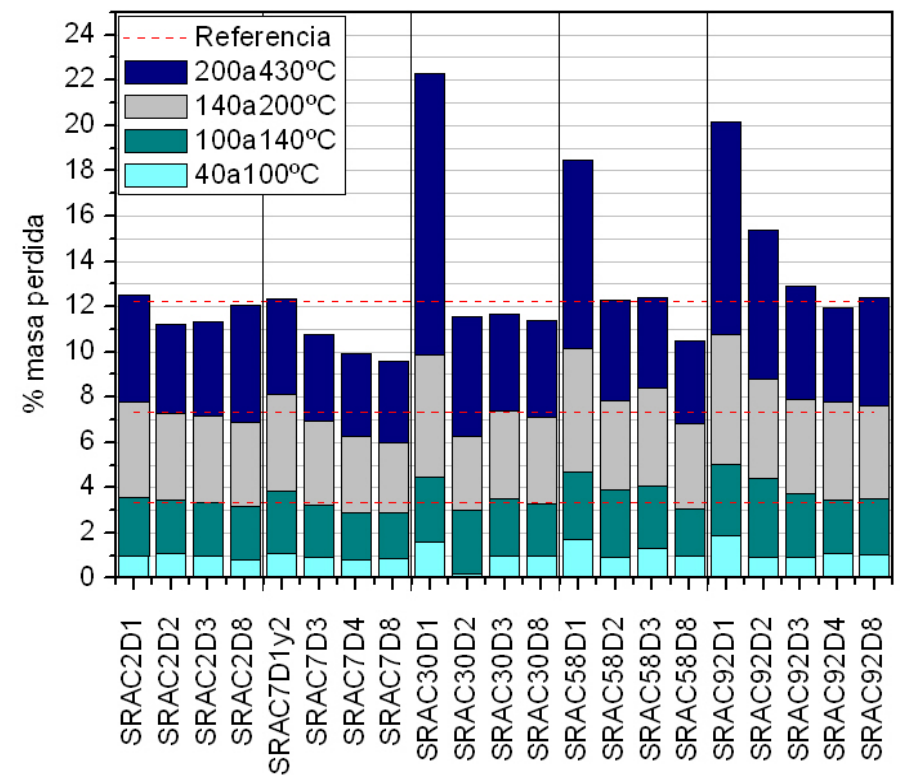

Figura 54. Pérdidas de masa en la región Ldh por tramos de temperatura en las muestras SRAC

Las muestras presentan un contenido de agua hasta $140^{\circ} \mathrm{C}$ muy próximo al que presentan las muestras de referencia a 2 días de exposición y en las secciones interiores de la probeta. A partir de 30 días el contenido de agua hasta $140^{\circ} \mathrm{C}$ aumenta ligeramente en la primera sección de las probetas y esta tendencia se extiende a secciones sucesivas a medida que transcurre el tiempo de exposición.

El incremento del contenido de agua en la primera sección de las probetas se mantiene en el resto de intervalos analizados y es especialmente relevante en el caso del intervalo entre $200 \mathrm{y}$ $430^{\circ} \mathrm{C}$, afectando a secciones cada vez más profundas a medida que transcurre el tiempo de exposición. El aumento de la cantidad de agua perdida a partir de $200^{\circ} \mathrm{C}$ podría estar relacionado con la transición de aluminatos hidratados hexagonales a hidratos cúbicos. Los aluminatos tipo $\mathrm{C}_{3} \mathrm{AH}_{6}$ deshidratan a temperaturas mayores, liberando cierta cantidad de agua libre. Esta transición cristalográfica de aluminados hidratados contribuiría al aumento de la porosidad del material, lo que a su vez condiciona que avance el proceso de degradación (Taylor, 2003).

El hecho de que el agua se pierda con mayor facilidad podría estar asociado a la desnaturalización de la estructura de los geles, que permitiría una liberación de agua rápidamente. Si observamos las curvas de TG de la Figura 53 se observa como un porcentaje 
elevado de la pérdida total de agua en la muestras degradadas (a partir de 30 días) se pierde entre los $100 \mathrm{y}$ los $600^{\circ} \mathrm{C}$.

Hay que tener en cuenta que las muestras estén expuestas a un medio ácido. Aunque la portlandita es el compuesto que presenta una susceptibilidad mayor a la interacción con un medio ácido, a pH próximos a su descomposición descomponen otros compuestos como el monosulfoaluminato de calcio y algunos aluminatos de calcio hidratados, a la vez que precipita etringita (Reardon, 1990), por lo que estaría justificado que aumenten los porcentajes de agua en las primeras secciones en contancto con la disolución agresiva.

La formación de hidratos hexagonales además favorece el aumento de la porosidad, lo que condicionaría un incremento de la velocidad de degradación. Las muestras estabilizan los contenidos de agua entorno a los 4-5 mm de profundidad y sólo se observa degradación de las muestras en este espesor a los 92 días de exposición.

En la Figura 55 se muestra los contenidos de portlandita y portlandita equivalente de las muestras. En ella se muestra en línea discontinua azul el valor de portlandita de las muestras de referencia, y en línea discontinua roja el valor de portlandita equivalente de referencia calculado con los datos de las muestras en medios SRCA y SRAI.

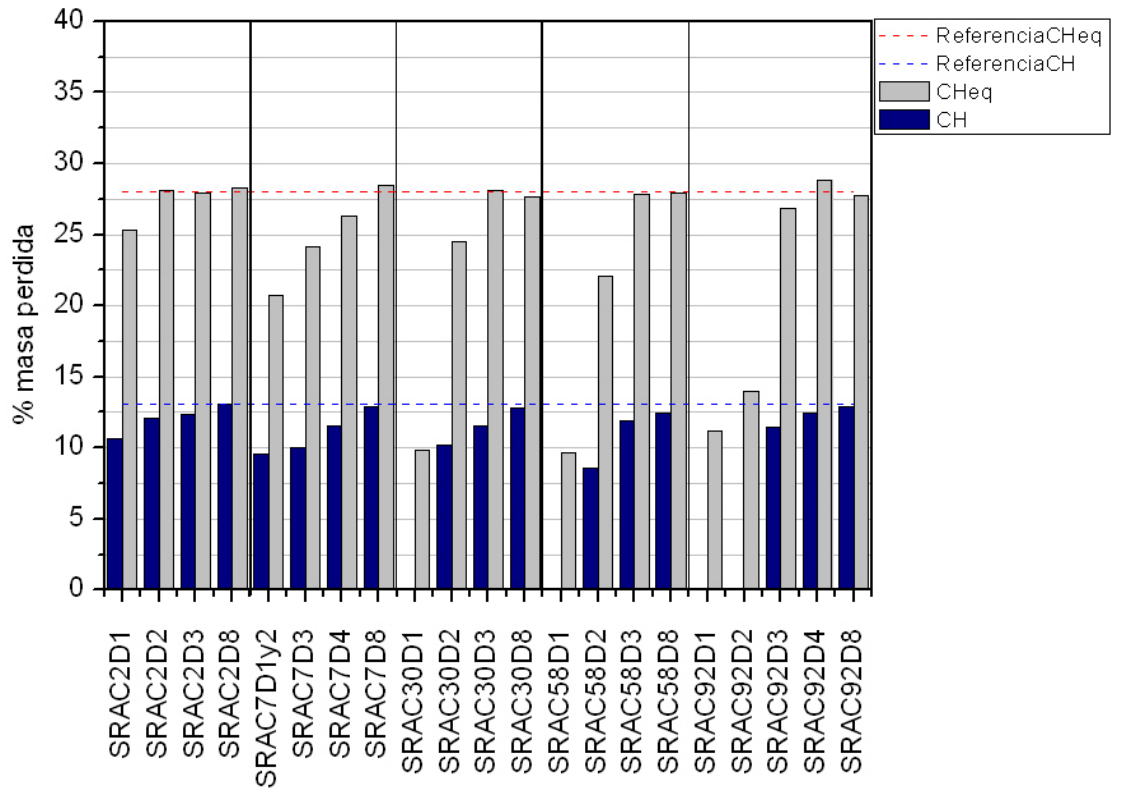

Figura 55. Contenidos de portlandita y portlandita equivalente en muestra SRAC 
La portlandita es el compuesto más sensible a en contacto con disoluciones con pH ácido por lo que resulta previsible que sea el que primero lixivie.

El contenido de portlandita calculado se encuentra por debajo de los niveles de referencia en prácticamente todas las muestras analizadas. Esto puede deberse a un grado de carbonatación diferencial en las muestras.

Si analizamos los resultados de portlandita equivalente se observa que las muestras presentan cierto perfil de lixiviavción en las secciones en contacto con la disolución agresiva.

A dos días de exposición la lixiviación de portlandita afecta a la primera sección en contacto con la disolución agresiva.

A 7 días de exposición las tres primeras secciones presentan perfil de lixiviación. El contenido de portlandita de la muestra se mantiene estable en las dos primeras secciones y sin embargo la portlandita equivalente desciende paulatinamente en profundidad de la probeta, por lo que debemos entender que esta lixiviando parte del carbonato procedente de las muestras.

En la Figura 56 se muestran el resultado de los termogramas registrados sobre las muestras de pasta de cemento II sumergidos en la disolución AC.

En las muestras de pasta de cemento II se observa una tendencia parecida a las muestras de cemento SR. Se observa una disminución progresiva de portlandita que afecta a una profundidad cada vez mayor. Este mineral está presente en todas las profundidades hasta los 30 días. Durante la primera semana la disolución es mas rápida que en pastas de cemento SR.

Sin embargo, a largo plazo, parece presentar mejor resistencia, y a 92 días aún presenta $\mathrm{CH}$ a 5 mm de espesor.

La desaparición de portlandita aparece asociada a la disolución de los carbonatos en las secciones más próximas a la disolución agresiva a partir de los 58 días de exposición. Se observa en una reducción de la banda y de la masa desprendida en la curva de TG correspondiente a la región Ldc.

En la región Ldh la forma de la curva comienza a redondearse a los 30 días, y pierde su hombro, probablemente asociado a la disolución de fases AFt, AFm. 
(a) 2 días

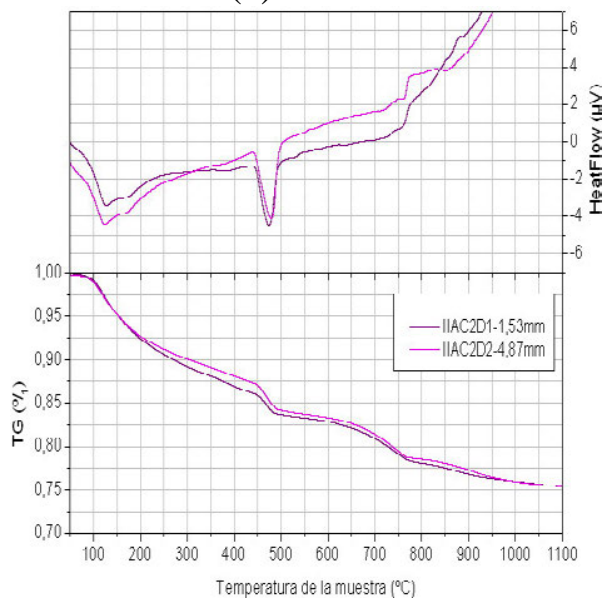

(c) 30 días

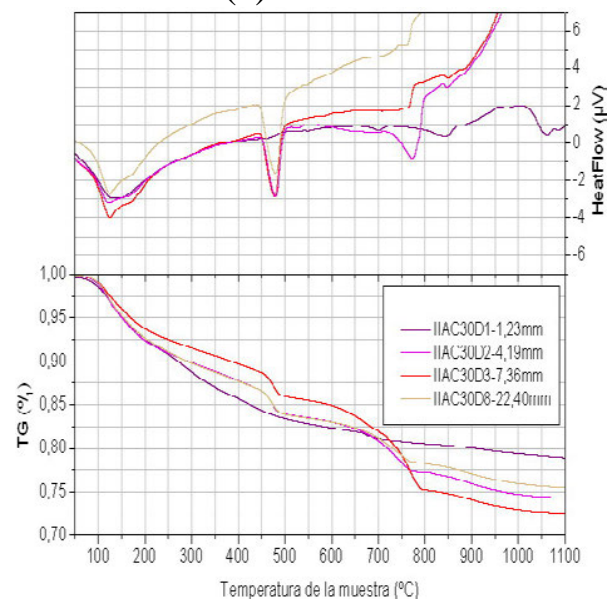

(e) 92 días

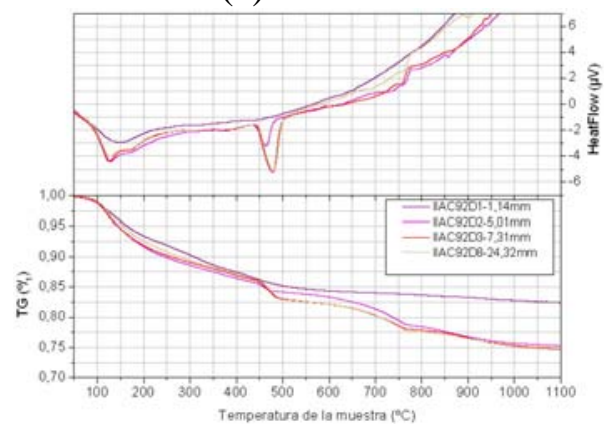

(b) 7 días

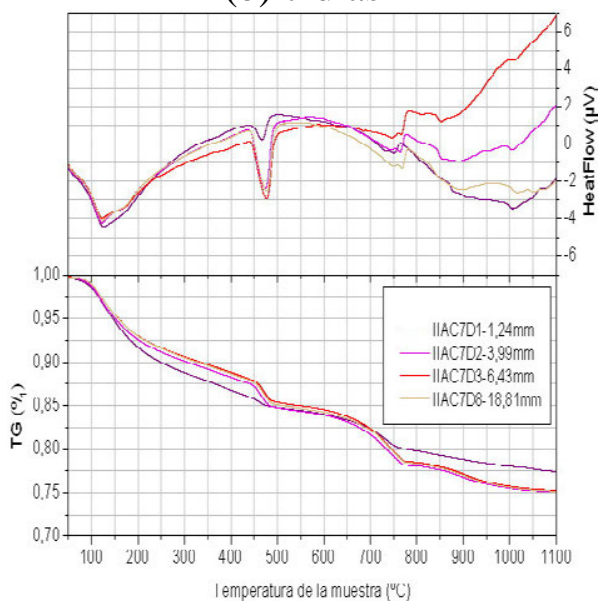

(d) 58 días

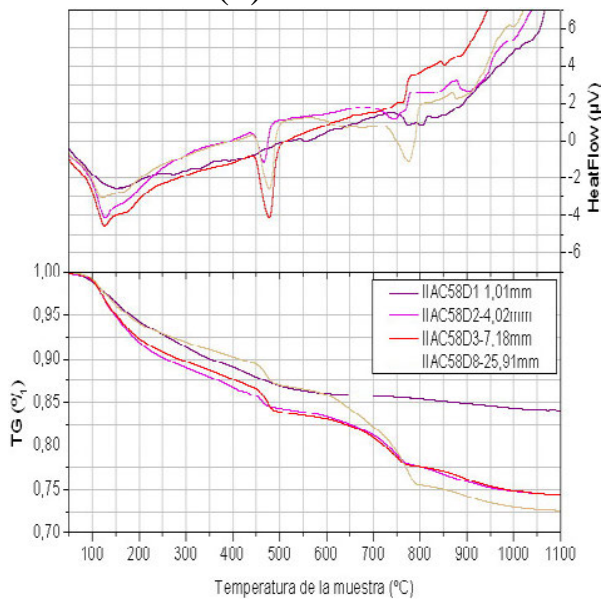

Figura 56. ATD-TG en muestras IIAC

En la Figura 57 se muestran los datos de las pérdidas de masa calculadas en las muestras de pasta de cemento SRAC. En ella se muestran, en línea roja discontinua, los valores de masa perdida de las muestras de referencia correspondientes a los tramos de $40^{\circ} \mathrm{C}$ hasta $140^{\circ} \mathrm{C}$, hasta 
el inicio de la banda de deshidroxilación (entorno a $430^{\circ}$ ) y el contenido total de agua desde $40^{\circ} \mathrm{C}$ hasta el inicio de la banda de deshidroxilación

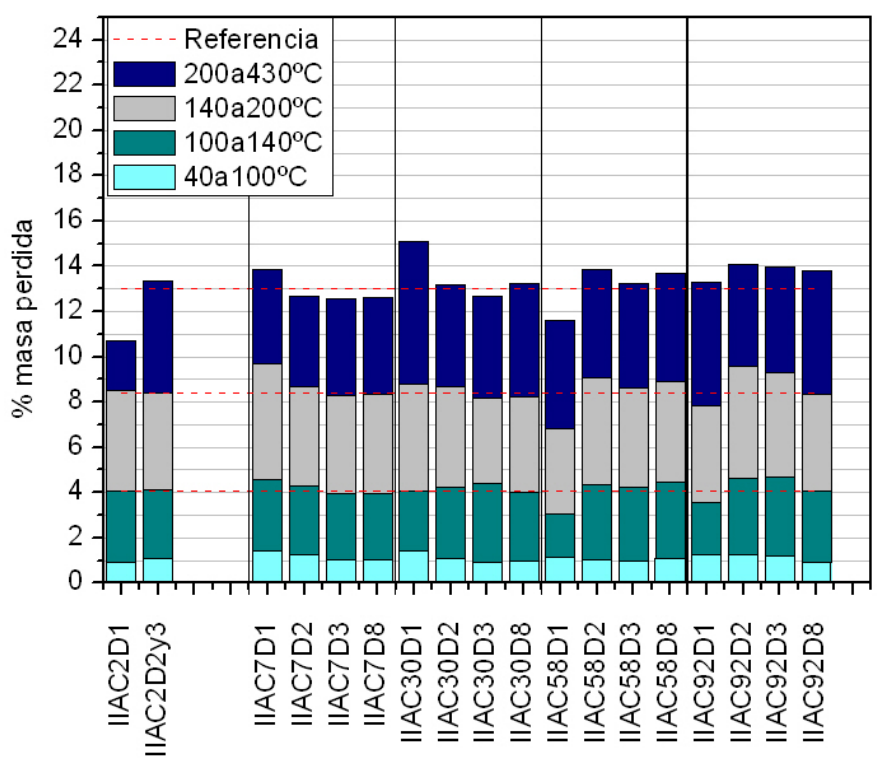

Figura 57. Pérdidas de masa en la región Ldh por tramos de temperatura en las muestras IIAC

A 2 días de exposición las muestras presentan un contenido de agua muy próximo al de las muestras de referencia hasta $200^{\circ} \mathrm{C}$. Sin embargo el contenido total perdido en la primera sección es menor.

Hasta $140^{\circ} \mathrm{C}$, la pérdida de agua que presentan las muestras de pasta de cemento II es muy próxima a las calculadas para las muestras de referencia. Sólo en el caso de la primera sección de las muestras expuestas durante 58 y 92 días aparece disminuida.

El contenido de agua total calculado es prácticamente constante en las muestras analizadas. Presentan anomalías las primeras secciones en contacto con la disolución agresiva. A 7 y 30 días de exposición es superior a las muestras de referencia. A 58 días es inferior y a 92 días se sitúa entorno al contenido de referencia. Este compotamiento diferenciado puede deberse a un aumento de la estabilidad térmica de los compuestos generados durante la hidratación que ya se puso de manifiesto cuando se calcularon las energías de activación (Tabla 26).

En la Figura 58 se muestra los contenidos de portlandita y portlandita equivalente de la muestras. Indicando en línea discontinua azul el valor de portlandita de las muestras de 
referencia, y en línea discontinua roja el valor de portlandita equivalente de referencia calculado con los datos de las muestras en medios IICA y IIAI.

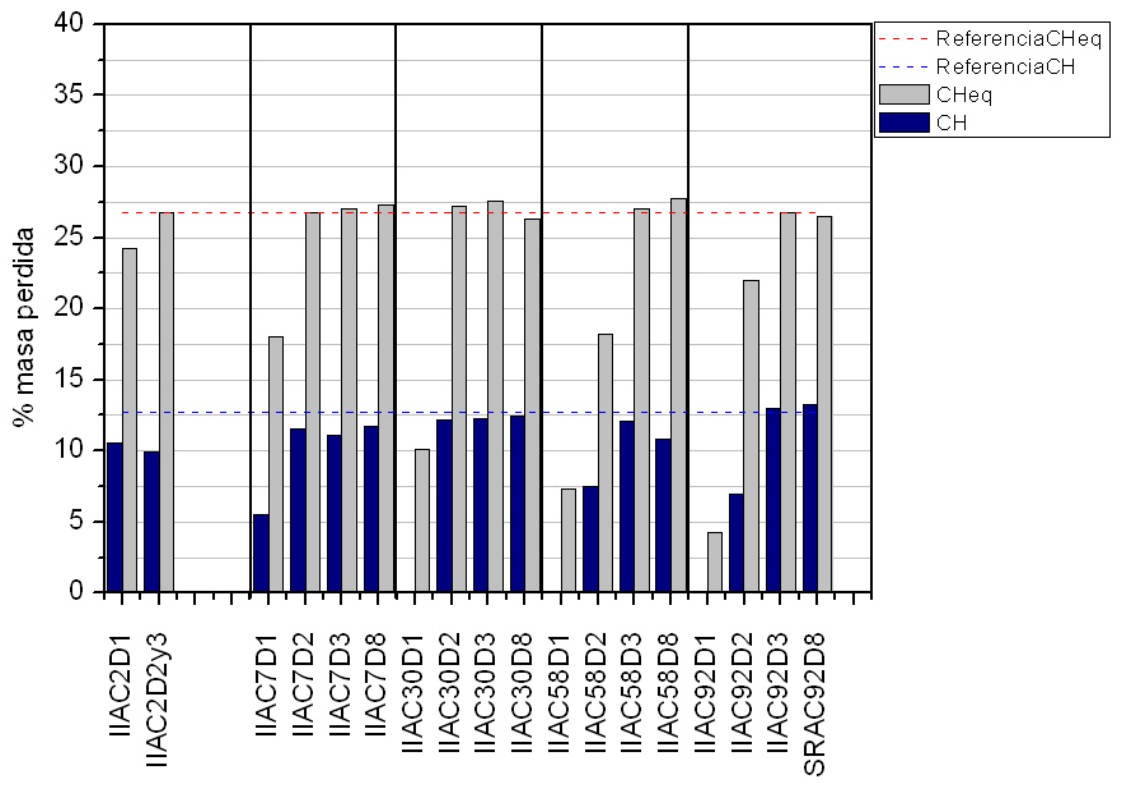

Figura 58. Contenidos de portlandita y portlandita equivalente en muestra IIAC

A 2 días de exposición el contenido de CH se encuentra por debajo de los niveles de referencia. Cuando corregimos el valor con el valor de portlandita equivalente se observa que la primera sección presenta un contenido de CHeq menor que el de referencia, por lo que ya ha empezado a lixiviar portlandita, pero el proceso de lixiviación no afecta a la segunda sección.

A 7 días de exposición el contenido de $\mathrm{CH}$ y CHeq sigue descendiendo en la primera sección. La reducción del contenido de CHeq en la primera sección corresponde con el descenso de $\mathrm{CH}$ en la muestras, por lo que debemos entender que en este momento los carbonatos en la muestra aún permanecen estables. El proceso de lixivición no afecta las siguientes secciónes, puesto que el contenido de CHeq se mantiene próximo al de las referencias.

A 30 días de exposición la primera sección no contiene portlandita. El valor de CHeq también aparece disminuido respecto a los que presentan las muestras de referencia. Puesto que los valores de $\mathrm{CH}$ y $\mathrm{CHeq}$ equivalente se conservan en el resto de secciones a esta edad de exposición, debemos entender que se esta produciendo la lixiviación de carbonatos presentes en la muestras, simultáneamente al proceso de difusión de $\mathrm{Ca}^{2+}$ en el interior de la probeta. 
A 58 días de exposición la lixiviación de portlandita afecta a las dos primeras secciones. En la primera de ellas no queda portlandita y la contribución de los carbonatos sobre el contenido de CHeq es aproximadamente la mitad de la inicial. En la segunda sección pese a que todavía queda portlandita, la contribución de los carbonatos sobre el contenido de CHeq también se ha reducido ligeramente. Debemos entender que portandita y carbonatos han lixiviado de forma conjunta.

Los datos a 92 días de exposición muestran que en la primera sección siguen lixiviando carbonatos. El contenido de $\mathrm{CH}$ en la segunda sección desciende ligeramente y sin embargo el de CHeq aumenta. La pérdida de masa asociada a la región Ldc podría estar relacionada con la estabilidad de las especies carbonatadas en función del pH del medio.

Además, parece observarse que a partir de 58 días las muestras hayan frenado el proceso de lixiviación. Esto podría venir determinado por un proceso de difusión iónica lento en el interior de las probetas, a que la disolución exterior se encuentre saturada, o incluso a ambas.

En la Figura 59 se muestran el resultado de los termogramas registrados sobre las muestras de pasta de cemento IV sumergidos en la disolución AC.

Se mantiene la tendencia de reducción progresiva de portlandita que afecta a una profundidad cada vez mayor. Está presente en todas las profundidades hasta los 30 días.

En este caso la disolución de carbonatos se observa claramente en la primera sección desde los 30 días de exposición y sólo a partir de 2 días parece ser más profunda su reducción, afectando a la sección de 4 mm de profundidad.

En la región Ldh el cambio más significativo es la desaparición de la banda a $190^{\circ} \mathrm{C}$ asociada con la presencia de monosulfoaluminato. También se observa menos aguda la banda a $125^{\circ} \mathrm{C}$. Estos cambios son evidentes en la sección en contacto con la disolución agresiva desde los 30 días de exposición. A medida que avanza el tiempo de exposición se observa a mayor profundidad, pero sólo a 92 días se observa claramente un ensanchamiento de la banda comparable al que se produce en la primera sección. 
(a) 2 días y 7 días

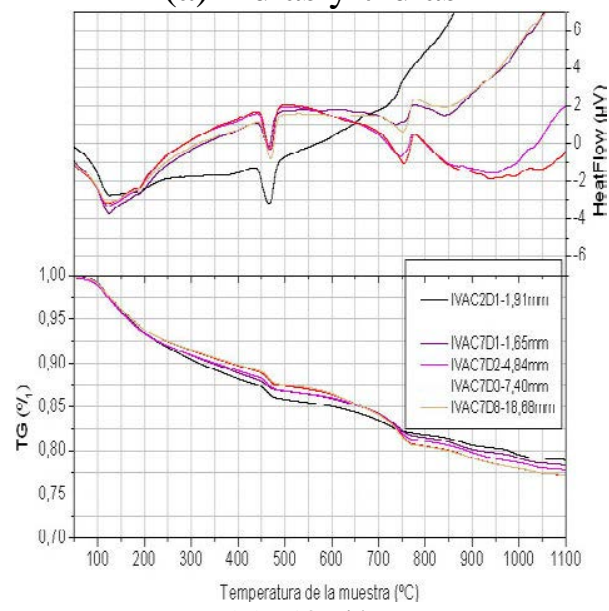

(c) 58 días

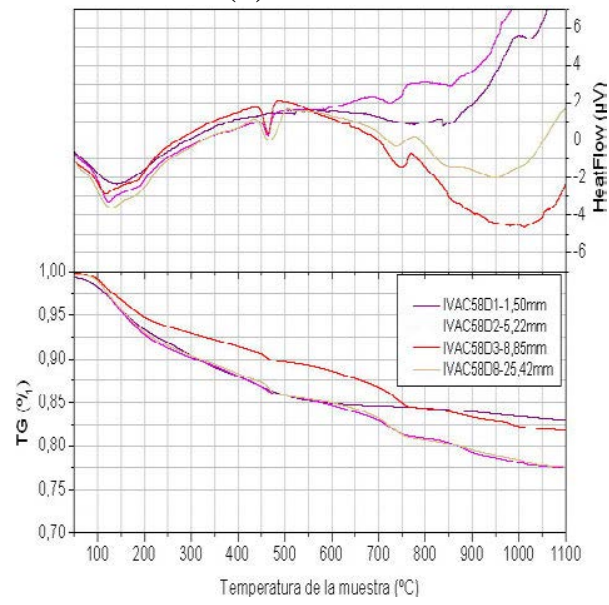

(b) 30 días

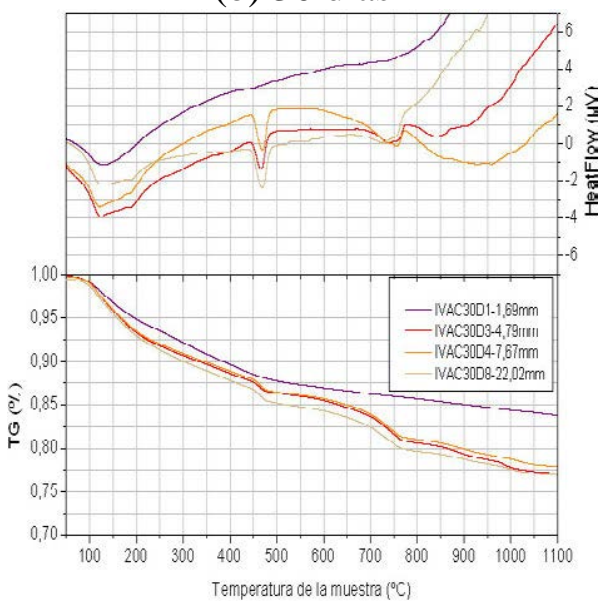

(d) 92 días

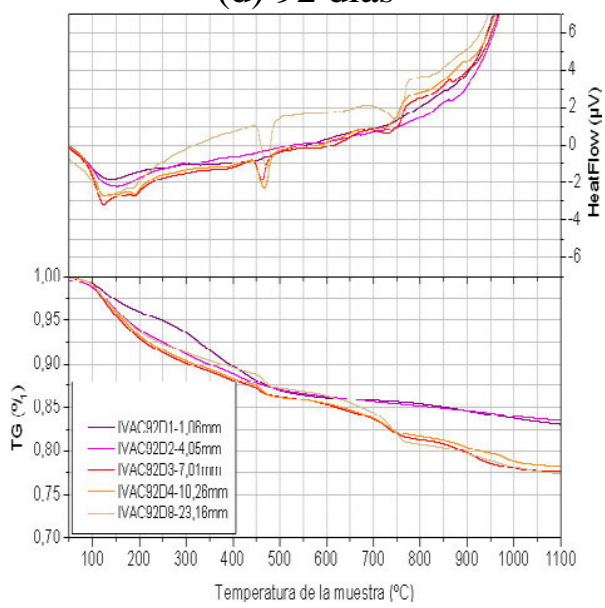

Figura 59. ATD-TG en muestras IVAC

En la Figura 60 se muestran los datos de las pérdidas de masa calculadas en las muestras de pasta de cemento IVAC. En ella se muestran, en línea roja discontinua, los valores de masa perdida de las muestras de referencia correspondientes a los tramos de $40^{\circ} \mathrm{C}$ hasta $140^{\circ} \mathrm{C}$, hasta el inicio de la banda de deshidroxilación (entorno a $430^{\circ}$ ) y el contenido total de agua desde $40^{\circ} \mathrm{C}$ hasta el inicio de la banda de deshidroxilación. 


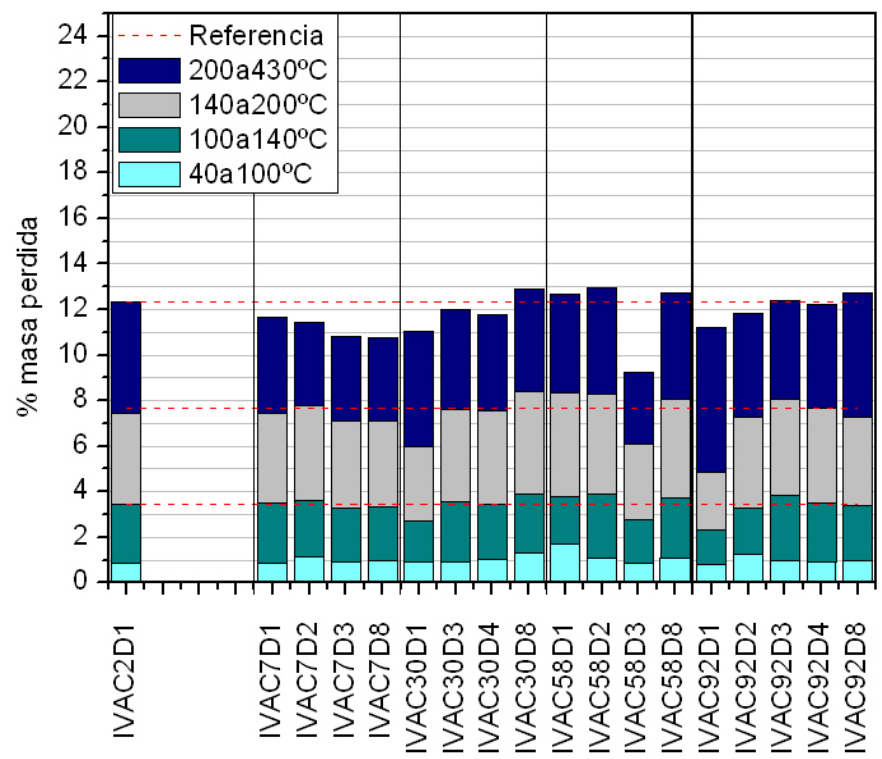

Figura 60. Pérdidas de masa en la región Ldh por tramos de temperatura en las muestras IVAC

A 2 días de exposición las muestras presentan un contenido de agua muy próximo al de las muestras de referencia en todos los tramos de temperatura.

En contenido total de agua muestra ligeras variaciones con respeco a la calculada en las muestras de referencia. Estas variaciones no presentan una tendencia clara, ni en la profundidad de la probeta, ni con el tiempo de exposición. Las curvas de TG mostradas en la Figura 59, muestran variaciones de masa muy similares para la mayoría de las muestras hasta $600^{\circ} \mathrm{C}$, razón por la cual las variaciones calculadas en los distintos tramos de temperatura apenas presentan variación ${ }^{12}$.

Por tramos de temperatura se observa que desciende ligeramente el contenido entre $100 \mathrm{y}$ $140^{\circ} \mathrm{C}$, y entre 140 y $200^{\circ} \mathrm{C}$ a partir de 30 días de exposición en las primeras secciones de las probetas. Probablemente la disolución de la portlandita acelere la descomposición de las fases

${ }^{12}$ La muestra IVAC58D3 presenta una curva de TG anómala y no se ha tenido en consideración. 
AFt y AFm. A 92 días también se observa un incremento del agua que se pierde entre los 200 y los $430^{\circ} \mathrm{C}$. Probablemente este incremento se deba a la desnaturalización estructural de los compuestos, que permitiría una pérdida de agua a regiones de temperatura más bajas como ya se ha observado en las pastas de los otros tipos de cemento.

En la Figura 61 se muestra los contenidos de portlandita y portlandita equivalente de la muestras. En ella se muestra en línea discontinua azul el valor de portlandita de las muestras de referencia, y en línea discontinua roja el valor de portlandita equivalente de referencia calculado con los datos de las muestras en medios IVCA y IVAI.

Los contenidos totales de $\mathrm{CH}$ y de CHeq son los más bajos como era de esperar en pastas de cemento puzolánico con adición de ceniza volante.

A 2 días de exposición este es el único tipo de pastas que no muestra síntomas de disolución de $\mathrm{CH}$, siendo los contenidos de $\mathrm{CH}$ y CHeq próximos a los de la referencia.

A 7 días de exposición presenta una ligera reducción del CH sólo en la primera sección y una reducción progresiva de CHeq hacia el exterior de la probeta en las dos primeras secciones. Aún con ello, es el tipo de muestra que presenta menor lixiviación de $\mathrm{CH}$ de las muestras analizadas a esta edad.

La ausencia de portlandita en la primera sección aparece a los 30 días de exposición y alcanza los 4-5 mm de espesor a los 92 días. En esta edad de exposición el contenido de $\mathrm{CH}$ y CHeq se mantiene entorno al contenido de referencia a partir de la segunda sección. 


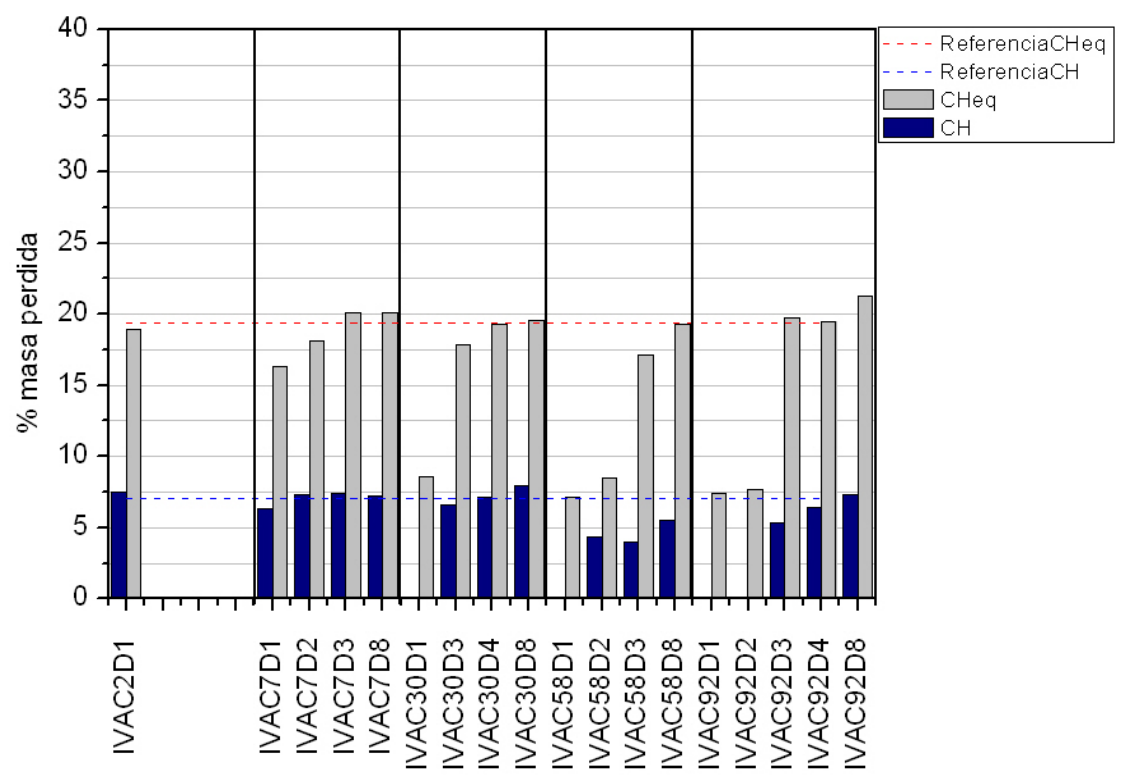

Figura 61. Contenidos de portlandita y portlandita equivalente en muestra IVAC

\section{Análisis térmico en el medio SU}

En la Figura 62 se muestran el resultado de los termogramas registrados sobre las muestras de pasta de cemento SR sumergidos en la disolución SU.

Desde el punto de vista cualitativo el cambio más significativo en las curvas es la agudización de la banda a $125^{\circ} \mathrm{C}$ en la curva de ATD. Este cambio es más evidente a mayor tiempo de exposición a la disolución, y en la primera sección. Se asocia este cambio con la formación de etringita propiciado por la presencia de sulfatos en el medio.

Para llevar a cabo un análisis más detallado de los posibles cambios sucedidos en la microestructura de estas pastas se presenta en la Figura 63 las pérdidas de masa asociadas a la región Ldh desglosadas por tramos de temperatura. En la figura se muestran, en línea roja discontinua, los valores de masa perdida de las muestras de referencia correspondientes a los tramos de $40^{\circ} \mathrm{C}$ hasta $140^{\circ} \mathrm{C}$, hasta el inicio de la banda de deshidroxilación (entorno a $430^{\circ}$ ) y el contenido total de agua desde $40^{\circ} \mathrm{C}$ hasta el inicio de la banda de deshidroxilación. 
(a) 2 días y 7 días

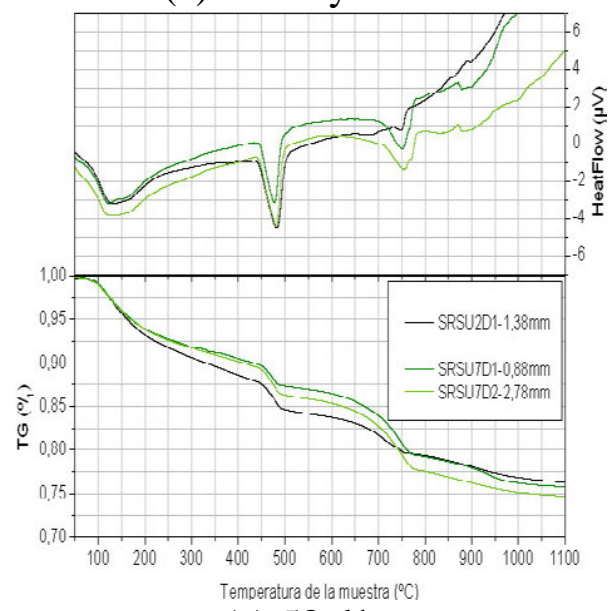

(c) 58 días

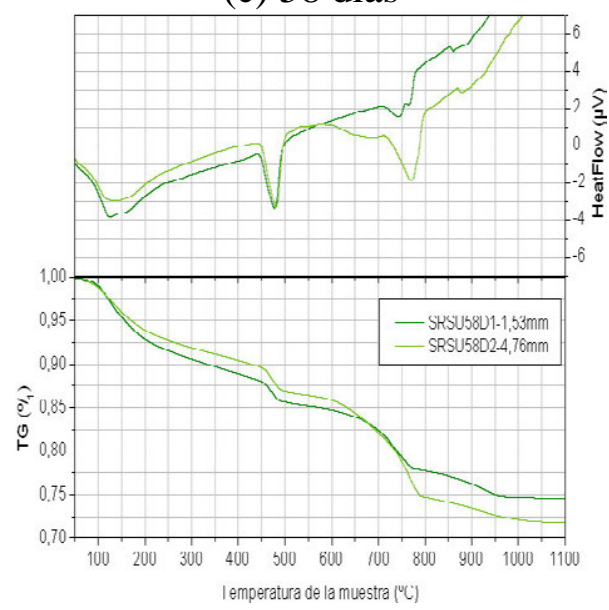

(b) 30 días

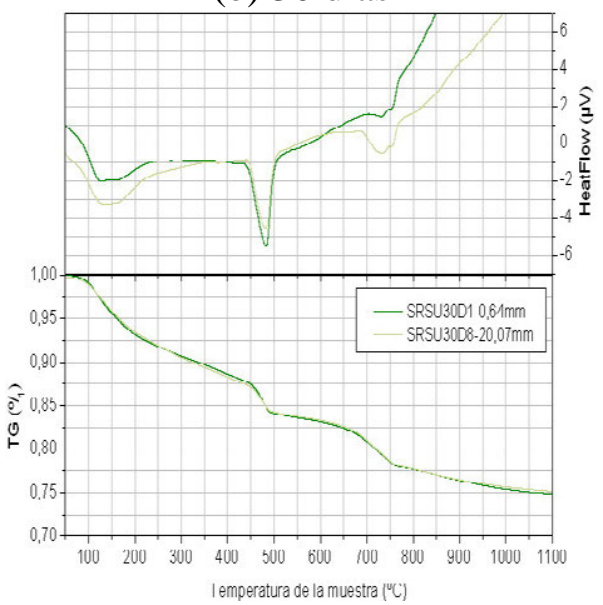

(d) 92 días

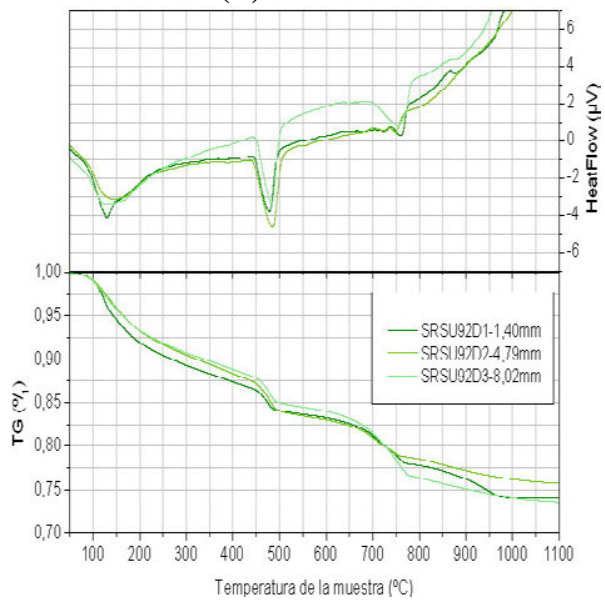

Figura 62. ATD-TG en muestras SRSU

Hasta temperatura de $140^{\circ} \mathrm{C}$ el contenido de agua se presenta ligeramente por encima del valor de referencia en las secciones en contacto con la disolución. Este incremento es más evidente a 92 días de exposición, probablenete debido a la formación de etringita que se reseñaba en las curvas de ATD.

En el resto de intervalos analizados se presentan ligeras variaciones con respecto a los contenidos de referencia, que nos se ajustan a una tendencia determinada.

El contenido total de agua de las muestras expuestas durante 92 días presenta un ligero incremento en las secciones más externas.

En la Figura 64 se muestra los contenidos de portlandita y portlandita equivalente de la muestras. Indicando en línea discontinua azul el valor de portlandita de las muestras de 
referencia, y en línea discontinua roja el valor de portlandita equivalente de referencia calculado con los datos de las muestras en medios SRCA y SRAI.

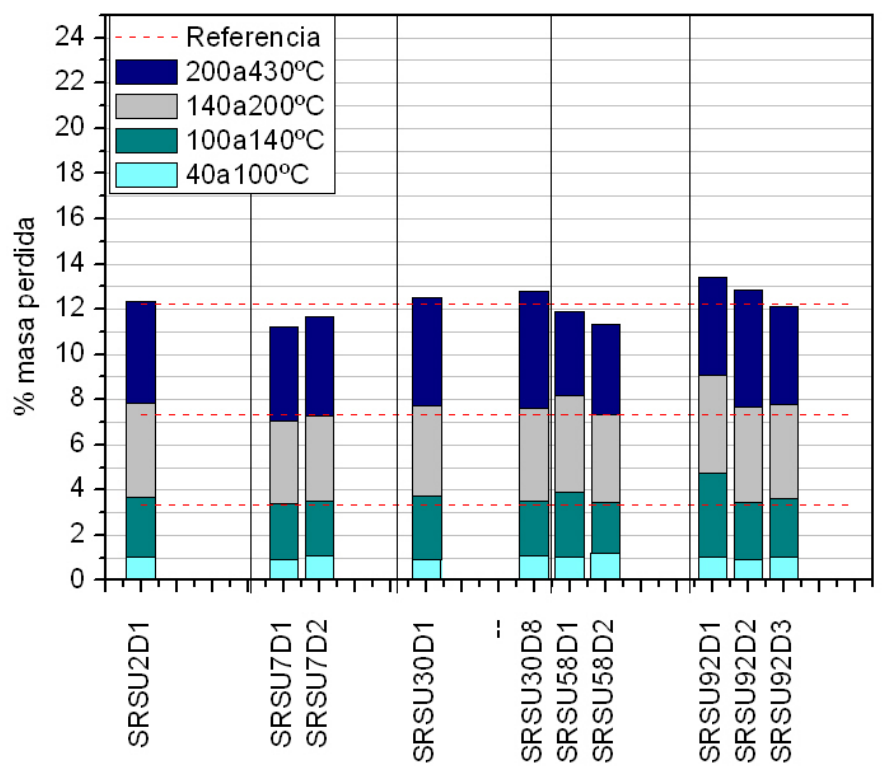

Figura 63. Pérdidas de masa en la región Ldh por tramos de temperatura en las muestras SRSU

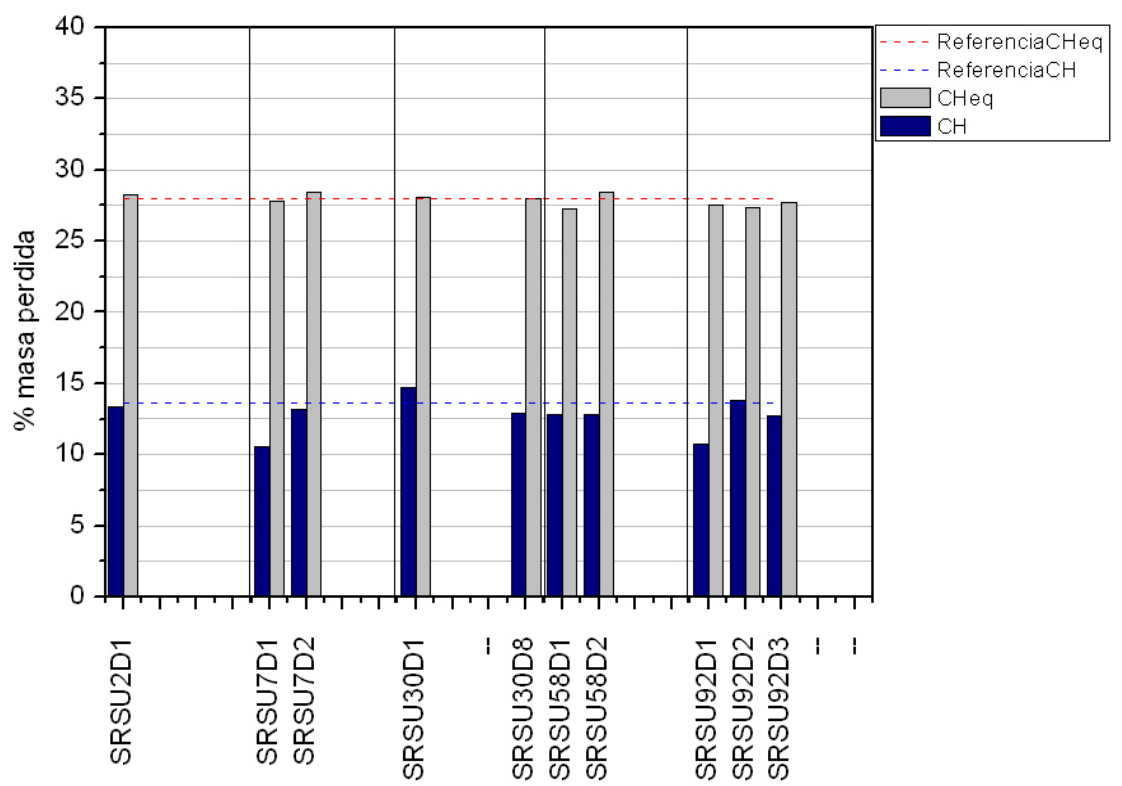

Figura 64. Contenidos de portlandita y portlandita equivalente en muestra SRSU

Los datos de $\mathrm{CH}$ calculados presentan ligeras variaciones con respecto a los calculados de referencia. Sin embargo cuando contrastamos los datos con los de CHeq, observamos que 
comparando con los contenidos de referencia no se observa lixiviación de este compuesto hacia la disolución.

La CH es el constituyente de la matriz con mayor solubilidad. En presencia de medio con alta fuerza iónica cabría esperar cierto grado de lixiviación de la misma, al menos en las secciones en contacto con la disolución agresiva, por lo que es presumible que la disolución presente cierto contenido de $\mathrm{Ca}^{2+}$.

En la sección 4.4.3.2 se muestra como las variaciones de $\mathrm{Ca}^{2+}$ en las muestras son muy pequeñas. El contenido de $\mathrm{Ca}^{2+}$ lixiviado hacia la disolución también es pequeño y se estabiliza en la disolución entorno a los 14 días de exposición con un valor aproximado para este cemento de 125 ppm. Por ello, puede que el la lixiviación de ion calcio no se apecie evaluando el contenido de $\mathrm{CH}$ de las probetas.

Además, cabe la posibilidad de que la lixiviación de $\mathrm{Ca}^{2+}$ procedente de los compuestos de la probeta se vea frenada por la saturación de la misma en $\mathrm{CaSO}_{4}$ en la disolución. La fluctuación de los contenidos de $\mathrm{CH}$ en la probeta puede ser debida a disolución y precipitación de la misma en función de los equilibrios de precipitación de otros compuestos en los que está presente el sulfato y el calcio como las fases AFt y los sulfatos cálcicos hidratados.

Si en material en contacto con la disolución de sulfatos se encuentran carbonatos cálcicos, éstos pueden estar disponibles para la formación de yeso o etringita, lo cual puede incidir en una reducción de la disolución de CH y descalcificación de los silicatos cálcicos hidratados (Girardi y Di Maggio, 2011).

En la Figura 65 se muestran el resultado de los termogramas registrados sobre las muestras de pasta de cemento II sumergidos en la disolución SU.

En las muestras de cemento II se observa la agudización de la banda a $125^{\circ} \mathrm{C}$ asociada con la formación de etringita desde los primeros días de exposición en la sección en contacto con la disolución agresiva. A 58 días de exposición parece intuirse una reducción de la cantidad de portlandita en la primera sección, pero esta tendencia no se conserva a los 92 días de ensayo.

En la Figura 66 se muestran los datos de las pérdidas de masa calculadas en las muestras de pasta de cemento IISU. En ella se muestran, en línea roja discontinua, los valores de masa 
perdida de las muestras de referencia correspondientes a los tramos de $40^{\circ} \mathrm{C}$ hasta $140^{\circ} \mathrm{C}$, hasta el inicio de la banda de deshidroxilación (entorno a $430^{\circ}$ ) y el contenido total de agua desde $40^{\circ} \mathrm{C}$ hasta el inicio de la banda de deshidroxilación.

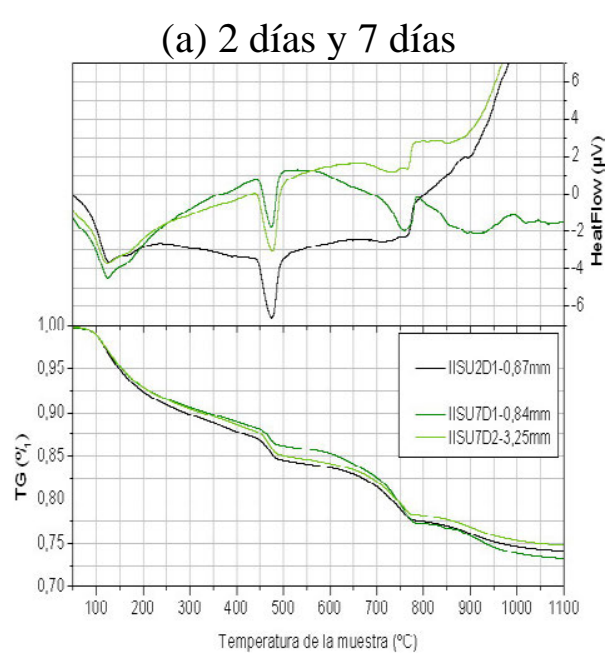

(c) 58 días

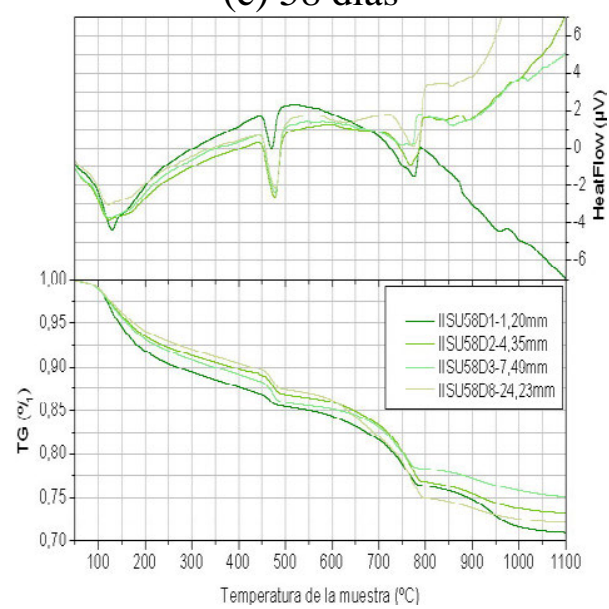

(b) 30días

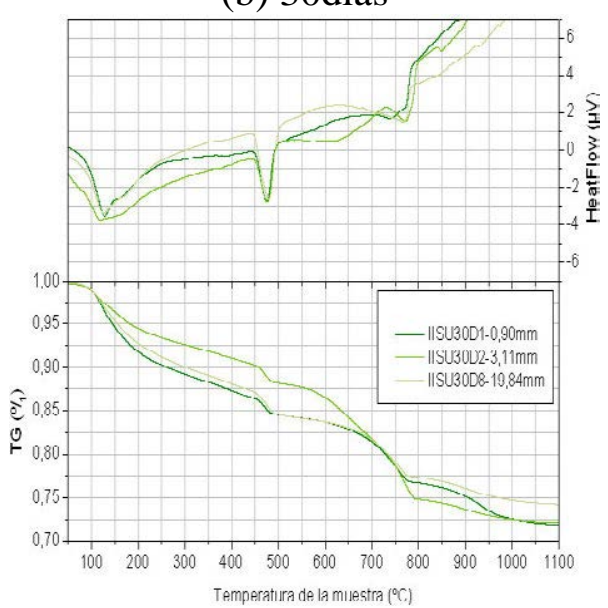

(d) 92 días

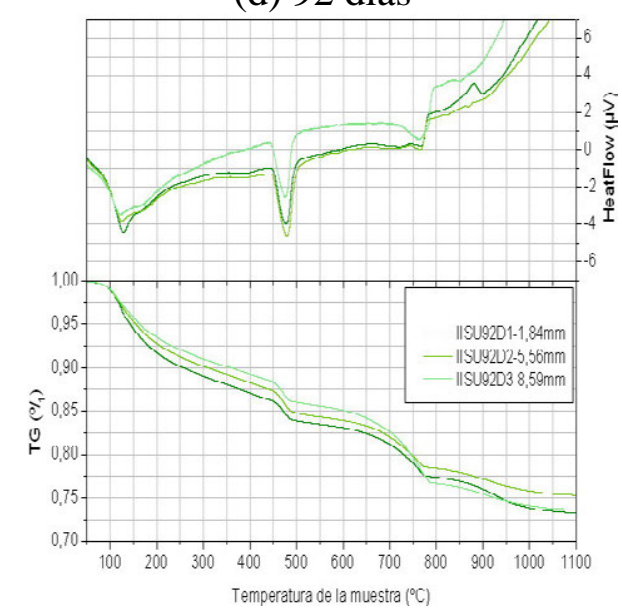

Figura 65. ATD-TG en muestras IISU 


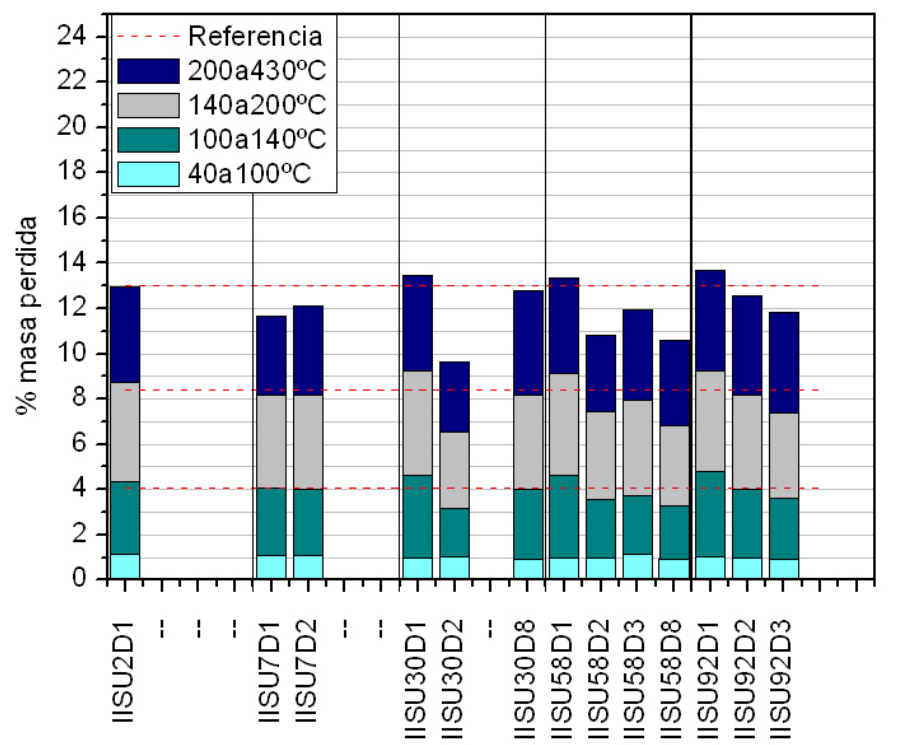

Figura 66. Pérdidas de masa en la región Ldh por tramos de temperatura en las muestras IISU

La masa de agua perdida hasta $140^{\circ} \mathrm{C}$ es ligeramente superior con respecto al contenido de las muestras de referencia en la primera sección analizada. Este incremento se observa desde el inicio del ensayo, pero empieza a ser más evidente a los 30 días de exposición, y sólo en las secciones en contacto con la disolución.

Como se comentó anteriormente la presencia de sulfato en el medio propiciaría la formación de fases AFt. La difusión de un ion grande como es sulfato es difícil, lo que condicionaría que esta formación sólo se llevara a cabo en la región más externa de la probeta.

La precipitación de etringita reduciría la concentración de sulfato en zona disolución próxima, lo que podría condicionar que una parte de esta etringita se transformase en fase AFm.

El agua calculada en la región 200 a $430^{\circ} \mathrm{C}$ desciende en todos los casos con respecto al valor de referencia, probablemente por la transformación de fases aluminato de composición intermedia en fases AFt y/o AFm.

En la Figura 67 se muestra los contenidos de portlandita y portlandita equivalente de la muestras. Indicando en línea discontinua azul el valor de portlandita de las muestras de referencia, y en línea discontinua roja el valor de portlandita equivalente de referencia calculado con los datos de las muestras en medios IICA y IIAI. 


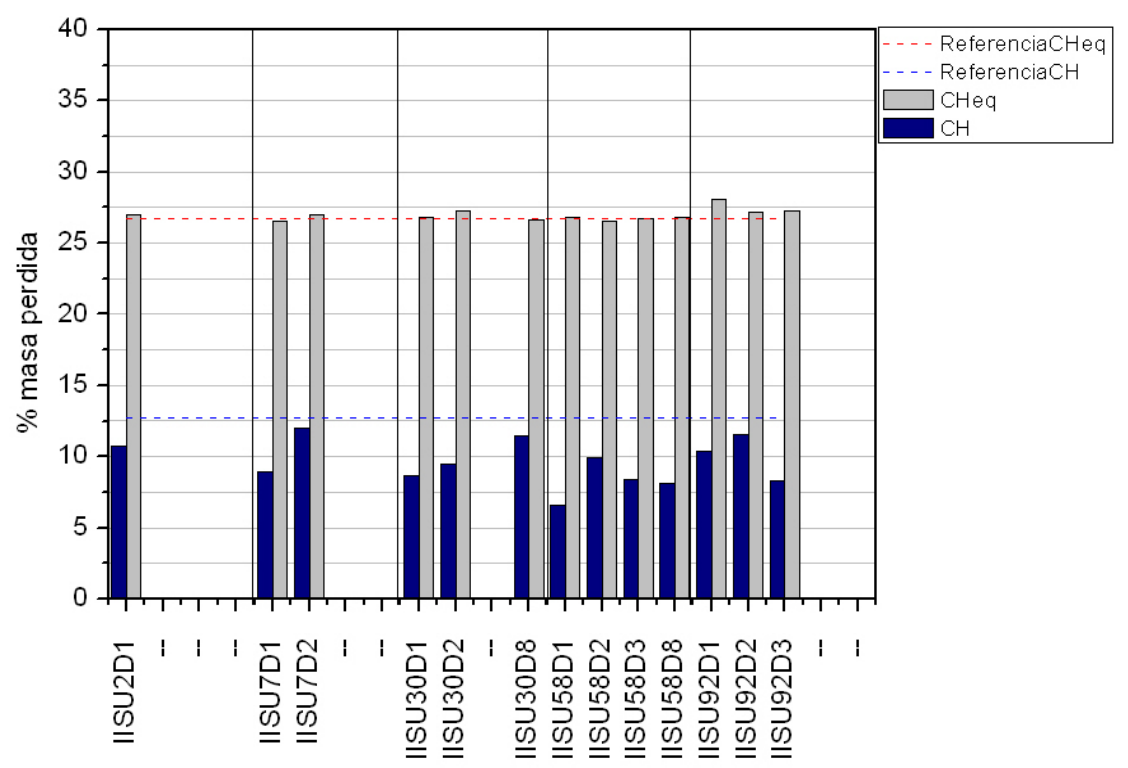

Figura 67. Contenidos de portlandita y portlandita equivalente en muestra IISU

El contenido de $\mathrm{CH}$ en prácticamente todos los casos analizados se mantiene por debajo del contenido en las muestras de referencia, por lo que debemos que el grado de carbonatación de las muestras es mayor.

Con respecto a los valores de CHeq, el contenido se sitúa próximo al de los valores en las muestras de referencia, por lo que no se observa lixiviación de portlandita en el medio.

Haciendo la misma consideración que en la muestras de pasta de cemento SR tenemos en cuenta las variaciones de $\mathrm{Ca}^{2+}$ en la probeta, así como la concentración de $\mathrm{Ca}^{2+}$ lixiviado. En este caso las variaciones en el contenido de $\mathrm{Ca}^{2+}$ en las muestras son más apreciables (Figura 106). El contenido de $\mathrm{Ca}^{2+}$ lixiviado hacia la disolución es pequeño y se estabiliza en la disolución entorno a los 14 días de exposición con un valor aproximado para este cemento de 155 ppm.

En este caso, parece que el contenido de portlandita en las muestras se mantiene y el contenido de fases AFt o sulfato cácico hidratado en las muestras aumenta. Por ello la reducción de ion calcio en el material y su incremento en la disolución agresiva parece ser debida a la disolución de otros compuestos cálcicos con $\mathrm{pH}$ de estabilidad próximos a los de la portlancita, cuyo proceso de lixiviación se ve limitado rápidamente por la saturación de la misma en $\mathrm{CaSO}_{4}$ en la disolución. 
En la Figura 68 se muestran el resultado de los termogramas registrados sobre las muestras de pasta de cemento IV sumergidos en la disolución SU.

(a) 2 días y 7 días

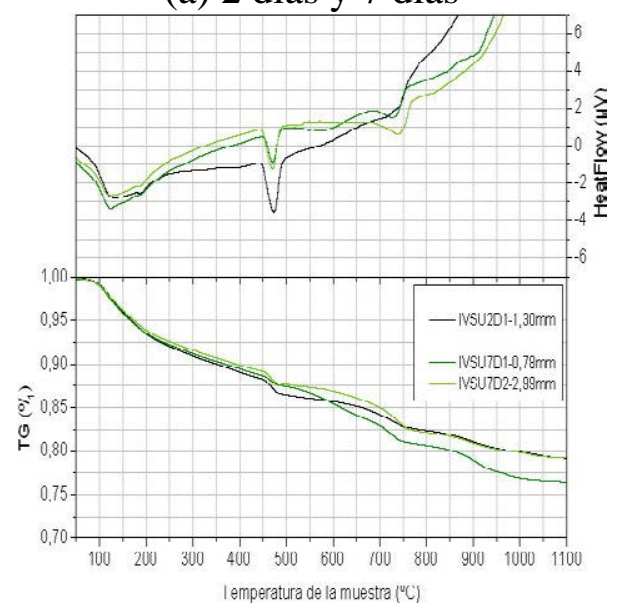

(c) 58 días

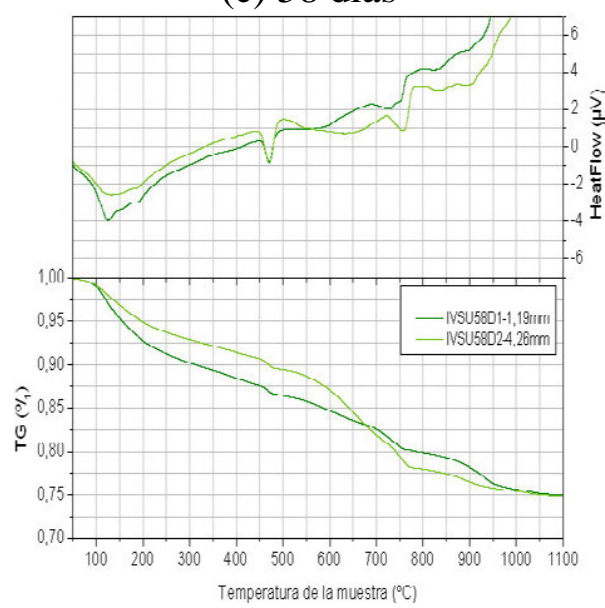

(b) 30 días

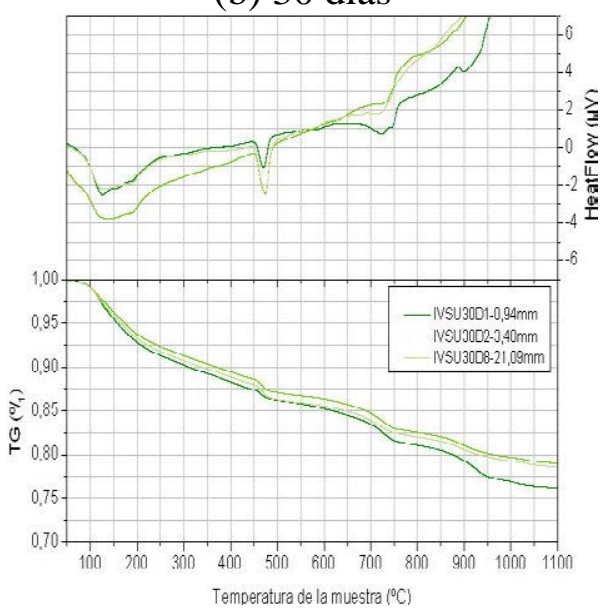

(d) 92 días

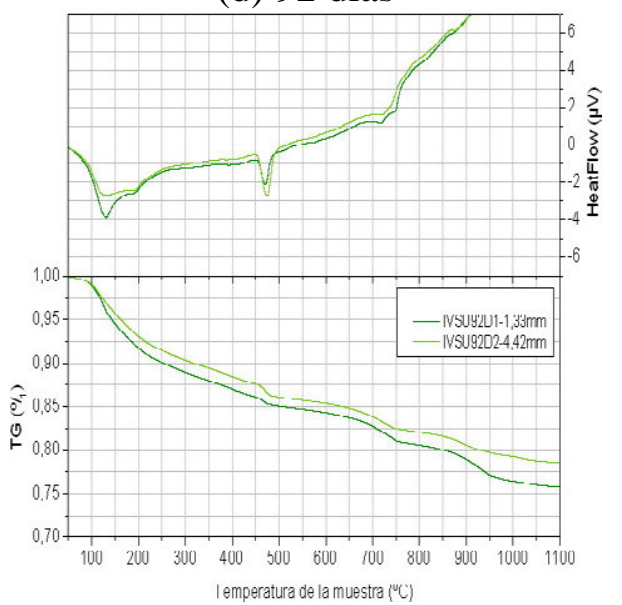

Figura 68. ATD-TG en muestras IVSU

Las pastas de cemento IV sumergidas en el medio SU también presentan más aguda la banda a $125^{\circ} \mathrm{C}$, en las primeras secciones, y desde los 7 días de exposición. Sin embargo la banda que definiría la fase monosulfoaluminato se mantiene prácticamente constante.

Los resultados de las pérdidas de agua calculadas por tramos de temperatura se muestran en la Figura 69. En ella se muestran, en línea roja discontinua, los valores de masa perdida de las muestras de referencia correspondientes a los tramos de $40^{\circ} \mathrm{C}$ hasta $140^{\circ} \mathrm{C}$, hasta el inicio de la banda de deshidroxilación (entorno a $430^{\circ}$ ) y el contenido total de agua desde $40^{\circ} \mathrm{C}$ hasta el inicio de la banda de deshidroxilación. 


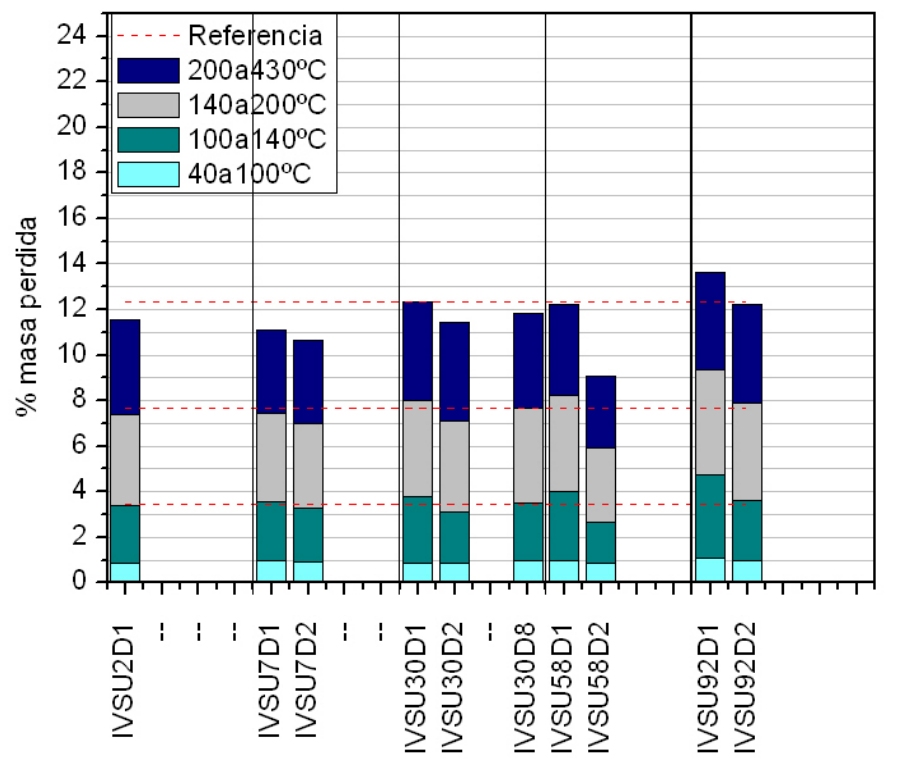

Figura 69. Pérdidas de masa en la región Ldh por tramos de temperatura en las muestras IVSU

En las pérdidas calculadas hasta $140^{\circ} \mathrm{C}$ se observa un incremento de la cantidad de agua perdida en las primeras secciones a partir de los 30 días de exposición. Una vez más parece que este incremento puede estar relacionado con el incremento de las fases AFt en las primeras secciones de las probetas propiciado por la disponibilidad de iones sulfato en el medio.

Con respecto a la cantidad total en la región Ldh, las muestras se encuentran ligeramente por debajo que la calculada para las muestras de referencia, y sólo en el caso de 92 días de exposición el contenido total del la primera sección se encuentra por encima de los valores de referencia.

En la Figura 70 se muestra los contenidos de portlandita y portlandita equivalente de la muestras. Indicando en línea discontinua azul el valor de portlandita de las muestras de referencia, y en línea discontinua roja el valor de portlandita equivalente de referencia calculado con los datos de las muestras en medios IVCA y IVAI. 


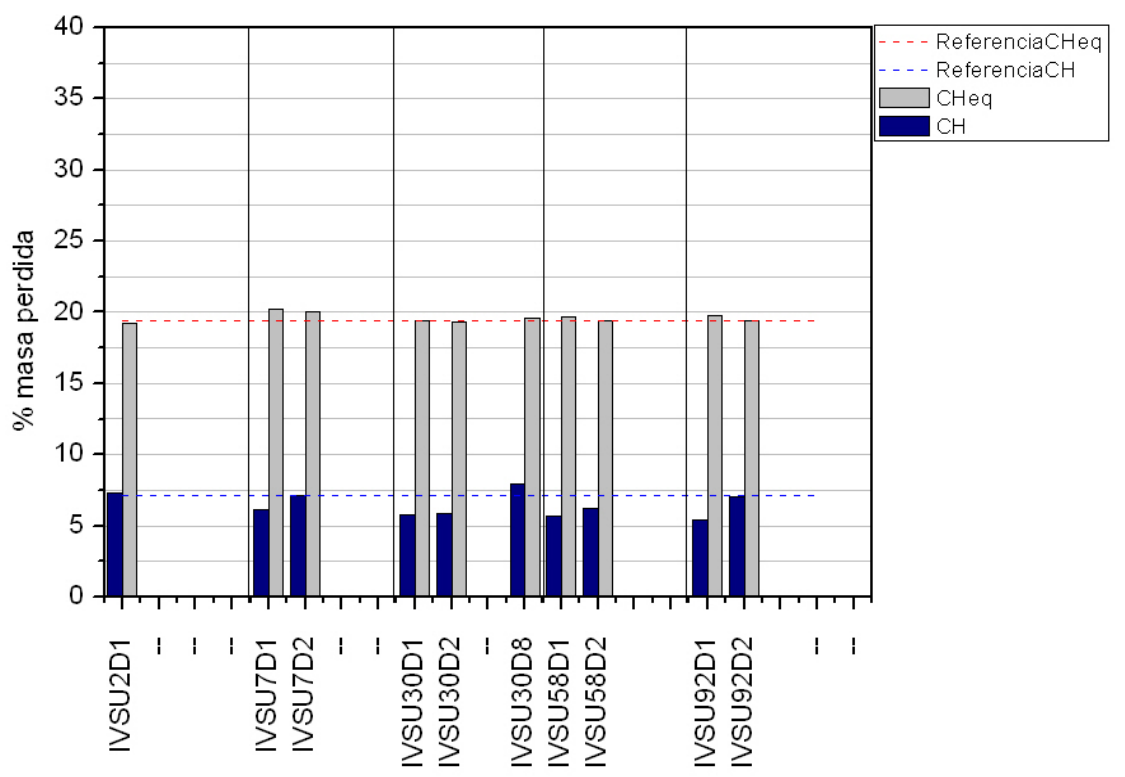

Figura 70. Contenidos de portlandita y portlandita equivalente en muestras IVSU

El contenido de portlandita se encuentra por debajo del contenido de referencia en las primeras secciones. Sin embargo si comparamos los resultados de portlandita equivalente las muestras presentan un contenido similar o ligeramente superior al de las muestras de referencia, por lo que se puede prever que no se ha producido lixiviación de este compuesto hacia la disolución.

En este caso, la variación de ion calcio en las probetas es la menor de todas como se verá más adelante (Figura 107). El contenido de ion calcio en la disolución es pequeño y se estabiliza en la disolución entorno a los 14 días de exposición con un valor aproximado para este cemento de $115 \mathrm{ppm}$. Si tenemos en cuenta estos valores y consideramos que la disolución puede encontrarse saturada por la presencia de una alta concentración de ion sulfato, se puede prever que el grado de lixiviación de las muestras de este tipo de pasta de cemento es pequeño.

\section{Análisis térmico en el medio AN}

En la Figura 71 se muestran el resultado de los termogramas registrados sobre las muestras de pasta de cemento SR sumergidos en la disolución AN. 
(a) 2 días y 7 días

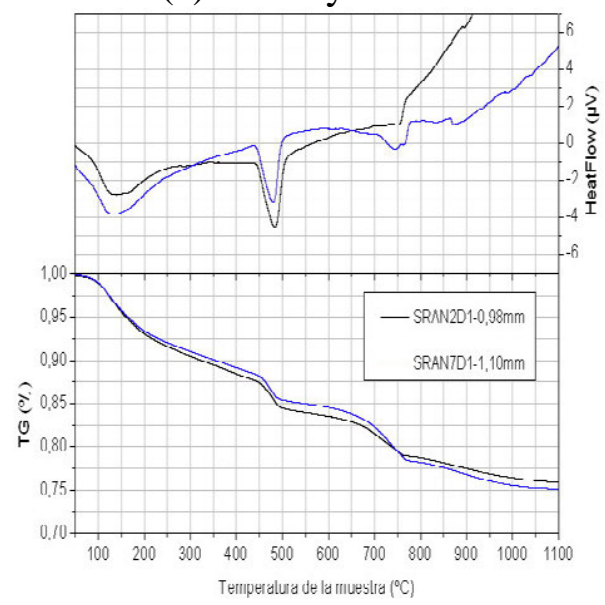

(c) 58 días

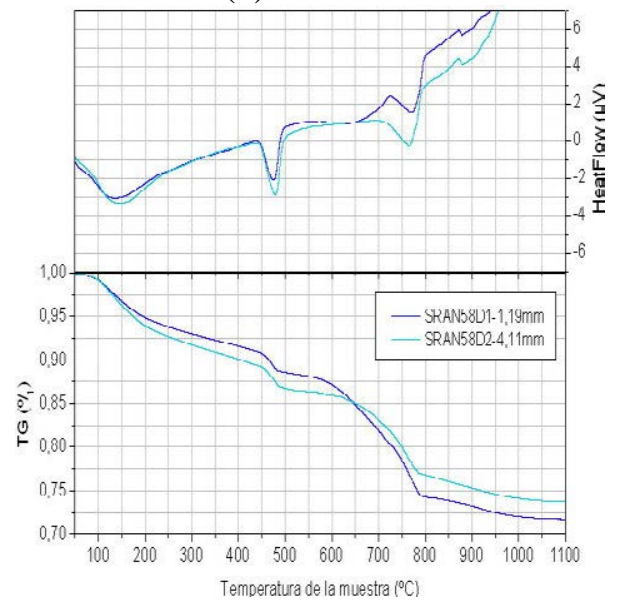

(b) 30 días

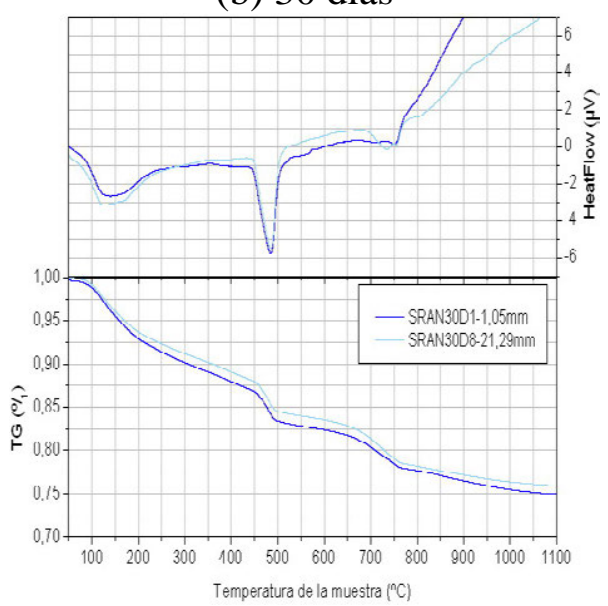

(d) 92 días

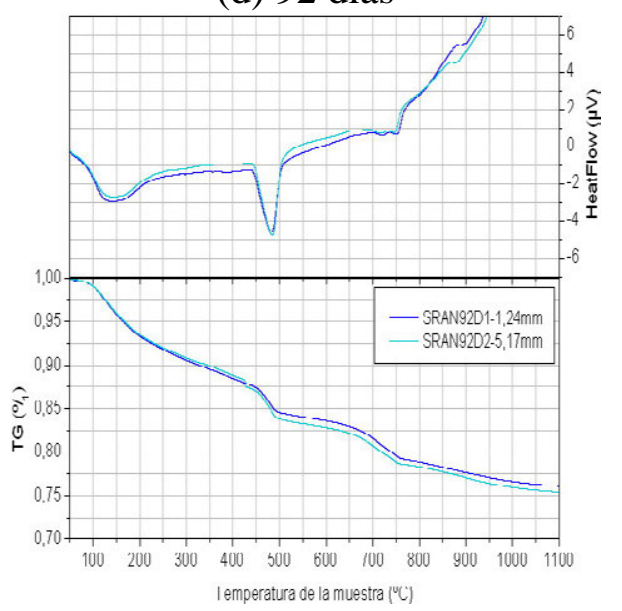

Figura 71. ATD-TG en muestras SRAN

Los cambios que presentan las muestras sumergidas en la disolución AN son escasos, las bandas son cualitativamente muy similares y no se observan procesos de lixiviación.

En la Figura 72 se muestran los datos de las pérdidas de masa calculadas en las muestras de pasta de cemento SRAN. En ella se muestran, en línea roja discontinua, los valores de masa perdida de las muestras de referencia correspondientes a los tramos de $40^{\circ} \mathrm{C}$ hasta $140^{\circ} \mathrm{C}$, hasta el inicio de la banda de deshidroxilación (entorno a $430^{\circ}$ ) y el contenido total de agua desde $40^{\circ} \mathrm{C}$ hasta el inicio de la banda de deshidroxilación. 


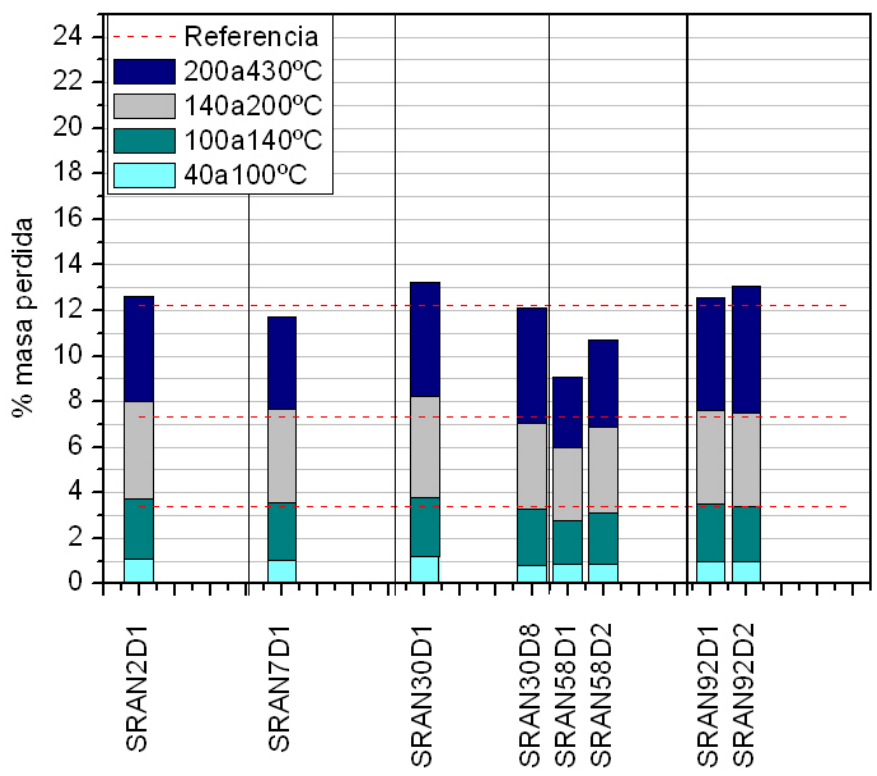

Figura 72. Pérdidas de masa en la región Ldh por tramos de temperatura en las muestras SRAN

Las cantidades de agua calculadas en cada uno de los tramos y por cantidades totales presenta pocas alteraciones a lo largo de la probeta, y con respecto al tiempo de exposición (excepto en el caso de la primera sección a 58 días, donde la cantidad de agua es inusualmente baja por lo que se ha descartado este dato).

Los contenidos de portlandita y portlandita equivalente se muestran en la Figura 73, indicando en línea discontinua azul el valor de portlandita de las muestras de referencia, y en línea discontinua roja el valor de portlandita equivalente de referencia calculado con los datos de las muestras en medios SRCA y SRAI.

Los contenidos de portlandita se mantienen ligeramente por debajo de los correspondientes a las muestras de referencia. Excepto a 30 días, lo cual puede ser causa de fenómenos de carbonatación diferencial.

Los contenidos de portlandita equivalente se mantienen en el rango de las muestras de referencia a lo largo de todo el tiempo de ensayo y en la profundidad de la probeta.

No se observa por tanto la incidencia de procesos de lixiviación en las muestras. 


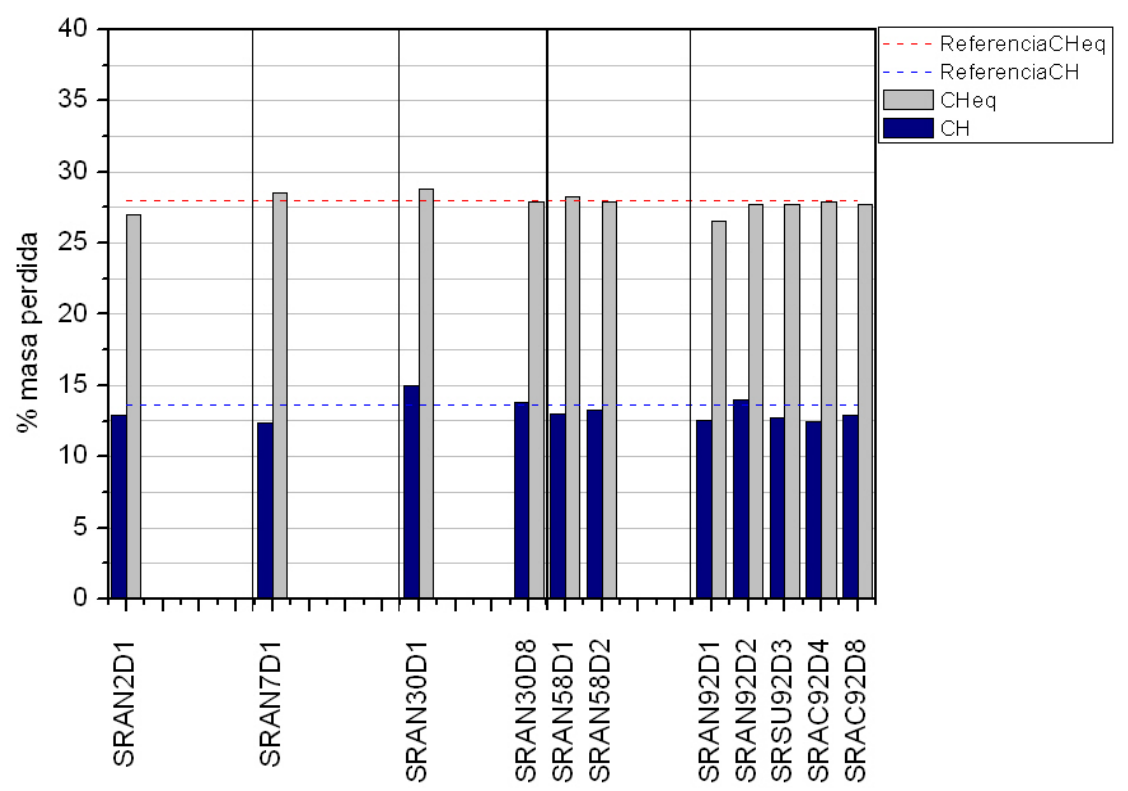

Figura 73. Contenidos de portlandita y portlandita equivalente en muestras SRAN

En la Figura 74 se muestran el resultado de los termogramas registrados sobre las muestras de pasta de cemento II sumergidos en la disolución AN.

$\mathrm{Al}$ igual que las pastas de cemento SR, los termogramas obtenidos con las muestras de cemento II presentan cambios poco significativos desde el punto de vista cualitativo.

En la Figura 75 se muestran los datos de las pérdidas de masa calculadas en las muestras de pasta de cemento IIAN. En ella se muestran, en línea roja discontinua, los valores de masa perdida de las muestras de referencia correspondientes a los tramos de $40^{\circ} \mathrm{C}$ hasta $140^{\circ} \mathrm{C}$, hasta el inicio de la banda de deshidroxilación (entorno a $430^{\circ}$ ) y el contenido total de agua desde $40^{\circ} \mathrm{C}$ hasta el inicio de la banda de deshidroxilación.

El contenido de agua total perdida y por tramos se mantiene constante a lo largo del tiempo de exposición y en la profundidad de la probeta.

Los contenidos de portlandita y portlandita equivalente se muestran en la Figura 76, indicando en línea discontinua azul el valor de portlandita de las muestras de referencia, y en línea discontinua roja el valor de portlandita equivalente de referencia calculado con los datos de las muestras en medios IICA y IIAI. 
En general los valores de portlandita son próximos a los valores de las muestras de referencia, excepto en el caso de las muestras a 7 y 58 días. Sin embargo cuando comparamos con el valor de portlandita equivalente total las muestras se encuentran en el rango de las muestras de referencia.

(a) 2 días y 7 días

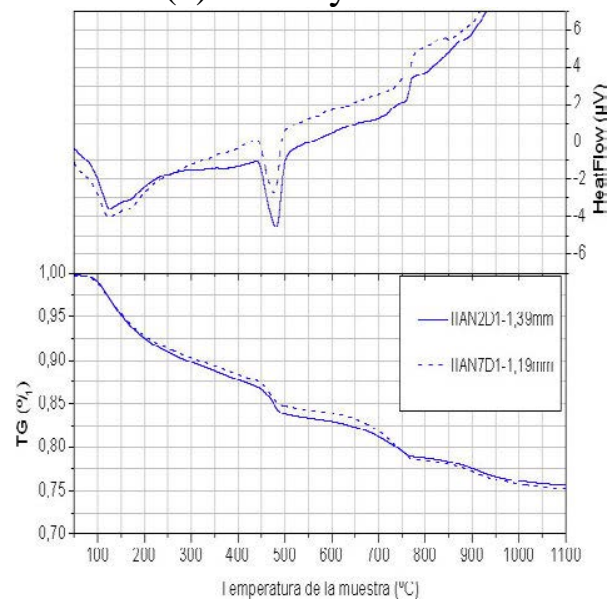

(c) 58 días y 92 días

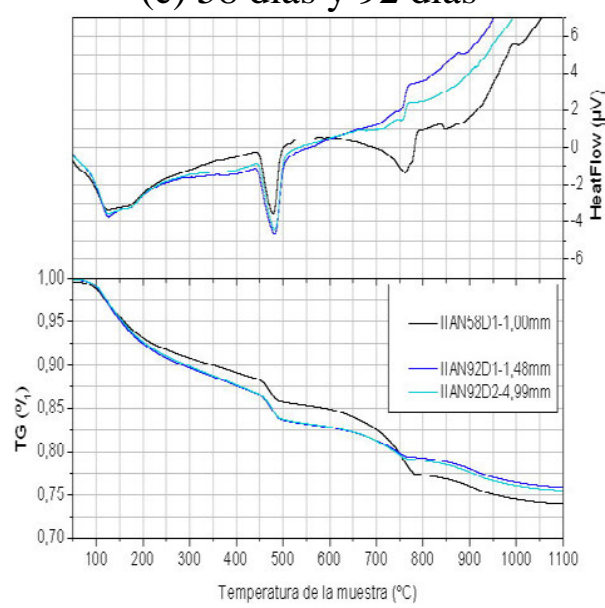

(b) 30 días

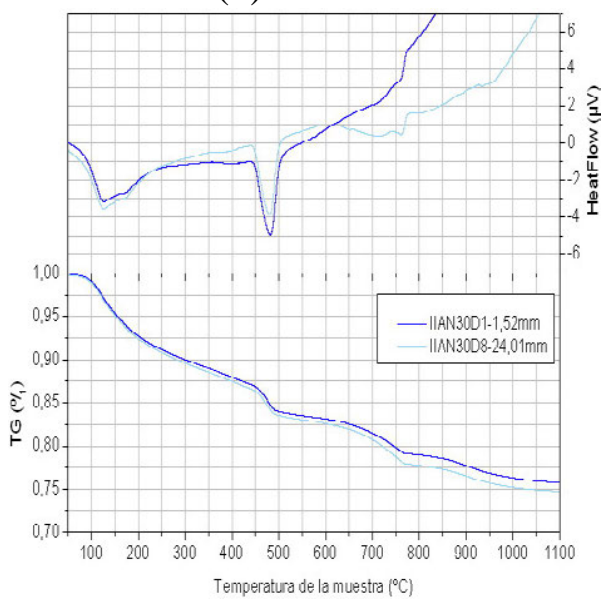

Figura 74. ATD-TG en muestras IIAN 


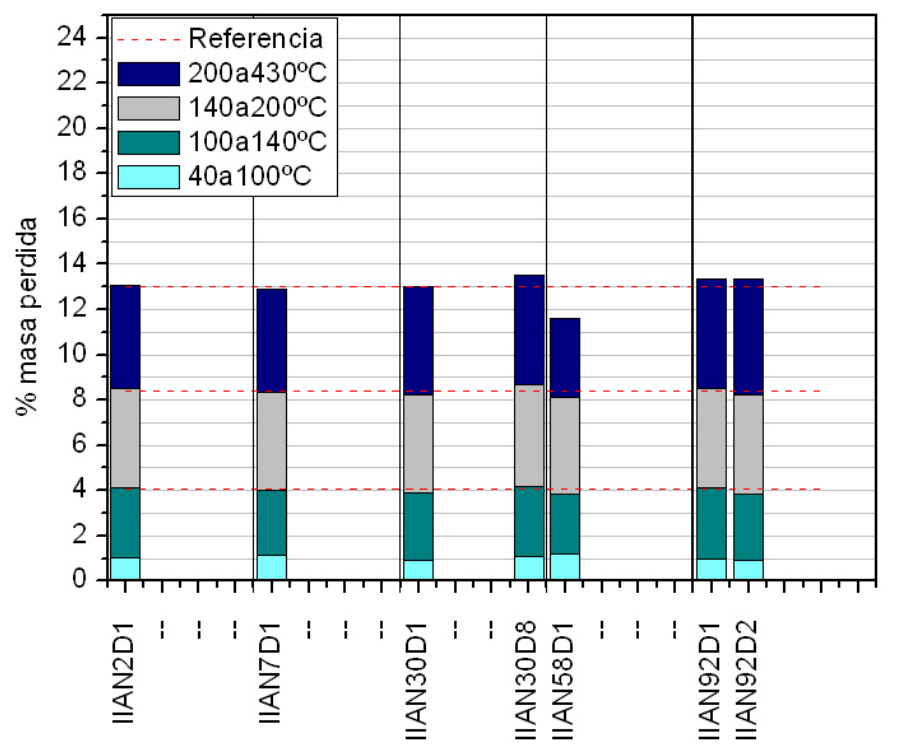

Figura 75. Pérdidas de masa en la región Ldh por tramos de temperatura en las muestras IIAN

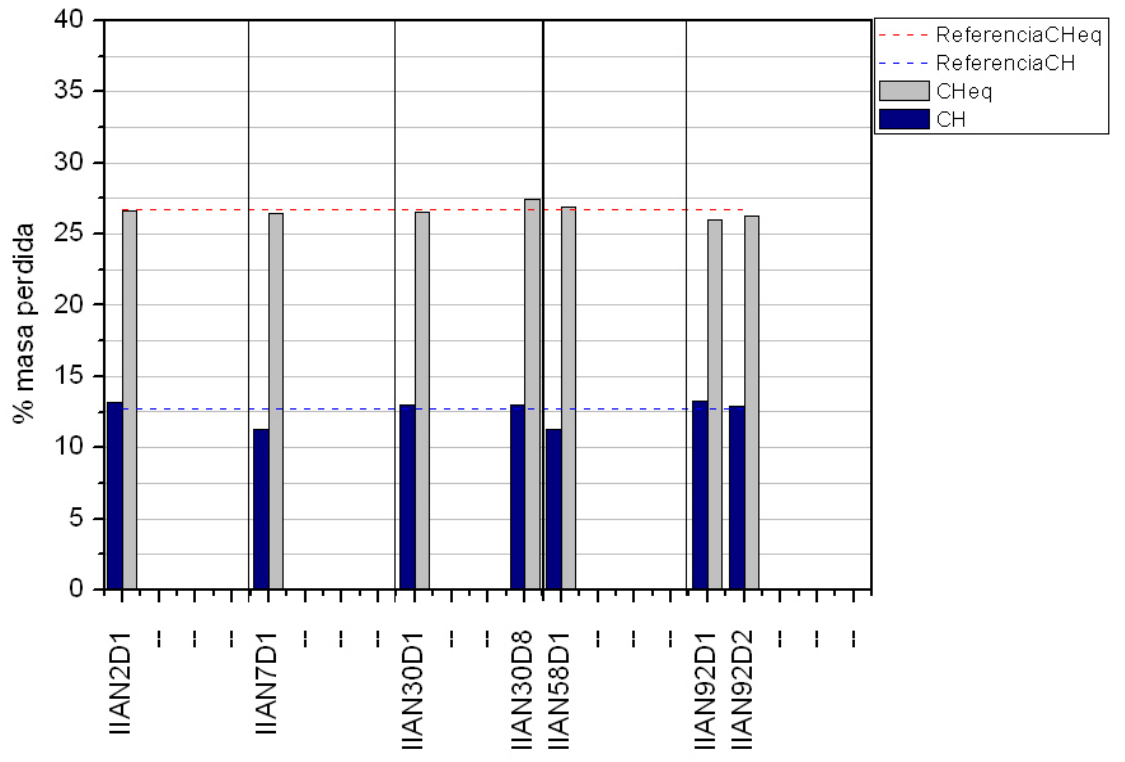

Figura 76. Contenidos de portlandita y portlandita equivalente en muestras IIAN

En la Figura 77 se muestran los termogramas de las muestras IVAN. En la Figura 78 los datos de las pérdidas de masa calculadas en las muestras de pasta de cemento IVAN. 
(a) 2 días y 7 días

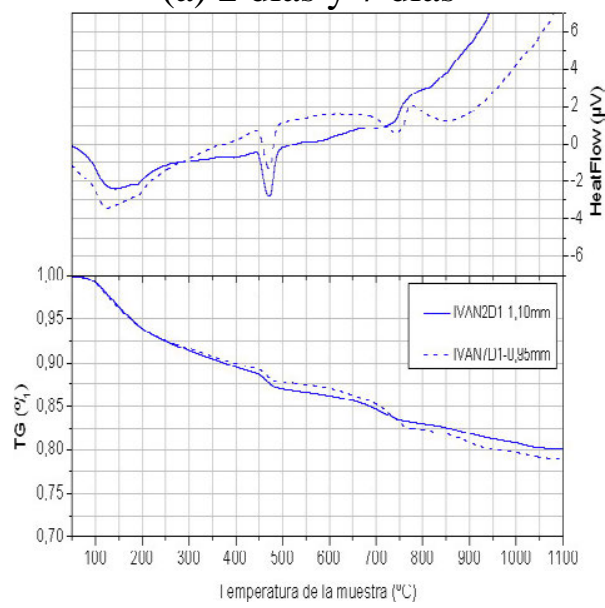

(c) 58 días

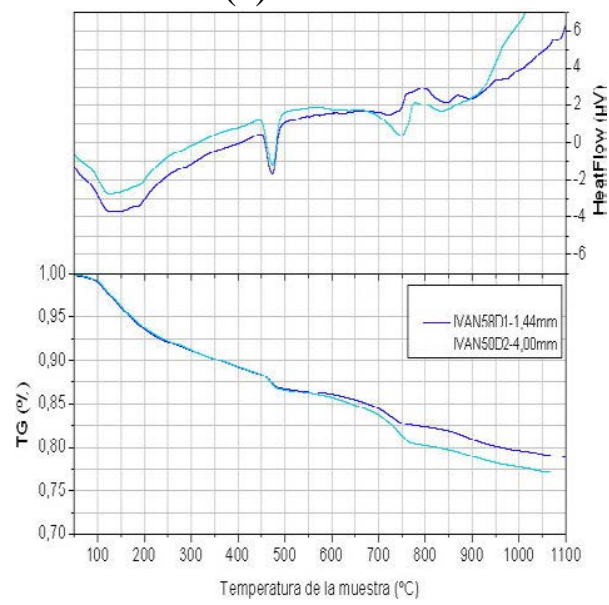

(b) 30 días

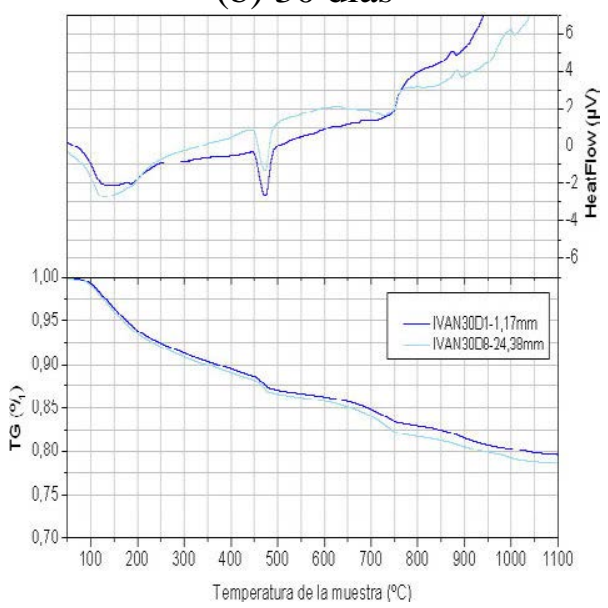

(d) 92 días

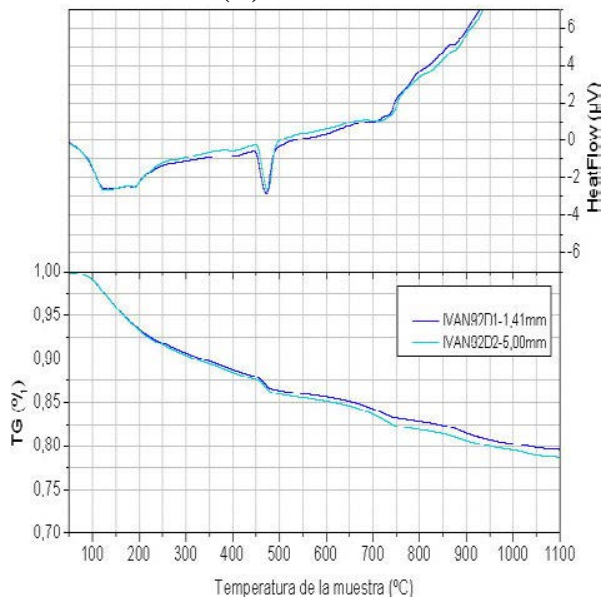

Figura 77. ATD-TG en muestras IVAN

$\mathrm{Al}$ igual que en el resto de las pastas analizadas en este medio, los termogramas obtenidos con las muestras de cemento IV presentan cambios poco significativos desde el punto de vista cualitativo.

El contenido de agua total perdida y por tramos se mantiene constante a lo largo del tiempo de exposición y en la profundidad de la probeta. 


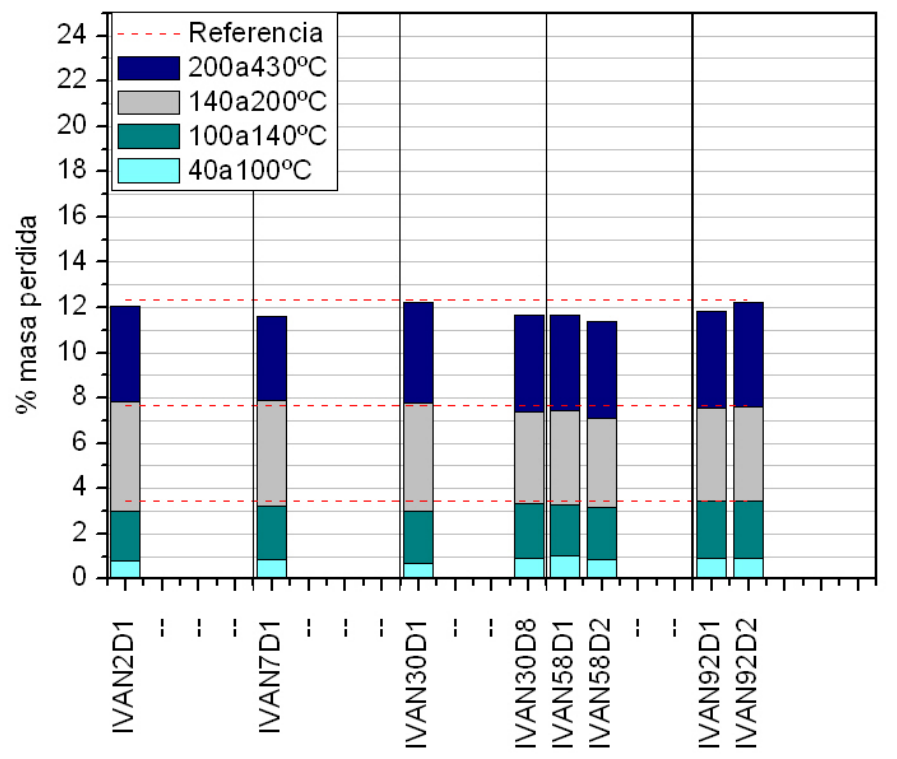

Figura 78. Pérdidas de masa en la región Ldh por tramos de temperatura en las muestras IVAN

En la Figura 79 se muestra los contenidos de portlandita y portlandita equivalente de la muestras, indicando en línea discontinua azul el valor de portlandita de las muestras de referencia, y en línea discontinua roja el valor de portlandita equivalente de referencia calculado con los datos de las muestras en medios IVCA y IVAI.

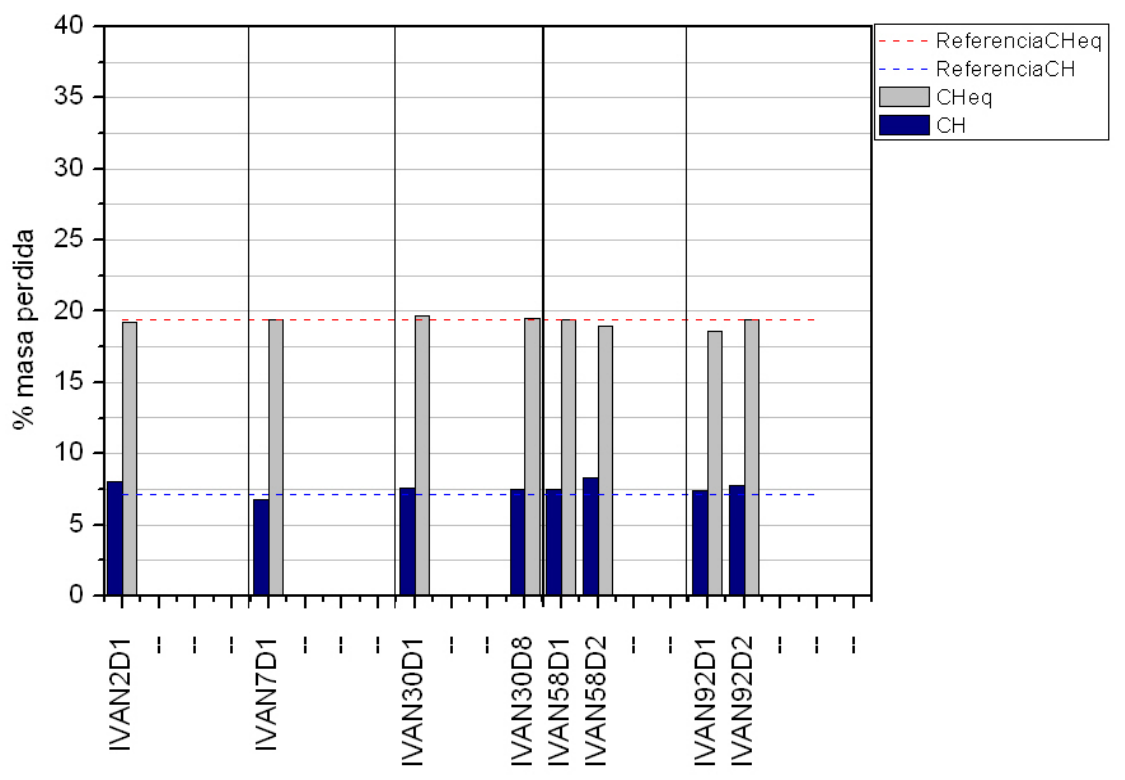

Figura 79. Contenidos de portlandita y portlandita equivalente en muestras IVAN 
Los valores de portlandita son próximos a los valores de las muestras de referencia. A partir de los datos calculados se puede afirmar que no se produce lixiviación de portlandita.

\subsubsection{DIFRACCIÓN DE RAYOS-X}

En este apartado se mostrarán los resultados de difracción de rayos-X realizados sobre las muestras de análisis obtenidas.

La identificación de compuestos cristalinos en las muestras de pasta de cemento se ha realizado por comparación de los difractogramas de las muestras analizadas con los difractogramas de los compuestos aislados. En esta tesis doctoral se han empleado las fichas cristalográficas del ICDD. En la Tabla 35 se muestra el listado de fichas empleadas en la identificación de compuestos.

Tabla 35. Listado de fichas del ICDD

\begin{tabular}{|c|c|c|}
\hline Compuesto & Ficha & Abreviatura \\
\hline $\mathrm{Ca}(\mathrm{OH})_{2}$ & 040733 & $\mathrm{P}$ \\
\hline $3 \mathrm{CaO} \cdot \mathrm{Al}_{2} \mathrm{O}_{3} \cdot 3 \mathrm{CaSO}_{4} \cdot 32 \mathrm{H}_{2} \mathrm{O}$ & 411451 & E \\
\hline $\mathrm{CaCO}_{3}$ (Calcita) & 050586 & $\mathrm{C}$ \\
\hline $\mathrm{CaCO}_{3}$ (Vaterita) & 330268 & $\mathrm{~V}$ \\
\hline Browmillerita & 300226 & $\mathrm{~B}$ \\
\hline Mullita & 150776 & M \\
\hline $3 \mathrm{CaO} \cdot \mathrm{Al}_{2} \mathrm{O}_{3} \cdot \mathrm{CaCO}_{3} \cdot 11 \mathrm{H}_{2} \mathrm{O}$ & 410219 & $\mathrm{D}$ \\
\hline $\mathrm{SiO}_{2}$ & 461045 & $\mathrm{~S}$ \\
\hline $\mathrm{CaO}$ & 030865 & $\mathrm{Z}$ \\
\hline $\mathrm{Fe}_{2} \mathrm{O}_{3}$ & 330664 & $\mathrm{~F}$ \\
\hline Augita & 240201 & $\mathrm{U}$ \\
\hline $3 \mathrm{CaO} \cdot \mathrm{Al}_{2} \mathrm{O}_{3} \cdot \mathrm{CaSO}_{4} \cdot 12 \mathrm{H}_{2} \mathrm{O}$ & 450158 & $\mathrm{~T}$ \\
\hline \begin{tabular}{ll}
\multirow{2}{*}{ idros } & $\beta \mathrm{C}_{2} \mathrm{~S}$ \\
\cline { 2 - 2 } & $\mathrm{C}_{3} \mathrm{~S}$
\end{tabular} & $\begin{array}{l}330302 \\
310301\end{array}$ & $\mathrm{X}$ \\
\hline
\end{tabular}

En la Figura 80 se muestras los difractogramas de las muestras de referencia de los tres tipos de pasta de cemento analizada. 


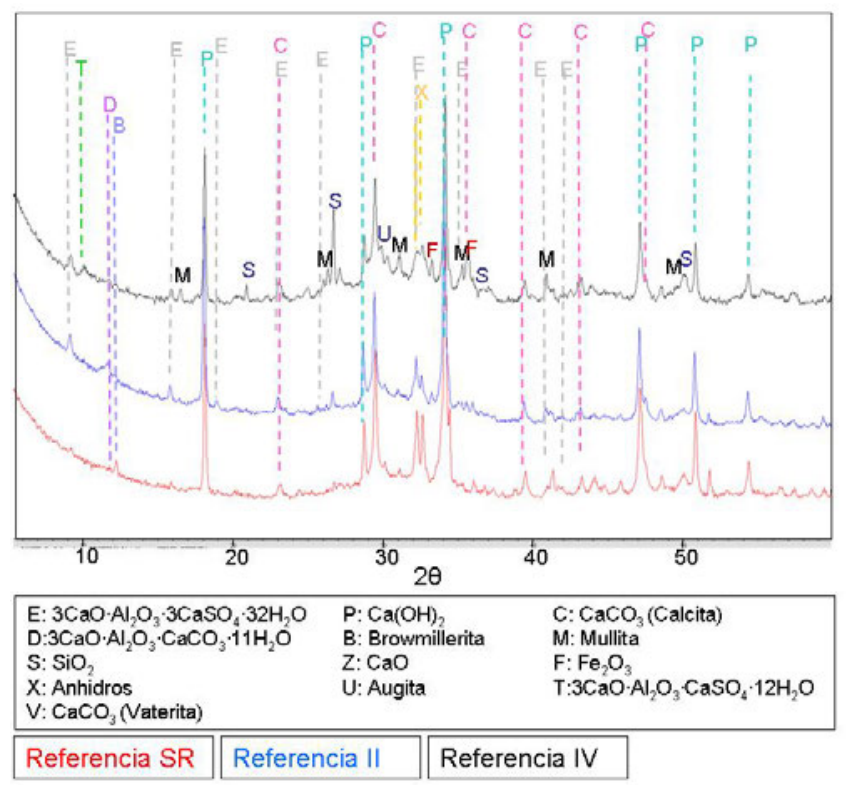

Figura 80.Análisis por DRX de las muestras de referencia

Si comparamos los tres tipos de pasta se observa que la pasta de cemento SR presenta una proporción de compuestos anhidros mayor que las otras dos. El contenido de etringita también es menor. Además presenta bandas de portlandita y calcita con una intensidad ligeramente superior.

La muestra de pasta de cemento II es la que presenta un contenido de etringita ligeramente superior. En esta muestra, además de los compuestos portlandita, etringita, calcita y compuestos anhidros, habituales en las pastas de cemento hidratadas, se observa la presencia de sílice y óxidos de hierro.

En la muestra de pasta de cemento IV ademas de portlandita, etringita, calcita y compuestos anhidros, habituales en las pastas de cemento hidratadas, aparecen las bandas correspondientes a mullita y monosulfoaluminato tetracálcico. La mullita es un mineral habitual en la composición de las cenizas volantes.

\subsubsection{Difracción de rayos- $X$ en las muestras expuestas al medio AC}

En la Figura 81, Figura 82 y Figura 83 se muestran los difractogramas de muestras de pasta de cemento SR, II y IV expuestas al medio AC durante dos días. 
A los dos días de exposición las muestras no presentan signos de degradación en ninguno de los tipos de pasta analizados. En la primera sección de los tres tipos de muestra analizados se conservan las bandas corrspondientes a portlandita, calcita y etringita con respecto a las presentadas por las muestras en secciones mas profundas.

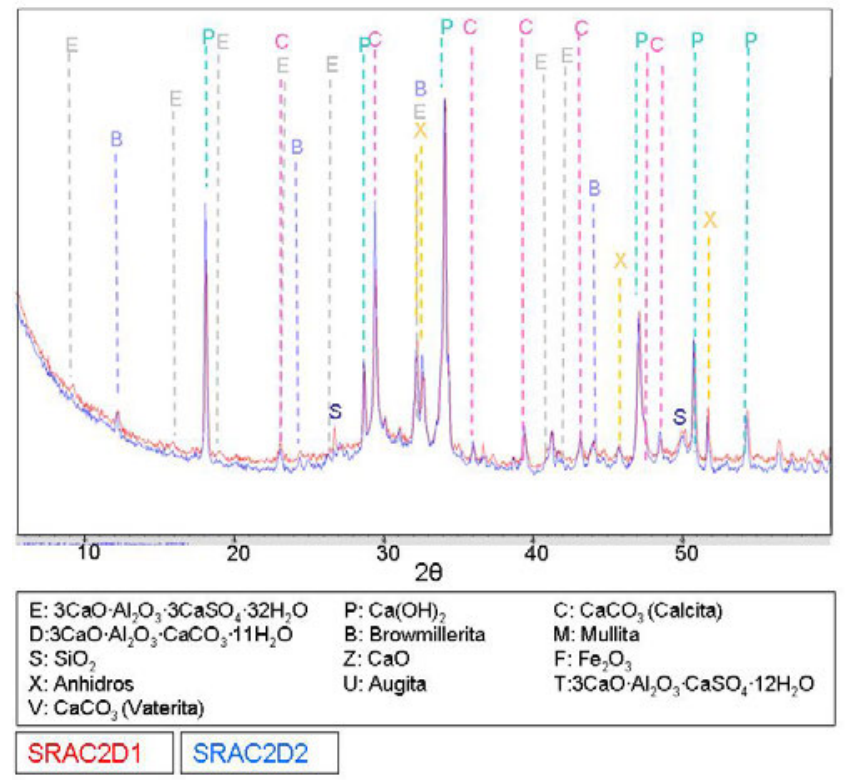

Figura 81. Análisis por DRX de las muestras SRAC2D

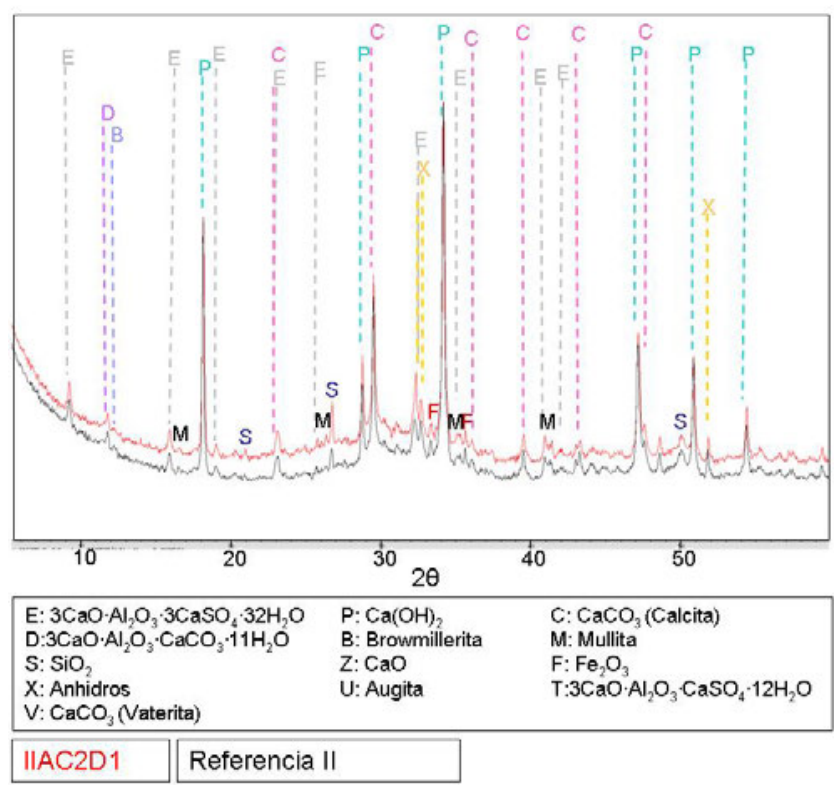

Figura 82. Análisis por DRX de las muestras IIAC2D 


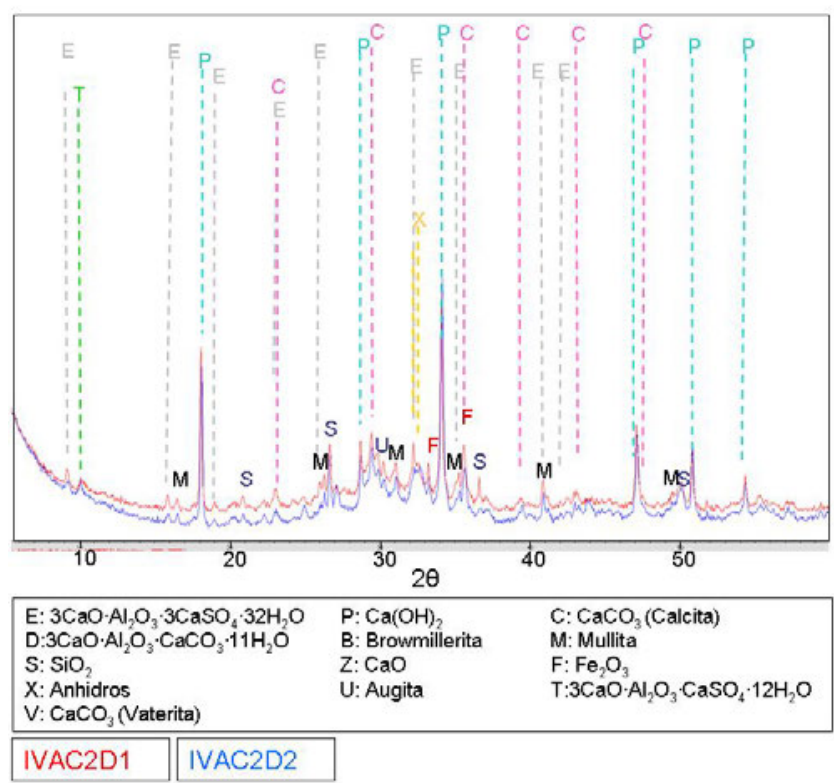

Figura 83. Análisis por DRX de las muestras IVAC2D

En la Figura 84, Figura 85 y Figura 86 se muestran los difractogramas de las muestras de pasta de cemento SR, II y IV expuestas al medio AC durante treinta días.

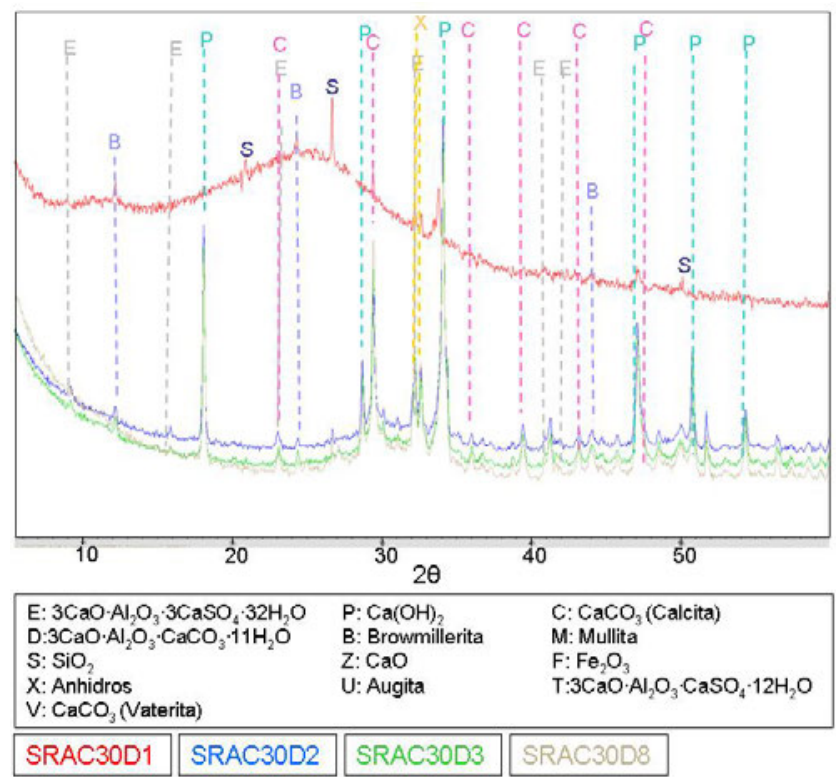

Figura 84. Análisis por DRX de las muestras SRAC30D

La muestra SRAC30D1 muestra evidencias de degradación. El difractograma presenta un gran halo que se atribuye a la formación de un gel rico en sílice producto de la descomposición. En esta sección se observan las bandas de los compuestos anhidros, sílice y calcita. 
Las secciones SRAC30D2, SRAC30D3 y SRAC30D8 presentan difractogramas con bandas e intensidades muy similares.

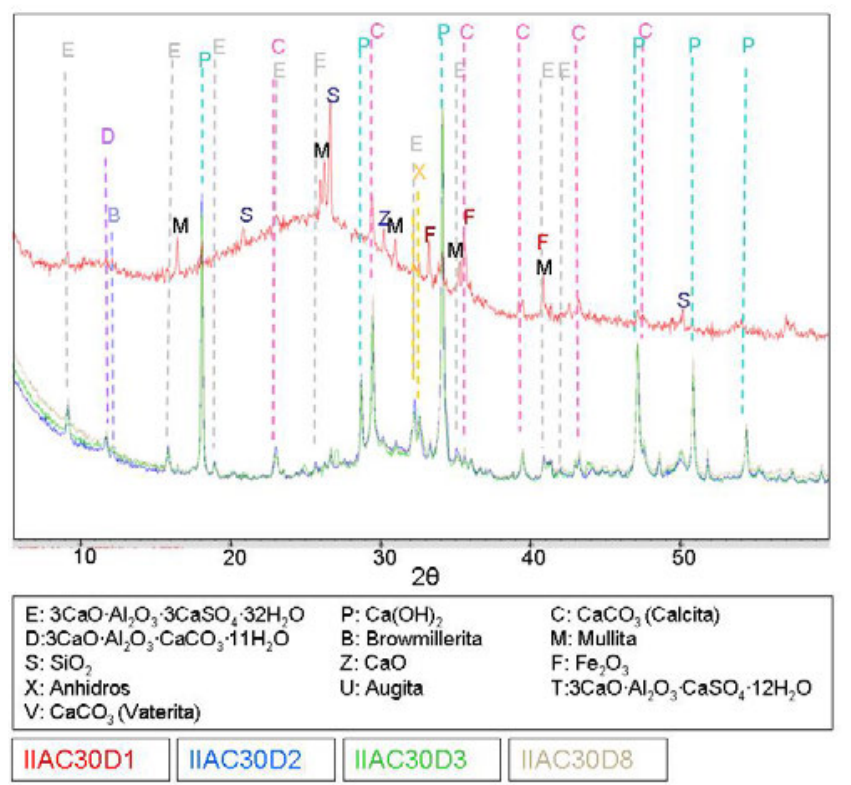

Figura 85. Análisis por DRX de las muestras IIAC30D

La sección IIAC30D1 presenta degradación, sin embargo aún se pueden observar las bandas más intensas de portlandita, calcita y etringita. La proporción de anhidros en la muestra es muy escasa. Se observan claramente las bandas correspondientes a sílice y mullita. En está sección tambien se puede observar la presencia de óxidos de hierro y cal. La formación de un gel rico en sílice producto de la descomposición se observa en la formación de un halo centrado entorno a $25^{\circ} 2 \theta$.

El resto de secciones analizadas no muestra signos de degradación, los difractogramas presentan bandas e intensidades muy similares entre sí.

En el difractograma de la muestra IVAC30D1 se observa la desaparición de las bandas de portlandita y etringita. La calcita presenta alguna de sus bandas más intensas por lo que su proporción en la muestra es baja. Los compuestos anhidros también se encuentran en muy baja proporción. Las bandas más evidentes son las de sílice y mullita. También se pueden observar bandas de cal, óxidos de hierro y augita. 
Si comparamos las secciones interiores se observa que la sección IVAC30D2 presenta los mismos compuestos cristalinos que la muestra de referencia en profundidad, sin embargo la intensidad de las bandas de portlandita y calcita es ligeramente inferior.

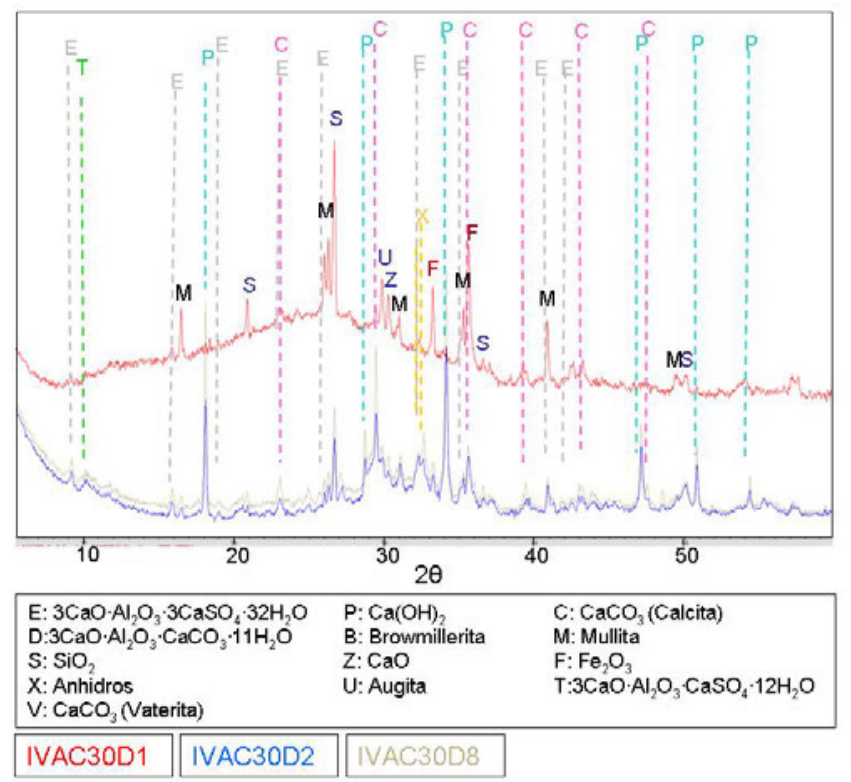

Figura 86. Análisis por DRX de las muestras IVAC30D

En la Figura 87, Figura 88 y Figura 89 se muestran los difractogramas de las muestras de pasta de cemento SR, II y IV expuestas al medio AC durante noventa y dos días.

La muestra SRAC92D1 presenta un halo centrado entorno a $25^{\circ} 2 \theta$ que muestra el estado vítreo de la pasta de cemento analizada. En esta muestra sólo pueden reconocerse las bandas correspondientes a sílice.

La sección SRAC92D2 presenta los mismos compuestos cristalinos que las muestras en secciones interiores, sin embargo la intensidad de la portlandita ha disminuido. La reducción de la intensidad de las bandas de este compuesto evidencia de forma más significativa la presencia de otros compuestos como la etringita, sin embargo no se puede afirmar que su proporporción en la muestra sea mayor.

El resto de secciones analizadas no muestra signos de degradación, los difractogramas presentan bandas e intensidades muy similares entre sí. 
La muestra IIAC92D1 también presenta un halo correspondiente al estrado vitreo de la muestra degradada. No presenta las bandas de portlandita, calcita, etringita ni anhidros. Se observan en la muestra la presencia de mullita, sílice, óxido de calcio y óxidos de hierro. El difractograma de la sección IIAC92D2 presenta los mismos compuestos cristalinos que las muestras internas de referencia. La intensidad de las bandas correspondientes a portlandita ha disminuido.

En el caso de las muestras de pasta de cemento IV la degradación afecta a las dos primeras secciones. En estas muestras no se observan las bandas de calcita, portlandita, etringita ni anhidros. Las bandas más evidentes corresponden a sílice, mullita, óxido de calcio, óxidos de hierro y augita. En la muestra IVAC92D2 aumenta ligeramente el contenido de etringita. Este hecho suele estar asocociado a la disolución de portalndita y disminución del pH en el material. El resto de bandas corresponden a las de la muestra de referencia en profundidad.

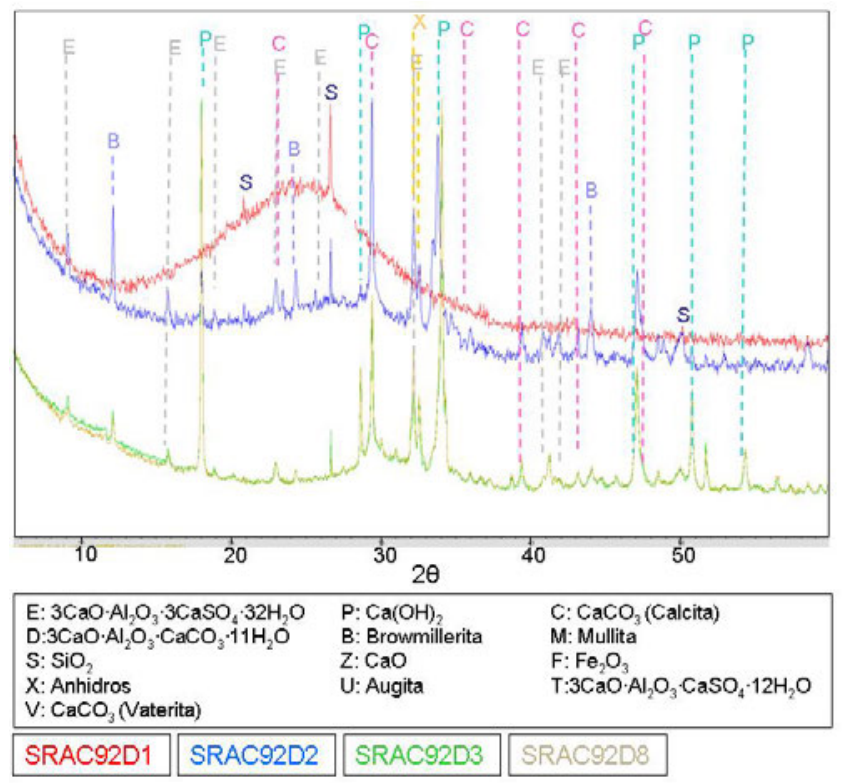

Figura 87. Análisis por DRX de las muestras SRAC92D 


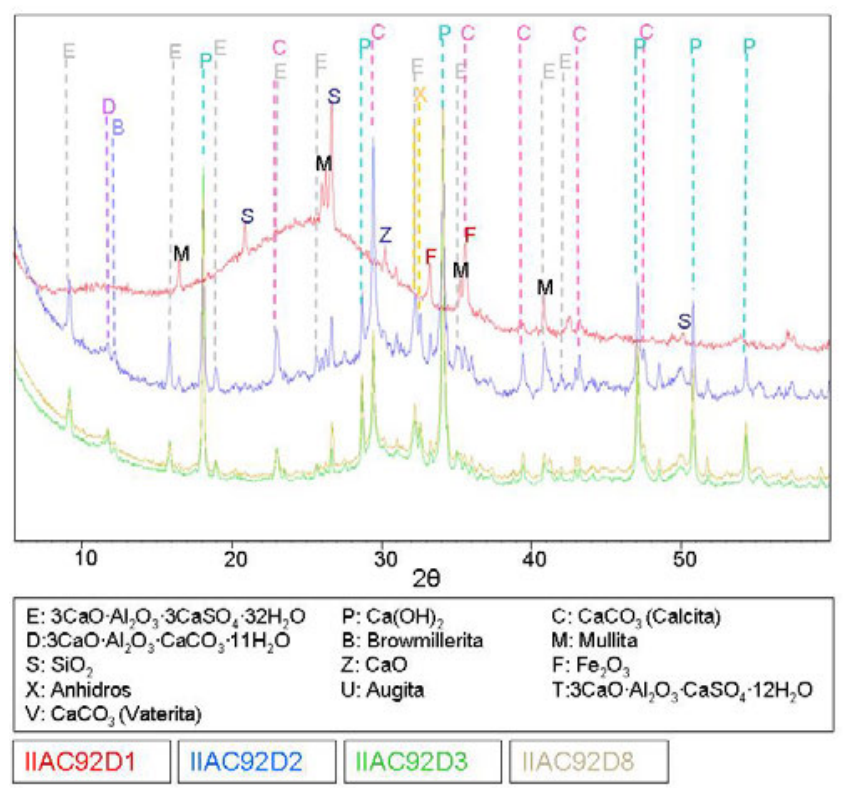

Figura 88. Análisis por DRX de las muestras IIAC92D

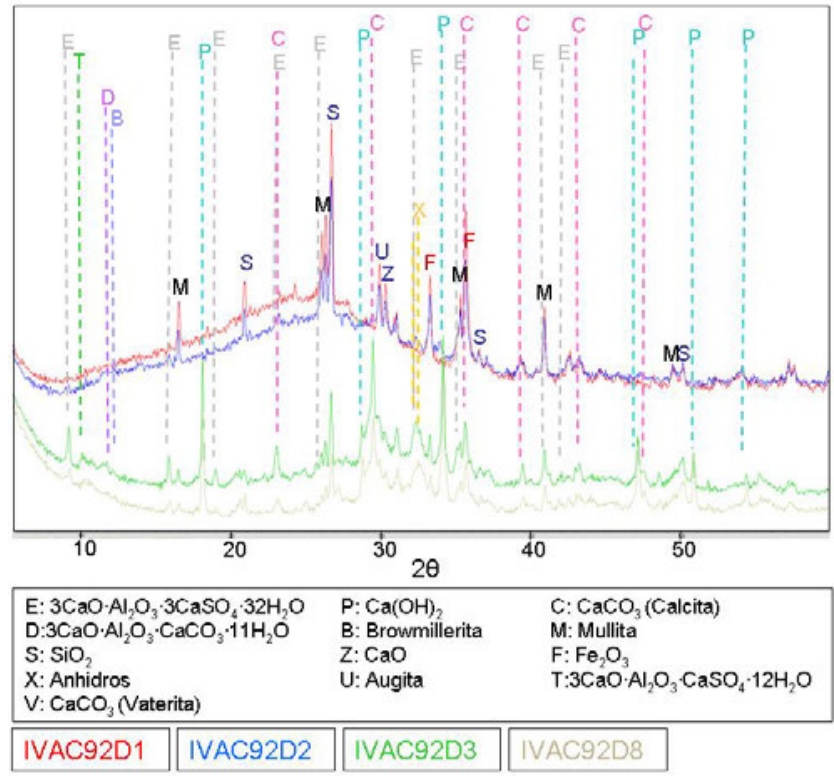

Figura 89. Análisis por DRX de las muestras IVAC92D

4.4.2.2. Difracción de rayos- $\mathrm{X}$ en las muestras expuestas al medio SU

En la Figura 90, Figura 91 y Figura 92 se muestran los difractogramas de muestras de pasta de cemento SR, II y IV expuestas al medio SU durante dos días. Las muestras analizadas a dos días de exposición no presentan signos de degradación en ninguno de los tipos de pasta analizados. En la primera sección de los tres tipos de muestra analizados se conservan las bandas 
correspondientes a portlandita, calcita y etringita con respecto a las presentadas por las muestras en secciones más profundas. La muestra IVSU2D1 presenta un ligero incremento de la intensidad de las banda debidas a portlandita con respecto a la muestra de referencia. En las pastas de cemento IV se observan además las bandas de monosulfoaluminato tetracálcico y la aparición de bandas de vaterita. Estos dos compuestos no se observan en el resto de cementos.

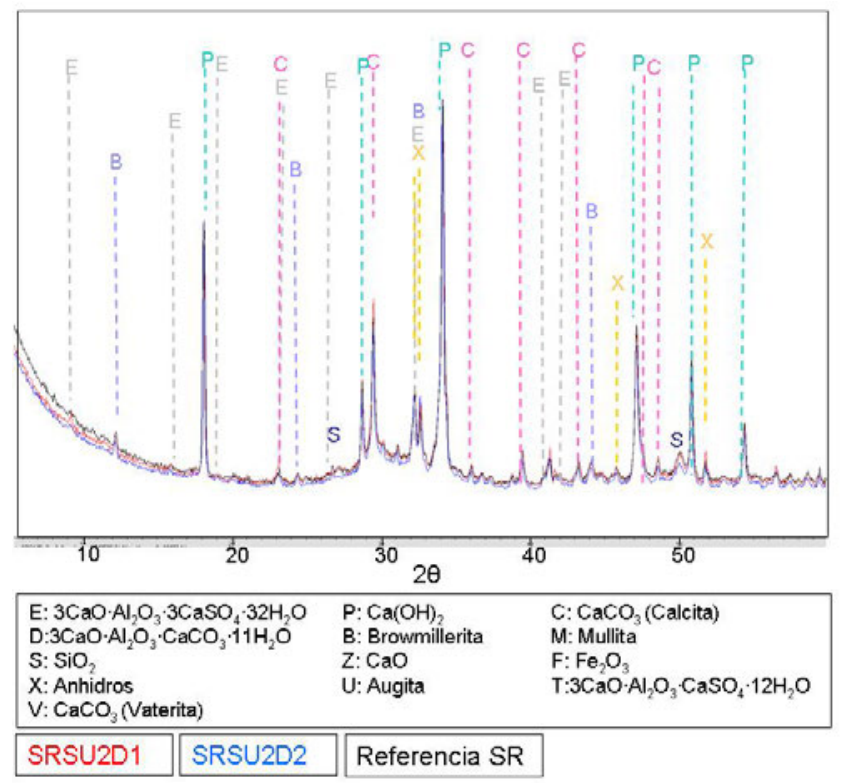

Figura 90. Análisis por DRX de las muestras SRSU2D

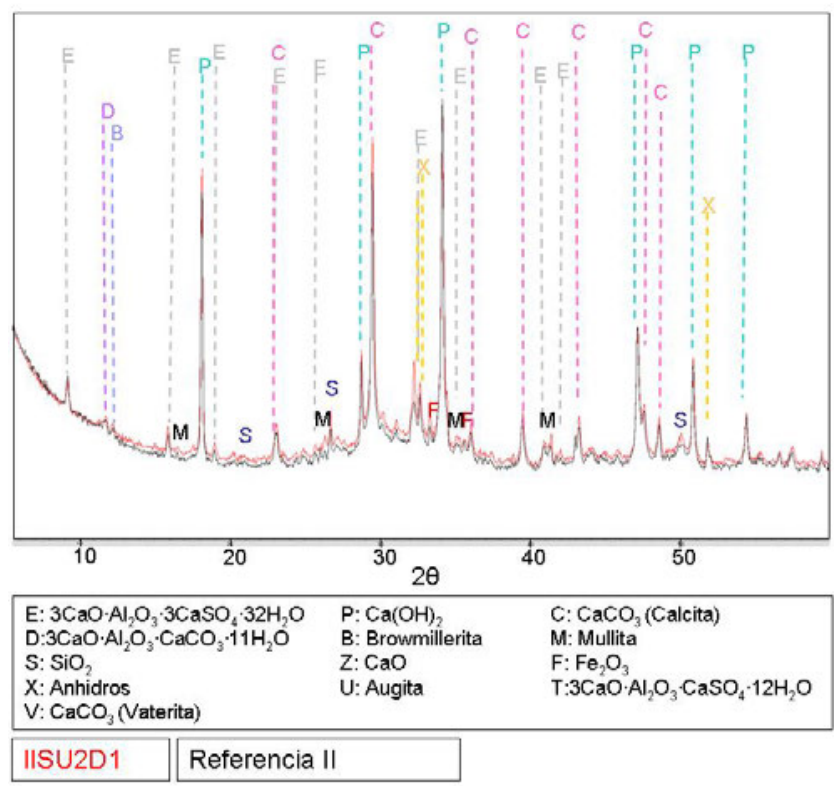

Figura 91. Análisis por DRX de las muestras IISU2D 


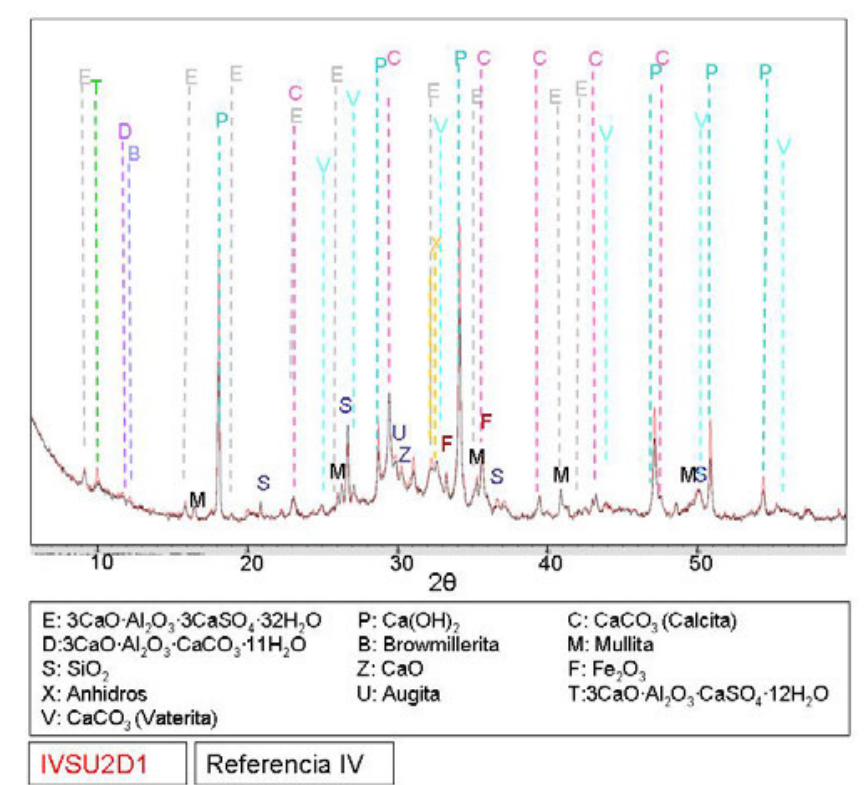

Figura 92. Análisis por DRX de las muestras IVSU2D

En la Figura 93, Figura 94 y Figura 95 se muestran los difractogramas de las muestras de pasta de cemento SR, II y IV expuestas al medio SU durante treinta días.

La muestra SRSU30D1 presenta las mismas bandas que la sección de referencia en profundidad. Sólo se observa un ligero incremento de la intensidad correpondiente a etringita.

La muestra IISU30D1 presenta las mismas bandas que la sección de referencia en profundidad. Sólo se observa un ligero incremento de la intensidad correpondiente a calcita en detrimento de la de las bandas de portlandita que puede atribuirse a diferente nivel de carbonatación en las muestras. El contenido de etringita permanece constante.

La muestra IVSU30D1 presenta las mismas bandas que la sección de referencia en profundidad. Al igual que en la pasta de cemento II se observa un ligero incremento de la intensidad correpondiente a calcita en detrimento de la de las bandas de portlandita que puede atribuirse a diferente nivel de carbonatación en las muestras. El contenido de etringita permanece constante.

En laFigura 96, Figura 97 y Figura 98 se muestran los difractogramas de las muestras de pasta de cemento SR, II y IV expuestas al medio SU durante noventa y dos días.

Los tres tipos de muestra presentan las mismas bandas que la sección de referencia en profundidad. Se observa un ligero incremento de la intensidad correpondiente a etringita en las 
muestras SRSU92D1 y IVSU92D1, así como un incremento de la intensidad de las bandas correspondientes a calcita, sin embargo en estas muestras no se observa disminución del contenido de portlandita.

En el caso de la muestra IISU92D no se observan variaciones con respecto a las muestras de referencia.

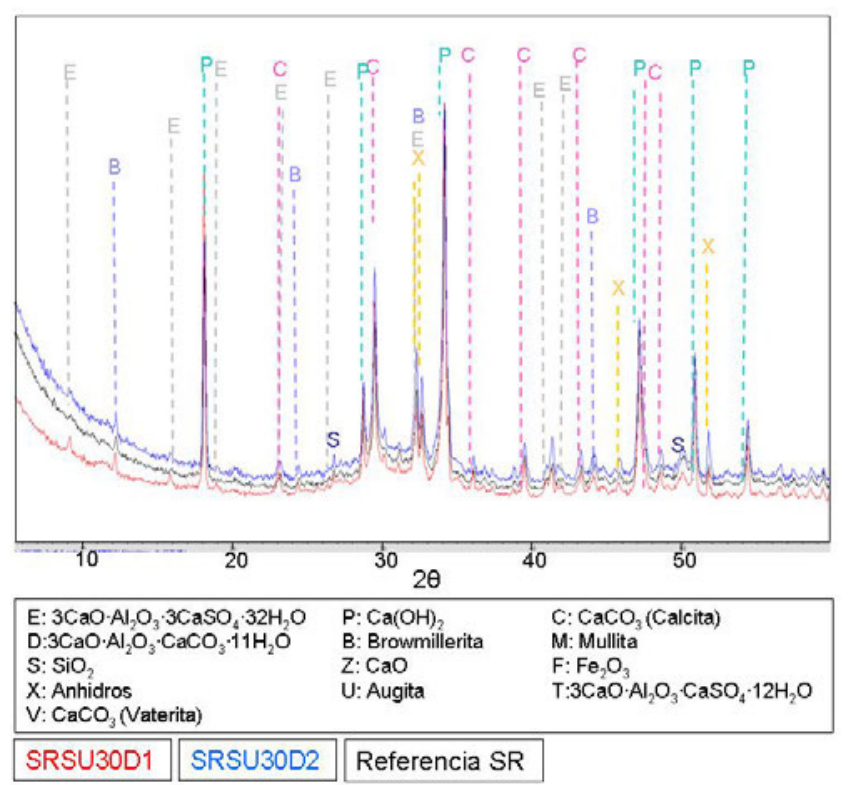

Figura 93. Análisis por DRX de las muestras SRSU30D

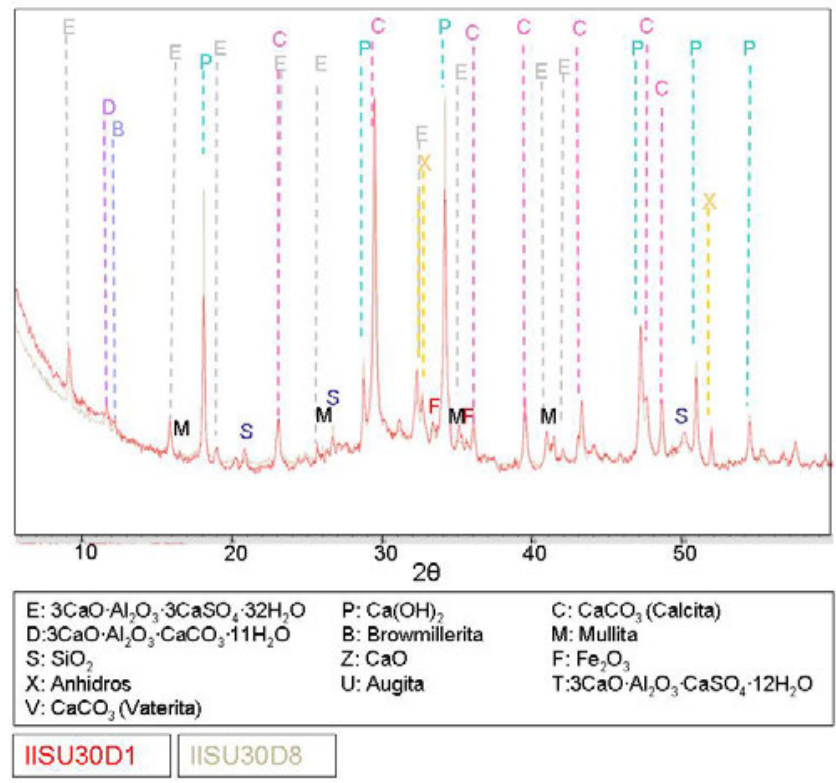


Figura 94. Análisis por DRX de las muestras IISU30D

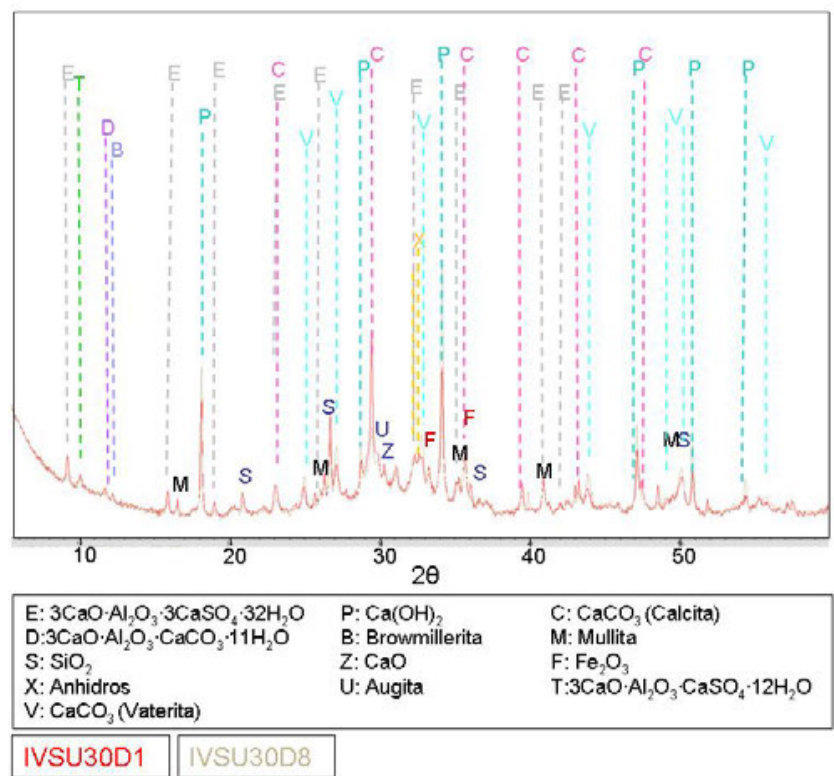

Figura 95. Análisis por DRX de las muestras IVSU30D

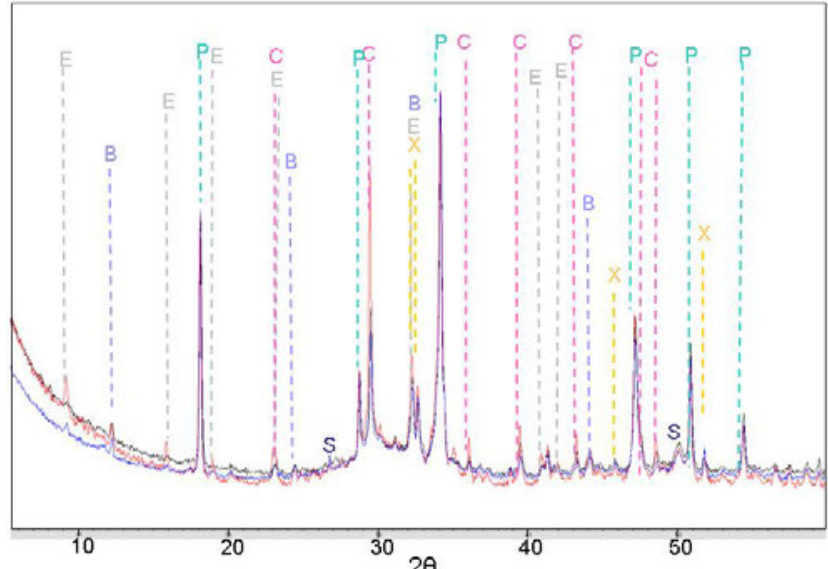

\begin{tabular}{|c|c|c|c|}
\hline \multicolumn{2}{|c|}{$\begin{array}{l}\mathrm{E}: 3 \mathrm{CaO} \cdot \mathrm{Al}_{2} \mathrm{O}_{3} \cdot 3 \mathrm{CaSO}_{4} \cdot 32 \mathrm{H}_{2} \mathrm{O} \\
\mathrm{D}: 3 \mathrm{CaOO} \cdot \mathrm{Al}_{2} \mathrm{O}_{3} \cdot \mathrm{CaCO}_{3} \cdot 11 \mathrm{H}_{2} \mathrm{O} \\
\mathrm{S}: \mathrm{SiO}_{2} \\
\mathrm{X}: \text { Anhidros } \\
\mathrm{V}: \mathrm{CaCO}_{3} \text { (Naterita) }\end{array}$} & $\begin{array}{l}\text { P: } \mathrm{Ca}(\mathrm{OH})_{2} \\
\mathrm{~B}: \text { Browmillerita } \\
\mathrm{Z}: \mathrm{CaO} \\
\mathrm{U}: \text { Augita }\end{array}$ & $\begin{array}{l}\mathrm{C}: \mathrm{CaCO}_{3} \text { (Calcita) } \\
\text { M: Mullita } \\
\mathrm{F}: \mathrm{Fe}_{2} \mathrm{O}_{3} \\
\mathrm{~T}: 3 \mathrm{CaO} \cdot \mathrm{Al}_{2} \mathrm{O}_{3} \cdot \mathrm{CaSO}_{4} \cdot 12 \mathrm{H}_{2} \mathrm{O}\end{array}$ \\
\hline SRSU92D1 & SRSU92D2 & Referencia SR & \\
\hline
\end{tabular}

Figura 96. Análisis por DRX de las muestras SRSU92D 


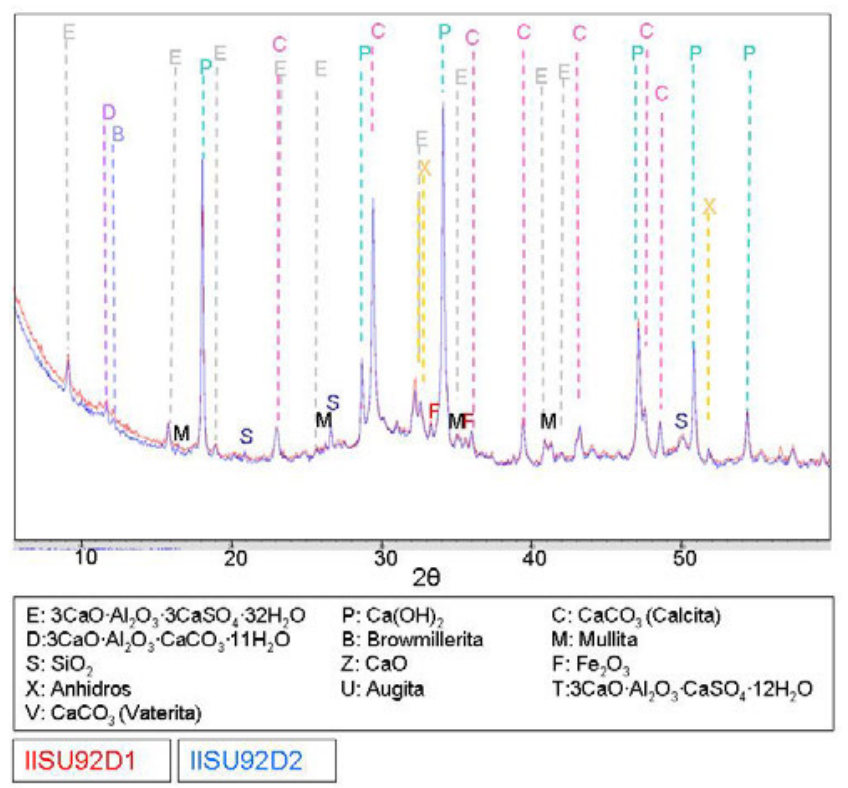

Figura 97. Análisis por DRX de las muestras IISU92D

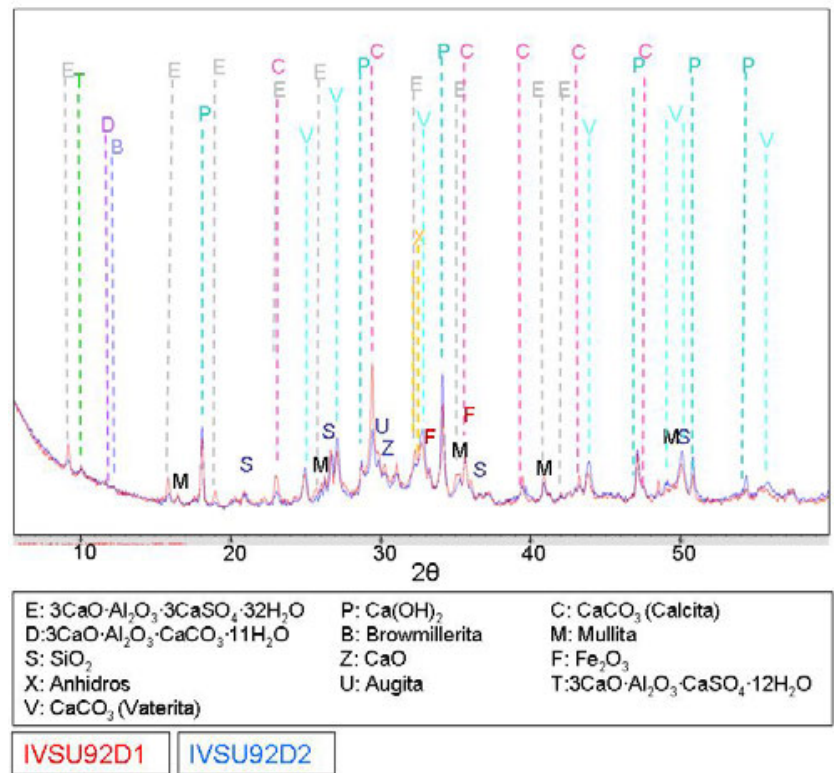

Figura 98. Análisis por DRX de las muestras IVSU92D

4.4.2.3. Difracción de rayos-X en las muestras expuestas al medio AN

En la Figura 99, Figura 100 y Figura 101 se muestran los difractogramas de muestras de pasta de cemento SRAN, IIAN y IVAN respectivamente. En las figuras se han mostrado los 
difractogramas de la sección en contacto con la disolución y se han comparado con la muestra de referencia en cada caso.

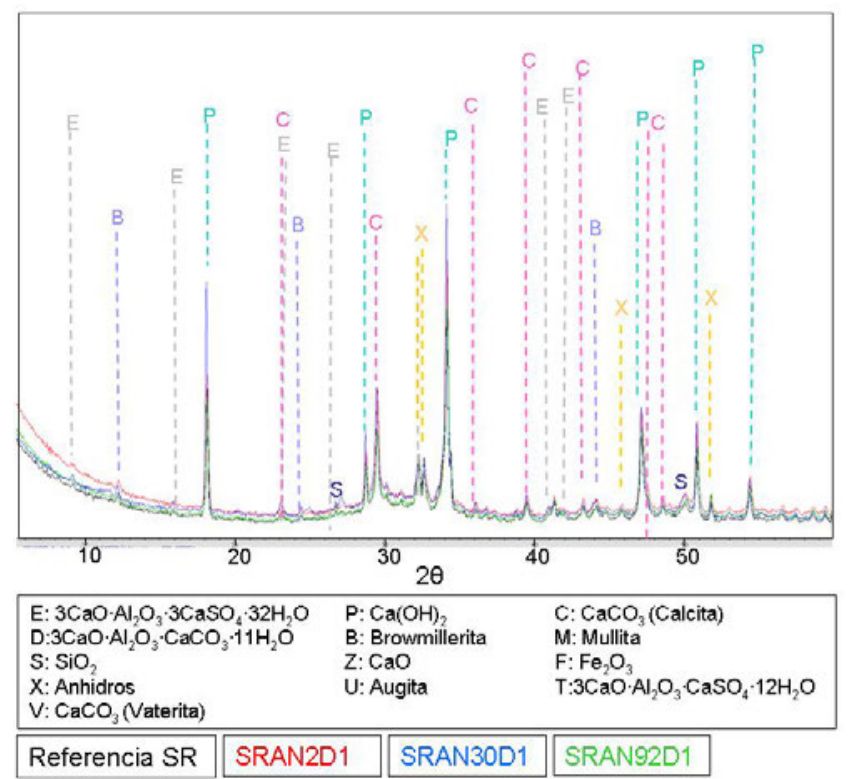

Figura 99.Análisis por DRX de las muestras SRAN

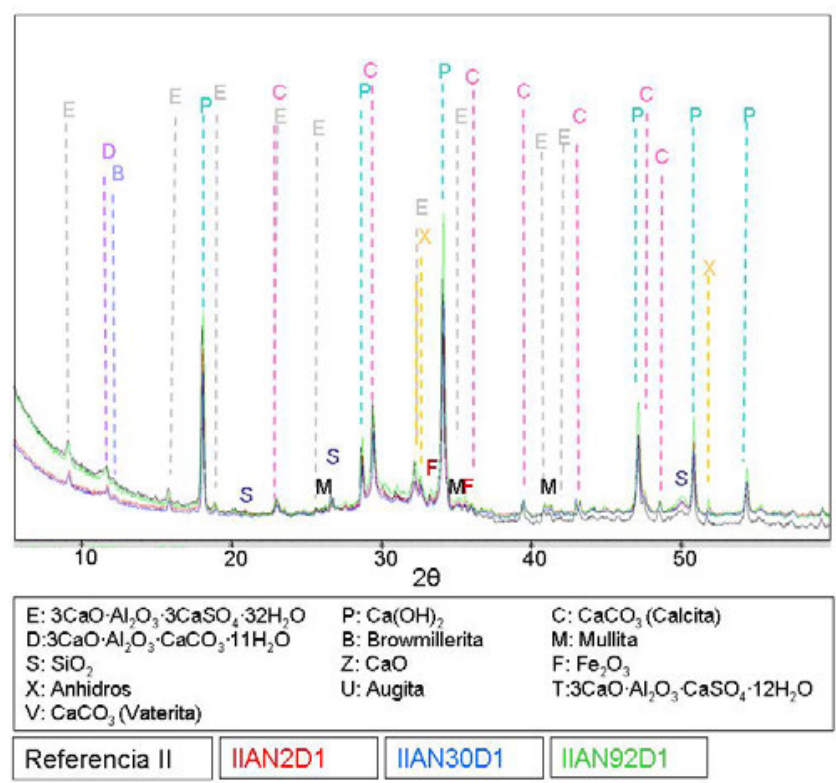

Figura 100. Análisis por DRX de las muestras IIAN 


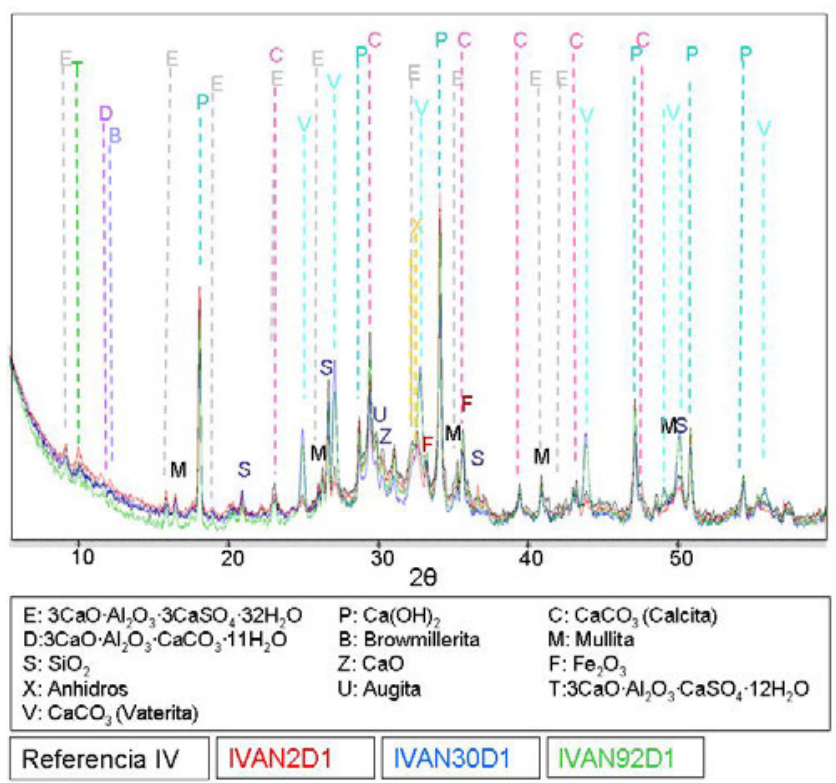

Figura 101. Análisis por DRX de las muestras IVAN

Si comparamos los difractogramas de las muestra con respecto a las muestras de referencia se puede decir que en contacto con el medio AN ninguno de los tipos de pasta analizado presenta variaciones en los compuestos cristalinos de la matriz.

\subsubsection{COMPOSICIÓN DE LAS MUESTRAS SÓLIDAS}

En esta sección se van a mostrar los resultados obtenidos en la determinación de $\mathrm{CaO}$, MgO, $\mathrm{SO}_{3}, \mathrm{Fe}_{2} \mathrm{O}_{3}$ y $\mathrm{Al}_{2} \mathrm{O}_{3}$ de las muestras de pasta expuestas en los medios AC, $\mathrm{SU}$ y AN.

Para comparar los resultados con el contenido inicial de cada óxido en las muestras, se presentan en los gráficos los valores obtenidos en las muestras de referencia.

En la obtención de los valores de referencia se han empleado los resultados promedio del contenido de óxido en las muestras expuestas a los medios AI y CA para cada uno de los tipos de pasta de cemento empleadas.

En la Figura 102, Figura 103 y Figura 104 se muestran los resultados obtenidos en el medio AC para las muestras de pasta de cemento SR, II y IV respectivamente. 
En la Figura 105, Figura 106 y Figura 107 se muestran los resultados obtenidos en el medio SU para las muestras de pasta de cemento SR, II y IV respectivamente.

En la Figura 108, Figura 109 y Figura 110se muestran los resultados obtenidos en el medio AN para las muestras de pasta de cemento SR, II y IV respectivamente.

En los gráficos se muestras los contenidos de cada óxido en profundidad. En las columnas de la izquierda se presentan los datos por edad de exposición. En las columnas de la izquierda se presentan los datos de la evolución del contenido de cada óxido a lo largo del proceso de exposición.

\subsubsection{Composición de las muestras en el medio AC}

En la Figura 102 se muestran los resultados obtenidos para las muestras de pasta de cemento SR expuestas al medio AC. En la Figura 103 los correspondientes a IIAC.

En los gráficos se observa que contenido de $\mathrm{CaO}$ desciende en la sección en contacto con el medio desde los primeros días de exposición. La reducción de $\mathrm{CaO}$ en las probetas es progresiva a medida que transcurren los días de exposición.

Entre 7 y 30 días se observa que la reducción de $\mathrm{CaO}$ en los primeros milímetros de probetas es muy importante, en este punto comienzan a descalcificar los compuestos más solubles de la pasta de cemento, fundamentalmente portlandita, pero también etringita y carbonato. A partir de este momento observamos que el contenido de $\mathrm{CaO}$ en los primeros milímetros es muy pequeño. A 58 días, la lixiviación de calcio en las probetas afecta a los 7 primeros milímetros de las probetas. Cuando llevamos 92 de días de exposición la profundidad afectada sigue siendo la misma y lo que se produce es una descalcificación más severa de estas primeras secciones.

Se puede afirmar que en los primeros días de ensayo la descalcificación de la probeta es muy rápida porque la disponibilidad de compuestos solubles permite una rápida disolución de los mismos. En tanto en cuanto esta disponibilidad se ve reducida, el proceso de descalcificación sería más lento y estaría controlado por la difusión del ion en el interior de la probeta.

Con respecto al contenido de $\mathrm{MgO}$ en las muestras se puede decir que es muy pequeño. Se produce una lixiviación inicial de este ion en la muestras en la primera sección de la probeta. 
Sin embargo la lixiviación de compuesto no progresa en profundidad a medida que avanza el tiempo de exposición.

El contenido de $\mathrm{SO}_{3}$ en la muestra desciende a partir de los 30 días de exposición. La reducción de $\mathrm{SO}_{3}$ en la muestra esta relacionado con la lixiviación de fases AFt y AFm en la pasta de cemento. A pesar de tratarse de un tipo de pasta de cemento elaborada con cemento sulforesistente, se observa en las muestras la formación de una pequeña cantidad de etringita en la muestra.

A medida que avanza el proceso de exposición se reduce el contenido de $\mathrm{SO}_{3}$ en los primeros milímetros de las probetas. El espesor medio afectado al final del ensayo es de 7 milímetros aproximadamente.

Si tenemos en cuenta que la portlandita es el compuesto más soluble de la pasta de cemento, es posible que la disolución de etringita esté asociada con el agotamiento de portlandita en determinadas regiones de la pasta deteriorada y que su disolución se aprecie cuando el aporte de ion calcio al entorno se vea reducido por el lento proceso de difusión desde otras regiones de la probeta.

El contenido de hierro y aluminio en la probeta apenas varía en los primeros días del ensayo. A partir de 30 días se observa que se produce un incremento de ambos iones en los primeros milímetros de las probetas. El hierro y el aluminio están presentes en algunos de los compuestos menos degradables de la pasta de cemento, por lo que era de esperar que la lixiviación de este tipo de iones fuera más lenta o inexistente durante el proceso de exposición. Atendiendo a que se produce una lixiviación severa de compuestos hidratados en la pasta de cemento, el hierro y el aluminio sufren una concentración en las zonas en las que la pasta está degradada.

A 92 días de exposición se observa como estos compuestos siguen presentando una concentración en las zonas de pasta degradada (aproximadamente hasta los 7 milímetros de profundidad). Pero sí se observa cierta reducción de los contenidos tanto de hierro como de aluminio en la zona más externa de la probeta, que sí estaría relacionada con la lixiviación de algunos de los compuestos más estables de la pasta de cemento. 
Composición en profundidad según la edad de exposición
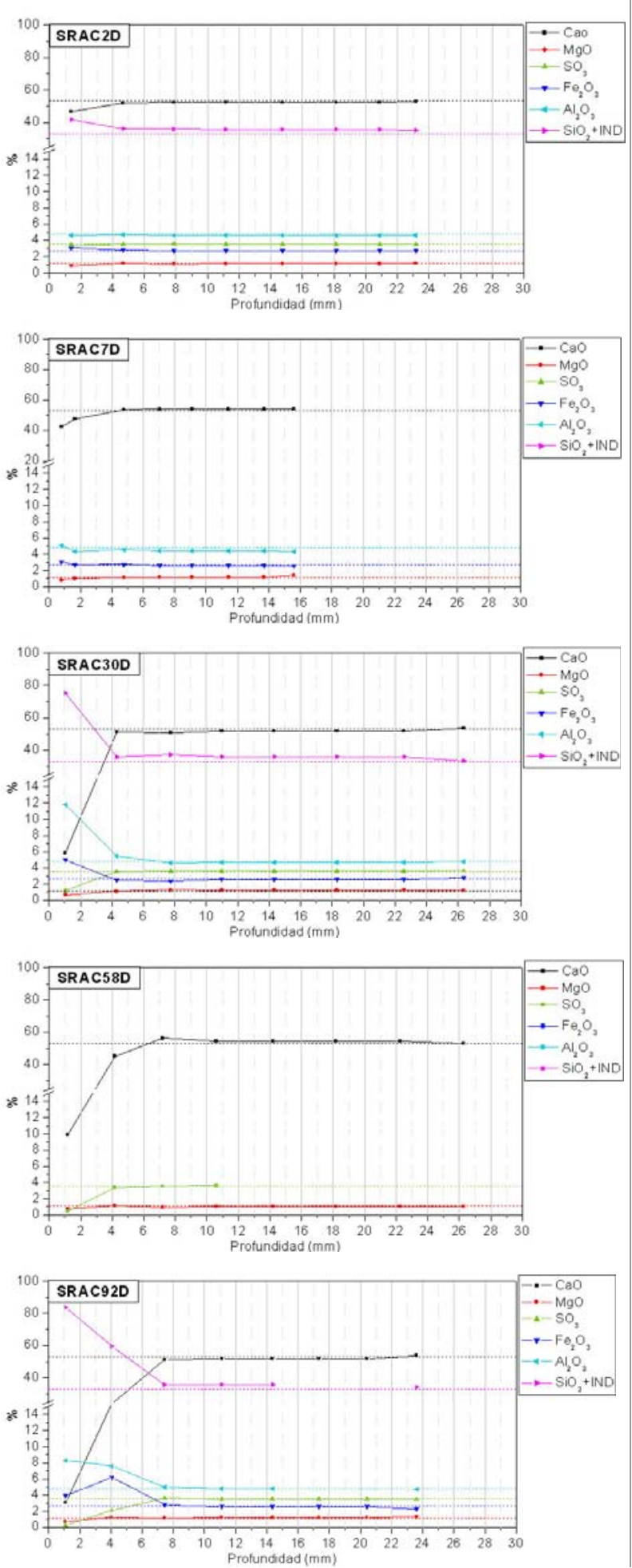

Evolución de los componentes a lo largo del proceso de exposición
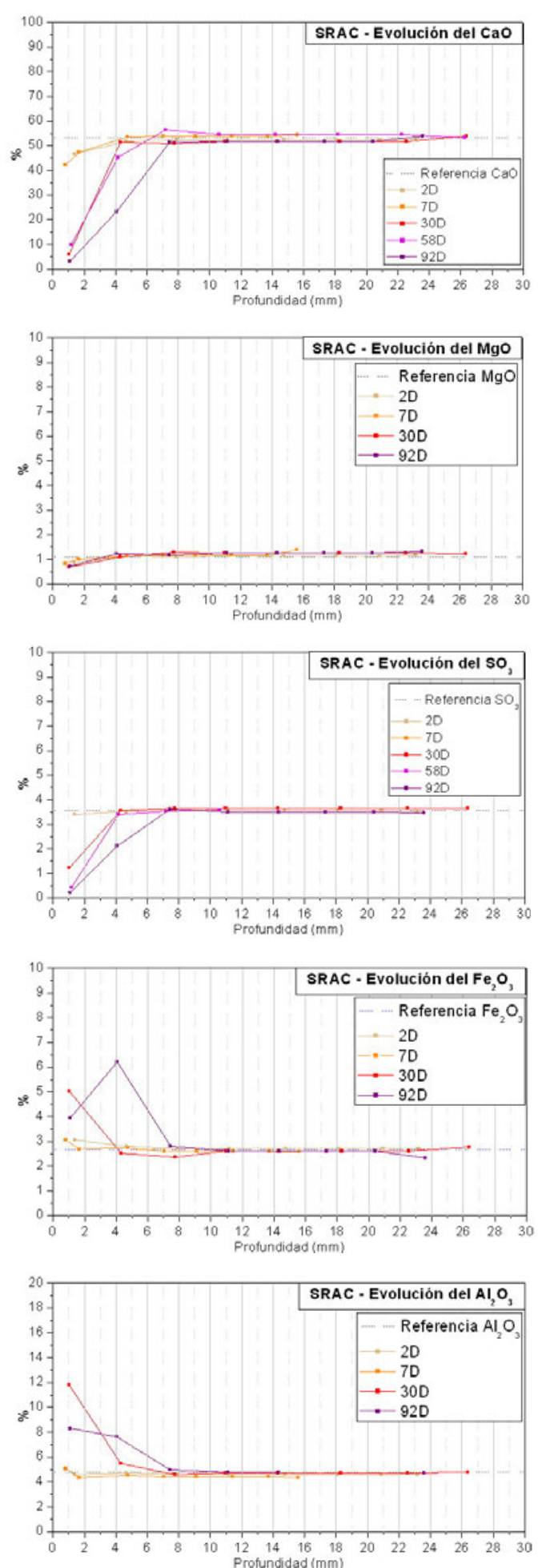

Figura 102. Composición de las pastas de cemento SR expuestas al medio AC 
Composición en profundidad según la edad de exposición
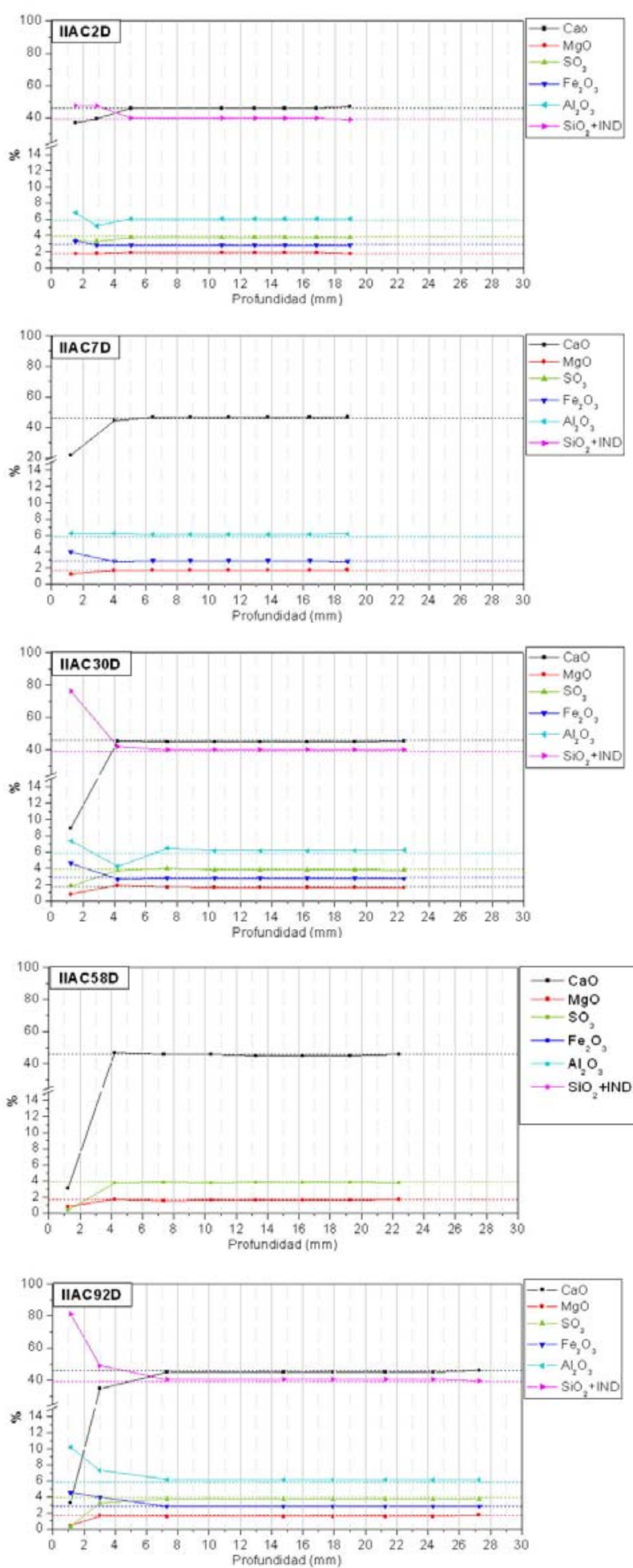

Evolución de los componentes a lo largo del proceso de exposición
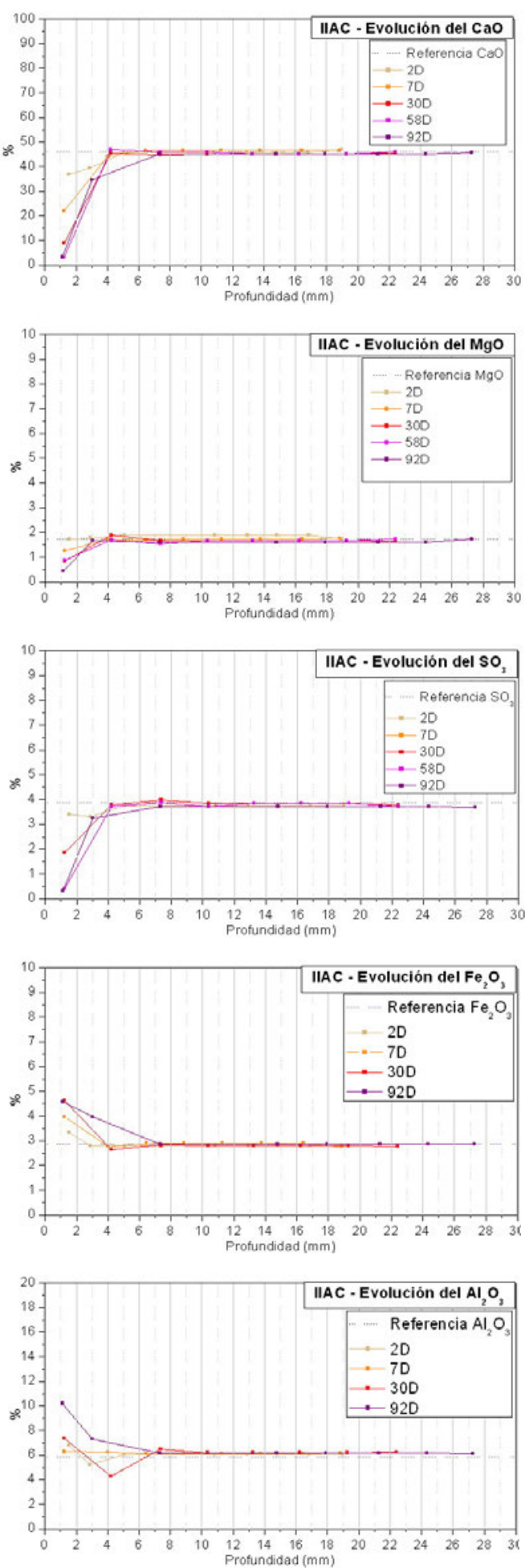

Figura 103. Composición de las pastas de cemento II expuestas al medio AC 
En las muestras de pasta de cemento tipo II se observa una tendencia parecida a la obtenida para las muestras de pasta de cemento SR.

Se observa que contenido de $\mathrm{CaO}$ desciende en la sección en contacto con el medio desde los primeros días de exposición. La reducción de $\mathrm{CaO}$ en las probetas es progresiva a medida que transcurren los días de exposición. En este caso la reducción de $\mathrm{CaO}$ en la probeta es mas paulatina que en el caso de las muestras de pasta de cemento SR. A 58 días de ensayo el contenido de $\mathrm{CaO}$ en la zona externa de la probeta es muy pequeño y la degradación afecta a los 4 primeros milímetros de la probeta.

El contenido de $\mathrm{CaO}$ analizado en 58 días de ensayo y 92 días de ensayo es muy similar en los primeros milímetros de probeta (hasta los $4 \mathrm{~mm}$ aprox.). La diferencia en el contenido de $\mathrm{CaO}$ de la probeta se produce entre los 4 y los $7 \mathrm{~mm}$ de profundidad, es este periodo es donde se hace más evidente la influencia del proceso de difusión en la lixiviación de ion calcio para este tipo de pasta.El MgO presenta una reducción progresiva a medida que avanza el proceso de degradación. El contenido de este ion es estable a los $3 \mathrm{~mm}$ de profundidad.

El contenido de $\mathrm{SO}_{3}$ en la muestra desciende desde los primeros días de exposición. La reducción de $\mathrm{SO}_{3}$ en las muestras está relacionada con la lixiviación de fases AFt y AFm en las pastas. Al final del ensayo la profundidad afectada es de $7 \mathrm{~mm}$ aproximadamente. Al final del ensayo los contenidos de $\mathrm{SO}_{3}$ en la primera sección son muy bajos y comparables a los medidos en las muestras de pasta de cemento SR. Sin embargo, se observa que en profundidad este tipo de muestra reduce menos su contenido en $\mathrm{SO}_{3}$.

El contenido de hierro y aluminio aumenta en la primera sección de la muestra. El incremento que presenta este tipo de pasta es más moderado que el calculado para las muestras de pasta de cemento SR. En el caso del hierro la concentración de hierro en la zona externa de las probetas es paulatina a lo largo del todo el proceso de exposición, y no se observan signos de lixiviación durante el tiempo ensayado. En el caso del aluminio, se observa que a 58 días de ensayo se produce una reordenación del contenido de aluminio en la probeta, con un descenso entorno a los $4 \mathrm{~mm}$ que podría estar motivado por la lixiviación en la muestra. Al final del ensayo el perfil de aluminio presenta incrementos netos en el contenido de aluminio en la probeta que afecta aproximadamente a los 7 primeros mm de profundidad.En la Figura 104 se muestran los resultados obtenidos para las muestras de pasta de cemento IV expuestas al medio AC. 
Composición en profundidad según la edad de exposición
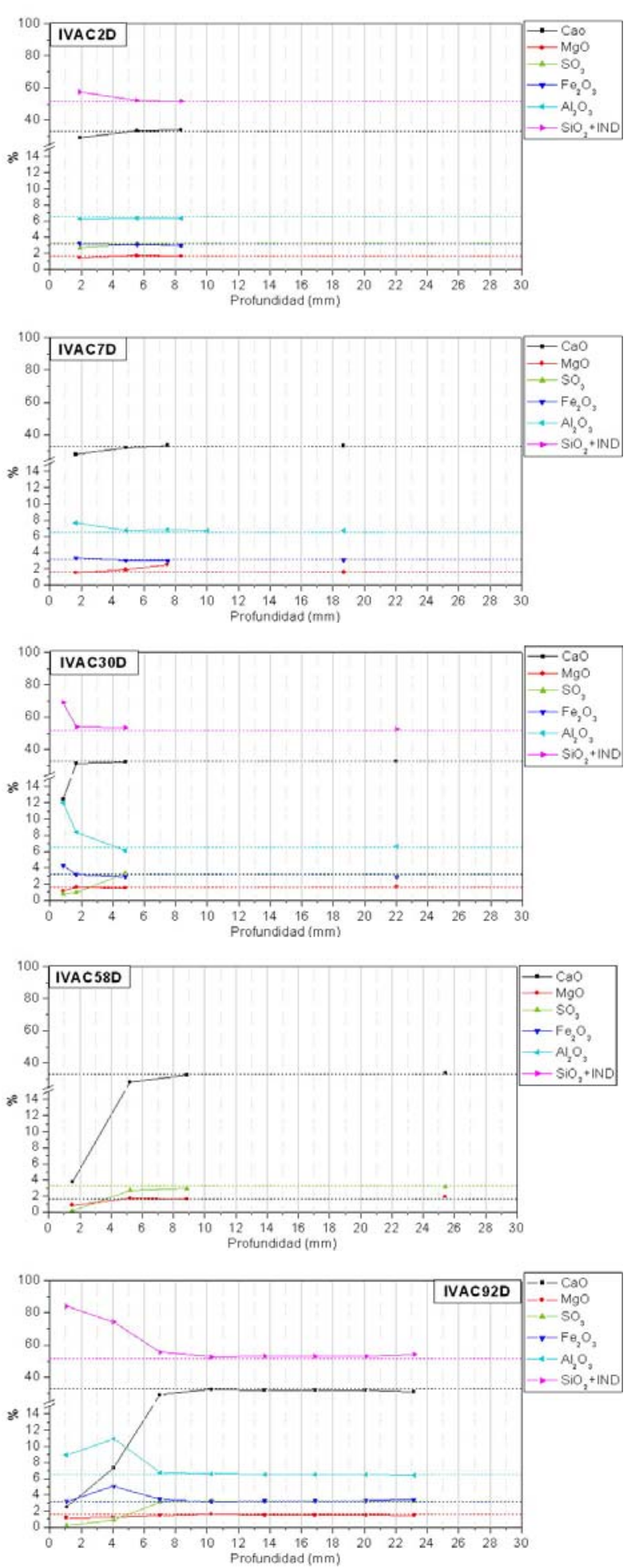

Evolución de los componentes a lo largo del proceso de exposición
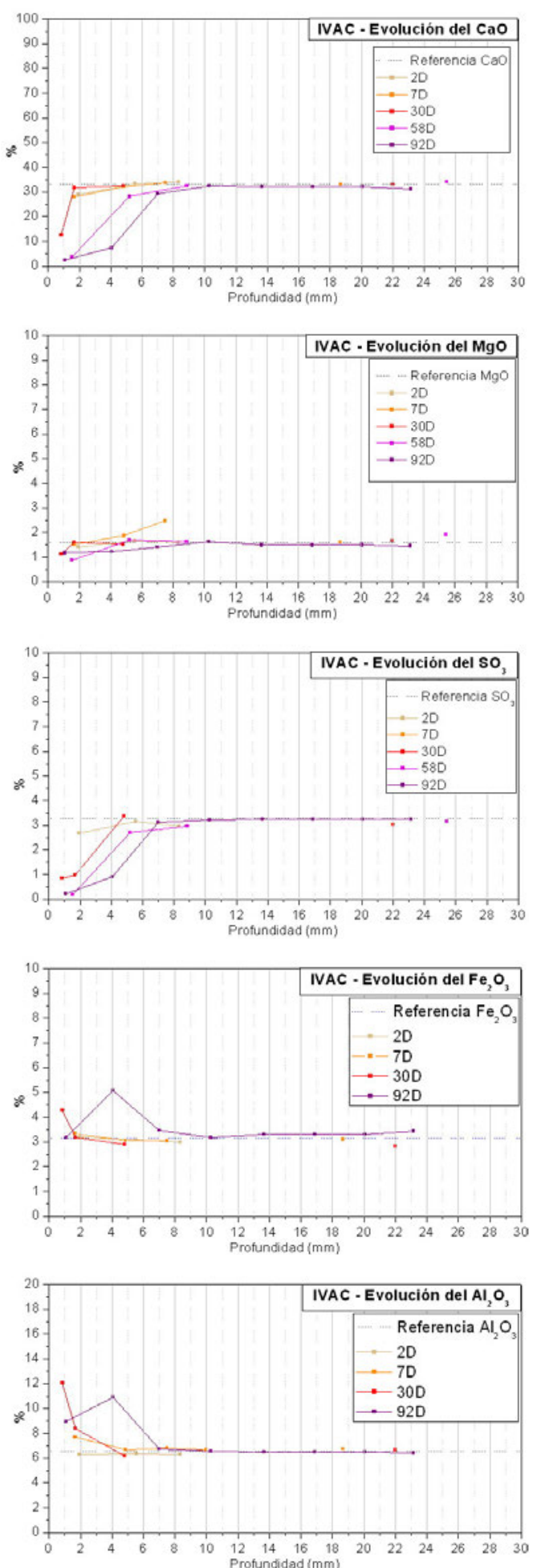

Figura 104. Composición de las pastas de cemento IV expuestas al medio AC 
En las muestras de pasta de cemento IV también se observa que contenido de CaO desciende en la sección en contacto con el medio desde los primeros días de exposición.

Hasta 30 días de exposición la reducción en el contenido de $\mathrm{CaO}$ sólo se observa en la primera sección de las probetas. Es posible que una cantidad de portlandita menor en la probeta condicione una menor lixiviación de ion calcio y por eso el contenido de $\mathrm{CaO}$ en las probetas se conserve.

A 58 días de ensayo el contenido de $\mathrm{CaO}$ en la zona externa de la probeta es muy pequeño y la degradación afecta a los 5 primeros milímetros de la probeta.

A 92 días de ensayo se observa una descalcificación severa de los 4 primeros milímetros de la probetas, y progresivamente menor hasta los 7 primeros milímetros. Pese a que este tipo de pasta presenta un contenido de portlandita inicial menor que el resto, la muestra obtenida al final del ensayo es la más descalcificada.

Los contenidos de $\mathrm{MgO}$ no presentan un perfil que pueda indicar lixiviación clara con el tiempo de exposición.

En el caso del contenido de $\mathrm{SO}_{3}$, se observa reducción de la cantidad desde los primeros días de ensayo. Esta reducción afecta a los 5 primeros milímetros hasta 30 días de exposición y a los 7 primeros al final del ensayo.

Si analizamos el contenido de hierro en las muestras se puede decir que no presenta alteraciones hasta los 58 días de exposición al medio. A 58 días se observa que una reducción del contenido de hierro en la primera sección respecto al que presenta el resto de la probeta en profundidad. Se pueden atribuir estos valores a una concentración previa de hierro en la zona exterior de la probeta con una lixiviación posterior de compuestos con hierro en la misma.

El contenido de aluminio en la muestra se concentra en la primera sección de probeta desde el inicio del ensayo. A 58 días se observa este fenómeno en los cinco primeros milímetros de probetas. A 92 días de ensayo se observa concentración de la cantidad de aluminio en la muestra entre 4 y 7 milímetros de profundidad, y se reduce el contenido de aluminio en la zona externa de las probetas, probablemente como consecuencia de procesos de lixiviación en la misma. 


\subsubsection{Composición de las muestras en el medio SU}

En la Figura 105 se muestran los resultados obtenidos para las muestras de pasta de cemento SR expuestas al medio SU.
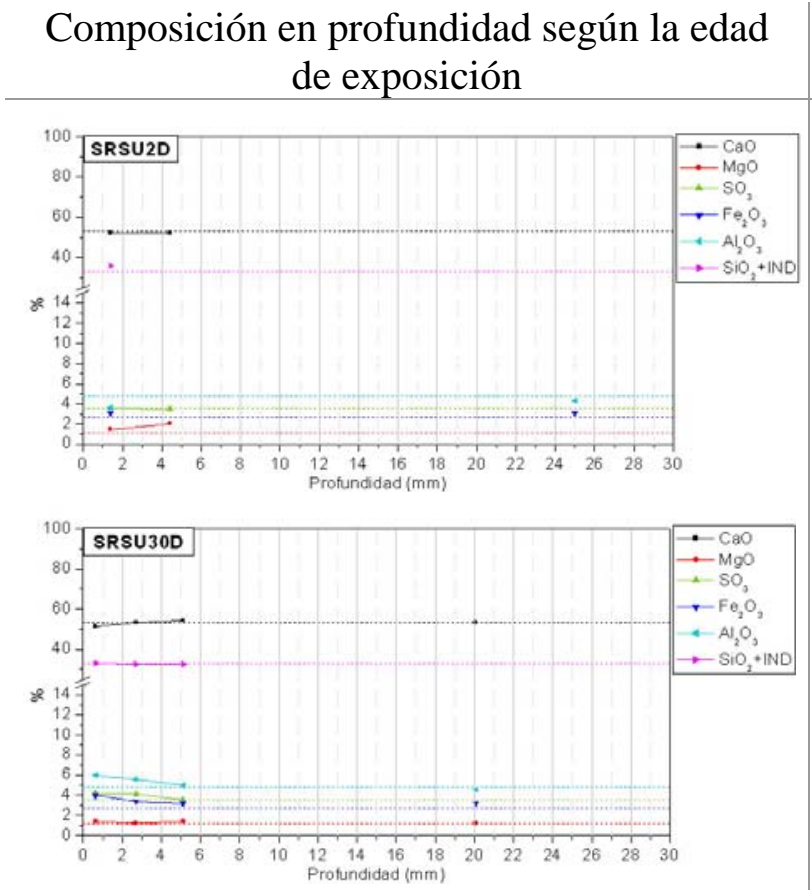

Evolución de los componentes a lo largo del proceso de exposición
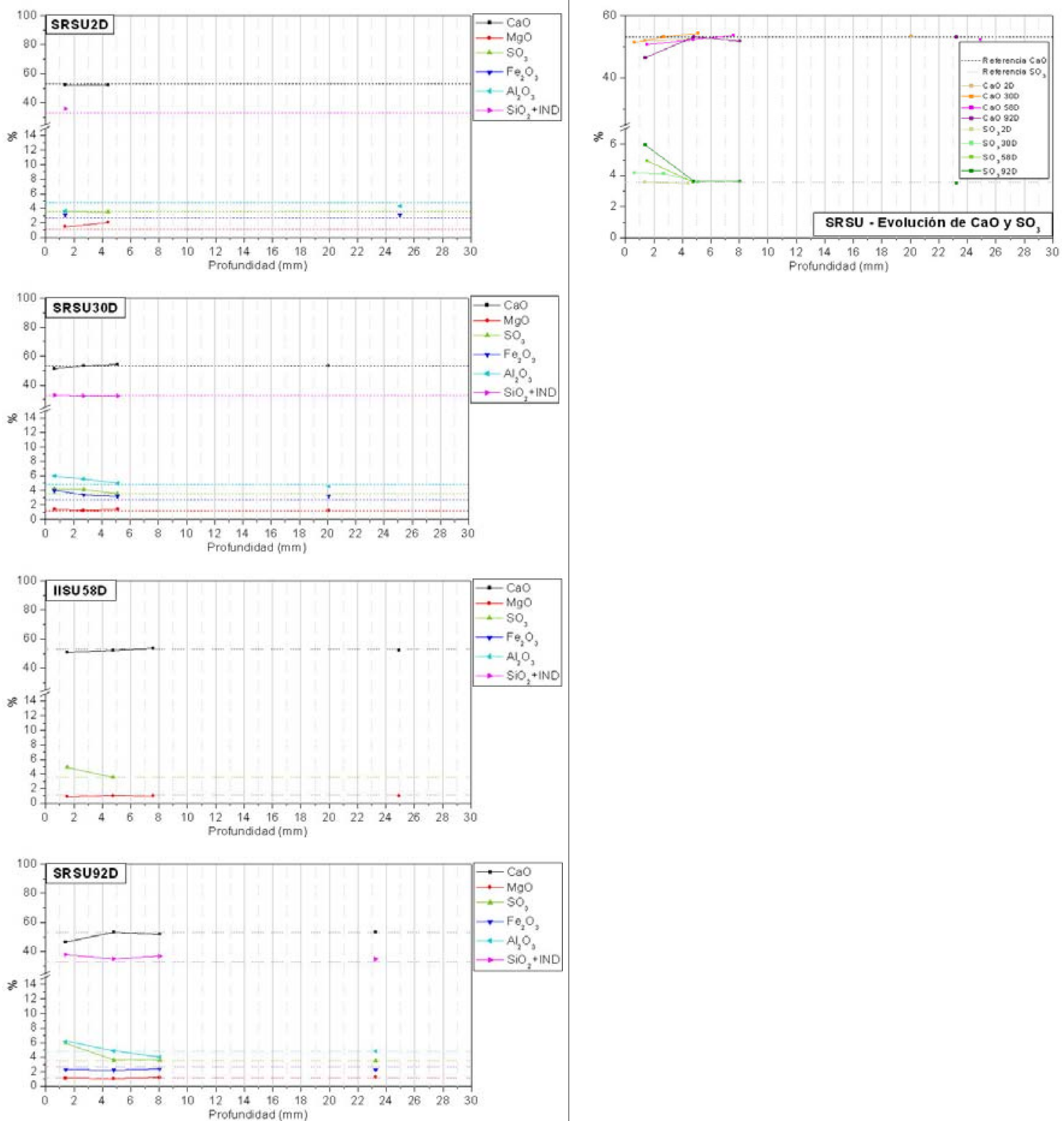

Figura 105. Composición de las pastas de cemento SR expuestas al medio SU 
Las muestras de pasta de cemento SR expuestas al medio SU presentan variaciones pequeñas con respecto al contenido de las muestras de referencia en contenidos de $\mathrm{MgO}$ y $\mathrm{Fe}_{2} \mathrm{O}_{3}$.

El contenido de $\mathrm{CaO}$ en las probetas es prácticamente constante hasta los 92 días de exposición. A esta edad de exposición se observa cierto grado de lixiviación de calcio en las probetas, puesto que el contenido total en la primera sección se reduce ligeramente. Teniendo en cuenta que el medio de exposición presenta una alta fuerza iónica, cabría esperar un grado de lixiviación mayor al encontrado. Incluso que se produjese la lixiviación de otro tipo de iones.

Las variaciones más significativas se producen en el incremento progresivo del contenido de $\mathrm{SO}_{3}$ en las probetas. Teniendo en cuenta que el medio de exposición está compuesto por una disolución de sulfato sódico, cabe la posibilidad de que parte de los iones sulfato penetren en los primeros milímetros de las probetas dando lugar nuevas fases sulfatadas. Si esto es así, es posible que parte del calcio quede retenido formando parte de los nuevos compuestos precipitados.

El contenido de aluminio en la muestras se presenta prácticamente constante a lo largo del periodo de ensayo hasta los 30 días de exposición. A partir de este momento se observa cierto aumento en la primera sección de las muestras expuestas que podría estar relacionado con la precipitación de sulfoaluminatos cálcicos en la zona externa de la probeta.

En la Figura 106 se muestran los resultados obtenidos para las muestras de pasta de cemento II expuestas al medio SU.

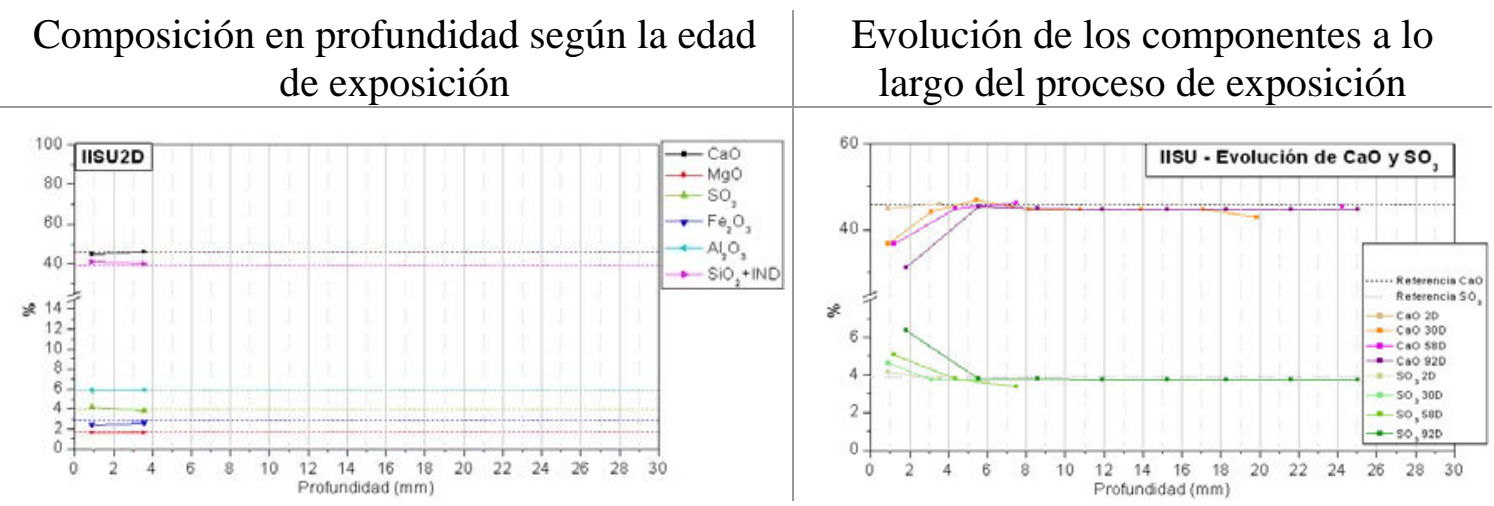


Composición en profundidad según la edad de exposición
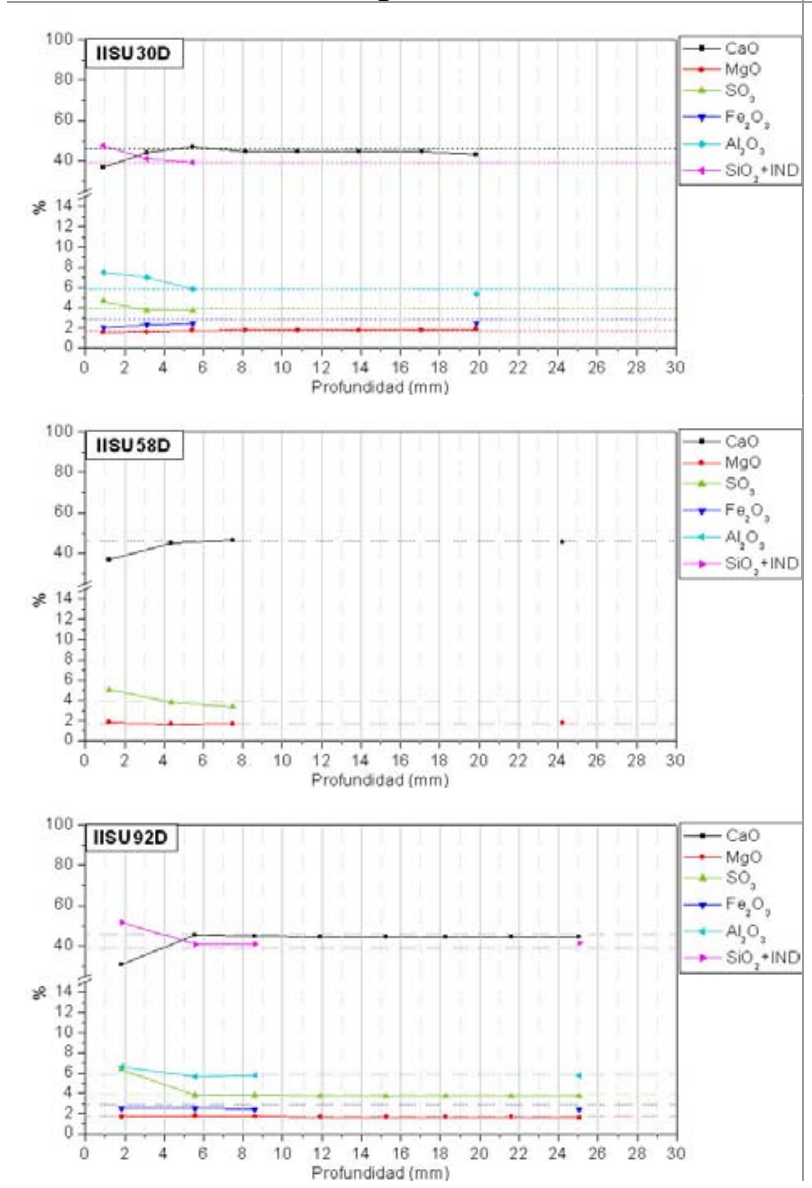

Figura 106. Composición de las pastas de cemento II expuestas al medio SU

Las muestras de pasta de cemento II presentan la misma tendencia que las pastas de cemento SR, con contenidos de $\mathrm{MgO}$ y $\mathrm{Fe}_{2} \mathrm{O}_{3}$ prácticamente constantes a lo largo de periodo de exposición.

Respecto al contenido de $\mathrm{CaO}$ en las probetas se observa una reducción mayor que la calculada para las pastas de cemento SR. A 30 días se observa cierta reducción del contenido de CaO que apenas progresa en el siguiente mes de ensayo y que afecta a los 3 primeros milímetros de probeta. Sin embargo a 92 días el contenido de $\mathrm{CaO}$ en la primera sección e ha reducido a aproximadamente la mitad del inicial y se observa descalcificación en los 5 primeros milímetros de probeta.
Evolución de los componentes a lo largo del proceso de exposición 
Las variaciones más significativas se producen en el incremento progresivo del contenido de $\mathrm{SO}_{3}$ en las probetas. Teniendo en cuenta que el medio de exposición está compuesto por una disolución de sulfato sódico, cabe la posibilidad de que parte de los iones sulfato penetren en los primeros milímetros de las probetas dando lugar nuevas fases sulfatadas.

El contenido de aluminio en la muestras se presenta prácticamente constante a lo largo del periodo de ensayo. Sólo a 30 días de exposición se observa cierto incremento en la primera sección de las muestras expuestas que podría estar relacionado con la precipitación de sulfoaluminatos cálcicos en la zona externa de la probeta y su posterior disolución.

En la Figura 107 se muestran los resultados obtenidos para las muestras de pasta de cemento IV expuestas al medio SU.

Las pastas de cemento IV presentan variaciones en el contenido de $\mathrm{CaO}$, $\mathrm{MgO}$ y $\mathrm{Fe}_{2} \mathrm{O}_{3}$ muy poco significativas a lo largo del proceso de exposición. Este tipo de pasta es el que presenta una menor alteración en medios de alta fuerza iónica.

El contenido de $\mathrm{SO}_{3}$ en la probeta crece en la primera sección de la probeta, en contacto con la disolución de sulfato sódico, pero su contenido no evoluciona a lo largo del tiempo. Cabría pensar que si la microestructura del material es muy cerrada, el ion sulfato, de gran tamaño, presenta dificultades para difundir en el seno de la disolución de los poros. Incluso cabría la posibilidad de que se produzca la precipitación de compuestos sulfatados en esta zona que obstaculicen tanto la salida como la entrada de iones en el material.

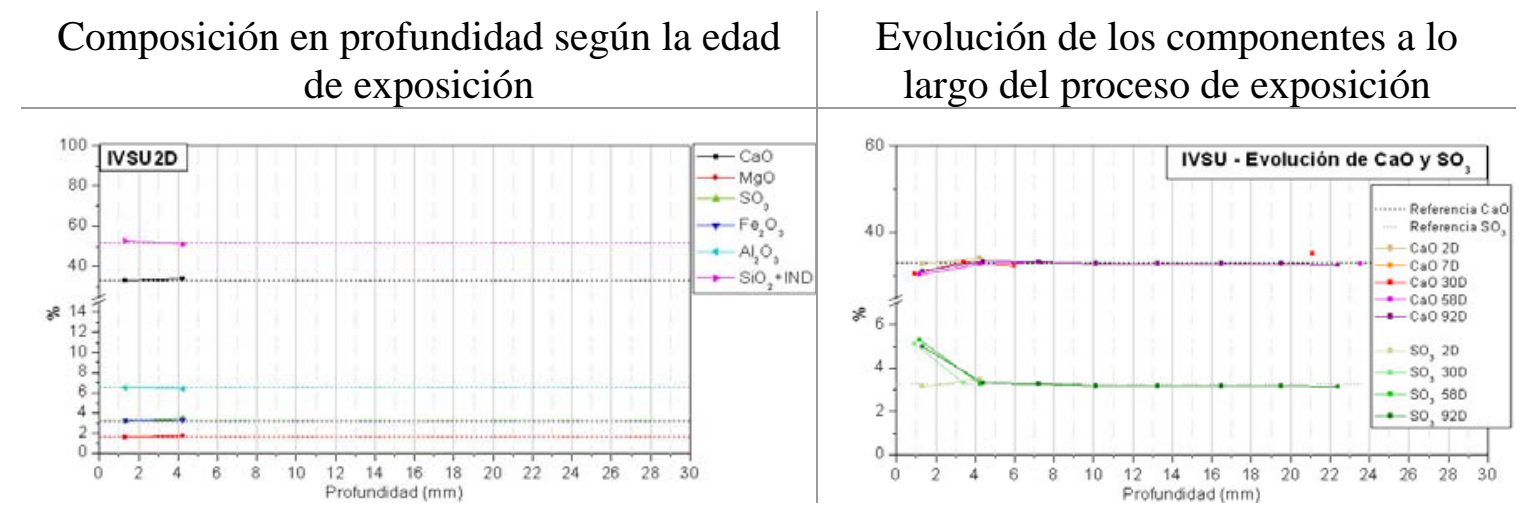


RESULTADOSY ANÁUSIS DE RESULTADOS

Composición en profundidad según la edad de exposición
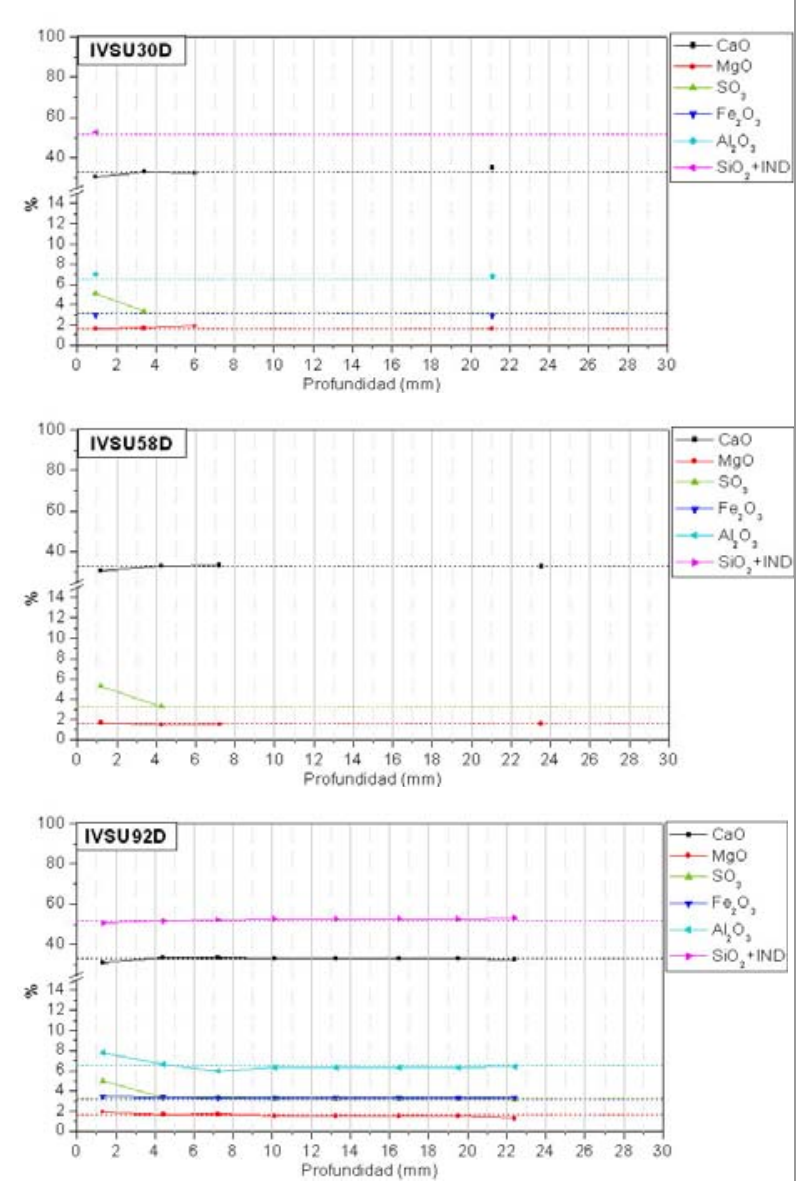

Figura 107. Composición de las pastas de cemento IV expuestas al medio SU
Evolución de los componentes a lo largo del proceso de exposición

\subsubsection{Composición de las muestras en el medio AN}

En la Figura 108, Figura 109 y Figura 110 se presentan los resultados de los contenidos analizados en las pastas de cemento SR, II y IV respectivamente expuestas al medio AN.

Las muestras de pasta de cemento SR no presentan variaciones en los contenidos de $\mathrm{CaO}$, MgO, $\mathrm{SO}_{3}, \mathrm{Fe}_{2} \mathrm{O}_{3}$ y $\mathrm{Al}_{2} \mathrm{O}_{3}$ en el periodo de tiempo estudiado. 
Composición en profundidad según la edad de exposición
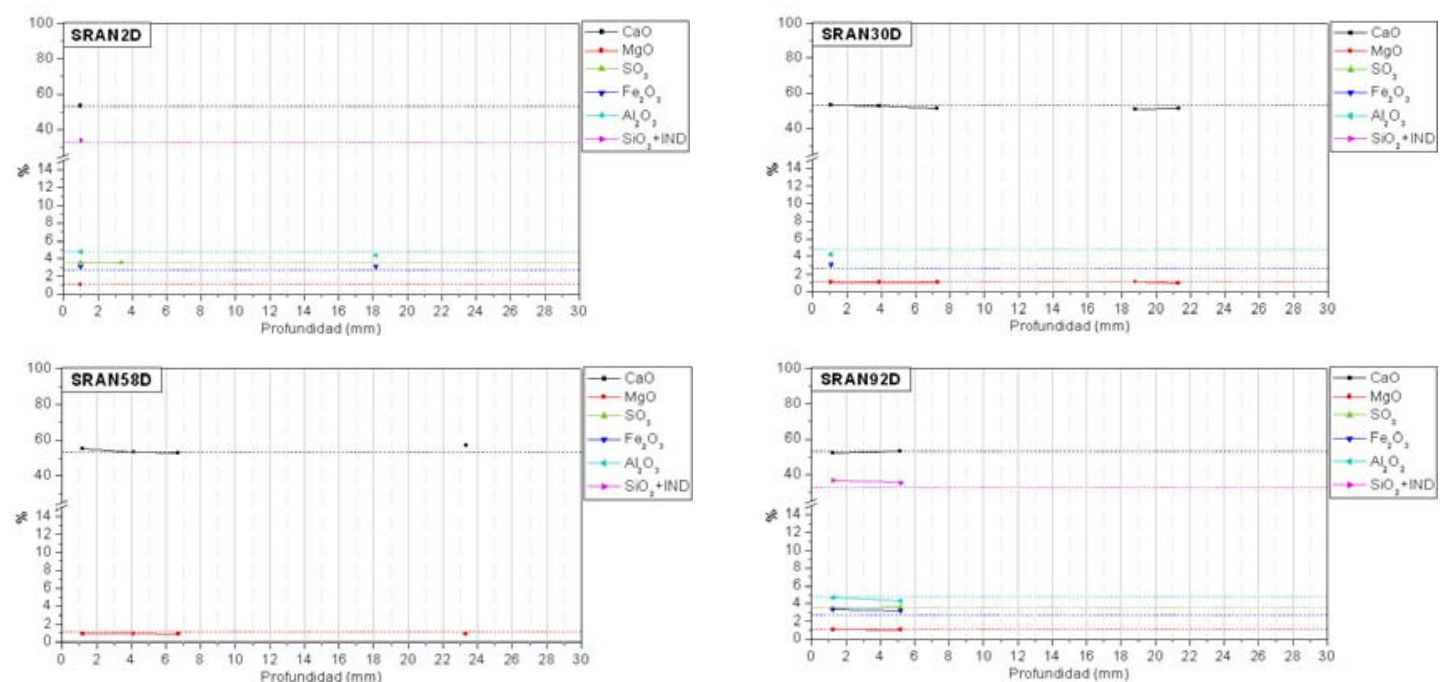

Figura 108. Composición de las pastas de cemento SR expuestas al medio AN

Composición en profundidad según la edad de exposición
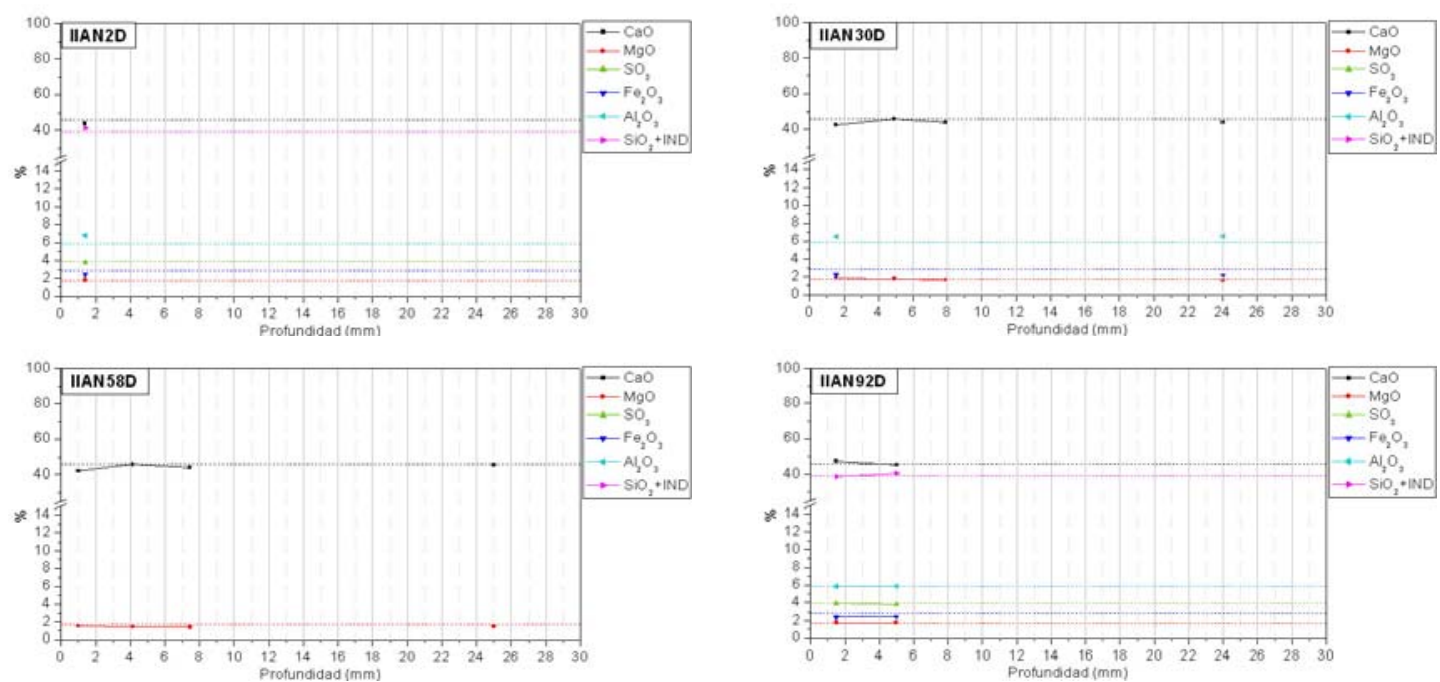

Figura 109. Composición de las pastas de cemento II expuestas al medio AN

Las muestras de pasta de cemento II no presentan variaciones en los contenidos de $\mathrm{CaO}$, MgO, $\mathrm{SO}_{3}, \mathrm{Fe}_{2} \mathrm{O}_{3}$ y $\mathrm{Al}_{2} \mathrm{O}_{3}$ en el periodo de tiempo estudiado. 


\section{Composición en profundidad según la edad de exposición}
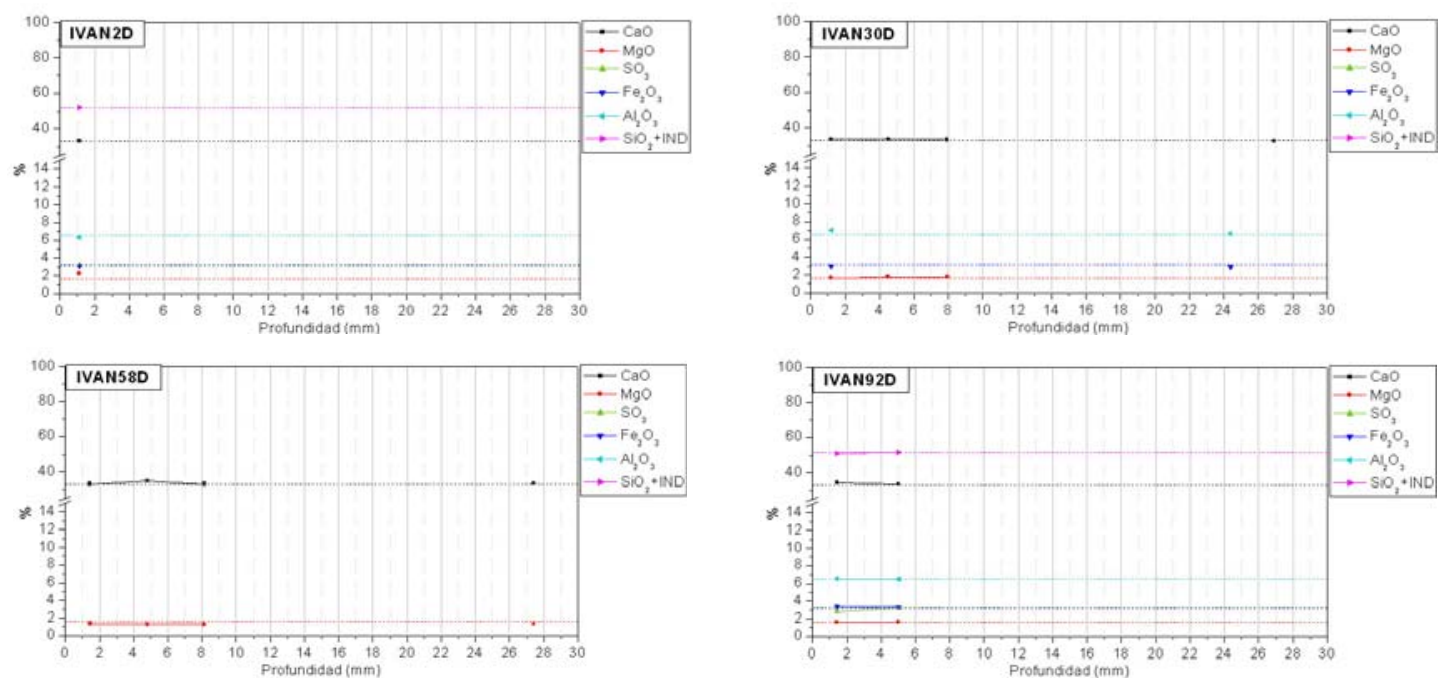

Figura 110. Composición de las pastas de cemento IV expuestas al medio AN

Las muestras de pasta de cemento IV no presentan variaciones en los contenidos de $\mathrm{CaO}$, MgO, $\mathrm{SO}_{3}, \mathrm{Fe}_{2} \mathrm{O}_{3}$ y $\mathrm{Al}_{2} \mathrm{O}_{3}$ en el periodo de tiempo estudiado.

\subsection{ANÁLISIS EN LOS MEDIOS DE EXPOSICIÓN}

El análisis de las características de las disoluciones de exposición durante el tiempo de ensayo nos permite evaluar la influencia que tiene el ambiente sobre las probetas. Además, el conocimiento del proceso de lixiviación resulta útil con el fin de estimar los cambios químicofísicos que se producen en el material.

\subsubsection{PH}

El pH de las disoluciones de exposición es una de las variables más importantes cuando se trata de procesos de lixiviación. Junto con la temperatura y la fuerza iónica, es uno de los factores que condiciona la solubilidad de los compuestos. Además, las oscilaciones de $\mathrm{pH}$ pueden estar relacionadas con la lixiviación de iones con propiedades ácido-base.

En la Figura 111 se muestran los datos de pH medidos en los medios de exposición. Se han agrupado los datos según los medios de exposición empleados. 


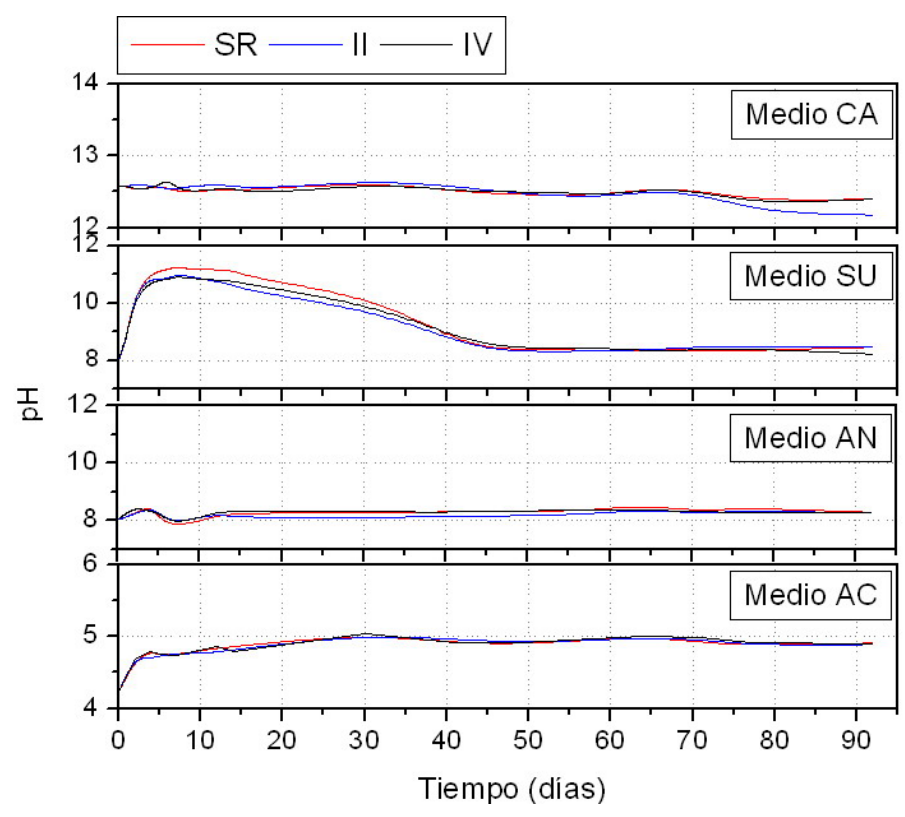

Figura 111.Evolución del pH en las disoluciones a lo largo del proceso de exposición

El pH en los medios saturados de hidróxido cálcico (CA) se mantiene constante, independientemente del cemento utilizado.

En los medios con presencia de sulfato (SU) se observan variaciones de $\mathrm{pH}$ similares para los tres tipos de pasta de cemento. Se registra un aumento inicial del pH en los 10 primeros días de ensayo. Se justifica este incremento del $\mathrm{pH}$ de las disoluciones por la lixiviación de hidroxilos procedentes de la portlandita de las probetas.

En los siguientes 30 días se registra un descenso del pH progresivo. La estabilización del pH en este medio coincide con la parada de lixiviación de calcio que veremos apartados posteriores.

Un descenso del pH en la disolución implica la variación de la concentración de iones hidroxilo en el medio. Teniendo en cuenta esto se pueden plantear diferentes hipótesis.

En la disolución original no hay especies capaces de formar una disolución reguladora, sin embargo, la lixiviación de carbonatos permitiría la formación del tampón $\mathrm{HCO}_{3}{ }^{-} / \mathrm{CO}_{3}{ }^{2-}$ con rangos de pH estables entre 8 y 12 unidades, en función de las concentraciones en la disolución.

La saturación de la disolución en una sal cálcica podría resultar en una inversión de los equilibrios de disolución-precipitación en la zona de la probeta en contacto con la disolución. Es 
preciso estudiar si se produce una precipitación de hidróxidos en la superficie de las probetas de ensayo.

En los medios AN se registraron ligeras oscilaciones de $\mathrm{pH}$ en los primeros días de ensayo. Como en el caso de los medios SU, la lixiviación de $\mathrm{CH}$ implicaría un aumento de la $\left[\mathrm{Ca}^{2+}\right]$ y del pH en la disolución.

Sin embargo hay que tener en cuenta que está disolución no es agua pura y contiene en su composición cierta cantidad de aniones y cationes habituales en aguas naturales. La presencia de especies con capacidad de tamponamiento, como $\mathrm{HCO}_{3}{ }^{-} / \mathrm{CO}_{3}{ }^{2-}$ y $\mathrm{H}_{2} \mathrm{PO}_{4}{ }^{-} / \mathrm{HPO}_{4}{ }^{2-} / \mathrm{PO}_{4}{ }^{3-}$, permiten la rápido estabilización del pH. La presencia de cierta $\left[\mathrm{Ca}^{2+}\right]$ inicial en la disolución condiciona la lixiviación $\mathrm{Ca}^{2+}$ procedente de las probetas y el contenido total de $\mathrm{Ca}^{2+}$ en la disolución por saturación de la misma en sales cálcicas de baja solubilidad.

Las sales de carbonato cálcico, fosfatos cálcicos y sulfatos cálcicos son relativamente insolubles, y teniendo en cuenta el $\mathrm{pH}$ de la disolución y las concentraciones iniciales de las mismas, la lixiviación de una pequeña cantidad de $\mathrm{Ca}^{2+}$ produciría la precipitación de estas sales, alterando la concentración de las especies en la disolución y reduciendo el pH ligeramente. $\mathrm{El} \mathrm{pH}$ final de las disoluciones $\mathrm{AN}$ corresponde al del equilibrio $\mathrm{HCO}_{3}{ }^{-} / \mathrm{CO}_{3}{ }^{2-}$.

En los medios AC, el pH crece unas décimas de unidad en los 30 primeros días de exposición y se estabiliza en un valor próximo a 5 durante el resto del tiempo de ensayo. Siendo el pH más bajo de los ensayados cabe esperar una lixiviación de compuestos mucho mayor que en otros medios.

Sin embargo, la presencia simultánea de las especies $\mathrm{CH}_{3} \mathrm{COOH}$ y $\mathrm{CH}_{3} \mathrm{COO}^{-}$determina que el pH en la disolución se mantenga amortiguado en torno al pKa de este ácido. Mientras no se rompa este tampón no hay variación significativa del pH del medio.

La presencia de medios tamponados es un factor a tener en cuenta en el estudio del efecto del $\mathrm{pH}$ en el deterioro de materiales base cemento, puesto que permite mantener en la disolución agresiva un $\mathrm{pH}$ menor durante mas tiempo, lo que condicionaría una disolución mayor de compuestos. La velocidad de disolución en ese caso se verá controlada por la velocidad de los procesos de difusión en la zona interior del material. La saturación de sales en la disolución 
también es un factor a tener en cuenta por la influencia que puede presentar en los equilibrios químicos de la disolución y especialmente en las primeras capas del material en contacto con las mismas.

\subsubsection{FUERZA IÓNICA}

Las características físico-químicas de las disoluciones influyen en los equilibrios de disolución precipitación de los compuestos. Por ello, y con el fin conocer mejor el proceso de lixiviación que se producen en los materiales de estudio es preciso caracterizar las disoluciones y evaluar los cambios que se producen a lo largo del proceso de ensayo.

La fuerza iónica (I) de la disolución es uno de los parámetros para medir esos cambios. Su valor influye en los coeficientes de actividad de los iones presentes y por tanto en los equilibrios de solubilidad. La Figura 112 muestra la variación de la actividad de los iones en función de la fuerza iónica a $25^{\circ} \mathrm{C}$. En la representación se ha empleado la ecuación de Debye-Hückel ampliada válida para disoluciones con I>0.01 (Sánchez, 2011).

$$
\log \gamma_{i}=\frac{-A z_{i}^{2} \sqrt{I}}{1+B a \sqrt{I}}-b I
$$

Donde:

- $A$ y $B$ son coeficientes que dependen de la temperatura, de la constante dieléctrica del disolvente y de la densidad.

- $\mathrm{Z}_{\mathrm{i}}$ hace referencia a la carga del ion.

- I es la fuerza iónica de la disolución.

- a es un parámetro semi-empírico que tiene en cuenta el tamaño de los iones delimitando la distancia de máxima de aproximación de otros iones.

- El término bI hace referencia a las correcciones introducidas cuando la fuerza iónica supera el valor de 0.1 . 


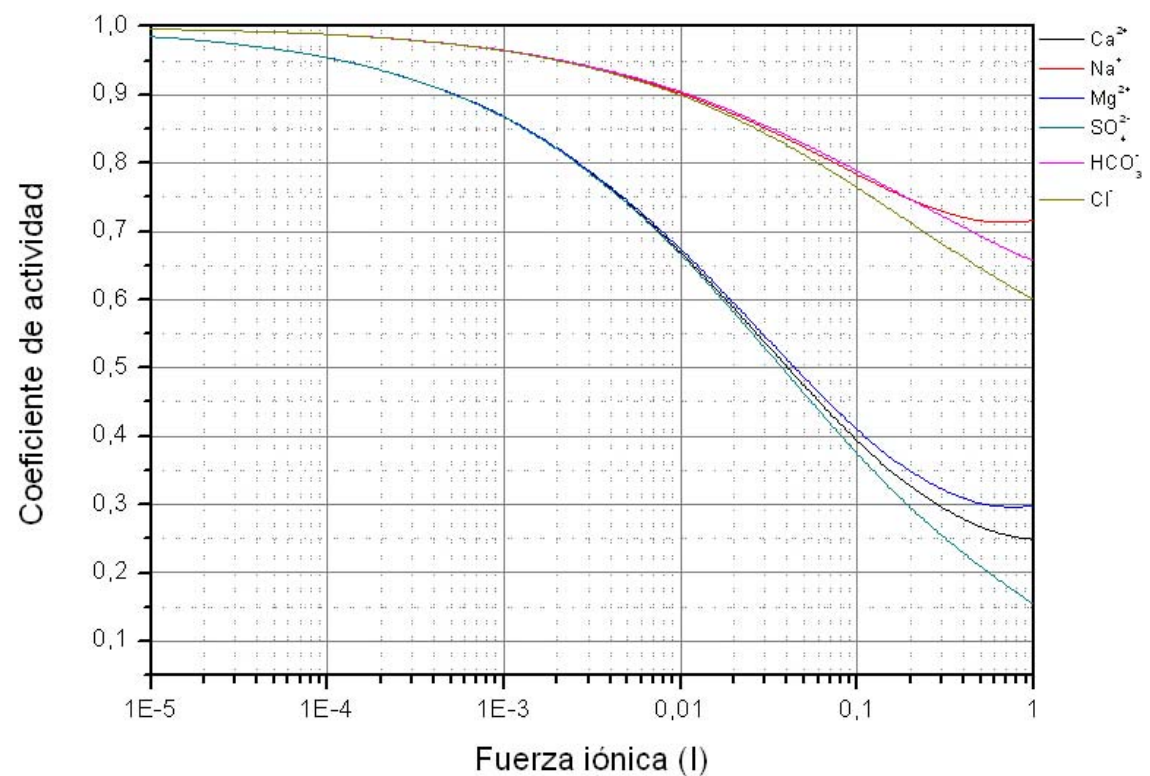

Figura 112. Evolución del coeficiente de actividad con la fuerza iónica de la disolución (Sánchez, 2011)

En la Tabla 36 se muestran los valores de fuerza iónica calculados en los medios de exposición iniciales.

Tabla 36. Fuerza iónica inicial calculada en los medios de exposición

\begin{tabular}{ccc}
\hline AC & SU & AN \\
\hline 0.10 & 0.60 & 0.008 \\
\hline
\end{tabular}

El valor de la fuerza iónica depende de la composición de las disoluciones. Por ello, se ha calculado el valor de la fuerza iónica en cada muestra tomada a lo largo del proceso de ensayo, y con ello los coeficientes de actividad.

En la Figura 113, Figura 114 y Figura 115 se muestran los resultados del cálculo de la fuerza iónica en las disoluciones a lo largo del proceso de ensayo para cada uno de los medios estudiados. 


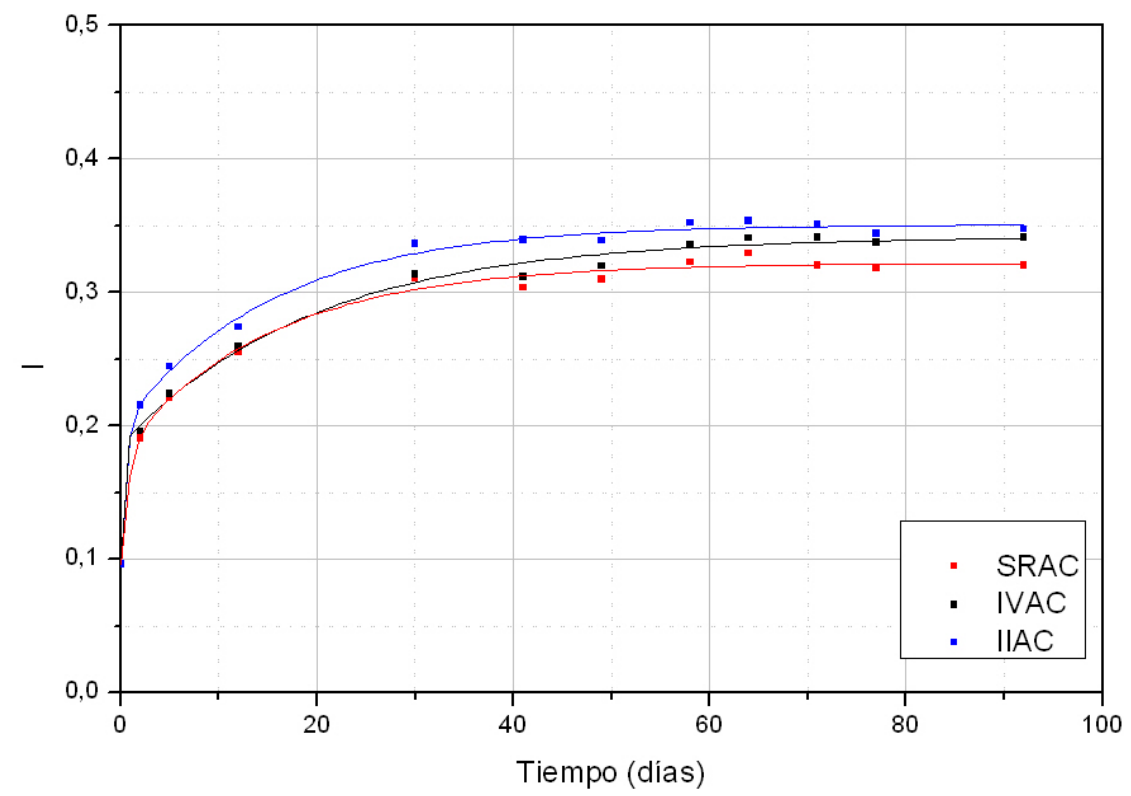

Figura 113. Evolución de I en las disoluciones AC a lo largo del proceso de ensayo

En los medios AC, la variación de fuerza iónica se produce fundamentalmente en los 30 primeros días de ensayo. En este tipo de medio con un $\mathrm{pH}$ entorno a 4.5 unidades es frecuente encontrar lixiviación de iones. La lixiviación de iones bivalentes merece especial atención por la contribución que tiene la caga en el cálculo de la fuerza iónica. En este sentido conviene observar que la mayor variación de fuerza iónica coincide con el aporte a la disolución de iones calcio, magnesio y sulfato.

La variación de pH también es un factor a tener en cuenta cuando se calcula la fuerza iónica, ya que se modifican las concentraciones de las especies en disolución y afecta a los equilibrios de precipitación de las sales en la disolución. En este caso las variaciones de $\mathrm{pH}$ son pequeñas porque se trata de un medio tamponado, pero sí se ha tenido en cuenta que el aporte de hidroxilos a la disolución produce una variación en la concentración de acetato en la disolución.

El ion calcio es uno de los que lixivia con mayor facilidad. A priori, los iones con mayores concentraciones son los más susceptibles de saturar en la disolución. Por ello, se ha estudiado la solubilidad que presenta la sal de acetato cálcico en la disolución, ya que no existen en la misma otros aniones capaces de formar sales insolubles. Teniendo en cuenta las concentraciones de calcio y acetato en la disolución (en función del $\mathrm{pH}$ ), y que la sal presenta una solubilidad de unos 40 gramos por cada $100 \mathrm{ml}$ de agua, se puede afirmar que no se produce en la disolución 
saturación de esta sal. Por tanto, el aumento de fuerza iónica en el medio no será un factor diferenciador desde el punto de vista de la solubilidad de compuestos.

En apartados posteriores se estudia la posibilidad de saturación de la disolución en otro tipo de sales cálcicas que podrían precipitar como el hidróxido cálcico o el sulfato cálcico.

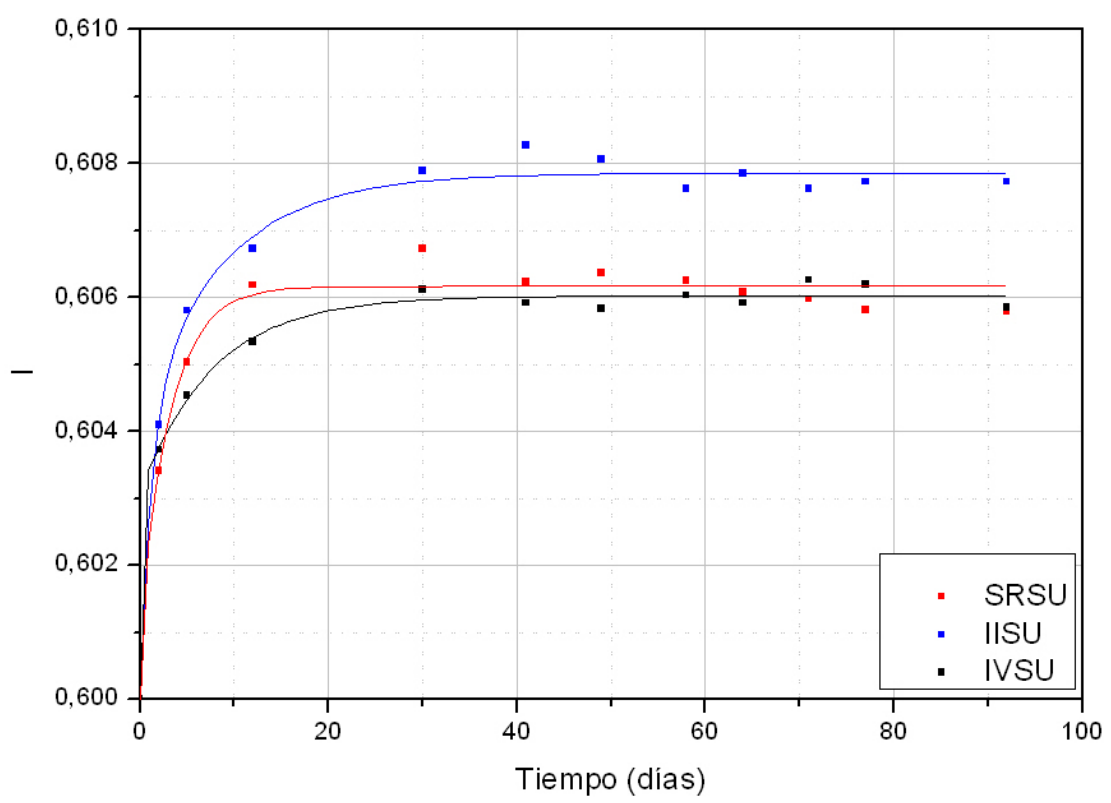

Figura 114. Evolución de I en las disoluciones SU a lo largo del proceso de ensayo

Las disoluciones SU presentan una variación de fuerza iónica importante en los primeros diez días de ensayo. En este medio, la variación de fuerza iónica se debe fundamentalmente al aumento de la concentración de calcio en la disolución. Las curvas presentan perfiles similares a las de la variación de la concentración del ión que se muestran en el apartado 4.5.3.2.

Las variaciones de $\mathrm{pH}$ en este medio afectan a los 50 primeros días de ensayo, por lo que en este caso es preciso evaluar si se produce saturación de hidróxido cálcico en la disolución. Teniendo en cuenta las concentraciones de hidroxilos, en función del pH, y la concentración de ion calcio analizada, con una constante de solubilidad de $5.5 \cdot 10^{-6}$, se puede afirmar que no se produce saturación de esta sal en la disolución en ninguno de los pH estudiados.

La presencia de una concentración de sulfato alta, junto con la lixiviación de ion calcio en la disolución puede dar lugar a la saturación de la disolución en sulfato cálcico $\left(\mathrm{Ks}=2 \cdot 10^{-4}\right.$ ). Con una concentración de sulfato de $0.2 \mathrm{M}$, la concentración de calcio que admite la disolución antes 
de saturar es de $10^{-3} \mathrm{M}$, por lo que sí es posible que la disolución se encuentre saturada. Es preciso evaluar si la fuerza iónica incrementa la solubilidad de la sal en la disolución. Se analiza este cálculo en el apartado 4.5.3.2.

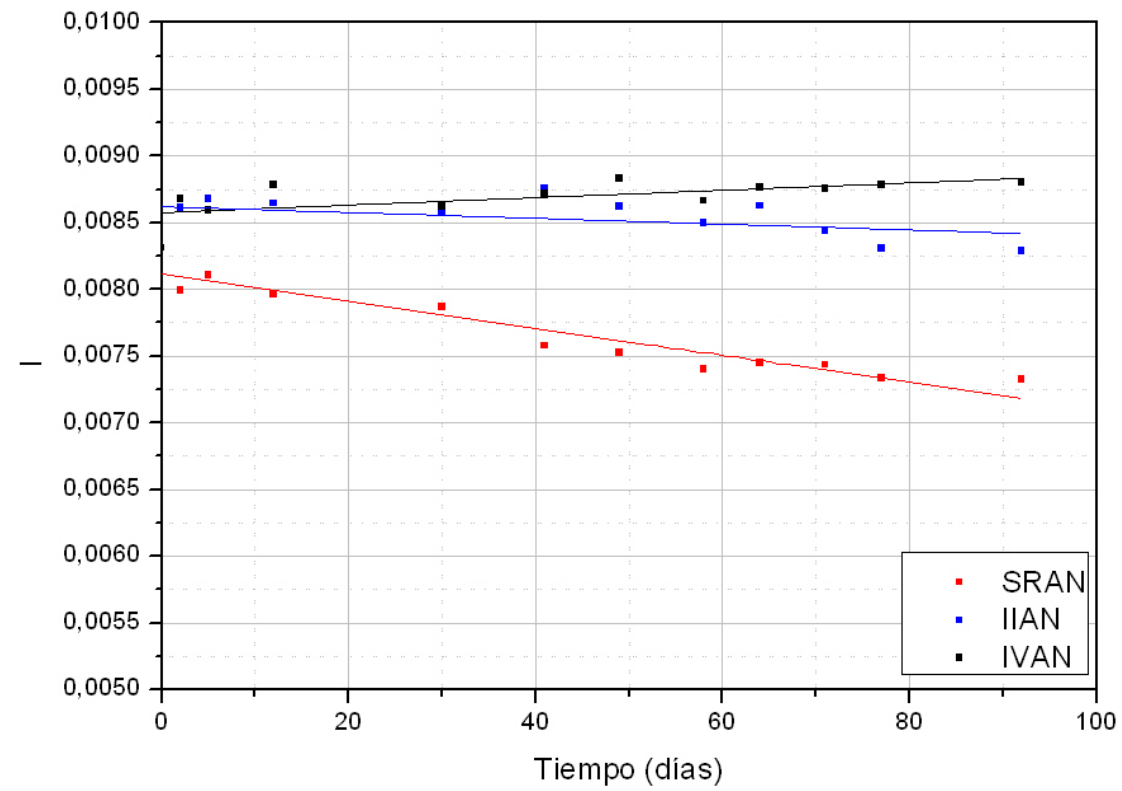

Figura 115.Evolución del I en las disoluciones a lo largo del proceso de ensayo

La fuerza iónica de las disoluciones AN era la más baja de las tres ensayadas. A lo largo del tiempo de ensayo se han observado variaciones escasas en el cálculo de esta propiedad.

La disolución que contenía las pastas de cemento SR presentó una reducción en la fuerza iónica del medio calculada. Este descenso se debe probablemente al descenso de la concentración de ion calcio en el medio. Si bien la concentración de sulfato sube ligeramente, no compensa el descenso de las cargas aportadas por la reducción de la concentración de ion calcio. A su vez, el pH presenta variaciones muy pequeñas, por lo que las concentraciones de las especies ácidobase varían poco y no suponen un factor diferenciador desde el punto de vista del cálculo de I.

La fuerza iónica calculada en las disoluciones IIAN y IVAN varía muy poco en el tiempo de ensayo. En el caso de la disolución IIAN la diferencia de concentración de ion sulfato en el medio es similar a la analizada en el medio SRAN, sin embargo el descenso de la concentración de calcio es menor. En el caso del medio IVAN la fuerza iónica calculada crece ligeramente porque la concentración de ion calcio en la disolución permanece prácticamente constante y la de ion sulfato crece ligeramente. 
El pH de la disolución y la fuerza iónica de la misma son dos de los factores que afectan a la solubilidad de compuestos, y ambas propiedades se modifican cuando se produce una lixiviación de portlandita procedente de las probetas. Es importante tener en cuenta en qué medida afecta una propiedad a la otra, y cómo influye la presencia de medios tamponados, por ello en la Figura 116 se muestra la relación que existe entre la fuerza iónica calculada en el medio y el pH de la disolución.

Cuando representamos todos los valores en el mismo gráfico, se puede apreciar que el medio AC es que presenta una dependencia mayor entre las propiedades $\mathrm{pH}$ y fuerza iónica.

En este medio el pH es ácido y se encuentra amortiguado con el tampón acético-acetato. Esto favorece la rápida disolución de compuestos, especialmente portlandita, y por tanto la lixiviación de iones. En este caso el pH y la fuerza iónica de la disolución ejercen un efecto sinérgico ya que el $\mathrm{pH}$ ácido y amortiguado permite la neutralización de hidroxilos procedentes de las probetas permitiendo una gran lixiviación de otros iones. El aumento de la concentración de iones en la disolución eleva la fuerza iónica, lo que a su vez se traduce en una disminución de los coeficientes de actividad de los iones y por tanto en una mayor cantidad de iones solubles en la disolución. De este modo el medio AC es el único que con una variación de pH relativamente pequeña (media unidad aproximadamente) duplica prácticamente su fuerza iónica.

En el medio AN no se aprecia una variación reseñable de la fuerza iónica con el pH. Al igual que el medio AC, se trata de un medio tamponado, pero en este caso la presencia de ciertos iones en la disolución con capacidad para saturar la disolución en sales cálcicas puede estar condicionando la lixiviación de iones a la disolución y consecuentemente la variación de la fuerza iónica.

En el caso del medio SU se observa una agrupación de medidas entre pH 8.2 y pH 8.6 en las cuales la fuerza iónica permanece practicamente constante independientemente del pH. En este medio, sin capacidad de tamponamiento, se produce un incremento de $\mathrm{pH}$ importante en los primeros días de ensayo, seguido de una reducción paulatina del mismo. Este incremento de pH se asocia con la lixiviación de los iones de la portlandita. La fuerza iónica del medio crece también debido a la lixiviación de iones calcio. Sin embargo, la reducción del pH no está asociada a una reducción de la fuerza iónica. Debemos entender entonces que la variación de concentración de los iones se ve compensada y no afecta al cálculo de la fuerza iónica, y que la 
reducción del $\mathrm{pH}$ se produce por consumo de iones hidroxilo en otras reacciones. Una vez estabilizado el pH de las disoluciones se observa que la fuerza iónica de la disolución también permanece constante.

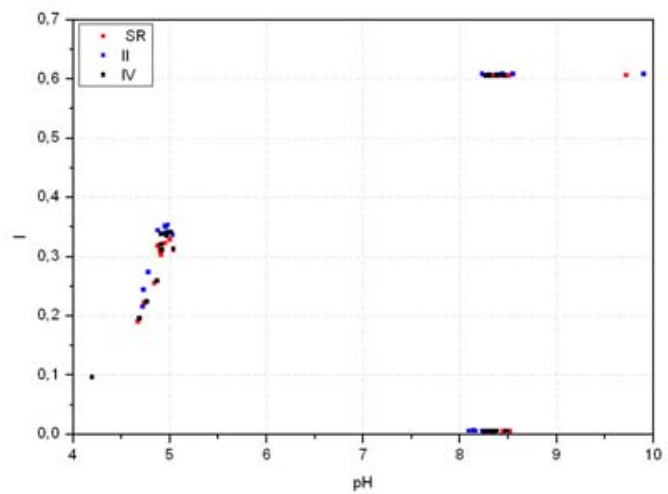

(a) Todos los valores

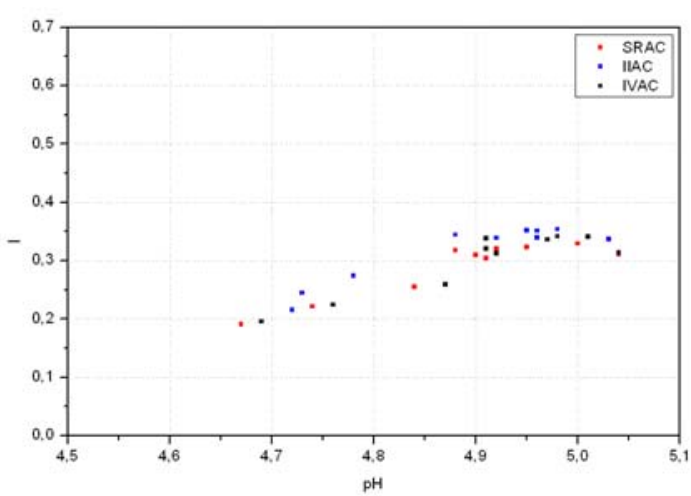

(b) Disoluciones AC

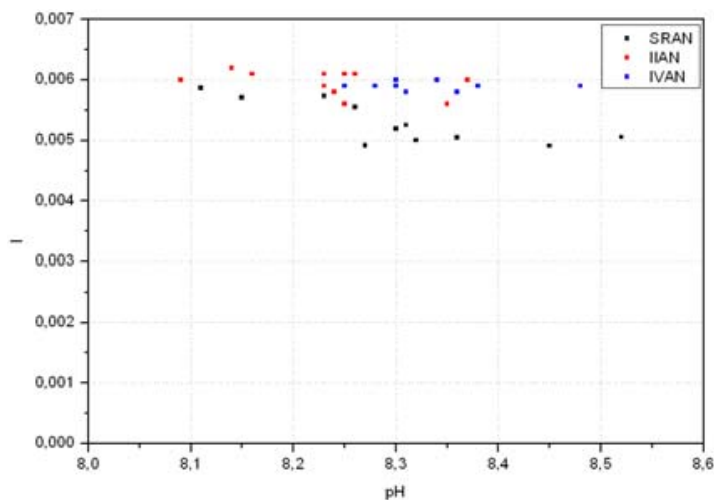

(c) Disoluciones AN

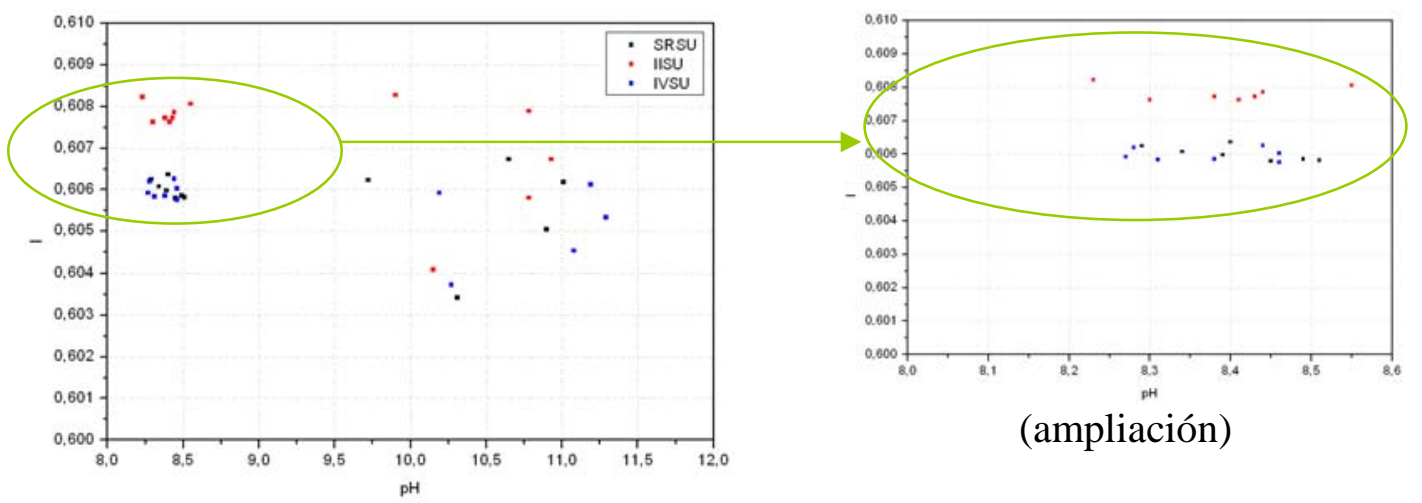

(d) Disoluciones SU

Figura 116. Relación entre la fuerza iónica y el pH del medio 


\subsubsection{COMPOSICIÓN IÓNICA DE LIXIVIADOS}

En este apartado se analiza la concentración de ion calcio, ion magnesio e ion sulfato en las disoluciones de exposición a lo largo del proceso de ensayo. En cada medio se han analizado las causas que producen la lixiviación de iones, y su relación con las características de la disolución.

\subsubsection{Análisis de iones en el medio AC}

El medio AC está compuesto por una disolución reguladora de ácido acético-acetato sódico, con una concentración de $0.35 \mathrm{M}$, un pH inicial de 4.8 unidades y una fuerza iónica de 0.1. A priori, es el medio que potencialmente puede resultar más agresivo desde el punto de vista de la solubilidad de compuesto por su acidez. La presencia de un tampón en su composición puede resultar relevante en el análisis de iones lixiviados.

\section{$\underline{\text { Ion } \mathrm{Ca}^{2+} \text { lixiviado en el medio AC }}$}

Si asumimos que el proceso de lixiviación cumple las leyes de Fick y está controlado por difusión, debe cumplirse que el proceso puede ser caracterizado mediante la siguiente ecuación (Segura, 2008):

$$
\chi=a \sqrt{t}
$$

Ecuación 32

En esta ecuación, el avance del proceso de degradación viene determinado por el parámetro $\chi$, pudiendo ser este cualquier parámetro que varie en función del avance del proceso de degradación. Una vez definido dicho parámetro se puede aplicar por tanto, una regresión simple lineal, para caracterizar el proceso y obtener, a partir de un ajuste lineal de la ecuación, el coeficiente "a” que indique la velocidad del proceso de degradación.

En este caso el parámetro elegido para medir la evolución de la degradación la variación del contenido de ion calcio en el medio agresivo.

En la Figura 117 se muestra la $\left[\mathrm{Ca}^{2+}\right]$ analizado en las muestras recogidas en el tiempo de ensayo (izquierda) y la dependencia de los valores con la raíz del tiempo. 

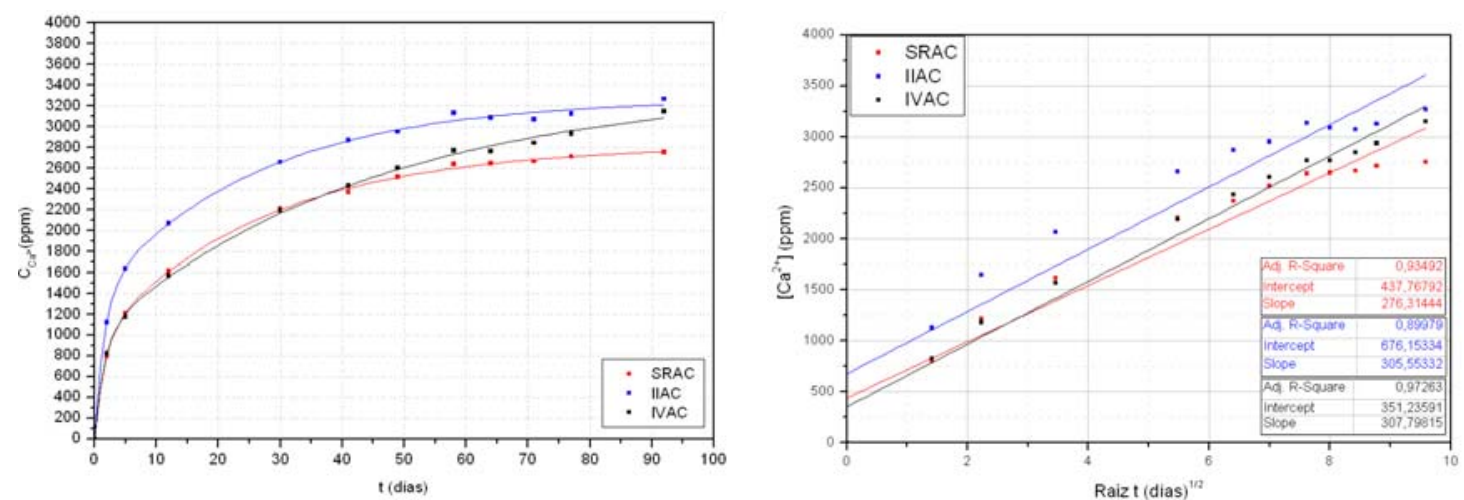

Figura 117. $\left[\mathrm{Ca}^{2+}\right]$ lixiviado en función del tiempo - Medio AC (izquierda).

Dependencia de la $\left[\mathrm{Ca}^{2+}\right]$ con la raíz del tiempo (derecha)

La Figura 117 muestra una primera etapa del proceso que claramente responde a la ecuación de difusión.

La concentración de ion calcio analizado en estos medios se sitúa entre las 800 ppm y las 3.200 ppm. Estas concentraciones son superiores a las analizadas en otros medios. Este resultado era de esperar puesto que el pH del medio influye en la solubilidad de los compuestos cálcicos.

El medio que mayor $\left[\mathrm{Ca}^{2+}\right]$ presenta es IIAC. En este medio es en el que se produce un gradiente de concentración más alto. Sin embargo si comparamos las pendientes de las curvas, los datos de las muestras IIAC y IVAC son muy parecidos. La disolución inicial es mayor en el cemento II, pero la velocidad de difusión es muy semejante para las tres muestras.

Los medios de los cementos cemento IV (IVAC) y SR (SRAC) presentan una $\left[\mathrm{Ca}^{2+}\right]$ similar hasta los 40 días. A partir de este tiempo la $\left[\mathrm{Ca}^{2+}\right]$ lixiviado es mayor en el medio IVAC. Sin embargo esta observación es relativa puesto que en todos los medios no existía el mismo número de probetas.

Para analizar comparativamente el comportamiento de las muestras de cada uno de los cementos en cada medio de ensayo es preciso tener en cuenta que los resultados que se presentan en la Figura 117 hacen referencia a la concentración total acumulada en la disolución.

La comparación de los resultados se ha realizado ponderando la concentración de calcio en la disolución con el número de probetas y el tiempo. Para el cálculo se ha denominado una "unidad de lixiviación” como la $\left[\mathrm{Ca}^{2+}\right]$ que lixiviaría una probeta por cada día de ensayo. De este modo, si hemos analizado la $\left[\mathrm{Ca}^{2+}\right]$ en una muestra, a los dos días de exposición a la 
disolución agresiva, e inicialmente había 63 probetas en la disolución, la cantidad de calcio lixiviado correspondería a 126 unidades de lixiviación de una superficie de 10 mm².

En los gráficos siguientes se muestran, a la izquierda, los resultados obtenidos al ponderar la concentración de calcio con las unidades de lixiviación a lo largo del proceso de degradación, y a la derecha el la dependencia de los valores con la raíz del tiempo.

La Figura 118 muestra los resultados obtenidos en las muestras del medio AC para los tres tipos de pasta de cemento.
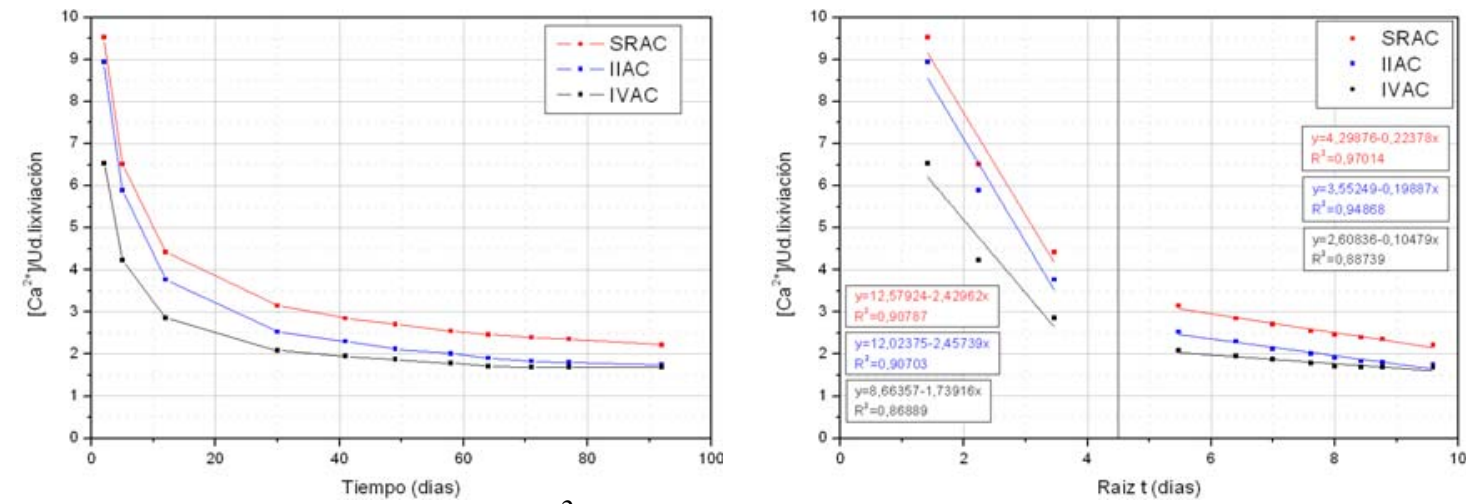

Figura 118. Evolución de la $\left[\mathrm{Ca}^{2+}\right] /$ unidades de lixiviación a lo largo del ensayo en el medio AC (izquierda). Análisis de los tramos de la curva obtenida en función de la raíz del tiempo (derecha)

Al analizar los tres tipos de pastas por unidades de lixiviación, observamos que la pasta de cemento que mayor cantidad de calcio lixivia es la SR, seguida de las muestras de pasta II y en último lugar las muestras de pasta de cemento IV. Si se corrige el efecto del diferente número de probetas, las muestras que mas lixivian son aquellas en la que se producía un gradiente de concentración mayor (Figura 117, dcha.).

En la Figura 118 (izquierda) se evalúa la velocidad de lixiviación en función de la raíz del tiempo. Se puede observar que existen dos tramos diferenciados en el proceso de lixiviación y que la lixiviación de ion calcio en la probeta corresponde a un perfil gobernado por difusión en dos etapas. En la segunda etapa claramente es un proceso de difusión y la linealidad es muy acusada. En la primera hay dos procesos disolución y difusión. En el proceso de difusión la fuerza impulsora del movimiento de iones es el gradiente de concentración, por lo que debemos 
evaluar los factores que están afectando a esa diferencia de concentración que afecta al proceso de difusión.

El primer tramo comprende los 12 primeros días de ensayo y correspondería a la zona con pendiente acusada. Podría interpretarse este tramo como aquel en el que se produce la disolución de compuestos cálcicos, especialmente portlandita, que es el compuesto más soluble en la pasta de cemento.

En este tramo tendrían especial relevancia los factores que afectan a la solubilidad de los compuestos, en primer lugar los relativos a las características de la disolución: pH y fuerza iónica de la disolución; y en segundo el contenido inicial de portlandita de las muestras. Esta secuencia, a priori coincide con el contenido estimado de portlandita que presentaría cada uno de los tipos de cemento. El contenido de portlandita de cada tipo de pasta de cemento queda condicionado por la composición del cemento empleado y el contenido y tipo de adición puzolánica usada.

Si analizamos la pendiente de las curvas en este tramo, se observa que la velocidad de disolución de la pasta de cemento II y de la de la pasta de cemento SR son muy similares, y ligeramente superiores a la de la pasta de cemento tipo IV.

El segundo tramo se caracteriza por un descenso de la velocidad de lixiviación de $\mathrm{Ca}^{2+}$ que estaría condicionado por una reducción del gradiente de concentración existente entre la disolución exterior y la disolución en el interior de los poros del material. Al final del tramo los valores comienzan a tener un aspecto asintótico. Se asume por tanto que el régimen de difusión está llegando a un régimen estacionario en el que todo el ion calcio que llega a la superficie de la probeta lixivia. En la figura analizada se estima a partir de los 30 días de ensayo. En cuanto a la velocidad de difusión en este tramo se observan velocidades próximas para las pastas de cementos SR y II y menor en las pastas de cemento IV.

\section{$\underline{\text { Ion } \mathrm{Mg}^{2+} \text { lixiviado en el medio AC }}$}

En la Figura 119 se muestra la $\left[\mathrm{Mg}^{2+}\right]$ analizado en las muestras recogidas en el tiempo de ensayo (izquierda), y la dependencia de los valores con la raíz del tiempo (derecha). 

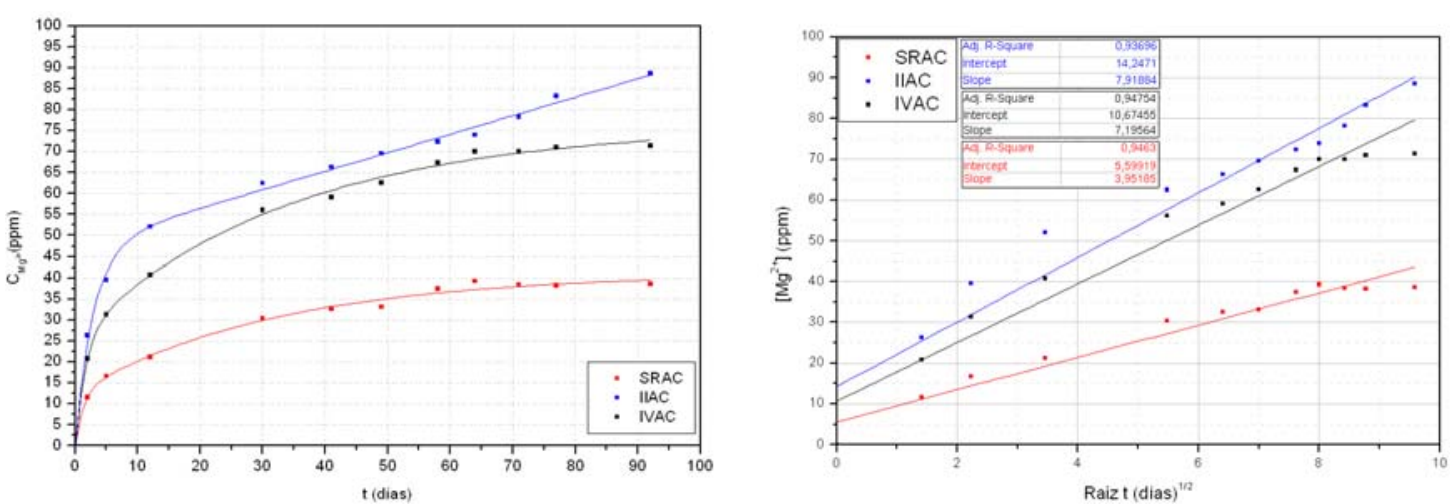

Figura 119. $\left[\mathrm{Mg}^{2+}\right]$ lixiviado en función del tiempo - Medio AC (izquierda). Dependencia de la $\left[\mathrm{Mg}^{2+}\right]$ con la raíz del tiempo (derecha)

Si analizamos el contenido de ion magnesio en el medio AC se observa la incidencia del pH en la solubilidad de los compuestos en este medio. En las disoluciones AC son las únicas en las que se produce la lixiviación de este ion. El medio que mayor $\left[\mathrm{Mg}^{2+}\right]$ recibe es el de la pasta de cemento II, seguido del medio con pastas de cemento tipo IV y por último el de las pastas de cemento SR.

La lixiviación de ion magnesio procedente de las probetas de ensayo se ajusta a un perfil de lixiviación gobernado por difusión. Las pastas de cemento SR son las que presentan una sensibilidad menor a la lixiviación de este ion.

En la Figura 120 se muestran, a la izquierda, los resultados obtenidos al ponderar la $\left[\mathrm{Mg}^{2+}\right]$ con las unidades de lixiviación a lo largo del proceso de degradación. A la derecha, la dependencia de los valores con la raíz del tiempo en las muestras del medio AC para los tres tipos de pasta de cemento.
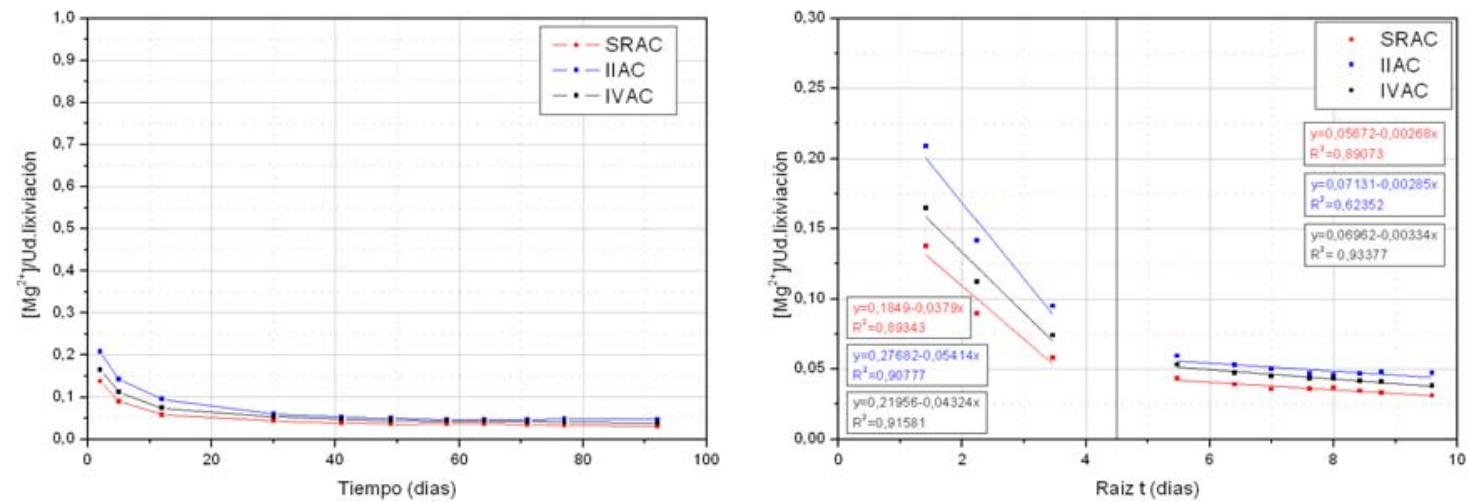

Figura 120. Evolución de la $\left[\mathrm{Mg}^{2+}\right]$ /unidades de lixiviación a lo largo del ensayo en el medio AC. Análisis de los tramos de la curva obtenida en función de la raíz del tiempo 
$\mathrm{Al}$ ponderar la $\left[\mathrm{Mg}^{2+}\right]$ con las unidades de lixiviación observamos que la pasta de cemento que mayor $\left[\mathrm{Mg}^{2+}\right]$ ha lixiviado es la tipo II, seguido de la pasta de cemento tipo IV, y en último lugar la de tipo SR.

En los primeros días de ensayo las muestras que mayor cantidad de magnesio lixivian mantienen un gradiente de concentración mayor y por tanto una velocidad de difusión más alta.

En este caso no se observa una dependencia tan acusada con respecto al contenido inicial de magnesio en las muestras. Es posible que, tratándose de pastas de cemento con adiciones, el magnesio se encuentre formando parte de compuestos con una solubilidad diferente a la que se encontraría si formasen parte de un hidróxido.

Hacia los 30 días de ensayo se estima que el proceso ha alcanzado su estado de difusión estacionaria en la probeta y el contenido de ion magnesio en la disolución se mantiene prácticamente constante.

\section{${\underline{\text { Ion } \mathrm{SO}_{4}}}_{4}{ }^{2-}$ lixiviado en el medio AC}

En la Figura 121 se muestra la $\left[\mathrm{SO}_{4}{ }^{2-}\right]$ analizado en las muestras recogidas en el tiempo de ensayo (izquierda), y la dependencia de los valores con la raíz del tiempo (derecha).
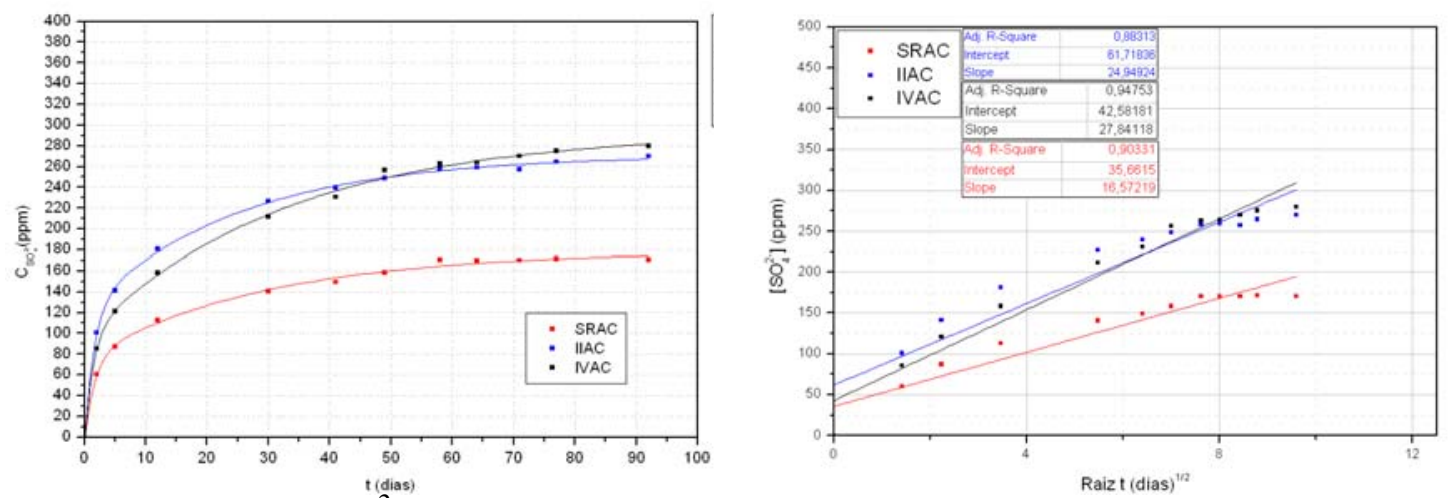

Figura 121. $\left[\mathrm{SO}_{4}^{2-}\right.$ ] lixiviado en función del tiempo - Medio AC (izquierda).

Dependencia de la $\left[\mathrm{SO}_{4}{ }^{2-}\right]$ con la raíz del tiempo (derecha)

La concentración de ion sulfato analizado en las disoluciones se sitúa entre 60 y 280 ppm. La concentración de sulfato lixiviada en el medio SRAC es significativamente menor que en el resto, sin embargo esta observación debe comprobarse al ponderar la cantidad de calcio lixiviado con el número de probetas en la disolución. 
En el caso de las concentraciones de ion sulfato en las disoluciones IIAC y IVAC son muy similares a lo largo del tiempo de ensayo.

Si analizamos la dependencia de la concentración de ion sulfato con la raíz del tiempo, se puede decir que las medidas realizadas en el medio de degradación indican que el proceso de lixiviación está gobernado por difusión.

En la Figura 122 se muestran, a la izquierda, los resultados obtenidos al ponderar la [ $\left.\mathrm{SO}_{4}{ }^{2-}\right]$ con las unidades de lixiviación a lo largo del proceso de degradación, y a la derecha el la dependencia de los valores con la raíz del tiempo en las muestras del medio AC para los tres tipos de cemento.
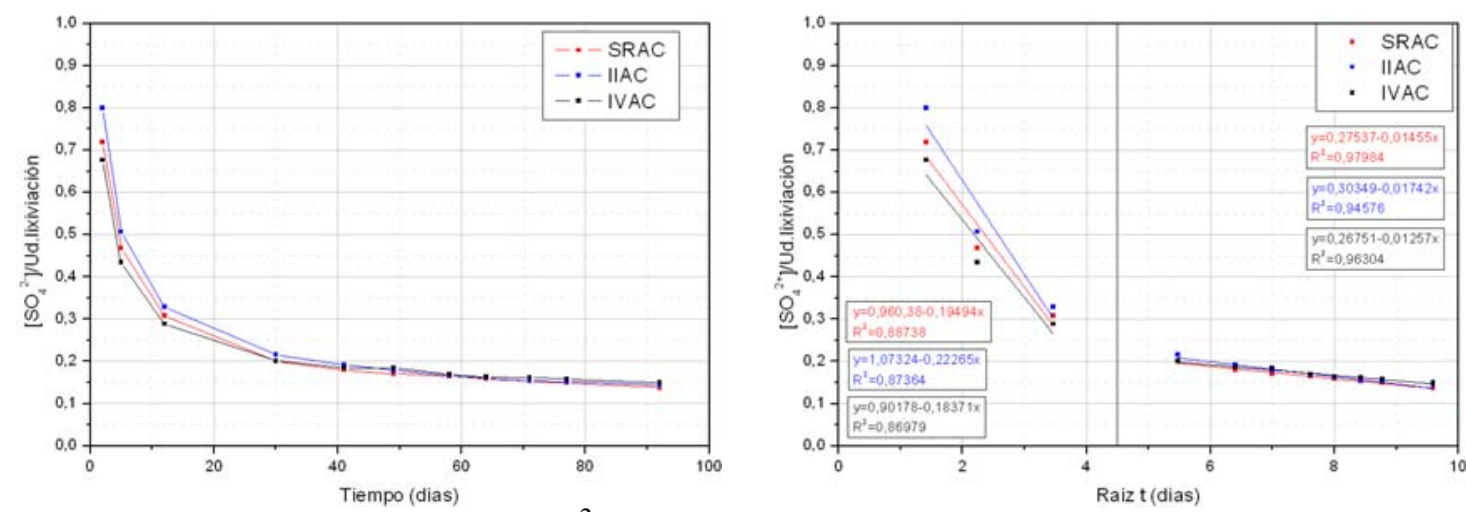

Figura 122. Evolución de la $\left[\mathrm{SO}_{4}{ }^{2-}\right] /$ unidades de lixiviación a lo largo del ensayo en el medio AC. Análisis de los tramos de la curva obtenida en función de la raíz del tiempo

Al ponderar los resultados de la lixiviación de sulfato en la disolución con el número de probetas de ensayo y días de exposición se observa que los tres tipos de pasta de cemento lixivian prácticamente las mismas cantidades de $\mathrm{SO}_{4}{ }^{2-}$. Si se generó un gradiente de concentración desigual entre los medios por el número desigual del número de probetas en la disolución, al ponderar el resultado no se observa que tenga un efecto determinante en la velocidad con la que lixivia el ion.

Como se ha analizado con otros iones lixiviados en el medio, se detectan dos tramos con distinta velocidad de difusión hacia la disolución. En ambos tramos se observan velocidades de difusión del ion muy próximas entre sí. Claramente en el primer tramo aparecen las diferencias correspondientes a la solubilidad de las especies sulfatadas en los diferentes tipos de cementos. 
Tanto en el caso de la concentración de ion calcio como de ion sulfato parece que la difusión de ambos iones alcanza un estado estacionario en el tramo final del ensayo, Pero teniendo en cuenta las concentraciones de analizadas en la disolución, es preciso analizar el nivel de saturación en $\mathrm{CaSO}_{4}$ de la disolución. La precipitación de esta sal en la disolución puede estar afectada por el incremento de fuerza iónica en la disolución.

En la Figura 123 se muestran los gráficos donde se han representado, en función del pH de la disolución, la concentración de ion calcio en la disolución, la concentración máxima de ion calcio que permitiría el equilibrio de solubilidad de la sal $\mathrm{CaSO}_{4}$ con una $\mathrm{Ks}=2 \cdot 10^{-4}$, y por último la concentración máxima de ion calcio que permitiría la disolución de de la sal $\mathrm{CaSO}_{4}$ con una $\mathrm{Ks}=2 \cdot 10^{-4}$ teniendo en cuenta el coeficiente de actividad de ambos iones en función de la fuerza iónica del medio en cada punto. Para el cálculo de la variación de la solubilidad se ha empleado la variación de los coeficientes de actividad que se muestran en la Figura 112.

En la figura se observa que la disolución SRAC no se encuentra saturada en ninguno de los puntos estudiados.

En el caso de las disoluciones IIAC y IVAC se observan algunos puntos entre pH 4.9 y 5 en los que si no tenemos en cuenta la fuerza iónica del medio la disolución se encuentra próxima a la saturación. Si tenemos en cuenta que la concentración de ion calcio y de ion sulfato no se estabilizan en la disolución, se puede pensar que la sal no ha llegado a la condición de saturación en la disolución.

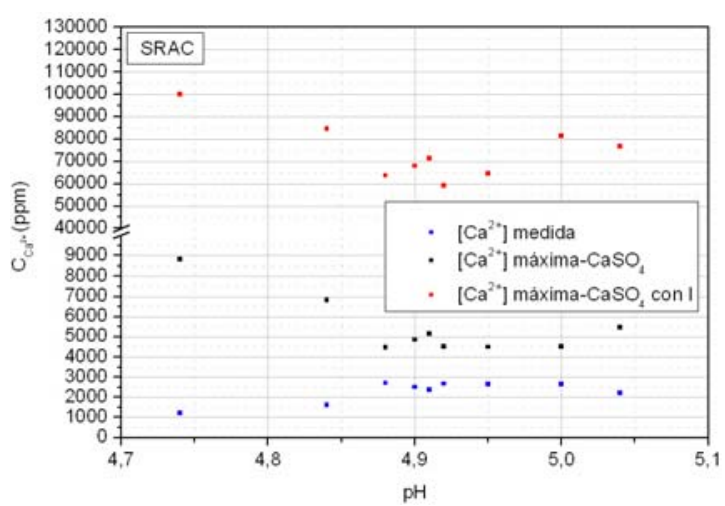


RESULTADOSY ANÁUSIS DE RESULTADOS
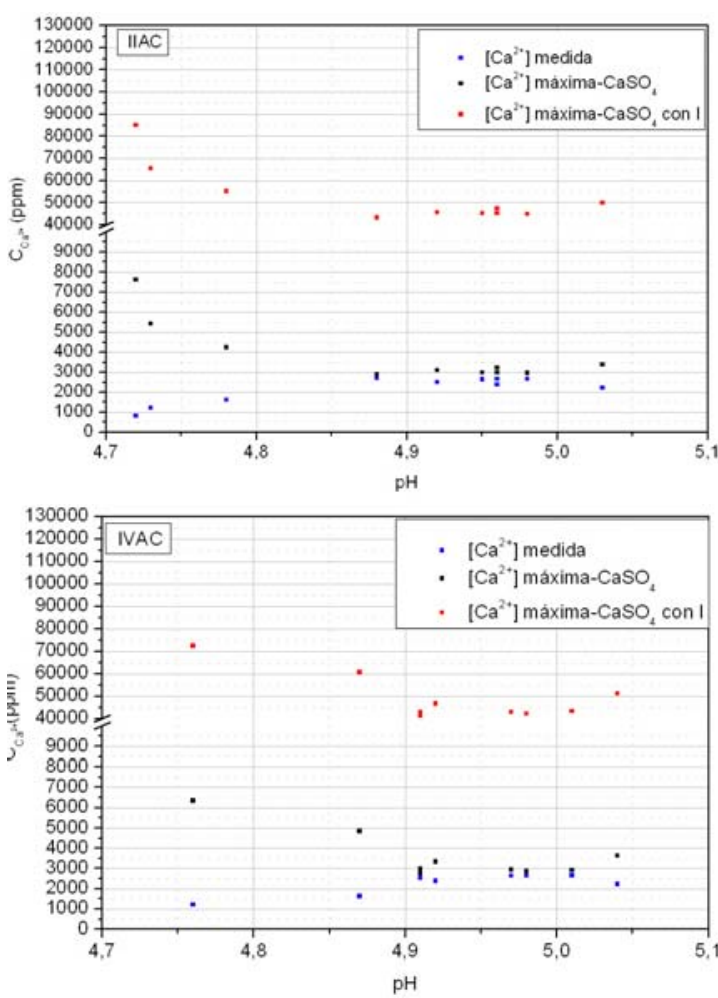

Figura 123. Análisis de la saturación de $\mathrm{CaSO}_{4}$ en los medios de exposición AC

\subsubsection{Análisis de iones en el medio SU}

El medio SU está compuesto por una disolución sulfato sódico, con una concentración de 0.2M y un $\mathrm{pH}$ inicial de 8 unidades. A priori, el potencial agresivo del medio es el pH próximo al neutro y la alta fuerza iónica de la disolución. Ambos factores pueden influir en la solubilidad de compuestos de la matriz cementicia en contacto con la disolución.

En la Figura 124 se muestra la $\left[\mathrm{Ca}^{2+}\right]$ analizado en las muestras recogidas en el tiempo de ensayo (izquierda) y la dependencia con la raíz del tiempo (derecha). 

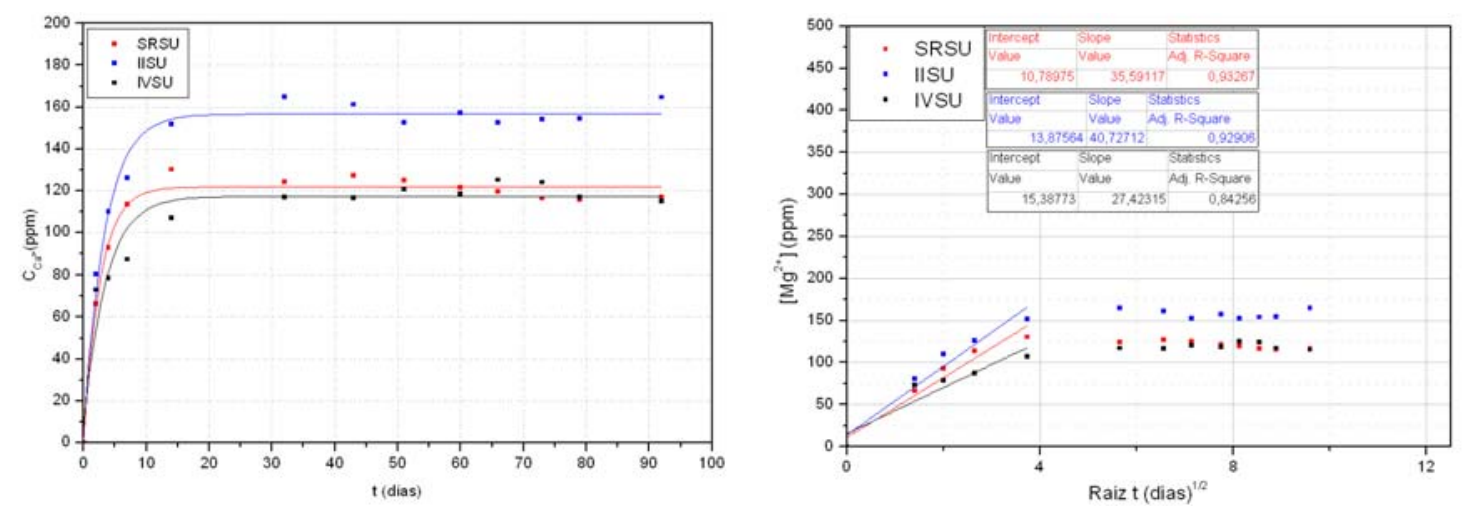

Figura 124. $\left[\mathrm{Ca}^{2+}\right]$ lixiviado en función del tiempo - Medio SU (izquierda). Dependencia de la $\left[\mathrm{Ca}^{2+}\right]$ con la raíz del tiempo (derecha)

La concentración de ion calcio en la disolución se encuentra entre 70 y 150 pmm. La disolución que mayor concentración de ion calcio presenta en el medio es IIAC, las concentraciones de los medios SRAC u IVAC son muy similares. Sin embargo esta observación es relativa, y hay que ponderar el resultado con el número de probetas inmersas en la disolución. La Figura 124 muestra claramente la estabilización de la concentración de calcio en la disolución para los distintos tipos de cementos. Claramente existen diferencias muy significativas entre el valor máximo que alcanzan los distintos tipos de cementos.

Las disoluciones presentan un perfil de difusión de ion calcio en los primeros días del ensayo. Entre los días 15 y 30 de ensayo la disolución llega a una concentración de calcio constante.

Si analizamos la dependencia de la concentración de calcio analizada en el medio frente a la raíz del tiempo trascurrido en la medida, se observa que los valores no presentan un perfil de difusión en todo el rango analizado.

Se ha calculado la dependencia en los primeros 15 días de ensayo comprobándose que el aporte de iones calcio a la disolución es un proceso controlado por difusión y la disolución. En el resto del ensayo la concentración de iones en la disolución es constante, por lo que se asume que la difusión ha llegado a un estado estacionario en el cual no se produce gradiente de concentración de calcio entre la disolución exterior y la disolución de la fase acuosa de poros en el interior del material en contacto con la disolución. En este punto es necesario analizar el nivel de saturación en la disolución para tratar de conocer las causas de la parada en el proceso de lixiviación de iones dentro de las probetas (Figura 126). 
En la Figura 125 se muestran, a la izquierda, los resultados obtenidos al ponderar la $\left[\mathrm{Ca}^{2+}\right]$ con las unidades de lixiviación a lo largo del proceso de degradación, y a la derecha la dependencia de los valores con la raíz del tiempo en las muestras del medio SU para los tres tipos de cemento.
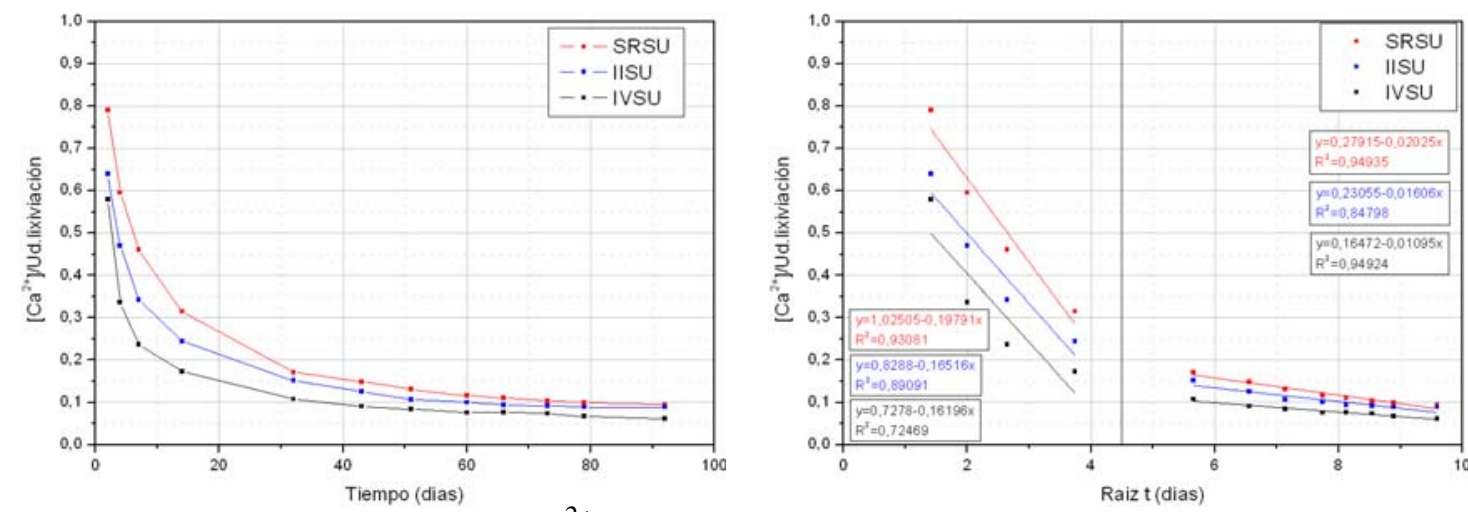

Figura 125. Evolución de la $\left[\mathrm{Ca}^{2+}\right] /$ unidades de lixiviación a lo largo del ensayo en el medio SU. Análisis de los tramos de la curva obtenida en función de la raíz del tiempo

En las muestras analizadas se observa la misma tendencia que en las muestras del medio AC. La muestra que mayor cantidad de $\mathrm{Ca}^{2+}$ lixivia es la SR, seguido del cemento tipo II y por último del tipo IV. La $\left[\mathrm{Ca}^{2+}\right]$ lixiviado/Ud. lixiviación se aproxima en los tres tipos de cemento a partir de 50 días.

Teniendo en cuenta que la concentración de sulfato que presentaba la disolución es alta, que la fuerza iónica de la disolución es elevada (en comparación con los otros medios), que se observa que la concentración de ion calcio en la disolución se estabiliza a partir de un determinado momento en la disolución, se analizó la posibilidad de precipitación de $\mathrm{Ca}^{2+}$ como $\mathrm{CaSO}_{4}$.

Se ha llevado a cabo la evaluación de la solubilidad de esta sal en función de la I de la disolución. En la Figura 126 se muestran los valores de $\left[\mathrm{Ca}^{2+}\right]$ analizado en las disoluciones (azul), los valores de la $\left[\mathrm{Ca}^{2+}\right]$ máxima en la disolución que permitiría el equilibrio de precipitación de la sal $\mathrm{CaSO}_{4}$ con una $\mathrm{Ks}=2 \cdot 10^{-4}$ sin tener en cuenta el efecto que produce la fuerza iónica en el medio (negro), y los valores de la $\left[\mathrm{Ca}^{2+}\right]$ máxima en la disolución que permitiría el equilibrio de precipitación de la sal $\mathrm{CaSO}_{4}$ con una $\mathrm{Ks}=2 \cdot 10^{-4}$ teniendo en cuenta el coeficiente de actividad de ambos iones en función de la fuerza iónica del medio en cada punto (rojo). Para el cálculo de la variación de la solubilidad se ha empleado la variación de los coeficientes de actividad que se muestran en la Figura 112. 
Los gráficos de la izquierda muestran la dependencia de la $\left[\mathrm{Ca}^{2+}\right]$ con el $\mathrm{pH}$ y los gráficos de la derecha la dependencia con la fuerza iónica.
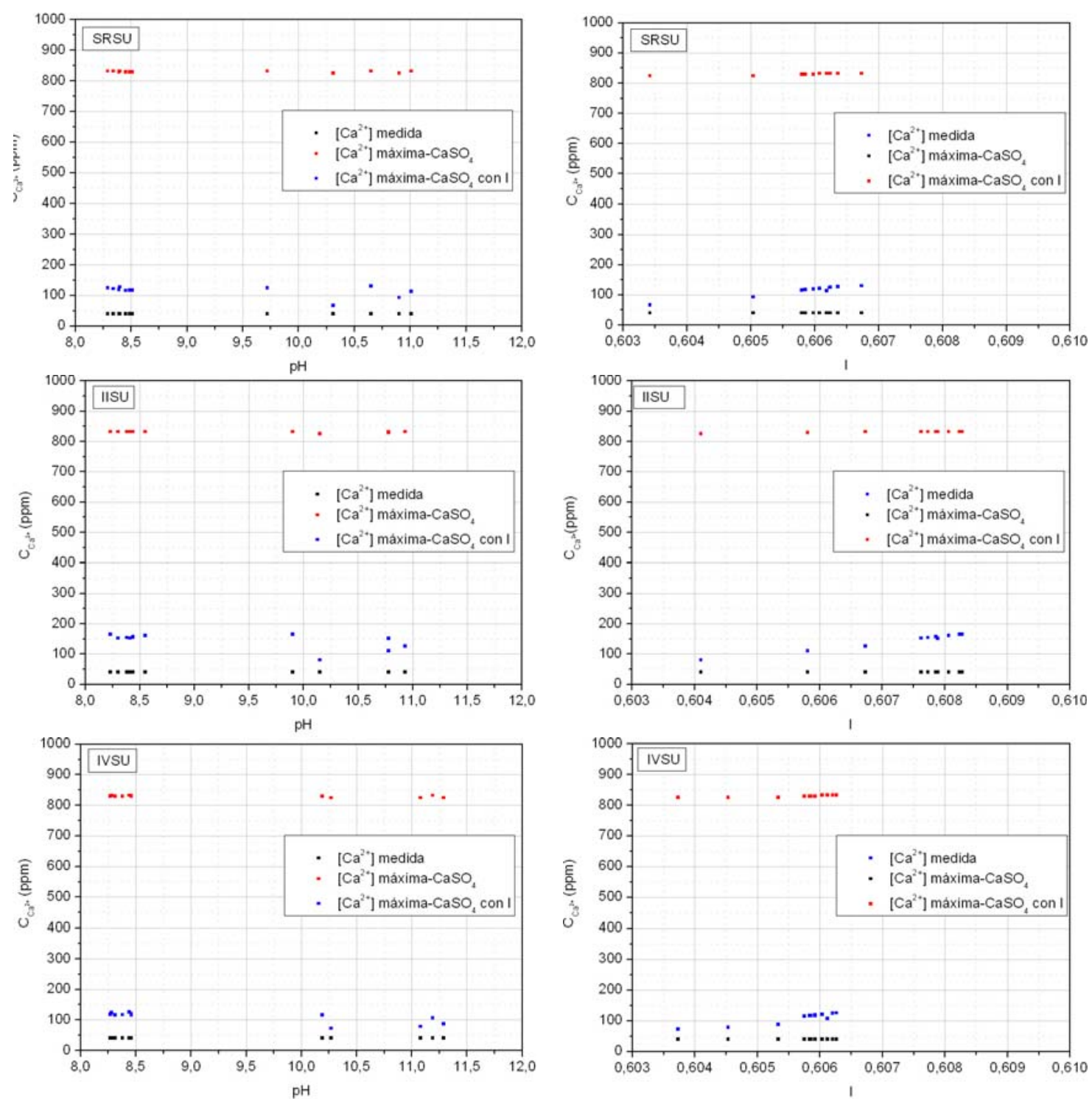

Figura 126. Análisis de la solubilidad de $\mathrm{CaSO}_{4}$ en el medio $\mathrm{SU}$

En todos los casos el contenido de ion calcio en la disolución es superior al que permite el producto de solubilidad del sulfato cálcico sin tener en cuenta la fuerza iónica de la disolución.

Si analizamos la concentración de calcio en la disolución en función del $\mathrm{pH}$, se observa que no se produce un aumento de la solubilidad de compuestos en la disolución por acidificación del $\mathrm{pH}$. 
A medida que aumenta la fuerza iónica de la disolución, se observa como la concentración de ion calcio que admite la disolución es ligeramente superior.

Con los datos analizados no se puede asegurar que la disolución se encuentre saturada, pero sí que la fuerza iónica del medio está ejerciendo un efecto sobre la solubilidad del $\mathrm{CaSO}_{4}$. Teniendo en cuenta los resultados de DRX y las altas concentraciones de ion calcio y sulfato en el medio, cabe la posibilidad que la precipitación de sales en la superficie de la probeta este condicionando la difusión de iones hacia el exterior. Se observa un ligero aumento de la cantidad de etringita en las muestras SRSU y IVSU a medida que transcurre el tiempo de exposición.

Se analizaron en las muestras obtenidas a lo largo del tiempo de ensayo la $\left[\mathrm{Mg}^{2+}\right]$, $\left[\mathrm{Fe}^{3+}\right]$ y $\left[\mathrm{Al}^{3+}\right]$, concluyendo que no se produce lixiviación de estos iones hacia las disoluciones en el tiempo de ensayo estudiado.

\subsubsection{Análisis de iones en el medio AN}

El medio AN está compuesto por una disolución de diferentes sales en baja concentración. La composición simula la de un agua que podemos encontrar en un medio natural $\left(\left[\mathrm{SO}_{4}{ }^{2-}\right]=1.14 \cdot 10^{-}\right.$ ${ }^{4} \mathrm{M} ; \quad\left[\mathrm{Cl}^{-}\right]=9.90 \cdot 10^{-4} \mathrm{M} ; \quad\left[\mathrm{NO}_{3}{ }^{-}\right]=1.68 \cdot 10^{-3} \mathrm{M} ; \quad\left[\mathrm{HCO}_{3}{ }^{-}\right]=2.14 \cdot 10^{-3} \mathrm{M} ; \quad\left[\mathrm{CO}_{3}{ }^{2-}\right]=3.06 \cdot 10^{-4} \mathrm{M}$; $\left[\mathrm{Na}^{+}\right]=2.14 \cdot 10^{-3} \mathrm{M} ;\left[\mathrm{K}^{+}\right]=6.11 \cdot 10^{-4} \mathrm{M} ;\left[\mathrm{Mg}^{2+}\right]=3.09 \cdot 10^{-4} \mathrm{M}$ y $\left.\left[\mathrm{Ca}^{2+}\right]=8.40 \cdot 10^{-4} \mathrm{M}\right)$. Es importante en este medio la presencia de especies con capacidad de tamponamiento. El pH inicial de la disolución es de 8 unidades, y la fuerza iónica es la menor de las analizadas con un valor de 0.008. A priori, el potencial agresivo del medio es el pH próximo al neutro.

\section{$\underline{\text { Ion } \mathrm{Ca}^{2+} \text { lixiviado en el medio AN }}$}

En la Figura 127 se muestra la $\left[\mathrm{Ca}^{2+}\right]$ analizado en las muestras recogidas en el tiempo de ensayo. 


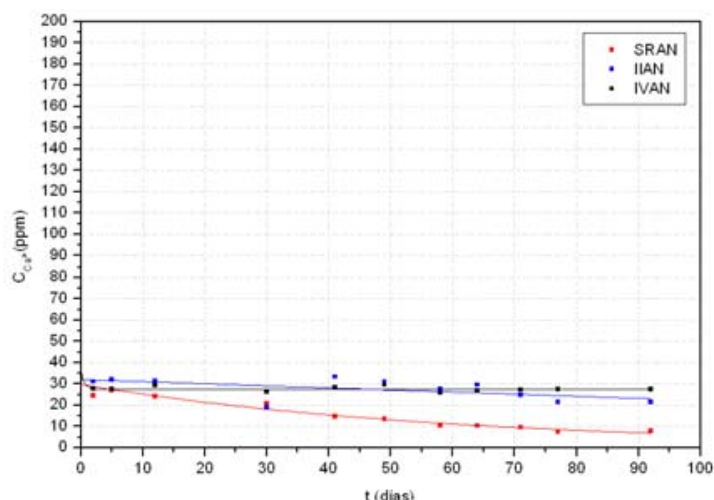

Figura 127. $\left[\mathrm{Ca}^{2+}\right]$ lixiviado en función del tiempo - Medio AN

$\mathrm{La}\left[\mathrm{Ca}^{2+}\right]$ analizado en el medio SRAN decrece exponencialmente en el medio llegando al 25\% de la inicial al final del ensayo. En el caso del medio IIAN se reduce a un tercio desde los primeros días y se mantiene constante a lo largo del ensayo. La disolución IVAN mantiene constante la $\left[\mathrm{Ca}^{2+}\right]$ a lo largo del tiempo de ensayo.

Teniendo en cuenta que el $\mathrm{pH}$ crece ligeramente en los 4 primeros días de ensayo, cabe esperar que se esté produciendo la lixiviación de hidroxilos procedentes de la portlandita, y ello implicaría la lixiviación de $\mathrm{Ca}^{2+}$. Además la variación de $\mathrm{pH}$ repercutiría en un aumento de la concentración de carbonato en la disolución.

Sin embargo, la $\left[\mathrm{Ca}^{2+}\right]$ en la disolución se mantiene constante en estos primeros días de ensayo, por lo que existe la posibilidad de precipitación de sales cálcicas.

En los disoluciones analizadas no se superan los productos de solubilidad de: $\mathrm{CaSO}_{4}, \mathrm{Ca}(\mathrm{OH})_{2}$, $\mathrm{CaCl}_{2}, \mathrm{MgCO}_{3}, \mathrm{ni} \mathrm{Mg}(\mathrm{OH})_{2}$.

Las especies con posibilidad de precipitación en el medio son los carbonatos cálcicos y los fosfatos cálcicos.

En la Figura 128 se muestran los valores de $\left[\mathrm{Ca}^{2+}\right]$ analizado en las disoluciones (azul), los valores de la $\left[\mathrm{Ca}^{2+}\right]$ máxima en la disolución que permitiría el equilibrio de precipitación de la sal $\mathrm{CaCO}_{3}$ con una $\mathrm{Ks}=8.7 \cdot 10^{-9}$ sin tener en cuenta el efecto que produce la fuerza iónica en el medio (negro), los valores de la $\left[\mathrm{Ca}^{2+}\right]$ máxima en la disolución que permitiría el equilibrio de precipitación de la sal $\mathrm{CaCO}_{3}$ con una Ks=8.7·10-9 teniendo en cuenta el coeficiente de actividad de ambos iones en función de la fuerza iónica del medio en cada punto (negro), y la [ $\left.\mathrm{Ca}^{2+}\right]$ 
máxima en la disolución que permitiría el equilibrio de precipitación de la sal $\mathrm{Ca}_{3}\left(\mathrm{PO}_{4}\right)_{2}$ con una $\mathrm{Ks}=1.2 \cdot 10^{-26}$ (verde).

Los gráficos de la izquierda muestran la dependencia de la $\left[\mathrm{Ca}^{2+}\right]$ con el $\mathrm{pH}$ y los gráficos de la derecha la dependencia con la fuerza iónica. Para el cálculo de la variación de la solubilidad se ha empleado la variación de los coeficientes de actividad que se muestran en la Figura 112.

En la disolución SRAN el contenido de ion calcio en la disolución se sitúa muy próximo a los valores que determinaría el equilibrio de solubilidad de la sal $\mathrm{CaCO}_{3}$. A pesar de que la sal fosfato es más insoluble, no se observa que se produzca la saturación de la misma en la disolución.

Los valores de $\left[\mathrm{Ca}^{2+}\right]$ analizados presentan una relación lineal con la reducción del pH, así como con el aumento de fuerza iónica en la disolución. En este medio, el equilibrio de precipitación del carbonato cálcico manda sobre la concentración de calcio en la disolución y no se observa que la fuerza iónica enga un efecto sobre la solubilidad de la sal en la disolución. En este medio, con un pH potencialmente agresivo para la pasta de cemento la lixiviación de ion calcio se ha frenado gracias a la saturación de la sal en la disolución.

En los medios IIAN y IVAN el contenido de $\mathrm{Ca}^{2+}$ en la disolución es superior al permitido por los equilibrios de solubilidad si no tenemos en cuenta la fuerza iónica de la disolución. Esta observación se produce cuando la fuerza iónica de la disolución es superior a 0.00825. A partir de este valor de fuerza iónica se deduce que los valores del coeficiente de actividad presentan una influencia en la solubilidad de las sales presentes en el medio y deben ser tenidos en consideración.

Con respecto a la dependencia de los valores analizados en las disoluciones IIAN y IVAN con el pH, no se ha encontrado una relación lineal entre las variables.

En el caso de la disolución IVAN se observa que los valores de $\left[\mathrm{Ca}^{2+}\right]$ se sitúan muy próximas a las que permite el equilibrio de solubilidad del $\mathrm{CaCO}_{3}$ teniendo en cuenta los coeficientes de actividad de los iones implicados en función de la fuerza iónica del medio. 

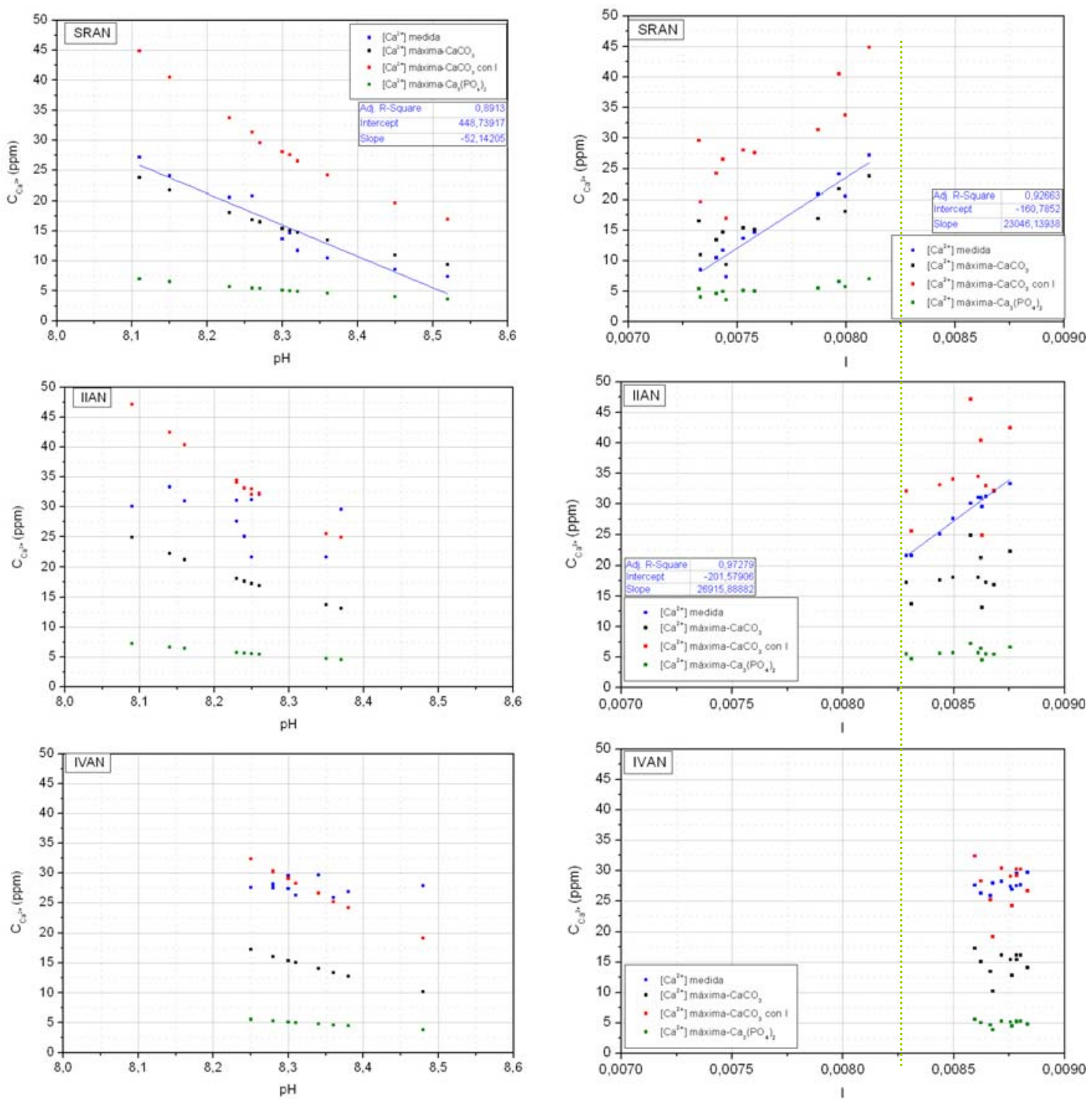

Figura 128. Análisis de la solubilidad de $\mathrm{CaCO}_{3}$ y $\mathrm{Ca}_{3}\left(\mathrm{PO}_{4}\right)_{2}$ en la disolución

\section{Otros iones en el medio AN}

En las disoluciones AN se analizaron la $\left[\mathrm{Mg}^{2+}\right],\left[\mathrm{Fe}^{3+}\right],\left[\mathrm{Al}^{3+}\right]$ y $\left[\mathrm{SO}_{4}{ }^{2-}\right]$ a lo largo del tiempo de ensayo.

En la Figura 129 se muestra la $\left[\mathrm{Mg}^{2+}\right]$ analizado en las muestras recogidas en el tiempo de ensayo. 


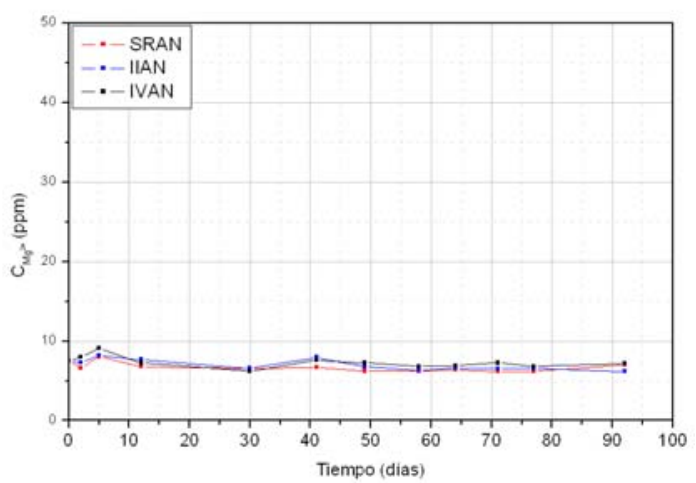

Figura 129. $\left[\mathrm{Mg}^{2+}\right]$ lixiviado en función del tiempo - Medio AN

No se ha observado variación de la $\left[\mathrm{Mg}^{2+}\right]$ en las disoluciones respecto a la concentración inicial en el medio.

Tampoco se ha determinado lixiviación de ion férrico y aluminio en las disoluciones en el tiempo de ensayo estudiado.

En la Figura 130 se muestra la $\left[\mathrm{SO}_{4}{ }^{2-}\right]$ analizado en las muestras recogidas en el tiempo de ensayo (izquierda), y la dependencia de los valores con la raíz del tiempo (derecha).
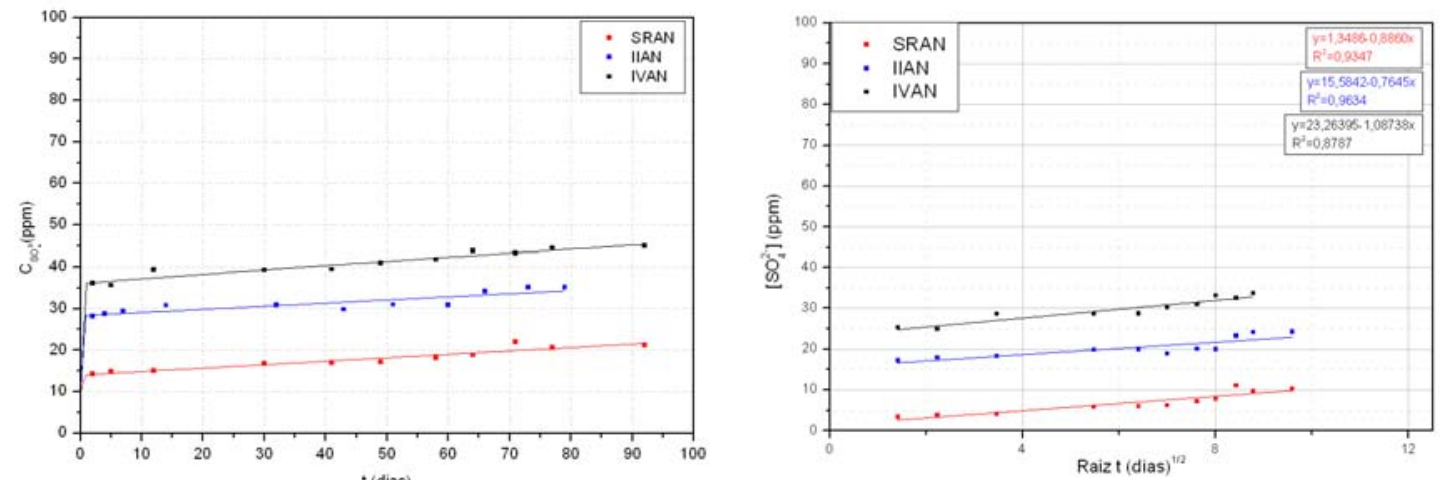

Figura 130. $\left[\mathrm{SO}_{4}{ }^{2-}\right]$ lixiviado en función del tiempo-Medio AN (izquierda).

Dependencia de la $\left[\mathrm{SO}_{4}{ }^{2-}\right]$ con la raíz del tiempo (derecha)

$\mathrm{La}\left[\mathrm{SO}_{4}{ }^{2-}\right]$ en las disoluciones se crece ligeramente en todos los medios de ensayo. El medio que mayor concentración de sulfato lixivia es el IVAN, seguido de IIAN y en último lugar SRAN. Sin embargo esta observación debe comprobarse al ponderar la cantidad de calcio lixiviado con el número de probetas en la disolución siguiendo el procedimiento descrito en el apartado 4.5.3.1. 
Si analizamos la dependencia de la concentración de ion sulfato con la raíz del tiempo, se puede decir que las medidas realizadas en el medio de degradación indican que el proceso de lixiviación está gobernado por difusión.

En la Figura 131 se muestran, a la izquierda, los resultados obtenidos al ponderar la $\left[\mathrm{SO}_{4}{ }^{2-}\right]$ con las unidades de lixiviación a lo largo del proceso de degradación, y a la derecha el la dependencia de los valores con la raíz del tiempo en las muestras del medio AC para los tres tipos de cemento.
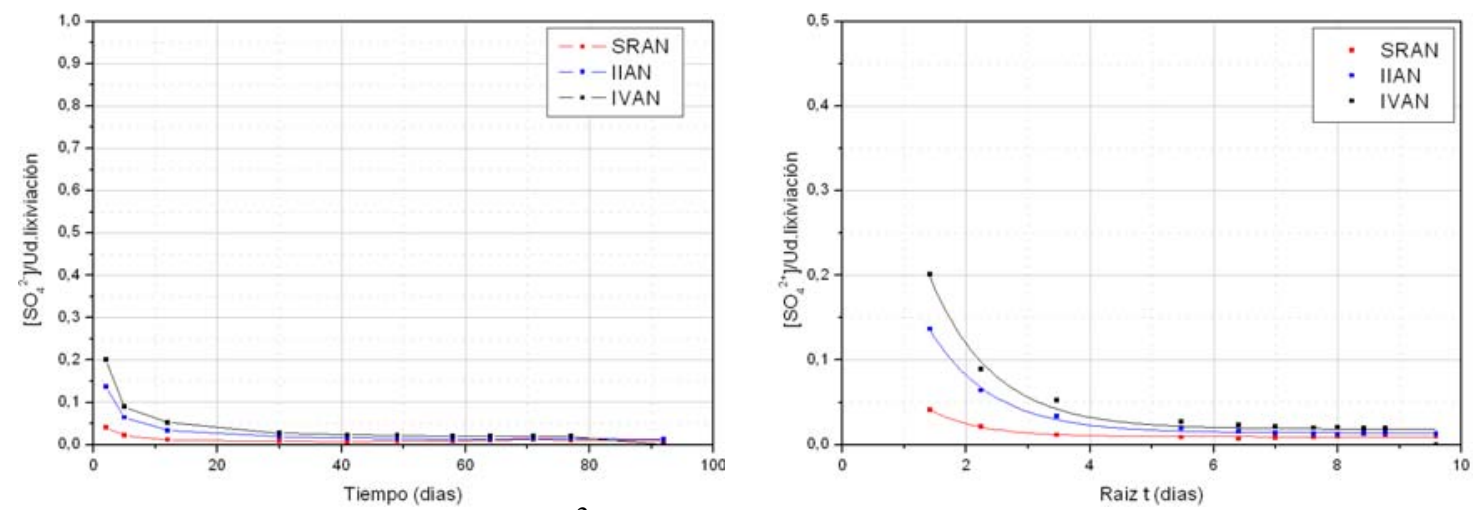

Figura 131. Evolución de la [SO $\left.{ }_{4}{ }^{2-}\right] /$ unidades de lixiviación a lo largo del ensayo en el medio AN. Análisis de los tramos de la curva obtenida en función de la raíz del tiempo

La tendencia de lixiviación analizada en la Figura 130 se mantiene cuando ponderamos por unidades de lixiviación. El medio al que mayor cantidad de sulfato lixivia es el IVAN, seguido de IIAN y por último SRAN. Sin embargo las concentraciones de ion sulfato lixiviado en este medio son pequeñas y las diferencias entre los distintos tipos de muestras sólo se aprecian en los primeros días del ensayo. Pasados los 20 primeros días de ensayo las concentraciones en las disoluciones son muy próximas entre sí y se puede decir que el proceso de difusión ha alcanzado un estado de difusión estacionaria.

La dependencia de la variable $\left[\mathrm{SO}_{4}{ }^{2-}\right] / \mathrm{Ud}$. Lixiviación con la raíz del tiempo no presenta una relación lineal en las primeras edades, mostrando claramente que no se trata exclusivamente de un proceso de difusión. La velocidad de lixiviación de ion sulfato en este medio decrece exponencialmente para todos los tipos de cemento analizados. 


\section{CONCLUSIONES Y LÍNEAS DE INVESTIGACIÓN FUTUTAS}

\subsection{CONCLUSIONES}

Los materiales base cemento son materiales ampliamente utilizados en la sociedad actual. Sus propiedades permiten su uso en ambientes industriales y naturales. Son materiales muy versátiles para su uso en este tipo de ambientes pero hay que considerar que sus propiedades durables son limitadas cuando son expuestos en ambientes donde se producen fenómenos de lixiviación y ataque por diversos iones agresivos. El agua está implicada en la mayoría de los procesos de degradación por ser un medio de transporte hacia el interior de la estructura de otras sustancias agresivas, como en el ataque por cloruros o sulfatos o por constituir un agresivo en sí mismo, como sucede en los fenómenos de lixiviación.

La caracterización de los materiales base cemento no es sencilla. Es un material poco homogéneo, que puede presentar adiciones de muy diverso tipo, por lo que la determinación de las características de la microestructura resulta complicada. Por ello es preciso conocer en profundidad las posibilidades que nos ofrecen las distintas técnicas de caracterización.

En base a este razonamiento se diseñó un procedimiento experimental que nos permitiese profundizar en el conocimiento de los cambios que se producen en la microestructura de los materiales base cemento cuando son expuestos a determinadas condiciones potecialmente agresivas, similares las encontradas en ambientes reales. Para detereminar que cambios se 
producen es preciso disponer de técnicas y modelos que permitan conocer en profundidad el material.

El objetivo principal de esta tesis doctoral es profundizar en el conocimiento de la matriz cementicia, especialmente de su grado de hidratación y cantidad y tipo de compuestos hidratados para, en base a su naturaleza, establecer si presentan una influencia en la protección del material frente a determinados ambientes potencialmete agresivos. En segundo término determinar las caracteristicas fisico químicas de los medios que inciden en cambios de la microestructura de la pasta de cemento estudiada.

En la búsqueda de este objetivo ha sido necesario poner a punto métodos de análisis más acordes con el volumen y la naturaleza de las muestras y validarlos respecto a los recomendados en la norma. Las conclusiones obtenidas con respecto a los métodos de análisis utilizados son:

- La disolución de las muestras empleando el método de disolución para la determinación

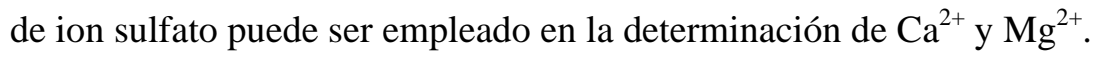

- El uso de la cromatografia iónica para determinar la composición iónica en disoluciones es un método muy preciso, rápido, fiable y reproducible. Esta técnica de análisis ofrece resultados comparables a los obtenidos por el método propuesto en la normativa para la determinación de $\mathrm{Ca}^{2+}, \mathrm{Mg}^{2+}$ y $\mathrm{SO}_{4}{ }^{2-}$, por lo que su uso resulta adecuado en muestras de pasta de cemento.

- La metodología de ensayo propuesta en la determinación de iones $\mathrm{Ca}^{2+}, \mathrm{Mg}^{2+} \mathrm{y} \mathrm{SO}_{4}{ }^{2-}$ ha permitido optimizar los procedimientos de ensayo. Las principales ventajas encontradas se resumen en la reducción de los tiempos de ensayo y un mejor aprovechamiento de la masa de la muestra ya que permite realizar la determinación de varios iones en la misma muestra con límites de detección bajos. Si la masa de muestra de que se dispone es pequeña puede llegar a ser el único método que nos permita obtener resultados fiables.

El estudio de la degradación de la fase sólida de los distintos cementos se ha llevado a cabo utilizando diferentes técnicas de análisis. La utilización de algunas de ellas ha supuesto un estudio en profundidad de la influencia de los diferentes parámetros que afectan al ensayo y que 
determinan en gran medida aspectos del análisis de los resultados. Este estudio ha permitido obtener las siguientes conclusiones:

- El uso de gas portador presenta influencia en la temperatura a la cual tienen lugar los diferentes procesos de pérdida de agua. Influye sobretodo en la pérdida de agua de mojado. En las muestras estudiadas, el uso de gas portador adelanta la tempetarura a la cual tiene lugar el mismo rendimiento de reacción que tendría la muestra en ausencia de gas portador. La eliminación de gas portador no mejora significativamente la resolución del termograma obtenido.

- La velocidad de calentamiento es un factor determinante desde el punto de vista de la temperatura a la cual se producen los diferentes procesos de pérdida de agua. Velocidades de calentamiento mayores retrasan la temperatura a la que finaliza la pérdida de los diferentes tipos de agua enlazada. Este hecho determina que para fijar la temperatura a la cual se considera que ha finalizado la pérdida del agua fisisorbida es necesario conocer la velocidad de calentamiento.

- La utilización de velocidades reducidas de calentamiento permite identificar la temperatura de finalización de las pérdidas de agua fisisorbida Para los diferentes cementos estudiados se ha comprobado que esta temperatura oscila entre los 102 y $108^{\circ} \mathrm{C}$. Este dato es coherente con el propuesto por algunos autores para el inicio de la pérdida de agua del gel.

- La utilización de la velocidad de calentamiento más habitual $\left(10^{\circ} \mathrm{C} /\right.$ minuto $)$ retrasa la temperatura final de pérdida del agua fisisorbida hasta valores próximos a los $140^{\circ} \mathrm{C}$ para los distintos cementos estudiados. Este valor es manejado por algunos investigadores como temperatura final de pérdida de agua fisisorbida. La utilización de mayores velocidades de calentamiento aumenta esta temperatura pero en menor medida. Para $30^{\circ} \mathrm{C} / \mathrm{min}$ la temperatura final es próxima a los $150^{\circ} \mathrm{C}$.

En base a los resultados obtenidos en el empleo del termoanálisis para conocer el mecanismo de deshidratación de las muestras se concluye: 
- El empleo de la velocidad de calentamiento resulta un buen método para evaluar el mecanismo de deshidratación de las muestras.

- Se ha empleado un método para determinar las variables termodinámicas que definen los procesos de descomposición térmica de los compuestos hidratados del material. En base a estos resultados se ha establecido un procedimiento para mejorar la determinación cuantitativa de compuestos hidratados.

- El modelo FWO ha resultado de mayor utilidad que el modelo de Kissinger porque permite estimar la complejidad del proceso y muestra la dependencia de la Ea con el grado de conversión en el proceso de deshidratación en el rango de temperatura estudiado. Además permite conocer los dataos de Ea sin conocer previamente el orden de reacción.

A partir de los datos obtenidos durante el proceso de exposición de las muestras a las disoluciones agresivas las conclusiones son:

- En las muestras expuestas a medio AC, la evaluación del contenido de agua en la región Ldh por sí solo no basta para evaluar el estado de degradación de las muestras.

- El contenido de portlandita en la muestra es un de los datos más importantes para evaluar el estado de degradación de las muestras. Siempre que sea posible se empleará el dato de portlandita libre. En los casos en los que se produce un porcentaje de carbonatación diferencial, se puede emplear el dato de portlandita equivalente comparado con el de la muestra de referencia, puesto que el contenido de carbonatos de partida será el mismo.

- En medios ácidos, la disolución de portlandita constituye una referencia para evaluar el estado de degradación de las muestras. La velocidad de difusión de $\mathrm{Ca}^{2+}$ procedente de portlandita condiciona la disolución de otras especies en el material como la calcita. Utilizando la portlandita libre como parámetro de degradación las muestras II y IV presentan un mejor comportamiento en medio ácido que las muestras SR.

- Los ensayos de difracción de rayos-X permiten evaluar la evolución de compuestos cristalinos en el material y evidenciar los signos de degradación del mismo. La variación 
de las intensidades de las bandas de portlandita, carbonato cálcico y etringita son las que ofrecen mayor información. La degradación del material queda evidenciada por la disolución de portlandita, etringita y calcita, y la formación de un gel rico en sílice. La pasta de cemento tipo IV es la que presenta mayor integridad de compuestos cristalinos en relación con la profundidad de la probeta.

- En las secciones de pastas SR y IV en contacto con la disolución SU aumenta la cantidad de etringita. No se observa formación de compuestos sulfatados en las secciones siguientes, lo que sugiere que la difusión de ion sulfato hacia el interior de la matriz puede esta limitada por la formación de una capa protectora de etringita precipitada.

- Según la EHE-08, el pH del medio agresivo entre 4.5 y 5.5 se considera ataque medio. Sin embargo esta clasificación no tiene en cuenta las otras características de la disolución agresiva como son la formación de tampones, la variación de fuerza iónica y la saturación de sales en la disolución. En nuestro estudio se ha observado que la formación de un medio tamponado y el aumento de la fuerza iónica de la disolución AC determina un grado de deterioro mayor que el corresponde según el pH del medio.

- La disolución SU sería considerado por la EHE-08 como un medio en el que se produce un ataque fuerte, puesto que la concentración de sulfatos es muy superior a 3000 ppm $(0.031 \mathrm{M})$. Sin embargo nuestras muestras presentan un estado de degradación escaso en el tiempo de estudio. La formación de etringita en la capa exterior y la saturación en sulfato cálcico de la disolución exterior parecen ser las causas del escaso grado de degradación de las muestras estudiadas.

- En el medio AN, la potencial agresividad que debiera presentar el medio por la tenencia de un $\mathrm{pH}$ próximo al neutro queda neutralizado por la saturación de la disolución en sales cálcicas. 


\subsection{LÍNEAS DE INVESTIGACIÓN FUTURAS}

- El uso de la cromatografía ha resultado de utilidad para determinar la variación de concentraciones iónicas que se producen a lo largo del proceso de degradación. En este sentido se propone el uso de esta técnica para conocer los cambios que se producen tanto en la disolución agresiva como en el interior de las probetas expuestas a otro tipo de agresivos.

- El estudio de termoanálisis ha permitido profundizar en el conocimiento del estado de hidratación de la matriz cementicia. En este sentido resultaría de gran utilidad comprobar la validez de las conclusiones extraídas a otros niveles de dosificación de materiales base cemento como pueden ser morteros y hormigones, más próximos a los empleados en estructuras reales. Del mismo modo que puede ampliarse el estudio empleando otro tipo de adiciones.

- El proceso de degradación nos ha permitido evaluar el estado de los materiales en distintos tipos de exposición. Los datos obtenidos pueden ser implementados en modelos de cálculo con el fin de estimar el comportamiento de los materiales a largo plazo. 


\section{REFERENCIAS BIBLIOGRÁFICAS}

Adenot, F. y Buil, M. (1992). Modelling of the corrosion of the cement paste by deionised water. Cement and Concrete Research, 22, 489-496.

Aligizaki, K. (2006). Pore Structure of Cement-Based Materials. Testing, interpretation and requirements. New York. Taylor \& Francis.

Antón, R., Pereira, L., Sánchez, E., y Moragues, A. (2008). Degradación acelerada de morteros en medios agresivos artificiales de origen agropecuario. XXV Encuentro del Grupo de Fractura. Anales de Mecánica de la Fractura, 2, 635-640.

Baker, G. y Bishop, P. L. (1997). Prediction of metal leaching rates from solidified/stabilized waster using the shrinking unreacted core leaching procedure. Journal of Hazardous Materials, 52, 311-333.

Bard, A. J., y Faulkner, L. R. (2001). Electrochemical Methods: Fundamentals and Applications. 2001. Ed. New York John Wiley \& Son, Inc.

Barnes, B. D., Diamond, S., Dolch, W. L. (1979). Hollow shell hydration of cement particles in bulk cement paste. Cement and Concrete Research, 8, 263-272. 
Beddoe, R. E. y Dorner, H. W. (2005). Modelling acid attack on concrete: Part I. The essential mechanisms. Cement and Concrete Research, 35, 2333-2339.

Bermúdez-Polonio, J. (1981). Métodos de Difracción de rayos-X. Principios y Aplicaciones. Madrid. Ed. Pirámide S.A.

Berner, U. R. (1988). Modelling the incongruent dissolution of hydrated cement minerals. Radiochimica Acta, 44/45, 387-393.

Berner, U. R. (1992). Evolution of pore water chemistry during degradation of cement in a radioactive waste repository environment. Waste Management, 12, 201-219.

Bertron, A., Jacquemet, N., Erable, B., Sablayrolles, C., Escadeillas, G., Albrecht, A. (2014). Reactivity of nitrate and organic acids at the concrete-bitumen interface of a nuclear waste repository cel. Nuclear Engineering and Design, 268, 51-57.

Bertron, A., Duchesne, J., Escadeillas, G. (2005a). Accelerated test of hardened cement pastes alteration by organic acids: analysis of the $\mathrm{pH}$ effect. Cement and Concrete Research, 35, 155166.

Bertron, A., Duchesne, J., Escadeillas, G. (2005b). Attack of cement pastes exposed to organic acids in manure. Cement and Concrete Composites, 27, 898-909.

Bertron, A., Duchesne, J., Escadeillas, G. (2007). Degredation of cement pastes by organic acids. Materials and estructures, 40, 341-354.

Bertron, A., Escadeillas, G., De Parseval P., Duchesne J. (2009). Processing of electron microprobe data from the analysis of altered cementitious materials. Cement and Concrete Research, 39, issue 10, 929-935.

Bertron, A., Escadeillas, G., Duchesne, J. (2004). Cement pastes alteration by liquid manure organic acids: Chemical and mineralogical characterization. Cement and Concrete Research, 34, 1823-1835.

Bhatty, J. I. (1986). Hydration versus strength in a portland cement developed from domestic mineral wastes - a comparative study. Thermochimica Acta, 106, 93-103. 
Borges, Paulo H.R., Costa, Juliana O., Milestone, Neil B., Lynsdale, Cyril J., Streatfield, Roger E. (2010). Carbonation of CH and C-S-H in composite cement pastes containing high amounts of BFS. Cement and Concrete Research, 40, issue 2, 284-292.

Brouwers, H. J. H. (2004). The work of Powers and Brownyard revisited: Part 1. Cement and Concrete Research, 34, 1697-1716.

Brouwers, H. J. H. (2005). The work of Powers and Brownyard revisited: Part 2. Cement and Concrete Research, 35, issue 10, 1922-1936.

Brouwers, H. J. H. (2007). The work of Powers and Brownyard revisited: Part 3. 12th International Conference in the Chemistry of Cement, Montreal, Canadá.

Brunauer, S., Greenberg, S. A. (1960). The Hydration of tricalcium silicate and B-dicalcium silicate at room temperature. 4th International Symposium on the Chemistry of Cement. Washington, D. C.

Buil, M., Revertegat, E. y Oliver, J. (1992). A model of the attack of pure water or undersaturated lime solutions on cement. Stabilization and solidification of hazardous, radioactive and mixed wastes. 2. STP 1123, Gillian, T.M. y Wiles, C.C. Wiles Eds. American Society for Testing and Materials. Philadelphia. 227-241.

BuildingGreen, I. Concrete, Flyash, and the Environment. Disponible en: http://www.buildinggreen.com/features/flyash/mehta.cfm

Burlion, N., Bernard, D. y Chen, D. (2006). X-Ray microtomography: Application to microstructure analysis of a cementitious material during leaching process. Cement and Concrete Research, 36, issue 2, 346-357.

Caballas, T., Díaz-Fierros, F. (1990). El purín de vacuno en Galicia. Caracterización, poder fertilizante y problemas ambientales. Xunta de Galicia, Santiago de Compostela.

Calavera, J. (2005). Patología de Estructuras de Hormigón Armado y Pretensado: Tomo 1. INTEMAC, S.A. Madrid. 
Calleja, J. (2005). The aggressive agents for concrete in agricultural livestock and agroalimentary industries. 4th. Int. Symposium Concrete for a Sustainable Agricultura, -Agro, Aqua and Community Applications Proceeding, San Lorenzo de El Escorial, Madrid, 139-153.

Cánovas, M. F., (1989). Hormigón. $6^{a}$ ed. Madrid: Colegio de Ingenieros de Caminos, Canales y Puertos.

Cardé, C. y Francois, R. (1997). Effect of the leaching of calcium hydroxide from cement paste on mechanical and physical properties. Cement and Concrete Research, 27, issue 4, 539-550.

Cardé, C. y Francois, R. (1999). Modelling the loss of strength and porosity increase due to the leaching of cement pastes. Cement and Concrete Composites, 21, 181-188.

Cardé, C., Francois, R. y Torrenti, J. (1996). Leaching of both calcium hydroxide and CSH from cement paste: modelling the mechanical behaviour. Cement and Concrete Research, 26, issue 8, 1257-1268.

Castellote Armero, M. M. (1997). Tesis doctoral: Aplicación de campos eléctricos para la caracterización de hormigones en relación al transporte de iones de cloruro. Ingeniería Química y Tecnología del Medio Ambiente Universidad de Zaragoza, Zaragoza.

Cestari, Antonio R., Vieira, Eunice F.S., Da Rocha, Fábio C. (2005). Kinetics of interaction of hardened oil-well cement slurries with acidic solutions from isothermal heat-conduction calorimetry. Thermochimica Acta, 430, issues 1-2, 211-215.

Chang, C.-F., Chen, J. W.; (2006). The experimental investigation of concrete carbonation depth. Cement and Concrete Research, 36, 1760-1767.

Chávez, A., Vargas, G., Almanza, J.M. (2008). Caracterización y preparación de ceniza volante para su uso como recubrimientos cerámicos sobre substratos metálicos. Boletín de la Sociedad Española de Cerámica y Vidrio, 47, nº. 6, 333-338. ISSN 0366-3175.

Chen, Jeffrey J., Thomas, Jeffrey J., Jennings, Hamlin M. (2006). Decalcification shrinkage of cement paste. Cement and Concrete Research, 36, issue 5, 801-809. 
Cullity, B. D., Stock, S. R., (2001). Elements of X-Ray Diffraction. 3rd Ed. New Jersey. Prentice Hall.

Daimon, S.A., Abo-El-Enein, G., Hosaka, S. G., Kondo, R. (1977). Pore structure of calcium silicate hydrate in hydrated tricalcium silicate. J Am Ceram Soc, 60, 110-114.

De Belie, N. (2008). Evaluation of methods for testing concrete degradation in aggressive solutions. Performance of cement-based materials in aggressive aqueous environments characterization, modelling, test methods and engineering aspects. RILEM Publications SARL, 73-84. ISBN: 978-2-35158-059-2

De Belie, N., Kratky, J., Van Vlierberghe, S. (2010). Influence of pozzolans and slag on the microstructure of partially carbonated cement paste by means of water vapour and nitrogen sorption experiments and BET calculations. Cement and Concrete Research, 40, issue 12, 17231733.

De Belie, N., Lenehan, J. J., Braam, C. R., Svennerstedt, B., Richardson, M., Sonck, B. (2000). Durability of building materials and components in the agricultural environment. Part III: Concrete Structures. J. Agricultural Engineering Research, 75, 225-241.

De Belie, N., Verselfer, H. J., De Blaere, B. Van Nieuwenburg, D., Verschoore, R. (1996). Influence of the cement type on resistance of concrete to feed acids. Cement and Concrete Research, 26, issue 11, 1717-1725.

Directiva 1999/31/EC relativa al vertido de residuos, 26 de abril de 1999.

EHE-08. (2008). Instrucción Española de Hormigón Estructural. Ministerio de Fomento, España.

Eijk, R.J. van, Brouwers, H. J. H. (1998). Study of the relation between hydrated Portland cement composition and leaching resistance. Cement and Concrete Research, 28, issue 6, 815828.

Escalante-García, J. I., Mendoza, G., Sharp, J. H. (1999). Indirect determination of the Ca/Si ratio of the C-S-H gel in Portland cements. Cement and Concrete Research, 29, 1999-2003. 
Escalante-García, J.I., (2003). Nonevaporable water from neat OPC and replacement materials in composite cements hydrated at different temperatures, Cement and Concrete Research, 33, 1883-1888.

España. Ley 10/1998 de Residuos. Boletín Oficial del Estado, 22 de abril de 1998, nº 96.

España. Real Decreto 261/1996 sobre protección de las aguas contra la contaminación producida por los nitratos procedentes de fuentes agrarias. Boletín oficial del estado, 11 de marzo de 1996, $n^{\circ} 61$.

España. Real Decreto 324/2000 sobre normas básicas de ordenación de las explotaciones porcinas. Boletín Oficial del Estado, 8 de marzo de 2000, nº 58.

España. Real Decreto Legislativo 1/2001 - Aprobación de la Ley de Aguas. Boletín Oficial del Estado, 24 de julio de 2001, $n^{\circ} 176$.

Faucon, P., Adenot F., Jacquinot, J. F., Petit, J. C., Cabrillac, R. y Jorda, M. (1998). Long-term behaviour of cement pastes used for nuclear waste disposal: Review of physico-chemical mechanisms of water degradation. Cement and Concrete Research, 28, issue 6, 847-857.

Faucon, Adenot, F., Jorda, M. y Cabrillac, R. (1997). Behaviour of crystallised phases of Portland cement upon water attack. Materials and Structures, 30, p. 480-485.

Feldman, R.F. y Sereda, P. (1970). A new model for hydrated Portland cement and its practical implications. Engineering Journal, 53, issue 8-9, 53-59.

Feng, X., Garboczi, E. J., Bentz, D. P., Stutzman, P. E., Mason, T. O. (2004). Estimation of the degree of hydration of blended cement pastes by a scanning electron microscopy point-counting procedure, Cement and Concrete Research, 34, issue 10, 1787-1739.

Frassi de Souza, K. (2002). Tesis doctoral: Utilización de cenizas procedentes de plantas incineradoras de residuos sólidos urbanos como material constituyente de hormigón de relleno. Universidad Politécnica de Madrid. Madrid.

Gabrilová, A., Havlica, J. y Sahu, S. (1991). Stability of calcium sulphoaluminate hydrates in water solutions with different pH. Cement and Concrete Research, 21, p. 1023-1027. 
Gaitero, J.J., Campillo, I., Guerrero, A. Reduction of the calcium leaching rate of cement paste by addition of silica nanoparticles. Cement and Concrete Research, 38, issues 8-9, 1112-1118.

García-Maté, M., De la Torre, A. G., León-Reina, L., Aranda, M. A. G., Santacruz, I. (2013). Hydration studies of calcium sulfoaluminate cements blended with fly ash. Cement and Concrete Research, 54, 12-20.

Garrabrants, A.C., Sanchez, F., Kosson, D.S. (2004). Changes in constituent equilibrium leaching and pore water characteristics of a Portland cement mortar as a result of carbonation. Waste Management, 24, issue 1, 19-36.

Gérard, B. y Le Bellego, C. (1999). Modelling the influence of ITZ on water leachin. Engineering and Transport Properties of the Interfacial Transition Zone in Cementitious Composites. Alexander, M.G., Arliguie, G., Ballivy, G., Bentur, A. y Marchand, J. RILEM Publications.

Gérard, B., Le Bellego, C. y Bernard, O. (2002). Simplified modelling of calcium leaching of concrete in various environments. Materials and Structures, 35, issue 10, 32-640.

Girardi, F., Di Maggio, R. (2011). Resistance of concrete mixtures to cyclic sulfuric acid exposure and mixed sulfates: Effect of the type of aggregate. Cement and Concrete Composites, 33, issue 2, p. 276-285.

Girardi, F., Vaona, W., Di Maggio, R. Resistance of different types of concretes to cyclic sulfuric acid and sodium sulfate attack. Cement and Concrete Composites, 32, issue 8, 595-602.

Giusquiani, P. L., Concezzi, L., Businelli, M., Macchioni, A. (1998). Fate of pig sludge liquid fraction in calcareous soil: agricultural and environmental implications. J. Environmental Quality, 27, 364-371

Glass, G., K., Reddy, B. y Buenfeld, N. R. (2000). Corrosion inhibition in concrete arising from its acid neutralisation capacity. Corrosion Science, 42, issue 9, 1587-1598.

Hadley, D.W., Dolch, W. L., Diamond, S. (2000). On the occurrence of hollow-shell hydration grains in hydrated cement paste. Cement and Concrete Research, 30, issue 1, 1-6. 
Haga, K., Sutou, S., Hironaga, M., Tanaka, S. y Nagasaki, S. (2005). Change in pore structure and composition of hardened cement paste during the process of dissolution. Cement and Concrete Research, 35, p. 943-950.

Haga, K., Sutou, S., Hironaga, M., Tanaka, S. y Nagasaki, S. (2005). Effects of porosity on leaching of Ca from hardened ordinary Portland cement paste. Cement and Concrete Research, 35, issue 9, 1764-1775.

Haynes, J.M. (1973). Determination of pore properties of constructional and other materials. Materials and Structures, 33, 169-174.

Helfferich,F. (1962). Ion exchange. New York: Mc Graw-Hill.

Heukamp, F. H., Ulm,F. y Germaine, J. T. (2001). Mechanical properties of calcium-leached cement pastes. Triaxial stress states and the influence of the pore pressures. Cement and Concrete Research, 31, 767-774.

Heukamp,F. H. (2003). Tesis doctoral: Chemomecanics of Calcium Leaching of Cement-Based Materials at Different Scales: The Role of CH-Dissolution and CSH Degradation on Strength and Durability Performance of Materials and Structures. Massachusetts Institute of Technology. Massachusetts.

Hewlett, P. C. (2004). Lea's Chemistry of Cement and Concrete. Elsevier.

Jennings, H. M. (1991). Towards establishing relationships between microstructure and properties of cement-based materials. Ceramics Transactions - Advances in cementitious materials, S. Mindess, Editor. The American Ceramic Society: Westerville, Ohio. 289-316.

Jennings, H. M. (2000). A model for the microstructure of calcium silicate hydrate in cement paste. Cement and Concrete Research, 30, 101-116.

Jennings, H. M., Tennis, P. D. (1994). Model for the developing microstructure in Portland Cement Pastes. Journal of the American Ceramic Society, 77, issue 12, 3161-3172.

Kakali, G., Tsivilis, S., Aggeli, E. y Bati, M. (2000). Hydration products of $C_{3} A, C_{3} S$ and Portland cement in the presence of $\mathrm{CaCO}_{3}$. Cement and Concrete Research, 30, 1037-1077. 
Khunthongkeaw, J., Tangtermsirikul, S. y Leelawat, T. (2005). A Study on Carbonation Depth Prediction for Fly Ash Concrete. Construction and Building Materials, 20, issue 9, 744 - 753.

Kissinger, H. E. (1956). Variation of peak temperature with heating rate in differencial thermal analysis. Journal of Research of National Bureau of Standards, 57, n 4, Research paper 2712.

Kjellsen, K. O., Jennings, H. M., Lagerblad, B. (1996). Evidence of hollow shells in the microstructure of cement paste. Cement and Concrete Research, 26, issue 4, 593-599.

Kjellsen, K.O., Lagerblad, B., Jennings, H. M. (1997). Hollow-shell formation - an important mode in the hydration of Portland cement. Journal of Materials Science, 32, 2921-2927.

Klug, H. P., Alexander, L. E. (1973). X-ray diffraction procedures for polycrystalline and amorphous materials. 2nd ed. New York: Wiley-Interscience.

Lagerblad, B. (2001). TR-01-27 Leaching performance of concrete based on studies of samples from old concrete constructions. Stockholm: Swedish Cement and Concrete Research Institute.

Lagerblad, B. y Trägardh, J. (1998): TR-98-11 Leaching of 90-year old concrete mortar in contact with stagnant water. Stockholm: Swedish Cement and Concrete Research Institute.

Larreur-Cayol, S., Bertron, A., Escadeillas, G. (2011). Degradation of cement-based materials by various organic acids in agro-industrial waste-waters. Cement and Concrete Research, 41, issue $8,882-892$.

Le Bellego, C., Gèrard, B. y Pijaudier-Cabot, G. (2000). Chemo-mechanical effects in mortar beams subjected to water hydrolysis. Journal of Engineering Mechanics, 126, issue 3, 266-272.

León, N., Massana, J., Alonso, F., Moragues, A. Sanchez-Espinosa, E. (2014). Effect of nano$\mathrm{Si}_{2} \mathrm{O}$ and nano- $\mathrm{Al}_{2} \mathrm{O}_{3}$ on cement mortars for use in agriculture and livestock production. Biosystems Engineering, 123, 1-11.

Li, C., Sun, H., Li, L.. (2010). A review: The comparison between alkali-activated slag (Si + Ca) and metakaolin (Si + Al) cements. Cement and Concrete Research, 40, issue 9, 1341-1349. 
Lilkov, V., Petrov, O., Tzvetanova, Y., Savov P. (2012). Mössbauer, DTA and XRD study of Portland cement blended with fly ash and silica fume. Construction and Building Materials, 29, 33-41.

Lilkov, V., Rostovsky, I., Petrov, O., Tzvetanova, Y., Savov, P. (2014). Long term study of hardened cement pastes containing silica fume and fly ash. Construction and Building Materials, 60, 48-56.

Llorente Carrasco, I. (2008). Tesis Doctoral: Degradación de hormigones de altas y ultra altas prestaciones por aguas naturales: análisis en función de diferentes escenarios de lixiviación. Instituto de ciencias de la construcción Eduardo Torroja. Consejo superior de investigaciones científicas. Madrid.

Lothenbach, B., Le Saout, G., Gallucci, E. y Scrivener, K. (2008). Influence of limestone on the hydration of Portland cements. Cement and Concrete Research, 38, 848-860.

Macías, A., Goñi, S., Madrid, J. (1999). Limitations of Köch-Steinegger test to evaluate the durability of cement pastes in acid medium. Cement and Concrete Research, 29, 2005-2009.

Mainguy, M., Tognazzi, C., Torrenti, J-M, Adenot, F.. Modelling of leaching in pure cement paste and mortar. Cement and Concrete Research, 30, issue 1, 83-90.

Maltais, Y., Samson, E. y Marchand, J. (2004). Predicting the durability of Portland cement systems in aggressive environments - laboratory validation. Cement and Concrete Research, 34, 1579-1589.

Marchand, J. y Delagrave, A. (1999). Influence of ITZ on ionic diffusion and leaching, en Engineering and Transport Properties of the Interfacial Transition Zone in Cementitious Composites. Alexander, M.G., Arliguie, G., Ballivy, G., Bentur, A. y Marchand, J. RILEM Publications.

Marchand, J.; (2001). Modelling the behaviour of unsaturated cement systems exposed to aggressive chemical environments. Materials and Structures, 34, issue 4, 195-200.

Massana, J. (2010). Durabilidad de morteros de cemento en contacto con purines de cerdo. Tesis Doctoral. E.T.S.I.Agrónomos. Universidad Politécnica de Madrid. 
Massana, J.; Guerrero, A.; Anton, R.; Garcimartin, M.A. Garcimartín; Sánchez, E. (2013). The aggressiveness of pig slurry to cement mortars. Biosystems Engineering, 114, 124-134.

Mc Cabe, W.L., y Smith, J. C. Operaciones básicas en Ingeniería Química. 1981. Barcelona: Reverté.

Mehta, P.K., Monteiro, P.J.M.(2001). Concrete: Microstructure, Properties and Materials. 2nd ed. Prentice-Hall international series in civil engineering and engineering mechanics, ed. Prentice-Hall. Englewood Cliffs. New Jersey.

Mindess, S., Young, J. F. y Darwin, D. (2002). Concrete. Englewood. Cliffs. New Jersey. Prentice Hall.

Molina-Bas, O. I. (2008). Tesis doctoral: La influencia de las cenizas volantes como sustituto parcial del cemento portland en la durabilidad del hormigón. Universidad Politécnica de Madrid. Madrid

Monteagudo Viera, S. (2014). Tesis Doctoral: Estudio microestructural y de los procesos de hidratación de cementos con adiciones. Universidad Politécnica de Madrid. Madrid.

Moragues, A., Macias, A. y Andrade, C. (1988). Equilibria of the chemical composition of the pore concrete solution. Part I. Calculation of equilibria constant of synthetic solution. 1988. Cement and Concrete Research, 17, 173-189.

Moral, R., Moreno-Caselles, J., Perez-Murcia, M. D., Perez-Espinosa, A., Rufete, B., Paredes, C. (2005). Characterisation of the organic matter pool in manures. Bioresource Technology, 96, 153-158.

Moranville, M., Kamali, S., Guillon, E. (2004). Physicochemical equilibria of cement-based materials in aggressive environments-experiment and modelling. Cement and Concrete Research, 34, issue 9, 1569-1578.

Mouret, M., Bascoul, A., Escadeillas, G. (1997). Study of the degree of hydration of concrete by means of image analysis and chemically bound water. Advanced Cement Based Materials, 6, issues 3-4, 109-115. 
Odler, I., (1998). Hydration, setting and hardening of Portland cement. Lea's Chemistry of Cement and Concrete, P.C. Hewlett, Editor Arnolds, London.

Oueslati, Duchesne. (2010). Resistance of blended cement pastes subjected to organic acids: Quantification of anhydrous and hydrated phases. Cement and Concrete Composites, 45, 89101.

Oueslati, O. y Duchesne, J. (2011). Acetic acid attack of cement matrix: Evaluation of durability parameters. International Congress on the Chemistry of Cement.

Oueslati, O. y Duchesne, J. (2012). The effect of SCMs and curing time on resistance of mortars subjected to organic acids. Cement and Concrete Research, 42, issue 1, 205-214.

Pane, I., Hansen, W., (2005). Investigation of blended cement hydration by isothermal calorimetry and thermal analysis. Cement and Concrete Research, 35, issue 6, 1155-1164.

Pavlik, V. (1995). Corrosion of hardened cement paste by acetic and nitric acids. Part III: Influence of water/cement ratio. Cement and Concrete Research, 26, issue 3, 475-490.

Pavlík, V. (1996). Corrosion of hardened cement paste by acetic and nitric acids Part III: Influence of water/cement ratio. Cement and Concrete Research, 26, issue 3, 475-490.

Pavlík, V. (2000). Effect of carbonates on the corrosion rate of cement mortars in nitric acid. Cement and Concrete Research, 30, issue 3, 481-489.

Pavlik, V. and Uncik, S. (1997). The rateo f corrosion of hardened cement pastes and mortars with additive of silica fume in acids. Cement and Concrete Research, 27, issue 11, 1731-1745.

Pavlíki V., Unčíki S. (1997). The rate of corrosion of hardened cement pastes and mortars with additive of silica fumes in acids. Cement and Concrete Research, 27, issue 11, 1731-1745.

Perlot, C., Verdier, J. y Carcassès, M. (2006). Influence of cement type on transport properties and chemical degradation: Application to nuclear waste storage. Materials and Structures, 39, 511-523. 
Plaza de Carlos, C. (2002) Tesis doctoral: Aprovechamiento agrícola del purín de cerdo en agroecosistemas semiáridos: Efectos sobre suelos y plantas. Facultad de Ciencias. Universidad Autónoma de Madrid. Madrid.

Popovics, S. (1998). Strength and Related Properties of Concrete: A Quantitative Approach, John Wiley \& Sons.

Powers, T.C. y Brownyard, T. L. (1948). Studies of the physical properties of hardened cement paste. Portland Cement Association: Chicago.

Rahman, M. M., Nagasaki, S. y Tanaka, S. (1999). A model for dissolution of $\mathrm{CaO}-\mathrm{SiO}_{2}-\mathrm{H}_{2} \mathrm{O}$ gel at $\mathrm{Ca} / \mathrm{Si}>1$. Cement and Concrete Research, 29, issue 7, 1097-1097.

Ramachandran, V.S., Paroli, R. M., Beaudoin, J.J., Delgado, A. H. (2002). Handbook of termal análisis of construction materials. ISBN 0-8155-1487-5.

RC-08 (2009). Instrucción para la recepción de cementos. Comisión permanenete del cemento. Ministerio de Fomento. Secretaría General Técnica. Madrid.

Reardon, E. J. (1990). An ion interaction model for the determination of chemical equilibria in cement/water systems. Cement and Concrete Research, 20, 175-192.

Revertegat, E., Richet, C. y Gégout, P. (1992). Effect of pH on the durability of cement pastes. Cement and Concrete Research, 22, 259-272.

Richardson, I. G. (2000). The nature of the hydration products in hardened cement pastes. Cement and Concrete Composites, 22, 97-113.

Riesen, R. (1988). Adjustment of heating rate for maximum resolution in TG and TMA. Journal of Thermal Analysis, 53, 365-374.

RILEM_TC-116-PCD (1999). Recommendation of TC 116-PCD: Tests for gas permeability of concrete". Materials and Structures, 32 (217), 174 - 179. 
Rivera Lozano, J. (2004). Tesis doctoral: Hidratación de pastas de cemento de con adiciones activas subproductos industriales y materiales de desecho. Universidad Autónoma de Madrid. Madrid.

Rostami, V., Shao, Y., Boyd, A.J., He, Z. (2012). Microstructure of cement paste subject to early carbonation curing. Cement and Concrete Research, 42, issue 1, 186-193.

Saito, H. y Deguchi, A. (2000). Leaching tests on different mortars using accelerated electrochemical method. Cement and Concrete Research, 30, 1815-1825.

Samson, E. y Marchand, J. (1999). Numerical solution of the Extended Nernst-Planck model. Journal of Colloid and Interface Science, 215, 1-8.

Samson, E. y Marchand, J. (2007). Modelling the transport of ions in unsaturated cement-based materials. Computers and Structures, 85, issues 23-24, 1740-1756.

Samson, E., Marchand, J. y Beaudoin, J. J. (1999). Describing ion diffusion mechanisms in cement-based materials using the homogenization technique. Cement and Concrete Research, 29, 1341-1345.

Samson, E., Marchand, J. y Beaudoin, J. J. (2000). Modelling the influence of chemical reactions on the mechanisms of ionic transport in porous materials. An overview. Cement and Concrete Research, 30, 1895-1902.

Samson, E., Marchand, J., Robert, J.-L. y Bournazel, J.-P.; (1999). Modelling ion diffusion mechanisms in porous media . International Journal for Numerical Methods in Engineering, 46, 2043-2060.

Sánchez, E. et al., Resistance and microstructure evolution of fly ash cement mortar pastes submerged in pig slurry. 2007. Cement and Concrete Research.

Sánchez, E., Moragues, A.; Massana, J.; Guerrero, A.; Fernández, F. (2009). Effect of pig slurry on two cement mortars: Changes in strength, porosity and crystalline phases. Cement and Concrete Research, 39, 798-804. 
Sánchez, E.; Massana; J.; Garcimartín, M. A., Moragues, A. (2008). Resistance and microstructure evolution of fly ash cement mortar pastes submerged in pig slurry. Cement and Concrete Research, 38, 717-724.

Sánchez, F. J. (2011). Medidas puntuales de permeabilidad. Universidad de Salamanca, 13 pp. (En: http://hidrologia.usal.es)

Sánchez, M., González, J. L. (2005). The fertilizer value of pig slurry. I. Values depending on the type of operation. Bioresource Technology, 96, 117-123.

Saviozzi, A., Levi-Minzi, R., Riffaldi, R., Vanni, G. (1997). Laboratory studies on the application of wheat straw and pig slurry to soil and the resulting environmental implications. Agriculture, Ecosystems and Environment, 61, 35-43.

Schröder, J. (2005). Revising the agronomic benefits of manure: a correct assessment and exploitation of its fertilizer value spares the environment. Bioresource Technology, 96, 253-261.

Segura Pérez I. (2008). Tesis Doctoral: Caracterización del proceso de descalcificación en morteros, mediante ensayos destructivos y no destructivos. Universidad Politécnica de Madrid. Madrid.

Segura Pérez, I., Moragues Terrades, A. y Anaya Velayos, J. J. (2008a). Caracterización microestructural de materiales base cemento mediante ensayos destructivos. Parte 1. Cemento y Hormigón.

Segura Pérez, I., Moragues Terrades, A. y Anaya Velayos, J. J. (2008b) Caracterización microestructural de materiales base cemento mediante ensayos destructivos. Parte 2. Cemento y Hormigón.

Segura, I., Anaya, J. J., Hernández, M. G., Macphee, D. E., Moragues, A. y Sánchez, T. (2007). Microstructural characterization of aged mortar by destructive and non-destructive testing. 12th International Congress on the Chemistry of Cement, Montreal, Canadá.

Segura, I.; Sánchez, E.; Moragues, A.; Hernández, M.G. (2010). Assessment of mortar evolution in pig slurry by mechanical and ultrasonic measurements. Construction \& Building Materials, 24, 1572-1579. 
Sepulcre Aguilar, A., Pinilla Melo, J., Hernández Olivares F. (2013). Microstructural analysis of aerated cement pastes with fly ash, Metakaolin and Sepiolite additions. Construction and Building Materials, 47, 282-292.

Sersale, R, Frigione, G, Bonavita, L. (1998). Acid Depositions and Concrete Attack: Main Influences. Cement and Concrete Research, 28, issue 1, 19-24.

Shazali, M. A., Baluch, M. H., Al-Gadhid, A. H., (2006). Predicting residual strength in unsaturated concrete exponed to sulfate attack. Materials in Civil Engeenering. 18, 343-354.

Stockdale, E. A., Lampkin, N. H., Hovi, M., Keatinge, R., Lennartsson, E. K. M., Macdonald, D. W., Padel, S., Tattersall, F. H., Wolfe, M. S., Watson, C. A. (2001). Agronomic and environmental implications of organic farming systems. Adv. Agron. 70:261-327.

Sugiyama, D. y Fujita, T. (2006). A thermodynamic model of dissolution and precipitation of calcium silicate hydrates. Cement and Concrete Research, 36, 227-237.

Tamás, F.D. et al. (1976). Effects of variables upon the silylation products of hydrated cements. Conference of Hydraulic Cement Pastes. Sheffield, 55-72.

Taylor, H. F. W. (2003). Cement Chemistry. 2nd Edition ed. 2003, London: Thomas Telford Publishing.

Tennis, P. D. y Jennings, H. M., (2000). A model for two types of calcium silicate hydrate in the microstructure of Portland cement pastes. Cement and Concrete Research, 30, 855- 863.

Tobón, J. I., Payá, J. J., Borrachero, M. V., Restrepo, O.J. (2012a). Mineralogical evolution of Portland cement blended with silica nanoparticles and its effect on mechanical strength. Construction and Building Materials, 36, 736-742.

Tobón, J. I., Payá, J. J., Borrachero, M. V., Soriano, L., Restrepo O. J. (2012b). Determination of the optimum parameters in the high resolution thermogravimetric analysis (HRTG) for cementitious materials. J. Therm. Anal. Calorim., 107, 233-239. DOI 10.1007/s10973-0100997-0. 
UNE 77040:2002. Calidad del agua. Determinación de la dureza del agua. Método complexométrico con AEDT. Madrid: Asociación Española de Normalización y Certificación.

UNE 80300:2000 IN. Cementos. Recomendaciones para el uso de los cementos. Asociación Española de Normalización y Certificación.

UNE-EN 196-2:2006. Métodos de ensayo de cementos. Parte 2: Análisis químico de cementos.. Asociación Española de Normalización y Certificación.

UNE-EN 196-3:2006. Métodos de ensayo de cementos. Parte 3: Determinación del tiempo de fraguado y de la estabilidad de volumen.

UNE-EN 197-1:2011. Cemento. Parte 1: Composición, especificaciones y criterios de conformidad de los cementos comunes.

Vedalakshmi, R, Sundara Raj, A., Srinivasan, S., S, Ganesh Babu, K. (2003). Quantification of hydrated cement products of blended cements in low and medium strength concrete using TG and DTA technique. Thermochimica Acta, 407, issues 1-2, 49-60.

Vila, E., (1989). Drx-tg Programa para tratamiento de difractogramas de rayos-X. ICMM-CSIC: Madrid.

Vu, D. D., Stroeven, P., Bui, V. B. (2001). Strength and durability aspects of calcined kaolinblended Pórtland cement mortar and concrete. Cement and Concrete Composites, 23, 471-478.

Wittmann, F.H. (1976). The structure of hardened cement paste - A basis for a better understanding of the materials properties. Cement and Concrete Ass, 96-117

Wittmann, F.H. (1982). Creep and shrinkage mechanisms. Creep and Shrinkage of Concrete Structures, 129-161

Wong, H. S., Buenfeld, N. R. y Head, M. K. (2006). Estimating transport properties of mortars using image analysis on backscattered electron images. Cement and Concrete Research, 36, 1556-1566. 
Wu Yinghai, Wang Chunbo, Tan Yewen, Jia Lufei, Anthony Edward J. (2011). Characterization of ashes from a $100 \mathrm{kWth}$ pilot-scale circulating fluidized bed with oxy-fuel combustion. Applied Energy, 88, issue 9, 2940-2948.

Yokozek, K., Watanabe, K, Sakata, N, Otsuki, N. (2004). Modeling of leaching from cementitious materials used in underground environment. Applied Clay Science, 26, issues 1-4, 293-308.

Yuzay I. E., Auras R., Soto-Valdez H., Selke S,. (2010). Effects of synthetic and natural zeolites on morphology and thermal degradation of poly(lactic acid) composites. Polymer Degradation and Stability, 95, issue 9, 1769-1777.

Zelic J., Ugrina L., Jozic D. (2007). Application of termal methods in the chemistry of cement: kinetic análisis of portlandite from non-isothermal thermogravimetric data. International Proficiency testing conference.

Zivica, V., Bajza A. (2001). Acidic attack of cement based materials - a review. Part 1. Principle of acidic attack. Construction and Building Materials, 15, issue 8, 331-340.

Zivica, V., Bajza A. (2002). Acidic attack of cement-based materials - a review Part 2. Factors of rate of acidic attack and protective measures. Construction and Building Materials, 16, issue 4, 215-222.

Zivica, V. (2004). Acidic attack of cement based materials - a review Part 3: research and test methods. Construction and Building Materials, Volume 18, Issue 9, November 2004, Pages 683-688. 